Jahrbuch des Frankreichzentrums der Universität des Saarlandes Band 15 | 2015/2016

Hans-Jürgen Lüsebrink,

Claudia Polzin-Haumann,

Christoph Vatter (Hg.)

»Alles Frankreich oder was? « Die saarländische Frankreichstrategie im europäischen Kontext

»La France à toutes les sauces? « La 'Stratégie France de la Sarre dans le contexte européen

\title{
Interdisziplinäre Zugänge
}

und kritische Perspektiven

Approches interdisciplinaires

et perspectives critiques

[transcript] FrankreichForum 
Hans-Jürgen Lüsebrink, Claudia Polzin-Haumann, Christoph Vatter (Hg.) »Alles Frankreich oder was?« - Die saarländische Frankreichstrategie im europäischen Kontext / »La France à toutes les sauces?« - La >Stratégie France< de la Sarre dans le contexte européen 


\section{Frankreich-Forum}

Jahrbuch des Frankreichzentrums

der Universität des Saarlandes

Band I5 (2015/2016) 
HANS-JÜRGEN LÜSEBRINK,

Claudia Polzin-Haumann,

Christoph Vatter (Hg.)

"Alles Frankreich oder was?" -

Die saarländische Frankreichstrategie im europäischen Kontext /

"La France à toutes les sauces?" -

La 'Stratégie France، de la Sarre dans le contexte européen

Interdisziplinäre Zugänge und kritische Perspektiven /

Approches interdisciplinaires et perspectives critiques

[transcript] 
Das Jahrbuch des Frankreichzentrums wird herausgegeben vom Kollegium des Frankreichzentrums der Universität des Saarlandes: Philippe Cossalter, Hans-Peter Dörrenbächer, Dietmar Hüser, Albrecht Ott, David Scheschkewitz, Thomas Schuster, Wolfgang Spitzer und Romana Weiershausen.

Unter Mitarbeit von Sandra Duhem und Jeanne Ruffing.

Kontaktadresse:

Frankreichzentrum der Universität des Saarlandes

Leiter: Dietmar Hüser

Geschäftsführerin: Sandra Duhem

Postfach 151150

66041 Saarbrücken

fz@mx.uni-saarland.de

http://www.uni-saarland.de/fz

\section{(@) $\mathbb{D} \Theta \Theta$}

Dieses Werk ist lizenziert unter der Creative Commons Attribution-NonCommercialNoDerivs 4.0 Lizenz (BY-NC-ND). Diese Lizenz erlaubt die private Nutzung, gestattet aber keine Bearbeitung und keine kommerzielle Nutzung. Weitere Informationen finden Sie unter https://creativecommons.org/licenses/by-nc-nd/4.o/deed.de/.

Um Genehmigungen für Adaptionen, Übersetzungen, Derivate oder Wiederverwendung zu kommerziellen Zwecken einzuholen, wenden Sie sich bitte an rights@ transcript-verlag.de

\section{(C) 2017 transcript Verlag, Bielefeld}

\section{Bibliografische Information der Deutschen Nationalbibliothek}

Die Deutsche Nationalbibliothek verzeichnet diese Publikation in der Deutschen Nationalbibliografie; detaillierte bibliografische Daten sind im Internet über http://dnb.dnb.de abrufbar.

Umschlagkonzept: Kordula Röckenhaus, Bielefeld

Redaktion: Julia Montemayor Gracia, unter Mitarbeit von Perrine Häfner, Franziska Malzer \& Nathalie Schnabel, Saarbrücken

Layout \& Satz: Julia Montemayor Gracia, Saarbrücken

Übersetzungen: Sandra Duhem und Louise Monnier, Saarbrücken

Druck: Majuskel Medienproduktion GmbH, Wetzlar

Print-ISBN 978-3-8376-3755-7

PDF-ISBN 978-3-8394-3755-1

Gedruckt auf alterungsbeständigem Papier mit chlorfrei gebleichtem Zellstoff.

Besuchen Sie uns im Internet: http://www.transcript-verlag.de

Bitte fordern Sie unser Gesamtverzeichnis und andere Broschüren an unter:

info@transcript-verlag.de 


\section{Inhaltsverzeichnis}

\section{Themenschwerpunkt}

„Alles Frankreich oder was?“ Die saarländische Frankreichstrategie im europäischen Kontext - Interdisziplinäre Zugänge und kritische Perspektiven "La France à toutes les sauces? » La 'Stratégie France' de la Sarre dans le contexte européen - Approches interdisciplinaires et perspectives critiques

Grußwort und Einleitung Mot de bienvenue et introduction

ANNEGRET KRAMP-KARRENBAUER: Grußwort

HANS-JÜRgEN LÜSEBRINK, CLAUdia POLZIN-HAUMANN UND

CHRISTOPH VATTER: „Alles Frankreich oder was?““

Die saarländische Frankreichstrategie/

"La France à toutes les sauces? » La 'Stratégie France' de la Sarre

Geschichte und Politik

Histoire et politique

HENRIK UTERWEDDE: Die saarländische Frankreichstrategie im Kontext der aktuellen deutsch-französischen Beziehungen

DiETMAR HÜSER: Die Saar-Politik und die deutsch-französische Geschichte an der Grenze. Herausforderungen, Handlungsmargen, ,Frankreichstrategien in Völkerbunds-, Saarstaats- und frühen Bundeslandzeiten 
CORINe DEFrance ET UlRICH PFEIL: Penser et vivre la frontière dans les relations franco-allemandes

REINER MARCOWITZ: Ein Blick von außen: Die Frankreichstrategie des Saarlandes aus lothringischer Perspektive

Umsetzung - Perspektiven aus Wissenschaft und Politik

La mise en application - Perspectives scientifiques et politiques

Claudia POLZIN-HAUMANN: Frankreichstrategie und Bildungspolitik. Bestandsaufnahme und Perspektiven aus der Sicht der Angewandten Linguistik und der Sprachlehr-/Sprachlernforschung

ROMANA WEIERSHAUSEN: Die Germanistik als neuer Weg nach Frankreich: Von der ,Nationalphilologie‘ zu einer interkulturellen Studienpraxis und ihren Potenzialen als Tor nach Frankreich und Brücke zu Deutschland

ALBERT RAASCH, WILFRIED SCHMIDT UND PETER TISCHER:

Im Kontext der Frankreichstrategie:

Auf dem Weg zu einer Mehrsprachigkeit für das Saarland

PATRICIA OSTER-STIERLE: Das Saarland als Testfeld

für deutsch-französische Hochschulkooperation

Die Großregion - Arbeit und Ausbildung,

Gesundheitswesen, Medien

La Grande Région - Emploi et formation, santé, médias

WOLFGANG MEYER: Grenzverkehrt -

Perspektiven des Arbeits- und Ausbildungsmarktes der Großregion

INES FUNK: Grenzüberschreitende Gesundheitsversorgung im Grenzraum Saarland-Lothringen:

Aktueller Stand, Herausforderungen und Potenziale

CHRISTOPH VATTER: Zwischen Marketing und Mindset.

Zur Rolle von Medien und grenzüberschreitender Berichterstattung im Kontext der Frankreichstrategie 
Zum internationalen Kontext - Einordnung und Ausblick

Le contexte international - Orientation et avenir

HANS-JÜRGEN LÜSEBRINK: Interkulturelle Dimensionen

und Herausforderungen der Frankreichstrategie

im Kontext der gegenwärtigen deutsch-französischen Beziehungen

SYLVERE MBONDOBARI: Frankophones Afrika

in den deutsch-französischen (saarländischen) Beziehungen

\section{Berichte}

Workshop: Neue Energien. Energiezukunft an der Schnittstelle von Technik, Kultur und Gesellschaft

(24.-25.09.2015)

Eva Hauser et Maria Hegner: Pour une formation doctorale transfrontalière et pluridisciplinaire - le service INTERDOC au Pôle France (Sarrebruck) se présente à l'occasion d'un atelier interdisciplinaire sur l'énergie

Veranstaltungsreihe: Exil und Migration von Frauen (Sommersemester 2016)

MECHTHILD GILZMER: Exil und Migration von Frauen.

Rückblick auf eine Veranstaltungsreihe im Sommersemester 2016

SABINE LIEBIG: Flucht und Migration von Frauen aus Genderperspektive. Ein Perspektivwechsel

Susanne GeHrmann: Neue literarische Perspektiven auf Migration im Werk der franko-senegalesischen Autorin Fatou Diome 


\section{Rezensionen}

Alemann, Ulrich von/Morlok, Martin/Roßner, Sebastian (Hg.):

Politische Parteien in Frankreich und Deutschland. Späte Kinder des

Verfassungsstaates, Baden-Baden 2015 (Gregor Halmes, Saarbrücken) ...... 307

Bauer, Elisabeth Carolin: Frankophone digitale Literatur. Geschichte,

Strukturen und Ästhetike einer neuen Mediengattung, Bielefeld 2016

(Nathalie Mälzer, Hildesheim)

Beck, Joachim/Larat, Fabrice (dir.): Transnationale Verwaltungskulturen in Europa - Bestandsaufnahme und Perspektiven. Les cultures administratives transnationales en Europe - Etat des lieux et perspectives,

Baden-Baden/Zürich 2015 (Eric Davoine, Fribourg/Suisse)

Boubeker, Ahmed/Ottersbach, Markus (dir.): Diversité et participation.

Approches franco-allemandes de l'action sociale pour la jeunesse

des quartiers marginalisés, Paris 2015 (Yves Bizeul, Rostock)

Dumoulin, Michel/Elvert, Jürgen/Schirmann, Sylvain (dir.):

Encore ces chers voisins. Le Benelux, l'Allemagne et la France

aux XIX $X^{e}$ et XXe siècles, Stuttgart 2014 (Michel Grunewald, Metz)

Filipová, Lucie: Erfüllte Hoffnung. Städtepartnerschaften als Instrument

der deutsch-französischen Aussöbnung, 1950-2000, Göttingen 2015

(Marie-France Chevron, Wien)

Hähnel-Mesnard, Carola/Herbet, Dominique (Hg.): Fuite et expulsions des Allemands. Transnationalité et représentations 19e-21e siècle, Villeneuve d'Ascq 2016 (Daniel Mollenhauer, München)

Hörner, Fernand/Mathis-Moser, Ursula (dir.): Das französische Chanson im Licht medialer (R)evolutionen/La chanson française à la lumière des (R)évolutions médiatiques, Würzburg 2013 (Patrick Farges, Paris)

Krumeich, Gerd/Prost, Antoine: Verdun 1916. Die Schlacbt

und ibr Mythos aus deutsch-französischer Sicht, Essen 2016

(Françoise Knopper, Toulouse)

Larralde, Jean-Manuel/Leclerc, Stéphane (dir.): Les 50 ans

du traité de l'Elysée 1963-2013. Le couple franco-allemand

dans la construction européenne, Paris 2016 (Sandra Schmidt, Paris) 
Lejot, Eve: Pratiques plurilingues en milieu professionnel international.

Entre politiques linguistiques et usages effectifs, Frankfurt/M. [u. a.] 2015

(Nadine Rentel, Zwickau)

Martin, Barbara: Zwischen Verklärung und Verführung. Die Frau in der französischen Plakatkunst des späten 19. Jahrbunderts, Bielefeld 2015 (Ingeborg Rabenstein-Michel, Lyon)

Perrefort, Marion (in Zusammenarbeit mit Martin Bauch und

Dominique Granoux): Der deutsch-französische Grundschullehreraustausch.

Mobilitätserfahrungen im Perspektivenwechsel, Münster/New York 2015

(Heidemarie Sarter, Potsdam)

Picker, Marion/Kimmich, Dorothee (dir.): Exil - Transfer - Gedächtnis/

Exil-Transfert-Mémoire. Deutsch-französische Blickwechsell

Regards croisés franco-allemands, Frankfurt/M. [u. a.] 2016

(Fabien Pillet, Genève)

Roffat, Sébastien: Esthétique et réception du dessin animé français sous l'occupation (1940-1944). L'émergence d'une école française?, Paris 2014 (Nathalie Mälzer, Hildesheim)

Stoupy, Joëlle: La littérature française dans „Betrachtungen eines Unpolitischen“ (1918) de Thomas Mann, Frankfurt/M. 2015 (Leslie Brückner, Metz)

Taylor, Imogen: Das zweisprachige Paar im französischen Roman von ,Zaide‘ bis ,Corinne', Würzburg 2016

(Odile Schneider-Mizony, Strasbourg)

Thomann, Pierre-Emmanuel: Le couple franco-allemand et le projet européen. Représentations géopolitiques, unité et rivalités, Paris 2015 (Sandra Schmidt, Paris)

Watrelot, Martine/Polzin-Haumann, Claudia: L'évaluation des compétences langagières: Un regard franco-allemand sur les défis et perspectives actuels, Namur 2015

(Eugeune Colinet Tatchouala, Montréal)

Witzigmann, Stéfanie/Rymarczyk, Jutta (Hg.): Mehrsprachigkeit

als Chance. Herausforderungen und Potentiale

individueller und gesellschaftlicher Mehrsprachigkeit, Frankfurt/M. [u. a.] 2015

(Heidemarie Sarter, Potsdam) 
Zier, Alexander: Frankreichs Sicherheitspolitik. Effiziente Selbstbehauptung zu Gunsten Europas?, Baden-Baden 2014

(Catherine Teissier, Aix-en-Provence)

Autorenverzeichnis 
1. Themenschwerpunkt:

„Alles Frankreich oder was?“ Die saarländische Frankreichstrategie im europäischen Kontext Interdisziplinäre Zugänge und kritische Perspektiven "La France à toutes les sauces?" La 'Stratégie France' de la Sarre dans le contexte européen Approches interdisciplinaires et perspectives critiques 

Grußwort und Einleitung

Mot de bienvenue et introduction 

Annegret Kramp-Karrenbauer

Grußwort

Im Wintersemester 2015/2016 haben das Frankreichzentrum und die Fachrichtung Romanistik der Universität des Saarlandes zusammen mit ihren Kooperationspartnern eine öffentliche Ringvorlesung zum Thema „Alles Frankreich oder was?" Die saarländische Frankreichstrategie im europäischen Kontext - interdisziplinäre Zugänge und kritische Perspektiven" angeboten. Namhafte Wissenschaftler haben sich mit den verschiedenen Handlungsfeldern der saarländisch-französischen Zusammenarbeit auseinandergesetzt und über grenzüberschreitende Lebenswirklichkeiten, Maßnahmen, Kooperationen und Mehrsprachigkeit diskutiert. Unabhängig davon, wie kontrovers die Debatte zu den verschiedenen Themenfeldern geführt wurde, macht dieses wissenschaftliche Interesse an der Frankreichstrategie des Saarlandes Mut, den eingeschlagenen Weg weiter zu beschreiten. Diese Ringvorlesung ist ein schöner Beleg dafür, dass die Zusammenarbeit zwischen Deutschland und Frankreich alles andere als überholt und weiterhin ein wichtiges Thema für die saarländische, die deutsch-französische und die europäische Zukunft ist.

Für viele Menschen im Saarland und im angrenzenden Lothringen gehören die deutsch-französischen Beziehungen zum Alltag. Dies gilt für die zahlreichen Berufspendler, aber auch für die, die diesseits und jenseits der Grenze einkaufen oder wohnen. Die Menschen in unserer Grenzregion profitieren besonders von den Chancen dieser Freundschaft. Beinahe täglich haben sie, manchmal zufällig oder ganz gezielt, grenzüberschreitende Kontakte zu Politik, Wirtschaft, Kultur und Lebensart. Diese funktionierende Partnerschaft verpflichtet aber auch, gemeinsame Perspektiven für die Zukunft zu entwickeln und gemeinsam voranzugehen.

Die Landesregierung des Saarlandes und der Landtag des Saarlandes arbeiten seit jeher eng mit einem breiten und gut aufgestellten Netzwerk verschiedener regionaler und nationaler Akteure in Frankreich zusammen. Das intensive Engagement der verschiedenen gesellschaftlichen Akteure der deutsch-französischen Institutionen wie dem Deutsch-Französischen Gymnasium, dem Deutsch-Französischen Sekretariat (DFS) und der DeutschFranzösischen Hochschule (DFH), dem Deutsch-Französischen Hochschulinstitut (DFHI-ISFATES), der Union des Français de Sarre oder der DeutschFranzösischen Gesellschaft, der Europäischen Akademie Otzenhausen und dem Frankreichzentrum der Universität des Saarlandes ist vorbildlich. Hinzu kommen beste Kontakte zu den Partnern des Gipfels der Großregion und Vertretern auf nationaler Ebene wie Abgeordneten der Assemblée Nationale oder der nationalen Regierung. Diese exzellenten Beziehungen sind die 
Frucht einer langjährigen, vertrauensvollen Zusammenarbeit und Partnerschaft und ganz im Interesse Europas und seiner Bürgerinnen und Bürger.

Die Überzeugung, dass die historisch gewachsene und stetig ausgebaute Frankreichkompetenz eine große Chance für die Zukunft unseres Landes und unserer Grenzregionen darstellt, veranlasste die saarländische Landesregierung Anfang 2014 die Frankreichstrategie ins Leben zu rufen, die das Erlernen der französischen Sprache, aber auch anderer Sprachen und die Förderung der interkulturellen Kompetenz in den Mittelpunkt stellt. Die Frankreichstrategie ist langfristig, nachhaltig und umfassend angelegt. Dabei setzt die Landesregierung auf die partizipative Beteiligung der Bürgerinnen und Bürger. Ein solcher Veränderungsprozess kann nicht verordnet werden. Er muss behutsam und mit allen Beteiligten gestaltet werden, mit den Saarländerinnen und Saarländern, mit den Französinnen und Franzosen, die im Saarland leben, mit den deutsch-französischen und französischen Einrichtungen im Land. Die Frankreichstrategie ist ehrgeizig, aber sie ist eine Chance für die Zukunft unseres Landes und der Grenzregion. Es ist daher wichtig, dass wir mutig sind und diesen Weg weiter gehen.

Ich danke allen, die an der vorliegenden Publikation mitgearbeitet haben, für ihr wissenschaftliches Interesse an der Frankreichstrategie. Die angestoßenen Diskussionen und die fundierte Auseinandersetzung mit dieser Thematik aus der historischen, politischen, wirtschafts- und sozial- sowie kulturwissenschaftlichen Perspektive setzen einen wichtigen Akzent zur Fortentwicklung der Frankreichstrategie. Ich hoffe, dass auch in Zukunft der wissenschaftliche Dialog diese wichtige Initiative konstruktiv begleitet.

Annegret Kramp-Karrenbauer

Ministerpräsidentin des Saarlandes 


\author{
„Alles Frankreich oder was?“ \\ Die saarländische Frankreichstrategie \\ "La France à toutes les sauces? » La 'Stratégie France' de la Sarre
}

Mit den im Januar 2014 vorgestellten Eckpunkte[n] einer Frankreichstrategie für das Saarland ${ }^{1}$ hat die saarländische Landesregierung nicht nur im eigenen Land und in der deutsch-französischen Grenzregion, sondern auch bundesweit für Aufsehen gesorgt und sogar international Interesse geweckt. Mit dieser Frankreichstrategie ist in erster Linie das ehrgeizige Ziel verbunden, das Saarland innerhalb von 30 Jahren zu einem „multilinguale[n] Raum deutsch-französischer Prägung“ zu machen. Als „Generation Elysée“" stehen die 2013, im Jahr des 50-jährigen Jubiläums des deutsch-französischen Freundschaftsvertrags von 1963, geborenen Saarländerinnen und Saarländer symbolisch für diese Idee - 2043 soll mit ihrer Hilfe das Französische als zweite Verkehrs- und Umgangssprache im Saarland etabliert sein.

Dieser sprach- und bildungspolitische Kern wurde in der Außenwirkung am stärksten wahrgenommen und häufig überzeichnet als Absicht dargestellt, eine deutsch-französische Zweisprachigkeit zu erreichen. Das ambitionierte und in Europa einzigartige Projekt zur Mehrsprachigkeit ist jedoch umfassender angelegt und zielt über den Aspekt der Sprache hinaus auf eine breite Palette von Maßnahmen zur interkulturell-grenzüberschreitenden Öffnung $\mathrm{ab}$, die in den verschiedensten Bereichen dazu beitragen sollen, sowohl die Außendarstellung des Saarlandes im Sinne des Standortmarketings mit einem deutsch-französischen Schwerpunkt zu gestalten als auch innerhalb der Region frankreichbezogene Aktivitäten zu verstärken und neu zu entwickeln. Hierzu waren in einem ersten Schritt Institutionen, zivilgesellschaftliche Akteurinnen und Akteure wie auch die interessierte Öffentlichkeit ab Januar 2014 dazu eingeladen, ihre Ideen für die Gestaltung der Frankreichstrategie einzubringen. Im Zuge dieses Konzertationsprozesses kamen auch kritische Stimmen auf, die v. a. auf begrenzte Gestaltungsmöglichkeiten angesichts der geringen finanziellen Mittel des durch die sogenannte, Schuldenbremse' zur Konsolidierung gezwungenen Saarlandes sowie auf Bedenken bezüglich der Sprachenfolge in der Schule verwiesen. Unter anderem wurde die Tatsache

1 Staatskanzlei des Saarlandes: Eckpunkte einer Frankreichstrategie für das Saarland, 2014, http://www.saarland.de/dokumente/res_stk/D_Eckpunkte_Frankreich-Strategie_210114. $\operatorname{pdf}(12.07 .2017)$, S. 3.

2 Staatskanzlei des Saarlandes: Eckpunkte einer Frankreichstrategie, S. 9 und S. 34. 
kritisiert, dass das Französische durchgehend und verpflichtend als erste Fremdsprache gelten solle, was aus der Sicht mancher Kritiker als Nachteil für die berufliche Zukunft der Schülerinnen und Schüler und als Hindernis für die innerdeutsche Mobilität der Eltern und ihrer Kinder angesehen wurde. Auch wurde angesichts der zunehmenden ökonomischen und politischen Probleme in Frankreich, v. a. im Zuge der Wirtschafts- und Finanzkrise seit 2008, die grundlegende Ausrichtung der Frankreichstrategie, die eine Privilegierung der wirtschaftlichen, politischen und kulturellen Beziehungen zum Nachbarland Frankreich impliziert, angezweifelt. Die Kritik an der Frankreichstrategie ist zweifellos auch durch eine noch nicht hinreichende Informationsstrategie bedingt, die v. a. im Bereich der Neuen Medien, wie eine wissenschaftliche Untersuchung gezeigt hat ${ }^{3}$, noch sehr defizitär ist.

Auf der Grundlage der verschiedenen Stellungnahmen wurde ein Maßnahmenpaket in Form einer Feuille de route ${ }^{4}$ mit einer Vielzahl von Etappenzielen veröffentlicht, das im Herbst 2016 auf Basis des bislang Erreichten überarbeitet und um ein neues Arbeitsprogramm, die Fenille de route $I{ }^{5}$, ergänzt wurde. Die Bündelung der vielfältigen grenzüberschreitenden Aktivitäten auf institutioneller wie zivilgesellschaftlicher Ebene, die damit verbundene Mobilisierung einer bereits vorhandenen „Frankreichkompetenz"6 sowie die Würdigung des Engagements für die deutsch-französische interkulturelle $\mathrm{Zu}$ sammenarbeit stellen sicherlich die Schlüsselfaktoren des Projekts dar. Sie verweisen zudem auf die drei Bezugsebenen, die mit dem Vorhaben ,Frankreichstrategie verknüpft sind: 1. die (inter-)regionale Ebene der grenzüberschreitenden Kooperation, auch unter Berücksichtigung der sogenannten Großregion SaarLorLux mit Luxemburg als Zentrum der interregionalen Verflechtungen, 2. die Ebene der deutsch-französischen (binationalen) Beziehungen, 3. die europäische Ebene, für die die Intensivierung grenzüber-

3 Picart, Malika: La stratégie „France" $d u$ Land de Sarre: campagne d'information du gouvernement sarrois et impact dans la presse en France et en Allemagne, Universität des Saarlandes/Université de Lorraine, Masterarbeit, 2016.

4 Landesregierung des Saarlandes: Feuille de route Frankreichstrategie 2015/2016, 2015, http://saarland.de/dokumente/ressort_finanzen/Feuille_de_route.pdf (12.07.2017).

5 Landesregierung des Saarlandes: Frankereichstrategie Fenille de route II 2017/2019, 2016, http://www.saarland.de/dokumente/thema_europa/2016-10-17_Feuille_de_route_20172019.pdf (12.07.2017). Vgl. auch Funk, Anne/Niedermeyer, Martin: Die Frankreich-Strategie des Saarlandes, Governance und territoriale Kohäsion als neue Dimensionen regionaler Entwicklungskonzepte, in: Lorig, Wolfgang H./Regolot, Sascha/Henn, Stefan (Hg.): Die Großregion SaarLorLux: Anspruch, Wirklichkeiten, Perspektiven, Berlin: Springer, 2016, S. 169-182.

6 Staatskanzlei des Saarlandes: Eckpunkte einer Frankreichstrategie, z. B. S. 1. Zu Vorkommen und Verwendung des Schlagworts „Frankreichkompetenz“ im Eckpunktepapier vgl. die Artikel von Claudia Polzin-Haumann und Hans-Jürgen Lüsebrink in diesem Band. 
schreitender Kooperation mit vielfältigen, insbesondere auch zivilgesellschaftlichen interkulturellen Kontaktzonen in einem mehrsprachigen Raum einen exemplarischen Charakter einnehmen könnte.

Diese drei Bezugsebenen verweisen natürlich auch auf Grenzen der Frankreichstrategie - ungeachtet eines möglichen Erfolges oder Misserfolges. Denn sowohl auf regionaler als auf binationaler Ebene bedarf es einer Reaktion auf französischer Seite. In der Deutschlandstrategie Lothringens ${ }^{7}$ scheint eine solche Perspektive durch, auch wenn abzuwarten bleibt, inwiefern sich die 2016 in Kraft getretene Territorialreform Frankreichs auf die bilaterale regionale Zusammenarbeit auswirken wird. Denn seitdem grenzt das Saarland nicht mehr ,nur' an Lothringen, sondern an die viel größere Region Grand Est, zu der einerseits mit Champagne-Ardenne auch sehr ,grenzferne ' Gebiete gehören. Andererseits ist aufgrund der Zugehörigkeit des Elsass zur neu geschaffenen Region Grand Est durch die etablierte und in vielen Bereichen auch seit vielen Jahren sehr gut funktionierende grenzüberschreitende Zusammenarbeit am Oberrhein in gewisser Hinsicht eine unmittelbare Konkurrenz zur Ausrichtung und Konzeption der Kooperation in der Großregion auf den Plan getreten. Auf der Ebene der binationalen deutsch-französischen Kooperation sind zahlreiche Akteure aktiv. Allerdings sind, wie auch Henrik Uterwedde in seinem Beitrag betont, Paris und Berlin nicht unbedingt auf saarländische Unterstützung angewiesen, um die deutschfranzösischen Beziehungen zu gestalten. Inwiefern der sich mit dem Wahlsieg Emmanuel Macrons im Mai und Juni 2017 abzeichnende neue Elan der deutsch-französischen Zusammenarbeit in und für Europa auch auf regionaler Ebene widerspiegeln wird, bleibt zum Zeitpunkt der Publikation dieses Buchs abzuwarten. Für die europäische Integration, die auch mit der deutsch-französischen Zusammenarbeit untrennbar verknüpft ist, stellt die strategische Förderung von Mehrsprachigkeit und interkulturellen Beziehungen - ob in Politik, Wirtschaft, Kultur und Medien, den Sozialbeziehungen oder der Zivilgesellschaft - durch ein Bundesland einen Schritt dar, dem angesichts der vielfach beschworenen Krise Europas Modellcharakter zukommen mag.

Erste Ergebnisse einer Studie der FU Berlin vom April 2017 bestätigen eine breite Unterstützung der Saarländerinnen und Saarländer für die Frankreichstrategie: 61,6\% der 1128 Befragten bewerteten die Frankreichstrategie als ,gut" oder „eher gut". 8 Die Erhebung zeigt jedoch auch, dass v. a. in den unmittelbar an der Grenze liegenden Landkreisen die Zustimmung

7 Vgl. den Beitrag von Reiner Marcowitz in diesem Band.

8 Krämer, Philipp: Pressedossier zum Forscbungsprojekt, „Sprachpolitik im Saarland: Einstellungen zur Frankreichstrategie“. Interdisziplinäres Zentrum „Europäische Sprachen“, FU Berlin, 2017, http://www.geisteswissenschaften.fu-berlin.de/izeus/media/Dossier_Frankreichstrategie Kraemer.pdf (12.07.2017). 
besonders hoch ist, während für andere Teile des Saarlandes der Nutzen nicht ganz so deutlich gesehen wird. Für die weitere Umsetzung wird die Einbeziehung der Menschen außerhalb des „funktionalen Kerns"c der grenzüberschreitenden Kooperation von zentraler Bedeutung sein, gerade um die Unkenntnis - und häufig auch Skepsis - gegenüber der Frankreichorientierung und ihrer Rolle im individuellen Alltag entgegen zu wirken.

\section{Zielsetzung und Aufbau dieses Bandes}

Dass die Zusammenarbeit mit dem Nachbarland Frankreich für das Saarland wirtschaftlich wie politisch von großer Bedeutung ist, ist kaum bestreitbar. Doch lässt sich daraus eine globale Strategie ableiten, die alle Bereiche der Wirtschaft, Politik, Kultur, Verwaltung und Zivilgesellschaft umfasst? Wäre nicht eher eine Pluralisierung der Strategieorientierungen erforderlich? Nach dem öffentlichkeitswirksamen Auftakt im Januar 2014 und den darauf folgenden, z. T. sehr emotional geführten Diskussionen um die Frankreichstrategie ist der vorliegende Band Teil eines Versuchs, die von der Politik gesetzten Impulse einer kritischen wissenschaftlichen Reflexion zu unterziehen, die sich von Euphorie und voluntaristischen Illusionen ebenso fernhält wie vom Rückfall in nationalistische Abwehrreflexe. Die hier versammelten Beiträge dokumentieren eine öffentliche Ringvorlesung, die das Frankreichzentrum der Universität des Saarlandes in Zusammenarbeit mit der Landeshauptstadt Saarbrücken und dem Europa-Kolleg CEUS veranstaltet hat, um aus wissenschaftlicher Sicht die saarländische Frankreichstrategie und die verschiedenen damit verknüpften Dimensionen der deutsch-französischen $\mathrm{Zu}$ sammenarbeit zu beleuchten. Im Zentrum stehen dabei eine Differenzierung der Zugänge und Perspektiven sowie eine Einordnung der Frankreichstrategie in die großregionalen, nationalen, europäischen und auch globalen Kontexte, die mit ihr verbunden sind.

Die Universität des Saarlandes und insbesondere das Frankreichzentrum nehmen in der Debatte um die Frankreichstrategie eine Doppelrolle ein: Einerseits ist die Universität aufgrund ihrer Geschichte und geographischen Lage seit jeher ein wesentlicher Akteur der Frankreichorientierung des Saarlandes, wie die zahlreichen deutsch-französischen Studiengänge, Forschungskooperationen oder auch institutionellen Vernetzungen (insbesondere in der Universität der Großregion, die neben der Universität des Saarlandes auch die

9 ESPON: METROBORDER. Grenzüberschreitende polyzentrische Metropolregionen. Zielgerichtete Analysen 2013/2/3. Abschlussbericht, Luxemburg: ESPON/University of Luxembourg, 31.12.2010, http://euregio.lu/wp-content/uploads/2011/11/metroborder_final_report_ de.pdf (31.07.2017). 
Université de Lorraine, die Université du Luxembourg sowie Partner in Belgien (Liège) und Rheinland-Pfalz (Kaiserslautern und Trier) umfasst) belegen; andererseits zeugen die verschiedenen Beiträge zu diesem Band vom wissenschaftlichen Selbstverständnis der unabhängigen Analyse und kritischen Reflexion gesellschaftlicher Prozesse sowie vom Dialog zwischen Wissenschaft und Zivilgesellschaft.

Der Aufbau des Bandes greift die skizzierten Herausforderungen und Perspektiven des ehrgeizigen saarländischen Experiments einer Frankreichstrategie im Sinne einer wissenschaftlich fundierten Begleitung und kritischen Diskussion auf. Der erste Themenblock reflektiert die saarländische Frankreichstrategie vor dem Hintergrund früherer strategischer Positionierungen des Saarlandes in Bezug auf Frankreich (Dietmar Hüser) sowie der wechselvollen Rolle der Grenze zwischen beiden Ländern (Corine Defrance und Ulrich Pfeil) ${ }^{10}$. Weitere Beiträge diskutieren politische Bezugsebenen im Rahmen der deutsch-französischen Beziehungen (Henrik Uterwedde) und die Reaktionen auf lothringischer Seite anhand der dort 2015 entwickelten Deutschlandstrategie (Reiner Marcowitz).

Die Beiträge im zweiten Teil widmen sich der Umsetzung der Frankreichstrategie in ausgewählten Feldern, v. a. auch hinsichtlich der Schaffung eines von deutsch-französischer Zweisprachigkeit geprägten Saarlandes. Neben der Frage nach den bildungspolitischen Voraussetzungen und Herausforderungen zur Realisierung von Mehrsprachigkeit in Schule und Hochschule (Claudia Polzin-Haumann) sowie in der Erwachsenenbildung (Albert Raasch, Wilfried Schmidt, Peter Tischer) werden auch spezifische Entwicklungsmöglichkeiten aus Sicht von Wissenschaft und Hochschulen aufgezeigt: Zum einen scheinen im Bereich integrierter deutsch-französischer Studiengänge noch Potenziale für eine verstärkte deutsch-französische Kooperation im Saarland brach zu liegen (Patricia Oster-Stierle), zum anderen zeigt das Beispiel der Frankophonen Germanistik (Romana Weiershausen) an der Universität des Saarlandes, wie ein traditionelles Fach durch die Ausrichtung auf die deutsch-französische Grenzsituation in produktiver Art und Weise neue Perspektiven zu entwickeln vermag.

Der dritte Themenblock reflektiert die saarländische Frankreichstrategie im Kontext der grenzüberschreitenden Zusammenarbeit in der Großregion SaarLorLux. Die Beiträge zum Arbeits- und Ausbildungsmarkt (Wolfgang Meyer), zur grenzüberschreitenden Gesundheitsversorgung und Patientenmobilität (Ines Funk) sowie zur interregionalen Berichterstattung und medialen Dimension der Frankreichstrategie (Christoph Vatter) illustrieren Praxisfelder der deutsch-französischen Kooperation im Saarland, in denen sich die

10 Der Beitrag beruht auf einem Plenarvortrag im Rahmen des 10. Kongresses des Frankoromanistenverbandes, der vom 28.09. bis 01.10.2016 zum Thema „Grenzbeziehungen Beziehungsgrenzen/liaisons frontalières“ an der Universität des Saarlandes stattfand. 
nationalen Grenzen zwar häufig als Hürden erweisen, sich aber gleichzeitig Perspektiven für deren Überwindung abzeichnen.

Im letzten Abschnitt wird die saarländische Frankreichstrategie anhand der vorliegenden Schwerpunktsetzungen kritisch beleuchtet und auf eventuelle Lücken oder blinde Flecken diskutiert (Hans-Jürgen Lüsebrink). Darüber hinaus könnte die Einbeziehung der Perspektive der Frankophonie, insbesondere des afrikanischen Kontinents, Chancen aufzeigen, die Frankreichstrategie in einem transnationalen und globalen Rahmen zu denken (Sylvère Mbondobari).

Die Frankreichstrategie des Saarlandes ist ein auf dreißig Jahre ausgelegtes Unterfangen, das in einem ständigen Dialog weiterentwickelt wurde und wird. Die mit dem vorliegenden Band beabsichtigte Bestandsaufnahme und kritische Diskussion ist daher als Momentaufnahme und Teil dieses Prozesses $\mathrm{zu}$ sehen. Die Beiträge dokumentieren den Stand der Diskussion um die Frankreichstrategie drei Jahre nach ihrer Verkündung im Januar 2014 und laden dazu ein, diesen kritischen Dialog weiter fortzuführen.

Unser Dank gilt an erster Stelle den Beiträgerinnen und Beiträgern, die unserem Aufruf zur Mitwirkung am kritischen Dialog über die Frankreichstrategie gefolgt sind und sich dazu bereit erklärt haben, ihre Ideen und Analysen zunächst im Rahmen der öffentlichen Ringvorlesung im Saarbrücker Rathausfestsaal vorzutragen und dann für die vorliegende Publikation aufzubereiten. Weiterhin danken wir der Stadt Saarbrücken, insbesondere Frau Christel Drawer von der Kontaktstelle Wissenschaft, der Staatskanzlei des Saarlandes und dotSaarland e.V. für die konstruktive Zusammenarbeit und die Unterstützung der Ringvorlesung sowie der Publikation. Das tatkräftige Team des Frankreichzentrums hat mit seiner kompetenten organisatorischen sowie redaktionellen Unterstützung die Ringvorlesung und diese Publikation erst möglich gemacht. Schließlich möchten wir auch allen Studierenden und Besucherinnen und Besuchern der Ringvorlesung danken, die mit ihren Diskussionsbeiträgen und Fragen die Auseinandersetzung mit dem Projekt ,Frankreichstrategie‘ in äußerst fruchtbarer Weise bereichert haben.

Hans-Jürgen Lüsebrink, Claudia Polzin-Haumann und Christoph Vatter 


\section{Literaturverzeichnis}

ESPON: METROBORDER. Grenzüberschreitende polyzentrische Metropolregionen. Zielgerichtete Analysen 2013/2/3. Abscblussbericht, Luxemburg: ESPON/University of Luxembourg, 31.12.2010, http://euregio.lu/wp-content/uploads/2011/11/metroborder_final_report_ de.pdf (31.07.2017).

Funk, Anne/Niedermeyer, Martin: Die Frankreich-Strategie des Saarlandes, Governance und territoriale Kohäsion als neue Dimensionen regionaler Entwicklungskonzepte, in: Lorig, Wolfgang H./Regolot, Sascha/Henn, Stefan (Hg.): Die Großregion SaarLorLux: Anspruch, Wirklichkeiten, Perspektiven, Berlin: Springer, 2016, S. 169-182.

Krämer, Philipp: Pressedossier zum Forschungsprojekt „Sprachpolitik im Saarland: Einstellungen zur Frankreichstrategie“. Interdisziplinäres Zentrum „Europäische Sprachen“, FU Berlin, 2017, http://www.geisteswissenschaften.fu-berlin.de/izeus/media/Dossier_Frankreichstrategie Kraemer.pdf (12.07.2017).

Landesregierung des Saarlandes: Feuille de route Frankreichstrategie 2015/2016, 2015, http:// saarland.de/dokumente/ressort_finanzen/Feuille_de_route.pdf (12.07.2017).

Landesregierung des Saarlandes: Frankereichstrategie Feuille de route II 2017/2019, 2016, http:// www.saarland.de/dokumente/thema_europa/2016-10-17_Feuille_de_route_2017-2019. $\operatorname{pdf}(12.07 .2017)$.

Picart, Malika: La stratégie „France" $d u$ Land de Sarre: campagne d'information du gouvernement sarrois et impact dans la presse en France et en Allemagne, Universität des Saarlandes/Université de Lorraine, Masterarbeit, 2016.

Staatskanzlei des Saarlandes: Eckpunkte einer Frankereichstrategie für das Saarland, 2014, http:// www.saarland.de/dokumente/res_stk/D_Eckpunkte_Frankreich-Strategie_210114.pdf (12.07.2017). 

Geschichte und Politik

Histoire et politique 



\section{Henrik Uterwedde}

\section{Die saarländische Frankreichstrategie im Kontext der aktuellen deutsch-französischen Beziehungen}

L'article porte un premier jugement sur la 'Stratégie France' de la Sarre et sur son potentiel à contribuer aux relations entre la France et l'Allemagne. Dans un premier temps, l'auteur élucide les éléments clés des rapports franco-allemands. Il traite aussi du dilemme démocratique de l'Union Européenne mis en évidence par la politique de crise de la zone euro. Les partenariats variés entre les sociétés civiles des deux pays pourraient être mis à profit pour ouvrir la voie à une nécessaire union civile européenne, qui serait un processus de longue haleine. Dans cette optique, l'auteur considère que le véritable intérêt de la 'Stratégie France' est de faire avancer la construction d'une société civile européenne.

À la mesure de ces considérations préalables, l'auteur évalue ensuite les différents éléments de la 'Stratégie France'. Il apprécie de manière positive le caractère volontariste de la stratégie, sa vision globale et à long terme ainsi que l'intention de réaliser le projet par étapes successives. L'auteur démonte le reproche fait à la 'Stratégie France' de lier la Sarre à la France de manière unilatérale. Pour la réussite de la stratégie, il faudra faire preuve de persévérance et impliquer de façon cohérente les acteurs de la société civile. En outre, l'auteur suggère de relier la stratégie à d'autres champs politiques, notamment à la stratégie de développement de la Sarre comme lieu d'implantation des entreprises.

Die saarländische Landesregierung hat 2014 eine umfassende, ehrgeizige Frankreichstrategie ins Leben gerufen, die im Saarland wie auch außerhalb Wellen geschlagen hat - zu Recht, weil sie Erwartungen weckt, Kritik hervorruft und auf jeden Fall eine Fülle von grundsätzlichen wie praktischen Fragen aufwirft, die einer breiten Diskussion bedürfen. Ich bin der Einladung, diesen Diskussionsprozess mit einem Blick von außen zu beginnen, gerne gefolgt. Zum einen, weil das Saarland über ein großes Potenzial und Knowhow verfügt, wenn es um die Beziehungen zu Frankreich und um Europa geht - ein Potenzial, das durch die Geschichte, die Nähe zum Nachbarland und zu Luxemburg und durch jahrzehntealtes Engagement vieler Akteure entstanden und gewachsen ist. Zum anderen, weil wir es mit einer bislang einzigartigen Initiative im deutsch-französischen Bereich zu tun haben, der in den vergangenen 50 Jahren wahrlich nicht arm an Initiativen gewesen ist.

Im Folgenden wird der Versuch unternommen, die Frankreichstrategie des Saarlandes und ihren möglichen innovativen Beitrag im Rahmen der deutsch-französischen Beziehungen zu verorten. Dazu ist zunächst ein Blick auf die Grundstrukturen, Dimensionen und hervorstechenden Eigenarten des 
deutsch-französischen Verhältnisses, aber auch auf das demokratische Dilemma der Währungsunion notwendig. Darauf aufbauend soll versucht werden, den Stellenwert der saarländischen Initiative zu beurteilen, und ihre Ziele, Ansprüche, Erfolgsaussichten sowie ihren möglichen Beitrag zur Vertiefung der deutsch-französischen Beziehungen zu bewerten. Die folgenden Ausführungen verstehen sich als kritisch-empathischer Blick eines Beobachters von außen, ohne besondere Insider-Kenntnisse der Strategie, und beruhen auf den bis Juli 2015 öffentlich zugänglichen Dokumenten. ${ }^{1}$

\section{Grundstrukturen und Dimensionen der deutsch-französischen Beziehungen}

Der besondere Charakter der deutsch-französischen Beziehungen ergibt sich aus ihren mehrfachen Dimensionen.

$\mathrm{Da}$ ist erstens die enge Kooperation auf Regierungsebene, die mit dem Elysée-Vertrag von 1963 institutionalisiert wurde. Sie hat ein dichtes Netz an politischer Abstimmung entstehen lassen und mit ihren Initiativen und Vorschlägen immer wieder den Gang der europäischen Integration entscheidend vorangebracht. Zweitens sind die vielfältigen zivilgesellschaftlichen Verflechtungen zwischen beiden Ländern unter- und außerhalb der Regierungsebene hervorzuheben, die aufgrund ihrer Dichte und Vielfalt in den bilateralen Beziehungen zwischen Staaten in Europa einmalig sind. Das Spektrum reicht von den Schul- und Städtepartnerschaften über deutsch-französische Gesellschaften, Jugendbegegnungen im Rahmen des Deutsch-Französischen Jugendwerks, wirtschaftliche Kooperationen, den kulturellen Austausch, Wissenschafts- und Forschungskooperationen (zu nennen hier nur die DeutschFranzösische Hochschule mit 177 Studiengängen und 6700 Studierenden) bis hin zu den deutsch-französischen Grenzregionen. Zigtausende Menschen sind an diesen Netzwerken beteiligt, die Alfred Grosser einmal als die „menschliche Infrastruktur der deutsch-französischen Beziehungen“2 bezeichnet hat. Schließlich ist drittens die deutsch-französische Kooperation kein Selbstzweck. Ihre eigentliche Begründung und Rechtfertigung liegt heute in ihrem Beitrag zu einem starken vereinigten Europa. Das sehen manche Beobachter und Akteure anders, die den deutsch-französischen Beziehungen auch einen eigenständigen genuinen Wert beimessen. Für meinen Teil betone ich diese europäische raison d'être, weil sie die dienende Funktion der deutsch-

1 Vgl. hierzu Staatskanzlei des Saarlandes: Eckpunkte einer Frankreichstrategie für das Saarland, 2014, http://www.saarland.de/dokumente/res_stk/D_Eckpunkte_Frankreich-Strategie_ 210114.pdf (19.07.2016).

2 Grosser, Alfred: Ein Erfolgsmodell wird 50, in: Das Parlament (01/03/2013), http://www. das-parlament.de/2013/01_03/Titelseite/42263576/321606 (19.01.2017). 
französischen Kooperation hervorhebt und auch weil sie vor einer wenig zielführenden deutsch-französischen Nabelschau schützt. Wir werden diesen drei Konstanten im Folgenden wieder begegnen.

\section{Die,Griechenlandkrise' als Symptom: das demokratische Dilemma der EU}

Zunächst aber einmal einige Worte zum aktuellen Stand der deutsch-französischen Beziehungen, v. a. zur, Griechenlandkrise'. Denn diese wirft ein Schlaglicht auf die gegenwärtigen Probleme der europäischen Integration aufgrund der Dramatik der jüngsten Ereignisse, der Abgründe, in die wir alle geschaut haben, der tiefen Spaltungen (zwischen den verschiedenen Ländern, zwischen Griechenland und den Partnern der Eurozone, nicht zuletzt auch zwischen Deutschland und Frankreich), schließlich auch aufgrund der schrillen politischen Begleittöne, die die Suche nach Lösungen begleitet haben, sowie der populistischen Strömungen von links und rechts, die die Stammtische zu beherrschen scheinen und zunehmend auch als Parteien erfolgreich sind.

Hier ist nicht der Ort, um die, Griechenlandkrise‘ auszuleuchten. Es geht um etwas anderes: Die gegenwärtige, seit spätestens 2010 andauernde Krise verweist geradezu paradigmatisch auf Wohl und Wehe des europäischen Einigungsprozesses und der Wirtschafts- und Währungsunion, aber auch auf Erfolge und Grenzen der deutsch-französischen Zusammenarbeit. Drei Punkte sind in diesem Zusammenhang hervorzuheben: zum Ersten die Unterschiede zwischen Deutschland und Frankreich sowie die Funktion der deutsch-französischen Kooperation, zur Kompromissbildung beizutragen; zum Zweiten das immer spürbare Vordringen politischer, ja ideologischer Kontroversen und die Entstehung einer Art europäischen Innenpolitik, schließlich zum Dritten das Demokratiedefizit und die Notwendigkeit einer europäischen Bürgergesellschaft.

Seit Beginn der Währungsunion gibt es unterschiedliche Grundvorstellungen über die Natur dieser Währungsunion, ihre leitenden Prinzipien, ihre Ziele, ihre Organisation und politische Steuerung. Diese Unterschiede spiegeln sich v. a. in den Positionen Frankreichs und Deutschlands wider. Sie sind in den jeweiligen Gesellschaften tief verankert, denn sie sind Ausdruck kollektiver Erfahrungen, Interessen und Präferenzen. Die Regierungen stehen bei Verhandlungen in Brüssel immer auch unter dem Druck ihrer Bürger, die jeweiligen nationalen Grundvorstellungen zu bewahren. Dieser Druck ist in Fragen der Eurozone besonders stark, da die zu treffenden europäischen Entscheidungen Kernbereiche der Haushalts-, Wirtschafts- und Sozialpolitik und damit auch die Interessen aller Bürger direkt betreffen. Das Drama ist 
nun, dass diese Stimmungen beide Regierungen oft in entgegengesetzte Richtungen ziehen und damit europäische Kompromisse noch schwieriger werden. In der ,Griechenlandkrise“ musste sich Angela Merkel gegen erhebliche Vorbehalte in ihrer eigenen Partei und gegen weite Teile der öffentlichen Meinung durchsetzen, denen die erzielte Lösung in Brüssel zu weit ging und die diese als Bruch mit den deutschen Grundwerten verstanden. François Hollande hatte es mit einer Stimmung zu tun, die die deutsche Haltung pauschal als dominant und antieuropäisch diffamierte, Solidarität mit Griechenland einforderte und im Übrigen die Stabilitätsregeln der Währungsunion ablehnte. Umso höher ist zu bewerten, dass beide Regierungen seit 2010 immer wieder in der Lage waren, ihre Differenzen zu überwinden und Kompromisse zu erarbeiten, die die Eurozone stabilisieren konnten.

Allerdings haben es beide Regierungen immer schwerer, innenpolitische Zustimmung zu den erzielten europäischen Kompromissen zu erhalten. Europäische Entscheidungen und Regeln engen die politischen Handlungsspielräume in den Mitgliedstaaten immer stärker ein. Da diese Entscheidungen auf höchster Ebene hinter verschlossenen Türen gefällt werden, macht sich allenthalben politischer Frust über die Ohnmacht der nationalen Demokratien gegenüber europäischen oder internationalen Sachzwängen, über die vermeintlich, von oben' aufgezwungene Europapolitik breit und organisiert sich teilweise in Form euroskeptischer, populistischer oder extremistischer Parteien. Wir haben es längst mit einer Art europäischer Innenpolitik zu tun, aber diese hat noch keine institutionelle Ausdrucksform gefunden, keine Arena, in der sie verhandelt und gestaltet werden könnte.

Das ist eben auch der Preis, den wir dafür zahlen, dass die Währungsunion nicht durch eine entsprechende politische Union ergänzt wurde. Den Entscheidungen im engsten Kreis der ,Chefs' im Europäischen Rat stehen nationale Öffentlichkeiten gegenüber, die sich empören und gegen vermeintlich antidemokratische Diktate aufbegehren. Dabei ist ein nachvollziehbares Gefühl der Ohnmacht gegenüber fernen, undurchschaubaren Mächten im Spiel, oft aber auch ein gutes Stück Demagogie.

Das große Dilemma in Europa ist also, dass es bislang nicht gelungen ist, die komplizierten innenpolitischen Abstimmungs- und Entscheidungsprozesse und die nicht minder komplizierten europäischen Kompromissfindungsprozesse miteinander zu verknüpfen. Hier besteht dringender Handlungsbedarf. Dabei geht es zum einen um neue institutionelle Reformen der EU und der Eurozone, die mehr parlamentarische Debatte, Kontrolle und die Legitimation fördern, die es erlauben, politische Debatten und Willensbildungsprozesse auf europäischer Ebene zu initiieren. Neue Institutionen reichen aber nicht aus. Wir brauchen deshalb zum anderen eine europäische Bürgergesellschaft: Bürger, die die europäische Innenpolitik mit Leben füllen können, die ihr Mitspracherecht einfordern, aber auch eigene aktive Beiträge leisten, damit Europa langsam zusammenwächst. Bürger, die bereit und fähig 
sind, über ihre eigene nationale Perspektive hinauszugehen, die ein Gespür für die kulturelle Vielfalt Europas haben, kurz: die in der Lage sind, europäisch zu denken und zu handeln. Das ist ein gewaltiger kollektiver Lernprozess, der seine Zeit brauchen wird.

\section{Die Frankreichstrategie des Saarlandes}

Hier können wir endlich den Bogen zur Frankreichstrategie schließen. Die eingangs erwähnte einmalige, enge zivilgesellschaftliche Verflechtung zwischen Deutschland und Frankreich lässt sich für diesen Lernprozess nutzen und kann damit ein wertvoller Baustein auf dem Weg zu einer europäischen Bürgergesellschaft sein. Denn sie kann europäische Vielfalt konkret erfahrbar machen und dabei helfen, sie als Reichtum und Chance zu verstehen. Die deutsch-französischen Netzwerke und Partnerschaften stellen in diesem $\mathrm{Zu}$ sammenhang wertvolle Lernfelder dar. Hier kann eingeübt werden, mit Differenzen konstruktiv umzugehen und mit dem Partner unter Respektierung des ,Anderen' und seiner Differenz zusammenzuarbeiten. Genau hier liegt auch die Schnittstelle mit der Frankreichstrategie des Saarlandes: Diese hebt stark auf die Bürger und die Zivilgesellschaft ab, die sie sprachlich und interkulturell befähigen will, das Zusammenleben zwischen Deutschen und Franzosen, im Saarland wie in der Großregion, aktiv zu gestalten. So kann die Strategie exemplarisch zeigen, wie grenzüberschreitende Räume in Europa zusammenwachsen können. Damit haben wir auch die zentrale Funktion umrissen, die die Frankreichstrategie erfüllen kann: Baustein, vielleicht auch Motor zu sein auf dem langen Weg zu einer europäischen Bürgergesellschaft.

Der politische Wille, der hier zum Ausdruck kommt und der offensichtlich von einem breiten politischen und gesellschaftlichen Spektrum getragen wird, ${ }^{3}$ hat etwas Erfrischendes. Wer beispielsweise in der Sprachenfrage die oft quälenden jahre-, ja jahrzehntelangen bürokratischen Abstimmungsprozesse in der Kultusministerkonferenz beobachtet hat, wer erlebt hat, wie oft die Bedenkenträger jeglicher Couleur neue Initiativen klein- und zerreden, der kann den Voluntarismus der Landesregierung nur nachdrücklich begrüßen.

3 Vgl. den fraktionsübergreifenden Antrag „Europa ist die Zukunft - Großregion als europäisches Vorbild stärken“, Landtag des Saarlandes, 15. Wahlperiode, Drucksache 15/1899NEU vom 12.07.2016, https://www.landtag-saar.de/Drucksache/Ag15_1899-NEU.pdf (19.01.2017). Nach einer Forsa-Umfrage für das Magazin Forum halten $70 \%$ der Befragten es für richtig und wichtig, dass Französisch anders als in anderen Bundesländern, die erste Fremdsprache ist. Vgl. die Meldung in Radio Salü vom 25.11.2016: „Große Zustimmung zur Frankreichstrategie“, http://www.salue.de/nachrichten/message-80859.phtml (19.01.2017). 
Ein ähnlich positives Vorurteil gilt dem innovativen und visionären Charakter der Frankreichstrategie, ebenso wie ihrem langfristigen Ansatz. Denn sie betritt völliges Neuland und hat den Mut zum großen Wurf. Außerdem: In einer Zeit, in der die Politik oft nicht über den Horizont der kommenden Wahlen hinaus denkt, hat dieses Generationenprojekt schon einen großen Charme.

Gleichzeitig ist zu begrüßen, dass die Visionen auch geerdet und in konkreten Einzelschritten umgesetzt werden, wie dies an der Feuille de route der Landesregierung sichtbar wird. ${ }^{4}$ Dort wird auch der Realismus erkennbar, der die ins Auge gefassten Maßnahmen zur Umsetzung mit den sehr begrenzten finanzpolitischen Spielräumen in Einklang zu bringen versucht.

Last, but not least gefällt der ganzheitliche Charakter der Frankreichstrategie, die sowohl als Querschnittspolitik verschiedene Politikfelder umfasst als auch den schon erwähnten zivilgesellschaftlichen Akteuren eine große Rolle zubilligt.

\subsection{Zielsetzungen und Ansprüche}

Zunächst einmal möchte ich darauf eingehen, was die Strategie nicht leisten kann. Der gesamte Bereich der Regierungszusammenarbeit, der v. a. die großen politischen und ökonomischen Themenfelder der EU (Binnenmarkt, Währungsunion, Außenpolitik etc.) umfasst, kann nicht das primäre Spielfeld einer saarländischen Frankreichstrategie sein, da sie weitgehend - ausgenommen natürlich die Kultur- und Bildungspolitik - in die Kompetenz des Bundes fällt.

Kritisch sind in diesem Zusammenhang manche Formulierungen im untengenannten Eckpunktepapier zu sehen, die die Möglichkeiten eines Bundeslandes überschätzen. Dies gilt etwa für den Anspruch, das Saarland solle bei „deutsch-französischen Themen unentbehrlich und unumgänglich“5 und „im Bundesgebiet erster Ansprechpartner für deutsch-französische Beziehungen werden“", oder aber den Anspruch auf ein „Alleinstellungsmerkmal“" zur „Frankreich-Kompetenz" ${ }^{\text {“7 }}$.

Ohne Zweifel kann sich das Saarland, eine erfolgreiche Umsetzung der Frankreichstrategie vorausgesetzt, als Brücke zwischen Deutschland und Frankreich, als „Brücke nach Deutschland“ aus französischer Sicht und als

4 Vgl Landesregierung des Saarlandes: Feuille de route Frankreich-Strategie 2015/2016, 2015, http://saarland.de/dokumente/ressort_finanzen/Feuille_de_route.pdf (19.07.2016).

5 Staatskanzlei des Saarlandes: Eckpunkte einer Frankreichstrategie, S. 8.

6 Staatskanzlei des Saarlandes: Eckpunkte einer Frankreichstrategie, S. 10.

7 Staatskanzlei des Saarlandes: Eckpunkte einer Frankreichstrategie, S. 17. 
„Tor zu Frankreich"8 verstehen. Die darin zumindest implizit mitschwingende Vorstellung aber, die Beziehungen zwischen beiden Ländern würden künftig gleichsam obligatorisch durch das saarländische Tor gehen, scheint deutlich überzogen - allein deshalb, weil die Beziehungen zwischen unseren beiden Ländern so vielfältig geworden sind und von zahlreichen politischen, wirtschaftlichen und gesellschaftlichen Akteuren auf allen Ebenen unterhalten werden. Bei allem Respekt: Nein, Berlin und Paris brauchen für zahlreiche Aspekte ihrer Kooperationsbeziehungen keinen saarländischen Brückenpfeiler.

Auch was das o. g. „Alleinstellungsmerkmal“ bei der Frankreichkompetenz angeht, wäre mehr Realismus angezeigt. Alleinstellungsmerkmal? Ja, wenn das Saarland einmal das einzige Bundesland sein wird, in dem Zweisprachigkeit im Alltag gelebt wird und in dem eine neue Qualität einer wirklichen grenzüberschreitenden Region entstanden ist. Nein, wenn es um den erhobenen Anspruch der Frankreichkompetenz geht: In ganz Deutschland gibt es auch außerhalb des Saarlandes zahllose Orte, Akteure, Institutionen, an denen diese Kompetenz existiert und tagtäglich entsteht, gepflegt und genutzt wird. Zudem haben sich, gerade in der Wirtschaft und in den zahlreichen Branchen- und Berufsverbänden, die Beziehungen auf der Nicht-Regierungsebene so stark ausdifferenziert (professionalisiert, würde mein Kollege Frank Baasner sagen) ${ }^{9}$ und sind von einer so starken Eigendynamik und Eigenlogik getragen, dass es auch professionellen Beobachtern der deutschfranzösischen Szene schwer fällt, noch die Übersicht zu behalten. Überall dort entwickelt sich Frankreichkompetenz, sodass es unrealistisch erscheint, hier ein Monopol für ein einziges Bundesland reklamieren zu wollen.

In diesem Zusammenhang mutet es überzogen an, wenn in den Eckpunkten mit Fleiß alle Spiegelstriche zusammengetragen worden sind, die in irgendeiner Weise das Saarland hervorheben. Erstes Beispiel: Das Amt des Bevollmächtigten für die deutsch-französischen Kulturbeziehungen wurde zwar von der saarländischen Ministerpräsidentin Kramp-Karrenbauer ausgeübt, es ist aber nicht per se im Saarland lokalisiert, sondern rotiert in regelmäßigen Abständen. ${ }^{10}$ Zweites Beispiel: Es wird ein Alumni-Netzwerk angeregt und in diesem Zusammenhang auf die Deutsch-Französische Hochschule mit Sitz in Saarbrücken verwiesen - dabei geschieht bekanntlich die eigentliche Arbeit in den zahlreichen Mitgliedsuniversitäten beider Länder, in den von ihnen gestalteten integrierten Studiengängen.

8 Staatskanzlei des Saarlandes: Eckpunkte einer Frankreichstrategie, S. 32.

9 Vgl. Baasner, Frank: Die aktuelle Architektur der deutsch-französischen Zusammenarbeit, in: Seidendorf, Stefan (Hg.): Deutsch-Französische Beziehungen als Modellbaukasten? Zur Übertragbarkeit von Aussöbnung und strukturierter Zusammenarbeit, Baden-Baden: Nomos, 2012, S. 76-88.

10 Seit Januar 2015 wird es z. B. von Hamburgs Bürgermeister Olaf Scholz bekleidet. 
Soviel Kritik darf und muss sein! Wie aber kann man positiv formulieren, welche Zielsetzung die Frankreichstrategie realistischer Weise haben könnte und sollte, und wo ihre Ambitionen sinnvoll angesiedelt sein können? Die Frankreichstrategie, wenn sie denn mit Leben erfüllt wird, stellt eine Lernund Ideenwerkstatt in großem Maßstab dar, die die Saarländer (oder jedenfalls einen nennenswerten Teil) nicht nur zu bilingualen und ,frankreichkompetenten' Bürgern macht, sondern darüber hinaus auch zu europäischen Bürgern, ohne die die europäische Einigung auf Dauer zum Scheitern verurteilt ist. Damit könnte sie eine Pilotfunktion einnehmen für den langen Weg hin zu einer europäischen Bürgerunion.

\subsection{Eine einseitige Strategie?}

Die Kritik an der Einseitigkeit der Frankreichstrategie hat zwei Facetten. Zum einen wird moniert, dass sich das Saarland einseitig an Frankreich binde und damit möglicherweise andere Möglichkeiten verpassen könnte. Zum anderen wird kritisiert, dass es sich um eine saarländische Strategie der Hinwendung und Öffnung nach Frankreich handele, ohne dass von der französischen Seite entsprechende Anstrengungen unternommen würden. Diese Kritik scheint nicht stichhaltig, sie sollte aber ernst genommen werden und auch dazu dienen, den Fokus der Frankreichstrategie genauer und differenzierter zu bestimmen.

Zur einseitigen Bindung an Frankreich: Dieser Vorwurf ist oft mit diffusen Ängsten verbunden. Dies hat sich z. B. in Baden-Württemberg gezeigt, wo es wahre Elternaufstände entlang der Rheinschiene gegeben hat, weil dort die Kinder in der Grundschule Französisch und nicht wie im übrigen Land Englisch lernen müssen. Die Ängste gingen dahin, man gefährde die Zukunft der Kinder, weil sie nicht die Sprache der Globalisierung lernen dürften. Das ist natürlich Unsinn - es sei auf die umfangreiche Literatur zum Spracherwerb verwiesen, die zeigt, wie schnell Englisch als lingua franca gelernt werden kann, auch wenn sie erst die zweite Fremdsprache ist.

Ein weiteres Argument zielt auf die mangelnde Bedeutung Frankreichs ab. Hier gibt es ja in den Medien, aber auch in manchen politischen Kreisen eine Tradition des ,Frankreich-Bashings', die bis in die Gegenwart fortgeführt wird: Sie reibt sich am angeblichen Weltmachtanspruch Frankreichs (gerne unterlegt mit dem in Frankreich überhaupt nicht verwendeten Begriff der ,Grande Nation'); sie verweist auf die in der Tat schweren strukturellen Probleme der französischen Wirtschaft; schließlich behauptet sie, eine gedeihliche Zusammenarbeit zwischen beiden Ländern sei aufgrund der grundlegenden Unterschiede in Politik, Wirtschaft und Gesellschaft nicht möglich. 
Stichhaltig ist diese Kritik nicht. In Bezug auf die Strategie des Saarlandes ist festzuhalten:

Erstens: Das Saarland hat nun einmal eine historisch bewegte, enge Nachbarschaft mit Frankreich und ist wie kein anderes Bundesland mit Frankreich und mit der Großregion vielfältig verbunden. Allein diese Tatsache ist ein gewichtiges Argument für eine saarländische Frankreichstrategie.

Zweitens: Frankreich ist wichtig, nicht nur für das Saarland, sondern für ganz Deutschland und Europa. Es ist nach wie vor die zweitstärkste Ökonomie Europas, unser wichtigster Handelspartner und ein unentbehrlicher Partner für die gemeinsame Gestaltung Europas. Auch wenn das in manche Köpfe nicht immer hinein will: Nur in der Partnerschaft (und Auseinandersetzung, das gehört auch dazu) mit Frankreich kann Deutschland seine Vorstellungen in Europa vorantreiben. Die jüngste ,Griechenlandkrise ' ist ein beredtes Beispiel dafür. Deutsche Alleingänge oder eine Allianz der Nordund mancher Ostländer sind illusorisch - genauso übrigens wie der manchmal in Frankreich gepflegte Traum von der Koalition des Südens gegen den deutschen Ordoliberalismus. Nur der Schulterschluss mit Paris verleiht Lösungsvorschlägen die notwendige Legitimität in Europa, damit sie auch von allen anderen Partnern akzeptiert werden können. Deshalb ist es sinnvoll, in der deutsch-französischen Zusammenarbeit nach tragfähigen Kompromissen zu suchen. Denn Europa ist immer Kompromiss und die Fähigkeit zur Kompromissfindung ist und bleibt ein wesentlicher Grundpfeiler für die Entwicklung der EU.

Die Landesregierung hat also überhaupt keinen Anlass, bei ihrer Frankreichstrategie Abstriche zu machen oder sich gar dafür zu entschuldigen. Der einzige Einwand, den ich machen würde, ist folgender: Der eigentliche Fokus aller deutsch-französischen Initiativen, also auch der Frankreichstrategie, ist Europa. Es gibt bei manchen Frankophilen die Neigung, sich in einer Art deutsch-französischer Exklusivität, oft auch liebevoll le franco-allemand genannt, gemütlich einzurichten. Eine solche Überhöhung und Überdehnung des Deutsch-Französischen wurde am Deutsch-Französischen Institut Ludwigsburg (DFI) immer für falsch gehalten. Denn das enge bilaterale Verhältnis zwischen unseren beiden Ländern ist kein Selbstzweck; es hat vielmehr eine dienende Funktion in und für Europa und muss sich immer auch an seinem Beitrag zur Lösung europäischer Probleme messen lassen. Dementsprechend kann die Frankreichstrategie nur gewinnen, wenn sie sich als ein Pilotprojekt für ein Europa der (Grenz-)Regionen, ein Europa der Bürger definiert, und wenn sie für andere Sprachen, andere Länder und Regionen offen bleibt. Dies scheint ja der Fall zu sein. In diesem Zusammenhang kann natürlich auch die Großregion eine wichtige Rolle spielen, in der die bilaterale Zweisamkeit bereits durch die Präsenz Luxemburgs aufgehoben ist.

Schließlich, was die Reziprozität von französischer Seite angeht: Es ist vollkommen richtig, zunächst einmal eine eigene saarländische Strategie zu 
definieren - wenn man bei derartigen Projekten von vorneherein deutschfranzösische Parität verlangen oder gar zur Voraussetzung machen wollte, wäre ein Scheitern fast vorprogrammiert. Aber es sind ja von Beginn an wichtige lothringische Partner in den Prozess eingebunden worden und haben sich dazu auch positiv positioniert. Die Erwartung, mit dieser Strategie eine Dynamik auszulösen, die dann auch bei den Nachbarn zu Anstößen führt, hat sich offensichtlich als richtig erwiesen. Die Ankündigungen einer 'Stratégie Allemagne' in Lothringen und entsprechende Initiativen im Departement Moselle sind jedenfalls gute Argumente dafür. ${ }^{11}$

\subsection{Erfolgsfaktoren der Frankreichstrategie}

Kommen wir abschließend zu den Faktoren, die für den Erfolg der Frankreichstrategie eine Rolle spielen.

Erstens: Es erscheint sinnvoll, diese Strategie als Teil einer generellen Standortpolitik (im weiten Sinne dieses Begriffes) für das Saarland zu verstehen. Anders - und etwas drastisch - ausgedrückt: Von Frankreichkompetenz alleine kann niemand leben! (Ähnliches gilt übrigens auch für Personen: Erst die Verknüpfung der Sprach- und der interkulturellen Kompetenz mit anderen Kompetenzfeldern verspricht Erfolg.) Deshalb ist es nur folgerichtig, wenn die Landesregierung ihr Konzept einbettet in andere zentrale Dimensionen der Landespolitik: Auf Seite 3 der Eckpunkte werden die Sicherung der Eigenständigkeit und die Einhaltung der Schuldenbremse angesprochen. ${ }^{12}$ Ich würde noch weiter gehen: Der Erfolg der Frankreichstrategie erfordert auch eine mit ihr abgestimmte, langfristig angelegte Standortstrategie, um das Saarland als Wirtschaftsraum attraktiv für Investoren und für Arbeitskräfte zu machen. In der Perspektive der Wissensgesellschaft und auch im Einklang mit der EU-Strategie „Europa 2020"13 sind hier v. a. Bildung und Ausbildung, Hochschulen, Forschung und Innovation angesprochen. Die Frankreichstrategie würde erheblich an Schlagkraft gewinnen, wenn es gelänge, sie mit dieser Standortstrategie zu verknüpfen. Ansatzpunkte gibt es dafür genug - man denke nur an die Arbeitskräfte, die im Saarland wie in Lothringen im Automobilsektor arbeiten. Synergieeffekte durch gemeinsame Exzellenzcluster bzw. pôles de compétitivité - das wären wichtige Elemente zur Stützung der Frankreichstrategie und umgekehrt.

11 Vgl. Tran, Doan: Stratégie Allemagne de la Lorraine - Rapport final, Conseil Municipal de Metz, Séance du 29 août 2015.

12 Vgl. Staatskanzlei des Saarlandes: Eckpunkte einer Frankreichstrategie, S. 3.

13 Europäische Kommission: Europa 2020. Eine Strategie für intelligentes, nachbaltiges und integratives Wachstum, Mitteilung Brüssel, 03.03.2010, http://eur-lex.europa.eu/LexUriServ/ LexUriServ.do?uri=COM:2010:2020:FIN:DE:PDF (19.01.2017). 
Zweitens soll nochmals auf den ganzheitlichen, langfristigen, zivilgesellschaftlichen Charakter des Projektes zurückgekommen werden. Um das Projekt wirklich auf Dauer zu stellen, muss die Politik der Versuchung widerstehen, kurzfristig politisches Kapital schlagen zu wollen. Ferner steht und fällt das Projekt mit der umfänglichen Einbeziehung u. a. der Zivilgesellschaft, der Vereine, Verbände und Institutionen. Nur sie können die Akzeptanz der Strategie, ihre Verankerung in der Bevölkerung fördern; ihr aktiver Beitrag ist gefragt, um die Strategie mit Leben und Dynamik zu füllen. All dies hat auch eine regionalpolitische Dimension. Einschlägige Untersuchungen haben immer wieder darauf hingewiesen, dass erfolgreiche Wirtschaftsräume ein besonders hohes $\mathrm{Maß}$ an Interaktion zwischen allen ihren öffentlichen und privaten Akteuren aufweisen, insbesondere wenn es ihnen gelingt, die genannten Partner für ein übergreifendes Projekt der politischen, wirtschaftlichen und sozialen Entwicklung zu mobilisieren. ${ }^{14}$

Schließlich noch eine Bemerkung zu den wichtigen Instrumenten und Hebeln der Strategie. Es ist richtig, in erster Linie an den Bereichen Sprache, Bildung und Ausbildung, Hochschulen und Forschung anzusetzen: Hier stehen dem Land erhebliche politische (leider nicht so viele finanzielle) Ressourcen zur Verfügung, hier kann es auch am ehesten autonome Akzente setzen, und hier stehen im Saarland wie in Lothringen Partner bereit, die willens sind, sich aktiv einzubringen. Wie oben erwähnt, sollte auch das Feld der regionalen Wirtschaftsförderung, der Standortpolitik einbezogen werden; hier hat das Land ebenfalls weitgehende politische Spielräume.

Auf anderen Ebenen sind die Mühen und Herausforderungen in der grenzüberschreitenden Kooperation bereits in Erscheinung getreten, etwa wenn es um die konkrete Umsetzung von grenzüberschreitender Mobilität geht, um steuerpolitische Regeln, Soziale Sicherung und das Gesundheitssystem. Hier besteht in hohem Maße eine Abhängigkeit vom guten Willen anderer Ebenen - vom Bund ebenso wie vom französischen Zentralstaat. Insofern mutet die folgende Formulierung in den Eckpunkten sehr optimistisch an: „Es wird angestrebt, dass das Steuer-, Sozial- und Gesundheitssystem diesen zunächst bilateralen Entwicklungen angepasst wird und sich als Modell für Europa etabliert" ${ }^{15}$ Ein sehr ambitioniertes Vorhaben, das sicherlich in einer langfristigen Perspektive gedacht werden müsste. Möglicherweise wäre die in den Eckpunkten ins Spiel gebrachte Experimentierklausel, die zeitlich befristete deutsch-französische Maßnahmen ermöglicht, ${ }^{16}$ eine Forderung, für die man politische Unterstützung einwerben könnte.

14 Vgl. Benko, Georges/Lipietz, Alain (Hg.): Les régions qui gagnent, Paris: PUF, 1992; Nuissl von Rein, Ekkehard: Netzwerkbildung und Regionalentwicklung, Oldenburg: Carl von Ossietzky Universität, 2013.

15 Staatskanzlei des Saarlandes: Eckpunkte einer Frankreichstrategie, S. 11.

16 Vgl. Staatskanzlei des Saarlandes: Eckpunkte einer Frankreichstrategie, S. 34. 


\section{Zum Schluss}

Die Frankreichstrategie ist ein sehr ehrgeiziges, in dieser Form bislang einmaliges Projekt, das geeignet ist, sowohl das Saarland selbst voranzubringen als auch einen innovativen Akzent für ein Europa der Bürger und der Regionen zu setzen. Es wird Hindernisse geben, Widerstände jeglicher Art und manchen Ideen werden womöglich Grenzen gesetzt werden. Es wird einen langen Atem brauchen. Und die Brötchen, die gebacken, und die Räder, die gedreht werden können, werden vielleicht für lange Zeit noch klein sein, kleiner jedenfalls, als es in den Visionen der Strategie zum Ausdruck kommt.

Aber: Dies alles ändert nichts an der Tatsache, dass es sich um einen im Kern richtigen, wegweisenden Ansatz handelt. Was die kleinen Brötchen angeht, so möchte ich mit dem Motto der Landesregierung schließen: „Großes entsteht immer im Kleinen“. Dem kann man nur zustimmen und hinzufügen: Bonne chance!

\section{Literaturverzeichnis}

Baasner, Frank: Die aktuelle Architektur der deutsch-französischen Zusammenarbeit, in: Seidendorf, Stefan (Hg.): Deutsch-Franz̈ösische Beqiehungen als Modellbaukasten? Zur Übertragbarkeit von Aussöbnung und strukturierter Zusammenarbeit, Baden-Baden: Nomos, 2012, S. 76-88.

Benko, Georges/Lipietz, Alain (Hg.): Les régions qui gagnent, Paris: PUF, 1992.

Europäische Kommission: Europa 2020. Eine Strategie für intelligentes, nachbaltiges und integratives Wachstum, Mitteilung Brüssel, 03.03.2010, http://eur-lex.europa.eu/LexUriServ/ LexUriServ.do?uri=COM:2010:2020:FIN:DE:PDF (19.01.2017).

Grosser, Alfred: Ein Erfolgsmodell wird 50, in: Das Parlament (01/03/2013), http://www.dasparlament.de/2013/01_03/Titelseite/42263576/321606 (19.01.2017).

Landesregierung des Saarlandes: Feuille de route Frankreich-Strategie 2015/2016, 2015, http:// saarland.de/dokumente/ressort_finanzen/Feuille_de_route.pdf (19.07.2016).

Landtag des Saarlandes: „Europa ist die Zukunft - Großregion als europäisches Vorbild stärken“, 15. Wahlperiode, Drucksache 15/1899-NEU vom 12.07.2016, https://www. landtag-saar.de/Drucksache/Ag15_1899-NEU.pdf (19.01.2017).

Nuissl von Rein, Ekkehard: Netzperkbildung und Regionalentwicklung, Oldenburg: Carl von Ossietzky Universität, 2013.

Radio Salü: „Große Zustimmung zur Frankreichstrategie“, 25.11.2016, http://www.salue.de/ nachrichten/message-80859.phtml (19.01.2017).

Staatskanzlei des Saarlandes: Eckpunkte einer Frankreichstrategie für das Saarland, 2014, http:// www.saarland.de/dokumente/res_stk/D_Eckpunkte_Frankreich-Strategie_210114.pdf (19.07.2016).

Tran, Doan: Stratégie Allemagne de la Lorraine - Rapport final, Conseil Municipal de Metz, Séance du 29 août 2015. 


\title{
Die Saar-Politik und die deutsch-französische Geschichte an der Grenze
}

\author{
Herausforderungen, Handlungsmargen, ,Frankreichstrategien“ \\ in Völkerbunds-, Saarstaats- und frühen Bundeslandzeiten
}

Avant et plus encore après la Première Guerre mondiale, l'bistoire des relations francoallemandes était plutôt mouvementée. De conflits, les deux pays sont passés à la communication. Les destins de la Sarre, quant à eux, étaient toujours fortement imbriqués dans cette bistoire. L'article met en lumière trois phases de l'bistoire franco-allemande de la Sarre: celle de la Société des Nations entre 1920 et 1935, celle de l'État de la Sarre entre 1945 et 1955 ainsi que celle du jeune Land tout au long des années 60. En gardant en toile de fond la 'Stratégie France' actuelle du gouvernement de la Sarre, l'article s'interroge sur les défis de chaque époque, sur les marges d'action et sur les 'stratégies France' de la politique sarroise durant ces trois phases. Aussi s'intéresse-il aux ressemblances et aux différences structurelles tout comme conjoncturelles des relations avec le voisin français à différentes époques.

Als die Landesregierung im Januar 2014 die seitdem intensiv und kontrovers diskutierten Eckpunkte einer Frankreichstrategie für das Saarland ${ }^{1}$ vorstellte, konnte die Saar bereits auf eine fast hundertjährige Geschichte zurückblicken, in deren Verlauf sich politische Akteure immer wieder aufs Neue als Staat und Nation gegenüber Frankreich zu positionieren hatten. Durchweg geschah dies auf der Folie eines deutsch-französischen Verhältnisses, das jahrzehntelang vorrangig unter konfliktuell-feindseligen, später dann unter konsensuell-verständigungspolitischen Vorzeichen stand. Von einem Novum kann deshalb keine Rede sein: ,Frankreichstrategien' für die Grenzregion zu entwickeln, bildete spätestens seit dem Ende des Ersten Weltkrieges 1918 eine der ganz zentralen Herausforderungen, mit denen sich die Saar-Politik stets konfrontiert sah. Selten bot sich dabei den Entscheidungsträgern vor Ort die Chance, die Dinge eigenständig in die Hand zu nehmen und voranzubringen. Nicht ein Wunderland unbegrenzter Möglichkeiten war die Regel, eher ein in vielerlei Hinsicht eingehegtes Politikfeld ,Frankreich“ mit Handlungsmargen, die nach 1920 gewiss geringer ausfielen als nach 1945 und die nach 1945 wiederum

1 Staatskanzlei des Saarlandes: Eckpunkte einer Frankreichstrategie für das Saarland, 2014, http:// www.saarland.de/dokumente/res_stk/D_Eckpunkte_Frankreich-Strategie_210114.pdf (16.08.2016). 
ganz anders ausgestaltet waren als zu Zeiten der Saar-Bundesland-Geschichte seit 1957.

\section{Zeitgeschichte \& ,Frankreichstrategien' an der Saar}

Wenn es nun weniger um aktuelle Debatten und politische Projekte für die nähere Zukunft geht, vielmehr darum, heutige Visionen in eine zeithistorische Perspektive zu rücken, dann sind die ,Frankreich-Strategien' näher zu betrachten, die Saar-Akteure unter den jeweils spezifischen Bedingungen der regionalgeschichtlichen Epochen und Zäsuren entwickelt haben, um auf die Herausforderungen der Internationalen Ordnung sowie respektive französischer und deutscher Ansprüche zu reagieren. Gemeint sind Situationen und Perioden nach 1918/19, als die Saar infolge des Versailler Friedensschlusses überhaupt erst als geschlossene politisch-administrative Einheit auf den Plan treten sollte, wenn auch unter der Ägide des gerade geschaffenen Völkerbundes. Die kommenden Jahrzehnte markierten dann eine ungewöhnliche, eine wahrhaft bewegte Geschichte im deutsch-französischen Grenzraum, die nichts anschaulicher dokumentiert als der mehrfache Wechsel des territorialen Status und der staatlichen Zugehörigkeit: Kaiserreich bis 1918, Völkerbundsmandat, Deutsches, sprich damals ,Drittes Reich', nach Kriegsende dann teilautonomer Saarstaat, seit 1957 schließlich: zehntes Land der jungen Bundesrepublik Deutschland. ${ }^{2}$

Dabei haben die Menschen an der Saar die Geschicke dieses Raumes nach 1918 erst einmal nicht selbst bestimmen können. Es war der Kohlereichtum, der die Saar nach Kriegsende auf die internationale Bühne spülte: freilich nicht als Akteur, sondern als Objekt, als Spielball eines europäischen Interessenausgleichs zwischen Siegern und Besiegten, zwischen Frankreich und Deutschland. Nach dem Zweiten Weltkrieg war dies ganz ähnlich. An zwei Wegmarken der Geschichte - am 13. Januar 1935 und am 23. Oktober 1955 - war die Saarbevölkerung allerdings aufgerufen, selbst zu entscheiden, wohin die Reise denn gehen solle. Die beiden Volksabstimmungen erbrachten eindeutige Ergebnisse: 1935 entfielen über $90 \%$ der abgegebenen Stimmen auf die Option „Heim ins Reich“, 1955 über 67 \% gegen die Option ,Saarstatut'. Ein Votum, das damals Politiker in Paris und Bonn umstandslos als Auftrag begriffen, die Saar in die Bundesrepublik einzugliedern. Beide Saar-Befragungen veranschaulichen Komplexität und Dilemmata europäischer Geschichte im

2 Als jüngste Überblickswerke zur Saargeschichte vgl. Behringer, Wolfgang/Clemens, Gabriele: Geschichte des Saarlandes, München: Beck, 2009; Burgard, Paul: Kleine Gescbicbte des Saarlandes, Leinfelden-Echterdingen: G. Braun Buchverlag, 2012; Herrmann, Hans-Christian/ Schmitt, Johannes (Hg.): Das Saarland. Geschichte einer Region, St. Ingbert: Röhrig, 2012. 
Zeitalter der Weltkriege und Nachkriegsjahre. Aber auch die ganze Komplexität und die Dilemmata der Saar-Geschichte und der Beziehungen zu Frankreich.

\section{Leitfragen und Erkenntnisinteressen}

Beiden Volksabstimmungen sind monatelange Abstimmungskämpfe vorausgegangen. Die Saar erlebte hochemotional, mit harten Bandagen und hohem Gewaltpotential ausgetragene politische Auseinandersetzungen, die dauerhaft tiefe Spuren in der Saar-Gesellschaft hinterlassen haben. ${ }^{3}$ Und es waren Abstimmungskämpfe, bei denen es in beiden Fällen auch um das Verhältnis zu Frankreich ging und um die ,Frankreichstrategien' der Saar-Politik nach dem Ersten und Zweiten Weltkrieg. Wenn wir auf den nächsten Seiten schlaglichtartige und diachron vergleichende Blicke auf die Saar in Völkerbundszeiten 1920 bis 1935, in Saarstaatszeiten 1945 bis 1955 und in den frühen Bundeslandzeiten nach 1957/59 werfen, stehen folgende Fragen im Fokus: Welche relevanten Politik-Entscheider lassen sich jeweils ausmachen? Welche waren die frankreichbezogenen bzw. deutsch-französischen Herausforderungen, die sich an der Saar widerspiegelten, und welche Handlungsmargen besaß denn die Saar-Politik überhaupt, um darauf zu reagieren, um ,Frankreichstrategien ${ }^{6}$ anzuregen? Welche Umsetzungspraktiken sind dabei erkennbar, mit welchen Konsequenzen und welchen Veränderungen im Zeitverlauf?

Der folgende Text wird dies nicht schematisch Punkt für Punkt abarbeiten, sondern versuchen, unsere Leitfragen etwas systematischer anzugehen. Zunächst durch einen genaueren Blick auf die Geschehnisse rund um die Großereignisse der Saar-Selbstbestimmung 1935 und 1955. Vor dem Hintergrund von eineinhalb Völkerbundsdekaden an der Saar und der nationalsozialistischen Machtübernahme in Deutschland zwei Jahre vor Ablauf des

3 Auch für die Forschungslandschaft zur Saargeschichte sind diese Spuren virulenter Konflikte weit über das Jahr 1955 hinaus prägend geblieben. Für die letzten 20 Jahre lässt sich aber ein Trend zur Historisierung feststellen. Nicht im Sinne einer glattgebügelten Meistererzählung der Saargeschichte im 20. Jahrhundert ohne jegliche Kontroverse. Historisierung meint aber, dass solche Meinungsverschiedenheiten aus den Fußstapfen politischer Konfliktlinien der Abstimmungszeit herausgetreten sind und inzwischen auf dem Feld der Wissenschaft ausgetragen werden. Vgl. besonders Hudemann, Rainer/Poidevin, Raymond (Hg.): Die Saar 1945-1955. Ein Problem der europäischen Geschicbte, München: Oldenbourg, 1995; Heinen, Armin: Saarjabre. Politike und Wirtschaft im Saarland 1945-1955, Stuttgart: Steiner, 1996; Hudemann, Rainer/Jellonnek, Burkhard/Rauls, Bernd (Hg.): Grenz-Fall. Das Saarland zwischen Frankereich und Deutschland 1945-1960, St. Ingbert: Röhrig, 1997; Linsmayer, Ludwig (Hg.): Die Geburt des Saarlandes. Zur Dramaturgie eines Sonderweges, Saarbrücken: Landesarchiv Saarbrücken, 2007 (Echolot 3); Küppers, Heinrich: Johannes Hoffmann 1890-1967. Geschichte eines Deutschen, Düsseldorf: Droste, 2008. 
Mandats werden Erklärungsangebote für das Votum der Wählerschaft am 13. Januar 1935 formuliert, die dann als Folie für die Jahre zwischen 1945 bis 1955 und die Resultate am 23. Oktober 1955 dienen. Auf das Benennen struktureller, frankreichstrategischer ${ }^{6}$ Ähnlichkeiten und Unterschiede der beiden Zeitabschnitte folgen abschließend ein paar perspektivische Hinweise auf ,Frankreichstrategien' saarländischer Politik unter den ziemlich veränderten Prämissen des Grenzraumes als zehntes Bundesland der Bundesrepublik Deutschland. Doch beginnen wir mit der Zeit nach 1920 und der Volksabstimmung im Januar 1935.

\section{Völkerbundszeiten 1920-1935 -}

\section{,Deutsch-Sein` an der Saar als defensive ,Frankreichstrategie‘}

Im Vergleich zu 1955 markiert 1935 das erklärungsbedürftigere und das ambivalentere Ereignis. ${ }^{4}$ Und dies aus zwei Gründen: Bei den Landesratswahlen 1932 erzielte die NSDAP an der Saar gerade einmal 6,7\% der abgegebenen Stimmen und musste sich - noch hinter den Liberalen - mit einem Platz als fünfte politische Kraft zufriedengeben. ${ }^{5}$ Die katholische Zentrumspartei, die seit Jahren dominierte, kam auf gut $43 \%$, Kommunisten und Sozialdemokraten gemeinsam auf knapp $33 \%$. Genau die Wählermilieus, die in Weimar vergleichsweise resistent gegenüber der NSDAP blieben, drückten der Saarpolitik der Völkerbundszeit den Stempel auf. Zweitens ließ sich bevor es 1935 zur Abstimmung kam - der Nationalsozialismus als Regime enthemmter politischer Gewalt und rassistisch-antisemitischer Ausgrenzung schon zwei Jahre lang verfolgen: im ,Dritten Reich'selbst, aber auch vor der eigenen Haustüre. Dort freilich in etwas gebremsteren Bahnen dank der Präsenz der internationalen Regierungskommission.

Gewiss sind damit 90,7\% der abgegebenen Stimmen für die Option Deutsches und ,Drittes Reich` besonders erklärungsbedürftig. Nicht alle relevanten Erklärungen sind frankreichbezogen, wie etwa die Rolle der Amtskirche im Vorfeld der Volksabstimmung, besonders des Trierer Bischofs, der

4 Als Standardwerk vgl. Linsmayer, Ludwig: Politische Kultur im Saargebiet 1920-1932. Symbolische Politik, verbinderte Demokratisierung, nationalisiertes Kulturleben in einer abgetrennten Region, St. Ingbert: Röhrig, 1992. Daneben Linsmayer, Ludwig (Hg.): Der 13. Januar. Die Saar im Brennpunkt der Geschichte, Saarbrücken: Landesarchiv Saarbrücken, 2005; Becker, Frank G.: „Deutsch die Saar, immerdar!“- Die Saarpropaganda des Bundes der Saarvereine 1919-1935, Saarbrücken: Kommission für Saarländische Landesgeschichte und Volksforschung, 2007 (Veröffentlichungen der Kommission für Saarländische Landesgeschichte und Volksforschung 40).

$5 \quad$ Klassisch Zenner, Maria: Parteien und Politik im Saargebiet unter dem Völkerbundsregime 1920_ 1935, Saarbrücken: Thinnes \& Nolte, 1966 (Veröffentlichungen der Kommission für Saarländische Landesgeschichte und Volksforschung 3), S. 251-256. 
ein Nein zur Rückkehr nach Deutschland als unchristlich und als Vaterlandsverrat geißelte. ${ }^{6}$ Nicht alle, aber doch etliche Erklärungsmuster haben unmittelbar mit Frankreich und dem Wahrnehmen französischer Ansprüche an der Saar zu tun.

Erstes Erklärungsmuster: Die Selbstverständlichkeit des Nationalen. Klassischerweise gilt das 19. Jahrhundert als Höhepunkt von Nationalismus und Nationalbewegungen; für die jüngere Forschung waren es aber vielfach erst die Jahre zwischen 1910 und 1945, die endgültig den „Durchbruch der Nation zum primären politischen und kulturellen Bezugspunkt ${ }^{67}$ in Europa markierten. Uberall traten in der Vor- und Zwischenkriegszeit ultranationalistische Gruppen und Bewegungen auf den Plan, um etablierte Ordnungen in Frage zu stellen. Dies galt auch für Frankreich. Allein im italienischen und im deutschen Fall gelangten sie an die Macht. Die Völkerbundszeit der Saar fällt in diese Hochphase des Nationalen. Auch hier wob sich der ideologische Großhorizont ,Nation' eng in kleinere Alltagswelten und kulturelle Praktiken ein.

Der Sonderstatus - politisch vom Reich abgetrennt, wirtschaftlich von Frankreich dominiert - tat ein Übriges, um Patriotismus und Nationalismus im Grenzland tief zu verankern. Der Bergarbeiterstreik 1923 und die rheinischen Jahrtausendfeiern 1925 wirkten als Verstärker. Beide Ereignisse waren zugleich scharfe und gewollte nationale Kraftproben mit Frankreich, standen für Distanz und Feindschaft gegenüber einer ausländischen Macht, die das Saargebiet zu gängeln und zu plündern schien. ${ }^{8}$ Der Selbstverständlichkeit des Nationalen an der Saar entsprach der völlige Konsens in Politik und Gesellschaft über das eigene Deutsch-Sein. Ohne großartig zu spekulieren, müssen wir davon ausgehen, dass ohne die ,Machtzulassung' Hitlers das Ergebnis 1935 noch eklatanter ausgefallen wäre. Erst der 30. Januar 1933 und die NS-Politik der Folgemonate boten Anlass zu Zweifeln und Fragen, die jahrelang nirgends auf der Agenda standen.

Zweites Erklärungsmuster: Die Undenkbarkeit des nüchternen Blicks. Kritische Selbstinspektion, nicht nur Opfer der Versailler Ordnung, sondern auch mitverantwortlich dafür zu sein, war nicht die Sache der Weimarer Republik.

6 Ausführlich zur Rolle der Kirche in den Abstimmungskämpfen vgl. Hüser, Judith: Saarkatholiken auf dem Sonderweg? Kirche und Konfession, Nation und Europa in einem deutsch-französischen Grenzland, in: Persch, Martin (Hg.): Geschichte des Bistums Trier, Trier: Paulinus, 2004, S. 671-697; Hüser, Judith: Quo vadis, Saarland? Die Haltung der Kirchen zum Sonderweg der Saar, in: Linsmayer (Hg.): Die Geburt des Saarlandes, S. 252-269.

7 Raphael, Lutz: Imperiale Gewalt und mobilisierte Nation. Europa 1914-1945, Bonn: Bundeszentrale für politische Bildung, 2014 (Schriftenreihe 1489), S. 17.

8 Aufschlussreich vgl. Beaupré, Nicolas: (Wieder-)Herstellen, löschen, verschieben: Grenzen in den Köpfen. Das Saarland zwischen Krieg und Volksabstimmung in den ersten Jahren der „Besatzungszeit“, in: François, Etienne/Seifarth, Jörg/Struck, Bernhard (Hg.): Die Grenze als Raum, Erfabrung und Konstruktion. Deutschland, Frankreich und Polen vom 17. bis zum 20. Jabrbundert, Frankfurt/New York: Campus, 2007, S. 163-182. 
Geschichte als Wissenschaft mag heute sachlich festhalten, dass der Versailler Vertrag ein Kompromissfriede war, der Deutschland langfristig kaum daran hinderte, künftig wieder international eine Rolle zu spielen. Nach dem Waffenstillstand im November 1918 war dies undenkbar: Erster Weltkrieg, Kriegsschuldfrage und Dolchstoßthese blieben parteiübergreifend hochemotionale Mobilisierungsthemen im öffentlichen Raum. An der Saar galt die Abtrennung und Besatzung als zusätzliches Unrecht, das es hinzunehmen galt ohne jegliche Chance auf Einfluss in den internationalen Verhandlungen der Sieger.

Dass Frankreich den Krieg als völlig ausgeblutetes Land beendet hatte, dass der Norden und Nordosten in Ruinen lag, dass die USA auf ein zügiges Tilgen der Kriegskredite bestanden, interessierte kaum jemanden, weder in Weimar, noch an der Saar. Grundlos gegängelt und geknebelt: Das war die Grundstimmung seit 1920. Besonders durch den Kriegssieger und Nachbarn hinter der Grenze. Die frühe Politik einer als fremd, als französisch empfundenen Regierungskommission spielte dem in die Karten. Truppenpräsenz, Saarflagge, Domanialschulen, Sprachunterricht, Francs-Einführung, die weitgehende Kontrolle von Kohlegruben, Stahlindustrie und Bankensektor: All dies und manches mehr schuf Ressentiments, die sich in klassische Erbfeindbilder einpassten. ${ }^{9}$ Dass sich das Regime liberalisierte, dass es an der Saar materiell in den 1920er Jahren vergleichsweise gut ging: All das ging im Sog der nationalen Frontstellung unter. Für einen nüchternen Blick war schon vor 1935 fast kein Platz.

Drittes Erklärungsmuster: Die Saft- und Kraftlosigkeit der Demokratie. Der Mangel an positiv besetzten demokratischen Erfahrungen und Idealen ließ sich an der Saar förmlich mit Händen greifen. Das Beteiligen an den Wahlen zur Weimarer Konstituante im Januar 1919 blieb an der Saar politisch folgenlos, denn das Saargebiet gehörte schon ein Jahr später nicht mehr zum Deutschen Reich. Seit 1922 stimmte die Wahlbevölkerung für einen beratend tätigen Landesrat ab, der weder Budget-, Legislativ- oder Kontrollbefugnisse besaß noch Einfluss auf die Exekutive, die Regierungskommission des Völkerbundes, hatte. ${ }^{10}$ Auch die labile Weimarer Ordnung taugte damals nur bedingt als erstrebenswertes zukunftsträchtiges Demokratie-Vorbild. Noch weniger die französische Dritte Republik, die im Schnitt alle paar Monate eine Regierung verschliss und die viele nach den antiparlamentarischen Groß-

9 Vgl. Linsmayer, Ludwig: Bewahrend oder bewegend? Zum Verhältnis von Gedächtnis und Geschichte in den Auseinandersetzungen um den 13. Januar 1935, in: ders. (Hg.): Der 13. Januar, S. 15-51, hier S. 25 f., S. 28 f. Zu den französischen Domanialschulen vgl. Becker: „Deutsch die Saar, immerdar!“, S. 34.

10 Zum „parlamentarischen Stil“ im Landesrat vgl. Linsmayer: Politische Kultur im Saargebiet, S. 181-183. 
demonstrationen am 6. Februar 1934 bereits am autoritären Abgrund wähnten. ${ }^{11}$ Europaweit schien die Demokratie als politische Lebensform massiv unter Druck geraten zu sein.

Viertes Erklärungsmuster: Die Zweifelhaftigkeit der Alternativen. Alternativen auf dem internationalen Parkett hatten sich in den 1920er Jahren sachte angedeutet, dann rasch wieder verflüchtigt. Die Phase der relativen Stabilisierung Weimars, die einherging mit tastenden deutsch-französischen Entspannungsbemühungen und die auch an der Saar gewisse Entkrampfungen mit sich brachte, blieb letztlich eine Episode. Die hochfliegenden Saarpläne, die Aristide Briand und Gustav Stresemann kurz nach dem deutschen Völkerbundsbeitritt im September 1926 in Thoiry oberhalb von Genf schmiedeten, waren bereits Makulatur, als die beiden Außenminister wieder zurück in Paris und Berlin waren. ${ }^{12}$ Auch der Friedensnobelpreis, den beide drei Monate später in Oslo entgegennahmen, änderte nichts daran, dass klassische Machtpolitik gesetzt, jede diplomatische Alternative chancenlos war. Selbst Ansätze ,aufgeklärter' Großmachtpolitik à la Briand und Stresemann - Stichwort: Locarno - blieben Strohfeuer.

1935 dann war die Option ,Frankreich', aber auch der Status quo - sprich: das Beibehalten des Völkerbundsregimes - alles andere als eine einleuchtende Alternative zum ,Heim ins Reich', für viele eher eine Gleichung mit vielen Unbekannten. Plausibilität und Zukunftsfähigkeit ließen sich kaum vermitteln. Schon wegen der langjährigen Zerstrittenheit zwischen KPD und SPD, auch weil der Status quo ,vor Hitler ${ }^{c}$ über alle politischen Lager hinweg völlig diskreditiert war: nicht zuletzt bei den kommunistischen, sozialdemokratischen und katholischen Hitler-Gegnern, die sich nun dafür stark machten. Der Rückenwind, der nach dem ,Röhmputsch` Ende Juni 1934 gerade im katholischen Lager aufzukommen schien, blieb am Ende ein laues Lüftchen. Auswärtiger Rückenwind blieb ebenfalls aus: Frankreichs Engagement war von vornherein gering, tendierte mit dem Amtsantritt Lavals als Außenminister im Oktober 1934 gegen Null. Der Völkerbund verzichtete auf eine Garantieerklärung für ein zweites Saar-Referendum für den Fall eines Hitlerschen Machtverlusts. Unterschwellig meinte Status quo nun: dauerhafte, definitive Separation vom Vaterland.

Fünftes und letztes Erklärungsmuster: Die Attraktivität des Deutschen ,Dritten Reiches: Die NS-Zeit an der Saar begann nicht erst nach der Abstimmung im Januar 1935, sondern schon zwei Jahre zuvor. ${ }^{13}$ Zwar hatte auch im

11 Dazu Winock, Michel: Le 6 février, in: ders.: La fièrre hexagonale. Les grandes crises politiques 1871-1968, Paris: Points-Seuil, 1987, S. 193-238.

12 Vgl. Beaupré, Nicolas: Deutsch-franz̈̈sische Geschichte Band VIII. Das Trauma des großen Krieges 1918-1932/33, Darmstadt: WBG, 2009, S. 56.

13 Auf neuestem Forschungsstand dazu nun der Sammelband von Herrmann, Hans-Christian/Bauer, Ruth (Hg.): Widerstand, Repression und Verfolgung. Beiträge zur Geschichte des Nationalsozialismus an der Saar, St. Ingbert: Röhrig, 2014. 
Grenzraum niemand die Reichskanzlerschaft Hitlers vorhersehen können, die Folgen zeigten sich aber unmittelbar. Die Ränge der Splitterpartei schwollen rasch an, auf rund 15000 Mitglieder kam die NSDAP im Frühsommer 1933, auf gut 30000 im Jahr darauf. Die Sogwirkung auf die bürgerlich-konservativen Parteien war gewaltig. Deren Schulterschluss und Selbstgleichschaltung wiederum machten die Nationalsozialisten noch hoffähiger. Marschrichtung und Ton der Deutschen Front gaben von Beginn an die Nazis vor. ${ }^{14}$ Was in Berlin passierte, fand Widerhall: so auch die frühen antisemitischen Maßnahmen des Dritten Reiches, wie etwa der Boykott jüdischer Geschäfte, Banken, Ärzte und Rechtsanwälte im April 1933. ${ }^{15}$ NS-Symbole, Hitlerbüsten, Hakenkreuzflaggen hielten ebenso Einzug wie z. B. Einrichtungen der NS-Volkswohlfahrt. Die ins Feld geführte Propagandamacht schreckte manche ab, zog aber viele andere an. In puncto Massenmobilisierung und Selbstinszenierung war es ohnehin nicht leicht, den Goebbels und Bürckels das Wasser zu reichen.

Auf einem ganz anderen Blatt stand freilich, dass es bei dem ganzen Berliner Aufwand keineswegs um die Saar als solche ging. Das Gebiet galt als erster wichtiger Markstein auf dem Weg zu Revision und Expansion. Weitere Etappen folgten rasch: im März 1935 die allgemeine Wehrpflicht, ein offener Bruch mit Versailles; ein Jahr später das Besetzen der entmilitarisierten Zone im Rheinland. Den Rest kennen wir: Es passierte im Grunde das, was die Befürworter des Status quo an der Saar befürchtet hatten. Auch wenn weder sie noch andere damals die Dimension künftiger Schandtaten, Kriegsgräuel und den Holocaust erahnen konnten. Proteste in Frankreich und Großbritannien hielten sich in engen Grenzen, die breite Masse der Menschen in Deutschland feierte die außenpolitischen ,Erfolge' Adolf Hitlers. Seine Popularität nahm zu, je länger die Friedensjahre der NS-Zeit dauerten. ${ }^{16}$ Auch an der ,heimgekehrten' Saar, wo der ,Führermythos' die Unzulänglichkeiten des Alltags und uneingelöste Versprechen der Rückgliederungspropaganda zu kanalisieren vermochte. ${ }^{17}$ Weshalb hätte dies an der Saar auch anders sein sollen als im Rest des Landes?

14 Klassisch vgl. Jacoby, Fritz: Die nationalsozialistische Herrschaftsübernahme an der Saar. Die innenpolitischen Probleme der Rückgliederung des Saargebietes bis 1935, Saarbrücken: Thinnes \& Nolte, 1973 (Veröffentlichungen der Kommission für Saarländische Landesgeschichte und Volksforschung 6), S. 102-104, S. 108-110.

15 Dazu nun Herrmann, Hans-Christian: Aspekte zum jüdischen Leben an der Saar: die Zeit vom 19. Jahrhundert bis zum Ende des Holocaust, in: ders./Bauer (Hg.): Widerstand, Repression und Verfolgung, S. 35-102, hier S. 87-89.

16 Vgl. Winkler, Heinrich-August: Geschichte des Westens. Die Zeit der Weltkriege 1914-1945, Bonn: Bundeszentrale für politische Bildung, 2011, S. 732-736, S. 740-742.

17 Vgl. Mallmann, Klaus-Michael/Paul, Gerhard: Herrschaft und Alltag. Ein Industrierevier im Dritten Reich, Bonn: Dietz, 1991, S. 45-49; Klöckner, Michelle: Treue Volksgenossen? Die 
90,7 \% der abgegebenen Stimmen für eine Rückkehr ins Deutsche Reich: Als Zwischenbilanz können wir konstatieren, dass am 13. Januar 1935 in den Augen der Saarwählerschaft offenbar vieles dafür und weniges dagegen zu sprechen schien. Das Nationale war eine Herzensangelegenheit, die es erlaubte, das ,Unrecht ${ }^{6}$ von Versailles und 15 Jahre gefühlte Fremdherrschaft durch Frankreich hinter sich zu lassen, um in eine bessere Zukunft aufzubrechen. Etliche mochten trotz Hitler für die Rückkehr stimmen, andere auch wegen Hitler. Dass Sozialdemokraten, selbst Kommunisten, von denen bis Ende 1934 reichsweit Tausende umgebracht, Zehntausende inhaftiert worden waren, mehrheitlich für Hitler-Deutschland stimmten, spricht schon eine klare Sprache. Die kaum verschleierte Willkür und Gewalt der NS-Diktatur bot für die Menschen an der Saar - bei allen, mehr oder weniger großen Vorbehalten, die es geben mochte - keinen hinreichenden Grund, nicht für Deutschland zu stimmen. Daneben gab es andere, für die Hitler ein zusätzlicher Anreiz war, ,Heim ins Reich 'zu wollen. Trotz Hitler oder wegen Hitler? Beides stimmt, Daten als Basis für genauere wahlsoziologische Analysen liegen nicht vor. ${ }^{18}$

Mit Blick auf die drei Untertitel-Stichwörter ,Herausforderungen', ,Handlungsmargen', ,Frankreichstrategien' lässt sich die Herausforderung nach Kriegsende leicht auf den Punkt bringen: Frankreich! Über die gesamte Völkerbundszeit hinweg diente der Kriegssieger und Nachbar als Negativfolie, die identitätsstiftende Wirkungen zeitigte und die Saar im Deutsch-Sein zusammenschweißte. Die Periode war kaum geeignet für konstruktive frankreichbezogene Initiativen. Das fast durchgängig konfliktuell aufgeladene Verhältnis zwischen Berlin und Paris machte dies schon nicht leicht. Auch die Nachwehen des Krieges spielten eine Rolle, die profunde Nationalisierung von Alltag und Freizeit, auch die gefühlte, doppelte Opferrolle' durch Kriegsschuld und Saar-Abtrennung sowie die innerlich nie ,verdaute ${ }^{‘}$ Niederlage gegen Frankreich. Wie vehement die Verlierer sich weigerten, Versailles zu akzeptieren, und wie überzeugt die Sieger davon waren, den Gegner nur unzureichend in die Schranken gewiesen zu haben, dokumentiert ein Beschwerdeschreiben eines ehemaligen französischen Frontkämpfers, der nun als höherer Angestellter in der Saarbrücker Saargrubenverwaltung arbeitete:

[...] seit der Unterzeichnung des Vertrages vergeht kein Tag im Saarland, insbesondere in Saarbrücken, ohne dass ein Franzose belästigt oder beleidigt wird. Unter dem Deckmantel des Beinamens, Saarländer', den man ihnen verliehen hat, lassen die Deutschen von Saarbrücken, die preussischer noch sind als die in Berlin, keine Gelegenheit aus, uns in jeglicher

Saar zwischen Resistenz und Zustimmung, in: Herrmann/Bauer (Hg.): Widerstand, Repression und Verfolgung, S. 149-183 (hier S. 156, S. 159-161, S. 176-178).

18 Eine Typologie der Wählerinnen und Wähler an der Saar bei der Volksabstimmung 1935 bietet Von Wegener, Alexander: Die ,saarländische Sphinx“. Zur Interpretation der Saarabstimmung 1935, in: Jabrbuch für westdeutsche Landesgescbicbte 20 (1994), S. 273-317. 
Form schlecht zu behandeln [...] Welche Maßnahmen ergreift man, um im Saarland die Sicherheit der Franzosen und ihrer Familien zu gewährleisten? Sollen wir uns hier als Sieger oder als Besiegte betrachten?19

Hinzu kam - Stichwort Handlungsmargen - die augenfällige Einflusslosigkeit der politischen Kräfte an der Saar, schon zu Zeiten des Friedensschlusses, aber auch danach im Zeichen von Völkerbundsmandat und Regierungskommission. Wenn wir über Akteure der Saar-Politik nach 1920 sprechen, dann sind dies zunächst die Vertreter der Parteien im demokratisch gewählten, aber reichlich macht- und kompetenzlosen Landesrat. Dass die Handlungsmargen, eigenständige Politikentwürfe durchzusetzen, zwangsläufig gegen Null tendierten, liegt auf der Hand. Von ,Frankreichstrategie' nach 1920 kann deshalb nur ganz bedingt und mittelbar die Rede sein. Bestenfalls im Sinne einer strammen Ablehnungsfront gegenüber Frankreich und seiner Politik, die Saar, so der Sozialdemokrat Dr. Sender, als „Objekt imperialistischer Machterweiterung " zu degradieren und, so der Zentrumspolitiker Levacher, die „Französisierung“ der deutschen Saar voranzutreiben. ${ }^{20}$ Eine Ablehnungs- und Einheitsfront vom Zentrum bis zur KPD gab es über alle politischen und weltanschaulichen Gegensätze der damaligen Milieuparteien hinweg. Die programmatischen Erklärungen der Landesratsfraktionen in der konstituierenden Sitzung am 19. Juli 1922 geben drastisch Aufschluss über anti-französische Grundhaltungen und Emotionen.

Natürlich war Frankreich an der Saar materiell präsent, auch in Wirtschaft und Handel, in Konsum- und Warenwelten, in Werbeanzeigen der florierenden Tagespresse, die deutsche wie französische Produkte gleichermaßen bewarb, und dies mit markanten Unterschieden. Saarbrücken war angesichts mehrerer tausend Französinnen und Franzosen, die dort lebten und arbeiteten, eine durchaus internationale Stadt, mit französischen Modeläden, Cafés und Restaurants. Vereinzelt - all das wäre noch weiter zu erforschen - mochte dies Interesse wecken und attraktiv erscheinen, es mochte zu diversen pragmatischen Kontakt- und Austauschformen kommen. Gleichwohl galt es aufzupassen, nicht zu weit zu gehen, denn einmal als ,Französling' diffamiert, fiel jeder und jede rasch aus der deutsch-nationalen Saargemeinschaft heraus. Französisches stand letztlich unter negativen Vorzeichen. Auf breiterer Front erzeugte deshalb ,Frankreich an der Saar ${ }^{\star}$ offenbar kein ausreichendes Attraktionspotenzial, um dann wiederum in nachhaltigere Kommunikationsstrukturen, kulturelle Interaktionsmuster oder institutionellen Verfestigungen mit

19 Beschwerdeschreiben von Octave Milers an Général Maudhuy, 01.07.1920, zit. in: Beaupré: Deutsch-franæö̈ische Geschichte Band VIII, S. 156 f.

20 Nachdruck der „Programmatischen Erklärungen der Landesratsfraktionen in der ersten Sitzung des Landesrates des Saarlandes am 19. Juli 1922“, in: Zenner: Parteien und Politik im Saargebiet, S. 338-347. 
dauerhafter Prägung zu münden. Angesichts rigider nationaler Frontstellungen erzeugte es vielmehr ebenso massenhaftes wie schroffes Ablehnen und Distanzieren.

\section{Saarstaatszeiten 1945-1955- Autonomie in Europa als offensive ,Frankreichstrategie“}

Verglichen mit der Zeit nach 1920 weisen die Jahre nach 1945 gewisse Ähnlichkeiten auf: Die Saar war wieder - jedenfalls zunächst einmal - Objekt der Geschichte, Spielball eines europäischen Interessenausgleichs zwischen Siegern und Besiegten;21 und die zentrale Herausforderung für die SaarPolitik, die nach und nach unter französischer Kontrolle wieder in Gang kam, blieb das Nachbarland im Westen. Aber es gab auch etliche Unterschiede: Unterschiede in den Nachkriegskontexten angesichts von 12 Jahren NSHerrschaft, von Holocaust und Zivilisationsbruch; Unterschiede, was dominante Frankreichwahrnehmungen durch Saar-Akteure und Vorstellungen für künftig erstrebenswerte deutsch-französische Beziehungen anging; Unterschiede im Aushandeln und Umsetzen ,frankreichstrategischer' Prämissen, die auf erweiterten autonomen Handlungsspielräumen beruhten sowie einem vielfach kreativen Umgang mit damaligen Zwängen im Zeichen von Niederlage und Neuanfang; Unterschiede im Übrigen, die Gegner des Europastatuts, zugleich ,Sieger' der Volksabstimmung von 1955, in den Jahren danach gern ausgeblendet wissen wollten.

Denn nach dem Einbinden der Saar in die Bundesrepublik 1957/59 wurzelte die historische Meistererzählung darin, die Zeit seit 1919 als Einheit zu betrachten: vier Jahrzehnte der Abwehr ungebührlicher französischer Versuche, die Saar mithilfe des Völkerbundes, dann mithilfe der Regierung unter Johannes Hoffmann politisch zu bevormunden und wirtschaftlich auszubeuten; vier Jahrzehnte mit den Kernphasen der Abstimmungskämpfe, die im Ergebnis eindeutige Voten für Deutschland erbracht hätten. Allein die nationale Frage habe gezählt, die Regimefrage: Diktatur oder Demokratie, nie eine Rolle gespielt. Diese Meistererzählung, diese Idee der Epocheneinheit von 1918 bis 1955, wird bis in unsere Tage hinein immer wieder bemüht. Im öffentlichen Wahrnehmen erscheinen 1935 und 1955 vielfach ziemlich deckungsgleich. Zwar spricht tatsächlich einiges dafür: die Protagonisten, die Lagerbildung, die Themen, die Plakate, die aufgepeitschte Atmosphäre, das Gewicht der Kirche, die asymmetrische Zugkraft und Evidenz der Optionen, auch die steten Rückbezüge im Jahr 1955 auf die Volksabstimmung 20 Jahre

21 Dazu Hüser, Dietmar: Die Saar in den internationalen Beziehungen nach dem Zweiten Weltkrieg - Ungewisse Planspiele, zögerliche Praxis und funktionales Potential in einem nachgeordneten Politikfeld, in: Hudemann/Jellonnek/Rauls (Hg.): Grenæ-Fall, S. 97-120. 
zuvor. ${ }^{22}$ Allerdings verstellt das (Über-)Betonen von Kontinuitäten und Ähnlichkeiten den Blick für Divergenzen, für Bruchlinien, für Lernprozesse, die Geschichte als Wissenschaft in den letzten Jahren und Jahrzehnten herausgearbeitet hat. Greifen wir kurz noch einmal die fünf Erklärungsangebote für das Abstimmungsergebnis von 1935 auf und übertragen diese auf 1955, um zu einem differenzierten Bild zu gelangen.

Erstes Erklärungsmuster: Die Selbstverständlicbkeit des Nationalen. Zweifelsfrei prägte auch nach 1945 Nationales weiter die Erfahrungs- und Lebenswelten der meisten Menschen in Europa. Zugleich war Nationales, war besonders übersteigerter Nationalismus in den Augen vieler Akteure in Politik und Zivilgesellschaft zutiefst diskreditiert. Die schiere Dynamik, Mobilisierungskraft und Breitenwirkung der Europa-Idee und Europa-Bewegung sind heute angesichts latenter Euro-Krisen kaum mehr vorstellbar, waren damals aber Realität. Schon während des Krieges hatten gerade Meinungsführer aus Widerstandskreisen verschiedener Länder Konzepte für eine Nachkriegsordnung erarbeitetet, in denen eine enge Zusammenarbeit europäischer Staaten eine zentrale Rolle spielte. Lernen aus Versailles und Sorgen um eine künftige Friedenssicherung spielten eine maßgebliche Rolle, kaum weniger ökonomische und machtpolitische Motive; das Machtgefälle gegenüber den neuen Weltmächten in Ost und West zeichnete sich bereits frühzeitig ab. ${ }^{23}$

Anders als nach 1918, als es an Europa-Plänen durchaus nicht fehlte, verschwanden die Initiativen nach 1945 nicht mehr von der politischen Agenda. Und komplett anders als nach 1918 fanden die Westintegrationspläne schon wenige Jahre nach Kriegsende tatsächlich Umsetzung, es entstanden Institutionen, die - wie der Straßburger Europarat - noch heute existieren oder solche, die - wie die Europäische Gemeinschaft für Kohle und Stahl - begründet als Vorläufer der Europäischen Union gelten können. Dies alles vollzog sich nicht als linearer Prozess und durchgängige Erfolgsgeschichte. Als fatal für die Abstimmung über das Europastatut an der Saar sollte sich 1955 erweisen, dass der erste ganz herbe Rückschlag für Europa-Begeisterte nur gut ein Jahr zuvor erfolgte: das Scheitern der Europäischen Verteidigungsgemeinschaft sowie der daran gekoppelten Europäischen Politischen Gemeinschaft vor der französischen Nationalversammlung am 30. August 1954. Selbstverständlich blieb Nationales auch nach 1945. Aber daneben schien nunmehr auch Europäisches, Grenzüberschreitendes, Transnationales immer relevanter, immer reizvoller, immer selbstverständlicher. Europäisierungsprozesse brachen sich

22 Vgl. den Versuch einer systematischen Gegenüberstellung von 1935 und 1955 bei Heinz, Joachim: Die Abstimmungen von 1935 und 1955 an der Saar im Vergleich, in: Stiftung Demokratie Saarland (Hg.): Der 23. Oktober 1955 - 50 Jabre danach, Saarbrücken: Stiftung Demokratie Saarland, 2007 (Dialog 15), S. 85-106.

23 Vgl. Elvert, Jürgen: Die europäische Integration, Darmstadt: WBG, 2006 (Geschichte kompakt), hier S. 35-46. 
Bahn als normale Begleitumstände des Übergangs von der Mangel- in eine immer mobilere und offenere Konsumgesellschaft. ${ }^{24}$

Zweite Erklärung: Die Undenkbarkeit des nüchternen Blicks. War schon nach 1920, erst recht 1935 kein Platz an der Saar für nüchterne Blicke und sachliche Analyse der Kriegsniederlage samt Folgen, so stellte sich dies nach 1945 etwas anders dar. Zwar konnte weder an der Saar noch anderswo in Deutschland von einem Anerkennen eigener Mitverantwortung für die Untaten des ,Tausendjährigen Reiches' die Rede sein. Zugleich aber überstieg der Zivilisationsbruch alles Begreifbare, machten Weltkrieg und Kapitulation, Verbrechen und Holocaust, Staatsbankrott und Trümmergesellschaft, ein erneutes Verschanzen hinter obskuren Dolchstoßthesen oder ein Sinnen auf Revanche gegenüber dem ,Erzfeind' undenkbar. Nichts war wie vorher, was Chancen bot für zukunftsoffenes Denken, für neue Ideen, Ansätze, Modelle, die den holperigen Beginn eines Neuanfangs markierten: weniger in eine affirmative Erfolgs- als eine mentale Wandlungsgeschichte. Lernen aus der Vergangenheit, das hatte auf deutscher Seite eine Menge mit dem Ausmaß der Katastrophe zu tun. 25

Ein Umdenken hatte 1944/45 auch in Frankreich eingesetzt, gerade unter den oft jungen, ehrgeizigen Eliten, die nun aus Résistancekreisen in staatliche Spitzenpositionen aufstiegen. Für viele hatte der Sieg 1945 das Debakel von 1940 nicht wettgemacht. Für viele war Frankreich selbst, waren Fehler und Versäumnisse der Zwischenkriegszeit mitverantwortlich dafür. Die Prämisse, das Land radikal umzukrempeln und zu modernisieren, zeigte sich auch im künftigen Umgang mit dem deutschen Nachbarn. Das blieb nicht ohne Folgen für die Saarpolitik. Die Idee, die Saar könne etwas anderes als deutsch sein, war vom Tisch. Frankreichs Interessenpolitik kam - bei allen Härten informeller, offener und flexibler daher, erlaubte einen Neubeginn und ein kooperatives Miteinander, das nach 1955 an der Saar überdauern sollte. ${ }^{26}$

24 Vgl. Kaelble, Hartmut: Kalter Krieg und Woblfahrtsstaat. Europa 1945-1989, München: Beck, 2011, hier S. 81-123.

25 Vgl. Herbert, Ulrich (Hg.): Wandlungsprozesse in Westdeutschland. Belastung, Integration, Liberalisierung 1945-1980, Göttingen: Wallstein, 2002; Jarausch, Konrad: Die Umkehr. Deutsche Wandlungen 1945-1995, München: Deutsche Verlags-Anstalt, 2004; Bauerkämper, Arnd/Jarausch, Konrad/Payk, Marcus (Hg.): Demokratiewunder. Transatlantische Mittler und die kulturelle Öffnung Westdeutscblands 1945-1970, Göttingen: Vandenhoeck \& Ruprecht, 2005.

26 Ausführliche Hinweise bei Hüser, Dietmar: Frankreichs ,doppelte Deutschlandpolitik“. Dynamike aus der Defensive - Planen, Entscheiden, Umsetzen in gesellschaftlichen und wirtschaftlichen, innen- und außenpolitischen Krisenzeiten 1944-1950, Berlin: Duncker \& Humblot, 1996; Hüser, Dietmar: Struktur- und Kulturgeschichte französischer Außenpolitik im Jahre 1945 - Für eine methodenbewußte Geschichte der internationalen Beziehungen, in: Historische Mitteilungen 16 (2003), S. 155-170. 
Oberflächlich betrachtet mögen die nationalistischen Aufwallungen im Abstimmungskampf 1955, den dann beide Seiten in den letzten Monaten erbittert, leidenschaftlich, mit allerhärtesten Bandagen geführt haben, dafür sprechen, dass ähnlich wie schon 1935 ein nüchterner Blick undenkbar blieb. Doch sollte niemand die Augen verschließen vor dem, was im Vorjahrzehnt an strukturellen Kooperationsgrundlagen und konstruktiven Initiativen für ein Mehr an Saarländisch-Französischem bereits auf den Weg gebracht worden war.

Dritte Erklärung: Die Saft- und Kraftlosigkeit der Demokratie. Anders als in den 1920er und 1930er Jahren standen die westeuropäischen Demokratien nach 1945 auf festen Füßen. Ausnahmen bildeten Spanien und Portugal, wo der Kalte Krieg und militärstrategische Erwägungen der Vereinigten Staaten dazu führten, dass mit Franco und Salazar zwei Diktatoren bis Mitte der 1970er Jahre in autoritären Regimen überdauern konnten. Auch die junge Bundesrepublik, die 1949 aus einer ,überwachten Verfassungsgebung ${ }^{627}$ entstanden war, sollte sich zu einem institutionell stabilen Staatswesen entwickeln und zahlreiche Skeptiker widerlegen. Auch die, innere Demokratisierung ${ }^{6}$ im Sinne politisch-kultureller Nachhaltigkeit demokratischer Leit- und Ordnungsvorstellungen, gelang im Laufe der 1960er Jahre. Eine Art ,Demokratiewunder ${ }^{228}$, wenn wir an die unmittelbare nationalsozialistische Vorgeschichte und die "personellen und mentalen Hinterlassenschaften der NS-Diktatur" ${ }^{\text {“29 }}$ denken.

Der Saarstaat, der mit der Verfassung im Dezember 1947 formal entstand, war das Ergebnis französisch-saarländischer Zusammenarbeit. ${ }^{30}$ Kaum jemand fand das prinzipiell ehrenrührig, auch wenn hier und da Meinungsverschiedenheiten oder Unmut über einzelne Maßnahmen und Vorgaben zu verzeichnen waren. Manches hatten Johannes Hoffmann und Gilbert Grandval - bis 1948 Militärgouverneur, bis 1952 Hoher Kommissar, bis 1955 dann Botschafter an der Saar - gemeinsam gegenüber Paris durchzusetzen gewusst. Die Verfassung selbst orientierte sich - bis auf die oktroyierte Präambel, die Wirtschaftsanschluss und Unabhängigkeit von Deutschland postulierte und vielerorts auf heftige Kritik stieß - an deutschen Vorbildern. Eine Verfassung jedenfalls, die nach 1955 auf das Bonner Grundgesetz hin anzugleichen, nicht

$27 \mathrm{Zu}$ Rolle und Beiträgen transnationaler Populärkultur zum ,Demokratiewunder vgl. Hüser, Dietmar: Miracle démocratique dans l'Allemagne de l'Ouest des décennies d'aprèsguerre - Histoire de la culture de masse comme histoire culturelle du politique, in: Histoire, économie et société 35 (2016), S. 14-31.

28 Vgl. Bauerkämper/Jarausch/Payk (Hg.): Demokratiewnnder.

29 Herbert, Ulrich: Geschicbte Deutschlands im 20. Jahrbundert, München: C. H. Beck, 2014, hier S. 16.

30 Vgl. Sander, Michael: Die Verfassung des Saarlandes. Politische Planung und politischer Erfolg, in: Hudemann/Poidevin (Hg.): Die Saar 1945-1955, S. 237-252. 
aber völlig neu zu schreiben war. Über Hoffmann - erster Saar-Ministerpräsident und Verfassungsvater - hinaus sind Kontinuitätslinien der Staatsgeschichte seit 1947 unübersehbar. Und erstmals machten damals Bürgerinnen und Bürger dauerhafte Erfahrungen mit der parlamentarischen Demokratie und mit Politikern, die die Saar ,aus dem Land heraus' regierten.

Die Saar der ,Ära Hoffmann` war kein demokratischer Musterstaat. Aber auch kein autoritäres Regime wie Francos Spanien oder Salazars Portugal. Die Motive für den ,demokratischen Paternalismus' à la Hoffmann lagen in den Erfahrungen der NS- und Emigrationszeit, die akute Zweifel an der Demokratiefähigkeit der Nachkriegsgesellschaft nährten. Eine Einschätzung, die Hoffmann mit manch anderen Staatslenkern in Westeuropa teilte, auch mit Konrad Adenauer oder mit Charles de Gaulle. ${ }^{31}$ In gewisser Weise nachvollziehbar wird das Misstrauen ,alter Männer an der Macht ${ }^{\star}$ vielleicht durch Allensbach-Umfragen, die für Westdeutschland bis weit in die 1950er Jahre mehrheitlich obrigkeitsstaatliche Grundhaltungen offenlegen und eben keine demokratisch geläuterte Bürgerschaft. ${ }^{32}$ An der Saar verschlechterte sich das Klima erst im Laufe der Zeit. Es waren weniger die gut 1800 Ausweisungen der Frühphase, die es belasteten und die Legitimationsgrundlagen auszuhöhlen begannen, als die verstärkte Pressezensur, das Verbieten oder Nichtzulassen von Parteien unter den veränderten Rahmenbedingungen der 1950er Jahre. Dass dies nun gerade die Kräfte harsch monierten, die 1935 mit fliegenden Fahnen ,Heim ins Reich ' wollten, empfanden besonders die Remigranten als perfide, als böse Ironie der Geschichte.

Vierte Erklärung: Die Zweifelhaftigkeit der Alternativen. 1935 lauteten die beiden Alternativen zum ,Heim ins Reich': Angliederung an Frankreich oder Status quo eines Völkerbundsregimes, das seit 1920 alle politischen Kräfte an der Saar ganz entschieden bekämpft hatte. Die Zweifelhaftigkeit der Alternativen drückt sich auch im Ergebnis aus: 0,4\% der abgegebenen Stimmen im ersten, weniger als $9 \%$ im zweiten Fall. 1955 ging es in der Volksabstimmung formal nicht um Frankreich oder die Bundesrepublik. Es ging um ein europäisches Saarstatut, das Adenauer mit dem französischen Ministerpräsidenten Pierre Mendès France ein Jahr zuvor ausgehandelt hatte. Für viele

31 Zur Adenauerschen Kanzlerdemokratie vgl. Conze, Eckart: Die Suche nach Sicherheit. Eine Geschichte der Bundesrepublik. Deutschland von 1949 bis in die Gegenwart, München: Siedler, 2009, hier S. 122-126; Schildt, Axel/Siegfried, Detlef: Deutsche Kulturgescbicbte. Die Bundesrepublik. 1945 bis zur Gegenwart, München: Hanser, 2009, hier S. 127-132. Zur de Gaulleschen ,,monarchie républicaine" vgl. Berstein, Serge: Le gaullisme, in: Rioux, Jean-Pierre/Sirinelli, Jean-François (Hg.): La France d'un siècle à l'autre 1914-2000. Dictionnaire critique, Paris: Hachette, 1999, S. 711-718; Becker, Jean-Jacques: La Ve République, in: Duclert, Vincent/ Prochasson, Christophe (Hg.): Dictionnaire critique de la République, Paris: Flammarion, 2002, hier S. 78-83.

32 Vgl. Noelle, Elisabeth/Neumann, Peter (Hg.): Jahrbuch der öffentlichen Meinung 1947-1955, Allensbach: Verlag für Demoskopie, ${ }^{21956}$, hier S. 114-142, S. 157-181. 
sprach vieles lange Zeit zugunsten einer solchen europäischen Lösung der Saarfrage, denn der zukunftsweisende Charakter ließ sich dem Projekt kaum absprechen: eine europäisierte Saarstaatsgründung fernab ausgetretener nationaler Pfade als dauerhafte Brücke zwischen Frankreich und Westdeutschland, als weiterer Baustein der Europäischen Integration. Diplomatie und Politik in Bonn und Paris sahen 1954/55 im Saarstatut ein probates Mittel, einen weiteren, damals fast den letzten Stolperstein aus dem Weg zu räumen und das übergeordnete Ziel bilateraler Verständigung und westeuropäischer Einigung weiter voranzutreiben.

Noch dazu lag eine Saar-Europa-Lösung ganz in der Logik eines offensiv europäisch ausgerichteten Grenzraumprojekts seit 1946/47, das der Region viel Europäisches beschert und in alltägliche Erfahrungshorizonte eingeschrieben hatte. Und wäre nicht die europäische Saar nach erfolgtem Ja auf dem Kontinent etwas ganz Besonderes gewesen, ein ,Vorzeige-Staat ${ }^{6}$ mit hoher Signalwirkung, der möglicherweise als Sitz künftiger Europa-Institutionen fungiert hätte? Dass dies niemand garantieren konnte, gerade daran entzündete sich die Opposition. Das Saarstatut mochte ein ambitioniertes Projekt sein, hieß es, da es aber an Praxiserfahrungen fehle, lasse sich kaum abschätzen, ob sich die hehren Hoffnungen der Ja-Sager auf einen lebensund leistungsfähigen Saar-Musterstaat erfüllen würden oder doch die NegativSzenarien der Nein-Sager. Den meisten Menschen gelang es nur begrenzt, sich die Saar als eigenständigen Akteur der internationalen Politik über den Straßburger Europarat und das Spitzensportgeschehen hinaus auszumalen. Schließlich war doch auch das Aushandeln des Europastatuts 1954 ohne offizielle Saarbeteiligung erfolgt. Die angedachte europäische Lösung der Saarfrage blieb für viele realitätsfern, auch irgendwie anstrengend, vielleicht widersprüchlich, jedenfalls mit vielen Fragezeichen verbunden und fernab eigener Lebenswelt wie Vorstellungskraft. Die ,deutsche Karte‘ zu spielen galt als die vermeintlich sicherere Variante: lieber ein guter Deutscher als europäische Avantgarde mit vielen Unbekannten!

Was die Zweifelhaftigkeit der Alternativen anbelangte, so stand die Option ,Bundesrepublik ${ }^{6}$ offiziell überhaupt nicht zur Debatte. Gleichwohl gingen immer breitere Kreise davon aus, es handele sich um eine realistische Alternative. Monatelang hatte alle Welt mit einem deutlichen Ja zum Europastatut gerechnet, doch nach und nach begann sich der Wind zu drehen und blies nun in die prodeutschen Segel: Laut einer Allensbach-Umfrage im April 1955 war alles offen, $21 \%$ stimmten Ja, $20 \%$ Nein, $50 \%$ der Befragten äußerten sich noch unentschieden. ${ }^{33}$ Mit der offiziellen Zulassung der prodeutschen Kräfte im Juli 1955 brachen dann alle Dämme, den Statut-Gegnern gelang es, eine Eigendynamik in Gang zu setzen, die das Votum über eine 
europäische Lösung der Saarfrage auf die Schwarz-Weiß-Formel ,Für Frankreich oder für Deutschland' zu bringen wusste. Und zurück nach Deutschland meinte anders als 1935 nicht ein Zurück in eine faschistische Diktatur, sondern einen demokratischen Rechtsstaat.

Fünfte Erklärung: Die Attraktivität des Deutschen ,Dritten Reiches'. Das Reich gab es nicht mehr, erst recht nicht das ,Dritte Reich‘. Es gab eine junge Bundesrepublik, die 1949 durch von innen erstrebte wie von außen forcierte Neuorientierungen als westdeutsches Staatswesen entstanden war. Aus anfänglichen Vorbehalten mancher Bundesbürger erwuchs nach und nach mehr Wertschätzung für die Bonner Demokratie. Dies war das Ergebnis wirtschaftlicher ,Wunder', wohlfahrtsstaatlicher Sicherheit und ungeahnter Konsumchancen immer breiterer Schichten, Ergebnis internationaler Anerkennungsfortschritte wie innenpolitischer Effizienz eines ,kanzlerdemokratischen' Regierungsstils, mit dem Konrad Adenauer die Brücke zwischen Kaiserreich und Bundesrepublik schlug und den Nerv einer politisch weder besonders interessierten noch informierten Gesellschaft traf. Saarländerinnen und Saarländer beobachteten dies mit Argusaugen, die Bundesrepublik diente mehr und mehr als Projektionsfläche des Deutsch-Seins an der Saar.

Bei Kriegsende artikulierte niemand gangbare, geschweige denn attraktivere Optionen verglichen mit der Saar-Autonomie. Da waren die ökonomischen Ansprüche in Paris, die Diplomaten in London und Washington angesichts vorausgegangener deutscher Invasion, Besetzung und Ausbeutung und zugunsten eines gesamteuropäischen Wiederaufbaus umstandslos stützten. Die nationale Frage war in der Zusammenbruchsgesellschaft gedeckelt. Einen deutschen Staat gab es nicht mehr, Europäisches als Leitlinie künftigen Friedens kursierte allenthalben. Auch materiell zahlten sich Sonderstatus, Teilautonomie und Wirtschaftsanschluss an der Saar aus: keine Demontagen, kaum Ostflüchtlinge, dafür einen privilegierten Zugriff auf Lebensmittel verglichen mit der französischen Besatzungszone im übrigen Südwesten. ${ }^{34}$ Über Jahre hinweg blieb es dabei: Das materielle, das wirtschaftliche und soziale Wohlergehen im Saarstaat sowie der früher als in Westdeutschland einsetzende Aufschwung erwiesen sich als „,die beste Garantie für politischen Erfolg“"35, wie selbst die Landtagswahlen Ende November 1952 noch bezeugten. Auf gerade einmal $7 \%$ belief sich die Wahlenthaltung, auf fast stattliche $64 \%$ die Mehrheit des Regierungslagers und lediglich 22,8\% betrug der Anteil ungültiger Stimmen: trotz ausdrücklich anderslautender Empfehlungen der prodeutschen, nicht zugelassenen Parteien.

Der politische und wirtschaftliche Status mochte in den Anfangsjahren des Saarstaats auf plausiblen Argumenten beruhen, doch diese galten in den

34 Vgl. Heinen: Saarjabre, S. 108-110, S. 190-192.

35 Vgl. Steinert, Marlies: Die Europäisierung der Saar - eine echte Alternative?, in: Hudemann/Jellonnek/Rauls (Hg.): Grenz-Fall, S. 63-79, hier S. 75. 
Jahren 1953, 1954, 1955 in den Augen etlicher Zeitgenossen kaum mehr in gleichem Maße. Ihnen zufolge versprach nun die Bundesrepublik eine politisch stabilere und wirtschaftlich glänzendere Zukunft, während in Frankreich alle halbe Jahre die eine Regierung eine andere ablöste und Kolonialabenteuer viel Geld verschlangen und jungen Menschen das Leben kosteten. Die Attraktionspotenziale begannen sich in den frühen 1950er Jahren zu verkehren, der einsetzende politische Klimawandel ließ sich bald kaum mehr übersehen. Besonders das, Wirtschaftswunder ${ }^{6}$ etablierte sich als erstrangiges Thema im Abstimmungskampf. Durch Schmuggelfahrten in grenznahe Städte war die westdeutsche Warenwelt längst vor dem 23. Oktober an der Saar präsent. Und deutsche Produkte galten schlicht als hochwertiger verglichen mit der französischen Konkurrenz: wohl nicht zuletzt wegen des symbolischen Gehalts, wegen des knappen Angebots, wegen der risikobehafteten Beschaffungspraktiken.

Als die Saar dann am 23. Oktober 1955 neuerlich über das eigene Schicksal befinden konnte, stimmten über $67 \%$ derer, die zur Wahlurne schritten, gegen das Saarstatut. ${ }^{36}$ Nur wenige politische Akteure in Paris, Bonn und Saarbrücken hätten es bei Unterzeichnung des Abkommens am 23. Oktober 1954 für möglich gehalten, dass sich ein Jahr später gut zwei Drittel der Wählerinnen und Wähler gegen das Europastatut aussprechen würden. Weniger überraschend liest sich das Resultat freilich sowohl in langfristiger als auch in kurzfristiger Perspektive: langfristig mit Blick auf das Votum 1935 und das damalige Ergebnis, kurzfristig mit Blick auf die zunehmende, geradezu atemberaubende Eigendynamik des Abstimmungskampfes in den letzten Wochen vor dem anberaumten Stichtag. Und auch im Rückblick aus heutiger Sicht überwiegen die Faktoren, die auf ein Ablehnen hindeuteten. Als das eigentlich Überraschende muss deshalb eher schon das Befürworten des Europastatuts durch knapp ein Drittel des Wahlvolks gelten. Immerhin optierte es doch damit für eine halbwegs unsichere Zukunft in Richtung einer europäischen Saar-Lösung.

Dass letzten Endes rund 200000 Bürgerinnen und Bürger einer autonomen Saar in Europa eine Chance geben wollten, mochte mit den bereits erwähnten Lernprozessen zu tun haben, aber auch mit Initiativen, Leistungen und Errungenschaften, die viele Ja-Sager weiter der Hoffmann-Regierung zurechneten: auf dem Gebiet sozial- und wohlfahrtsstaatlicher Absicherung, im privaten Wohnungsbau oder im konsequent europäisch gedachten Bildungs-,

36 Vgl. Hüser, Judith: Frankreich und die Abstimmung vom 23. Oktober 1955. Innen- und außenpolitische Problemstellungen zur Lösung der Saarfrage, in: Hudemann/Poidevin (Hg.): Die Saar 1945-1955, S. 359-379; Hannig, Jürgen: Separatisten - Nationalisten? Zum Abstimmungskampf 1955, in: Hudemann/Poidevin (Hg.): Die Saar 1945-1955, S. 381396. 
Kultur- und Mediensektor. ${ }^{37}$ Mit dem Saarländischen Rundfunk, der Universität des Saarlandes oder den Vorläufern der Hochschule für Bildende Kunst bzw. für Technik und Wirtschaft vermochten sich dort damals innovative Institutionen zu etablieren, die der Saar dauerhaft erhebliche deutschfranzösische und europäische Mehrwerte bescheren sollten. Es sind Initiativen, Leistungen und Errungenschaften, die teils in Verhandlungen oder in Kooperation mit französischen Verwaltungskräften um Gilbert Grandval zustande gekommen sind, teils in eigenständigem Ermessen der autonomiebestrebten Hoffmann-Regierung. Und es sind Initiativen, Leistungen und Errungenschaften, die einer ,Frankreichstrategie ${ }^{`}$ der politisch verantwortlichen Saar-Akteure geschuldet waren. Anders formuliert, auf den 23. Oktober 1955 bezogen: Die seit 1946/47 initialisierte ,Frankreichstrategie“ konnte - trotz widriger Begleitumstände - bis zuletzt auf gut ein Drittel der Saar-Wählerschaft zählen.

Rückbezogen auf ,Herausforderungen', ,Handlungsmargen', ,Frankreichstrategien' lässt sich festhalten, dass Frankreich auch nach 1945 die zentrale Herausforderung für die Saar-Politik blieb. Konnte jedoch von eigenständigen Aktionsspielräumen nach 1920 keine Rede sein, geschweige denn von einer ,Frankreichstrategie' im engeren Sinne, so lagen die Dinge nun anders. Es gab demokratisch legitimierte Saar-Akteure, die noch dazu auf etlichen Politikfeldern beträchtliche Handlungsmargen besaßen, um gesteckte Ziele in die Praxis umzusetzen. Dies erlaubte eine ,Frankreichstrategie‘ auf breiterer Front und mit Fokus auf einen möglichst autonomen Kleinstaat, auf ein eigenstaatliches Gebilde an der Saar, das als Brücke zwischen Deutschland und Frankreich sowie als Symbol für ein neues Europa fungieren sollte. ${ }^{38}$ Auf Autonomie zu setzen, war im Sinne Grandvals und des Quai d'Orsay, aber auch ein Herzensanliegen von Hoffmann und seinen Mitstreitern, geboren aus schmerzhaften Erfahrungen mit Nationalsozialismus und Emigration. Letztlich wurzelte Hoffmanns ,Frankreichstrategie، im Abstimmungskampf 1935 und fand 1945 unter denen Rückhalt, die als Gegner des ,Heim ins Reich' nach dem Votum aus unmittelbarer Sorge um Leib und Leben und mit der furchtbaren Aussicht auf dramatische Folgejahre auswandern mussten.

37 Zur Sozialpolitik vgl. Herrmann, Hans-Christian: Sozialer Besitzstand und gescheiterte Sozialpartnerschaft. Sozialpolitik und Gewerkschaften im Saarland 1945-1955, Saarbrücken: SDV, 1996. $\mathrm{Zu}$ Schule und Hochschule vgl. Küppers, Heinrich: Bildungspolitik im Saarland 1945-1955, Saarbrücken: Thinnes \& Nolte, 1984 (Veröffentlichungen der Kommission für Saarländische Landesgeschichte und Volksforschung 14); Heinen, Armin/Hudemann, Rainer (Hg.): Universität des Saarlandes 1948-1988, Saarbrücken: Universität des Saarlandes, 1988; Müller, Wolfgang: Die Universität des Saarlandes. Impressionen aus 60 Jahren, Erfurt: Sutton, 2008. Zu den Medien vgl. Zimmermann, Clemens/Hudemann, Rainer/Kuderna, Michael (Hg.): Medienlandschaft Saar von 1945 bis in die Gegenwart, 3 Bde, München: Oldenbourg 2010.

38 Vgl. Küppers: Johannes Hoffmann, S. 276-279. 
Als Lehre aus einer jahrzehntelangen deutsch-französischen Konfliktgeschichte und als Baustein einer künftigen Verständigungsgeschichte galt es nun die Saar-Autonomie nachdrücklich ins Werk zu setzen, demonstrativ zur Schau zu stellen und dauerhaft abzusichern.

Dass dies in der europäischen Nachkriegskonstellation nicht umstandslos und vollständig gelingen würde, war Hoffmann ebenso klar wie die Tatsache, dass selbst kleine Schritte auf dem Weg dorthin - etwa im Wirtschaftssektor stets der Feinabstimmung und des Interessensausgleichs mit Frankreich bedurften. Und es gab Bereiche, in denen - wie im Fußballsport - sowohl Grandval als auch Hoffmann die Autonomie mit einigem Elan zu realisieren gedachten und dennoch grandios scheiterten: an Gegnern in Frankreich wie in Deutschland, auch an Saar-Fußballfunktionären, die es sich Anfang der 1950er Jahre einfach anders überlegten und verbandspragmatisch die spürbaren Vorboten einer veränderten (sport-)politischen Großwetterlage nutzten. Einerseits waren damit die Saar-Clubs seit 1951/52 wieder in das deutsche Ligasystem integriert, andererseits existierte seit Juni 1950 dank der Aufnahme in die FIFA ein Saar-Nationalteam. Es setzte sich fast ausnahmslos aus Aktiven des 1. FC Saarbrücken zusammen, die faktisch Woche für Woche in der Oberliga Südwest das politische Autonomiekonzept sportlich aushöhlten, gleichzeitig aber als ,Nationalspieler' gegen den Rest der Welt den autonomen Saarstaat repräsentierten. Anschaulicher als auf dem symbolischen Kampffeld des Fußballplatzes lassen sich Widersprüche und Paradoxien kaum skizzieren. ${ }^{39}$

,Frankreich an der Saar': Das blieb auch nach 1945 für viele Menschen ambivalent, ganz anders allerdings als nach 1918 stand ,Frankreich an der Saar` längst nicht mehr unter durchweg negativen Vorzeichen. Die Erfahrungen im Alltag oder am Arbeitsplatz blieben vielfach durchsetzt von kulturellen Missverständnissen, die bestenfalls als Fremdheit, mitunter auch als politischer Interessenskonflikt empfunden wurden. ${ }^{40}$ Zugleich gestaltete sich das Miteinander von Saar- und französischer Bevölkerung alles in allem entspannter als nach 1920. Auch das zeigt sich im Ergebnis von 1955. Mehr als damals - und bei allen Vergleichsblicken gen Osten - schienen auch

39 Vgl. Reichelt, Bernd: Fußball im deutsch-franæösischen Grenæraum Saarland/Moselle 1900-1955. Eine transnationale Geschichte politischer Inszenierung und sportlicher Emanzipation, Stuttgart: Steiner, 2014; Hüser, Dietmar: Sport et Politique - De la difficile quête d'autonomie du football sarrois entre 1945 et 1956, in: Pfeil, Ulrich (Hg.): Football et Identité en France et en Allemagne, Villeneuve-d'Ascq: Septentrion, 2010, S. 65-83; Hüser, Dietmar: Sport als symbolische Arena politischer Konfliktaustragung - Fußball im Vorfeld der Saar-Abstimmungskämpfe 1935 und 1955, in: Clemens, Gabriele (Hg.): Scblïsseljabre. Zäsuren und Kontinuitäten an der Saar - 1815-1935-1955, Saarbrücken: Saarländische Kommission für Landesgeschichte und Volksforschung, 2017, S. 123-144.

40 Vgl. Heinen: Saarjabre, S. 521-526. 
französische Produkt- und Warenwelten in der aufkommenden Konsumgesellschaft reizvoll. Hinzu kamen ganz frühe Europäisierungsprozesse auf der Basis alltäglicher Erfahrungen und erweiterter Horizonte: durch forcierte Begegnungsmöglichkeiten und dauerhaft prägende Frankreichaufenthalte für junge Leute aus gehobenen wie aus Arbeiterkreisen, etwa im Rahmen von Lehrlingsreisen der Régie des Mines; oder auch durch vielfach ,buntere' Kulturund Musikwelten, die über Frankreich an der Saar Einzug hielten, die freilich noch näher zeithistorisch zu untersuchen wären. ${ }^{41}$

Aus den Jahren nach 1920 war wenig Zukunftsweisendes, wenig Europäisches herauszulesen. Wer heute gern den besonders europäischen Anstrich der Saar betont, wird sich ziemlich schwertun, in der Völkerbundsperiode oder den zehn Saarjahren des, tausendjährigen Reiches ${ }^{\natural}$ allzu viele schlüssige Anknüpfungspunkte zu finden. Wohl aber in der Hoffmann-Zeit: Gerade für das ,gelebte Europa' im Alltag der Menschen, gerade in Bildung, Kultur und Medien, in Erfahrungs- und Lebenswelten gab es eine Menge Kontinuität über 1955 hinaus. Aber auch im Politisch-Staatsrechtlichen: Verfassungsfragen, Demokratie-Einüben und Selbstregierung ,aus dem Land heraus 'wurden bereits thematisiert. Mehr noch: Hoffmanns Autonomie-Ziel, die Eigenstaatlichkeit der Saar, blieb im Bundesland bestehen, schließlich verteilt der deutsche Bundesstaat seine hoheitlichen Aufgaben auf zwei Träger, den Bund und die Länder. Für ,Frankreichstrategien' aber setzte die Bundesland-Geschichte der Saar gänzlich andere Rahmenbedingungen. Dazu abschließend ein paar kursorische Hinweise.

\section{Bundeslandzeiten nach 1957 bzw. 1959 - Grenzraumkooperation als unpolitische ,Frankreichstrategie}

Wenig verwunderlich, dass die Karten an der Saar neu gemischt wurden. Auf deutsch-französischer Spitzenebene schrieben sich die Regierungschefs Edgar Faure und Konrad Adenauer gleich nach dem Aus für das Europastatut Telegramme: Das bilaterale Verhältnis dürfe durch das Votum nicht belastet

41 Erste relevante Einsichten lassen sich herauslesen aus zwei Ausstellungskatalogen: Regionalgeschichtliches Museum Saarbrücken: Von der „Stunde 0" zum „Tag X" - Das Saarland 1945-1949, Merzig: Merziger Druckerei, 1990; Historisches Museum Saar: Mebr als nur Reklame. Saarländische Gebrauchsgrafik. 1945-1960, Stuttgart: Oktagon, 1995. Daneben nun weitere Hinweise bei Burgard, Paul/Linsmayer, Ludwig: Der Saarstaat - L'Etat sarrois, Saarbrücken: Landesarchiv Saarbrücken, 2005 (Echolot 2); Herrmann, Hans-Christian: Saarbrücken in Fabrt. 125 Jabre Automobil an der Saar, Marpingen: Edition Schaumberg, 2011; Herrmann, Hans-Christian: Saarbrücken à la carte. Die Gescbichte der Genussregion Saarland, Marpingen: Edition Schaumberg, 2012; Herrmann, Hans-Christian/Bauer, Ruth/Schmidt, Kathrin (Hg.): 150 Jahre Babnhofstraße. Schaufenster des Lebens, Marpingen: Edition Schaumberg, 2014. 
werden, hieß es. Beide waren Verlierer und Gewinner: Beide hatten sich eher emotionslos für das Statut eingesetzt, konnten aber mit dem Resultat leben. Einigkeit bestand in Bonn und Paris, rasch über ein bundesdeutsches Eingliedern der Saar und Gegenleistungen für Frankreich zu verhandeln, allerdings ohne Saar-Repräsentanten. In Saarbrücken erklärte Johannes Hoffmann seinen Rücktritt, eine Übergangsregierung trat auf den Plan, die Landtagswahlen am 18. Dezember führten zum Sieg der pro-deutschen Parteien und zum Amtsantritt der ,Heimatbund'-Regierung unter Hubert Ney am 10. Januar 1956. ${ }^{42}$ Nach einer Landtagserklärung zur Vereinigung mit der Bundesrepublik Ende Januar erfolgten Verhandlungen zwischen Bonn und Paris, die im Oktober in die Luxemburger Verträge mündeten. Die Beitrittserklärung im Saar-Landtag und das Beitrittsgesetz im Bundestag machten im Dezember den Weg frei für das politische Eingliedern zum 1. Januar 1957. Nach dem Ablauf ausgehandelter Übergangsfristen sollte das wirtschaftliche Eingliedern samt DM-Einführung gut zweieinhalb Jahre später erfolgen: der berühmte ,Tag X'.

Nach dem Beseitigen des verbliebenen bilateralen Stolpersteins meinten veränderte Rahmenbedingungen für ,Frankreichstrategien' an der Saar in deutsch-französischer Perspektive ein dauerhaft stabilisiertes, auf Verständigung, Ausgleich und Kooperation gegründetes Verhältnis zwischen Bonn und Paris. Bei allen (außen-)politischen und wirtschaftlichen Asymmetrien, bei allen Meinungs- und Interessenunterschieden, die weiter zum Tagesgeschäft gehörten und auch künftig kaum zu vermeiden waren, konnte doch von Konflikten im Grundsätzlichen keine Rede mehr sein. Auch auf zivilgesellschaftlicher Ebene gewannen Annäherungs- und Austauschprozesse an Dynamik, längst bevor der Elysée-Vertrag im Januar 1963 einen weiteren Schub gab. Meinungsumfragen zeigten auf, dass der Paradigmenwechsel vom deutsch-französischen Konflikt- zum Verständigungstopos der zweiten Nachweltkriegszeit nicht mehr nur politisch, von oben', sondern mehr und mehr gesellschaftlich, von unten' gewollt war. ${ }^{43}$ Und auch europäisch blieben die Folgen des an der Saar abgelehnten Europastatuts begrenzt, fanden sich rasch durch die wenige Monate zuvor mit der Konferenz von Messina wieder

$42 \mathrm{Zu}$ den politischen Verwerfungen der Übergangszeit vgl. Herrmann, Hans-Christian: Das Saarland als Bundesland: trotz Dauerkrise auch eine Geschichte der Erfolge, in: Herrmann/Schmitt (Hg.): Das Saarland, S. 339-398; zu politisch-kulturellen Entwicklungstrends der Folgejahrzehnte vgl. Hüser, Dietmar: Wahlen, Parteien und politische Kultur im Saarland der 70er und 80er Jahre - Aspekte eines Umbruchs mit Konstanten, in: Dillmann, Edwin/van Dülmen, Richard (Hg.): Lebenserfabrungen an der Saar. Studien zur Alltagskultur 1945-1995, St. Ingbert: Röhrig, 1996, S. 40-65, S. 415-442.

43 Bundesdeutsche und französische Umfragen, zit. bei Ziebura, Gilbert: Die deutsch-franżösischen Beziehungen seit 1945. Mythen und Realitäten, Stuttgart: Klett-Cotta, 1997, hier S. 119121. 
in Gang gesetzte relance européenne kompensiert, die über weitere Etappen 1958 in die Europäische Wirtschaftsgemeinschaft münden sollte. ${ }^{44}$

Mehr noch hatten sich die Rahmenbedingungen für ,Frankreichstrategien' an der Saar im Grenzland selbst modifiziert. Politisch modifiziert, weil nun die Akteure als Landesregierung eines Bundeslandes die Verantwortung trugen, die als Autonomie-Gegner im Hoffmann-Staat vom Zugriff auf die Macht ausgeschlossen waren und am 23. Oktober 1955 - zumindest implizit - auf die westdeutsche statt europäische Karte gesetzt hatten. Eine differenzierte, mitunter eben auch positive Leistungsbilanz des letzten Jahrzehnts mochte damals niemand gern zugestehen. Geschichtspolitisch galt es eher, alte Rechnungen zu begleichen und die leuchtende Jetztzeit von der schwarzgemalten Vorzeit abzusetzen. Dabei blieb vieles auf der Strecke, nicht zuletzt der erste Saar-Ministerpräsident persönlich, dem nun erst recht das Stigma des frankophilen Verräters und Unterdrückers anhaftete. Hoffmann-Einschätzungen, die nahtlos aus den heißen Phasen des Abstimmungskampfes in dominante Geschichtsbilder eingedrungen sind, die in der Forschung aber längst als völlig überholt gelten. ${ }^{45}$

Die große Herausforderung war nun - anders als nach dem Ersten und Zweiten Weltkrieg - nicht mehr Frankreich. Im Fokus standen unmittelbar drängende wirtschaftliche und soziale Problemlagen sowie der wachsende Unmut darüber, dass die im Abstimmungskampf geschürten Hoffnungen auf einen reibungslosen Import des bundesdeutschen, Wirtschaftswunders' ${ }^{6}$ an der Saar rasch verpufften und nüchternen Realitäten wichen. Zutage trat, dass regional orientierte Mittelständler nur bedingt gegen eine wettbewerbsroutinierte Konkurrenz aus dem Westen gewappnet waren und dass die Saarökonomie zugleich nach langjährigem Einbinden in französische Marktstrukturen kaum unmittelbar über geeignete Mittel und Wege verfügte, um den bundesdeutschen Markt zu erobern. Hinzu kamen augenfällige montanindustrielle Krisenvorboten: 1958/59 setzte eine erste Kohlekrise ein; erste Grubenschließungen waren die Folge. Und Bergleute wie Hüttenarbeiter klagten über Reallohneinbußen wegen des Wegfalls der großzügigen französischen allocations familiales. ${ }^{46}$

Aus eigener Kraft war das Eingliedern der Saar in den westdeutschen Wirtschaftsraum offenbar kaum zu schaffen. Es gestaltete sich trotz mehrjähriger Übergangsfristen deutlich schwieriger als dies manche derer, die nun die Regierungsgeschäfte leiteten, in der anfänglichen Euphorie über den

44 Vgl. Defrance, Corine/Pfeil, Ulrich: Deutsch-französische Geschichte, Bd. 10: Eine Nachkeriegsgeschichte in Europa 1945 bis 1963, Darmstadt: WBG, 2010, S. 83-85.

45 Vgl. Küppers: Johannes Hoffmann, S. 340-343.

46 Vgl. Rösler, Jörg: Die wirtschaftliche Rückgliederung der Saar. Erwartungen, Enttäuschungen, Entwicklungen, in: Hudemann/Jellonnek/Rauls (Hg.): Grenz-Fall, S. 445-464. 
Abstimmungssieg gedacht hatten. Und um die ganz grundlegenden Strukturprobleme der Saarwirtschaft zu beheben, reichten auch keine zwischenzeitlichen Sonderregelungen und Hilfsmaßnahmen. Im Gegenteil: Das Sonderregime und die praktizierte Landespolitik verstärkten noch die strukturellen Defizite. ${ }^{47}$ Meinungsumfragen der frühen 1960er Jahre zufolge glaubte fast die Hälfte der Saarländerinnen und Saarländer, verglichen mit der Zeit vor dem Eingliedern in die bundesdeutsche Ökonomie habe sich die eigene wirtschaftliche Lage nachteilig entwickelt. Nur 7\% der Befragten meinten, es gehe ihnen seitdem besser. Auch Umfragen in den folgenden Jahren wiesen mehr Unzufriedene als Zufriedene mit dem ,Tag X“ und den ökonomischen Konsequenzen aus. ${ }^{48}$

Kurzum: Die Herausforderung der Saar-Politik hatte sich verlagert und bestand für die kommenden Jahre und Jahrzehnte im Überwinden, im möglichst kreativen Kanalisieren der Strukturkrise der Montanindustrie, die sich seit 1974/75 weiter verschärfen sollte. Sich gegenüber Frankreich und dem französischen Grenzraum zu positionieren, blieb weiter wichtig, bildete aber kein Politikum ersten Ranges mehr. Den Hoffmannschen Saarstaat zunächst einmal geschichtspolitisch unter Quarantäne zu stellen, bedeutete für die nachfolgenden Regierungen nicht, auf Kontaktpflege sowie ein gutes Verhältnis zu Frankreich und den Nachbarregionen zu verzichten. Gerade FranzJosef Röder, promovierter Romanist und seit 1959 für zwei Jahrzehnte Ministerpräsident, bemühte sich redlich darum. Klar war, dass das wirtschaftliche Wohlergehen des Saarlandes dauerhaft auch auf eine enge Abstimmung mit Frankreich und auf eine grenzüberschreitende Zusammenarbeit mit den französischen Nachbarregionen angewiesen war. ${ }^{49}$ Und klar war, dass dies die primäre Stoßrichtung künftiger ,Frankreichstrategien` sein musste. Seit Anfang der 1960er Jahre erfolgten entsprechende Initiativen: Grenzraumkooperation, Raumordnungsfragen, Infrastrukturprojekte, Industrieansiedlungen, Strukturwandel der Montanregionen; das waren wichtige Themen der ersten Stunde, stets begleitet durch Aktivitäten und Vorhaben im Kultur-, Medien- und Unisektor.

47 Vgl. Hahn, Marcus: Das Saarland im doppelten Strukturwandel 1956-1970. Regionale Politik zwischen Eingliederung in die Bundesrepublik. Deutschland und Koblekrise, Saarbrücken: Saarländische Kommission für Landesgeschichte und Volksforschung, 2003 (Veröffentlichungen der Kommission für Saarländische Landesgeschichte und Volksforschung 36), hier S. 110-113.

48 Vgl. Wettmann-Jungblut, Peter: Land am Fluss. Das Erbe des saarländischen Sonderweges, in: Linsmayer (Hg.): Die Geburt des Saarlandes, S. 279-303; Rösler: Die wirtschaftliche Rückgliederung, S. $456 \mathrm{f}$.

49 Vgl. Hahn: Das Saarland im doppelten Strukturvandel 1956-1970, S. 319, S. 322, S. 353; Herrmann: Das Saarland als Bundesland, S. 388-390. 
Die aktuelle Frankeichstrategie der Landesregierung steht in dieser Tradition. Es geht darum, die Saar in den kommenden Jahren und Jahrzehnten sprachlich und interkulturell, infrastrukturell und wirtschaftlich fit zu machen für die Zukunft. Das Saarland als Brücke zu Frankreich, um selbst davon zu profitieren und um sich nach außen zu profilieren. Die Konsequenz, mit der die Große Koalition die Frankreichstrategie seit Januar 2014 in Selbstrepräsentation und Außendarstellung hochhält, legt nahe, dass das Projekt ernster gemeint war, als manche Beobachter damals annahmen. Nun gilt es, die Landesregierung beim Wort zu nehmen und zu sehen, ob es sich - gerade angesichts der schwierigen Finanzlage und selbstgesteckter Sparziele im Land - mittelund langfristig in ähnlicher Konsequenz in die Praxis umsetzen lässt.

\section{Literaturverzeichnis}

Bauerkämper, Arnd/Jarausch, Konrad/Payk, Marcus (Hg.): Demokratiewunder. Transatlantische Mittler und die kulturelle Öffnung Westdeutschlands 1945-1970, Göttingen: Vandenhoeck \& Ruprecht, 2005.

Beaupré, Nicolas: (Wieder-)Herstellen, löschen, verschieben: Grenzen in den Köpfen. Das Saarland zwischen Krieg und Volksabstimmung in den ersten Jahren der „Besatzungszeit“, in: François, Etienne/Seifarth, Jörg/Struck, Bernhard (Hg.): Die Grenze als Raum, Erfabrung und Konstruktion. Deutschland, Frankereich und Polen vom 17. bis zum 20. Jabrbundert, Frankfurt/New York: Campus, 2007, S. 163-182.

Beaupré, Nicolas: Deutsch-französische Geschicbte Band VIII. Das Trauma des großen Krieges 19181932/33, Darmstadt: WBG, 2009.

Becker, Frank G.: „Deutsch die Saar, immerdar!“- Die Saarpropaganda des Bundes der Saarvereine 19191935, Saarbrücken: Kommission für Saarländische Landesgeschichte und Volksforschung, 2007 (Veröffentlichungen der Kommission für Saarländische Landesgeschichte und Volksforschung 40).

Becker, Jean-Jacques: La Ve République, in: Duclert, Vincent/Prochasson, Christophe (Hg.): Dictionnaire critique de la République, Paris: Flammarion, 2002.

Behringer, Wolfgang/Clemens, Gabriele: Geschichte des Saarlandes, München: Beck, 2009.

Berstein, Serge: Le gaullisme, in: Rioux, Jean-Pierre/Sirinelli, Jean-François (Hg.) : La France d'un siècle à l'autre 1914-2000. Dictionnaire critique, Paris: Hachette, 1999, S. 711-718.

Burgard, Paul/Linsmayer, Ludwig: Der Saarstaat - L'Etat sarrois, Saarbrücken: Landesarchiv Saarbrücken, 2005 (Echolot 2).

Burgard, Paul: Kleine Geschichte des Saarlandes, Leinfelden-Echterdingen: G. Braun Buchverlag, 2012.

Conze, Eckart: Die Suche nach Sicherbeit. Eine Gescbichte der Bundesrepublik. Deutschland von 1949 bis in die Gegenwart, München: Siedler, 2009.

Defrance, Corine/Pfeil, Ulrich: Deutsch-französische Geschichte, Bd. 10: Eine Nachkeriegsgeschichte in Europa 1945 bis 1963, Darmstadt: WBG, 2010.

Elvert, Jürgen: Die europäische Integration, Darmstadt: WBG, 2006 (Geschichte kompakt).

Hahn, Marcus: Das Saarland im doppelten Strukturwandel 1956-1970. Regionale Politik zwischen Eingliederung in die Bundesrepublik. Deutscbland und Koblekrise, Saarbrücken: Saarländische Kommission für Landesgeschichte und Volksforschung, 2003 (Veröffentlichungen der Kommission für Saarländische Landesgeschichte und Volksforschung 36). 
Hannig, Jürgen: Separatisten - Nationalisten? Zum Abstimmungskampf 1955, in: Hudemann/ Poidevin (Hg.): Die Saar 1945-1955, S. 381-396.

Heinen, Armin/Hudemann, Rainer (Hg.): Universität des Saarlandes 1948-1988, Saarbrücken: Universität des Saarlandes, 1988.

Heinen, Armin: Saarjahre. Politik und Wirtschaft im Saarland 1945-1955, Stuttgart: Steiner, 1996.

Heinz, Joachim: Die Abstimmungen von 1935 und 1955 an der Saar im Vergleich, in: Stiftung Demokratie Saarland (Hg.): Der 23. Oktober 1955 - 50 Jabre danach, Saarbrücken: Stiftung Demokratie Saarland, 2007 (Dialog 15), S. 85-106.

Herbert, Ulrich (Hg.): Wandlungsprozesse in Westdeutschland. Belastung, Integration, Liberalisierung 1945-1980, Göttingen: Wallstein, 2002.

Herbert, Ulrich: Geschicbte Deutschlands im 20. Jahrbundert, München: C. H. Beck, 2014.

Herrmann, Hans-Christian: Sozialer Besitzstand und gescheiterte Sozialpartnerschaft. Sozialpolitik und Gewerkschaften im Saarland 1945-1955, Saarbrücken: SDV, 1996.

Herrmann, Hans-Christian: Saarbrücken in Fabrt. 125 Jabre Automobil an der Saar, Marpingen: Edition Schaumberg, 2011.

Herrmann, Hans-Christian: Das Saarland als Bundesland: trotz Dauerkrise auch eine Geschichte der Erfolge, in: Herrmann/Schmitt (Hg.): Das Saarland, S. 339-398.

Herrmann, Hans-Christian/Schmitt, Johannes (Hg.): Das Saarland. Geschichte einer Region, St. Ingbert: Röhrig, 2012.

Herrmann, Hans-Christian: Saarbrücken à la carte. Die Gescbicbte der Genussregion Saarland, Marpingen: Edition Schaumberg, 2012.

Hermann, Hans-Christian: Aspekte zum jüdischen Leben an der Saar: die Zeit vom 19. Jahrhundert bis zum Ende des Holocaust, in: ders./Bauer: Widerstand, Repression und Verfolgung, S. 35-102.

Herrmann, Hans-Christian/Bauer, Ruth (Hg.): Widerstand, Repression und Verfolgung. Beiträge zur Geschichte des Nationalsozialismus an der Saar, St. Ingbert: Röhrig, 2014.

Herrmann, Hans-Christian/Bauer, Ruth/Schmidt, Kathrin (Hg): 150 Jabre Babnhofstraße. Schaufenster des Lebens, Marpingen: Edition Schaumberg, 2014.

Historisches Museum Saar: Mebr als nur Reklame. Saarländische Gebrauchsgrafik 1945-1960, Stuttgart: Oktagon, 1995.

Hudemann, Rainer/Jellonnek, Burkhard/Rauls, Bernd (Hg.): Grenz-Fall. Das Saarland zwischen Frankreich und Deutschland 1945-1960, St. Ingbert: Röhrig, 1997.

Hudemann, Rainer/Poidevin, Raymond (Hg.): Die Saar 1945-1955. Ein Problem der europäischen Gescbicbte, München: Oldenbourg, 1995.

Hüser, Dietmar: Frankreichs „doppelte Deutscblandpolitik“. Dynamik aus der Defensive - Planen, Entscheiden, Umsetzen in gesellschaftlichen und wirtschaftlichen, innen- und außenpolitischen Krisenzeiten 1944-1950, Berlin: Duncker \& Humblot, 1996.

Hüser, Dietmar: Wahlen, Parteien und politische Kultur im Saarland der 70er und 80er Jahre Aspekte eines Umbruchs mit Konstanten, in: Dillmann, Edwin/van Dülmen, Richard (Hg.): Lebenserfahrungen an der Saar. Studien zur Alltagskultur 1945-1995, St. Ingbert: Röhrig, 1996, S. 40-65, S. 415-442.

Hüser, Dietmar: Die Saar in den internationalen Beziehungen nach dem Zweiten Weltkrieg Ungewisse Planspiele, zögerliche Praxis und funktionales Potential in einem nachgeordneten Politikfeld, in: Hudemann/Jellonnek/Rauls (Hg.), Grenz-Fall, S. 97-120.

Hüser, Dietmar: Struktur- und Kulturgeschichte französischer Außenpolitik im Jahre 1945 Für eine methodenbewußte Geschichte der internationalen Beziehungen, in: Historische Mitteilungen 16 (2003), S. 155-170. 
Hüser, Dietmar: Sport et Politique - De la difficile quête d'autonomie du football sarrois entre 1945 et 1956, in: Pfeil, Ulrich (Hg.): Football et Identité en France et en Allemagne, Villeneuved'Ascq: Septentrion, 2010, S. 65-83.

Hüser, Dietmar: Miracle démocratique dans l'Allemagne de l'Ouest des décennies d'après-guerre Histoire de la culture de masse comme histoire culturelle du politique, in: Histoire, économie et société 35 (2016), S. 14-31.

Hüser, Dietmar: Sport als symbolische Arena politischer Konfliktaustragung - Fußball im Vorfeld der Saar-Abstimmungskämpfe 1935 und 1955, in: Clemens, Gabriele (Hg.): Scblïsseljabre. Zäsuren und Kontinuitäten an der Saar - 1815-1935-1955, Saarbrücken: Saarländische Kommission für Landesgeschichte und Volksforschung, 2017, S. 123-144.

Hüser, Judith: Frankreich und die Abstimmung vom 23. Oktober 1955. Innen- und außenpolitische Problemstellungen zur Lösung der Saarfrage, in: Hudemann/Poidevin (Hg.): Die Saar 1945-1955, S. 359-379.

Hüser, Judith: Saarkatholiken auf dem Sonderweg? Kirche und Konfession, Nation und Europa in einem deutsch-französischen Grenzland, in: Persch, Martin (Hg.): Geschicbte des Bistums Trier, Trier: Paulinus, 2004, S. 671-697.

Hüser, Judith: Quo vadis, Saarland? Die Haltung der Kirchen zum Sonderweg der Saar, in: Linsmayer (Hg.): Die Geburt des Saarlandes, S. 252-269.

Jacoby, Fritz: Die nationalsozialistische Herrschaftsïbernabme an der Saar. Die innenpolitischen Probleme der Rückgliederung des Saargebietes bis 1935, Saarbrücken: Thinnes \& Nolte, 1973 (Veröffentlichungen der Kommission für Saarländische Landesgeschichte und Volksforschung 6).

Jarausch, Konrad: Die Umkehr. Deutsche Wandlungen 1945-1995, München: Deutsche VerlagsAnstalt, 2004.

Kaelble, Hartmut: Kalter Krieg und Woblfahrtsstaat. Europa 1945-1989, München: Beck, 2011.

Klöckner, Michelle: Treue Volksgenossen? Die Saar zwischen Resistenz und Zustimmung, in: Herrmann/Bauer (Hg.): Widerstand, Repression und Verfolgung, S. 149-183.

Küppers, Heinrich: Bildungspolitik im Saarland 1945-1955, Saarbrücken: Thinnes \& Nolte, 1984 (Veröffentlichungen der Kommission für Saarländische Landesgeschichte und Volksforschung 14).

Küppers, Heinrich: Johannes Hoffmann 1890-1967. Geschichte eines Deutschen, Düsseldorf: Droste, 2008.

Linsmayer, Ludwig: Politische Kultur im Saargebiet 1920-1932. Symbolische Politik, verbinderte Demokratisierung, nationalisiertes Kulturleben in einer abgetrennten Region, St. Ingbert: Röhrig, 1992.

Linsmayer, Ludwig: Bewahrend oder bewegend? Zum Verhältnis von Gedächtnis und Geschichte in den Auseinandersetzungen um den 13. Januar 1935, in: ders. (Hg.): Der 13. Januar, S. 15-51.

Linsmayer, Ludwig (Hg.): Der 13. Januar. Die Saar im Brennpunkt der Geschichte, Saarbrücken: Landesarchiv Saarbrücken, 2005.

Linsmayer, Ludwig (Hg.): Die Geburt des Saarlandes. Zur Dramaturgie eines Sonderveges, Saarbrücken: Landesarchiv Saarbrücken, 2007 (Echolot 3).

Mallmann, Klaus-Michael/Paul, Gerhard: Herrschaft und Alltag. Ein Industrierevier im Dritten Reich, Bonn: Dietz, 1991.

Müller, Wolfgang: Die Universität des Saarlandes. Impressionen aus 60 Jabren, Erfurt: Sutton, 2008.

Noelle, Elisabeth/Neumann, Peter (Hg.): Jahrbuch der öffentlichen Meinung 1947-1955, Allensbach: Verlag für Demoskopie, ${ }^{2} 1956$.

Raphael, Lutz: Imperiale Gewalt und mobilisierte Nation. Europa 1914-1945, Bonn: Bundeszentrale für politische Bildung, 2014 (Schriftenreihe 1489). 
Regionalgeschichtliches Museum Saarbrücken: Von der „Stunde 0“ zum „Tag X“-Das Saarland 1945-1949, Merzig: Merziger Druckerei, 1990.

Reichelt, Bernd: Fußball im deutsch-französischen Grenzraum Saarland/Moselle 1900-1955. Eine transnationale Geschichte politischer Inszenierung und sportlicher Emanzipation, Stuttgart: Steiner, 2014.

Rösler, Jörg: Die wirtschaftliche Rückgliederung der Saar. Erwartungen, Enttäuschungen, Entwicklungen, in: Hudemann/Jellonnek/Rauls (Hg.): Gren₹-Fall, S. 445-464.

Sander, Michael: Die Verfassung des Saarlandes. Politische Planung und politischer Erfolg, in: Hudemann/Poidevin (Hg.): Die Saar 1945-1955, S. 237-252.

Schildt, Axel/Siegfried, Detlef: Deutsche Kulturgeschichte. Die Bundesrepublik 1945 bis zur Gegenwart, München: Hanser, 2009.

Staatskanzlei des Saarlandes: Eckpunkte einer Frankreichstrategie für das Saarland, 2014, http:// www.saarland.de/dokumente/res_stk/D_Eckpunkte_Frankreich-Strategie_210114.pdf (16.08.2016).

Steinert, Marlies: Die Europäisierung der Saar - eine echte Alternative?, in: Hudemann/ Jellonnek/Rauls (Hg.): Grenz-Fall, S. 63-79.

Wegener, Alexander von: Die „saarländische Sphinx“. Zur Interpretation der Saarabstimmung 1935, in: Jahrbuch für westdeutsche Landesgescbichte 20 (1994), S. 273-317.

Wettmann-Jungblut, Peter: Land am Fluss. Das Erbe des saarländischen Sonderweges, in: Linsmayer (Hg.): Die Geburt des Saarlandes, S. 279-303.

Winkler, Heinrich-August: Geschicbte des Westens. Die Zeit der Weltkriege 1914-1945, Bonn: Bundeszentrale für politische Bildung, 2011.

Winock, Michel: Le 6 février, in: ders.: La fièvre hexagonale. Les grandes crises politiques 1871-1968, Paris: Points-Seuil, 1987, S. 193-238.

Zenner, Maria: Parteien und Politik im Saargebiet unter dem Völkerbundsregime 1920-1935, Saarbrücken: Thinnes \& Nolte, 1966 (Veröffentlichungen der Kommission für Saarländische Landesgeschichte und Volksforschung 3).

Ziebura, Gilbert: Die deutsch-französischen Beziehungen seit 1945. Mythen und Realitäten, Stuttgart: Klett-Cotta, 1997.

Zimmermann, Clemens/Hudemann, Rainer/Kuderna, Michael (Hg.): Medienlandschaft Saar von 1945 bis in die Gegenwart, 3 Bde, München: Oldenbourg 2010. 


\section{Penser et vivre la frontière dans les relations franco-allemandes}

Grenzen bestimmten lange Zeit die deutsch-französischen Beziebungen und baben folgenschwere Konflikte zwischen den beiden Nachbarvölkern ausgelöst. In deren Mittelpunkt stand naturgemäß der Rhein, der einen Teil der deutsch-französischen Grenze ausmacht und über die Jahrhunderte eine emotionale und nationale Aufladung erbielt, welche starke Antagonismen zutage gefördert hat. Nachdem sich die Spannungen im Laufe des 19. Jahrbunderts verstärkt hatten und in einem ersten keriegerischen Konflikt sowie den katastrophalen Ereignissen des 20. Jabrbunderts gipfelten, war ein anderes Grenzdenken vonnöten, um den Völkern ein neues Miteinander zu ermöglichen. Aber wie konnte aus dieser, historischen Narbe' ein dauerhaft stabiles Bündnis zwischen den beiden Ländern im Herzen Europas entstehen?

Der vorliegende Beitrag seţt beim veränderten Grenzempfinden im Rahmen der deutsch-französischen Beziehungen nach 1945 an. Äbnlich wie das Bild von der, Erbfeindschaft' musste auch die deutsch-franä̈sische Grenze politisch, militärisch, kulturell und mental demobilisiert werden, um den ,Schnitt', den der Rhein dargestellt hatte, in eine ,Nabt" umzuwandeln und diesen ,Nil des Okeqidents" von einer Grenzlinie zu einem europäischen Beziehungsraum werden zu lassen. Inwiefern war die Grenznähe dabei ein $V$ orteil oder aber, zumindest in der ersten Zeit, ein Hindernis für die bilateralen Bestrebungen einer Annäherung?

Ausgehend von einer bistorischen Auseinandersetzung mit dem Grenzbegriff unter Gegenüberstellung der Konzeptionen einer, natürlichen Grenze; eines deutschen, französischen oder europäischen Rheins, zeigt dieser Beitrag, wie es Franzosen und Deutschen gelungen ist, mit dieser schmerzhaften Vergangenheit abzuschließen, indem sie nach 1945 den grenzüberschreitenden Kontakt und Dialog gesucht haben. Folglich werden die beiden Länder heute oft als Vorzeigemodell für eine gelungene Versöhnung verstanden und die grenzüberschreitende bilaterale Kooperation ist zum Aushängeschild sowie zu einem spannenden Erprobungsfeld ibrer Beqiehung geworden.

«La cicatrice de l'histoire/die Narbe der Geschichte ». C'est ainsi qu'en 1973 Alfred Mozer, journaliste et homme politique germano-néerlandais, qualifia la frontière franco-allemande qu'il voulait transformer en un foyer de coopération locale et régionale. ${ }^{1}$ Aujourd'hui, 50000 travailleurs frontaliers se rendent

1 Mozer, Alfred : Entwicklungspolitik zu Hause, ds. : Schöndube, Claus (dir.) : Entwicklungsregionen in der $E W G$, Bonn : Bundeszentrale für politische Bildung (Schriften der Bundeszentrale für politische Bildung), 1973, p. 14-25, ici p. 14, cité d'après Wassenberg, Birte : 
de France en Allemagne (dont un quart de résidents allemands en France) et 4000 Allemands viennent chaque jour en France. ${ }^{2}$ Les $451 \mathrm{~km}$ de frontière passant entre trois Länder allemands et trois départements français sont un lieu d'échanges permanents et intenses. Les ponts sur le Rhin, à Strasbourg notamment, canalisent la circulation des flux et sont aussi un symbole du lien : " pont de l'Europe », inauguré en 1960 en symbole du rapprochement bilatéral ; " passerelle des deux rives » créée en 2004 ; nouveau pont de chemin de fer ouvert en 2010 et, pont du tram reliant Kehl et Strasbourg, depuis le printemps 2017. Le pont entre la France et l'Allemagne est devenu l'un des emblèmes de l'histoire bilatérale. En 2003, pour le 40e anniversaire du traité de coopération franco-allemande, Tomi Ungerer a dessiné un timbre représentant un pont reposant sur des pieds 'humains', dépassant le fossé rhénan, double évocation de la frontière et du fossé de l'histoire. Plus que le rapprochement, il dépeint une histoire d'amour sur toile de fond européenne. C'est un condensé iconographique du grand récit de la réconciliation franco-allemande ! Près d'un siècle plus tôt, la France et l'Allemagne étaient en guerre et la question des frontières avait été l'un des buts de guerre de la France. Le pont a aussi été souvent un symbole de dissociation (l'expulsion de 100000 Allemands en 1918/19), de séparation (le pont fermé au lendemain de la Grande Guerre) et de la guerre elle-même (le pont de Strasbourg, détruit en 1940).

L'histoire des relations franco-allemandes est donc pour partie une histoire des relations à la frontière. Nous nous proposons de saisir le retournement de la valeur de la frontière dans ces relations après 1945 - symboliquement, on pourrait dire du Rhin - même s'il ne s'agit évidemment pas de cette seule frontière. Dans quelle mesure le facteur de proximité ou d'éloignement par rapport à la frontière a-t-il été un atout pour l'engagement bilatéral ? Comment la frontière a-t-elle été et reste-t-elle perçue par ceux qui y vivent ? Avant d'examiner la phase du rapprochement franco-allemand et celle de la coopération entre des voisins 'réconciliés' et 'amis' - au cours de laquelle les régions frontalières sont devenues une vitrine - il faut jeter un regard sur un passé plus lointain, où se sont succédé différentes conceptions de la frontière qui ont fini par cristalliser l'antagonisme franco-allemand et ont affecté profondément le quotidien des populations locales.

Grenzorte. Von der Konfrontation zur Kooperation. Das Beispiel des Oberrheins, ds. : Defrance, Corine/Pfeil, Ulrich (dir.) : Verständigung und Versöhnung nach dem „Zivilisationsbruch"? Deutschland in Europa nach 1945, Bruxelles : Peter Lang, 2016, p. 349-368.

2 Mission Opérationnelle Transfrontalière: Frontière France-Allemagne, http://www. espaces-transfrontaliers.org/ressources/territoires/frontieres/frontieres-en-europe/ frontiere-france-allemagne/frontiere-france-allemagne-2/ (10/01/2017). 
1. Frontière et idée de la frontière jusqu'à la Deuxième Guerre mondiale

\subsection{L'établissement de la frontière franco-allemande :} le cas emblématique du Rhin

Comme l'a souligné l'historien Daniel Nordman, il n'y a pas de frontières naturelles, mais seulement une théorie des frontières naturelles. ${ }^{3}$ L'idée de 'frontière naturelle' est une construction relativement tardive, qui a pour but d'ancrer dans la géographie la coupure politique. C'est une manière de légitimer, par le recours à l'évidence de la nature, les identités nationales.

Au XVI ${ }^{e}$ siècle et pendant une bonne partie du XVII ${ }^{e}$ siècle encore, la revendication d'une frontière sur le Rhin avait été rare. ${ }^{4}$ Richelieu ne plaidait pas pour une frontière rhénane linéaire, mais entendait s'assurer des têtes de pont sur le Rhin et des voies d'accès vers l'intérieur de l'Empire. Progressivement, au cours du XVIIe siècle, émergea la notion de 'limite naturelle'. L'idée a notamment circulé dans les manuels d'histoire et de géographie rédigés par les jésuites, véhiculant l'image d'une France bornée par la mer, les Pyrénées et le Rhin en référence à la Gaule de César. Avec les traités de Westphalie (1648), une grande partie de l'Alsace passa sous souveraineté française, mais les limites en restèrent floues et contestées, incluant des territoires sur la rive droite du Rhin. La situation évolua avec l'annexion de Strasbourg en 1681 puis surtout avec la paix de Ryswick entre la France et le Saint-Empire (1697) : «A Ryswick, la construction de la France est parvenue à son terme sur la ligne du Rhin $»^{5}$. Mais c'est surtout à partir de 1793 et la proclamation de Danton selon laquelle les limites de la France seraient marquées par la nature que s'est ancrée l'idée de 'frontières naturelles' qui devait connaître une popularité considérable au siècle suivant. En 1798, quatre départements français furent créés sur la rive occidentale du Rhin. Mais en 1806, suite à la formation de la Confédération du Rhin, étroitement liée à l'Empire napoléonien, le Rhin perdit sa fonction de frontière et devint quasiment un fleuve français. En 1815, au congrès de Vienne, la frontière de 1792 fut rétablie. Le Rhin redevient la 'frontière naturelle' au niveau de l'Alsace et du Grand-Duché de Bade, puis un 'fleuve allemand' en aval, mais de part et d'autre les revendications ne s'apaisèrent pas: Rhin allemand ('deutscher Strom') contre 'frontière naturelle' de la France. Avec la Prusse désormais installée sur les rives du fleuve et l'essor industriel et économique des régions rhénanes, l'instrumentalisation

3 Nordman, Daniel : Frontières de France. De l'espace au territoire. XV $T^{e}-X I X^{e}$ siècles, Paris : Gallimard, 1998, p. 11.

4 Zeller, Gaston : Aspects de la politique française sous l'Ancien Régime, Paris : PUF, 1964.

5 Nordman : Frontières de France, p. 311. 
politique du Rhin s'amplifia. ${ }^{6}$ D'un point de vue géopolitique, la situation ne changea qu'au lendemain de la guerre de 1870/71. Le Rhin devint un fleuve allemand. En France, on se mobilisa pour recouvrer les 'provinces perdues' (Alsace et une partie de la Lorraine). Avec le traité de Versailles de 1919, on en revint au Rhin frontière sur son cours supérieur et au Rhin allemand au nord de l'Alsace, mais avec l'hypothèque de l'occupation qui amena la France et ses alliés sur le Rhin, voire au-delà du Rhin (cf. l'occupation de la Ruhr notamment). En 1930, l'occupation de la rive gauche du Rhin prit fin, mais le Rhin resta en zone démilitarisée. L'entrée de la Webrmacht sur la rive gauche du Rhin en mars 1936 fut un triomphe pour la revendication du 'Rhin allemand'.

La Seconde Guerre mondiale reposa immédiatement la question des frontières. Reprit le cycle de l'annexion de facto (Alsace/Moselle en 1940), puis, après la guerre, de l'occupation - notamment par la France -, cette fois-ci sur les deux rives du Rhin, et des incertitudes sur l'avenir de la Sarre jusqu'au référendum de 1955. Depuis le retour de la Sarre à la République fédérale, la frontière franco-allemande est une frontière fixée et acceptée, qui lie bien plus qu'elle ne sépare. De coupure, elle est devenue couture. Avant d'en venir à la frontière passerelle, arrêtons-nous sur la frontière comme moteur et lieu de cristallisation de l'antagonisme franco-allemand.

\subsection{Le Rhin, symbole de l'antagonisme franco-allemand : construction et diffusion d'un grand récit}

Au début du XIX ${ }^{\text {e }}$ siècle, en plein romantisme, le Rhin était loué par les peintres et poètes, allemands et étrangers. Mais bientôt, en réaction aux conquêtes napoléoniennes et aux revendications du Rhin 'frontière naturelle' de la France voire du 'Rhin français', les combattants allemands des 'guerres de libération' se mobilisèrent pour défendre le 'Rhin allemand' à l'instar de Ernst Moritz Arndt selon l'argument que la seule frontière naturelle serait celle de la langue. ${ }^{7}$ Après avoir un temps été fasciné par la France révolutionnaire, il fut l'un de ceux qui attisa le sentiment antifrançais.

En 1840, la résurgence de revendications françaises sur la rive gauche du Rhin provoqua un nouveau choc des nationalismes qu'illustre la 'guerre des poètes'. Nicolaus Becker, dans Der freie Rhein (1840), s'écria : «Ils ne l’auront

6 Cf. Suckow, Dirk : Deutscher Rhein, französischer Rhein, ds. : Bundeszentrale für politische Bildung: Geschichte im Fluss, Flüsse als europäische Erinnerungsorte, 11/05/2012, http:// www.bpb.de/geschichte/zeitgeschichte/geschichte-im-fluss/135684/deutscher-rheinfranzoesischer-rhein? $\mathrm{p}=$ all3 $(10 / 01 / 2017)$.

7 Suckow : Deutscher Rhein, französischer Rhein. 
pas le libre Rhin allemand $»^{8}$, à quoi Alfred de Musset répliqua « Nous l'avons eu, votre Rhin allemand. Il a tenu dans notre verre $»^{9}$, dans un bref poème d'une rare brutalité (Le Rhin allemand, 1841). La réponse de Lamartine - La Marseillaise de la Paix -, à l'époque jugée trop molle par ses concitoyens, mit en lumière le Rhin comme fleuve de la paix liant les peuples. Il rêvait du Rhin qui réconcilie, irriguant une civilisation et la culture européenne. Le Rhin devint sous sa plume le « Nil de l'Occident $»^{10}$. Ce fut aussi la vision de Victor Hugo dans Le Rhin, lettres à un ami, paru en 1842. Ces poètes français répliquèrent donc par l'image d'un Rhin européen et pacifique - ce qui était une idée très française. Dans le sillage de cette 'crise du Rhin', le fleuve devint un paysage identitaire où confluèrent nature, histoire et culture. ${ }^{11}$ L'étranger proche devint 'l'ennemi national', indispensable à la construction et à l'affirmation de sa propre identité. ${ }^{12}$ Cette 'guerre lyrique' mit en lumière la force de l'émotion en ce milieu de siècle. C'est surtout la postérité de ces poèmes et chants qui est étonnante. Ainsi la Wacht am Rhein de Max Schneckenburger devint l'hymne des armées allemandes pendant la guerre de 1870 et servit encore de modèle pour une 'Garde sur la Somme' des soldats allemands en $1916 .{ }^{13}$

Outre les écrivains et les poètes, les peintres et les sculpteurs mobilisèrent leur art au service de la 'guerre des images'. En 1860, Lorenz Clasen peignit pour la mairie de Krefeld Germania auf der Wacht am Rhein. La seule présence de Napoléon III à Paris rappelait dans une Allemagne pas encore unifiée les souvenirs de Napoléon I ${ }^{\text {er }}$ et des Français sur le Rhin. C'est cette même allégorie de la nation allemande que l'on retrouve au bord du Rhin, près de Rüdesheim, au monument du Niederwald érigé en 1883 pour célébrer la victoire de 1871 contre la France et l'unité allemande. En 1889, les artistes lorrains Émile Gallé et Victor Prouvé répliquèrent par la table monumentale

8 Vgl. Becker, Nicolaus: Der freie Rhein, d'abord ds.: Trierische Zeitung 257, 18/09/1840. Voir aussi Becker, Nicolaus: Gedichte, Köln : DuMont-Schauberg, 1841, p. 216-218.

9 Musset, Alfred de : Le Rhin allemand, in : La Revue de Paris, 06/06/1841.

10 «Roule libre et superbe entre tes larges rives, / Rhin, Nil de l'Occident, coupe des nations ! », Lamartine, Alphonse de : La Marseillaise de la Paix, ds. : La Revue des deux Mondes 4/26 (1841), p. 794-799.

11 Walter, François : Les figures paysagères de la nation. Territoire et paysage en Europe (16e-20e siècle), Paris : Editions Ecole des Hautes Etudes en Sciences sociales, 2004.

12 Jeismann, Michael : Das Vaterland der Feinde. Studien zum nationalen Feindbegriff und Selbstverständnis in Deutschland und Frankreich 1791-1918, Stuttgart : Klett-Cotta, 1992 (paru en français sous le titre : La patrie de l'ennemi. La notion d'ennemi national et la représentation de la nation en Allemagne et en France de 1792 à 1918, Paris : CNRS Editions, 1997).

13 Beaupré, Nicolas : Le Rhin. Une géographie, Paris : La documentation française, 2005 (Documentation photographique, dossier $n^{\circ}$ 8044), p. 12. 
nommée Le Rhin où l'on voit la figure paternelle du Rhin protéger des Germains une allégorie féminine de la Moselle. Ils revendiquent ainsi l'idée du Rhin 'frontière naturelle' de la France et réclament, en profitant de la visibilité que leur donne l'Exposition universelle, le retour des provinces perdues à la France. Prouvé s'exclame : c'est « la plus belle gifle qu'on puisse leur flanquer pour le moment $»{ }^{14}$

Les historiens usèrent eux aussi de leur science comme d'une arme. Après la Première Guerre mondiale, les historiens allemands participèrent aux diverses campagnes pour une révision du traité de Versailles. Dès 1919 furent créés plusieurs instituts de recherche et d'études le long des frontières du Reich, à Francfort et Bonn notamment, ayant un objectif commun : «Faire le point sur la guerre, sur les nouvelles frontières, les référendums, les pertes de territoire et de population, et donner à tout cela une dimension historique qui remonte le plus loin possible - le Moyen Âge, l'Antiquité -, afin de prouver par la science de l'histoire que les revendications allemandes sont justifiées $»^{15}$. Pendant l'entre-deux-guerres, ils pratiquèrent une sorte d'auto-mobilisation autour de la thèse de l'inimitié héréditaire entre la France et l'Allemagne. C'est ce que reflète l'attitude ouvertement francophobe de l'historien Hermann Oncken, déclarant en 1924 : «L'ennemi n'est ni à droite ni à gauche, l'ennemi est sur le Rhin ! ». ${ }^{16}$

\subsection{Vivre à la frontière - percevoir la frontière}

A l'époque moderne, alors que la frontière du Rhin était une voie de délimitation, les populations riveraines, relevant de souverainetés politiques différentes, n'étaient pas séparées. La circulation sur le fleuve liait les peuples et toutes sortes de métiers caractéristiques du Rhin donnaient à la région une identité.

14 Beaupré : Le Rhin. Une géographie, p. 28. Voir aussi Perrin, Jérôme : La collaboration entre Emile Gallé et Victor Prouve, ds. : Annales de l'Est n ${ }^{\circ}$ spécial (2005), p. 199-210 ; Plessen, Marie-Louise von [et al.] : Marianne et Germania. 1789-1889. Un siècle de passions franco-allemandes, Paris : Musée du Petit Palais, 1997.

15 Schöttler, Peter : La Zeitgeschichte allemande, ds. : Écrire l'bistoire 11 (2013), p. 61-68, ici p. 61 ; voir aussi : Schöttler, Peter : Geschichtsschreibung als Legitimationswissenschaft 1918-1945, Frankfurt/M. : Suhrkamp, 1997 ; Freund, Wolfgang: Das wissenschaftliche Institut der Elsass-Lothringer im Reich an der Universität Frankfurt a. M. (1920-1945), ds. : Pfeil, Ulrich (dir.) : Deutsch-französische Kultur- und Wissenschaftsberiebungen im 20. Jabrbundert. Ein institutionengeschichtlicher Ansatr, München : Oldenbourg, 2007, p. 47-71.

16 Oncken, Hermann : Nation und Geschichte, Berlin : Grote, 1935, p. 197. Voir aussi Pfeil, Ulrich : Eugen Ewig. „Créer un ordre transnational“. Von einem Mittler zwischen Deutschland und Frankreich, ds. : Pfeil, Ulrich (dir.) : Das Deutsche Historische Institut Paris und seine Gründungsväter, München : Oldenbourg, 2007, p. 294-322. 
Des traits culturels et religieux, des modes de vie aussi, constituaient l'espace rhénan. ${ }^{17}$

Même avec l'établissement de la frontière politique sur le Rhin, pendant longtemps, le fleuve n'a pas été perçu par les contemporains comme la séparation entre la France et les États allemands. Dans les récits de voyage de la fin du XVIII e siècle, le passage de la frontière n'est parfois même pas mentionné, et surtout les voyageurs décrivent une absence de rupture : la langue, l'aspect des villages, la façon de s'habiller, les habitudes alimentaires ne se modifiaient que très graduellement. Certains disent que c'est en Lorraine, voire en Champagne seulement, qu'ils ont eu le sentiment d'arriver en France... Ils brossaient ainsi le portrait d'une zone frontière de culture mêlée francogermanique. La perception de la frontière changea radicalement après 1815 : le voyageur éprouvait désormais le passage d'une ligne frontière séparant sa patrie de l'étranger. ${ }^{18} \mathrm{Ce}$ n'est pas tant la frontière qui avait changé que sa perception. Pour le voyageur allemand, elle était désormais perçue et vécue à l'aune des guerres de la Révolution puis de l'Empire. Les défaites face aux armées napoléoniennes puis les guerres de libération transformèrent radicalement la perception du voisin et, par voie de conséquence, de la frontière.

Bien sûr, même avant les guerres de la Révolution et de l'Empire, les confins avaient été régulièrement des terres d'invasion, de pillages ou de massacres. Mais l'émergence des identités nationales suscita la prise de conscience d'une domination étrangère dont les violences étaient particulièrement intolérables. Les populations frontalières connurent souvent des destins particulièrement rudes, marqués par les occupations et les annexions. Elles furent souvent suspectées - parce qu'elles étaient géographiquement à la marge et culturellement au contact de l'étranger - de manquer de loyauté et même d'être des traitres potentiels. Elles furent soumises à des expériences et des violences extrêmes en période de conflit : évacuations, répression, incorporations de force dans l'armée, expulsions. C'est dans ces territoires et en raison du sort de ces territoires - surtout au cours du premier $\mathrm{XX}^{\mathrm{e}}$ siècle - que grandit la haine de l'autre. La campagne antifrançaise atteignit son acmé lors de l'occupation de la rive gauche du Rhin et de la Ruhr au lendemain de la Première Guerre mondiale. Quelques années plus tard, Hitler remobilisa cette haine antifrançaise. Inversement, les régions frontalières - en raison de leurs expériences spécifiques, ne jouèrent qu'un rôle mineur dans le bref rapproche-

17 Cf. Nordman : Frontières de France, p. 310-311.

18 Cf. Struck, Bernhard/Gantet, Claire : Revolution, Krieg und Verflecbtung: 1789-1815, Darmstadt : WBG, 2008, p. 21 (paru en français sous le titre : Révolution, guerre et interférences, 17891815, Villeneuve d'Ascq : PU du Septentrion, 2013). 
ment franco-allemand de la seconde moitié des années 1920. Les universitaires allemands, par exemple, évitèrent l'Université Strasbourg dans la reprise des relations intellectuelles entre les deux pays. ${ }^{19}$

\section{Frontière et rapprochement franco-allemand dans l'après 1945}

\subsection{Les nouvelles frontières et l'évolution des discours sur la frontière}

Après 1945, avec en mémoire les erreurs de l'après Grande Guerre et sous la pression de la guerre froide naissante, il fallut régler la question de la frontière franco-allemande. Au sud - en Alsace - le rétablissement de la frontière sur le Rhin fut considéré comme une évidence (hormis l'annexion temporaire de Kehl jusqu'en 1949), ${ }^{20}$ mais plus au nord, jusqu'à la frontière néerlandaise, la question fit débat. Le gouvernement français, non sans ambiguïté, affirma qu'il n'avait pas de velléités annexionnistes. Il entendait initialement séparer la rive gauche du Rhin du reste de l'Allemagne pour assurer sa sécurité, intégrer économiquement la Sarre à la France et internationaliser la Ruhr. Si le gouvernement français maintint officiellement ses exigences jusqu'à la conférence de Moscou en 1947, notamment pour tenir compte d'une opinion française germanophobe, il se rallia courant 1946 au projet d'un futur ensemble ouestallemand. L'idée de construire l'Europe, qui avait déjà fait l'objet de discussions animées dans l'entourage de De Gaulle à Alger en 1943, faisait son chemin. Elle se forgeait autour de l'espace rhénan. Le plan Schuman du 9 mai 1950 fut une étape décisive. Pour illustrer la communauté européenne du charbon et de l'acier, le caricaturiste ouest-allemand Klaus Pielert représenta Robert Schuman cousant solidement, à la machine, la frontière franco-allemande. ${ }^{21}$

Il fallait encore apaiser les inquiétudes de l'opinion publique française. Le résultat du plébiscite sarrois de 1955, impliquant le retour de la Sarre à l'Allemagne, fut accueilli avec soulagement en Alsace où l'on redoutait que cette affaire ne ravive l'irrédentisme allemand. Quelques mois plus tard, Carlo Schmid, vice-président du Bundestag et figure majeure du SPD, déclara explicitement, le 23 septembre 1956: «Les hommes de l'Alsace se sont décidés pour la nation française au moins depuis la Révolution [...]. Depuis lors ils

19 Cf. Defrance, Corine : Sentinelle ou Pont sur le Rhin ? Le Centre d'Études Germaniques et l'apprentissage de l'Allemagne en France (1921-2001), avec la collaboration de Christiane FalbisanerWeeda, Paris : CNRS Éditions, 2008, p. 67-77.

20 Cf. Stüwe, Hartmut : Evakuierung, Besetzung, Freigabe. Kebler Stadtgeschichte, 1944-1953, Kehl : Kultur-und Verkehrsamt, 2003.

21 Cf. Pielert, Klaus : "Erfinderstolz: Hoffentlich entwickelt sich das Ding besser als die Sicherheitsnadeln », ds. : Rhein-Echo, Düsseldorf, 07/07/1950. 
veulent être et sont effectivement des fils et des citoyens de la nation française. Leur capitale s'appelle Paris. Ce sont des Français ».22

Ces actions de Schuman ou Schmid sont des moments clés du processus d'apprentissage du rapprochement et de la réconciliation des années 1950. L'histoire de la fondation de l'Institut historique allemand de Paris en est l'un des témoins parce qu'elle montre l'évolution du discours sur la frontière. Le discours inaugural de Eugen Ewig, le premier directeur, le 21 novembre 1958, reflète cette attitude : en faisant référence à la devise et au blason de la ville de Paris «Fluctuat, nec mergitur », et à l'adresse du nouveau centre de recherche, rue du Havre, il décrivit la route de la 'barca' venant d'Allemagne et contournant les brisants administratifs pour arriver à bon port à Paris. ${ }^{23}$ En citant des historiens comme Henri Pirenne et Wilhelm Levison, Ewig inscrivit volontairement l'Institut historique allemand dans un courant historiographique dépassant les frontières nationales : il fallait cesser de présenter le Rhin comme un fleuve découpant l'espace et séparant les hommes. Dans la tradition de Lucien Febvre, il fit des voies d'eau des espaces communicants favorisant les échanges socio-culturels et imbrications intellectuelles, et du Rhin un fleuve européen. En dénationalisant l'espace, il participa à sa réorganisation et à sa redéfinition mentale.

\subsection{Vivre à la frontière : vivre avec le voisin ?}

Une note d'information de la préfecture de Strasbourg de 1953 précisait: "Une frontière ne doit pas former, pour ceux qui y habitent, la fin d'un monde $»{ }^{24}$ Dans les années 1950, le risque de la frontière comme borne des 'cartes mentales' était encore bien réel. Ce qui ressort d'une première étude sur les régions frontières, c'est la grande diversité des situations et la variabilité des résultats en fonction des critères retenus pour les saisir. Ainsi, si l'on considère la conclusion des premiers jumelages franco-allemands jusqu'en 1963 qui sont un des gestes les plus symboliques du rapprochement bilatéral par la base - il s’avère que la majeure partie des cités allemandes concernées était située dans les Länder frontaliers de la Rhénanie-Palatinat et du Bade-Wurtemberg. ${ }^{25}$ En revanche, aucune ville sarroise n'était encore jumelée avec une

22 Cité d'après Defrance, Corine : La dimension régionale dans le rapprochement francoallemand. L'Alsace face à l'Allemagne de l'immédiat après-guerre au début des années 1970, ds. : Dénéchère, Yves/Vincent, Marie-Bénédicte (dir.) : Vivre et construire l'Europe à l'échelle territoriale de 1945 à nos jours, Bruxelles : Peter Lang, 2010, p. 145-158.

23 Cf. Pfeil, Ulrich : Vorgeschichte und Gründung des Deutschen Historischen Instituts Paris. Darstellung und Dokumentation, Ostfildern : Thorbecke, 2007 (Instrumenta, vol. 17), p. 432-434.

24 Archives départementales du Bas-Rhin, 544D220, note d'information, préfecture de Strasbourg, 16/06/1953.

25 Cf. Defrance, Corine : Les jumelages franco-allemands : aspect d'une coopération transnationale, ds. : Vingtième Siècle 99 (2008), p. 189-201. 
commune française. Le poids des tensions suscitées par la question du statut de la Sarre puis la campagne du référendum avaient laissé des traces. Pourtant, si l'on considère la coopération intellectuelle et universitaire, la Sarre avait incontestablement eu un rôle pionnier, que l'on pense ici à la radio sarroise ou à l'Université de la Sarre. ${ }^{26}$ Côté français, la Lorraine et l'Alsace se plaçaient loin derrière la région parisienne ou la Bourgogne pour le nombre de jumelages avec des villes allemandes. Si Nancy et Karlsruhe et Metz et Trèves se jumelèrent respectivement en 1955 et 1957, Strasbourg ne se lia à Stuttgart qu'en 1962. L'hypothèse d'une difficulté alsacienne particulière à entrer en relation avec le voisin allemand est confirmée par un propos de Pierre Pflimlin, alors maire de Strasbourg, déconseillant en 1963 au consul général de la RFA à Nancy l'ouverture d'un Institut Goethe dans sa ville comptant encore « trop de méfiants et de malveillants $»{ }^{27}$ Le principal problème à l'égard du voisin résultait de ce qu'on appelle le 'malaise alsacien'. La situation devient suraiguë à l'issue du procès de Bordeaux, en 1953, jugeant les coupables du massacre d'Oradour-sur-Glane. Parmi les inculpés se trouvaient douze incorporés de force alsaciens. ${ }^{28}$ Avec leur condamnation, les Alsaciens eurent le sentiment d'être incompris. Avec leur amnistie s'instaura une profonde crise entre Alsaciens et Limousins, voire 'Français de l'Intérieur'. Ce procès laissa des traces profondes et durables. Les Alsaciens, se sentant considérés comme des 'collabos' par leurs compatriotes, eurent des difficultés à tendre la main au voisin allemand.

Finalement, c'est la nécessité du 'vivre ensemble' dans un même espace qui a permis la reprise de l'échange. La dimension culturelle, portée par le dialecte, le bilinguisme et les intérêts économiques l'ont facilitée. Le statut particulier de la Sarre et son intégration économique à la France ont aussi entraîné des échanges frontaliers dès l'immédiat après-guerre. ${ }^{29}$ Les échanges furent facilités en 1954 par la suppression du visa pour les ressortissants allemands puis par la suppression fin 1956 du passeport entre la France et l'Allemagne ce qui ouvrit la voie au tourisme. ${ }^{30}$

26 Cf. Defrance, Corine : Les relations universitaires franco-allemandes avant 1963. Impulsions institutionnelles et initiatives privées, ds. : Lendemains 27 (2002) 107/108, p. 202-219, ici p. 210 ; Müller, Wolfgang : Die Universität des Saarlandes in der politischen Umbruchsituation 1955/56, ds. : Hudemann, Rainer/Jellonek, Burkhard/Rauls, Bernd (dir.) : Gren₹Fall. Das Saarland zwischen Frankreich und Deutschland 1945-1960, St. Ingbert : Röhrig, 1997, p. 413-425.

27 Politisches Archiv/Auswärtiges Amt : B. 96, vol. 876, note de Hans Günther, consul de la RFA à Nancy, 24/07/1963.

28 Cf. Vonau, Jean-Laurent : Les Malgré-Nous et le drame d'Oradour, Le procès de Bordeaux, Strasbourg : Éditions du Rhin, 2003.

29 Cf. Wille, Christian : Grenægänger und Räume der Grenze. Raumkonstruktionen in der Großregion SaarLorLux, Frankfurt/M. : Peter Lang, 2012.

30 Defrance : La dimension régionale dans le rapprochement franco-allemand. 


\section{Frontière dépassée - Frontière européanisée ?}

Historiquement, c'est dans l'espace rhénan qu'ont été expérimentées les premières formes d'autodépassement de la frontière, ensuite encouragées et développées par Bruxelles, notamment dans le cadre des programmes Interreg depuis les années 1990. La frontière franco-allemande et franco-germanosuisse a été le berceau des coopérations transfrontalières et des euro-régions. Depuis 2013, c'est aussi en région frontière - en Sarre - qu'est entrepris l'un des projets les plus novateurs et ambitieux. La Frankreichstrategie, en s'appuyant principalement sur la nouvelle génération, vise à faire du Land un territoire bilingue, véritable 'porte de la France' et 'pont vers l'Allemagne', à l'horizon 2043.31

\subsection{Apprivoiser la frontière franco-allemande pour construire l'Europe}

Dès 1946, mu par le souci de trouver de nouvelles voies pour assurer la paix, la sécurité et la prospérité en Europe, le ministre néerlandais et politologue Willem Johan Rudolf Thorbecke (1892-1989), dans un ouvrage ressuscitant l'expression de Lamartine "Rhin, Nil de l'Occident », développa l'idée du bassin rhénan comme noyau d'un groupement politique et économique plus vaste, misant sur la " cohésion supranationale » des pays riverains. ${ }^{32}$

L'idée d'une Europe qui abolirait les frontières des États-nations était bien présente dans le milieu fédéraliste. Elle était populaire chez les jeunes et s'exprimait par des actions symboliques spectaculaires. Ainsi, le 6 août 1950, de jeunes Européens firent brûler les barrières de bois à un poste-frontière franco-allemand près de Wissembourg pour réclamer la création d'un parlement, d'un traité et d'un passeport européen. Il y eut ensuite de nombreuses répliques dans d'autres petits postes-frontières. L'un des participants à ces actions d'août 1950 fut un certain Helmut Kohl. Rétrospectivement, ce dernier fit remonter à cet événement fondateur son engagement pour l'intégration européenne. ${ }^{33}$ En 2007, un mémorial européen a été inauguré sur le site de l'ancien poste-frontière. ${ }^{34}$

31 Cf. Staatskanzlei des Saarlandes : Eckpunkte einer Frankreichstrategie für das Saarland, 2014, http://www.saarland.de/dokumente/res_stk/D_Eckpunkte_Frankreich-Strategie_

210114.pdf (11/01/2017), p. 13. Voir aussi les autres contributions réunies dans ce volume.

32 Thorbecke, Willem Johan Rudolf : La Hollande et le Rhin, ds. : Dumont, Jean (dir.) : Le Rhin, Nil de l'Occident, Paris : Les Editions Sfelt, 1946, p. 297-309.

33 Cf. Kohl, Helmut : Erinnerungen 1930-1982, München : Droemer, 2004, p. 76.

34 Cf. Bock, Hans Manfred [et al.] (dir.) : Les jeunes dans les relations transnationales. L'Office francoallemand pour la Jeunesse, 1963-2008, Paris: PSN, 2008, p. 8. 
En 1951, le Rhin romantique fut le théâtre de la plus importante rencontre européenne de la jeunesse : 35000 jeunes, essentiellement français et allemands, s'y retrouvèrent à l'été. La rencontre de la Loreley avait été conçue comme une première étape dans la voie de la constitution d'un véritable mouvement européen. ${ }^{35}$ Au début des années 1950, la frontière franco-allemande - et symboliquement le Rhin - furent investis d'une valeur particulière dépassant la dimension franco-allemande au profit de l'Europe. Et les jeunes en furent à la fois les acteurs et les destinataires.

\subsection{La coopération frontalière franco-allemande :} vitrine de la coopération européenne?

Depuis les débuts du processus d'intégration européenne, l'axe rhénan en a constitué la colonne vertébrale géographique et économique. Au niveau local, la frontière relie par la pratique linguistique, par les complémentarités économiques, par les liens affectifs et familiaux. ${ }^{36}$

Les échanges se densifièrent au point que plusieurs projets de coopération transfrontalière furent élaborés dès le tournant des années 1960 et 1970. Ils furent les ancêtres de l'eurorégion du Rhin supérieur et de l'eurodistrict Regio PAMINA. Certaines sont très vastes comme l'euroregio SaarLorLux ou la Grande Région, plus circonscrites comme la Regio PAMINA (Palatinat, Mittlerer Oberrhein, Alsace du Nord), ou bien, locales comme l'eurodistrict Strasbourg-Kehl.

Birte Wassenberg a mis en lumière le caractère pragmatique de ces coopérations initiales. Il s'agissait par exemple, entre villages voisins, de régler des problèmes de voiries ou de traitement des eaux. Le passage de la confrontation à la coopération s'est opéré lentement et, dans le cas de la coopération du Rhin supérieur, la Suisse a joué un rôle d'initiateur et de médiateur dans la fondation de la Regio Basiliensis dès $1963 .{ }^{37} \mathrm{Si}$ sa finalité était d'abord économique, la coopération transfrontalière visait à mettre en lumière les facteurs de convergence sur la longue durée aux dépens de ce qui avait divisé les voisins dans l'histoire récente. Dans le cas de l'eurodistrict Kehl-Strasbourg, l'initiative fut lancée dès le début des années 1950 dans le cadre du Conseil de l'Europe $^{38}$ et elle avait aussi pour objectif d'œuvrer au rapprochement. Le projet était alors prématuré et il n'a finalement été réalisé que dans les années

35 Cf. Plum, Jacqueline : Das Europäische Jugendtreffen auf der Loreley im Sommer 1951 : Ein jugendpolitischer Einigungsversuch, ds. : Lendemains 107/108 (2002), p. 190-201.

36 Cf. Piralla, Steve/Barbier, Isabelle : Mariages lorrains. Des frontières qui tissent des liens, ds. : INSEE, Economie. Lorraine n 314 (06/2013).

37 Cf. Wassenberg, Birte : Vers une eurorégion? La coopération transfrontalière franco-germano-suisse dans l'espace du Rhin supérieur de 1975 à 2000, Bruxelles : Peter Lang, 2007.

38 Cf. Wassenberg, Birte : Histoire du Conseil de l'Europe (1949-2009), Bruxelles : Peter Lang, 2012, p. 75. 
1990. Tirant le bilan de ces coopérations transfrontalières, Wassenberg conclut : « Konfrontationen wurden dadurch nicht ganz verhindert, aber es wurde eine feste Plattform geboten, auf der diese diskutiert, verhandelt und überbrückt werden können $» .39$

Lucien Febvre estimait que c'était moins le contrôle exercé que les émotions ressenties qui caractérisaient la frontière et que le Rhin, en raison de cette charge émotionnelle, avait été des décennies durant «l'otage des hommes » ${ }^{40}$. Claire Gantet et Bernhard Struck lui donnent raison, mais seulement à partir de 1806/1815. Auparavant la frontière politique ne suscitait guère d'émoi. La frontière était perçue comme espace de transition. C'est au cours du XIXe siècle que la frontière franco-allemande devint pour les deux voisins le symbole du choc des nations bientôt qualifiées 'd'ennemis héréditaires'. La haine s'y est cristallisée. L'émotion a-t-elle disparu avec la frontière apaisée de l'après 1945 ? Sans doute pas à en juger par la destruction des installations frontalières à l'été 1950. Mais elle a changé de nature. Ce fut alors l'exaltation de brûler une 'barrière' pour ouvrir la voie à l'Europe au nom de la paix et du rapprochement. Cependant, il faut se garder de surinvestir la frontière, et bien des coopérations à la frontière ont été initiées par pragmatisme pour rapprocher les peuples blessés et séparés par l'histoire récente. Aujourd'hui encore, le vivre ensemble peut s'avérer parfois un peu délicat alors que la France et l'Allemagne se trouvent dans des situations économiques et sociales différentes et que la question de la migration et du contrôle des frontières est revenue sur le devant de la scène. Mais force est de constater que la frontière garde une valeur symbolique particulière dans les relations franco-allemandes. Le vocabulaire et la représentation iconographique en témoignent: la coupure, la barrière, la cicatrice sont devenues des coutures et des ponts. D'une part, au niveau 'national', la frontière est l'emblème de son propre dépassement. Comme elle avait autrefois symbolisé l'antagonisme, elle devint le lieu métaphorique de la réconciliation, inséparable de la construction européenne. Elle est souvent identifiée au Rhin, lieu de mémoire français, allemand, francoallemand et européen par excellence. D'autre part, la frontière franco-allemande est devenue un modèle de coopération transfrontalière en Europe et la vie à la frontière a changé : on s'y sent moins à la périphérie de la France et de l'Allemagne qu'au cœur de l'Europe et peut-être même d'un territoire mixte franco-allemand ou rhénan comme l'illustre aujourd'hui la 'Stratégie France' de la Sarre.

39 Wassenberg: Grenzorte, p. 366.

40 Cité d'après Suckow : Deutscher Rhein, französischer Rhein, p. 1. 


\section{Bibliographie sélective}

Beaupré, Nicolas : Le Rbin. Une géographie, Paris : La documentation française, 2005 (Documentation photographique, dossier $\left.n^{\circ} 8044\right)$.

Becker, Nicolaus : Der freie Rhein, d'abrod ds. : Trierische Zeitung 257, 18/09/1840.

Becker, Nicolaus : Gedichte, Köln : DuMont-Schauberg, 1841.

Bock, Hans Manfred [et al.] (dir.) : Les jeunes dans les relations transnationales. L'Office franco-allemand pour la Jeunesse, 1963-2008, Paris : PSN, 2008.

Defrance, Corine : Les relations universitaires franco-allemandes avant 1963. Impulsions institutionnelles et initiatives privées, ds. : Lendemains 27 (2002) 107/108, p. 202-219.

Defrance, Corine : Les jumelages franco-allemands : aspect d'une coopération transnationale, ds. : Vingtième Siècle 99 (2008), p. 189-201.

Defrance, Corine : Sentinelle ou Pont sur le Rhin? Le Centre d'Études Germaniques et l'apprentissage de l'Allemagne en France (1921-2001), avec la collaboration de Christiane Falbisaner-Weeda, Paris : CNRS Éditions, 2008.

Defrance, Corine : La dimension régionale dans le rapprochement franco-allemand. L'Alsace face à l'Allemagne de l’immédiat après-guerre au début des années 1970, ds. : Dénéchère, Yves/Vincent, Marie-Bénédicte (dir.) : Vivre et construire l'Europe à l'échelle territoriale de 1945 à nos jours, Bruxelles : Peter Lang, 2010, p. 145-158.

Freund, Wolfgang : Das wissenschaftliche Institut der Elsass-Lothringer im Reich an der Universität Frankfurt a. M. (1920-1945), ds. : Pfeil, Ulrich (dir.) : Deutsch-fran₹ösische Kultur-und Wissenschaftsberiehungen im 20. Jahrbundert. Ein institutionengeschichtlicher Ansať, München: Oldenbourg, 2007, p. 47-71.

Jeismann, Michael : Das Vaterland der Feinde. Studien zum nationalen Feindbegriff und Selbstverständnis in Deutschland und Frankreich 1791-1918, Stuttgart : Klett-Cotta, 1992.

Kohl, Helmut : Erinnerungen 1930-1982, München : Droemer, 2004.

Lamartine, Alphonse de : La Marseillaise de la Paix, ds. : La Revue des deux Mondes 4/26 (1841), p. 794-799.

Mission Opérationnelle Transfrontalière : Frontière France-Allemagne, http://www.espacestransfrontaliers.org/ressources/territoires/frontieres/frontieres-en-europe/frontierefrance-allemagne/frontiere-france-allemagne-2/ (10/01/2017).

Mozer, Alfred : Entwicklungspolitik zu Hause, ds. : Schöndube, Claus (dir.) : Entwicklungsregionen in der $E W G$, Bonn : Bundeszentrale für politische Bildung (Schriften der Bundeszentrale für politische Bildung), 1973, p. 14-25.

Müller, Wolfgang : Die Universität des Saarlandes in der politischen Umbruchsituation 1955/56, ds. : Hudemann, Rainer/Jellonek, Burkhard/Rauls, Bernd (dir.) : Gren₹-Fall. Das Saarland zwischen Frankreich und Deutschland 1945-1960, St. Ingbert : Röhrig, 1997, p. 413-425.

Musset, Alfred de : Le Rhin allemand, in : La Revue de Paris, 06/06/1841.

Nordman, Daniel : Frontières de France. De l'espace au territoire. XV Te-XIXe siècles, Paris : Gallimard, 1998.

Oncken, Hermann : Nation und Geschichte, Berlin : Grote, 1935.

Perrin, Jérôme: La collaboration entre Emile Gallé et Victor Prouvé, ds. : Annales de l'Est $\mathrm{n}^{\circ}$ spécial (2005), p. 199-210.

Pfeil, Ulrich: Eugen Ewig. „Créer un ordre transnational“. Von einem Mittler zwischen Deutschland und Frankreich, ds. : Pfeil, Ulrich (dir.) : Das Deutsche Historische Institut Paris und seine Gründungsväter, München : Oldenbourg, 2007, p. 294-322. 
Pfeil, Ulrich : Vorgescbichte und Gründung des Deutschen Historischen Instituts Paris. Darstellung und Dokumentation, Ostfildern : Thorbecke, 2007 (Instrumenta, vol. 17).

Pielert, Klaus : « Erfinderstolz : Hoffentlich entwickelt sich das Ding besser als die Sicherheitsnadeln », ds. : Rhein-Echo, Düsseldorf, 07/07/1950.

Piralla, Steve/Barbier, Isabelle: Mariages lorrains. Des frontières qui tissent des liens, ds. : INSEE, Economie. Lorraine n ${ }^{\circ} 314$ (06/2013).

Plessen, Marie-Louise von [et. al] : Marianne et Germania. 1789-1889. Un siècle de passions francoallemandes, Paris : Musée du Petit Palais, 1997.

Plum, Jacqueline : Das Europäische Jugendtreffen auf der Loreley im Sommer 1951: Ein jugendpolitischer Einigungsversuch, ds. : Lendemains 107/108 (2002), p. 190-201.

Politisches Archiv/Auswärtiges Amt : B. 96, vol. 876, note de Hans Günther, consul de la RFA à Nancy, 24/07/1963.

Schöttler, Peter : Geschichtsschreibung als Legitimationswissenschaft 1918-1945, Frankfurt/M. : Suhrkamp, 1997.

Schöttler, Peter : La Zeitgeschichte allemande, ds. : Écrire l'bistoire 11 (2013), p. 61-68.

Staatskanzlei des Saarlandes : Eckpunkte einer Frankreichstrategie für das Saarland, 2014, http:// www.saarland.de/dokumente/res_stk/D_Eckpunkte_Frankreich-Strategie_210114.pdf (11/01/2017).

Struck, Bernhard/Gantet, Claire: Revolution, Krieg und Verflechtung: 1789-1815, Darmstadt: WBG, 2008.

Stüwe, Hartmut : Evaknierung, Besetzung, Freigabe. Kebler Stadtgeschichte, 1944-1953, Kehl : Kulturund Verkehrsamt, 2003.

Suckow, Dirk : Deutscher Rhein, französischer Rhein, ds. : Bundeszentrale für politische Bildung : Geschichte im Fluss, Flüsse als europäische Erinnerungsorte, 11/05/2012, http:// www.bpb.de/geschichte/zeitgeschichte/geschichte-im-fluss/135684/deutscher-rheinfranzoesischer-rhein? $\mathrm{p}=$ all3 $(10 / 01 / 2017)$.

Thorbecke, Willem Johan Rudolf : La Hollande et le Rhin, ds. : Dumont, Jean (dir.) : Le Rhin, Nil de l'Occident, Paris : Les Editions Sfelt, 1946, p. 297-309.

Vonau, Jean-Laurent: Les Malgré-Nous et le drame d'Oradour, Le procès de Bordeaux, Strasbourg: Éditions du Rhin, 2003.

Walter, François : Les figures paysagères de la nation. Territoire et paysage en Europe (16 $-20^{e}$ siècle), Paris : Editions Ecole des Hautes Etudes en Sciences sociales, 2004.

Wassenberg, Birte : Vers une eurorégion? La coopération transfrontalière franco-germano-suisse dans l'espace du Rhin supérieur de 1975 à 2000, Bruxelles : Peter Lang, 2007.

Wassenberg, Birte : Histoire du Conseil de l'Europe (1949-2009), Bruxelles : Peter Lang, 2012.

Wassenberg, Birte: Grenzorte. Von der Konfrontation zur Kooperation. Das Beispiel des Oberrheins, ds. : Defrance, Corine/Pfeil, Ulrich (dir.) : Verständigung und Versöbnung nach dem „Zivilisationsbruch"? Deutschland in Europa nach 1945, Bruxelles : Peter Lang, 2016, p. 349-368.

Wille, Christian : Grenægänger und Räume der Grenæe. Raumkonstruktionen in der Großregion SaarLorLux, Frankfurt/M. : Peter Lang, 2012.

Zeller, Gaston : Aspects de la politique française sous l'Ancien Régime, Paris : PUF, 1964. 

Reiner Marcowitz

\section{Ein Blick von außen:}

\section{Die Frankreichstrategie des Saarlandes aus lothringischer Perspektive}

Cet article traite, tout d'abord, de la réaction française et plus spécifiquement lorraine majoritairement positive à la 'Stratégie France' de la Sarre pour autant qu'elle se reflète dans la presse et dans les prises de positions des différents acteurs de la société civile. Ensuite, l'article analyse la genèse et le contenu de la 'Stratégie Allemagne' de la Lorraine qui se trouve être une réponse directe à son équivalent sarrois. Enfin, l'article développe différents scénarios sur l'évolution future et sur l'éventuelle réussite ou bien l'échec de ces deux projets complémentaires. Il attire également l'attention sur le fait que leur réalisation est importante tant au niveau régional qu'au niveau (inter)national afin d'agir contre le désintérêt croissant dans les sociétés allemande et française pour le voisin respectif, et afin de rendre au partenariat franco-allemand son importance qui est non seulement historique, mais également indispensable pour la réussite de l'Union Européenne.

Das Ziel dieses Beitrags ist es, Einblicke in die lothringische Sicht auf die saarländische Frankreichstrategie zu geben und über das Echo zu berichten, das diese Initiative jenseits der Grenze gefunden hat. ${ }^{1}$ Dies geschieht in drei Schritten: Zunächst werden die unmittelbaren Reaktionen auf das saarländische Projekt in den lothringischen bzw. französischen Medien sowie seitens einzelner zivilgesellschaftlicher Institutionen untersucht (1.). In einem zweiten Schritt werden dann die Überlegungen zu einer lothringischen Deutschlandstrategie vorgestellt, die gewissermaßen die kongeniale Antwort auf die saarländische Initiative darstellen (2.). Schließlich werden die Zukunftsaussichten beider Strategien erörtert (3.).

1 Der Autor hat im Rahmen seiner beruflichen Tätigkeit im Frühjahr/Sommer 2015 eine Arbeitsgruppe zum Thema Hochschule und Forschung geleitet, die für diesen Bereich einen Beitrag zur Ausarbeitung einer Deutschlandstrategie Lothringens geleistet hat. Die betreffende Arbeit, die im vorliegenden Beitrag noch näher vorgestellt wird, wurde in völliger Unabhängigkeit geleistet. Zudem ist sie zumindest für den Augenblick abgeschlossen und auch insofern gibt der vorliegende Aufsatz nur die persönliche Meinung des Verfassers wieder. 


\section{Die saarländische Frankreichstrategie und ihr lothringisches Echo}

Wie letztlich nicht anders zu erwarten, war das Medienecho auf die Ankündigung der saarländischen Frankreichstrategie Anfang 2014 in Frankreich im Allgemeinen und in Lothringen im Besonderen positiv. Das saarländische Bekenntnis zur von den Journalisten gerne zitierten Sprache Molières entsprach, ja schmeichelte dem nationalen französischen Selbstverständnis, als Kulturnation gerade auch eine sprachliche mission civilisatrice zu haben. ${ }^{2}$ Im Falle Lothringen kam noch die geographische und geschichtliche Nähe hinzu: ${ }^{3}$ Die Grenzen und die nationale Zugehörigkeit waren hier jahrhundertelang fließend und wechselten einander ab. Entsprechend sind gerade diese beiden Regionen in vielfältiger Weise besonders miteinander verflochten. Folglich war auch hier das Medienecho auf die Ankündigung der saarländischen Frankreichstrategie sehr positiv: Zunächst wurde die Originalität der saarländischen Initiative und deren Beitrag zur deutsch-französischen Zusammenarbeit auch in der nächsten, der etwas missverständlich sogenannten „Generation Elysée“ gelobt. ${ }^{4}$ Dies ging sodann einher mit der Einsicht in die ökonomischen Vorteile, die die forcierte Frankreichorientierung des deutschen Nachbarn gerade auch der eigenen Region und seinen Berufspendlern eröffnete. Allerdings wurde in einigen Artikeln auch bereits auf die Probleme hingewiesen, die die saarländische Landesregierung zu ihrer Initiative bewogen habe: der Bevölkerungsrückgang des ohnehin schon bevölkerungsschwachen und kleinen Bundeslandes, die hohe Verschuldung des 'deutschen Griechenlands' („Grèce de l'Allemagne“"5), der deshalb zumindest mittel- und langfristig drohende Verlust der Autonomie im Rahmen einer etwaigen Fusion mit einem der angrenzenden Bundesländer. Vor diesem Hintergrund wurde von einigen Journalisten ebenfalls die Frage nach der Finanzierbarkeit des Projekts gestellt. Ebenso wurde zumindest vereinzelt darauf hingewiesen, dass v. a. bei saarländischen Eltern Widerstände gegen das erzwungene Erlernen der französischen Sprache bestünden, zumal wenn dieses auf Kosten des Englischunterrichts ginge.

2 Vgl. Delorme, Florian: La bataille des langues en Europe (2/4) - De l'école au travail, enjeux linguistiques en zones transfrontalières, in: France Culture Radio, 18.03.2014, http:// www.franceculture.fr/emissions/culturesmonde/la-bataille-des-langues-en-europe-24-delecole-au-travail-enjeux (14.04.2016).

3 Zur Geschichte Lothringens vgl. Parisse, Michel (Hg.): Lotbringen. Geschichte eines Grenzlandes, Saarbrücken: Saarbrücker Druckerei u. Verl., 1983; Bastien, René: Histoire de la Lorraine, Metz: Editions Serpenoise, 1993.

4 Vgl. Knoepffler, Christian: Frankreich über alles, in: Le Républicain Lorrain, 05.02.2014, S. 7.

5 O. A.: Pour survivre, la Sarre parie sur le parler français, in: Le Télégramme, 03.03.2014, S. 1. 
Seitens der Zivilgesellschaft reagierte der lothringische Wirtschafts-, Sozialund Umweltrat, eine Einrichtung des Regionalrats von Lothringen, sicher am enthusiastischsten: Er lud den saarländischen Europa- und Finanzminister Stephan Toscani im Mai 2014 sogar ein, die Strategie vor Ort den eigenen Delegierten zu präsentieren. ${ }^{6}$ Zudem arbeitete er im Frühjahr 2014 eine ausführliche Stellungnahme aus, die bereits den programmatischen Untertitel trug: 'eine Gelegenheit, die ergriffen werden muss, eine Verpflichtung zu handeln'?. Anknüpfend an eine große Studie, die der Conseil Economique, Social et Environnemental (CESEL) bereits im November 2011 unter dem ebenfalls ,sprechenden' Titel 'Deutschland, ein unersetzlicher Partner Lothringens' vorgestellt hatte, ${ }^{8}$ erinnerte er an die Bedeutung Deutschlands und speziell des Saarlandes für die lothringische Wirtschaft: So pendeln trotz eines seit 2002 spürbaren Rückgangs um 5000 Menschen aktuell immer noch fast 20000 Lothringer (Stand 2013) jeden Tag zur Arbeit nach Deutschland, zudem hängen weitere 42000 Arbeitsplätze in Lothringen an deutschen Investitionen in der Region sowie am Export lothringischer Unternehmen nach Deutschland. ${ }^{\text {? }}$

Vor diesem Hintergrund begrüßte der CESEL in seiner Stellungnahme vom Frühjahr 2014 einhellig die Frankreichstrategie des Saarlandes: Diese nutze die besondere Kompetenz des Saarlandes und gebe diesem gleichzeitig ein Alleinstellungsmerkmal als 'Versuchslabor' für neue Formen grenzüberschreitender Zusammenarbeit. Folglich könne das Projekt ein 'Sprungbrett' sein, 'um diesen Status eines Versuchslabors zu bekräftigen'10. Gleichzeitig unterbreitete der CESEL acht Vorschläge für konkrete Maßnahmen von lothringischer Seite, die die saarländische Frankreichstrategie unterstützen sollten. ${ }^{11}$ Sie kulminierten in der Forderung nach einer lothringischen Deutschlandstrategie, komplementär zum Frankreichprojekt des Saarlandes. Bei der entsprechenden Umsetzung der beiden Strategien sollte zudem auf die Integration von Vertretern des Partnerlandes geachtet werden, wenn möglich

6 Vgl. Conseil Economique, Social et Environnemental de Lorraine (CESEL): A la Une. Stratégie France: le CESEL présente 8 pistes d'actions côté lorrain, 20.05.2014, http:// www.ceselorraine.eu/fr/strategie-france-le-cesel-presente-8-pistes-d-actions-cote-lorrain/ a-la-une-du-cese-lorraine.html (14.04.2016).

7 Vgl. CESEL: Avis du CESEL sur la Stratégie France de la Sarre. Une opportunité à saisir, une obligation d'agir. Avis adopté à l'unanimité en Séance Plénière du 16 mai 2014, http:// www.ceselorraine.eu/img_base/ged_v2/278/2014-cesel-avis-strategie-france-sarre.pdf (14.04.2016).

8 Vgl. CESEL: L'Allemagne, partenaire incontournable de la Lorraine. Projet. Séance Plénière du 18 octobre 2011, http://www.ceselorraine.eu/UserFiles/File/ressources/ rapports/2011/2011-cesel-rapport-allemagne.pdf (14.04.2016).

9 Vgl. CESEL: Avis du CESEL sur la Stratégie France, S. 4 f.

10 Vgl. CESEL: Avis du CESEL sur la Stratégie France, S. 8.

11 Vgl. CESEL: Avis du CESEL sur la Stratégie France, S. 9-12. 
sogar die Bildung spiegelbildlicher Einrichtungen angestrebt werden, analog dem Frankreichzentrum der Universität des Saarlandes und seiner jüngeren lothringischen ,Schwestereinrichtung, dem Centre franco-allemand de Lorraine (CFALOR).

Mit dem letzten Punkt wurde bereits an die Vorbildrolle der Universität des Saarlandes und der Universität Lothringen für die regionale Kooperation erinnert. Auf diese berief sich auch die Leitung der Universität Lothringen in ihrem Kommentar zur Frankreichstrategie, um die die saarländische Landesregierung sie gebeten hatte. ${ }^{12}$ Tatsächlich bietet die lothringische Universität allein 47 Studiengänge mit Deutschlandbezug an, darunter 24 in Kooperation mit der Hochschule für Technik und Wirtschaft in Saarbrücken oder mit der Universität des Saarlandes. Vor diesem Hintergrund resümierte die Stellungnahme der Universität, „dass Deutschland das Zielland Nr. 1 der Universität ${ }^{\text {"13 }}$ sei, weswegen Ende 2012 auch das CFALOR gegründet worden sei. Insofern wurden auch die konkreten Maßnahmen und insbesondere die sprachpolitische Ambition der saarländischen Frankreichstrategie begrüßt. Folgerichtig formulierte auch die Universitätsleitung den Wunsch, dass Lothringen analog zum saarländischen Projekt eine eigene Deutschlandstrategie entwickeln solle.

Die Stellungnahmen von CESEL und der Universität zur saarländischen Frankreichstrategie verwiesen also, wie im Übrigen auch schon der eine oder andere Pressekommentar, auf die geradezu logisch anmutende Konsequenz einer komplementären lothringischen Deutschlandstrategie. Diesen Ball nahm die Politik dann auch tatsächlich Ende 2014 auf.

\section{Die lothringische Deutschlandstrategie als Pendant zur saarländischen Frankreichstrategie}

Im September 2014 erteilte der Präsident der Region Lothringen (CRL), JeanPierre Masseret, dem Präsidenten des Departements Meurthe et Moselle (CD 54), Jean-Matthieu Klein, den Auftrag, in Kooperation mit Patrick Weiten, dem Präsidenten des Conseil départemental Moselle (CD 57), eine Deutschlandstrategie Lothringens auszuarbeiten. ${ }^{14}$ Eine Pilotgruppe von Vertretern der verschiedenen Gebietskörperschaften, Berufsverbänden, der Universität und dem französischen Generalkonsulat beschloss anschließend im

12 Vgl. Stellungnahme der Universität Lothringen zur Frankreichstrategie des Saarlandes vom 02.06.2014, Kopie im persönlichen Besitz des Autors.

13 Stellungnahme der Universität Lothringen zur Frankreichstrategie des Saarlandes.

14 Vgl. Stratégie Allemagne de la Lorraine. Rapport final. Synthèse et propositions juin 2015, 2015, http://metz.fr/pages/conseil_municipal/seances/cm151029/doc/5_d1445930773387. $\operatorname{pdf}(14.04 .2016)$, S. 2. 
Frühjahr 2015, acht Arbeitsgruppen mit einem thematischen Schwerpunkt zu bilden, deren Führung jeweils einem institutionellen Tandem oblag: Wirtschaft - Beschäftigung - Berufsausbildung (CD 57 - CRL - Chambre Régionale de Commerce et d'Industrie); Hochschule und Forschung (CRL Université de Lorraine); Erlernen der Sprache des Nachbarn und Schüleraustausch (CD 54 et 57 - Rectorat de l'Académie Nancy-Metz); Kultur und Tourismus (Communauté Urbaine du Grand Nancy - Communauté d'Agglomération de Metz Métropole/Sillon); Öffentlichkeitsarbeit (CRL et CESEL); Organisation des institutionellen und des Verwaltungsaustauschs (CD 54 Centre National de la Fonction Publique Territoriale); Mobilität (CRL CD 57); Bürgeraustausch (Metz - Nancy). Alle Gruppen hatten ein und dieselbe Doppelaufgabe: Für ihren jeweiligen Themenbereich eine Bestandsaufnahme der schon existierenden deutsch-französischen Aktivitäten vorzunehmen und auf dieser Basis Vorschläge für deren Weiterentwicklung zu machen. Dank der Arbeit dieser acht Arbeitsgruppen legte die politische Pilotgruppe schließlich im Sommer 2015 ihren Abschlussbericht vor, der Impulse für eine Intensivierung der Zusammenarbeit mit Deutschland in drei Etappen - kurz-, mittel- und langfristig - umfasst.

Im Hinblick auf die jeweiligen Zeithorizonte wurde als das generelle Ziel für alle Bereiche formuliert: 2015/16 die Kommunikation und die Koordination des Bestehenden zu verstärken; 2016/17 nicht nur Bestehendes, sondern auch neue Projekte voranzutreiben und schließlich ab 2018 die Zusammenarbeit tatsächlich sukzessive zu vertiefen. Um diese Ziele zu erreichen, sollen die ehemaligen acht Arbeitsgruppen in ,groupes opérationnels“ ('operationelle Gruppen') umgewandelt werden, die ihre Arbeit unter der Leitung der auch weiter bestehenden politischen Pilotgruppe durchführen. ${ }^{15}$ Diese wiederum soll ad hoc deutsche Partner und Spezialisten für einzelne Themenbereiche kooptieren. Klar ist dabei, dass sich ähnlich der Frankreichstrategie des Saarlandes auch die Deutschlandstrategie Lothringens nicht auf die regionale deutsch-französische Zusammenarbeit beschränken will, sondern das Partnerland insgesamt in den Blick nimmt. Zudem versteht auch sie sich als Beitrag zur Vertiefung der europäischen Einigung. Angesichts des spezifischen Kontextes der französischen Territorialreform ist schließlich die Hoffnung, dass die lothringische Deutschlandstrategie geradezu strukturbildend für die neue Großregion Alsace - Champagne - Ardenne - Lorraine (ACAL) werden könnte. Für diese sollte die transregionale und europäische Zusammenarbeit aufgrund ihrer geographischen Lage und ihrer Grenzen mit vier europäischen Ländern eine Selbstverständlichkeit, ja eine Notwendigkeit sein.

Der 'Aktionsplan', den sich die politisch Verantwortlichen im Sommer 2015 vorgegeben haben, wird interessanterweise jenseits seiner allgemeinen 
Ankündigungen auch schon recht konkret: ${ }^{16}$ So erscheint 2015/16 als eine ,Scharnierphase', die dank dreier Aktionen die Bedeutung der neuen Deutschlandstrategie verdeutlichen soll: erstens der Unterzeichnung einer gemeinsamen Konvention der Gebietskörperschaften mit dem Erziehungsministerium, um das Erlernen der deutschen Sprache weiterzuentwickeln; zweitens die Bildung saarländisch-lothringischer Cluster im Bereich der Automobilindustrie und der silver economy; drittens eine Kommunikationsoffensive, um die breite Öffentlichkeit von der Bedeutung der Beziehungen mit Deutschland zu überzeugen. Darüber hinaus enthält der Abschlussbericht vom Sommer 2015 eine Fülle von Vorschlägen aus den verschiedenen Arbeitsgruppen, jeweils gegliedert in die drei genannten zeitlichen Etappen. Alles in allem haben die acht Arbeitsgruppen der Entwicklung einer lothringischen Deutschlandstrategie sicher wertvolle Impulse vermittelt und zudem vielversprechende Perspektiven für eine Verzahnung dieses Projekts mit der saarländischen Frankreichstrategie aufgezeigt. Es bleibt nun abzuwarten, ob die Vorschläge auch in die Tat umgesetzt werden können.

\section{Perspektiven der saarländischen Frankreichstrategie und der lothringischen Deutschlandstrategie}

Im Laufe der letzten gut drei Jahre ist es der saarländischen Landesregierung gelungen, die eigene Frankreichstrategie diskursiv fest zu verankern, sogar über die regionale Ebene hinaus. Insofern hat der sogenannte zweite Teil der Frankreichstrategie, die „Kommunikationsstrategie (Vermarktung der saarländischen Frankreich-Kompetenz nach außen, d. h. nach Frankreich und nach Deutschland)"17 durchaus schon Erfolge gezeigt. Dank ihr hat das Saarland deutlich an Sichtbarkeit gewonnen, ein Umstand, der angesichts seiner demographischen und wirtschaftlichen Probleme nicht gering zu schätzen ist. Gleichzeitig sichert dies dem Bundesland auch einen deutlichen Vorsprung vor seiner französischen Partnerregion, die sicher zu zögerlich die Gunst der Stunde genutzt hat, um eine spiegelbildliche Strategie zu gestalten. Immerhin liegt nun auch hier eine sehr nützliche Bestandsaufnahme des eigenen deutsch-französischen Kapitals und dessen zu entwickelnden Potentials vor. Sinnvoll bleibt zweifellos auch für beide Regionen, ihre jeweilige Strategie auszubauen und sich hierbei abzustimmen, denn letztlich leiden beide unter denselben Problemen: einer fehlenden Reputation auf nationaler und internationaler Ebene und ungelösten wirtschaftlichen Problemen. Gleichzeitig

16 Vgl. Stratégie Allemagne de la Lorraine, S. 42-44.

17 Staatskanzlei des Saarlandes: Eckpunkte einer Frankreichstrategie für das Saarland, 2014, http:// www.saarland.de/dokumente/res_stk/D_Eckpunkte_Frankreich-Strategie_210114.pdf (14.04.2016), S. 3. 
ergänzen sich gerade im wirtschaftlichen Bereich saarländische und lothringische Interessen: Dem demographisch bedingten Arbeitskräftemangel im Saarland steht ein Arbeitskräfteüberhang in Lothringen gegenüber.

Nicht nur die bereits zitierten aktuellen Zahlen, sondern auch die Projektionen für die kommenden zehn Jahre sind hier eindeutig: Das französische Statistik- und Wirtschaftsforschungsinstitut INSEE prognostiziert für den Zeitraum bis 2025 einen jährlichen Anstieg der erwerbstätigen französischen Bevölkerung von 110000 Personen. ${ }^{18}$ Für Deutschland wird hingegen von einem jährlichen Rückgang um 100000 Personen ausgegangen. Hier, so ist die lothringische Hoffnung, könnten sich besondere Möglichkeiten für die eigene Region ergeben, zumal die Vorhersagen auch für den unmittelbaren saarländischen Nachbarn einen Bevölkerungsrückgang auf unter 900000 bis 2030 vorhersagen. Bereits jetzt fehlen der saarländischen Industrie Facharbeiter. Insofern ist das Rahmenabkommen zur grenzüberschreitenden Berufsausbildung, das Lothringen und das Saarland im Juni 2014 unterzeichnet haben, ein Schritt in die richtige Richtung. ${ }^{19}$ Auch ist es offensichtlich, dass beide Regionen aufgrund ihrer Grenzlage eine Pilotrolle für die deutschfranzösischen Beziehungen spielen könnten, und zudem im Bereich der Automobilindustrie, aber auch der sogenannten silver economy gemeinsam lohnende Projekte entwickeln könnten.

Indes sind auch die Probleme bei der Umsetzung der beiden ambitionierten Großprojekte ebenso unübersehbar und auch sie betreffen zumindest teilweise das Saarland wie Lothringen gleichermaßen: Erstens lässt die konkrete Umsetzung der Frankreichstrategie, also die sogenannte „Binnenstrategie“, die „Stärkung der Frankreichkompetenz im Land“20 und insbesondere deren Kernelement, die Zweisprachigkeit, noch auf sich warten. Natürlich ist hier Geduld gefordert, schließlich hat sich die Landesregierung ja bewusst 30 Jahre Zeit gegeben. Indes muss man realistisch sein: Damit das Zieldatum 2043 eingehalten werden kann und die Frankreichstrategie nicht im Zuge politischer Wechsel in den nächsten Jahren und Jahrzehnten grundsätzlich wieder in Frage gestellt wird, muss sie bald deutliche Fortschritte machen, sozusagen den point of no return überschreiten und eine Pfadabhängigkeit kreieren, um damit unumkehrbar und verbindlich auch für die zukünftige

18 Vgl. Stratégie Allemagne de la Lorraine, S. 7; vgl. Sievert, Stephan/Klingholz, Reiner: Ungleiche Nachbarn. Die demografische Entwicklung in Deutschland und Frankreich verläuft gegensätzlich - mit enormen Langzeitfolgen; Berlin: Berlin-Institut für Bevölkerung und Entwicklung, 2009, http: //www.berlin-institut.org/fileadmin/user_upload/Veroeffentlichungen/Frankreich/ Ungleiche_Nachbarn_online_NEU.pdf (14.04.2016).

19 Vgl. Abkommen über die grenzüberschreitende Berufsausbildung Saarland-Lothringen/ Accord relatif à l'apprentissage transfrontalier Sarre-Lorraine, http://www.saarland.de/ dokumente/thema_europa/gufb_Abkommen.pdf (14.04.2016).

20 Staatskanzlei des Saarlandes: Eckpunkte einer Frankreichstrategie, S. 3. 
Landespolitik zu werden. Diese Ambition stößt sich indes an Haushaltszwängen, unter denen auch diverse frankreichspezifische Aktivitäten leiden. Hier müsste zweitens eine klare Prioritätensetzung erfolgen. Drittens sollte noch mehr als bisher der Kontakt mit der Zivilgesellschaft und ein wirklicher Erfahrungsaustausch mit den frankreichspezifischen Akteuren im Land, aber auch darüber hinaus, erfolgen, um die Frankreichstrategie noch stärker innergesellschaftlich zu verankern, aber auch um weitere konkrete Anregungen und ggf. sogar Lösungsvorschläge für bestehende Probleme zu erhalten. Die Expertise ist vorhanden, sie müsste abgerufen werden und gleichzeitig müsste dabei offen, wohl auch offener als bisher, über noch bestehende Defizite geredet werden. Die bereits eingeführte Veranstaltungsform des ,Runden Tischs', der sich zuletzt am 17. Januar 2017 in der Staatskanzlei getroffen hat ${ }^{21}$ ist sicher eine lobenswerte Idee. Indes sollten die Veranstaltungen weniger grande messe, sondern vielmehr echte Arbeitstreffen mit offenem, wenn nötig auch kontroversem Meinungsaustausch sein.

Fortschritte der saarländischen Frankreichstrategie könnten gleichzeitig die lothringische Deutschlandstrategie vorantreiben - und umgekehrt. Indes ist die Herausforderung auf französischer Seite noch größer: Erstens ist Lothringen seit dem 1. Januar 2016 nur noch Teil der schon erwähnten größeren Region Grand Est. ${ }^{22}$ Damit stellt sich die Frage nach der Kompetenzverteilung und folglich nach der zukünftigen Rolle der lothringischen Teilregion im neuen Gesamtgefüge. Mit dem Elsass gibt es nun einen weiteren, deutschlandpolitisch sehr starken Akteur, der regional indes eher nach BadenWürttemberg ausgerichtet ist. Champagne-Ardenne wiederum ist nicht nur geographisch weiter von Deutschland entfernt. Insofern ist die Deutschlandorientierung innerhalb des Grand Est nicht überall gleich stark ausgeprägt. Das Interesse Lothringens müsste es dennoch auf jeden Fall sein, weiter von seiner spezifischen Deutschlandkompetenz zu profitieren, sei es unter Beibehaltung seiner eigenen entsprechenden Strategie oder nun im Rahmen einer gemeinsamen Strategie der neuen französischen Großregion, deren unmittelbare regionale Partner in Deutschland dann sowohl das Saarland als auch Baden-Württemberg wären. Bislang sprechen hierfür aus lothringischer Perspektive, wie schon erwähnt, starke arbeitsmarktpolitische Erwägungen. Hier aber muss eine zweite Einschränkung gemacht werden: Der aktuelle Zuzug von Hunderttausenden von Flüchtlingen könnte zumindest langfristig Deutschlands demographische Probleme lösen und eine weitere gezielte Anwerbung von Arbeitskräften aus dem EU-Ausland, darunter auch aus Frankreich,

21 Vgl. Saarnews: Runder Tisch Frankreichs, 18.01.2017, http://saarnews.com/index.php/ 2017/01/18/runder-tisch-frankreich (31.07.2017).

22 Grillmeyer, Dominik: Territorialreform in Frankreich. Ambitionierter Start, Schwächen im Abschluss (= DGAPAnalyse 13, 28.10.2015), https://dgap.org/de/think-tank/ publikationen/dgapanalyse/territorialreform-frankreich-0 (13.04.2016). 
obsolet werden lassen. Allerdings ändert dieser Einwand zumindest nichts an der kurz- und vielleicht sogar mittelfristigen Perspektive. Zudem kann sich auch eine nur vorübergehende Beschäftigung beim deutschen Nachbarn als ein Turbo für eine weitere berufliche Laufbahn in Frankreich erweisen. In diesem Zusammenhang ist sehr bedauerlich, dass bisher nur wenige junge Deutsche und Franzosen erkennen, welche arbeitsmarktpolitischen Vorteile ihnen das Erlernen der Sprache des Anderen, ergänzend natürlich zum Englischen, bietet, gerade weil diese Option aktuell in beiden Ländern nur von einer kleinen Minderheit gewählt wird, die den tatsächlichen Bedarf an gut ausgebildeten und sprachlich sicheren, aber auch interkulturell erfahrenen Nachwuchskräften in Kultureinrichtungen, öffentlicher Verwaltung und Unternehmen nicht stillen kann.

Drittens ist im Hinblick auf die Zukunftsaussichten der beiden Strategien daran zu erinnern, dass beide Regionen - das Saarland wie der Grand Est für die Verankerung der deutsch-französischen Beziehungen eine wichtige Rolle spielen könnten. Seit gut anderthalb Jahrzehnten erleben wir national wie international einen umfassenden Generationenwechsel: Jene Altersgruppe, die den Zweiten Weltkrieg und seine Folgen noch selbst erlebt hat und der die Aussöhnung mit den Nachbarn daher nach 1945 eine Herzensangelegenheit war, macht endgültig einer neuen Platz, für die „Europa [...] nicht mehr eine Sache des Instinkts oder des Herzens [ist], es ist eine Sache der Vernunft “23. Gleichzeitig ist die deutsch-französische Aussöhnung zum Opfer ihres eigenen Erfolges geworden. Das beeindruckend hohe Maß an Austausch, Kenntnis und Zusammenarbeit wird von einer jüngeren Generation nicht nur für selbstverständlich erachtet, sondern hat die deutschfranzösischen Beziehungen geradezu banalisiert. Dies erklärt zweifellos auch die Abnahme der Deutschlerner in Frankreich und jene der deutschen Schüler, die Französisch lernen wollen. Hieraus rührt die bekannte Klage Pierre Noras von 2012, Deutsche und Franzosen hätten sich ,auseinandergelebt“"24, oder Peter Sloterdijks Feststellung, das deutsch-französische Verhältnis sei „günstigenfalls als das einer wohlwollenden gegenseitigen NichtBeachtung oder benignen Entfremdung ${ }^{\text {“25 }}$ zu bezeichnen. In der Tat drohen

23 Vernet, Daniel: Ungewissheiten in der Europa-Politik. Neue deutsch-französische Entscheidungsträger, in: Internationale Politik 9 (1998), S. 1-6, hier S. 3; vgl. Baasner, Fritz: Der Generationswechsel nach der Aussöhnung, in: Dokumente. Zeitschrift für den deutsch-französischen Dialog 3 (2006), S. 30-33.

24 Guez, Olivier: Man hat sich auseinandergelebt. Lässt sich dem recht bescheiden gewordenen kulturellen Austausch zwischen Frankreich und Deutschland aufhelfen? Der prominente Historiker Pierre Nora bleibt skeptisch, in: Frankfurter Allgemeine Zeitung, 16.02.2012, http://www.faz.net/aktuell/feuilleton/deutsch-franzoesisches-verhaeltnis-man-hat-sichauseinandergelebt-11651980.html (13.04.2016).

25 Sloterdijk, Peter: Theorie der Nachkriegszeiten. Bemerkungen zu den deutsch-französischen Beziebungen seit 1945, Frankfurt/M.: Suhrkamp, 2008, S. 9. 
die eingetretenen Automatismen und Rituale Deutsche und Franzosen dazu zu verleiten, sich allzu sehr in der Sicherheit einer endgültigen Pfadabhängigkeit und damit Unumkehrbarkeit des Erreichten zu wiegen.

Indes darf auch nicht unterschätzt werden, wie stark sich beide Völker mittlerweile ,zusammengelebt“ 26 haben und wie sehr gerade diese Sonderbeziehung immer noch eine vielversprechende Zukunft haben kann. Das integrierte Europa ist dank der beiden Länder und ihrer Zusammenarbeit in den 1950er Jahren überhaupt erst entstanden. ${ }^{27}$ Auch wenn es im Europa der 28 von heute - oder nach dem vollzogenen ,Brexit' dann der 27 - andere Gewichtungen gibt als im einstigen Europa der 6, so gilt doch weiterhin die Regel: Ohne ein Einvernehmen von Deutschland und Frankreich ist die Europäische Union nicht handlungsfähig. ${ }^{28}$ Eine andauernd effektive Kooperation setzte allerdings voraus, dass die Eliten wie die Masse der Bevölkerung beider Länder sich auch zukünftig für die deutsch-französischen Beziehungen interessieren: Hierzu ihren Beitrag zu leisten, dazu sind insbesondere die Grenzregionen aufgerufen. Das Saarland und Lothringen bzw. der französische Grand Est könnten hierbei eine prominente Pilotrolle spielen. Insofern ist der politische Voluntarismus, wie er sich in den spiegelbildlichen Strategieprojekten der beiden Regionen offenbart, auf jeden Fall zu begrüßen und ihm Nachhaltigkeit zu wünschen, gleich ob er am Ende seine jeweiligen Maximalziele erreicht oder nicht.

26 Teufel, Erwin/Baasner, Fritz: Deutsch-Französische Verständigung. Wir haben uns zusammengelebt. Pessimismus ist hier fehl am Platz: Deutsche und Franzosen verstehen sich auch in einer zunehmend komplexen Welt noch gut. Eine Antwort auf Pierre Nora., in: Frankfurter Allgemeine Zeitung, 26.03.2012, http://www.faz.net/aktuell/feuilleton/deutschfranzoesische-verstaendigung-wir-haben-uns-zusammengelebt-11698459.html (05.10.2016).

$27 \mathrm{Zu}$ den deutsch-französischen Beziehungen nach 1945 im europäischen Kontext vgl. Defrance, Corine/Pfeil, Ulrich: Eine Nachkeriegsgeschichte in Europa 1949 bis 1963, Darmstadt: WBG, 2011; Miard-Delacroix, Hélène: Im Zeichen der europä̈schen Einigung. 1963 bis in die Gegenwart, Darmstadt: WBG, 2011; Seidendorf, Stefan (Hg.): Deutsch-Französische Beriehungen als Modellbankasten? Zur Übertragbarkeit von Aussöbnung und strukturierter Zusammenarbeit, Baden-Baden: Nomos, 2012; Marcowitz, Reiner/Miard-Delacroix, Hélène (Hg.): 50 ans de relations franco-allemandes, Paris: Nouveau monde éditions, 2013.

28 Vgl. Martens, Stephan/Gustin, Philippe: Relancer le moteur de l'Europe, Paris: Lemieux Editeur, 2016. 


\section{Literaturverzeichnis}

Abkommen über die grenzüberschreitende Berufsausbildung Saarland-Lothringen/Accord relatif à l'apprentissage transfrontalier Sarre-Lorraine, http://www.saarland.de/dokumente/ thema_europa/gufb_Abkommen.pdf (14.04.2016).

Baasner, Fritz: Der Generationswechsel nach der Aussöhnung, in: Dokumente. Zeitscbrift für den deutsch-französischen Dialog 3 (2006), S. 30-33.

Bastien, René: Histoire de la Lorraine, Metz: Editions Serpenoise, 1993.

Conseil Economique, Social et Environnemental de Lorraine (CESEL): L'Allemagne, partenaire incontournable de la Lorraine. Projet. Séance Plénière du 18 octobre 2011, http://www. ceselorraine.eu/UserFiles/File/ressources/rapports/2011/2011-cesel-rapport-allemagne. $\operatorname{pdf}(14.04 .2016)$.

Conseil Economique, Social et Environnemental de Lorraine (CESEL): Avis du CESEL sur la Stratégie France de la Sarre. Une opportunité à saisir, une obligation d'agir. Avis adopté à l'unanimité en Séance Plénière du 16 mai 2014, http://www.ceselorraine.eu/img_base/ ged_v2/278/2014-cesel-avis-strategie-france-sarre.pdf. (14.04.2016).

Conseil Economique, Social et Environnemental de Lorraine (CESEL): A la Une. Stratégie France: le CESEL présente 8 pistes d'actions côté lorrain, 20.05.2014, http://www. ceselorraine.eu/fr/strategie-france-le-cesel-presente-8-pistes-d-actions-cote-lorrain/a-laune-du-cese-lorraine.html (14.04.2016).

Defrance, Corine/Pfeil, Ulrich: Eine Nachkriegsgeschichte in Europa 1949 bis 1963, Darmstadt: WBG, 2011.

Delorme, Florian: La bataille des langues en Europe (2/4) - De l'école au travail, enjeux linguistiques en zones transfrontalières, in: France Culture Radio, 18.03.2014, http://www. franceculture.fr/emissions/culturesmonde/la-bataille-des-langues-en-europe-24-delecole-au-travail-enjeux (14.04.2016).

Grillmeyer, Dominik: Territorialreform in Frankreich. Ambitionierter Start, Schwächen im Abschluss (= DGAPAnalyse 13, 28.10.2015), https://dgap.org/de/think-tank/publikationen/ dgapanalyse/territorialreform-frankreich-0 (13.04.2016).

Guez, Olivier: Man hat sich auseinandergelebt. Lässt sich dem recht bescheiden gewordenen kulturellen Austausch zwischen Frankreich und Deutschland aufhelfen? Der prominente Historiker Pierre Nora bleibt skeptisch, in: Frankfurter Allgemeine Zeitung, 16.02.2012, http://www.faz.net/aktuell/feuilleton/deutsch-franzoesisches-verhaeltnis-man-hat-sichauseinandergelebt-11651980.html (13.04.2016).

Knoepffler, Christian: Frankreich über alles, in: Le Républicain Lorrain, 05.02.2014, S. 7.

Marcowitz, Reiner/Miard-Delacroix, Hélène (Hg.): 50 ans de relations franco-allemandes, Paris: Nouveau monde éditions, 2013.

Martens, Stephan/Gustin, Philippe: Relancer le moteur de l'Europe, Paris: Lemieux Editeur, 2016.

Miard-Delacroix, Hélène: Im Zeichen der europäischen Einigung. 1963 bis in die Gegenwart, Darmstadt: WBG, 2011.

O. A.: Pour survivre, la Sarre parie sur le parler français, in : Le Télégramme, 03.03.2014, S. 1.

Parisse, Michel (Hg.): Lotbringen. Geschichte eines Gren₹landes, Saarbrücken: Saarbrücker Druckerei u. Verl., 1983.

Saarnews: Runder Tisch Frankreichs, 18.01.2017, http://saarnews.com/index.php/2017/01/ 18/runder-tisch-frankreich (31.07.2017).

Seidendorf, Stefan (Hg.): Deutsch-Franఇösische Beriebungen als Modellbaukasten? Zur Übertragbarkeit von Aussöbnung und strukturierter Zusammenarbeit, Baden-Baden: Nomos, 2012. 
Sievert, Stephan/Klingholz, Reiner: Ungleiche Nacbbarn. Die demografische Entwicklung in Deutschland und Frankereich verläuft gegensätəlich - mit enormen Langzeitfolgen, Berlin: Berlin-Institut für Bevölkerung und Entwicklung, 2009, http://www.berlin-institut.org/fileadmin/user_ upload/Veroeffentlichungen/Frankreich/Ungleiche_Nachbarn_online_NEU.pdf (14.04.2016).

Sloterdijk, Peter: Theorie der Nachkriegszeiten. Bemerkungen zu den deutsch-franzö̈sischen Beziebungen seit 1945, Frankfurt/M.: Suhrkamp, 2008.

Staatskanzlei des Saarlandes: Eckpunkte einer Frankreichstrategie für das Saarland, 2014, http:// www.saarland.de/dokumente/res_stk/D_Eckpunkte_Frankreich-Strategie_210114.pdf (14.04.2016).

Stellungnahme der Universität Lothringen zur Frankreichstrategie des Saarlandes vom 02.06.2014, Kopie im persönlichen Besitz des Autors.

Stratégie Allemagne de la Lorraine. Rapport final. Synthèse et propositions juin 2015, 2015, http:/ / metz.fr/ pages/conseil_municipal/seances/cm151029/doc/5_d1445930773387.pdf (14.04.2016).

Teufel, Erwin/Baasner, Fritz: Deutsch-Französische Verständigung. Wir haben uns zusammengelebt. Pessimismus ist hier fehl am Platz: Deutsche und Franzosen verstehen sich auch in einer zunehmend komplexen Welt noch gut. Eine Antwort auf Pierre Nora., in: Frankfurter Allgemeine Zeitung, 26.03.2012, http://www.faz.net/aktuell/feuilleton/ deutsch-franzoesische-verstaendigung-wir-haben-uns-zusammengelebt-11698459.html (05.10.2016).

Vernet, Daniel: Ungewissheiten in der Europa-Politik. Neue deutsch-französische Entscheidungsträger, in: Internationale Politik 9 (1998), S. 1-6. 
Umsetzung - Perspektiven aus Wissenschaft und Politik La mise en application - Perspectives scientifiques et politiques 



\title{
Frankreichstrategie und Bildungspolitik
}

\author{
Bestandsaufnahme und Perspektiven aus der Sicht der \\ Angewandten Linguistik und der Sprachlehr-/Sprachlernforschung
}

La 'Stratégie France' de la Sarre a éveillé l'intérêt des médias dès sa publication en janvier 2014. Un des aspects qui se trouvent au centre des débats est la question des langues. Mais très souvent, celle-ci est simplifiée par les médias. C'est pour cette raison que dans un premier temps, nous analysons le texte même de la 'Stratégie France'. Cette analyse se concentre sur les passages dont le sujet touche à la linguistique appliquée. Puis nous examinerons les dispositifs mis en place dans le système éducatif sarrois pour promouvoir l'enseignement et l'apprentissage des langues selon les visions exprimées dans la 'Stratégie France'. Ces mesures politiques seront d'une part évaluées à la lumière de résultats de recherche existants, d'autre part nous porterons un regard sur leur réalisation pratique. En conclusion, l'article livre des perspectives d'avenir ainsi qu'un bilan critique.

\section{Einleitende Überlegungen}

Die Frankreichstrategie des Saarlandes hat seit der Veröffentlichung des Eckpunktepapiers $^{1}$ im Januar 2014 immer wieder mediale Aufmerksamkeit auf sich gezogen. Einer der Punkte, die dabei, oft allerdings auch verkürzt, thematisiert werden, ist die Sprachenfrage. Dies spiegelt sich bereits in den Pressereaktionen nach der Veröffentlichung des Eckpunktepapiers im Januar 2014. Sowohl in der deutschen als auch in der französischen Presse wird ausschließlich der Aspekt des Französischen fokussiert, wie aus den folgenden Belegen exemplarisch hervorgeht:

(1a) Das Saarland will zweisprachig werden. ${ }^{2}$

(1b) Das Saarland soll zweisprachig werden. ${ }^{3}$

1 Staatskanzlei des Saarlandes: Eckpunkte einer Frankreichstrategie für das Saarland, 2014, http:// www.saarland.de/dokumente/res_stk/D_Eckpunkte_Frankreich-Strategie_210114.pdf (12.04.2017).

2 Holl, Thomas: Das Saarland will zweisprachig werden, in: Frankfurter Allgemeine Zeitung, 22.01.2014, https://fazarchiv.faz.net/fazDocument/saveSingleDoc/FAZ_FD2201401 224167145 (16.05.2017).

3 Holl, Thomas: Frankreichstrategie. Das Saarland soll mehrsprachig werden, in: Frankfurter Allgemeine Zeitung, 21.01.2014, http://www.faz.net/aktuell/politik/inland/frankreichstrategie-das-saarland-soll-zweisprachig-werden-12762333.html (16.05.2017). 
(1c) Das kleine Saarland wird jetzt zweisprachig. ${ }^{4}$

(2a) Allemagne: quand la Sarre se voit francophone en $2043 .{ }^{5}$

(2b) La Sarre veut devenir un Land bilingue. [...] En 2043, tous les Sarrois devront parler le français. ${ }^{6}$

(2c) La Sarre veut faire du français sa seconde langue.?

Auch, wenn das Französische natürlich eine zentrale Rolle spielt: Die Frankreichstrategie auf diesen Aspekt zu reduzieren, entspricht nicht der Darstellung im Eckpunktepapier. Gleichzeitig können solche Pressediskurse Auslöser für reflexhafte Abwehrhaltungen sein, auf die mit der durchaus provokativpolemisch gemeinten Formulierung des Titels dieses Bandes angespielt wird: „Alles Frankreich oder was?“ Wir werden auf diesen Aspekt im weiteren Verlauf dieses Beitrags noch zurückkommen. In einem ersten Schritt soll aber das Ausgangsdokument einer genaueren Analyse im Hinblick auf bildungspolitische Aspekte unterzogen werden. Dabei sollen besonders die aus sprachwissenschaftlicher Sicht relevanten Passagen in den Blick genommen werden. Auf dieser Grundlage wird genauer beleuchtet, welche bildungspolitischen Voraussetzungen für das Sprachenlehren und -lernen im Sinne der Frankreichstrategie bereits geschaffen wurden, wie diese Voraussetzungen im Lichte vorliegender Forschungsergebnisse im Hinblick auf die formulierten Zielsetzungen zu beurteilen sind und wie sich der praktische Umgang mit diesen Voraussetzungen darstellt - zwei aus Sicht der Angewandten Linguistik wichtige Aspekte. Es versteht sich von selbst, dass wir uns auf ausgewählte und in Bezug auf unsere Fragestellung besonders zentrale Punkte konzentrieren müssen. Der Beitrag schließt mit einer kritischen Bilanz.

4 Crolly, Hannelore: Frankreich-Strategie. Das kleine Saarland wird jetzt zweisprachig, in: Die Welt, 21.01.2014, unter http://www.welt.de/politik/deutschland/article124090161/ Das-kleine-Saarland-wird-jetzt-zweisprachig.html (16.05.2017). Auf die unterschiedliche Modalität in den verschiedenen Belegen (,will“, „,soll“, „wird“) wird hier nicht weiter eingegangen.

5 Lemaitre, Frédéric: Allemagne: quand la Sarre se voit francophone en 2043, in: Le Monde, 21.02.2014, http://www.lemonde.fr/le-magazine/article/2014/02/21/dans-la-sarre-lefrancais-ca-sert_4370289_1616923.html (16.05.2017).

6 Madelin, Thibaut: La Sarre veut devenir un Land bilingue. [...] En 2043, tous les Sarrois devront parler le français, in: Les Echos, 28.01.2014, http://www.lesechos.fr/economiepoitique/regions/lorraine/0203271889015-la-sarre--veut-devenir-un-land-bilingue646034.php (16.05.2017).

7 O.A.: La Sarre veut faire du français sa seconde langue, in: L'Essentiel, 21.01.2014, http:// www.lessentiel.lu/fr/news/grande_region/story/22026394 (16.05.2017). 


\section{Die Frankreichstrategie des Saarlandes: linguistische Aspekte und bildungspolitische Kontexte}

Es wäre durchaus reizvoll, das Eckpunktepapier aus diskurslinguistischer Sicht ${ }^{8}$ einer eingehenden Analyse zu unterziehen. Besondere Aufmerksamkeit würde etwa das Schlagwort „Frankreichkompetenz“ verdienen, das (überwiegend in der Graphie „Frankreich-Kompetenz") insgesamt $26 \mathrm{Mal}^{9}$ im Text auftaucht, auf etwas offenbar bereits Vorhandenes verweist, aber an keiner Stelle explizit definiert wird. Lediglich an einigen Stellen werden Bezüge hergestellt, die immerhin ein wenig zur Konkretisierung beitragen, wie beispielsweise

(3) Frankreich-Kompetenz beinhaltet nicht nur entsprechende Sprachkompetenzen, sondern auch die Vertiefung weiterer Kompetenzfelder, wie Fachkompetenz, Regionalkompetenz und interkulturelle Kompetenz. ${ }^{10}$

Auch eine Analyse der verwendeten Metaphern, wie im DIMEAN-Modell von Spitzmüller/Warnke vorgesehen ${ }^{11}$, könnte aufschlussreich sein. Besonders auffällig sind z. B. die Brückenmetapher („Das Saarland versteht sich als Brücke zwischen Deutschland und Frankreich"12; hieran schließen Verben wie z. B. „ausbauen“ und „stabilisieren“13 an und schaffen damit aus textlinguistischer Sicht Isotopiestränge) oder die Tormetapher („Das Saarland soll aus französischer Sicht zu einer Brücke nach Deutschland und zum Tor zu Frankreich aus deutscher Sicht werden $[\ldots]^{\text {"14 }}$, mit weitergeführten Isotopien wie ,'Türöffner" ${ }^{15}$.

8 Vgl. z. B. Spitzmüller, Jürgen/Warnke, Ingo: Diskurslinguistik: eine Einführung in Theorien und Methoden der transtextuellen Sprachanalyse, Berlin/New York: de Gruyter, 2011. Der Begriff Diskurs ist sowohl im akademischen als auch im außerwissenschaftlichen Sprachgebrauch hochfrequent; nach dem grundlegenden Beitrag von Foucault haben sich in der Wissenschaft unterschiedliche Zugriffe und Forschungstraditionen entwickelt. Eine Auseinandersetzung mit diesen ist nicht Intention dieses Beitrags. Vgl. Foucault, Michel: L'Ordre du discours, Paris: Gallimard, 1971.

9 Alle Angaben in diesem Abschnitt beziehen sich auf die deutschsprachige Version des Eckpunktepapiers, vgl. Staatskanzlei des Saarlandes: Eckpunkte einer Frankreichstrategie.

10 Staatskanzlei des Saarlandes: Eckpunkte einer Frankreichstrategie, S. 21.

11 Spitzmüller/Warnke: Diskurslinguistik, S. 201.

12 Staatskanzlei des Saarlandes: Eckpunkte einer Frankreichstrategie, S. 1.

13 Staatskanzlei des Saarlandes: Eckpunkte einer Frankereichstrategie, S. 14.

14 Staatskanzlei des Saarlandes: Eckpunkte einer Frankreichstrategie, S. 11.

15 Staatskanzlei des Saarlandes: Eckpunkte einer Frankreichstrategie, S. 14. Interessant wäre es auch, die im Ausgangstext und im Pressediskurs verwendeten Metaphern vergleichend zu untersuchen. Eine Stichprobe ergab, dass durchaus nicht dieselben Metaphern verwendet werden. Genaueres müsste in einer ausführlichen, dieser Frage gewidmeten Korpusanalyse ermittelt werden. 
Eine eingehende diskursanalytische Auseinandersetzung mit diesem Dokument muss allerdings einem zukünftigen Beitrag vorbehalten bleiben. Ziel der folgenden Abschnitte ist es vielmehr, die aus Sicht der Linguistik bzw. der Sprachlehr-/Sprachlernforschung relevanten Passagen zusammenzustellen und in die entsprechenden (europäischen, nationalen und regionalen) Kontexte einzuordnen. Dabei werden neben dem Eckpunktepapier auch die beiden Fenilles de route ${ }^{16}$ berücksichtigt.

Auch wenn an mehreren Stellen im Eckpunktepapier das Stichwort ,Zweisprachigkeit', bezogen auf die beiden Sprachen Deutsch und Französisch, fällt, ${ }^{17}$ wirbt das Dokument letztlich für einen mehrsprachigen Ansatz, in dem freilich diesen beiden Sprachen eine tragende Rolle zukommt, wie etwa folgende Passage verdeutlicht:

(4) Nur wenn die Frankreich-Kompetenz des Saarlandes in der Breite gestärkt und von der Bevölkerung mitgetragen wird, kann tatsächlich ein leistungsfähiger mehrsprachiger Raum deutsch-französischer Prägung innerhalb einer Generation entstehen. ${ }^{18}$

Fundierte Französischkenntnisse und die zugleich angestrebte Stärkung des Französischen im Alltag ${ }^{19}$ sollen also keineswegs andere Fremdsprachen, insbesondere die Weltsprache Englisch ausschließen, wie dies an mehreren Stellen zum Ausdruck gebracht wird, z. B.

(5) Im Rahmen der politischen Zielsetzung, die Mehrsprachigkeit der Saarländerinnen und Saarländer zu stärken, kommt der Schaffung eines leistungsfähigen multilingualen Raums deutsch-französischer Prägung eine besondere Bedeutung zu. Vom Vorbild Luxemburg zu lernen, heißt zu verstehen, dass die Präsenz einer Sprache im öffentlichen Raum, und damit die dauerhafte Begegnung des Bürgers als Sprachenlerner mit einer Sprache, die nicht seine Muttersprache ist, eine wesentliche Bedeutung für den Lernerfolg hat. Dies ist, wie man in Luxemburg sieht, dann besonders erfolgreich, wenn die Bürger - unabhängig von ihrem Alter - tagtäglich in einem mehrsprachigen Raum leben und arbeiten. Ziel der Landesregierung ist es deshalb, für eine stärkere Präsenz der französischen Sprache im öffentlichen Raum im Saarland Sorge zu tragen. Dies steht nicht im Widerspruch der Erfordernis [sic]

16 Vgl. Landesregierung des Saarlandes: Feuille de route Frankereich-Strategie 2015/2016, 2015, http://www.saarland.de/dokumente/ressort_finanzen/Feuille_de_route.pdf (12.04.2017) sowie Landesregierung des Saarlandes: Frankreichstrategie Feuille de route II 2017/2019, 2016, http://www.saarland.de/dokumente/thema_europa/2016-10-17_Feuille_de_route_ 2017-2019.pdf (09.05.2017).

17 Vgl. Staatskanzlei des Saarlandes: Eckpunkte einer Frankreichstrategie, S. 5, 11, 12, 26. In Bezug auf die Sprachensituation in Luxemburg von ,,[... einer echten Zweisprachigkeit [...]“ (ebd., S. 5) zu sprechen, ist aus soziolinguistischer Sicht etwas vereinfachend.

18 Staatskanzlei des Saarlandes: Eckpunkte einer Frankreichstrategie, S. 4, vgl. auch S. 9, 17.

19 Vgl. Staatskanzlei des Saarlandes: Eckpunkte einer Frankreichstrategie, z. B. S. 9, 10, 26 f. 
zur Vermittlung englischer Sprachkenntnisse auf hohem Niveau in saarländischen Schulen, im Gegenteil - es öffnet den Raum für das Erlernen von Englisch und weiteren Fremdsprachen. ${ }^{20}$

Ähnlich wird wenig später argumentiert, wo allerdings noch die - zunehmend wichtiger werdenden - sogenannten Herkunftssprachen, d. h. die Sprachen von Migranten bzw. von Geflüchteten mit einbezogen werden:

(6) Innerhalb einer Generation, d. h. innerhalb von 30 Jahren, soll die Amts- und Bildungssprache Deutsch möglichst konsequent durch Französisch als weitere Verkehrssprache ergänzt werden. Damit umfasste das weitere Fremdsprachenlernen auf der Grundlage einer hohen Kompetenz in der Bildungssprache Deutsch und gegebenenfalls einer anderen Herkunftssprache das Lernen der Verkehrssprache Französisch, der globalen Lingua franca Englisch und gegebenenfalls weiterer Sprachen. ${ }^{21}$

Die Bedeutung solcher „[...] mehrsprachigen Kompetenzen mit Schwerpunkt Französisch und Englisch von Arbeitnehmern und Hochschulab-

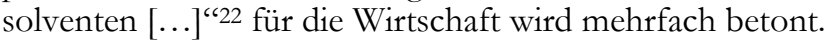

Damit werden Aspekte angesprochen, die auch in zentralen Dokumenten der europäischen Sprachen- und Bildungspolitik verankert sind, beginnend 1995 mit dem Weißsbuch zur allgemeinen und beruflichen Bildung23, in dem Forderungen zum Lehren und Lernen im Allgemeinen und zum Sprachenlernen im Besonderen formuliert werden und der Stellenwert des Fremdsprachenlernens unterstrichen wird. ${ }^{24}$

Die Zielvorgabe, dass jeder EU-Bürger während seiner schulischen Ausbildung möglichst zwei weitere Sprachen erlernen soll („,Muttersprache plus

20 Staatskanzlei des Saarlandes: Eckpunkte einer Frankreichstrategie, S. 9.

21 Staatskanzlei des Saarlandes: Eckpunkte einer Frankreichstrategie, S. 10.

22 Staatskanzlei des Saarlandes: Eckpunkte einer Frankreichstrategie, S. 15.

23 Vgl. Europäische Kommission: Weißbuch zur allgemeinen und beruflichen Bildung: Lebren und Lernen. Auf dem Weg zur kognitiven Gesellschaft, KOM (1995) 590 vom 29.11.1995, Strasbourg, 1995, http://europa.eu/documents/comm/white_papers/pdf/com95_590_de.pdf (12.04.2017). Vgl. auch Europarat: Entschließung des Rates vom 16. Dezember 1997 über die frühzeitige Vermittlung der Sprachen der Europäischen Union [Amtsblatt C 1 vom 03.01.1998], 1997, http://europa.eu/legislation_summaries/education_training_youth/ lifelong_learning/c11042_de.htm (18.04.2017).

24 Weitere wichtige Stichworte sind die Kompetenzdifferenzierung und die modularisierte Vermittlung einzelner (Teil-)Kompetenzen, die 2001 mit dem Gemeinsamen europäischen Referen₹rahmen für Sprachen systematisiert werden sollten. Vgl. Europarat: Gemeinsamer europäischer Referenærahmen für Sprachen: Lernen, lebren, beurteilen, 2001, deutsche Version http:// www.goethe.de/z/50/commeuro/deindex.htm (12.04.2017). Ein weiteres wichtiges Dokument für das Mehrsprachenlernen ist der Referenzrahmen für plurale Ansätze, vgl. Europarat: Referenarahmen für plurale Ansätze (REPA)/Cadre de Référence pour les approches plurielles (CARAP), 2004ff., http://carap.ecml.at/(18.04.2017). 
zwei weitere Sprachen“"25) - wie dies im Eckpunktepapier mit Französisch und Englisch der Fall ist - wird explizit im Aktionsplan „Förderung des Sprachenlernens und der Sprachenvielfalt" (2004-2006) formuliert ${ }^{26}$ und auch in nachfolgenden europäischen Papieren wiederholt. ${ }^{27}$

Der Gedanke, dass Sprachkenntnisse als Wettbewerbsvorteil gelten können, der genutzt werden sollte, wird auch im Bericht der Hochrangigen Gruppe für Mehrsprachigkeit aus dem Jahr 2007 betont. ${ }^{28}$ Auch die interkulturelle und die identitätsstiftende Dimension werden hier angesprochen; Sprachenlernen wird als wichtig für die soziale und kognitive Entwicklung einer Person angesehen. Die Gruppe gibt verschiedene Empfehlungen für die Erleichterung des Fremdsprachenerwerbs, u. a. sportliche Aktivitäten. Dieser Aspekt wird auch im Eckpunktepapier ${ }^{29}$ und in der Fexille de route $I I^{30}$ aufgegriffen, allerdings ohne ihn weiter zu konkretisieren.

Die Einbindung der Sprachenfrage in eine umfassende Politik, die über den Bildungssektor hinausreicht, wie dies auch für die Frankreichstrategie charakteristisch ist, wird im 2008 erschienenen Dokument „Mehrsprachigkeit: Trumpfkarte Europas, aber auch gemeinsame Verpflichtung ${ }^{\text {“31 }}$ ausführlich thematisiert.

25 Durch Migration und Flucht ist diese Formel mittlerweile nicht mehr uneingeschränkt aktuell. Insofern findet sich sowohl im Eckpunktepapier als auch in dem im Weiteren einbezogenen saarländischen Sprachenkonzept eine differenzierte Sicht; s. hierzu die Ausführungen im weiteren Verlauf dieses Abschnitts sowie Ministerium für Bildung und Kultur Saarland: Sprachenkonzept Saarland 2011, 2011a, http://www.saarland.de/dokumente/ res_bildung/Das_Sprachkonzept_Saarland_2011.pdf (12.04.2017).

26 Kommission der europäischen Gemeinschaften: MITTEILUNG DER KOMMISSION AN DEN RAT, DAS EUROPÄISCHE PARLAMENT, DEN WIRTSCHAFTS- UND SOZIALAUSSCHUSS UND DEN AUSSCHUSS DER REGIONEN. Förderung des Sprachenlernens und der Sprachenvielfalt: Aktionsplan 2004-2006, 2003, http://eurlex.europa.eu/legal-content/DE/ALL/?uri=CELEX:52003DC0449 (12.04.2017).

27 Allerdings ist dies laut der Eurobarometer-Befragung 2012 nur bei einem Viertel der Befragten auch tatsächlich der Fall, obwohl $72 \%$ zustimmen, dass man in der EU mehr als eine weitere Sprache neben der eigenen beherrschen sollte. Vgl. Europäische Kommission: DIE EUROPÄISCHEN BÜRGER UND IHRE SPRACHEN. Spezial Eurobarometer 386, 2012, http://ec.europa.eu/public_opinion/archives/ebs/ebs_386_de.pdf (18.04.2017), S. 6, 10.

28 Vgl. Hochrangige Gruppe Mehrsprachigkeit: Empfehlungen für das Sprachenlernen, 2007, kurze Zusammenfassung auf Deutsch http://europa.eu/rapid/pressReleasesAction.do? reference $=\mathrm{IP} / 07 / 1396 \&$ format $=$ HTML\&aged $=0$ \&language $=\mathrm{DE} \&$ guiLanguage $=\mathrm{en}$ ) (12.04.2017).

29 Vgl. Staatskanzlei des Saarlandes: Eckpunkte einer Frankreichstrategie, S. 26.

30 Vgl. Landesregierung des Saarlandes: Fenille de route II, S. 14.

31 Kommission der europäischen Gemeinschaften: Mitteilung der Kommission an das Europäische Parlament, den Rat, den Europäischen Wirtschafts- und Sozialausschuss und den 
Sowohl im Eckpunktepapier als auch in den beiden Fenilles de route spiegelt sich die auch auf der europapolitischen Ebene über die Jahre vollzogene Erweiterung und Fokussierung des Begriffs ,Mehrsprachigkeit‘. Der Akzent liegt nunmehr weniger auf der Gesellschaft (Erhalt der Sprachenvielfalt), wie dies in früheren Dokumenten der Fall war, als auf dem Individuum und den Möglichkeiten, die ein mehrsprachiges Profil eröffnet, sowohl für die individuelle interkulturelle Entwicklung als auch für den grenzüberschreitenden Arbeitsmarkt.

Konkretere Aussagen darüber, wie die angestrebte Mehrsprachigkeit im Einzelnen erreicht werden soll, enthält das Eckpunktepapier allerdings nicht; vielmehr wird auf das Sprachenkonzept des Saarlandes verwiesen. ${ }^{32}$ Dieses Dokument, das die Mehrsprachigkeit bereits im Titel trägt (Neue Wege zur Mehrsprachigkeit im Bildungswesen) ${ }^{33}$, soll daher hier abschließend kurz betrachtet werden ${ }^{34}$. Neben dem Ausdruck der großen Bedeutung des Sprachenlernens für die Persönlichkeitsentwicklung 35 und der Notwendigkeit einer höheren „Wertschätzung" von Mehrsprachigkeit ${ }^{36}$ sind hier v. a. die Passagen, die das Erlernen des Französischen und des Englischen betreffen, von Relevanz. Bezüglich dieser beiden Sprachen trifft das Sprachenkonzept eine klare Aussage:

Die Entscheidung, im Saarland mit dem Lernen der Nachbarsprache Französisch schon im Kindergarten oder der Grundschule zu beginnen und dann Englisch als weitere Sprache folgen zu lassen, beruht auf einem breiten gesellschaftlichen Konsens. Sie wird von Experten befürwortet und hat sich in der Praxis bewährt. ${ }^{37}$

Zur Konstellation ,Englisch nach Französisch' wird darüber hinaus an anderer Stelle festgehalten: „Mehrsprachigkeit lässt sich generell sehr viel erfolgreicher erwerben, wenn mit einer anderen Sprache als mit Englisch begonnen wird“. 38

Dies wird mit linguistischen Argumenten untermauert: Englisch weise aufgrund der genealogischen Verwandtschaft mit dem Deutschen und den historischen Einflüssen des Französischen Bezüge zu beiden Sprachen auf

Ausschuss der Regionen - Mehrsprachigkeit: Trumpfkarte Europas, aber auch gemeinsame Verpflichtung, KOM(2008) 566 endgültig vom 18.09.2008, 2008, http://eur-lex. europa.eu/legal-content/DE/TXT/?uri=URISERV\%3Aef0003 (18.04.2017).

32 Vgl. Staatskanzlei des Saarlandes: Eckpunkte einer Frankreichstrategie, S. 21.

33 Ministerium für Bildung und Kultur Saarland: Sprachenkonzept.

34 Die zum Zeitpunkt der Arbeit an diesem Beitrag in Arbeit befindliche neue Version des Sprachenkonzepts kann hier nicht berücksichtigt werden.

35 Vgl. Ministerium für Bildung und Kultur Saarland: Sprachenkonzept, S. 3.

36 Ministerium für Bildung und Kultur Saarland: Sprachenkonzept, S. 80.

37 Ministerium für Bildung und Kultur Saarland: Sprachenkon₹ept, S. 12.

38 Ministerium für Bildung und Kultur Saarland: Sprachenkonzept, S. 81. 
und könne somit problemlos als dritte Fremdsprache erworben werden, ohne dass im Ergebnis Probleme mit dem Kompetenzniveau zu erwarten seien. ${ }^{39}$

Sehr deutlich wird betont, dass die Entscheidung für diese Konstellation lediglich eine zeitliche Priorisierung darstellt, nicht aber eine Aussage zur Wertigkeit beinhaltet:

\footnotetext{
Es wäre in der heutigen Zeit anachronistisch, eine Konkurrenz zwischen den Schulfremdsprachen Französisch und Englisch im Saarland zu sehen. Die Devise darf nicht lauten: „Entweder Englisch oder Französisch“, sondern sie muss für die Zukunft aller Schülerinnen und Schüler lauten: „Sowohl als auch!“ ${ }^{40}$
}

Wie dieses „Sowohl als auch“ im Einzelnen umgesetzt werden soll, wird allerdings nicht weiter ausgeführt. Wir werden im Laufe des Beitrags darauf zurückkommen.

\section{3. „[...E]in leistungsfähiger mehrsprachiger Raum deutsch-französischer Prägung ${ }^{\text {“41 }}$ als Ziel - und der Weg dorthin?}

Um es gleich vorweg zu nehmen: Die klaren Worte im Sprachenkonzept im Hinblick auf die beiden Sprachen Französisch und Englisch spiegeln sich nicht in vollem Umfang in einer der Programmatik entsprechenden Bildungspolitik. Zwar nimmt das Französische ohne Zweifel im saarländischen Bildungssystem eine besondere Stellung ein: Immerhin ist es das einzige Bundesland, das Französisch als Fremdsprache in der Grundschule verankert hat, während in den übrigen Bundesländern mit Englisch begonnen wird, und im Schuljahr 2014/15 lernten insgesamt 59,7 \% aller Schülerinnen und Schüler im Saarland Französisch, was im Bundesdurchschnitt bei Weitem den größten Anteil bedeutet. ${ }^{42}$ Doch kann von einer konsequenten Ausrichtung an der im Eckpunktepapier formulierten und im Sprachenkonzept zumindest etwas konkretisierten Vision (noch?) nicht gesprochen werden (vgl. Kap. 3.1). Über

39 Ministerium für Bildung und Kultur Saarland: Sprachenkon₹ept, S. 81.

40 Ministerium für Bildung und Kultur Saarland: Sprachenkon₹ept, S. 12.

41 Staatskanzlei des Saarlandes: Eckpunkte einer Frankreichstrategie, S. 4.

42 Statistisches Bundesamt: Scbulen auf einen Blick. Ausgabe 2016, Wiesbaden, 2016, https:// www.destatis.de/DE/Publikationen/Thematisch/BildungForschungKultur/Schulen/Br oschuereSchulenBlick.html (18.04.2017), S. 20 f. Dieser Anteil hat sich im Vergleich zu 2014 sogar noch erhöht, wo er bei 57,1 \% lag. Vgl. Statistisches Bundesamt: Schulen auf einen Blick. Ausgabe 2014, Wiesbaden, 2014, https://www.destatis.de/DE/Publikationen/ Thematisch/BildungForschungKultur/AlteAusgaben/SchulenBlickAlt.html (18.04.2017), S. 20. 
die Gründe dafür kann man natürlich nur spekulieren. Die ,öffentliche Meinung ${ }^{6}$ jedenfalls scheint dem Projekt gegenüber offenbar ganz positiv eingestellt zu sein, wie das Ergebnis einer Umfrage des Meinungsforschungsinstituts Forsa im Auftrag des Magazins Forum vom November $2016^{43}$ zeigt. In dieser Umfrage wurde auch das Meinungsbild zu verschiedenen bildungspolitischen Entscheidungen erfragt, u. a. zur frühen Vermittlung des Französischen und zum Französischen als erster Fremdsprache. Laut dieser Umfrage halten $70 \%$ der Befragten Französisch als erste Fremdsprache für ,wichtig und richtig“" lediglich $28 \%$ befürchten Nachteile für die Kinder. Diese deutliche Zustimmung geht über alle Altersgruppen hinweg, ist allerdings besonders stark bei der Generation der über 60-Jährigen. Auch, wenn es sich hier natürlich um eine schlaglichtartige Momentaufnahme handelt und just in neuerer Zeit die Validität von Meinungsumfragen immer wieder in die Kritik geraten ist: Diese fast überraschend deutliche Zustimmung sollte für die politisch Verantwortlichen im Grunde ein Ansporn sein, um die programmatischen Aussagen im Eckpunktepapier und im Sprachenkonzept konsequent umzusetzen. Im Folgenden werden wesentliche Beispiele im Hinblick darauf kritisch beleuchtet.

3.1 Weichenstellungen in der saarländischen Bildungspolitik: ein kritischer Blick auf ausgewählte Beispiele

Der zwei- bzw. mehrsprachigen Erziehung wird im Sprachenkonzept des Saarlandes ein hoher Stellenwert eingeräumt. ${ }^{44}$ Dabei werden einerseits die Herkunftssprachen einbezogen (s. o.), andererseits wird das Französische als Sprache des Nachbarn und wichtigsten Handelspartners ganz besonders hervorgehoben. Für den Vorschulbereich wird als Ziel formuliert:

In den zweisprachigen Kindertageseinrichtungen erreichen die Kinder in der französischen Sprache altersgemäße sprachlich-interkulturelle Kompetenzen im Bereich des Hörverstehens, aber auch des Sprechens, die je nach Länge und Intensität der zweisprachigen Erziehung differieren. ${ }^{45}$

Mittel- bzw. langfristig soll es eine flächendeckende zweisprachige Erziehung und Bildung an allen saarländischen Kindergärten geben:

43 Vgl. Hilt, Oliver: Großer Stimmungstest zur Wahl, in: Forum. Das Wochenmagazin, 25.11.2016, http://www.magazin-forum.de/news/politik/gro\%C3\%9Fer-stimmungstestzur-wahl (18.04.2017).

44 Vgl. Ministerium für Bildung und Kultur Saarland: Sprachenkonzept, S. 17 f.

45 Ministerium für Bildung und Kultur Saarland: Sprachenkonzept, S. 20. 
Langfristig wird angestrebt, dass alle saarländischen Kindertageseinrichtungen auf der Grundlage der Vorgaben des Bildungsprogramms für saarländische Kindergärten das Konzept der zweisprachigen Erziehung und Bildung in ihre Arbeit integrieren. Bei der Ausweitung ist zu beachten, dass eine Fortführung in der Grundschule gewährleistet sein muss und deshalb ein konzertiertes Vorgehen notwendig ist. ${ }^{46}$

Aktuell bieten nach Angaben des Ministeriums für Bildung und Kultur über 190 Kitas eine immersive Vermittlung (d. h. mit mindestens einer Person mit der Muttersprache Französisch unter den pädagogischen Fachkräften) des Französischen an (eine Einrichtung arbeitet auch Englisch-Deutsch). ${ }^{47}$ Das entspricht einer Quote von knapp $40 \%$. Rund $18 \%$ aller bilingualen Einrichtungen in Deutschland befinden sich im Saarland.

Am 22. Januar 2013 wurde eine Qualitätscharta für zweisprachige Kindertagesstätten verabschiedet, die Standards für die Erteilung des Qualitätslabels „Bilinguale Kindertageseinrichtung - Elysée 2020 Kita“ definiert. 40 saarländische Kitas wurden bisher in diesen Kreis aufgenommen (von bundes- und frankreichweit insgesamt 109). ${ }^{48}$

Eine wichtige Rolle besonders für den Bereich der frühkindlichen Bildung spielt auch das Projekt Trilingua ${ }^{49}$. Es handelt sich um eine INTERREG IV A-Maßnahme, die ab dem Schuljahr 2008/09 bis Mitte 2015 durchgeführt wurde. Zentrale Idee ist die Förderung einer Mehrsprachenkompetenz in den Sprachen Deutsch, Französisch und Englisch; Projektpartner sind der Generalrat des Departements Moselle, das Ministerium für Bildung im Saarland, die Schulbehörde der Moselle, die Christliche Erwachsenenbildung e.V., das rheinland-pfälzische Ministerium für Bildung, Wissenschaft, Weiterbildung

46 Ministerium für Bildung und Kultur Saarland: Sprachenkonzept, S. 23. Hier wird einmal mehr deutlich, dass die verschiedenen Abschnitte im Bereich der sprachlichen Bildung ,zusammengedacht' werden müssen, u. a. durchgängige Vermittlung des Französischen ab der frühen Kindheit, Einsatz entsprechender Fachkräfte, besonderer Stellenwert des Französischen in der Grundschullehrerausbildung, flächendeckende Einführung des FranzösischUnterrichts in Grundschulen. Vgl. Staatskanzlei des Saarlandes: Eckpunkte einer Frankreichstrategie, S. 20-23.

47 Die Einführung des Französischen in den frühkindlichen Bereich reicht länger zurück; vgl. dazu Hammes-Di Bernardo, Eva: Zweisprachige Kindergärten im Saarland, Vortrag auf dem Internationalen Kongress Frübkindliche Mehrsprachigkeit, Saarbrücken, 17.-18.09.2007, http://www.fruehkindliche-mehrsprachigkeit.de/referenten/evahammesdibernardo.html (12.04.2017). Vgl. auch Hammes-Di Bernardo, Eva: Zweisprachige Bildung und Betreuung in der Großregion Saar-Lor-Lux: Eine Idee wird zum pädagogischen Konzept, in: Mazurkiewicz-Sokolowska, Jolanta/Westphal, Werner/Gąszczyk, Alicja (Hg.): Mehrsprachigkeit und Spracherwerb in Theorie und Praxis, Hamburg: Kovač, 2012, S. 53-62.

48 Vgl. Ministerium für Bildung und Kultur Saarland: Netzwerk der zweisprachigen Kindergärten „Elysée-Kitas“, 2016c， http://www.saarland.de/SID-427ECC6A-8D58AFEC/ 138921.htm (18.04.2017).

49 Vgl. CEB e.V.: Trilingua, http://www.trilingua.saarland/de (18.04.2017). 
und Kultur und das Ministerium für Integration, Familie, Kinder, Jugend und Frauen, die Aufsichts- und die Dienstleistungsdirektion und das Pädagogische Landesinstitut Rheinland-Pfalz sowie die eingebundenen Gemeinden der drei Regionen. Im Mittelpunkt steht die Fort- und Weiterbildung von Fachkräften, aber auch die Entwicklung von didaktischem Material.

Obwohl das Projekt mittlerweile ausgelaufen ist, bleibt zu hoffen, dass die damit verbundenen Weichenstellungen im Sinne der Frankreichstrategie nachhaltig wirken, wie dies in der Projektbeschreibung auf der Homepage programmatisch zum Ausdruck gebracht wird:

Trilingua legt einen Grundstein für eine dreisprachige Bildung und Erziehung (Französisch, Deutsch, Englisch) in der Grenzregion. Das Projekt ergänzt die umfassenden pädagogischen Angebote zum Erlernen der Sprache des Nachbarn von der Grundschule bis zum jeweiligen nationalen Abitur oder dem deutsch-französischen Abitur sowie im Rahmen der beruflichen Bildung. ${ }^{50}$

Als Zwischenfazit kann damit festgehalten werden, dass im frühkindlichen Bereich offenbar schon seit Längerem daran gearbeitet wird, eine möglichst umfassende Französischorientierung umzusetzen. Die Zahl der Einrichtungen, die das Französische in ihr Konzept integriert haben, ist deutlich angestiegen. Hier kann durchaus von einer guten Grundlage im Sinne der Vision der Frankreichstrategie gesprochen werden. ${ }^{51}$ Dies gilt auch für die durch Trilingua geschaffene Erweiterung um das Englische.

Wie sieht es im Bereich der Grundschule aus? Im Sprachenkonzept wird hierfür folgendes Ziel definiert:

Im Französischunterricht erwerben die Schülerinnen und Schüler eine elementare mündliche Kommunikationsfähigkeit. Am Ende der Klassenstufe 4 sind sie in der Lage, eine Reihe von elementaren Alltagssituationen mit sehr einfachen sprachlichen Mitteln zu bewältigen. ${ }^{52}$

Für Kinder mit Sprachförderbedarf werden verschiedene Förderprogramme angeboten. ${ }^{53}$

50 CEB e.V.: Projektbeschreibung, http://www.trilingua.saarland/de/projektbeschreibung (18.04.2017).

51 Vgl. auch Mohr, Anne: Die Frankreichstrategie des Saarlandes - eine Vision und ihr bildungspolitisches Potenzial, in: Mentz, Olivier/Bühler, Marie-Louise (Hg.): Deutsch-französische Beriebungen im europäischen Kontext. Ein vergleichendes Mosaik aus Scbule und Hochschule, Berlin: LIT-Verlag, 2017, S. 161-192, hier S. 172-174.

52 Ministerium für Bildung und Kultur Saarland: Sprachenkonzept, S. 24.

53 Vgl. Ministerium für Bildung und Kultur Saarland: Sprachenkonæept, S. 24-26. 
Grundlegende Leitlinien für den grundschulischen Französischunterricht sind die Vermittlung einer positiven, von Freude, Aufgeschlossenheit und Motivation geprägten Haltung gegenüber anderen Sprachen allgemein und dem Französischen im Besonderen, außerdem der Vorrang von Mündlichkeit, die Ausprägung kommunikativer Fertigkeiten, eine möglichst immersive Begegnung mit der französischen Sprache und die Förderung interkultureller Kompetenz. ${ }^{54}$ Diese Leitlinien sind sicher ganz im Sinne der Ziele der Frankreichstrategie.

Der schulische Französischunterricht im Saarland beginnt in der Regel ab der dritten Klasse mit zwei Unterrichtsstunden pro Woche. An den Grundschulen, die von 2001 bis 2010 am Schulversuch „Französisch ab Klasse 1“ teilgenommen haben, setzt er ab der ersten Klasse ein, ebenfalls im Umfang von zwei Wochenstunden. An den vier Grundschulen mit bilingualem Zug im Saarland wird neben dem regulären Französischunterricht auch Fachunterricht in französischer Sprache ab Klasse 1 angeboten. Damit erhöht sich die Kontaktzeit hier auf zehn Stunden in der Woche. ${ }^{55}$ Es gibt im Saarland bislang also drei Konstellationen: Französischunterricht ab Klasse 1 in ca. einem Viertel der Schulen (2h/Woche), ab Klasse 3 (ca. drei Viertel der Schulen; $2 \mathrm{~h} /$ Woche) und schließlich bilinguale Züge in vier Grundschulen (10 h/Woche). ${ }^{56}$ Am Ende der Grundschulzeit verfügen die Schülerinnen und Schüler damit über recht heterogene Kompetenzen, was für den Übergang in die weiterführende Schule eine problematische Ausgangssituation schafft.

Diese interne Heterogenität kann nicht im Sinne der im Eckpunktepapier formulierten Vision sein; eine konsequente Ausrichtung an dieser Vision

54 Vgl. Ministerium für Bildung und Kultur Saarland: Bildung baut Brücken - Formation sans frontières, o.J. 2, http://www.saarland.de/36209.htm (18.04.2017). S. auch Kernlehrplan für die Klassenstufen 3 und 4; vgl. Ministerium für Bildung und Kultur: Kernlehrplan Französisch Grundschule. Klassenstufen 3/4, 2011b, http:/ /www.saarland.de/SID-72699ADD63B0B9D4/209624.htm (18.04.2017), S. 4-6. Einen Lehrplan, der das Französischlehren und -lernen ab Klassenstufe 1 erfasst, gibt es noch nicht. Mohr weist zu Recht auf diese für die Umsetzung der im Frankreichstrategie-Eckpunktepapier genannten Ziele zentrale Lücke hin. Vgl. Mohr: Die Frankreichstrategie des Saarlandes, S. 178.

55 In den bilingualen Zügen liegen die Kompetenzerwartungen nach der Grundschulzeit entsprechend höher: „Schülerinnen und Schüler, die einen bilingualen Zug durchlaufen haben, sind in der Lage, auch komplexere altersgemäße Kommunikationssituationen mit sprachlich anspruchsvolleren Mitteln zu bewältigen. Ihre Sprachkompetenz am Ende von Klassenstufe 4 umfasst insbesondere auch sprachliche Mittel zu Themen, Inhalten und Situationen der bilingual unterrichteten Sachfächer" (Ministerium für Bildung und Kultur Saarland: Sprachenkonzept, S. 24).

56 Vgl. auch Kultusministerkonferenz: Bericht „Fremdsprachen in der Grundschule - Sachstand und Konzeptionen 2013“, 2013, https://www.kmk.org/suche.html?tx_kesearch_pi1[sword]= fremdsprachen+in+der+grundschule\&tx_kesearch_pi1 [page]=1\&tx_kesearch_pi1[resetF ilters]=0\&tx_kesearch_pi1[sortByField] =\&tx_kesearch_pi1[sortByDir] $=$ asc (17.05.2017), S. 55-57. 
würde vielmehr die sukzessive Einführung des flächendeckenden Französischunterrichts ab Klassenstufe 1 erwarten lassen. Ebenso wäre die Einrichtung weiterer bilingualer Züge an Grundschulen (insbesondere im Einzugsgebiet von zweisprachigen Kindergärten) ein in mehrfacher Hinsicht wichtiger Schritt: Nicht nur könnten damit die im Frühbereich gelegten Grundlagen des Sprachenlernens ohne Brüche weiter ausgebaut werden; durch die Verbindung von Sprachenlernen und fachlichem Lernen würde darüber hinaus auch im Hinblick auf die kommunikative Kompetenz eine solide Grundlage für die weiterführende Schule gelegt, und nicht zuletzt wäre auch auf motivationaler Ebene ein positiver Effekt zu erwarten.

Darüber hinaus gilt es einen weiteren Aspekt zu bedenken: Auch über den Französischunterricht hinaus ist ein gewisser Bezug zum bzw. eine gewisse Präsenz des französischen Nachbarn im Alltag wichtig. Eine Studie im Schuljahr 2014/15 ermittelte diesbezüglich ein recht ernüchterndes Ergebnis. Auf die Frage an Eltern, deren Kinder an den DELF Prim-Prüfungen teilnehmen, „Spielt Frankreich in Ihrem Alltag eine Rolle?" antworteten $66 \%$ der Befragten mit „Nein“ - und dies, obwohl gleichzeitig $68 \%$ Zustimmung zum Französischen als erster Fremdsprache äußerten. ${ }^{57}$ Diese Diskrepanz führt zu der Frage nach dem Umgang mit der Nähe der Zielsprache und -kultur im Französischunterricht gerade in Grenzregionen, die in jüngerer Zeit wieder in den Fokus gerückt ist. ${ }^{58}$ Eine spezifische Didaktik für Grenzräume, d. h. eine Grenzraumdidaktik zu entwickeln, bleibt aktuell allerdings noch ein Forschungsdesiderat. ${ }^{59}$

Anders als die Zielsetzungen der Frankreichstrategie und die Aussagen im Sprachenkonzept dies erwarten lassen, ist das Französische im Sekundarbereich nicht verpflichtend die erste Fremdsprache im Saarland. Angesichts

57 Vgl. Polzin-Haumann, Claudia/Reissner, Christina: (Sprach-)Grenzen überschreiten. Zur Rolle der Sprache(n) in der Großregion. Traverser les frontières et les langues dans la Grande Région, in: Hamez, Grégory (Hg.): Réalités, perceptions et représentations des frontières de l'Union européenne, im Druck a.

58 Vgl. z. B. Putsche, Julia: Spracheinstellungen von Grundscbülerinnen und Grundschülern in einer Grenzregion: qualitative Untersuchung in zwei paritätisch unterricbteten ersten Klassen mit Zielsprache Französisch, Bern [u. a.]: Lang, 2011; Rohmann, Sabine: Vivre, travailler et apprendre ensemble dans les régions transfrontalières européennes au XXI siècle, in: Raasch, Albert/ Schlemminger, Gerald (Hg.): Régions transfrontalières, langues des voisins et l'Europe, Berlin: Avinus, 2013, S. 57-69. Vgl. bereits Raasch, Albert: Fremdsprachendidaktik für Grenæregionen, Konzepte, Erfabrungen, Anregungen, Saarbrücken: Universität des Saarlandes, 1999.

59 Im Sprachenkonzept wird dieser wichtige Aspekt ebenfalls angesprochen, allerdings unter der Bezeichnung „Nähedidaktik/Grenzdidaktik“. Der Französischunterricht müsse auf „reale Begegnungsmöglichkeiten“ vorbereiten und „zahlreiche reale Kommunikationsgelegenheiten für die Lerner schaff[en]" (Ministerium für Bildung und Kultur Saarland: Sprachenkonzept, S. 72). 
der dezidierten Weichenstellungen für das Französische im Früh- und Primarbereich und im Sinne einer Kontinuität der sprachlichen Bildung wäre ein flächendeckender Beginn mit Französisch in der Sekundarstufe allerdings konsequent; das Englische könnte ab der 6. Klasse als Tertiärsprache ${ }^{60}$ folgen. ${ }^{61}$

Einen neuen Ansatz gibt es im Bereich der Gemeinschaftsschule mit dem sogenannten Sprachkurs. Ab dem Schuljahr 2012/13

[...] lernen alle Schülerinnen und Schüler ab Klassenstufe 5 die beiden Fremdsprachen Französisch und Englisch, eine davon als abschlussrelevante ,erste Fremdsprache', die andere als Sprachkurs zur Vorbereitung auf mündliche Kommunikationssituationen in Alltag und Beruf. Letztere können die Schülerinnen und Schüler als vierstündiges Wahlpflichtfach ab der Klassenstufe 7 auch als die für den Übergang in die gymnasiale Oberstufe bedeutsame ,zweite Fremdsprache“ wählen. ${ }^{62}$

Die Leistungsbewertung im Sprachkurs erfolgt notenfrei; die dort erworbenen Fertigkeiten werden in einem Kompetenztest zertifiziert. ${ }^{63}$ Das Konzept wirft viele Fragen auf, u. a. die der Wahrnehmung des Sprachkurses durch die verschiedenen Akteure. Interessant zu untersuchen wäre ebenso, ob sich durch dieses Format die Akzeptanz der jeweils zweiten Fremdsprache erhöht und inwiefern in Bezug auf das Französische der Sprachkurs sich auf die gewünschte Stärkung des Französischen als Sprache des Nachbarn auswirkt. Eine Studie hierzu liegt bislang noch nicht vor.

Ab dem Schuljahr 2016/17 wurde zusätzlich eine weitere Variante des Sprachkurses geschaffen: Im Rahmen eines Schulversuchs werden an ausgewählten Schulen beide Fremdsprachen in den Klassenstufen 5 und 6 gleichwertig je dreistündig unterrichtet ${ }^{64}$; die Notenfreiheit gilt sowohl für

60 Vgl. Herdina, Philip/Jessner, Ulrike: The dynamics of third language acquisition, in: Cenoz, Jasone/Jessner, Ulrike (Hg.): English in Europe. The acquisition of a third language, Clevedon: Multilingual Matters, 2000, S. 84-98.

61 Sicher würde eine solch klare Entscheidung nicht auf ungeteilte Zustimmung v. a. seitens der Eltern stoßen. Mohr weist auf die starke Kritik der Elternvertretung (allerdings im Gemeinschaftsschulbereich) hin. Vgl. Mohr: Die Frankreichstrategie des Saarlandes, S. 182. Die Diskrepanz zwischen dem kritischen Standpunkt der Landeselternvertretung(en) und den erwähnten positiven Haltungen zum Französisch-Schwerpunkt in der Forum-Umfrage und der DELF Prim-Studie ist nicht von der Hand zu weisen und bliebe zu erklären.

62 Ministerium für Bildung und Kultur Saarland: Zwei-Säulen-Modell: Gymnasium und Gemeinschaftsschule, o.J. 1, http://www.saarland.de/99370.htm (18.04.2017).

63 Vgl. Landesinstitut für Pädagogik und Medien: Beitrag des Sprachkurses zur Bildung an der Gemeinschaftsschule, http://www.lpm.uni-sb.de/typo3/fileadmin/Benutzer/erzgesamtschule/Sprachkurs.pdf (18.04.2017).

64 Vgl. Ministerium für Bildung und Kultur Saarland: Erlass zur Einrichtung eines Schulversuchs zur Erprobung einer abweichenden Gestaltung des Unterrichtsangebotes in den 
Französisch als auch für Englisch. Hier ist deutlich zu erkennen, dass beide Sprachen auf eine Stufe gestellt werden sollen. Diese Variante bietet sich noch stärker als die Grundkonstellation des Sprachkurses für vernetztes Sprachenlernen an, in dem Sprachreflexion und Sprach(lern)bewusstsein eine wichtige Rolle spielen. Auch hier steht allerdings eine wissenschaftliche Untersuchung zum Lehren und Lernen in bzw. mit diesem neuen Format noch aus.

Abschließend soll noch ein kurzer Blick auf einen innovativen Schritt im gymnasialen Bereich geworfen werden. Um der kommunikativen Orientierung stärker als bislang Rechnung zu tragen und die Mündlichkeit im Fremdsprachenunterricht weiter zu stärken, erwog das Ministerium eine Neugestaltung der Abiturprüfungen in den Fächern Französisch und Englisch in Form einer mündlichen Prüfungskomponente. Diese Sprechprüfungen wurden im Oktober 2015 probeweise landeszentral durchgeführt und in einer wissenschaftlichen Begleitung umfassend ausgewertet. ${ }^{65}$ Diese Studie konnte viele aufschlussreiche Ergebnisse zutage fördern und für dieses Format insgesamt ein positives Fazit ziehen. Es zeigte sich, dass alle befragten Akteure einer Einführung der Sprechprüfungen trotz skeptischer Einzelstimmen und punktuell formulierten Nachbesserungsbedarfs generell positiv gegenüberstehen. Die Ergebnisse belegen darüber hinaus den mit diesem Prüfungsformat verbundenen Innovationswert für den Fremdsprachenunterricht.

Natürlich ist es nicht leicht, die Komplexität mündlicher Kommunikationssituationen für zwei Fremdsprachen gleichzeitig in einem standardisierten Prüfungsformat abzubilden und in den schulischen Alltag zu integrieren, auch wenn der Stellenwert von Mündlichkeit im Fremdsprachenunterricht v. a. mit dem Gemeinsamen europä̈schen Referenzrabmen für Sprachen sukzessive zugenommen hat. Eine solche grundlegende Neuorientierung kann nur in einem längeren Zeitraum vollzogen werden. Mit der Entscheidung für diesen Ansatz hat die Landesregierung jedenfalls einen innovativen Schritt unternommen, der einerseits konsequent eine Entwicklungslinie des Fremdsprachenunterrichts weiterführt, andererseits aber gerade im Sinne der Frankreichstrategie und der Zielvorgabe eines „mehrsprachigen Raum[s] deutsch-französischer Prägung "666 auch zum Motor des beschriebenen Wandels werden kann. Es bleibt zu hoffen, dass sich das Format der Sprechprüfungen im Abitur konsolidiert.

Fremdsprachen in den Klassenstufen 5 und 6 an Gemeinschaftsschulen im Saarland, in: Amtsblatt des Saarlandes Teil I, 25.05.2016, 2016a, S. 352-354.

65 Vgl. Ministerium für Bildung und Kultur Saarland: Fremdsprachenabitur im Saarland: Erfolgreiche Erprobung landeszentraler Sprechprüfungen, 2016b, http://www.saarland. de/SID-F78F1D05-3502522A/138723.htm (18.04.2017).

66 Staatskanzlei des Saarlandes: Eckpunkte einer Frankreichstrategie, S. 16. 


\subsection{Transferprozesse und Synergien}

Die Ergebnisse der Umfrage von November $2016^{67}$ unterstreichen, wie wichtig es ist, gerade auch die jüngeren Bevölkerungsschichten von der Relevanz und dem Mehrwert des Französischen bzw. des Französischlernens zu überzeugen. Zugleich wurde deutlich ${ }^{68}$, dass die Sprachenvernetzung stärker als bisher im Fremdsprachenunterricht präsent sein sollte. Gerade in einer zweistündig unterrichteten Sprache z. B. kann es nicht wie bisher vorrangig um sprachliche Mittel in einer Einzelsprache gehen, vielmehr sollten die Lernenden für Ähnlichkeiten (aber auch für starke Kontraste) zwischen den beiden vermittelten Fremdsprachen (und natürlich auch in Bezug auf ihre Erstsprache(n)) sensibilisiert werden, damit sie ein entsprechendes metasprachliches Bewusstsein ${ }^{69}$ entwickeln und - im Sinne der Lernerautonomie - Transferprozesse wagen. Wichtig ist außerdem, Strategien interlingualer Vernetzung zu trainieren. Wie kann der Transfer neuerer Erkenntnisse aus der sprachwissenschaftlichen Forschung ${ }^{70}$ in die Schule unterstützt werden?

Eine wichtige Rolle kommt hier ohne Zweifel der Lehrerbildung zu. An der Universität des Saarlandes werden Französischlehrkräfte für das Gymnasium, die Gemeinschaftsschule, die Berufsschule und seit Wintersemester 2015/16 auch für die Primarstufe ausgebildet. ${ }^{71}$ Das „,Frühe Fremdsprachenlernen Französisch" hat im Lehramtsstudium für die Primarstufe an der Universität des Saarlandes einen besonderen Platz und kann im Rahmen des Wahlpflichtbereiches „Frühes Sprachenlernen und Mehrsprachigkeit“ gewählt werden (neben „Deutsch als Zweitsprache“).72

67 Vgl. Hilt: Großer Stimmungstest, vgl. Kap. 3.

68 Vgl. oben Kap. 3.1.

69 Vgl. Knapp-Potthoff, Annelie: Sprach(lern)bewußtheit im Kontext, in: Fremdsprachen Lehren und Lernen, 26/1997, S. 9-23; Jessner, Ulrike: Zur Rolle des metalinguistischen Bewusstseins in der Mehrsprachigkeitsforschung, in: Hufeisen, Britta/Marx, Nicole (Hg.): Beim Schwedischlernen sind Englisch und Deutsch gan₹, hilfsvoll. Untersuchungen zum multiplen Sprachenlernen, Frankfurt/M. [u. a.]: Lang, 2004, S. 17-32; Morkötter, Steffi: Language Awareness und Mehrsprachigkeit. Eine Studie zu Spracbbewusstheit und Mehrsprachigkeit aus der Sicht von Fremdsprachenlernern und Fremdsprachenlebrern, Frankfurt/M. [u. a.]: Lang, 2005.

70 Vgl. z. B. Burwitz-Melzer, Eva/Königs, Frank G./Krumm, Hans-Jürgen (Hg.): Sprachenbewusstheit im Fremdsprachenunterricht, Tübingen: Narr, 2012.

71 Dieser Studiengang löste den Lehramtsstudiengang für die Primarstufe und die Sekundarstufe I (LPS1) ab; vgl. Universität des Saarlandes: Lernbereiche der Primarstufe, http://www.uni-saarland.de/campus/studium/studienangebot/az/l/primar.html (18.04.2017).

72 Im Hinblick auf die Frankreichstrategie und ihre Vision wäre es sicher von Vorteil, den Anteil des Französischen zu erhöhen. Angesichts der Vielzahl der fachlichen Inhalte gerade im Primarstufenstudium ist dies allerdings nur schwerlich möglich. Mit der Initiative „TriPrimar“ (s.u.) gibt es allerdings einen Ansatz, in dem das Französische bzw. der Aspekt der Mehrsprachigkeit stärker präsent sein dürfte. 
Das Lehrangebot umfasst neben den grundlegenden fachwissenschaftlichen Aspekten des Sprachenlehrens und -lernens auch Aspekte der praktischen Umsetzung und Anwendung im schulischen Alltag. Ein weiterer Schwerpunkt liegt auf dem Bereich der Mehrsprachigkeit, insbesondere der Vermittlung sprachenübergreifender Kompetenzen und dem sprachenvernetzenden Lehren und Lernen auf der Grundlage des Französischen. Die Studierenden werden mit Konzepten vertraut gemacht, mit denen die lebensweltliche Mehrsprachigkeit der Kinder in den schulischen Unterricht einbezogen wird; auch praktische Umsetzungsbeispiele werden erarbeitet. ${ }^{73}$

Dasselbe gilt für die Lehrerausbildung im Sekundarbereich. Im Lehrangebot der Fachrichtung Romanistik an der Universität des Saarlandes sind mittlerweile Lehrveranstaltungen zur europäischen Mehrsprachigkeit und ihrer Vermittlung fest implementiert. In Veranstaltungen im Bereich der Angewandten Sprachwissenschaft können alle Romanistikstudierenden, auch angehende Lehrkräfte für Französisch und Spanisch, das Interkomprehensionskonzept und den interkomprehensiv basierten EuroComRom-Ansatz ${ }^{74}$ kennenlernen. Ein Seminarformat, das speziell für Letztere konzipiert wurde, ist dabei besonders hervorzuheben: die sogenannten Schulprojektseminare. Es handelt sich hierbei um ein Format, bei dem der Wissenstransfer von der Universität in die Gesellschaft, genauer den schulischen Alltag, im Vordergrund steht. Die Lehramtsstudierenden tragen hier ihr zuvor in der Theorie erworbenes Wissen unmittelbar in die Schulpraxis. Auf der Grundlage der Konzepte und Strategien, die sie sich im universitären Unterricht angeeignet und der eigenen Lernerfahrungen mit unbekannten Sprachen, die sie in diesem Kontext gemacht haben, entwickeln die Studierenden eigene Lehr-/ Lerneinheiten zur Mehrsprachigkeit, die gebündelt im Rahmen von mehrtägigen Schulprojekten umgesetzt werden. Die Aktivitäten werden universitär begleitet und abschließend an der Universität reflektiert und analysiert. ${ }^{75}$

73 Vgl. hierzu Fernández Ammann, Eva Maria/Kropp, Amina/Müller-Lancé, Johannes (Hg.): Herkunftsbedingte Mehrsprachigkeit im Unterricht der Romanischen Sprachen, Berlin: Frank \& Timme, 2015; Reissner, Christina: Das Vorwissen im (Fremd)Sprachenunterricht nutzen Beispiele aus der Praxis sprachenübergreifender Schulprojektseminare im Saarland, in: Fernández Ammann/Kropp/Müller-Lancé (Hg.): Herkunftsbedingte Mehrsprachigkeit, S. 207230.

74 Vgl. Reissner, Christina: Europäische Intercomprehension in und zwischen Sprachfamilien, in: Hinrichs, Uwe (Hg.): Handbuch der Eurolinguistik, Leipzig: Harrassowitz, 2010, S. 821-842; Reissner, Christina: Europäische Interkomprehension und ihre institutionelle Verankerung, in: Reissner, Christina (Hg.): Interkomprehension und Mehrsprachigkeit in Europa, Stuttgart: Ibidem, 2011, S. 181-198.

75 Vgl. ausführlich Polzin-Haumann, Claudia/Reissner, Christina: Annäherung an die Fremdheit: Sprachgrenzen überwinden, in: Wowro, Iwona/Jakosz, Mariusz/Kozieł, Renata (Hg.): Sprachliche Dimensionen der Fremdheit und Andersartigkeit, Frankfurt/M. [u. a.]: Lang, im Druck b. 
Damit werden einerseits innovative Elemente in der Lehrerbildung verankert, andererseits neue Ansätze, in denen Sprachbewusstheit und Sprachlernkompetenz im Vordergrund stehen - wie dies auch in den Bildungsstandards für die modernen Fremdsprachen ${ }^{76}$ erstmals explizit festgeschrieben wird in den Schulen erprobt ${ }^{77}$. Die Erfahrungen aus allen schulischen Aktivitäten werden forschend begleitet.

Seit Januar 2016 wird die Kooperation zwischen dem EuroComRomKonzept, in dem der Fokus primär auf der Mehrsprachigkeit im Fremdsprachenbereich liegt, und deutschdidaktischen Ansätzen (v. a. „Fit in Deutsch“) systematisiert; darüber hinaus werden auch die Kontakte zum Bereich DaZ und zur Anglistik verstärkt. Für eine solche Kooperation im Sprachenbereich sprechen die Erkenntnisse aus der Neuro- und der Kognitiven Linguistik, der Psycholinguistik und der Sprachlehr- und Sprachlernforschung: Verschiedene Sprachen werden nicht strikt getrennt ${ }^{78}$; Assoziationsprozesse lassen sich nicht einzelnen Sprachen zuordnen. Die Kooperationen und Aktivitäten finden statt im Cluster „Sprachen und Mehrsprachigkeit“ im saarländischen Verbundprojekt SaLUt (Optimierung der saarländischen Lehrer/-innenausbildung: Förderung des Umgangs mit Heterogenität und Individualisierung im Unterricht) im Rahmen der durch das BMBF geförderten „Qualitätsoffensive Lehrerbildung“. So wurde u. a. ein Lehr-Lern-Atelier eingerichtet, in dem sich auch angehende Lehrkräfte der verschiedenen Fächer austauschen können. ${ }^{79}$

Ein hervorragendes Terrain, um den Mehrwert des Französischen konkret zu erfahren sowie mehrsprachige Lernprozesse gemeinsam zu erleben und zu reflektieren, bietet die Universität der Großregion (UniGr). Dieses Netzwerk, bestehend aus den sechs Universitäten Luxemburg, Lothringen (Standorte Metz und Nancy), Lüttich, Kaiserslautern, Trier und Saarbrücken wurde ab 2008 im Rahmen des INTERREG-Förderprogramms der Europäischen Union aufgebaut und existiert seit 2015 als Verbund, d. h. als feste

76 Vgl. Kultusministerkonferenz: Bildungsstandards für die fortgeführte Fremdsprache (Englisch/Französisch) für die Allgemeine Hochschulreife, Berlin, 2012, https://www.kmk.org/dokumentationund-statistik/beschluesse-und-veroeffentlichungen/bildung-schule/qualitaetssicherungin-schulen.html\#c2365 (18.04.2017).

77 Das Konzept wird auch in der Lehrerfortbildung angeboten. Vgl. Lehrstuhl für Romanische Sprachwissenschaft (Prof. Dr. Claudia Polzin-Haumann): Lehrerfortbildung, http://www.uni-saarland.de/lehrstuhl/polzin-haumann/lehrerfortbildung.html (18.04.2017).

78 Vgl. z. B. Aitchison, Jean: Words in the mind - an introduction to the mental lexicon, Malden/ Mass.: Blackwell, 32003.

79 Vgl. Institut für Sprachen und Mehrsprachigkeit (ISM) an der Universität des Saarlandes: Lehr-Lern-Atelier des ISM, http://lernwerkstatt.saarland/lehr-lern-atelier-des-ism (18.04.2017). Vgl. auch http://ism.uni-saarland.de/ (17.05.2017). 
Struktur mit eigener Rechtsform ${ }^{80}$. Die UniGr arbeitet systematisch an der Schaffung eines grenzüberschreitenden Hochschulraums durch die Förderung der Mobilität von Studierenden, Dozierenden und Doktoranden. Ein erklärtes Ziel ist es dabei, als „Motor der Großregion“ Impulse zu geben und die Studierenden für den grenzüberschreitenden Arbeitsmarkt auszubilden; dabei spielt auch die Mehrsprachigkeit eine zentrale Rolle. ${ }^{81}$

Ein konkretes Beispiel: In einem trinationalen Hauptseminar, das seit dem Sommersemester 2010 regelmäßig angeboten wird, erkunden Studierende der Universität des Saarlandes (Fachrichtung Romanistik/Französisch) sowie der Universitäten Luxemburg und Metz gemeinsam die vielfältigen Facetten der Mehrsprachigkeit und ihre Bedeutung für Individuum und Gesellschaft, insbesondere auch in der Großregion. Dabei arbeiten sie gemeinsam an den drei Standorten in den drei nationalen Kontexten zu ganz unterschiedlichen Themen, z. B. Sprache(n) im Bildungsbereich oder Wirtschaft und Sprache(n) in der Grenz-/Großregion. ${ }^{82}$ Hierin liegt eine der wesentlichen Besonderheiten der Veranstaltung: Die Teilnehmerinnen und Teilnehmer lernen nicht nur über das Thema; sie bewegen sich sozusagen in dem Thema, und zwar sowohl die sprachliche als auch die interkulturelle Ebene betreffend. Sie erfahren, wie auch die Schülerinnen und Schüler in den o. g. Schulprojektseminaren, dass Mehrsprachigkeit mehr als die Summe der Einzelsprachen bedeutet. Auch die gemeinsame Reflexion bestimmter Prozesse ist Teil der Seminararbeit. Für die spätere Berufstätigkeit, sei es als Fremdsprachenlehrkräfte oder Arbeitnehmer auf dem globalen, ggf. großregionalen Arbeitsmarkt, werden hier wichtige Kompetenzen vermittelt; sicher dürfte auch ein Stück „Frankreichkompetenz“ im Sinne des Eckpunktepapiers dabei sein. ${ }^{83}$

80 Für weitere Einzelheiten vgl. Université de la Grande Région/Universität der Großregion: Die UniGR in Zahlen, http://www.uni-gr.eu/de/die-unigr-zahlen/ (18.04.2017).

81 Vgl. Université de la Grande Région/Universität der Großregion: Ziele, http://www.unigr.eu/de/ziele/ (18.04.2017).

82 Vgl. zu verschiedenen Aspekten im Einzelnen Polzin-Haumann, Claudia: Von der Mehrsprachigkeitsforschung zur Ausbildung mehrsprachiger und mehrsprachigkeitsbewusster Akteure: Arbeitsbericht aus einem Pilotprojekt im Rahmen der „Universität der Großregion“, in: Bürgel, Christoph/Siepmann, Dirk (Hg.): Sprachwissenschaft und Fremdsprachendidaktik: Neue Impulse, Baltmannsweiler: Schneider-Verlag Hohengehren, 2013, S. 103-116; Reissner, Christina: Umgang mit Wissen in multilingualen Kontexten: Erfahrungen aus der trinationalen Universitätslehre, in: Muttersprache. Vierteljahresschrift für deutsche Sprache 1-2/ 127 (2017), Themenheft Deutsch als Fremd- und Wissenschaftssprache im Kontext der Mehrsprachigkeit am Beispiel der Grande Région/Großregion, S. 74-82.

83 Vgl. oben, Kap. 2. 


\section{Bilanz und Perspektiven}

Es ist unbestritten, dass die Verkündung der Frankreichstrategie im Januar 2014 auf verschiedenen Ebenen für Dynamik gesorgt hat und weiterhin sorgt. Auf einigen Gebieten werden Prozesse weitergeführt und teils intensiviert, die schon vorher existierten (wie etwa im Bereich der frühkindlichen Begegnung mit Französisch), auf anderen wurden neue Anstöße vermittelt. Die Synergieeffekte beispielsweise mit der Universität der Großregion sind unübersehbar.

Wichtig ist zweifellos, dass auch auf der anderen Seite der Grenze entsprechende Aktivitäten entfaltet werden. Insofern ist die ,Stratégie Allemagne auf Lothringer Seite, bei der u. a. die Stärkung des Deutschen eine wichtige Rolle spielt, sicher ein wichtiger Schritt. ${ }^{84}$ Der nächste Schritt besteht nun darin, aufbauend auf diesen Initiativen zu beiden Seiten der Grenze, die einen geteilten Erfahrungsraum und eine erste Vernetzung erlauben, gemeinsame Strukturen zu schaffen, mit denen die Partner noch enger zusammenwachsen können. Erwähnt sei hier als ein Beispiel der Masterstudiengang „Border Studies“, der von vier Universitäten (Universitäten des Saarlandes, Luxemburg, Lothringen und TU Kaiserslautern) in drei Ländern gemeinsam entwickelt wurde und der zum Wintersemester 2017/18 startet. Dieser zumindest in Europa ohne Zweifel einmalige Studiengang, der ein komplett integriertes grenzüberschreitendes Studium ermöglicht und auf die Ausbildung von GrenzraumexpertInnen u. a. für Wirtschaft, Kultur, Verwaltung und Politik zielt, stellt ein Ergebnis der engen Zusammenarbeit und gemeinsamen Erfahrungen seit 2008 dar und überführt diese nun auf eine neue Ebene. Gestartet wird zunächst mit einem kultur- und sprachwissenschaftlichen sowie einem raumwissenschaftlichen Schwerpunkt, doch sind Erweiterungen nicht ausgeschlossen.

Ein zweites Beispiel sind die Planungen zur Schaffung eines gemeinsamen grenzüberschreitenden Arbeitsmarkts für Lehrkräfte im Primarstufenbereich (,TriPrimar“; Universität des Saarlandes, Universität Luxemburg, Université de Lorraine sowie Institutionen der zweiten Ausbildungsphase in den drei Ländern). Das Ziel ist sicher angesichts der unterschiedlichen Bildungssysteme und Studienstrukturen ein ehrgeiziges, doch wenn man auch im Hinblick auf Lehrkräfte die Mobilität im grenzüberschreitenden Arbeitsmarkt fördern und zukünftige Schülergenerationen an einen gemeinsamen Sprach-, Lebens- und Arbeitsraum heranführen möchte, ist es nur konsequent, an der Vision eines gemeinsamen Ausbildungsgangs konkret zu arbeiten.

$\mathrm{Zu}$ den wichtigen Forschungsdesiderata im Bereich der Angewandten Linguistik bzw. der Sprachlehr-/Sprachlernforschung zählt sicher die sogenannte Grenzraumdidaktik. Seit geraumer Zeit wird die Notwendigkeit

84 Vgl. hierzu den Beitrag von Reiner Marcowitz in diesem Band sowie Polzin-Haumann/ Reissner: (Sprach-)Grenzen überschreiten, vgl. Kap. 3.2.2. 
einer Fremdsprachendidaktik für Grenzregionen betont ${ }^{85}$; der Begriff der ,Grenz(raum)didaktik ${ }^{6}$ taucht in verschiedenen bildungspolitischen Dokumenten auf. Gleichwohl wurde bisher noch kein umfassendes Konzept zum Lehren und Lernen in Grenzregionen ausgearbeitet. Eine kritische Auseinandersetzung mit Fragen des Französischlehrens und -lernens in Grenzregionen (und nicht nur in der SaarLorLux-Region) ist nötig. Was ist spezifisch für Grenzräume allgemein und für den Grenzraum SaarLorLux im Besonderen (z. B. im Vergleich zum Oberrhein)? Wie kann/sollte eine, Grenzraumdidaktik ${ }^{\varsigma}$ gestaltet sein? Gibt es bereits Ansätze zu einem solchen Konzept? Ist ein solches überhaupt nötig?

Das Saarland und der französische Grand Est wollen zur „Modellregion für Mehrsprachigkeit" werden. ${ }^{86}$ Es ist erfreulich, dass hier ein gemeinsames Ziel im Sinne der Frankreichstrategie und der ,Stratégie Allemagne formuliert wird. Der vorliegende Beitrag hat einerseits gezeigt, dass in der saarländischen Bildungspolitik schon einige Weichenstellungen unternommen wurden, um diesem Ziel näher zu kommen, andererseits auch Widersprüche und Desiderata herausgearbeitet. Dass diese existieren, ist angesichts der ambitionierten und langfristig angelegten Zielsetzung nicht weiter ungewöhnlich. Wichtig ist aber, diese Widersprüche und Desiderata konsequent zu bearbeiten und die jeweiligen Akteure (u. a. in der Universität) - auch im Hinblick auf finanzielle Fragen - bestmöglich zu unterstützen. Denn letztlich kann die Umsetzung dieser Vision nur gelingen, wenn die Expertise, auch die kritische Begleitung, in den verschiedenen Bereichen konstruktiv genutzt wird und alle Beteiligten vom Mehrwert der Frankreichstrategie überzeugt sind. ${ }^{87}$

85 Vgl. z. B. Raasch: Fremdsprachendidaktik für Grenæregionen; Raasch, Albert/Schlemminger, Gérald (Hg.): Régions transfrontalières, langues des voisins et l'Europe, Berlin: Avinus, 2013; Raasch, Albert/Wessela, Eva (Hg.): Europäische Nachbarschaftspolitik: Soziale Kobäsion durch Sprache. Dokumentation eines Bilanz- und Impulskolloquiums der Europä̈schen Akademie Otzenhausen, Nonnweiler: Europäische Akademie Otzenhausen, 2008; Putsche: Spracheinstellungen.

86 Lorenz, Udo: „Neuer Schwung für Europa“. Saarland und Grand Est sollen zur Modellregion für Mehrsprachigkeit werden, in: Saarbrücker Zeitung, 12.12.2016, S. B2.

87 Insbesondere sollte in der Bevölkerung dafür geworben werden, dass das Englische, dem vielfach ein hoher Stellenwert beigemessen wird, mit der Frankreichstrategie nicht im Bildungssystem marginalisiert wird; vgl. hierzu Polzin-Haumann, Claudia/Reissner, Christina: Perspectives du français en Sarre: politiques et réalités, in: Cichon, Peter/Ehrhart, Sabine/Stegu, Martin (Hg.): Les politiques linguistiques explicites et implicites en domaine francophone, Berlin: Avinus, 2012, S. 129-143, hier S. 140. 


\section{Literaturverzeichnis}

\section{Wissenschaftliche Literatur}

Aitchison, Jean: Words in the mind - an introduction to the mental lexicon. Malden/Mass.: Blackwell, 32003.

Burwitz-Melzer, Eva/Königs, Frank G./Krumm, Hans-Jürgen (Hg.): Sprachenbewusstheit im Fremdsprachenunterricht, Tübingen: Narr, 2012.

Fernández Ammann, Eva Maria/Kropp, Amina/Müller-Lancé, Johannes (Hg.): Herkunftsbedingte Mehrsprachigkeit im Unterricht der Romanischen Sprachen, Berlin: Frank \& Timme, 2015.

Foucault, Michel: L'Ordre du discours, Paris: Gallimard, 1971.

Hammes-Di Bernardo, Eva: Zweisprachige Kindergärten im Saarland, Vortrag auf dem Internationalen Kongress Frübkindliche Mebrsprachigkeit, Saarbrücken, 17.-18.09.2007, http://www.fruehkindliche-mehrsprachigkeit.de/referenten/evahammesdibernardo.html (12.04.2017).

Hammes-Di Bernardo, Eva: Zweisprachige Bildung und Betreuung in der Großregion Saar-LorLux: Eine Idee wird zum pädagogischen Konzept, in: Mazurkiewicz-Sokolowska, Jolanta/Westphal, Werner/Gąszczyk, Alicja (Hg.): Mehrsprachigkeit und Spracherwerb in Theorie und Praxis, Hamburg: Kovač, 2012, S. 53-62.

Herdina, Philip/Jessner, Ulrike: The dynamics of third language acquisition, in: Cenoz, Jasone/ Jessner, Ulrike (Hg.): English in Europe. The acquisition of a third language, Clevedon: Multilingual Matters, 2000, S. 84-98.

Jessner, Ulrike: Zur Rolle des metalinguistischen Bewusstseins in der Mehrsprachigkeitsforschung, in: Hufeisen, Britta/Marx, Nicole (Hg.): Beim Schwedischlernen sind Englisch und Deutsch ganz. hilfsvoll. Untersuchungen zum multiplen Sprachenlernen, Frankfurt/M. [u. a.]: Lang, 2004, S. 17-32.

Knapp-Potthoff, Annelie: Sprach(lern)bewußtheit im Kontext, in: Fremdsprachen Lehren und Lernen, 26/1997, S. 9-23.

Mohr, Anne: Die Frankreichstrategie des Saarlandes - eine Vision und ihr bildungspolitisches Potenzial, in: Mentz, Olivier/Bühler, Marie-Louise (Hg.): Deutsch-französische Beziebungen im europä̈schen Kontext. Ein vergleichendes Mosaik aus Schule und Hochscbule, Berlin: LIT-Verlag, 2017, S. 161-192.

Morkötter, Steffi: Language Awareness und Mehrsprachigkeit. Eine Studie zu Sprachbewusstheit und Mehrsprachigkeit aus der Sicht von Fremdsprachenlernern und Fremdsprachenlebrern, Frankfurt/M. [u. a.]: Lang, 2005.

Polzin-Haumann, Claudia: Von der Mehrsprachigkeitsforschung zur Ausbildung mehrsprachiger und mehrsprachigkeitsbewusster Akteure: Arbeitsbericht aus einem Pilotprojekt im Rahmen der „Universität der Großregion“, in: Bürgel, Christoph/Siepmann, Dirk (Hg.): Sprachwissenschaft und Fremdsprachendidaktik: Neue Impulse, Baltmannsweiler: Schneider-Verlag Hohengehren, 2013, S. 103-116.

Polzin-Haumann, Claudia/Reissner, Christina: Perspectives du français en Sarre: politiques et réalités, in: Cichon, Peter/Ehrhart, Sabine/Stegu, Martin (Hg.): Les politiques linguistiques explicites et implicites en domaine francophone, Berlin: Avinus, 2012, S. 129-143.

Polzin-Haumann, Claudia/Reissner, Christina: (Sprach-)Grenzen überschreiten. Zur Rolle der Sprache(n) in der Großregion. Traverser les frontières et les langues dans la Grande Région, erscheint in: Hamez, Grégory (Hg.): Réalités, perceptions et représentations des frontières de l'Union européenne, im Druck a. 
Polzin-Haumann, Claudia/Reissner, Christina: Annäherung an die Fremdheit: Sprachgrenzen überwinden, in: Wowro, Iwona/Jakosz, Mariusz/Kozieł, Renata (Hg.): Sprachliche Dimensionen der Fremdheit und Andersartigkeit, Frankfurt/M. [u. a.]: Lang, im Druck b.

Putsche, Julia: Spracheinstellungen von Grundscbülerinnen und Grundscbülern in einer Grenzregion: qualitative Untersuchung in zwei paritätisch unterrichteten ersten Klassen mit Zielsprache Französisch, Bern [u. a.]: Lang, 2011.

Raasch, Albert: Fremdsprachendidaktik, für Grenæregionen, Konzepte, Erfahrungen, Anregungen, Saarbrücken: Universität des Saarlandes, 1999.

Raasch, Albert/Schlemminger, Gérald (Hg.): Régions transfrontalières, langues des voisins et l'Europe, Berlin: Avinus, 2013.

Raasch, Albert/Wessela, Eva (Hg.): Europäische Nachbarschaftspolitik: Soziale Kobäsion durch Sprache. Dokumentation eines Bilanz- und Impulskolloquiums der Europäischen Akademie Otzenhausen, Nonnweiler: Europäische Akademie Otzenhausen, 2008.

Reissner, Christina: Europäische Intercomprehension in und zwischen Sprachfamilien, in: Hinrichs, Uwe (Hg.): Handbuch der Eurolinguistik, Leipzig: Harrassowitz, 2010, S. 821-842.

Reissner, Christina: Europäische Interkomprehension und ihre institutionelle Verankerung, in: Reissner, Christina (Hg.): Interkomprehension und Mehrsprachigkeit in Europa, Stuttgart: Ibidem, 2011, S. 181-198.

Reissner, Christina: Das Vorwissen im (Fremd)Sprachenunterricht nutzen - Beispiele aus der Praxis sprachenübergreifender Schulprojektseminare im Saarland, in: Fernández Ammann/ Kropp/Müller-Lancé (Hg.): Herkunftsbedingte Mebrspracbigkeit, Berlin: Frank \& Timme, 2015, S. 207-230.

Reissner, Christina: Umgang mit Wissen in multilingualen Kontexten: Erfahrungen aus der trinationalen Universitätslehre, in: Muttersprache. Vierteljabresscbrift für deutsche Sprache 1-2/127 (2017), Themenheft Deutsch als Fremd- und Wissenschaftssprache im Kontext der Mehrsprachigkeit am Beispiel der Grande Région/Großregion, S. 74-82 .

Rohmann, Sabine: Vivre, travailler et apprendre ensemble dans les régions transfrontalières européennes au XXIe siècle, in: Raasch, Albert/Schlemminger, Gerald (Hg.): Régions transfrontalières, langues des voisins et l'Europe, Berlin: Avinus, 2013, S. 57-69.

Spitzmüller, Jürgen/Warnke, Ingo: Diskurslinguistik: eine Einfübrung in Theorien und Methoden der transtextuellen Sprachanalyse, Berlin/New York: de Gruyter, 2011.

Wichtige Grundlagentexte und Internetquellen

CEB e.V.: Projektbeschreibung, http://www.trilingua.saarland/de/projektbeschreibung (18.04.2017).

CEB e.V.: Trilingua, http://www.trilingua.saarland/de (18.04.2017).

Crolly, Hannelore: Frankreich-Strategie. Das kleine Saarland wird jetzt zweisprachig, in: Die Welt, 21.01.2014, http://www.welt.de/politik/deutschland/article124090161/Das-kleine-Saarland-wird-jetzt-zweisprachig.html (16.05.2017).

Europäische Kommission: Weißbuch zur allgemeinen und beruflichen Bildung: Lebren und Lernen. Auf dem Weg zur kognitiven Gesellschaft. KOM (1995) 590 vom 29.11.1995, Strasbourg, 1995, http: //europa.eu/documents/comm/white_papers/pdf/com95_590_de.pdf (12.04.2017).

Europäische Kommission: DIE EUROPÄISCHEN BÜRGER UND IHRE SPRACHEN. Spezial Eurobarometer 386, 2012, http://ec.europa.eu/public_opinion/archives/ebs/ ebs_386_de.pdf (18.04.2017).

Europarat: Entschließung des Rates vom 16. Dezember 1997 über die frühzeitige Vermittlung der Sprachen der Europäischen Union [Amtsblatt C 1 vom 03.01.1998], 1997, http:// 
europa.eu/legislation_summaries/education_training_youth/lifelong_learning/c11042_de.h tm (18.04.2017).

Europarat: Gemeinsamer europäischer Referenzrabmen für Sprachen: Lernen, lehren, beurteilen, 2001, deutsche Version http://www.goethe.de/z/50/commeuro/deindex.htm (12.04.2017).

Europarat: Referenzrabmen für plurale Ansätze (REPA)/Cadre de Référence pour les approches plurielles (CARAP), 2004ff., http:// carap.ecml.at/ (18.04.2017).

Hilt, Oliver: Großer Stimmungstest zur Wahl, in: Forum. Das Wochenmagazin, 25.11.2016, http://www.magazin-forum.de/news/politik/gro\%C3\%9Fer-stimmungstest-zur-wahl (18.04.2017).

Hochrangige Gruppe Mehrsprachigkeit: Empfehlungen für das Sprachenlernen, 2007, kurze Zusammenfassung auf Deutsch, http://europa.eu/rapid/pressReleasesAction.do?reference $=\mathrm{IP} / 07 / 1396 \&$ format $=$ HTML\&aged $=0 \&$ language $=$ DE\&guiLanguage $=$ en $)(12.04 .2017)$.

Holl, Thomas: Frankreichstrategie. Das Saarland soll mehrsprachig werden, in: Frankfurter Allgemeine Zeitung, 21.01.2014, http://www.faz.net/aktuell/politik/inland/frankreich-strategie -das-saarland-soll-zweisprachig-werden-12762333.html (16.05.2017).

Holl, Thomas: Das Saarland will zweisprachig werden, in: Frankfurter Allgemeine Zeitung, 22.01.2014, https://fazarchiv.faz.net/fazDocument/saveSingleDoc/FAZ_FD2201401224167145 (16.05.2017).

Institut für Sprachen und Mehrsprachigkeit (ISM) an der Universität des Saarlandes: http:// ism.uni-saarland.de/ (17.05.2017).

Institut für Sprachen und Mehrsprachigkeit (ISM) an der Universität des Saarlandes: Lehr-LernAtelier des ISM, http://lernwerkstatt.saarland/lehr-lern-atelier-des-ism (18.04.2017).

Kommission der europäischen Gemeinschaften: MITTEILUNG DER KOMMISSION AN DEN RAT, DAS EUROPÄISCHE PARLAMENT, DEN WIRTSCHAFTS- UND SOZIALAUSSCHUSS UND DEN AUSSCHUSS DER REGIONEN. Förderung des Sprachenlernens und der Sprachenvielfalt: Aktionsplan 2004-2006, 2003, http://eur-lex. europa.eu/legal-content/DE/ALL/?uri=CELEX:52003DC0449 (12.04.2017).

Kommission der europäischen Gemeinschaften: Mitteilung der Kommission an das Europäische Parlament, den Rat, den Europäischen Wirtschafts- und Sozialausschuss und den Ausschuss der Regionen - Mehrsprachigkeit: Trumpfkarte Europas, aber auch gemeinsame Verpflichtung, KOM(2008) 566 endgültig vom 18.09.2008, 2008, http://eurlex.europa.eu/legal-content/DE/TXT/?uri=URISERV\%3Aef0003 (18.04.2017).

Kultusministerkonferenz: Bildungsstandards für die fortgefübrte Fremdsprache (Englisch/Franæösisch) für die Allgemeine Hochschulreife, Berlin, 2012, https://www.kmk.org/dokumentation-undstatistik/beschluesse-und-veroeffentlichungen/bildung-schule/qualitaetssicherungin-schulen.html\#c2365 (18.04.2017).

Kultusministerkonferenz: Bericht „Fremdsprachen in der Grundschule - Sachstand und Konzeptionen 2013“, 2013, https://www.kmk.org/suche.html?tx_kesearch_pi1[sword]=fremdsprachen+in+der +grundschule\&tx_kesearch_pi1[page] $=1 \&$ tx_kesearch_pi1[resetFilters]=0\&tx_kesearch_pi $1[$ sortByField] $=\&$ tx_kesearch_pi1[sortByDir] =asc (17.05.2017).

Landesinstitut für Pädagogik und Medien: Beitrag des Sprachkurses zur Bildung an der Gemeinschaftsschule, http://www.lpm.uni-sb.de/typo3/fileadmin/Benutzer/erz-gesamtschule/ Sprachkurs.pdf (18.04.2017).

Landesregierung des Saarlandes: Fenille de route Frankreich-Strategie 2015/2016, 2015, http:// www.saarland.de/dokumente/ressort_finanzen/Feuille_de_route.pdf (12.04.2017).

Landesregierung des Saarlandes: Frankreichstrategie Feuille de route II 2017/2019, 2016, http:// www.saarland.de/dokumente/thema_europa/2016-10-17_Feuille_de_route_2017-2019. $\operatorname{pdf}(09.05 .2017)$. 
Lehrstuhl für Romanische Sprachwissenschaft (Prof. Dr. Claudia Polzin-Haumann): Lehrerfortbildung, http://www.uni-saarland.de/lehrstuhl/polzin-haumann/lehrerfortbildung.html (18.04.2017).

Lemaitre, Frédéric: Allemagne: quand la Sarre se voit francophone en 2043, in: Le Monde, 21.02.2014, http://www.lemonde.fr/le-magazine/article/2014/02/21/dans-la-sarre-lefrancais-ca-sert_4370289_1616923.html (16.05.2017).

Lorenz, Udo: „Neuer Schwung für Europa“. Saarland und Grand Est sollen zur Modellregion für Mehrsprachigkeit werden, in: Saarbrücker Zeitung, 12.12.2016, S. B2.

Madelin, Thibaut: La Sarre veut devenir un Land bilingue. [...] En 2043, tous les Sarrois devront parler le français, in : Les Echos, 28.01.2014, http://www.lesechos.fr/economie-poitique/ regions/lorraine/0203271889015-la-sarre--veut-devenir-un-land-bilingue-646034.php (16.05.2017).

Ministerium für Bildung und Kultur Saarland: Zwei-Säulen-Modell: Gymnasium und Gemeinschaftsschule, o.J. 1, http://www.saarland.de/99370.htm (18.04.2017).

Ministerium für Bildung und Kultur Saarland: Bildung baut Brücken - Formation sans frontières, o.J. 2, http://www.saarland.de/36209.htm (18.04.2017).

Ministerium für Bildung und Kultur Saarland: Spracbenkonzept Saarland 2011, 2011a, http:// www.saarland.de/dokumente/res_bildung/Das_Sprachkonzept_Saarland_2011.pdf (12.04.2017).

Ministerium für Bildung und Kultur Saarland: Kernlehrplan Französisch Grundscbule. Klassenstufen 3/4, 2011b, http://www.saarland.de/SID-72699ADD-63B0B9D4/209624.htm (18.04.2017).

Ministerium für Bildung und Kultur Saarland: Erlass zur Einrichtung eines Schulversuchs zur Erprobung einer abweichenden Gestaltung des Unterrichtsangebotes in den Fremdsprachen in den Klassenstufen 5 und 6 an Gemeinschaftsschulen im Saarland, in: Amtsblatt des Saarlandes Teil I, 25.05.2016, 2016a, S. 352-354.

Ministerium für Bildung und Kultur Saarland: Fremdsprachenabitur im Saarland: Erfolgreiche Erprobung landeszentraler Sprechprüfungen, 2016b, http://www.saarland.de/SIDF78F1D05-3502522A/138723.htm (18.04.2017).

Ministerium für Bildung und Kultur Saarland: Netzwerk der zweisprachigen Kindergärten „Elysée-Kitas“, 2016c, http://www.saarland.de/SID-427ECC6A-8D58AFEC/138921. htm (18.04.2017).

O.A.: La Sarre veut faire du français sa seconde langue, in: L'Essentiel, 21.01.2014, http://www. lessentiel.lu/fr/news/grande_region/story/22026394 (16.05.2017).

Staatskanzlei des Saarlandes: Eckpunkte einer Frankreichstrategie für das Saarland, 2014, http:// www.saarland.de/dokumente/res_stk/D_Eckpunkte_Frankreich-Strategie_210114.pdf (12.04.2017).

Statistisches Bundesamt: Scbulen auf einen Blick. Ausgabe 2014, Wiesbaden, 2014, https:// www.destatis.de/DE/Publikationen/Thematisch/BildungForschungKultur/AlteAusgab en/SchulenBlickAlt.html (18.04.2017).

Statistisches Bundesamt: Scbulen auf einen Blick. Ausgabe 2016, Wiesbaden, 2016, https:// www.destatis.de/DE/Publikationen/Thematisch/BildungForschungKultur/Schulen/Br oschuereSchulenBlick.html (18.04.2017).

Universität des Saarlandes: Lernbereiche der Primarstufe, http://www.uni-saarland.de/ campus/studium/studienangebot/az/l/primar.html (18.04.2017).

Université de la Grande Région/Universität der Großregion: Die UniGR in Zahlen, http:// www.uni-gr.eu/de/die-unigr-zahlen/ (18.04.2017).

Université de la Grande Région/Universität der Großregion: Ziele, http://www.uni-gr.eu/ de/ziele/ (18.04.2017). 



\title{
Die Germanistik als neuer Weg nach Frankreich: Von der ,Nationalphilologie' zu einer interkulturellen Studienpraxis und ihren Potenzialen als Tor nach Frankreich und Brücke zu Deutschland ${ }^{1}$
}

\begin{abstract}
L'bistoire de la philologie allemande est étroitement liée à la France - et ce, tout d'abord, de manière négative. Ces débuts en tant que matière universitaire se déroulent dans le contexte d'une construction identitaire nationale, c'est-à-dire pendant l'époque napoléonienne alors qu'il n'était pas encore question de l'Allemagne comme état. Les prémisses discutables de cette matière fondée sur le concept d'une philologie nationale se font ressentir jusque dans le présent. Dans la zone frontalière germano-francophone, la philologie allemande est cependant renouvelée : elle se conçoit dorénavant par-delà les frontières. L'étude de la civilisation germanophone, qui ne se limite pas seulement au territoire national allemand, devient alors le point de départ d'un apprentissage interculturel qui s'opère dans des groupes d'étudiants provenant de différentes universités en coopération de chaque côté de la frontière. Pour les étudiants sarrois, une chance particulière s'offre à eux avec la 'Stratégie France' : les études d'allemand permettent ainsi d'acquérir parallèlement une compétence sur la France.
\end{abstract}

Warum sollte man im Rahmen einer Ringvorlesung zur Frankreichstrategie über die Germanistik reden? Wenn man neben Politik, Wirtschaft und Jura an Philologien denkt, dann doch eher an die Romanistik. Dass allerdings im Saarland die Germanistik sehr viel mit der Frankreichstrategie zu tun hat, hängt direkt mit der jüngeren Geschichte des Landes zusammen. Aufgrund dieser Geschichte gibt es mit der Frankophonen Germanistik innerhalb des Fachs eine in Deutschland einzigartige Konstellation, die Einiges von der besonderen Situation der Region verrät und davon, warum ein so gewagtes Zukunftsprojekt wie die Frankreichstrategie hier tatsächlich funktionieren könnte. Zunächst erfolgt ein Blick zurück auf (1) die Fachgeschichte und auf (2) die historische Entwicklung der Frankophonen Germanistik in Saarbrücken, bevor es (3) um ihre heutige Rolle für die Frankreichstrategie sowie (4) um Zukunftsperspektiven gehen wird.

1 Vgl. Staatskanzlei des Saarlandes: Eckpunkte einer Frankreichstrategie für das Saarland, 2014, http://www.saarland.de/dokumente/res_stk/D_Eckpunkte_Frankreich-Strategie_210114. pdf (23.08.2016), hier S. 1. Der vorliegende Beitrag baut auf dem folgenden Artikel auf: Weiershausen, Romana: „Frankophone Germanistik“ in Saarbrücken: Chancen für die Germanistik im deutsch-französischen Grenzraum, in: Romanische Studien 1 (2015), S. 267280. 


\section{Anfänge des Fachs: Kultur als deutsche Identitätspolitik}

In Deutschland ist Germanistik ein Fach, in dem es um die erklärte, eigene Kultur' geht, das also wie kein anderes Fach mit Prozessen nationaler Selbstverortung verbunden ist. Germanistik als Weg nach Frankreich? Aus historischer Perspektive ist das geradezu paradox. Denn der Weg führte zunächst einmal in die andere Richtung, weg von Frankreich. Die Phase, in der das Fach im Verlauf des 19. Jahrhunderts mit Lehrstühlen an Universitäten institutionalisiert wurde, begann in einer Zeit des direkten Konflikts mit Frankreich, nämlich in der Zeit der napoleonischen Fremdherrschaft.

Es ist eine in der Forschung bekannte These, dass die ,Einheit' einer Nation immer erst diskursiv (über Reden, Erzählungen, sprachliche Tradierungen) erzeugt werde und nicht umgekehrt - was Homi K. Bhabha mit Eric Hobsbawm auf die bündige Formel „narration of the nation“2 gebracht hat. Im Fall Deutschlands, das lange keine Nation im staatsrechtlichen Sinne war, gilt dies verstärkt. An der „narration of the nation“ hat die Wissenschaft ihren Anteil, speziell wenn ihr Gegenstand die ,nationale“ Kultur ist.

Fragt man nach den wesentlichen Faktoren, die dazu führten, dass man an deutschen Universitäten das Fach Germanistik einrichtete, so lässt sich keine eindeutige Antwort geben. Es ist ein „Bündel von Faktoren“, wie Uwe Meves betont: Die politisch gewollte Beförderung eines ,Deutschtums' gehört dazu, aber auch ein rein funktionaler Zusammenhang, nämlich der offizielle Auftrag der Lehrerbildung. ${ }^{3}$ Bei aller Vielschichtigkeit bleibt festzuhalten, dass in der Gründungsphase der Disziplin das Bemühen um eine Kulturnation, wo man über keine staatliche Nation verfügte, einen bedeutsamen Hintergrund bildete. Im Fortgang des 19. Jahrhunderts, das insgesamt für die moderne Wissenschaftslandschaft prägend wirkte, erhielt auch die deutsche Philologie ihren Zuschnitt als Nationalphilologie - und dies durchaus mit kulturpolitischer Dimension. Bei Literarhistorikern des 19. Jahrhunderts konstatiert Gisela Brinker-Gabler in ihrem Überblick eine „Modellhaftigkeit hinsichtlich spezifischer deutscher Bildung und Sprache", die es erlaubt habe, „sowohl eine Abgrenzung nach außen, gegenüber den anderen Nationen“" zu vollziehen, als auch „nach innen, und zwar als [...] Verpflichtung auf eine

2 Bhabha, Homi K.: DissemiNation: Zeit, Narrative und die Ränder der modernen Nation, in: ders.: Die Verortung der Kultur, Tübingen: Stauffenburg, 2000, S. 149-194, hier S. 150.

3 Meves, Uwe: Die Institutionalisierung der Germanistik als akademisches Fach an den Universitätsneugründungen in Preußen, in: ders.: Ausgewäblte Beiträge zur Geschichte der Germanistik und des Deutscbunterrichts im 19. und 20. Jabrbundert, Hildesheim: Weidmann, 2004, S. 335368, hier S. 335. 
homogene Kultur angesichts einer heterogenen politischen und kulturellen Landschaft." “4

Grundsätzlich besteht die Gefahr einer Ideologisierung. Wie leicht sich das Fach im Dritten Reich im Sinne einer nationalistisch und rassistisch geprägten ,Deutschkunde' hatte funktionalisieren lassen, ist bekannt. In der Nachkriegszeit erwuchs daraus eine große Herausforderung für die Germanistik. Man erkannte die Notwendigkeit einer permanent selbstkritischen Auseinandersetzung mit dem eigenen Umgang mit Literatur. Insbesondere wurde offenkundig, wie eng Literatur und deren Wissenschaft mit gesamtgesellschaftlichen Prozessen zusammengehören. Für den Konnex von Nation und Bildung, und damit soll der Blick auf die lokale Situation gelenkt werden, stand unsere Grenzregion von jeher in einem besonderen Brennpunkt.

\section{Gründung der Universität im Saarland und die Vision einer französischen Germanistik}

Die Konstellation einer Germanistik an der deutsch-französischen Grenze evoziert die ganze Bandbreite in den Beziehungen der beiden Länder. Der historische Antagonismus war im Fall einer Region, auf die sowohl Frankreich als auch Deutschland Anspruch erhoben, zusätzlich brisant: Das Elsass, Lothringen und das Saarland spielten schließlich hinsichtlich ihrer nationalen Zugehörigkeit eine besondere Rolle in der jüngeren konfliktreichen Geschichte, die im Krieg von 1870/71, im Ersten und im Zweiten Weltkrieg kulminierte. Angesichts der katastrophischen Beziehung zwischen Deutschland und Frankreich war die Universitätsgründung im Saarland ein Akt, dessen symbolische Bedeutung gar nicht überschätzt werden kann. In der Grenzregion wurde begründet, was der Schriftsteller Ernst Stadler einst für sein Elsass imaginiert hatte - kurz vor Ausbruch des Ersten Weltkriegs, der alle Träume zunichtemachte - eine

freie Universität [...] und so weiter, kurz: Straßburg als kulturelles Zentrum unter Heranziehung französischer und deutscher Kapazitäten [...]. Das ist alles etwas phantastisch und vag, aber es scheint mir wirklich, als wäre der Augenblick nahe, wo hier etwas zu machen ist. $^{5}$

4 Brinker-Gabler, Gisela: Vom nationalen Kanon zur postnationalen Konstellation, in: Heydebrand, Renate von: Kanon - Macht - Kultur: Theoretische, historische und soziale Aspekte ästhetischer Kanonbildungen, Stuttgart [u. a.]: Metzler, 1998, S. 78-96, hier S. 82.

5 Ernst Stadler, Brief an René Schickele im Juli 1914. Abgedruckt bei Schickele, René: Das ewige Elsass, in: ders.: Werke in drei Bänden. Bd. 3, Köln/Berlin: Kiepenheuer \& Witsch, 1959, S. 589-620, hier S. 604 f. 
Zwei Kriege später wurde nun in Saarbrücken die einstige Kaserne zum Ort der Bildung umgewandelt und einem europäischen Ideal geweiht. ${ }^{6}$ Die Europa-Orientierung, die heute neben Nanotechnologie und Informatik eine der drei Hauptsäulen der Universität des Saarlands ist und die vom Votum des Wissenschaftsrates Anfang 2014 neu eingefordert wurde, geht in ihren Anfängen auf die direkte Nachkriegszeit zurück; auf eine Zeit, als gegenseitige Vereinnahmungen versucht wurden, aber auch der Wunsch entstand, nach der Vergangenheit nationalistischer Antagonismen eine gemeinsame Zukunft in der Mitte Westeuropas aufzubauen. Als 1950, wenige Jahre nach der Gründung, der französische Germanist Joseph-François Angelloz das Rektorenamt antrat, bekräftigte er die europäische Idee: „Wir wollen auch vor allem aus Saarbrücken einen europäischen Kreuzweg machen. Unsere Universität $[\ldots]$ wird eine geistige Tauschstelle werden [...] ${ }^{\text {" }}{ }^{7}$ Ein deutsch-französischer Ansatz für einen ,europäischen Kreuzweg" - das klingt ganz ähnlich wie die in der Frankreichstrategie anvisierte „Brücke zwischen Deutschland und Frankreich" 8 mit internationaler Vernetzung. Und doch gibt es maßgebliche Akzentverschiebungen.

Zunächst einmal muss für die Gründungsphase der Universität in der unmittelbaren Nachkriegszeit die Wortwahl präzisiert werden, denn deutschfranzösisch war der Ansatz eigentlich ja nicht, sondern saarländisch-französisch. Das ist ein erheblicher Unterschied - zumal in der Zeit direkt nach dem Zweiten Weltkrieg. Dass ein strategisches Interesse ein Faktor war, nämlich das Saarland, dessen Zugehörigkeit noch nicht entschieden war, stärker an Frankreich zu binden, ist dabei nicht von der Hand zu weisen. Hierbei maß man der Kultur eine wichtige Bedeutung bei. Im Oktober 1946 fand ein vom Gouverneur Gilbert Grandval in Saarbrücken einberufenes Treffen mit Vertretern höherer französischer Bildungsinstitutionen statt, wo man die Möglichkeiten einer Annäherung des Saarlandes an Frankreich über eine kulturelle Annäherung erörterte. Hintergrund und Ausprägung dessen lassen sich bei Hélène Viot nachlesen, die 2014 eine Masterabschlussarbeit zur Entwicklung

6 Wolfgang Müller, dem Leiter des Universitätsarchivs, ist die Aufbereitung der Quellen zur Universitätsgründung zu verdanken. Sie bescheinigen den europäischen Leitgedanken.

7 Alken, Carl-Erich/Angelloz, Joseph-François: Europä̈sche Universität des Saarlandes - Université européenne de la Sarre, Saarbrücken: Presse-Verlag, 1950, hier S. 16. Vgl. dazu Müller, Wolfgang: „Eine Pflegestätte des Geistes, der die Enge zu überwinden sucht und nach europäischer Weite strebt" - Impressionen zur Geschichte der Universität des Saarlandes, in: Kuhn, Bärbel/Pitz, Martina/Schorr, Andreas (Hg.): ,Grenzen' obne Fächergrenzen. Interdisziplinäre Annäherungen, St. Ingbert: Röhrig, 2007, S. 265-302, hier S. 271.

8 Staatskanzlei des Saarlandes: Eckpunkte einer Frankreichstrategie, S. 1. 
der französischen Abteilung der Germanistik 1948-1970 verfasst hat. ${ }^{9}$ Als zentrales Dokument einer vereinnahmenden ,pénétration culturelle“ ist, wie Wolfgang Müller konstatiert, bereits die Aussage des Gouverneurs Grandval bei einem frühen Festakt für das Homburger Institut im März 1947 gewertet worden:

Durch diese Initiative soll das seit einem Jahrhundert von Preußen kolonisierte Saarland
wieder in die Lage versetzt werden, eine geistige Elite hervorzubringen, die seiner würdig
und die unentbehrlich ist für materiellen und geistigen Wiederaufstieg in einem wahrhaft
demokratischen Geiste. In Übereinstimmung mit dem Hauptziel unserer gemeinsamen
Politik werden schließlich hierdurch engere kulturelle Bande zwischen Frankreich und dem
Saarland geschaffen, gemäß den geschichtlichen und geographischen Gegebenheiten. ${ }^{10}$

Es ist aber auch etwas anderes in dem Zitat zu lesen: das tiefe Misstrauen gegen einen deutschen Staat, mit dem man die schlimmsten Erfahrungen gemacht hatte, und die Sonderrolle, die man dem Saarland zutraute. Das Saarland war also schon damals eine ,Brücke‘ auf einem längeren Weg nach Deutschland.

Für die saarländischen Studierenden sollte mit den Studienmöglichkeiten zunächst ein ,Tor nach Frankreich' geschaffen werden - und dies ganz praktisch, denn die französischen Hochschullehrer, die in der ersten Phase dominierten, unterrichteten die französischen Methoden, sodass eine Fortsetzung der Studien in Frankreich nahelag. Um den Standort zu stärken, begann man etwas später, auch die andere Richtung zu fördern, nämlich mehr Franzosen ins Saarland zu ziehen. In diesem Zusammenhang wurde erkannt, dass eine grenznahe und an Frankreich angebundene Universität in deutschsprachiger Umgebung für französische Studierende der deutschen Philologie besonders attraktiv sein könnte. Dies ist der Hintergrund, warum die Germanistik in der zunächst an Frankreich orientierten Hochschulpolitik eine Vorreiterrolle zugesprochen bekam. Im Vergleich zu anderen grenznahen GermanistikInstituten, die sich in jüngerer Zeit um eine europäische Kontextualisierung des Fachs verdient machen (mit Frankreichnähe z. B. Freiburg, Trier u. a.), ist dies im Fall der Saarbrücker Germanistik integral mit ihrer Geschichte verknüpft.

Bei den wenigen, ausgesuchten ,frankophonen Lehrstühlen', die als Zeichen einer wechselseitigen Öffnung an der Universität eingerichtet und mit

9 Viot, Hélène: La Section française de germanistique de l'université de la Sarre. Naissance et institutionnalisation (1948-1970). Masterarbeit, eingereicht im Juli 2014 an der École Normale Supérieure de Lyon. Online verfügbar: http://saardok.sulb.uni-saarland.de/archive/frei/ bsz452202493/0/seconde_version_m_moire_m2_h._viot.pdf (23.08.2016).

10 Aus einem Brief von Grandval an den Vorsitzenden der Verwaltungskommission Erwin Müller, veröffentlicht in der Saarbrücker Zeitung vom 06.03.1947, zit. n. Müller: Eine Pflegestätte des Geistes, S. 268. 
dem Recht ausgestattet wurden, französische Abschlüsse zu vergeben, bedachte man auch die Germanistik. ${ }^{11}$

Und heute? Ursprünglich eine ,Germanistik für Frankophone', die sich im Sinne einer Fremdsprachengermanistik an französische Studierende richtete, haben sich die Bedürfnisse nach der Bologna-Reform gewandelt. Wir tragen dem Rechnung, indem wir heute als Frankophone Germanistik eine grenzüberschreitende Germanistik in der deutsch- und französischsprachigen Grenzregion betreiben. Inhaltlich deckt sie ansonsten die gesamte deutschsprachige Literaturgeschichte vom 17. Jahrhundert bis heute ab. Aufgrund ihrer Kooperationen mit den französischsprachigen Nachbarländern ist die Frankophone Germanistik in Angelegenheiten der Frankreichstrategie natürlich besonders angesprochen.

\section{Frankreichstrategie in der Germanistik}

Im Bereich der Forschung kann man zunächst einmal feststellen: Die Saarbrücker Germanistik allgemein trägt zur Frankreichstrategie bei und hat dies schon getan, bevor dieselbe ausgerufen wurde. Als Beispiele seien nur einige Projekte der Kolleginnen und Kollegen genannt, die einen dezidierten Frankreichbezug haben: etwa zu der aus Lothringen stammenden und Mitte des 15. Jahrhunderts verstorbenen Gräfin Elisabeth von Nassau-Saarbrücken, zu den Siedlungs- und Flurnamen in den Regionen Lothringen und Saarland und zu Theorien und Methoden der Literatur- und Kulturbeziehungen aus deutsch-französischer Perspektive. ${ }^{12} \mathrm{Im}$ Folgenden werde ich hinsichtlich der Frage nach der Frankreichstrategie einen Schwerpunkt auf die Lehre legen, weil dies einen direkten und strukturellen Praxisbezug hat. Hier liegt natürlich ein Kerngeschäft der Frankophonen Germanistik.

In diesem Zusammenhang sind einige grundsätzliche Vorbemerkungen angebracht und deshalb soll noch einmal auf die Vergangenheit zurückgekommen werden. Die lange Ausschweifung in die Universitätsgeschichte hatte zwei Beweggründe. Es ging mir natürlich um den europäischen Geist, der in einer höchst unwahrscheinlichen Situation entstand und Beeindruckendes bewirkt hat. Es ging mir aber auch um einen Aspekt, aus dem man für die

11 Die Frankophone Germanistik, die zusammen mit drei frankophonen Lehrstühlen in anderen Fächern bis heute Bestand hat, ist in dieser Reihe besonders, weil sie die einzige ist, die sich nicht auf frankreichspezifische Gegenstände richtet. Die anderen Professuren liegen in der Rechtswissenschaft (Französisches Öffentliches Recht, Französisches Zivilrecht) und in der frankophonen Romanistik (Französische Literatur im europäischen Kontext).

12 Für eine Übersicht über weitere Projekte der Fachrichtung Germanistik der Universität des Saarlandes: http://www.uni-saarland.de/fachrichtung/germanistik/frankreichstrategie.html (23.08.2016). 
Frankreichstrategie lernen kann. Denn in der Anfangszeit, als nach dem Institut in Homburg eine eigenständige Universität gegründet wurde und sich für diese Universität die Leitvorgaben zwischen französischer und deutscher Studienpraxis entwickelten und wandelten, zeigte sich, dass eine politische Idee und ein von oben oktroyiertes Angebot allein nicht reichten. Die saarländischen Studierenden ließen sich nicht nach Frankreich lotsen, nur weil sie nach französischem Modell unterrichtet wurden. Erst mit der Öffnung wechselseitiger Möglichkeiten entstand das viel gerühmte ,internationale Flair ${ }^{\varsigma}$ auf dem Campus, und die europäische Vision begann, gelebte Wirklichkeit zu werden.

Ich glaube, es reicht nicht aus, wenn man einseitig auf die Sprache setzt und auf die frühkindliche und grundschulbezogene Erziehung. Natürlich ist das wichtig, es schafft Voraussetzungen. Aber ein Sprachvermögen allein bewirkt noch keine interkulturelle Praxis. Man lernt eine Sprache anders, wenn man weiß, warum. Dieses Warum ist ein ganz persönliches, eines, das aus dem eigenen Leben heraus entsteht. Und man muss die Motivation auch bei den Erwachsenen erhöhen oder gar erst erzeugen, v. a. auch bei denen, die auf der Schwelle stehen, Entscheidungsträger zu werden.

Man kennt die Vorbehalte, die nicht zuletzt von besorgten Eltern angesichts befürchteter zwangsverordneter französischer Kindergärten und einer neuen Dominanz des Französischen an den Schulen geäußert werden: die Angst, die sprachpolitischen Maßnahmen ,überforderten vor allem Schüler/-innen“, und den Vorwurf, „die ausschließliche Orientierung an Frankreich und der französischen Sprache [sei darüber hinaus] nicht zeitgemäß“, um aus der Ankündigung zu dieser Ringvorlesung zu zitieren. ${ }^{13}$ Diese Debatte ist sehr verständlich: Das Programm wird als Zumutung empfunden, wenn es sich nicht sinnvoll mit persönlichen Lebensperspektiven verbindet. Das Eckpunktepapier der Landesregierung zur Frankreichstrategie formuliert eine diesbezüglich entscheidende Einsicht: „Vor allem braucht die Frankreichstrategie eine starke Vision, um eine breite Unterstützung im Land und darüber hinaus zu mobilisieren und ihre Potenziale und Wirkkräfte zu entfalten. “14 Und weiter heißt es:

Nur wenn die Frankreich-Kompetenz des Saarlandes in der Breite gestärkt und von der Bevölkerung mitgetragen wird, kann tatsächlich ein leistungsfähiger mehrsprachiger Raum deutsch-französischer Prägung innerhalb einer Generation entstehen. ${ }^{15}$

13 Ankündigung der Ringvorlesung zur Frankreichstrategie: http://www.uni-saarland.de/ en/institution/frz/veranstaltungen/koll/archiv/ringvorlesung-zur-frankreichstrategie. $\mathrm{html}(23.08 .2016)$.

14 Staatskanzlei des Saarlandes: Eckpunkte einer Frankreichstrategie, S. 3.

15 Staatskanzlei des Saarlandes: Eckpunkte einer Frankreichstrategie, S. 4. 
Es wird daher versprochen, neben der „Umsetzung eigener Maßnahmen“ auch die frankreichbezogenen ,Aktivitäten der zivilgesellschaftlichen Akteure $[\ldots]$ zu stärken [und] [...] die vielfältigen lothringischen Partner [...] miteinzubinden" ${ }^{16}$ Die Germanistik bietet noch einen besonderen, anders akzentuierten Weg. Dazu möchte ich von einem Experiment erzählen, das vor knapp vier Jahren begann. ${ }^{17}$ Die Idee war einfach und setzte auf die Ressourcen unserer Region als Großregion: ein gemeinsam von den Germanistik-Instituten in Saarbrücken, Metz und Luxemburg angebotenes grenzüberschreitendes Deutsch-Studium. Seit 2012 gibt es nun den trinationalen Masterstudiengang „Literatur-, Kultur- und Sprachgeschichte des deutschsprachigen Raums“. Der etwas umständliche Titel verrät indirekt, über welche national verschieden geprägten Studienausrichtungen man sich dabei verständigen musste. Der Begriff der Kulturgeschichte etwa verweist auf den geschichtswissenschaftlichen Anteil, der in der französischen Germanistik so wichtig ist.

Wesentlich für das Programm ist der Bezug auf einen - wie der Name betont - ,deutschsprachigen Raum', der nicht nur Deutschland, Österreich und die Schweiz umfasst, sondern eben auch die zwei- oder mehrsprachigen Regionen mit Deutsch als einer der Sprachen. Die historische Situation in Lothringen und im Elsass gehört hier ebenso dazu wie die Mehrsprachigkeit in Luxemburg und - wenn die Frankreichstrategie greift - die zukünftige Zweisprachigkeit im Saarland. Um die Möglichkeit eines Studienschwerpunkts in diesem Bereich zu unterstützen, besteht seit Neuestem eine Zusammenarbeit mit der Mehrsprachigkeitsforschung im Teilfach Deutsch als Fremdsprache in Saarbrücken. ${ }^{18}$ Die literaturwissenschaftlichen Studienangebote schließen den Kontakt zum Literaturarchiv Saar-Lor-Lux-Elsass ${ }^{19}$ ein, das den Studierenden ermöglicht, mit Manuskripten von Schriftstellerinnen und Schriftstellern der Großregion zu arbeiten.

Das Besondere dieses Studiengangs, der von der Deutsch-Französischen Hochschule gefördert wird, besteht darin, dass er anders als sonstige bi- und trinationale Studienprogramme keine Abfolge von Inlands- und Auslandssemestern vorgibt. Wer eingeschrieben ist, kann in jedem Semester das

16 Staatskanzlei des Saarlandes: Eckpunkte einer Frankreichstrategie, S. 4.

17 Hier haben in der Anfangsphase Pierre Béhar, Ralf Bogner, Françoise Lartillot, Michel Grunewald und Georg Mein Maßgebliches geleistet. Einige der Kolleginnen und Kollegen sind immer noch beteiligt sowie aktuell auch Daniel Kazmaier und Till Dembeck. Homepage des trinationalen Studiengangs Germanistik: http://www.uni-gr.eu/de/studieren/ grenzueberschreitende-studiengaenge/trinationaler-germanistik-master (08.08.17).

18 Leitung: Stefanie Haberzettl. Der Wahlbereich Mehrsprachigkeitsforschung korreliert mit entsprechenden Angeboten in Luxemburg, während in Metz der sprachwissenschaftliche Akzent auf der Übersetzung liegt.

19 Siehe hierzu Literaturarchiv Saar-Lor-Lux-Elsass: http://literaturarchiv.uni-saarland.de (23.08.2016). Dem Engagement von Sikander Singh und Hermann Gätje ist hier besonders zu danken. 
Kursangebot aller drei Universitäten nutzen. Dies ist nur möglich aufgrund der großen räumlichen Nähe: Es sind pendelbare Strecken. Die erhöhten Fahrkosten, die das notwendigerweise verursacht, werden durch Mobilitätsbeihilfen der Deutsch-Französischen Hochschule aufgefangen. Dabei ist nicht zu leugnen, dass der trinationale Studienalltag von den Studierenden einiges mehr an organisatorischem Aufwand abverlangt. Es ist ungleich einfacher - übrigens auch für uns, die wir das Programm leiten -, wenn die Aufenthalte semesterweise vorgeschrieben sind. Warum nehmen wir diesen Mehraufwand in Kauf? Abgesehen davon, dass es die inhaltlich-thematischen Wahlmöglichkeiten für die Studierenden enorm erhöht, ist uns an einem Nebeneffekt gelegen: Die Studierendengruppen mischen sich und dies auch jahrgangsübergreifend. Von Anfang an studieren Franzosen, Deutsche und Luxemburger zusammen. Daraus ergibt sich interkulturelles Lernen in der Praxis. Denn die Studierenden lernen nicht nur den Lebensalltag im jeweils anderen Land kennen, es ergeben sich auch innerhalb gemischter Gruppen ganz andere Kontakte: freundschaftliche und professionelle. Dies ist eine nicht zu unterschätzende ganz praktische, lebensweltliche Ebene, die eine Verbindung über die Grenzen hinweg stiftet, und sich weiterhin auch in fachlicher Hinsicht positiv auswirkt. Im Hinblick auf die Methoden und behandelten Gegenstände ergibt sich somit eine, interkulturelle Germanistik ${ }^{\text {‘ }}$ auf der Metaebene. Fachbezogene länderübergreifende Kooperationen helfen, die Grenzen im eigenen disziplinären Denken zu erkennen. Denn man sieht, indem man mit anderen Arten, Germanistik zu betreiben, konfrontiert wird, dass die eigenen Selbstverständlichkeiten nicht so selbstverständlich sind - etwa bezüglich der Eigentümlichkeiten deutscher Sprache und ihrer Entwicklung, für die Fremdsprachenlerner immer einen sensibleren Blick haben, im Zuschnitt des literarischen Kanons, in der Problematisierung dessen, was unter ,deutscher ${ }^{6}$ Literatur überhaupt gefasst wird, und im methodischen Zugriff darauf.

Hinzugefügt werden kann, dass sich der Zuschnitt des Studiengangs auch auf die konkrete Seminarsituation auswirkt. Es ist etwas anderes, ob man in einem Seminar über den Ersten Weltkrieg mit deutschen Studierenden diskutiert oder ob man dies mit einer gemischten Studierendengruppe von Deutschen und Franzosen tut und ob man neben Texten von Jünger, Remarque und Döblin kontrastiv vergleichend dazu französische Texte, etwa von Henri Barbusse und Henri Laporte, und auch Texte von in der zweisprachigen Region aufgewachsenen Autoren untersucht, zum Beispiel von René Schickele, Yvan Goll und Adrienne Thomas.

Insgesamt stellt das natürlich größere Anforderungen an die Studierenden. Die Hoffnung, dass der Gewinn die Schwierigkeiten eines solchen mehrperspektivischen Studiums überwiegt, wird uns von Studierenden mehrheitlich bestätigt. Man muss aber sagen, dass es auch Fälle gibt, in denen sich einzelne Studierende entscheiden, auf den Dreifachabschluss aller beteiligten 
Länder zu verzichten und den Master nur an einer Universität zu studieren und zum Abschluss zu bringen. Diese Option besteht selbstverständlich.

Ich komme auf die Frankreichstrategie und die Frage der Motivation zurück. Mit dem beschriebenen Studiengang bietet die Saarbrücker Germanistik einen anderen Weg nach Frankreich, und zwar einen, der Studierende anspricht, bei denen nicht sowieso schon vorher ein Sprachinteresse am Französischen vorlag. Unsere Studienanfänger bringen in der Regel einen Bachelorabschluss in Germanistik mit und wollen dieses Fachstudium weiter vertiefen. Sie sehen aber einen Vorteil auf dem Arbeitsmarkt, wenn sie ein Masterdiplom dreier Länder erwerben. Die wenigsten haben zu Beginn des Studiengangs nennenswerte Frankreicherfahrungen oder Französischkenntnisse, die über den Stand einer während der Schulzeit erlernten zweiten oder dritten Fremdsprache hinausgehen. Sie sind aber hochmotiviert und neugierig; viele fühlen sich auch besonders verbunden mit der Region.

Für unseren trinationalen Germanistik-Master gilt, dass man zunächst einmal keine überdurchschnittlichen Französischkenntnisse benötigt, um den Schritt nach Frankreich zu machen. Die Studien richten sich ja auf deutschsprachige Gegenstände. Durch den Studien- und Lebensalltag an den französischsprachigen Partneruniversitäten und durch die persönlichen Freundschaften mit französischen Mitstudierenden entsteht jedoch meist schnell der eigene Wunsch, neben dem Studium das Französische auszubauen. Die Deutsch-Französische Hochschule stellt Angebote für Online-Kurse bereit, und auch an unserer Universität gibt es natürlich Sprachkurse, die sich im Optionalbereich im Studienplan anrechnen lassen. „Lust auf Frankreich“ machen - ich glaube, dieses Stichwort aus dem Eckpunktepapier der Landesregierung zur Frankreichstrategie ${ }^{20}$ lässt sich gut auf unser Programm beziehen.

Ein weiteres Argument kommt hinzu: die Möglichkeit, grenzüberschreitend Berufspraktika zu absolvieren. Ein Praktikum ist vorgesehen und kann in den Studienplan eingebracht werden, wenn ein fachlicher Bezug besteht. Unsere Studierenden machen z. B. Praktika als Fremdsprachenassistenten im Deutschunterricht an einer französischen Schule, in der Öffentlichkeitsarbeit und Veranstaltungsbegleitung am Theater Le Carreau in Forbach, an Goethe-Instituten, im Literaturarchiv Saar-Lor-Lux-Elsass oder bei ARTE in Straßburg. Wenn im Rahmen des fachlichen Studienprogramms genügend Freiräume für eigenes Engagement bleibt, zahlt sich das in der Regel aus, und zwar nicht zuletzt im Hinblick auf eine spätere Berufspraxis. Wozu dies auch im Studienalltag führen kann, zeigt das Beispiel einer eigenen Tagung, die Studierende ausgehend von einem Seminar im Februar 2016 unter dem Titel „Grenzenlos durch die Bildung?! Interkulturelle Strategien in Kultur, Politik und Schule in der mehrsprachigen Großregion" organisiert haben. Das Thema entstammte einem gemeinsamen Interesse an praktizierter Interkulturalität.

20 Staatskanzlei des Saarlandes: Eckpunkte einer Frankreichstrategie, S. 24. 
Erfahrungen, die die Studierenden in Praktika gesammelt hatten, wurden theoretisch reflektiert und diskutiert. Eine interkulturelle Kompetenz wird in der heutigen Zeit immer wichtiger, und unsere Grenzregion liefert dafür eine gute Basis.

\section{Entwicklungen und Zukunftschancen}

In zwei Bereichen versuchen wir die deutsch-französische Vernetzung für Studierende der Germanistik auszubauen. Der eine ist noch Zukunftsmusik, der andere bereits Realität: Zum Studienjahr 2015/16 wurde ein Antrag bei der Deutsch-Französischen Hochschule auf ein Doktorandenprogramm bewilligt, das auf unseren und einen in der Romanistik bestehenden trinationalen Masterstudiengang („Deutsch-Französische Studien: Grenzüberschreitende Kommunikation und Kooperation", in Saarbrücken von Hans-Jürgen Lüsebrink geleitet) aufbaut. Mit der Kooperation setzen wir auf einen interdisziplinären Synergieeffekt. Der gemeinsame Promotionszweig zielt auf das, was unsere Studiengänge eint, nämlich Interkulturalität. Entsprechend heißt das Programm „Interkulturalität in Literaturen, Medien und Organisationen“. Von der grenzüberschreitenden Germanistik ausgehend erhalten die Studierenden Zugang zum Anwendungsbereich des Kulturbetriebs in konkreter Ausrichtung auf Frankreich, von der grenzüberschreitenden Kommunikation in den Deutsch-Französischen Studien ausgehend erhalten die Studierenden Zugang zur Literatur im historischen Längsschnitt und im Blick auf die Kulturgeschichte der Region. Interkulturalität steht im Zentrum, dies aber in deutscher und französischer Akzentuierung und rückgebunden an die konkreten Möglichkeiten der Großregion Saar-Lor-Lux. Der andere Bereich, den wir in enger Zusammenarbeit mit der Romanistik, in diesem Fall mit Patricia Oster-Stierle und Claudia Polzin-Haumann, verfolgen wollen, ist ein Lehramtsprogramm zwischen dem Saarland und Lothringen. Das - zugegebenermaßen ehrgeizige - Ziel ist, dass deutsche Muttersprachler, die Deutsch auf Lehramt bei uns studieren, die Lehrbefugnis auch für Frankreich erwerben können, und umgekehrt französische Muttersprachler mit dem Unterrichtsfach Lettres Modernes auch in Deutschland Französisch unterrichten dürfen. Hier sind noch alle Hürden zu nehmen, nicht zuletzt bürokratischer Art, aber wenn es gelingt, werden sich die beruflichen Möglichkeiten für die Lehramtskandidaten unserer Region erheblich erweitern. Hinzu käme der positive Effekt für die von Muttersprachlern unterrichteten Schülerinnen und Schüler.

Jenseits der Zukunftspläne kann man festhalten, dass sich die „Zwei Facetten eines Landes“ als Brücke zu Deutschland und Tor nach Frankreich, die im Eckpunktepapier als die „Pfeiler der Frankreichstrategie“ ausgewiesen 
werden, ${ }^{21}$ nicht nur in den Forschungsaktivitäten des Germanistik-Kollegiums wiederfinden, sondern für unsere Studierenden bereits jetzt Praxis sind. Zur wechselseitigen Verbindung trägt zudem die Vermittlung deutschsprachiger Kultur durch unsere Absolventen bei - und nicht zuletzt der Erfahrungsaustausch im Rahmen gelebter Mehrsprachigkeit und Interkulturalität. Auf beiden Bereichen liegt gleichzeitig ein starker Forschungsakzent (mit interdisziplinären Kooperationen an der Universität des Saarlandes und internationalen mit den Partneruniversitäten), der den Studierenden in ihrer fachlichen Ausbildung zugutekommt.

Jenseits dieser konkreten Aspekte ist die grundsätzliche Gesellschaftsrelevanz von Literatur zu betonen, als Speicher von „Lebenswissen“, wie Ottmar Ette es nennt, ${ }^{22}$ das über historisches Faktenwissen weit hinausgeht. Im Eckpunktepapier heißt es: „Die Erlebbarkeit der gemeinsamen deutsch-französischen Geschichte und Kultur ist als einmaliges historisches Erbe verstärkt zu nutzen. "23 Hier sehe ich die eigentliche Bedeutung der Literatur, und zwar auch der Literatur vergangener Zeiten. Literatur ist ein zentraler Träger der Kultur und dabei Speichermedium des historischen gesellschaftlichen Bewusstseins - oder, im Vokabular der Erinnerungstheorie, des kollektiven Gedächtnisses. Sich mit Literatur und Literaturgeschichte zu befassen, ermöglicht Einblicke in aktuelle oder auch lange zurückliegende Bewusstseinsprozesse. Sie ist Medium der Reflexion und der Auseinandersetzung. Für den interkulturellen Austausch ist Kunst allgemein - Literatur, Theater, Film, Musik, Bildende Kunst - unverzichtbar, wobei vielleicht der Sprachkunst innerhalb der Frankreichstrategie noch einmal eine besondere Rolle zukommt.

Anfang des Jahres 2016 hatte Valérie Deshoulières ${ }^{24}$ in die Villa Europa eingeladen, um mit dem Buchautor und Europaratsmitglied Jean-Christophe Bas und Jocelyne Caballero, der französischen Botschafterin im Europarat, über die Vision Europa zu diskutieren und darüber, welchen Stellenwert sie heute noch hat. Eine Studentin fragte, wie man denn überhaupt etwas Positives mit einem Europa verbinden könne, das auf Krieg und Völkermord gründe. Eine „tristesse européenne“ nannte sie es. Die Antwort darauf wäre tatsächlich auch meine Antwort gewesen: Gerade die Tatsache, dass nach der dunkelsten Stunde unserer Geschichte so etwas wie die europäische Idee entstehen konnte, zeigt, wie viel man auf sie geben kann. Ein Kern dessen ist die deutsch-französische Feindschaft, aus der eine Freundschaft wurde. Dafür stehen auch das Saarland und seine Universität - und selbst die bloße Existenz

21 Staatskanzlei des Saarlandes: Eckpunkte einer Frankreichstrategie, S. 13.

22 Ette, Ottmar: ÜberLebenswissen. Die Aufgabe der Philologie, Berlin: Kadmos, 2004, S. 13.

23 Staatskanzlei des Saarlandes: Eckpunkte einer Frankreichstrategie, S. 15.

24 Professorin für Französische Literatur im europäischen Kontext an der Universität des Saarlandes und Leiterin des Institut d'études françaises in der Villa Europa, Saarbrücken. 
einer Frankophonen Germanistik ist ein Ausdruck davon. Speziell die Germanistik, wie zu Beginn dieses Beitrags ausgeführt wurde, ist als Fach erklärter ,eigener' Kultur Indikator und Faktor von gesellschaftlichen Prozessen. Angesichts der aktuellen Krisensituation, in der sich Europa neu bewähren muss, könnten wir wieder eine positive Europa-Vision gebrauchen. Hier hat das Saarland eine geschichtlich im deutsch-französischen Kontext gewachsene Kompetenz. Warum sollten wir sie nicht nutzen?

\section{Literaturverzeichnis}

Alken, Carl-Erich/Angelloz, Joseph-François: Europäische Universität des Saarlandes - Université européenne de la Sarre, Saarbrücken: Presse-Verlag, 1950.

Ankündigung der Ringvorlesung zur Frankreichstrategie: http://www.uni-saarland.de/en/ institution/frz/veranstaltungen/koll/archiv/ringvorlesung-zur-frankreichstrategie.html (08.08.2017).

Bhabha, Homi K.: DissemiNation: Zeit, Narrative und die Ränder der modernen Nation, in: ders.: Die Verortung der Kultur, Tübingen: Stauffenburg, 2000, S. 149-194.

Brinker-Gabler, Gisela: Vom nationalen Kanon zur postnationalen Konstellation, in: Heydebrand, Renate von: Kanon - Macht - Kultur: Theoretische, historische und soziale Aspekte ästhetischer Kanonbildungen, Stuttgart [u. a.]: Metzler, 1998, S. 78-96.

Ette, Ottmar: ÜberLebenswissen. Die Aufgabe der Philologie, Berlin: Kadmos, 2004.

Frankreichstrategie der Fachrichtung Germanistik der Universität des Saarlandes: http://www. uni-saarland.de/fachrichtung/germanistik/frankreichstrategie.html (08.08.2017).

Homepage des trinationalen Studiengangs Germanistik: http://www.uni-gr.eu/de/studieren/ grenzueberschreitende-studiengaenge/trinationaler-germanistik-master (08.08.2017).

Literaturarchiv Saar-Lor-Lux-Elsass: http://literaturarchiv.uni-saarland.de (08.08.2017).

Meves, Uwe: Die Institutionalisierung der Germanistik als akademisches Fach an den Universitätsneugründungen in Preußen, in: ders.: Ausgewählte Beiträge zur Geschichte der Germanistik und des Deutschunterrichts im 19. und 20. Jahrbundert, Hildesheim: Weidmann, 2004, S. 335368.

Müller, Wolfgang: „Eine Pflegestätte des Geistes, der die Enge zu überwinden sucht und nach europäischer Weite strebt" - Impressionen zur Geschichte der Universität des Saarlandes, in: Kuhn, Bärbel/Pitz, Martina/Schorr, Andreas (Hg.): ,Grenzen“ obne Fächergrenzen. Interdisziplinäre Annäherungen, St. Ingbert: Röhrig, 2007, S. 265-302.

Schickele, René: Das ewige Elsass, in: ders.: Werke in drei Bänden. Bd. 3, Köln/Berlin: Kiepenheuer \& Witsch, 1959, S. 589-620.

Staatskanzlei des Saarlandes: Eckpunkte einer Frankreichstrategie für das Saarland, 2014, http:// www.saarland.de/dokumente/res_stk/D_Eckpunkte_Frankreich-Strategie_210114.pdf (08.08.2017).

Viot, Hélène: La Section française de germanistique de l'université de la Sarre. Naissance et institutionnalisation (1948-1970). Masterarbeit, eingereicht im Juli 2014 an der École Normale Supérieure de Lyon. Online verfügbar: http://saardok.sulb.uni-saarland.de/archive/frei/bsz452202493/ 0/seconde_version_m_moire_m2_h._viot.pdf (08.08.2017).

Weiershausen, Romana: „Frankophone Germanistik“ in Saarbrücken: Chancen für die Germanistik im deutsch-französischen Grenzraum, in: Romanische Studien 1 (2015), S. 267-280. 



\section{Im Kontext der Frankreichstrategie: Auf dem Weg zu einer Mehrsprachigkeit für das Saarland}

Quelles opportunités la 'Stratégie France' offre-t-elle aux établissements de formation pour adultes en Sarre afin d'encourager le plurilinguisme dans ce Land? À quels défis la formation pour adultes devra-t-elle faire face? Deux établissements régionaux importants répondront, au travers de leurs directeurs respectifs, aux questions concernant les concepts pédagogiques et les offres d'apprentissage actuels et futurs. Ils justifieront chacun des moyens spécifiques mis en place pour développer le plurilinguisme en Sarre. Une courte introduction au plurilinguisme en Sarre sera proposée avant de résumer l'entretien.

\section{Einleitung: Das Saarland und die Mehrsprachigkeit}

\subsection{Mehrsprachigkeit, politisch-aktuell und angewandt-linguistisch betrachtet}

Das Saarland und die Saarländer sind in vielfacher Hinsicht bereits mehrsprachig, z. B. durch Familie, grenzüberschreitende Kontakte, Bildungsstätten (Kitas, Kindergärten, Schulen, Hochschulen, öffentlich geförderte und private Erwachsenenbildung) oder Medien. Neue Impulse ergeben sich durch die aktuelle Zuwanderung von Sprechern, die z. T. aus entfernten Kulturkreisen ins Saarland kommen. Diese Bedarfe, diese Herausforderungen, aber auch diese Chancen fügen sich zu der Mehrsprachigkeit hinzu, die durch die Frankreichstrategie angestrebt und gefördert wird.

Drei Säulen tragen also heute die Mehrsprachigkeit im Saarland: die ,gewachsene 'Mehrsprachigkeit der grenznah wohnenden saarländischen Bevölkerung, die Förderung der Mehrsprachigkeit durch die Frankreichstrategie und die notwendige Integration von neu ankommenden Sprechern v. a. auBereuropäischer Sprachen.

Aus dieser Situation wird deutlich: Sprache lernen ist politisches Handeln. Keine Sprache lernen ist ebenfalls politisches Handeln. Wer Sprache lehren will, benötigt daher Einsicht in das politische Verständnis von Sprache und in das gesellschaftliche Funktionieren von Sprache. Auch der Lerner braucht ein politisches Verständnis von Sprache, von sprachlichem Handeln, von den Voraussetzungen, den Wirkungen und den Konsequenzen sprachlichen Handelns. Wenn man das Lernen von Sprache fördern will, muss man in der Gesellschaft das Bewusstsein fördern, was Sprache eigentlich ist und wie Sprachenlernen und Sprachenlehren zu verstehen sind. Diese Einsicht ist wichtig 
für Eltern, für Lehrer, für die ausbildenden Hochschulen, für Verbände und Institutionen der Politik und der Bildungspolitik.

Die Bezüge zwischen Sprache und gesellschaftlichem oder politischem Handeln stehen seit langem im Fokus der Angewandten Linguistik, der Kommunikationswissenschaft, der Sprachsoziologie und anderer Disziplinen. Es ist daher folgerichtig, dass in der Diskussion um die Frankreichstrategie Politiker und Spracheninteressierte das Gespräch miteinander suchen. Und es ist einleuchtend, dass die Förderung der Frankreichstrategie und die sprachliche Betreuung von Zuwanderern, Flüchtlingen und Asylsuchenden nicht im Widerspruch und nicht in Konkurrenz zueinander stehen.

Die Mehrsprachigkeit, die wir fördern wollen, muss mehrere Bedingungen erfüllen:

- Sie muss speziell auf das Saarland zugeschnitten sein, d. h. die Besonderheiten der Grenzregion berücksichtigen, in der die Nachbarsprachen vorrangig gefördert werden.

- Sie muss die Herausforderungen der Integration zahlreicher Flüchtlinge aufgreifen.

- Sie muss sich im Kontext der Frankreichstrategie verstehen.

Zum besseren Verständnis des letzten Punktes zitieren wir aus dem Eckpunktepapier der Landesregierung, in dem die Besonderheit der angestrebten Mehrsprachigkeit für das Saarland so formuliert wird: „Ziel der Landesregierung ist es, für eine stärkere Präsenz der französischen Sprache im öffentlichen Raum im Saarland Sorge zu tragen" ". Geplant ist dabei, dass Französisch als weitere Verkehrssprache etabliert wird.

Damit umfasst das weitere Fremdsprachenlernen auf der Grundlage einer hohen Kompetenz in der Bildungssprache Deutsch und gegebenenfalls einer anderen Herkunftssprache das Lernen der Verkehrssprache Französisch, der globalen Lingua franca und gegebenenfalls weiterer Sprachen. ${ }^{2}$

Dieser mehrsprachige Weg soll bei der Kita beginnen und in das Erwachsenenalter hinein weitergeführt werden.

\subsection{Erwachsenenbildung im Saarland}

Wir konzentrieren uns im vorliegenden Beitrag auf die Erwachsenenbildung im Saarland, und dafür sprechen zwei Gründe:

1 Staatskanzlei des Saarlandes: Eckpunkte einer Frankreichstrategie für das Saarland, 2014, http:// www.saarland.de/dokumente/res_stk/D_Eckpunkte_Frankreich-Strategie_210114.pdf (26.10.2016), hier S. 9.

2 Staatskanzlei des Saarlandes: Eckpunkte einer Frankreichstrategie, S. 10. 
1. Mehrsprachigkeit bei Kindern und Jugendlichen steht im Zentrum einer breiten wissenschaftlichen und öffentlichen Diskussion. Demgegenüber ist die einschlägige Literatur über Erwachsene erheblich ärmer oder zumindest weniger bekannt.

2. Ein zweites Argument hängt mit der Perspektive ,Frankreichstrategie zusammen. Natürlich ist es nötig, die Mehrsprachigkeit ausgehend von dem familiären Umfeld, vom Kita- und Kindergartenalter, von der Grundschule und der weiterführenden Schule aus systematisch aufzubauen, aber es erscheint sinnvoll, zugleich auch anzustreben, für Erwachsene Lernwege aufzuzeigen, nicht nur um die veranschlagten Zeiträume zur Umsetzung der Strategie zu verkürzen, sondern auch, um die hier, im Erwachsenenbereich, vorhandenen spezifischen Möglichkeiten zu erschließen.

\section{Mehrsprachigkeit und Institutionen der Erwachsenenbildung: zwei Beispiele}

Wir beschränken uns im Folgenden aus Platzgründen auf zwei Beispiele saarländischer Erwachsenenbildung, der Volkshochschule Regionalverband Saarbrücken und dem Zentralen Institut für Sprachen und Kommunikation (Sprachenzentrum) der Universität des Saarlandes, und fragen zunächst nach dem Ist-Zustand des Sprachenangebots.

\subsection{Der Ist-Zustand}

Frage 1: Worin besteht das derzeitige Sprachenangebot (im Hinblick auf Mehrsprachigkeit) in den Institutionen, die bier vertreten sind?

* Volkshochschule Regionalverband Saarbrücken

Volkshochschulen sind v. a. im außerschulischen Bereich, d. h. in der Erwachsenenbildung, tätig. Die Weiterbildung geschieht vorwiegend berufsbegleitend und auf freiwilliger Basis, oft auch nach der Erwerbsphase. Viele Volkshochschulen bieten daneben auch spezielle Firmenkurse zur Mitarbeiterqualifikation an. In Deutschland gibt es knapp 1000 Volkshochschulen, im Saarland 16 mit über 70 Nebenstellen. Neben den Volkshochschulen gibt es eine ganze Reihe anderer Weiterbildungsanbieter, die staatlich anerkannt sind und Förderungen nach dem saarländischen Weiterbildungsgesetz erhalten.

Die Volkshochschule des Regionalverbandes ist die größte der saarländischen Volkshochschulen. Sie bietet ihr Weiterbildungsangebot in der Landeshauptstadt und den Umlandgemeinden an und hat jährlich ca. 35000 Teilnehmende an Kursen, Seminaren, Vorträgen, Exkursionen und Studienfahrten. 
Der Sprachenbereich umfasst jährlich über 700 Sprachkurse in fast 20 Sprachen mit rund 7500 Teilnehmenden. Die Sprachkurse machen ca. ein Viertel des Gesamtangebotes an Kursen und Teilnehmenden aus, mit über 30000 Unterrichtsstunden aber fast die Hälfte der insgesamt durchgeführten Unterrichtsstunden. Weitaus größter Bereich des Jahresangebotes an Sprachkursen ist Deutsch als Fremdsprache, danach folgen Englisch, Französisch, Spanisch, Italienisch und die weiteren Fremdsprachen. Im Jahr 2015 haben an der Volkshochschule des Regionalverbandes 120 Französischkurse mit rund 1200 Teilnehmenden stattgefunden.

* Zentrales Institut für Sprachen und Kommunikation (Sprachenzentrum) der Universität des Saarlandes (UdS)

Das Sprachenzentrum bietet den Studierenden des Saarlandes die Möglichkeit, studienbegleitend Sprachkenntnisse zu erwerben oder auszubauen. In vielen Studiengängen können die Sprachkurse des Instituts heute auch in einem Wahl- oder Wahlpflichtbereich eingebracht werden. Als zentrale Einrichtung gehört das Zentrum keiner Fakultät direkt an und ist für Studierende aller Studiengänge der UdS gleichermaßen zuständig. Auch steht das Angebot den Studierenden der Universität der Großregion (Metz, Nancy, Luxemburg, Lüttich, Trier und Kaiserslautern) sowie den Studierenden des Universitätsverbunds Südwest (Universität des Saarlandes, Technische Universität Kaiserslautern, Universität Koblenz-Landau, Universität Trier) offen.

Das Sprachenzentrum bietet im Jahr 2016 Lehrveranstaltungen in ca. 15 Fremdsprachen an. Die höchste Nachfrage gibt es natürlich für Englisch, relativ dicht gefolgt von Spanisch. Französisch folgt mit einem gewissen Abstand, bildet aber dennoch einen zentralen Anteil des Sprachenportfolios, da ein ganz erheblicher Teil des internationalen Austauschs der UdS mit Frankreich stattfindet und viele Studierende nach ihrem Abschluss aufgrund der engen Wirtschaftsbeziehungen zwischen Frankreich und Deutschland mit unserem westlichen Nachbarn zusammenarbeiten werden. Auch ist in diesem Zusammenhang erwähnenswert, dass Französisch in einer sehr großen Anzahl von Ländern weiterhin Amtssprache oder wichtige Verkehrssprache ist.

Insgesamt schreiben sich jährlich über 3000 Studierende sowie Mitarbeiterinnen und Mitarbeiter zu den Kursen des Sprachenzentrums ein und nehmen bis zu 5000 Kurs-Buchungen vor. Neben den Kursen bietet das Sprachenzentrum diverse Selbstlernmöglichkeiten, Einstufungstests, Beratungen und natürlich Zertifikate, darunter das hochschulübergreifende Fremdsprachenzertifikat UNIcert ${ }^{\circledR}$, welches in neun verschiedenen Sprachen auf verschiedenen Niveaus erworben werden kann, an. 


\subsection{Perspektiven}

Um den Ist-Zustand im Hinblick auf Förderung der individuellen Mehrsprachigkeit weiterzuentwickeln, kann man sich verschiedene Fragen vorlegen, wie man den bestehenden Unterricht entsprechend gestalten oder umgestalten sollte.

Frage 2: Erscheint es realistisch, Teilkompetenzen zu vermitteln (also ₹. B. Lesen von Texten lernen; Hörverstehen anstreben; Lesen und Schreiben vermitteln, statt alle vier Fertigkeiten im Lernziel unterzubringen)? Könnte das ein akzeptables Lernziel sein, würde ein solches Unterrichtsprofil auf Akzeptanz stoßen? Könnte man auf diese Weise dem einzelnen Lerner vielleicht Kompetenzen in mehr Sprachen vermitteln?

* Volkshochschule Regionalverband Saarbrücken

Bisher wiegt generell bei der Sprachvermittlung der Ansatz vor, dass alle vier Fertigkeiten parallel erworben werden sollten. Man muss sich in der Tat die Frage stellen, ob jeder eine Fremdsprache z. B. unbedingt lesen und schreiben können sollte, oder ob eine partielle Zweisprachigkeit für ein bestimmtes Zielpublikum genügt. Die maximalistischen Forderungen nach Perfektion in allen sprachlichen Kompetenzen haben sich im Unterrichtswesen bisher als illusionär erwiesen. Viele Teilnehmer an vhs-Kursen wären mit Teilzielen auch zufrieden. Eine stärkere Betonung der einen oder anderen Fertigkeit bei der Sprachvermittlung hätte natürlich auch Auswirkungen auf die Didaktik und auf die Lehrmaterialien, die angepasst werden müssten, ebenso auf das Format der zum Abschluss eines Kurses zu erwerbenden Sprachenzertifikate. Eine solche neue Gewichtung bzw. Differenzierung hätte sicherlich auch positive Auswirkungen auf die Motivation der Kursteilnehmer.

* Zentrales Institut für Sprachen und Kommunikation (Sprachenzentrum) der Universität des Saarlandes

Es ist zwar eine lieb gewonnene didaktische Grundannahme, dass sich die Fremdsprachenkompetenz in allen vier Fertigkeiten - Hören, Sprechen, Lesen, Schreiben - gleichermaßen und parallel entwickeln sollte. Praktisch alle Lehrpläne sowie auch die nationalen und internationalen Sprachzertifikate gehen hiervon aus. Dies erscheint jedoch als ein Konstrukt, wenn nicht gar ein Mythos, welcher der Überprüfung an der Realität nicht standhält. Selbst in der Muttersprache ist es bei praktisch jedem Menschen so, dass nicht alle Fertigkeiten gleichermaßen entwickelt sind.

Insofern kann man das ehrgeizige und auf den ersten Blick kaum realisierbar scheinende Ziel der kompletten Mehrsprachigkeit des Saarlandes als 
Chance begreifen, zu einer differenzierteren und viel stärker an den Wünschen und Möglichkeiten der Lernerinnen und Lerner orientierten Definition zu gelangen. Dies wird ganz automatisch dazu führen, dass einzelne Teilkompetenzen eine stärkere Gewichtung erfahren als andere. Und dies sollte dann auch ausdrücklich nicht als defizitärer Erwerb betrachtet werden, sondern als bewusste Entscheidung für die Fertigkeiten, die zur Erreichung individueller Lernziele nötig sind. Natürlich würde ein solches Umdenken auch massive Änderungen in der Didaktik erforderlich machen.

Frage 3: Wie weit müssen die erworbenen produktiven Sprachkenntnisse (Sprechen und Schreiben) korrekt sein? Könnte man Toleranżen gestatten?

\section{Volkshochschule Regionalverband Saarbrücken}

Es muss bezweifelt werden, dass man in der Erwachsenenbildung das Ziel einer lückenlos korrekten Sprachanwendung erreichen kann. Eine gewisse Fehlertoleranz muss eingeräumt werden. Ziel ist letztlich die Kommunikationsfähigkeit, und die ist sicherlich auch möglich, wenn gewisse Fehler in der Zielsprache gemacht werden. Solange die Kommunikation nicht erheblich erschwert ist, kann das funktionieren. Das ist ja z. T. auch bei unseren Mitbürgerinnen und Mitbürgern mit Migrationshintergrund der Fall. Eine Frage ist, wie sich diese Fehlertoleranz auch auf das Format der Sprachzertifikate und die Bewertungsschlüssel auswirken würde.

Aber: Die allermeisten Teilnehmenden an unseren Sprachkursen benötigen kein Zertifikat zum Nachweis ihrer Fremdsprachenkenntnisse - von Teilnehmenden in Deutschkursen abgesehen. Sprachenlernen, z. B. Französischlernen, ist an der Volkshochschule weniger abschlussorientiert. Es geht vornehmlich um Kommunikationsfähigkeit im Zielsprachenland.

* Zentrales Institut für Sprachen und Kommunikation (Sprachenzentrum) der Universität des Saarlandes

Universitäre Sprachkursteilnehmende sind sicherlich mehr an Zertifikaten interessiert als die Lernenden an einer Volkshochschule, da der Nachweis von Fremdsprachenkenntnissen eine wertvolle Zusatzqualifikation ist, die sie neben ihrem Studium erwerben können und die den Einstieg in das zunehmend globalisierte Erwerbsleben erleichtert. Aus diesem Grunde gibt es z. B. das hochschulübergreifende Fremdsprachenzertifikat UNIcert ${ }^{\circledR}$, das vom Dachverband der Hochschulsprachenzentren AKS getragen wird und an knapp 50 deutschen Universitäten und Fachhochschulen sowie einigen ausländischen Hochschulen erworben werden kann. Zudem werden an Akademiker höhere Anforderungen im Hinblick auf die Korrektheit ihrer sprachlichen Äußerungen gestellt. Gleichwohl sollten diese Anforderungen auch 
nicht übermäßig hoch sein und das Erreichen des primären Zieles der kommunikativen Kompetenz gefährden. Hier gilt es, genau hinzusehen, wann inkorrekte Äußerungen zu Missverständnissen oder gar zum Zusammenbruch der Kommunikation führen.

Frage 4: Kann man Codeswitching oder ,Sprachenhopping' (zeitweisen Wechsel in eine andere Sprache) gestatten/anbieten/lehren?

Volkshochschule Regionalverband Saarbrücken

Sprachwissenschaftler gehen davon aus, dass ein Wechseln zwischen Sprachen nicht willkürlich erfolgt, sondern durch die Situation des Gesprächs, die emotionale Beteiligung, den Gesprächsgegenstand, die Notwendigkeit, die eigene Identität auszudrücken, etc. bedingt ist. Codeswitching ist nicht ganz unumstritten, es ist aber durchaus sinnvoll, wenn es dem Sprecher schwer fällt, etwas auszudrücken, sobald der Sachverhalt für ihn komplexer wird, z. B. wenn er Schwierigkeiten hat, eine Handlung in der gleichen Sprache fortzusetzen oder ein bestimmtes Wort zu finden. Hier kann durch den Wechsel in die andere Sprache sicherlich die Hemmschwelle, sich z. B. in Französisch auszudrücken, gesenkt, und eine ,angstfreiere' Kommunikation ermöglicht werden.

Zentrales Institut für Sprachen und Kommunikation (Sprachenzentrum) der Universität des Saarlandes

Auch hier gilt es, sich in der Didaktik mehr an den tatsächlichen Gebrauch anzunähern. Denn bei vielen Sprechern ist das Wechseln zwischen verschiedenen Sprachen nicht unüblich, in manchen Ländern bzw. Kommunikationskontexten sogar ganz alltäglich. Zu Recht wird daher von Didaktikern und auch Sprachpolitikern gefordert, funktionale Mehrsprachigkeit zu fördern und entsprechende Vermittlungskonzepte zu entwickeln.

Frage 5: Kann man rezeptive Mehrsprachigkeit (d. b. jeder Kommunikationspartner spricht in seiner eigenen Sprache) anbieten, wird sie akzeptiert?

Volkshochschule Regionalverband Saarbrücken

Rezeptive Mehrsprachigkeit ist ja ein Postulat der Europäischen Kommission, damit Mehrsprachigkeit überhaupt erreicht werden kann. Die Forschergruppe EuroCom hat sich als Programm gesetzt, Mehrsprachigkeit über den Einstieg in rezeptive Kompetenzen modularisiert und kognitiv über Transferbasen innerhalb von Sprachfamilien zu erreichen. EuroCom steht dabei als Kürzel für Eurocomprehension, ein Akronym für Europäische Interkomprehension 
in den drei großen Sprachengruppen Europas, der romanischen, slawischen und germanischen. Aber: Rezeptive Zwei- bzw. Mehrsprachigkeit erfordert eine hohe interkulturelle Kompetenz, besonders bei Begrifflichkeiten, die in den verschiedenen Sprachen unter Umständen etwas ganz anderes bedeuten; sie ist aber auch als Chance für ,kleinere'Sprachen zu sehen.

\section{* Zentrales Institut für Sprachen und Kommunikation (Sprachenzentrum) der Universität des Saarlandes}

Die Beschränkung auf rezeptive Fertigkeiten kann man aus Gründen der Lernökonomie und der Lernerzentrierung gutheißen. Gerade im akademischen Kontext kann dies Sinn ergeben. Nicht wenigen Studierenden oder Forschern genügt es, Originaltexte aus ihrem Wissensbereich in Französisch, Italienisch oder Portugiesisch lesen zu können, ohne jemals substantielle produktive Fertigkeiten zu erlernen. Gerade die Verwandtschaft der romanischen Sprachen bietet hier eine Chance für den schnellen Erwerb einer zentralen Kompetenz. Freilich wäre zu untersuchen, ob der völlige Verzicht auf das Einüben produktiver Fertigkeiten sich nicht negativ auf den Gesamtlernerfolg auswirkt.

\section{Zusammenarbeit mit der Frankreichstrategie}

Frage 6: Kann die Frankreichstrategie Anregung und Motor für die Weiterentwicklung der hiesigen Sprachenangebote sein?

* Volkshochschule Regionalverband Saarbrücken

Durch die Frankreichstrategie kann sich die Volkshochschule ein neues Zielpublikum erschließen, indem sie ihre Angebote z. B. noch stärker als bisher an den Bedürfnissen bestimmter Berufsgruppen orientiert. Man sollte aber die Grenznähe zu Frankreich noch sinnvoller nutzen als dies bereits geschieht. Es gibt ja bereits Erfahrungen mit einer, Grenzdidaktik' beim Sprachenlernen, also mit dem Sprachenlernen unter Einbeziehung des Lebensraums der Lernenden bzw. des Zielsprachenlandes. Begegnung und Austausch mit unserem Nachbarland müssen auf allen Ebenen noch stärker als bisher stattfinden.

Die Betonung der Alltagsrelevanz des Frankreichbezugs ist von großer Bedeutung. Nur wenn die breite Bevölkerung den Nachbarn mit einer positiven Grundhaltung wahrnimmt, die Auseinandersetzung mit der französischen Kultur genießt, grenzüberschreitende Begegnungen mit den Nachbarn als Bereicherung empfindet, wird die Strategie Aussicht auf Erfolg haben. Die Beschäftigung mit der Kultur Frankreichs - auch im Sinne einer ,Alltagskultur ${ }^{6}$ - kann durchaus Motor und Anreiz sein. Das Frankreichprogramm 
der saarländischen Volkshochschulen geht in diese Richtung. Ziel dieser Angebote ist es, Empathie für den Nachbarn und seine Sprache zu entwickeln bzw. zu stärken. Der emotionale Bezug zur Nachbarsprache ist Grundbedingung für die Bereitschaft, sie zu erlernen.

Was die eigentliche Sprachvermittlung betrifft, müssen die Volkshochschulen moderne Medien noch stärker nutzen: Online-Lernen, Lernplattformen, hybride Lernarrangements. Hier haben Volkshochschulen noch erhebliches Entwicklungspotenzial, wenn man Lerner ansprechen will, die bisher noch nicht erreicht wurden.

- Zentrales Institut für Sprachen und Kommunikation (Sprachenzentrum) der Universität des Saarlandes

Die Hochschulsprachenzentren und damit auch das Saarbrücker Sprachenzentrum setzen schon seit längerer Zeit neue Medien intensiv ein. So wird in Saarbrücken bereits seit 2005 die Lernplattform Moodle verwendet, die inzwischen in knapp der Hälfte der Kurse begleitend eingesetzt wird. In verschiedenen Projekten wurden zudem Unterrichtsmaterialien entwickelt. Auch der Online-Einstufungstest des Sprachenzentrums, an dem bis zu 2000 Studierende pro Semester teilnehmen, ist Ergebnis eines Projektes. Daneben werden andere Vermittlungsformen wie etwa Podcasts (vgl. www.ropecast.de) am Sprachenzentrum der UdS erprobt.

Die Frankreichstrategie ist durch ihre ambitionierte Zielsetzung zugleich Anlass und Ansporn, innovative Ansätze auszuweiten und neue Angebote zu schaffen. $\mathrm{Zu}$ denken wäre hier etwa an die Erarbeitung neuer Online-Lernmaterialien oder auch, aufbauend auf den positiven Erfahrungen mit RoPeCast, die Entwicklung eines Podcasts für Französischlernerinnen und -lerner. Im Bereich Testen und Prüfen hat die Frankreichstrategie bereits zu konkreten Neuerungen geführt. So werden die erwähnten Online-Tests inzwischen nicht mehr nur für Studierende, sondern auch für Bedienstete und weitere neue Benutzergruppen eingesetzt. Hinzu kommt als jüngste Entwicklung, dass das Sprachenzentrum seit 2016 als DELF/DALF-Prüfungszentrum akkreditiert ist und 2017 erstmals diese Prüfungen durchgeführt hat.

\section{Frage 7: Können Volkshochschulen und Sprachen₹entrum umgekehrt die Frankreich- strategie fördern?}

Volkshochschule Regionalverband Saarbrücken

Sinnvoll ist sicherlich eine stärkere Einbeziehung Europas und speziell unserer Grenzregion in den Sprachunterricht an der Volkshochschule. Hier kann sich das Angebot der Volkshochschule weiterentwickeln, idealerweise in Kooperation mit Erwachsenenbildungseinrichtungen in Frankreich. Es gibt 
bereits seit längerem Kooperationen mit französischen Volkshochschulen (Universités Populaires) in Grenznähe: Die Volkshochschule Regionalverband hat eine Partnerschaft mit der Université Populaire Sarreguemines Confluences, Völklingen hat gemeinsam mit Forbach die Université Populaire Transfrontalière. Ziel ist die, gelebte ' Zweisprachigkeit, es geht um Begegnung und Austausch, d. h. aber auch: Die Frankreichstrategie des Saarlandes muss ein reziproker Prozess sein, der von der Nachbarseite mitgetragen wird. Die Deutschlandstrategie Lothringens muss mit einbezogen werden, ebenso z. B. nicht-institutionelle Initiativen wie der Verein für die Förderung der Zweisprachigkeit und der Sprachenrat Saar.

\section{* Zentrales Institut für Sprachen und Kommunikation (Sprachenzentrum) der Universität des Saarlandes}

Für den Französischunterricht am Sprachenzentrum der Universität des Saarlandes ist sicherlich die Universität der Großregion der wichtigste institutionelle Anknüpfungspunkt. Durch den Verbund von sechs Hochschulen aus vier Ländern, von denen drei Französisch als Amtssprache haben und zwei offiziell mehrsprachig sind, ergeben sich Kooperationsmöglichkeiten und Lernwege, die es zu nutzen gilt.

\section{Frage 8: Könnte die Entwicklung im Saarland auch nach , außen' wirken?}

\section{* Volkshochschule Regionalverband Saarbrücken}

Das Thema Frankreich ist offensichtlich bundesweit positiv besetzt und das Saarland kokettiert ja mit seiner deutsch-französischen Vergangenheit. Die Frankreichstrategie ist also eine ,positive Vision'. Die Reaktionen aus dem Deutschen Volkshochschulverband auf die Frankreichstrategie sind ebenfalls durchaus positiv. Der Plan wird aber auch als ambitioniert eingeschätzt und man ist gespannt auf die Ergebnisse, v. a. vor dem Hintergrund, dass die Zahl der Französischlernerinnen und -lerner in anderen vhs-Landesverbänden, insbesondere im Norden der Republik, ständig zurückgeht. Hier kann die Förderung des Französischen im Rahmen der Frankreichstrategie sicherlich Impulse für andere Regionen Deutschlands setzen.

Zentrales Institut für Sprachen und Kommunikation (Sprachenzentrum) der Universität des Saarlandes

Eigentlich muss man diese Frage gar nicht mehr stellen, denn die Frankreichstrategie hat schon nach ,außen' gewirkt. Viele Medien haben darüber berichtet und eine ganze Reihe von Fachleuten schaut interessiert auf das Saarland, um zu sehen, in welchem Umfang und auf welche Weise sich die 
Vision eines zweisprachigen Bundeslandes realisieren lässt. Diesen positiven Schwung sollten alle Akteure - die Schulen, die Hochschulen, sonstige Bildungsträger, Wirtschaftsverbände, Behörden, politische Institutionen - nutzen, nicht nur, um für das Saarland zu werben, sondern auch um Partner für die Realisierung ihrer Ziele zu gewinnen.

\section{Die Zuwanderung von Flüchtlingen und die Mehrsprachigkeit}

Frage 9: Welche Auswirkungen hat die aktuelle Flüchtlingssituation auf die Förderung der Mebrsprachigkeit?

* Volkshochschule Regionalverband Saarbrücken

Für die meisten Flüchtlinge geht es zunächst um die Kompetenz der Zweisprachigkeit, also der Herkunftssprache und Deutsch. Viele haben aber bereits auch eine andere Sprache, vornehmlich Englisch, gelernt. Wichtig wäre, die Zwei- oder Dreisprachigkeit von Migranten für das Erlernen des Französischen zu nutzen. Französisch wäre dann eventuell sogar die Viertsprache. In den Deutsch-Integrationskursen der Volkshochschule wäre es wichtig, die Bedeutung Frankreichs für das Saarland und die französische Sprache zu thematisieren. Gerade hier finden sich Zielgruppen, die ansonsten noch zu wenig von weiteren Bildungsangeboten der Volkshochschulen erreicht werden. Hier bietet sich eine Chance, in der Frankreichstrategie wirklich alle Bevölkerungsgruppen - insbesondere eben auch die Menschen, die neu zu uns kommen - zu berücksichtigen.

* Zentrales Institut für Sprachen und Kommunikation (Sprachenzentrum) der Universität des Saarlandes

Man muss sicherlich sehen, dass mit den Flüchtlingen einerseits weitere Muttersprachen im Saarland eine größere Verbreitung finden und dass sich andererseits die Flüchtlinge längere Zeit darauf konzentrieren werden, die Amtssprache ihres Gastlandes zu erwerben. Dadurch könnte das Französische auf mehreren Ebenen ins Hintertreffen geraten. Auch hier sind Bildungseinrichtungen, Verbände und alle übrigen Akteure gefordert, die Frankreichstrategie weiterhin im Bewusstsein der Bevölkerung zu halten und das Erlernen der französischen Sprache zu fördern. 



\section{Das Saarland als Testfeld für deutsch-französische Hochschulkooperation}

Avec la 'Stratégie France', qui est orientée sur le long terme, le gouvernement de la Sarre soubaite exploiter davantage les potentiels de la région. La proposition majeure est de faire de la Sarre, d'ici 2043, un espace plurilingue performant et d'empreinte franco-allemande. Le français est censé devenir, au côté de l'allemand, une langue vébiculaire, une langue officielle et une langue d'apprentissage en Sarre. Mais est-il suffisant d'enseigner la langue? Ne serait-il pas important d'intégrer aussi la coopération universitaire dans les objectifs stratégiques? Ce serait tenir compte de la dynamique franco-allemande au sein même de l'Université de la Sarre, fondée par la France, et de la volonté de coopération transfrontalière exprimée par la fédération des universités en une "Université de la Grande Région » et réalisée à l'échelle des deux nations par l'Université franco-allemande qui propose une variété de cursus à double diplôme.

Die Frankreichstrategie des Saarlandes ist eine mutige Vision. Der größte Respekt gebührt der Ministerpräsidentin des Saarlandes, Annegret KrampKarrenbauer, und dem saarländischen Landtag, der sich in einer eindrucksvollen Sitzung geschlossen für die Frankreichstrategie ausgesprochen hat.

Die deutsch-französische Freundschaft bedarf auch heute noch einer Vision. Die Saarbrücker Ärztin Frau Dr. Jesinghaus ließ mir vor einiger Zeit einen noch unveröffentlichten Brief des deutschen Schriftstellers Carl Zuckmayer aus dem Jahr 1963 an den Ministerialrat Ernst Klischer aus Riegelsberg zukommen:

Seit ich im ersten Weltkrieg gegen Frankreich kämpfen musste, und jeden Tag vor Verdun oder an der Somme als einen Tag des Brudermords empfand, liegt mir die endgültige Versöhnung der beiden Völker am Herzen. Nur gemeinsam und niemals getrennt oder verfeindet können sie ihre europäische Aufgabe erfüllen und ihrer historischen und kulturellen Sendung gerecht werden. Der erste Schritt zu dieser Aussöhnung ist getan, die Zukunft möge sich als dauerhaft und fruchtbar erweisen! (vgl. Abb. 1). 
Sesz is in exaten Lelotinig Segen Frankreich Taingugen mists, nzed fider fof wor herdin ocler as der vomme als liven Tag les Praider monds empland, liegh mis die and gi"ltige Versoinning der beiden Folffer an Wenten. Nin genciusare utd nienals grtienut oder verfeindet Konnes tic the eniropsaivalue Arjgobe enfillen nsed tures histariscer wid Ki'thirellen Sendury

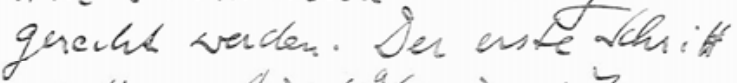

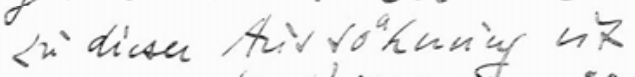
Getan, - dic tiknzyt moge tic

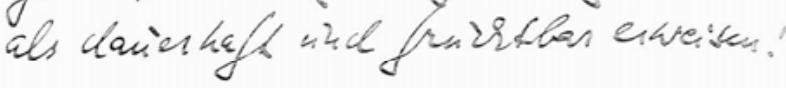

Gas-7ee, $28 \cdot T \cdot 963$

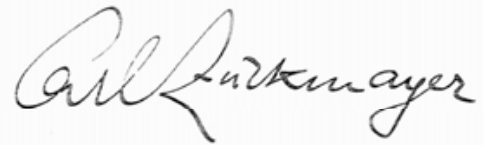

Abb. 1: Brief von Carl Zuckmayer an Ministerialrat Ernst Klischer, Saas-Fee, 28.01.1963. 
Zuckmayer gibt in dem Brief an den saarländischen Freund der Hoffnung Ausdruck, dass die Aussöhnung zwischen Deutschland und Frankreich zum Wohl Europas auf Dauer gestellt sein möge. Die Frankreichstrategie des Saarlandes gewinnt mit Blick auf das europäische Projekt und einmal mehr vor dem Hintergrund des ,Brexit' eine ganz neue Aktualität. Denn das Saarland verfolgt mit seiner Frankreichstrategie ein zivilgesellschaftliches Projekt, das für das deutsch-französische Verhältnis von großer Bedeutung ist. Aus einer aktuellen, binationalen Meinungsumfrage (Juni 2016) der beiden Forschungsinstitute infratest-dimap und TNS-Sofres im Auftrag des Saarländischen Rundfunks und des Deutsch-Französischen Journalistenpreises (DFJP) wird deutlich, dass das Ansehen Deutschlands und Frankreichs im jeweiligen Nachbarland von großer gegenseitiger Sympathie geprägt ist: $85 \%$ der Deutschen halten den französischen Nachbarn für sympathisch, umgekehrt sind es $74 \%{ }^{1}$ Sympathie zwischen den ehemals verfeindeten Völkern ist sicherlich wichtig, auch Solidarität, wie man sie angesichts der Attentate in Frankreich in Deutschland beobachten kann. Doch wirklich auf Dauer gestellt, wie von Zuckmayer erhofft, kann die deutsch-französische Freundschaft nur durch die vertiefte Kenntnis der Kultur und Sprache des Nachbarlandes sein. Gerade weil in vielen anderen Bundesländern kaum noch Französisch in den Schulen unterrichtet wird, ist es eine Chance, wenn im Saarland viele zukünftige Frankreichexperten ausgebildet werden und sich französischen Unternehmen im Saarland ein Brückenkopf nach Deutschland erschließt. „Die historisch gewachsene und in den letzten Jahrzehnten mit großen Anstrengungen ausgebaute Frankreichkompetenz ist eine große Chance für die Zukunft und die Eigenständigkeit unseres Landes“, heißt es programmatisch auf der ersten Seite der Eckpunkte einer Frankreichstrategie für das Saarland. ${ }^{2}$

Im Saarland soll bis 2043 neben der deutschen Sprache Französisch als zweite Verkehrs- und Umgangssprache etabliert werden, ein deutsch-französisch geprägter multilingualer Raum soll an der Grenze zu Frankreich und Luxemburg entstehen. Das Englische ist dabei als dritte Sprache immer mitgedacht. Eine Grenzraumdidaktik sieht das Französische als Begegnungssprache vor. Der Unterricht des Französischen vom Kindergarten an wird deshalb zu einer Priorität. Es würde sich daher anbieten, das Saarland als Ausbildungsort von ausgezeichneten Französischlehrern für ganz Deutschland zu profilieren.

1 Vgl. Saarländischer Rundfunk: Deutsch-Franz̈ösische Meinungsumfrage, http://www.sr.de/sr/ home/der_sr/kommunikation/aktuell/20160628_pm_deutsch_franzoesische_umfrage1 00.html (08.07.2016).

2 Staatskanzlei des Saarlandes: Eckpunkte einer Frankreichstrategie für das Saarland, 2014, http:/ / www.saarland.de/dokumente/res_stk/D_Eckpunkte_Frankreich-Strategie_210114.pdf (21.01.2014), hier S. 1. 
Doch die Konzentration auf das Frühfranzösisch in Kindergärten und Grundschulen, das eine wichtige Voraussetzung für eine erfolgreiche Umsetzung der Frankreichstrategie ist, hat einen blinden Fleck erzeugt. Denn eine Zukunftsvision braucht auch konkrete Ziele. Die Kinder und ihre Eltern müssen wissen, warum es für sie einen Vorteil darstellt, neben dem Englischen auch Französisch zu beherrschen. Gute Französischkenntnisse sind ein ,Sesam öffne Dich' für hoch attraktive deutsch-französische Studiengänge in Fachhochschulen und Universitäten im Saarland und in ganz Deutschland und Frankreich und stellen eine Versicherung für die Zukunft dar. Der französische Generalkonsul Frédéric Joureau hat dies auch erkannt: „Allein der Bildungsbereich bietet [im Saarland] ein ungeheuer großes Angebot, wie das deutsch-französische Gymnasium, das deutsch-französische Sekretariat für berufliche Mobilität und die deutsch-französische Hochschule“, erklärte er in einem Interview. ${ }^{3}$ Deshalb müsste in die Eckpunkte einer Frankreichstrategie ein weiteres Alleinstellungsmerkmal unter allen Umständen aufgenommen werden: die deutsch-französische Hochschulkooperation. Denn im Saarland und der Grenzregion SaarLorLux ist ein einzigartiges und in Deutschland einmaliges Labor für die Erprobung deutsch-französischer Studiengänge und Forschungskooperationen entstanden.

Die Universität des Saarlandes ist gleichsam ein Vorreiter der Frankreichstrategie, denn sie verdankt sich als zweisprachige Universität einer französischen Gründung. Schon 1946 begannen medizinisch-klinische Fortbildungskurse im Landeskrankenhaus Homburg/Saar. Am 8. März 1947 erfolgte die Eröffnung des anfangs unter der Ägide der Universität Nancy stehenden Centre Universitaire d'Etudes Supérieures de Hombourg für Mediziner. Unter Verschmelzung französischer und deutscher Bildungstraditionen öffnete die seinerzeit zweisprachige (!) Universität des Saarlandes im November 1948 ihre Pforten. Der Rektor Jean Barriol wünschte mit seiner Universität einer neuen Idee, einem neuen Ziel zu entsprechen:

Es handelt sich darum, diese Universität, an der Professoren und Studenten verschiedener Sprachen zusammenkommen werden, zum Werkzeug einer wahrhaft europäischen Gesinnung zu machen. [...] Die junge Universität des Saarlandes wird morgen ihren Platz inmitten der alten Universitäten Europas einnehmen. ${ }^{4}$

3 SR3-Interview mit Generalkonsul Frédéric Joureau vom 21.01.2014, Dauer 3 Minuten, https://www.welt.de/politik/deutschland/article124090161/Das-kleine-Saarland-wirdjetzt-zweisprachig.html (19.01.2017).

4 Barriol, Jean: Eröffnung der Universität des Saarlandes im November 1948, http://www.unisaarland.de/en/info/university/about/history/saarland-university-sixty-years-in-pictures/ eroeffnung1948.html (17.06.2016). 
Genau hier sollte eine Frankreichstrategie, die auch die lange Tradition der deutsch-französischen Universitätskooperation im Blick hat, ansetzen. Denn hier findet sich ein Alleinstellungsmerkmal, das in Zeiten der allseits geforderten Internationalisierung der Universitäten in Deutschland eine besondere Aufmerksamkeit verdient. Die erste juristische Lehrveranstaltung fand am 15. Februar 1948 statt. 1951 wurde das Europa-Institut gegründet, 1955 das Centre Juridique Franco-Allemand. Hier lehren zwei französische Professoren französisches Recht und vergeben - ein weiteres Alleinstellungsmerkmal in Deutschland - nationale französische Diplome. Bis heute verfügt die Universität auf Grund eines Staatsvertrags zwischen dem Saarland und der französischen Regierung darüber hinaus über eine durch eine Französin besetzte Professur in der Romanistik, die zugleich Direktorin des Institut d'Etudes françaises von Saarbrücken ist. Romana Weiershausen, die ebenfalls mit einem Beitrag in diesem Band vertreten ist, hat gegenwärtig die Professur für frankophone Germanistik an der Universität des Saarlandes.

Die Universität verfügt außerdem über ein Frankreichzentrum, das Disziplinen übergreifend alle deutsch-französischen Aktivitäten bündelt. V. a. aber bietet die Universität jungen Saarländerinnen und Saarländern, die des Französischen mächtig sind, eine erfolgreiche Zukunft mit ihren zahlreichen deutsch-französischen Doppeldiplomstudiengängen in Physik, Chemie, Human- und Molekularbiologie, Bioinformatik, Germanistik, Musikwissenschaft, Materialwissenschaft, Mechatronik, Jura, Geschichte und Geographie, Betriebswirtschaft, European Management und klassischer Archäologie. AuBerdem gibt es trinationale Studiengänge mit Luxemburg in der Physik und der Romanistik.

Doch die Internationalisierungs- und Mehrsprachigkeitsstrategie der Universität geht noch weiter. Mit den Universitäten von Luxemburg, Lüttich, Lorraine, Trier und Kaiserslautern hat sich die Universität des Saarlandes in einem Universitätsverbund, der Université de la Grande Région (UniGR), zusammengeschlossen (vgl. Abb. 2). Den 115000 Studierenden in der Großregion eröffnet sich die Möglichkeit eines Studiums in vier Ländern, in drei Sprachen und an sechs Universitäten, wenn sie die Sprache des Nachbarlandes erlernt haben! Denn sie können sich problemlos an den Universitäten des Netzwerks einschreiben und Veranstaltungen, die Mensa und die Bibliothek der anderen Universitäten besuchen und erhalten sogar die Fahrkosten zwischen den unterschiedlichen Standorten erstattet. Auch die Forschung ist grenzüberschreitend. Ein europäischer Doktortitel kann erworben werden, es gibt gemeinsame Workshops und Seminare, eine Forschungsdatenbank und eine Liste der Forschungsgroßgeräte, auf die die Forscher im Netzwerk der Großregion zurückgreifen können. 


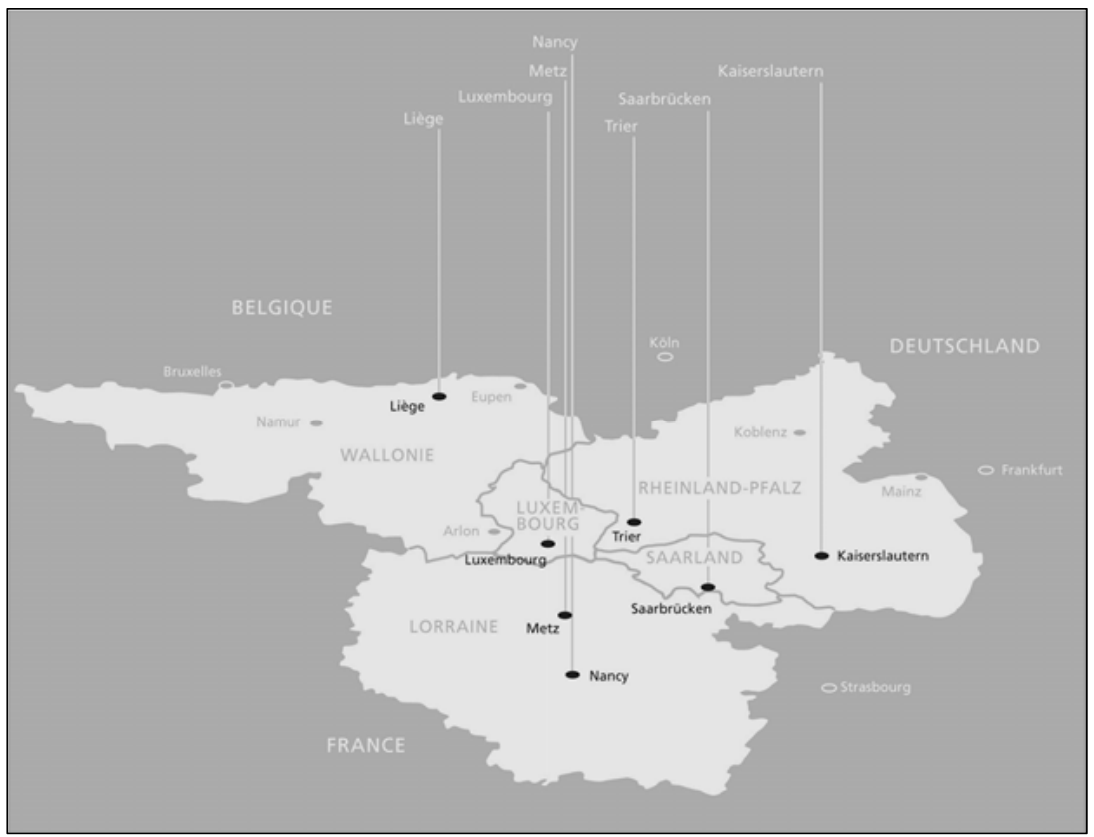

Abb. 2: Universität der Großregion (UniGR). ${ }^{5}$

Auch an der Hochschule für Technik und Wirtschaft des Saarlandes (HTW) eröffnet sich allen Studierenden mit Französischkenntnissen eine interessante Perspektive im Deutsch-Französischen Hochschulinstitut für Technik und Wirtschaft (DFHI), dem Institut Supérieur Franco-Allemand de Techniques d'Economie et de Sciences (ISFATES). Es ist ein gemeinsames, bereits 1978 gegründetes Saarbrücker Institut der Hochschule für Technik und Wirtschaft und der Université de Lorraine, das zwölf integrierte deutsch-französische Studiengänge mit Doppelabschlüssen anbietet und zwar in den Fächern Betriebswirtschaft (Bachelor und Master), Logistik (Bachelor), Internationales Tourismusmanagement (Bachelor), Informatik und Web-Engineering (Bachelor und Master), Elektrotechnik - Intelligente Systeme (Bachelor und Master), Maschinenbau (Bachelor und Master) und Europäisches Baumanagement (Bachelor und Master).

5 Universität der Großregion: Les universités, http://www.uni-gr.eu/fr/universites (19.01.2017). 
Doch das Saarland bietet nicht nur zahlreiche deutsch-französische Studiengänge an der HTW und der Universität. Alle integrierten deutsch-französischen Studiengänge an der Universität des Saarlandes, der Universität der Großregion und der HTW werden zusätzlich von der Deutsch-Französischen Hochschule evaluiert und gefördert. Diese hat ihren Sitz im Saarland, wird paritätisch vom deutschen und französischen Staat finanziert und bietet in Kooperation mit ihren 185 Mitgliedshochschulen, zu denen Universitäten, Fachhochschulen und Grandes Ecoles in ganz Frankreich und in ganz Deutschland, aber natürlich auch im Saarland und in Lothringen gehören, eine Vielzahl von deutsch-französischen Studiengängen an: in Ingenieurwissenschaften, Naturwissenschaften, Mathematik, Informatik, Rechtswissenschaften, Wirtschaftswissenschaften, Geistes- und Sozialwissenschaften, in der Lehrerbildung und Architektur. An die Studierenden vergibt sie Mobilitätsstipendien. Nach einem erfolgreichen Studium ohne eine Verlängerung ihrer Regelstudienzeit erhalten die Studierenden zwei nationale Abschlüsse. Der Reiz dieser deutsch-französischen Ausbildung liegt im Studium in einer deutsch-französischen Gruppe, denn die deutschen und französischen Studierenden verbringen die Hälfte ihres Studiums gemeinsam in Frankreich und die andere Hälfte gemeinsam in Deutschland. Dies garantiert eine vertiefte interkulturelle Erfahrung. Die Studierenden sind weltoffen, flexibel, neugierig und bilden ihre Persönlichkeit aus. Dies vermisst man oftmals in den am Bologna-System krankenden Studiengängen, in denen es nur noch um Scheinerwerb zu gehen scheint. Saarländische Schülerinnen und Schüler, die über Französischkenntnisse verfügen, wären prädestiniert für diese exzellenten Studiengänge, die ihnen beste Voraussetzungen für ihren beruflichen Werdegang garantieren. Aus einer Absolventenstudie von 2014 geht hervor, dass $70 \%$ der Absolventen der deutsch-französischen Studiengänge unter dem Dach der Deutsch-Französischen Hochschule bereits nach drei Monaten eine Stelle gefunden haben. ${ }^{6}$ Sie sind überall so begehrt, dass die Unternehmen inzwischen schon versuchen, sie bereits während des Studiums auf Grund ihrer Zweisprachigkeit und der interkulturellen Erfahrung, über die sie verfügen, durch Stipendien an sich zu binden. Frankreichkompetenz bzw. Deutschlandkompetenz erweist sich hier also als durchaus lukrativ. Die saarländischen Schülerinnen und Schüler, die über Französischkenntnisse verfügen, können unter fast 180 deutsch-französischen Studiengängen in ganz Deutschland und Frankreich wählen, allein im Saarland stehen Ihnen 25 deutsch-französische Studiengänge an der HTW und der Universität offen und sie erhalten die Aussicht auf eine sichere Anstellung. Wenn das kein Grund ist, Französisch in der Schule zu wählen!

6 Vgl. Deutsch-Französische Hochschule: Absolventenstudie 2014, https://www.dfh-ufa.org/ alumni/absolventenstudie/ (17.07.2016). 
Es wird Zeit, den blinden Fleck in der Frankreichstrategie zu tilgen und die bereits Wirklichkeit gewordene Vision einer weitreichenden deutsch-französischen Hochschulkooperation stärker in die Frankreichstrategie einzubinden.

\section{Literaturverzeichnis}

Barriol, Jean: Eröffnung der Universität des Saarlandes im November 1948, http:/ /www.uni-saarland. $\mathrm{de} / \mathrm{en} /$ info/university/about/history/saarland-university-sixty-years-in-pictures/ eroeffnung1948.html (17.06.2016).

Brief von Carl Zuckmayer an Ministerialrat Ernst Klischer, Saas-Fee, 28.01.1963.

Deutsch-Französische Hochschule: Absolventenstudie 2014, https://www.dfh-ufa.org/alumni/ absolventenstudie/ (17.07.2016).

Saarländischer Rundfunk: Deutsch-Franæösische Meinungsumfrage, http://www.sr.de/sr/home/ der_sr/kommunikation/aktuell/20160628_pm_deutsch_franzoesische_umfrage100.html (08.07.2016).

SR3-Interview mit Generalkonsul Frédéric Joureau vom 21.01.2014, Dauer 3 Minuten, https:// www.welt.de/politik/deutschland/article124090161/Das-kleine-Saarland-wird-jetztzweisprachig.html (19.01.2017).

Staatskanzlei des Saarlandes: Eckpunkte einer Frankereichstrategie für das Saarland, 2014, http:// www.saarland.de/dokumente/res_stk/D_Eckpunkte_Frankreich-Strategie_210114.pdf (21.01.2014).

Universität der Großregion: Les universités, http://www.uni-gr.eu/fr/universites (19.01.2017). 
Die Großregion - Arbeit und Ausbildung,

Gesundheitswesen, Medien

La Grande Région - Emploi et formation, santé, médias 



\section{Grenzverkehrt - Perspektiven des Arbeits- und Ausbildungsmarktes der Großregion}

Le marché du travail transfrontalier de la Grande Région est particulier en Europe, et ce, pas seulement depuis l'accord de Schengen. Presqu'aucune autre région européenne ne présente une histoire aussi mouvementée du tracé de ses frontières que l'on doit surtout à des raisons économiques. L'ouverture de la Grande Région est aujourd'bui un acquis historique qui n'est remis en question ni par différents intérêts économiques ni par des divergences d'opinions entre Berlin et Paris.

Cependant, malgré d'énormes efforts, cette ouverture ne s'est pas encore vue renforcée par une politique de la Grande Région qui mettrait les intérêts stratégiques communs audessus des égoïsmes nationaux. On observe cela notamment au niveau du marché du travail et de l'apprentissage qui offre des chances et des perspectives communes, mais dont la réalisation échoue fréquemment parce que les frontières persistent.

\section{Grenzen verkehrt - wächst zusammen, was zusammengehört?}

Die Zeiten haben sich verändert. Die Euphorie eines friedlich vereinten und grenzenlosen Europa ist verflogen und einer Renaissance der nationalen Egoismen gewichen. Im Schengen-Raum werden wieder Mauern und Zäune gebaut und in allen Mitgliedsstaaten haben antieuropäische, nationalistische Bewegungen Zulauf. Auch in Deutschland ist es wieder zur Mode geworden, über Fremde zu hetzen und Brandsätze in bereitgestellte Unterkünfte zu werfen - wer mag schon neben Jérôme Boateng wohnen, wenn er neben Alexander Gauland ${ }^{1}$ leben kann? Im Zeichen von Debatten über ,Grexit', ,Brexit ${ }^{\star}$ (und wer immer noch aus der EU austreten möchte) erscheint die Frankreichstrategie eines deutschen Bundeslandes seltsam antiquiert und gegen den Trend.

1 Am Sonntag, den 29. Mai 2016, hat der stellvertretende AfD-Vorsitzende Alexander Gauland in einem Interview mit der Frankfurter Allgemeinen Sonntagszeitung entsprechend des Berichts gesagt: „Die Leute finden ihn als Fußballspieler gut. Aber sie wollen einen Boateng nicht als Nachbarn haben." Schlimm ist weniger die Aussage an sich, als die Tatsache, dass solche Positionen mittlerweile von einem Fünftel der Bundesbürger geteilt oder zumindest mit ihrer Unterstützung goutiert werden. Vgl. Wehner, Markus/Lohse, Eckart: „Nicht als Nachbarn“ Gauland beleidigt Boateng, in: Frankfurter Allgemeine Zeitung, 29.05.2016, http://www.faz.net/aktuell/politik/inland/afd-vize-gauland-beleidigtjerome-boateng-14257743.html (20.12.2016). 
Es ist nicht das erste Mal, dass von der Region an Saar und Mosel grenzüberschreitende Impulse ausgehen. Noch vor hundert Jahren hätte der Terminus ,Frankreichstrategie eine ganz andere Bedeutung gehabt. Man hätte darunter den von der Generalität des Deutschen Reichs ausgearbeiteten und als vollkommen ,alternativlos ${ }^{6}$ angesehenen Schlieffen-Plan verstanden, der eine schnelle militärische Unterwerfung Frankreichs durch die Umgehung der barrière de fer vorsah, damit sich die deutschen Kräfte dann auf die Ostfront hätten konzentrieren können. Diese ,Frankreichstrategie endete im Desaster des brutalen Grabenkriegs und in der Hölle von Verdun, die heute zum Mahnmal deutsch-französischer Aussöhnung geworden ist.

Im Saarland, in der Pfalz, im Elsass, in Lothringen und in den Ardennen also auch in Gebieten Belgiens und Luxemburgs - sind viele Zeugnisse dieser blutigen Geschichte des ,alten Europa' zu finden: Bitche, Spicheren und die Kampfgebiete des Deutsch-Französischen Kriegs 1870/71; Hackenberg, Schoenenbourg und die anderen Befestigungsanlagen der Maginot-Linie; die Schlachtfelder und Grabenanlagen des Ersten Weltkriegs zwischen Saint-Mihiel und Lille; die Kriegsgebiete der Ardennenoffensive im Zweiten Weltkrieg zwischen Bastogne und St. Vith. Die Großregion Lothringen, Luxemburg, Rheinland-Pfalz, Saarland und Wallonien ist wie kaum ein anderer geographischer Raum in Europa durch Grenzziehungen und die damit verbundenen Kriege gezeichnet. Es mag daran liegen, dass die Menschen hier dem Gedanken eines grenzenlosen Europa intensiver verbunden sind als anderswo. Eine ,Frankreichstrategie“ zur Aussöhnung und Sicherstellung des friedlichen $\mathrm{Zu}-$ sammenlebens war dementsprechend dringend notwendig.

Und es hat sie auch gegeben: Die Großregion ist nämlich mittlerweile nicht nur zu einer politischen Einheit zusammengewachsen, ${ }^{2}$ sie war auch Motor der europäischen Einigung und des Abbaus von Grenzen. Es begann schon unmittelbar nach dem Zweiten Weltkrieg mit einem der bedeutendsten Söhne dieser Region, Robert Schuman, der als Reichsdeutscher in Luxemburg geboren wurde, als französischer Staatsbürger zum Außenminister aufstieg und wie kein zweiter Politiker die deutsch-französische Aussöhnung und die europäische Einigung vorantrieb. ${ }^{3}$ Der von ihm entwickelte Schuman-Plan half, diese Ziele zu verwirklichen, und mündete schließlich in die Europäische Union.

Es ist auch kein Zufall, dass mit dem ehemaligen deutschen Bundeskanzler Helmut Kohl ein anderer großer Europäer diese Region zum Ausgangspunkt des Falls der Grenzen und zum Symbol der europäischen Einheit

2 Vgl. Internetseite der Großregion: http://www.granderegion.net (10.07.2016).

3 Zum Leben und Wirken von Schuman vgl. Benning, Hermann J.: Robert Schuman. Leben und Vermächtnis, München [u. a.]: Verlag Neue Stadt, 2013. 
werden ließ. Das auf einem Schiff im Dreiländereck bei Schengen unterzeichnete und v. a. in Saarbrücken und Metz verhandelte Abkommen ${ }^{4}$ öffnete die Grenzen, für die über Jahrhunderte in der Großregion Blutzoll gezahlt wurde und schlug ein neues Kapitel in der europäischen Geschichte auf. Wiederum erscheint 2015 eine ,Frankreichstrategie“ des Saarlandes seltsam überholt und wenig aktuell, wenn auch aus vollständig anderen Gründen.

Wer sich der Frage nähern will, warum gerade heute eine ,Frankreichstrategie‘ im Saarland sinnvoll sein mag, kann verschiedene Wege einschlagen. Der gewählte Zugang erfolgt über die Ökonomie. Angesichts der Diskussionen über die transatlantischen Freihandelsabkommen CETA (Comprehensive Economic and Trade Agreement) und TTIP (Transatlantic Trade and Investment Partnership), deren Vorgängerinitiative MAI (Multilaterales Abkommen über Investitionen) übrigens am Widerstand Frankreichs scheiterte, ${ }^{5}$ ist die Frage nach Grenzen in der Ökonomie gerade sehr aktuell. Die damit verbundenen Herausforderungen sollen im nächsten Abschnitt am Beispiel des grenzüberschreitenden Pendelverkehrs in der Großregion skizziert werden.

Aus einem solchen grenzüberschreitenden Pendelverkehr ergibt sich ein Regelungsbedarf, der nicht auf bestehende Institutionen zurückgreifen kann. Die aus politischen Einheiten auf unterschiedlichen Ebenen zusammengesetzte Großregion hat deshalb schon früh grenzüberschreitende Institutionen zur Gestaltung des grenzüberschreitenden Arbeitsmarktes gebildet, auf die im dritten Kapitel eingegangen werden soll. Schließlich ist die Frage zu erörtern, inwieweit die Frankreichstrategie des Saarlandes den Herausforderungen des grenzüberschreitenden Arbeitsmarktes gerecht wird.

\section{Der Grenzverkehr - Wanderungsströme und ihre Gründe}

Die Wirtschaft ist schon immer einer der wichtigsten Anlässe gewesen, Grenzen zu überschreiten. Dies lässt sich in der Großregion jeden Tag beobachten,

4 Genau genommen handelt es sich um die erste einer Reihe von Vereinbarungen, die zur Grenzöffnung in Europa führte. Gemeint ist hier das „Übereinkommen vom 14. Juni 1985 zwischen den Regierungen der Staaten der Benelux-Wirtschaftsunion, der Bundesrepublik Deutschland und der Französischen Republik betreffend den schrittweisen Abbau der Kontrollen an den gemeinsamen Grenzen“" (Schengen I; EUR-Lex: http:/ /eur-lex.europa. eu/legal-content/DE/TXT/?uri=CELEX\%3A42000A0922(01) (11.06.2016)). Zur Geschichte der Schengener Abkommen vgl. Pudlat, Andreas: Schengen. Zur Manifestation von Grenze und Grensschutz, in Europa, Hildesheim [u. a.]: Georg Olms Verlag, 2013 (Historische Europa Studien Band 7).

5 Vgl. Glunck, Fritz R. (Hg.): Das MAI und die Herrschaft der Konzerne. Die Veränderung der Welt durch das Multilaterale Abkommen über Investitionen, München: dtV, 1998. 
wenn z. B. die lothringische Familie in der Saarbrücker Innenstadt ihre Einkäufe macht, die Saarländer nach Luxemburg zum Tanken fahren oder die Luxemburger sich aufgrund der günstigeren Immobilienpreise eine Wohnung in Trier anmieten. Dies alles ist mittlerweile genauso selbstverständlich geworden wie die Tatsache, dass Produkte aus Belgien, Deutschland, Frankreich und Luxemburg (und vielen anderen Ländern der Welt) in jedem Supermarkt in der Großregion zu kaufen sind.

Und doch kennzeichnet die Großregion bezüglich des grenzüberschreitenden Wirtschaftens eine Besonderheit, die der Geologie geschuldet ist und die Politik der letzten beiden Jahrhunderte nachhaltig geprägt hat. Kohle, Eisen und Stahl waren seit Mitte des 19. Jahrhunderts die Triebfedern der Industrialisierung und die entsprechenden Rohstoffe konnten in der Großregion reichhaltig gefunden werden. ${ }^{6}$ Die Montanindustrie war sowohl im Saarland als auch in Lothringen und Luxemburg der Motor für wachsenden Wohlstand und wirtschaftliche Prosperität. ${ }^{7}$

Kohleflöze und Erzlagerstätten halten sich allerdings nicht unbedingt an die von Menschen gezogenen Grenzen ${ }^{8}$ und so war mit dem Aufstieg der Montanindustrie in der Region ein intensiver grenzüberschreitender Handel mit Rohstoffen verbunden, der schon früh zur Herausbildung multinationaler Konzerne geführt hat (und sich dabei nicht nur auf den Bereich von Kohle, Eisen und Stahl beschränkte). ${ }^{9}$ Die industrielle Bedeutung der Montanindustrie und ihrer Produkte weckte jedoch auch die Begehrlichkeiten des Nachbarn

6 Zur Bedeutung in Deutschland siehe z. B. Czymoch, Kai-Uwe: Die deutsche Stablindustrie im 20. Jabrbundert: Der Niedergang eines Führungssektors, Saarbrücken: AV Akademiker Verlag, 2012; Ziegler, Dieter (Hg.): Rohstoffgeninnung im Strukturwandel. Der deutsche Bergbau im 20. Jabrbundert, Münster: Aschendorff, 2013. Speziell im Saarland siehe Slotta, Delf: Das Steinkoblerevier an der Saar. Eine Zeitreise durch mehr als 250 Jabre Industrie- und Landesgeschichte, Saarbrücken: RAG, 2011; Schreiber, Karsten/Zwick, Martin: Die regionalwirtschaftliche Bedeutung der Stablindustrie für das Saarland, Saarbrücken: Verband der Saarhütten, 2012.

7 Vgl. z. B. Gehring, Jean-Marie: Développement industriel en espace transfrontalier: l'exemple de Saar-Lor-Lux, in: Mosella. Revue du Centre d'études géographiques de l'Université de Meto, Tome XVII (1987), nº spécial, S. 43-56. Vgl. zudem Als, Georges: L'évolution de l'industrie luxembourgeoise. Mutations économiques et mutations industrielles, in: FEDIL (Fédération des industriels luxembourgeois) (Hg.): FEDIL 1918-1993, Luxembourg: FEDIL, 1993, S. 43-63; vgl. zudem Roth, François: Réflexions sur l'industrialisation de la Lorraine et du Luxembourg (1850-1950), in: Hémecht. Revue d'bistoire luxembourgeoise 3 (1994), S. 637653.

8 Die Steinkohlevorkommen in der Großregion konzentrierten sich weitgehend auf das Saarland vom Warndt bis Neunkirchen. Dagegen konnte das für die Stahlproduktion notwendige phosphorreiche Eisenerz in der Gegend um Nancy und westlich der Mosel von Metz und Thionville bis Longwy gewonnen werden (die lothringische Minette).

9 Siehe z. B. Becker, Susan: „Multinationalität hat verscbiedene Gesichter“. Formen internationaler Unternehmenstätigkeit der Société Anonyme des Mines et Fonderies de Zinc de la Vieille Montagne und der Metallgesellschaft vor 1914, Wiesbaden: Franz Steiner Verlag, 2002. 
und die deutsch-französischen Kriege des 19. und 20. Jahrhunderts hatten soweit es die Region um Saar und Mosel betraf - auch immer wirtschaftliche Komponenten. ${ }^{10}$

Der Rohstoffreichtum der Region war somit Segen und Fluch zugleich und dies betraf auch die wirtschaftliche Entwicklung nach Kriegsende. Bis in die 1960er Jahre hinein waren im Saarland knapp 100000 Menschen in der Montanindustrie beschäftigt und diese Zahl reduzierte sich dann in Folge der Strukturkrise auf ca. 15 000, die heute nach der Einstellung des Kohlebergbaus noch im Stahlsektor tätig sind. Die Entwicklungen in Lothringen und in Luxemburg verliefen ähnlich dramatisch und die Produktion von Kohle und Stahl hat in der Großregion insgesamt in den letzten vierzig Jahren an Bedeutung verloren (vgl. Abb. 1).

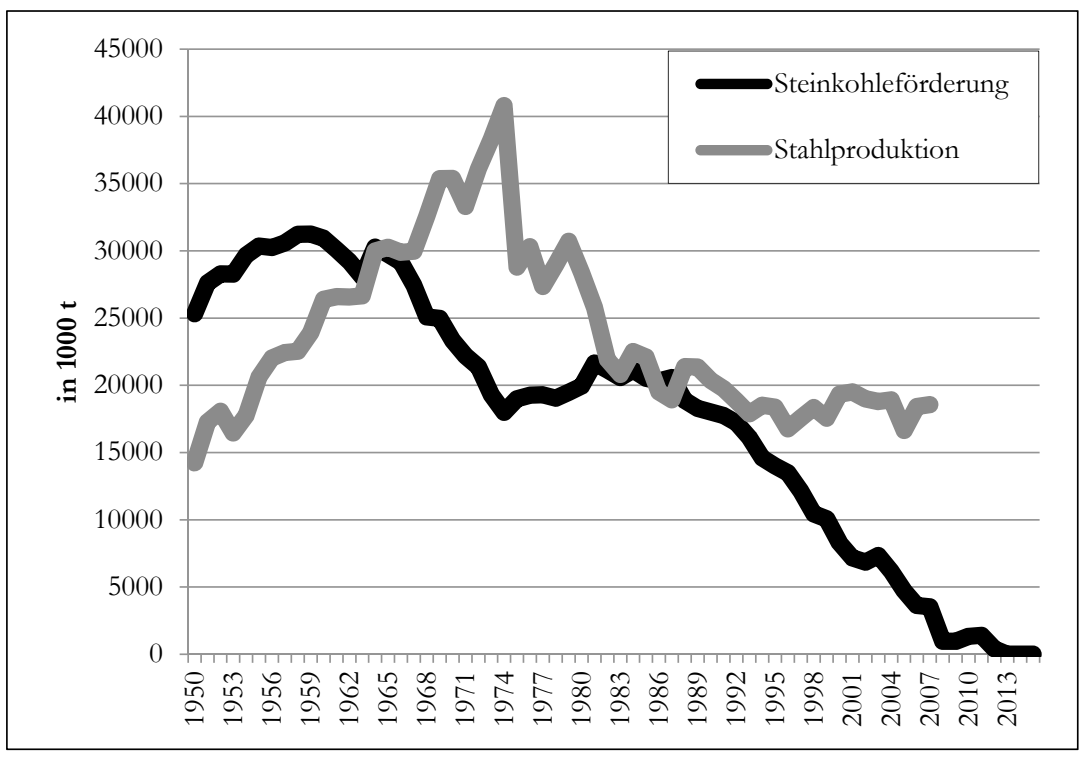

Abb. 1: Steinkohleförderung und Stahlproduktion in der Großregion 1950 bis 2015.11

10 Vgl. z. B. Henning, Friedrich-Wilhelm: Die Industrialisierung in Deutschland 1800 bis 1914, Paderborn [u. a.]: Schöningh, 2008 (UTB, 9).

11 Eigene Darstellung. Vgl. Statistik der Großregion: http://www.grande-region.lu/ (09.11.2016) (Saarland: Produktionsstatistiken; Lorraine: Ministère en charge de l'énergie CGDD/SOeS, Direction régionale de l'environnement, de l'aménagement et du logement DREAL, Centre professionnel des statistiques de l'acier; Luxembourg: Arcelor Mittal; Wallonie: GSV). 
Dies wirkt sich auch auf den Arbeitsmarkt aus: Im grenznahen Frankreich (Champagne, Elsass und Lothringen) ist die Beschäftigung im Industriesektor in den letzten zehn Jahren um über $20 \%$ zurückgegangen. ${ }^{12}$ In Luxemburg ist die Beschäftigungsentwicklung in der Industrie in vergleichbar drastischem Maße rückläufig. Mittlerweile trägt die Montanindustrie nur noch marginal zum Bruttosozialprodukt des Landes bei (2,7\%). Viele der wirtschaftlichen Probleme der Großregion sind dieser Strukturkrise in der Montanindustrie geschuldet.

Der Niedergang der Montanindustrie, die viele Jahrzehnte Motor des grenzüberschreitenden Handels und Warenverkehrs gewesen ist, mündete jedoch nicht in einem Rückgang der Grenzgänger. Vielmehr war das Gegenteil der Fall: Bedingt durch das Schengener Abkommen ist der arbeitsbedingte Grenzverkehr seit Mitte der 1980er Jahre kontinuierlich angestiegen und hat im letzten Jahr mit 215000 Grenzgängern eine neue Rekordmarke erreicht. ${ }^{13}$ Insgesamt können dabei fünf verschiedene grenzüberschreitende Mobilitätsprozesse unterschieden werden, die zumeist Luxemburg zum Ziel haben (vgl. Abb. 2).

Während die noch zu Beginn der 1980er Jahre dominierende arbeitsplatzbedingte Mobilität von Lothringen ins Saarland in den letzten zehn Jahren relativ gesehen an Bedeutung verloren hat, scheint die Wichtigkeit des Luxemburger Arbeitsmarktes für die Großregion unaufhaltsam zu wachsen. Zwischen 1985 und 2001 sind in Luxemburg 117000 neue Arbeitsplätze geschaffen worden, und auch im 21. Jahrhundert setzte sich der Trend - trotz einer Krise im Jahr 2009 - nahezu unverändert fort. ${ }^{14}$

12 Vgl. Institut national de la statistique et des études économiques (INSEE): Un tissu productif régional tonjours spécialisé dans l'industrie, Strasbourg: INSEE, 2016 (INSEE Analyses AlsaceChampagne-Ardenne-Lorraine $\mathrm{n}^{\circ} 6$ Mars).

13 Vgl. IBA-Aktuell, 20.05.2016, http://www.iba-oie.eu/fileadmin/user_upload/IBAAktuell/160520_Entwurf_IBA-Aktuell_Einpendlerzahlen_Lux_SL_RLP_Wallonie_ 2015_FR.pdf (20.12.2016).

14 Anstieg der Arbeitsplätze zwischen 2000 und 2013 um 83,4 \%, für Details siehe Dautel, Vincent/Walther, Olivier: Beschäftigungsdynamik in der Metropolregion, in: Bousch, Patrick [u. a.] (Hg.): Der Luxemburg Atlas - Atlas du Luxembourg, Luxemburg: emons, 2009, S. $128 \mathrm{f}$. 


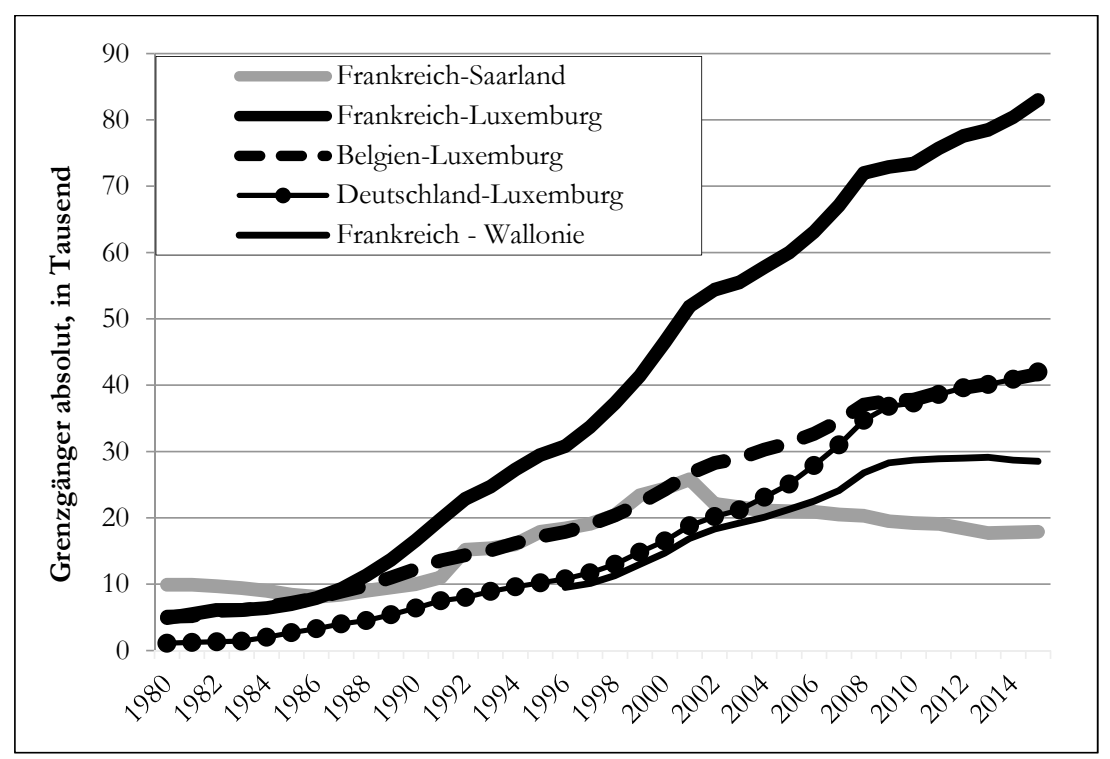

Abb. 2: Grenzgängerentwicklung in der Großregion 1980 bis 2015.15

Gleichzeitig stieg dabei auch die Bedeutung der Grenzgängerbeschäftigung in Luxemburg: Mittlerweile ist dort fast jeder zweite Arbeitsplatz (43,5\%) durch Pendler aus der Großregion besetzt und bis 2009 wurden zwei Drittel der neugeschaffenen Arbeitsplätze durch ausländische Staatsbürger eingenommen. ${ }^{16}$ Motor dieser Entwicklung ist der Dienstleistungssektor (insbesondere im Finanzbereich), welcher nicht nur den dramatischen Rückgang der Beschäftigung in der luxemburgischen Montanindustrie kompensieren, sondern auch den ebenfalls stark von der Strukturkrise betroffenen lothringischen Arbeitsmarkt entlasten konnte. Die Grenzöffnung und die damit verbundenen Erleichterungen für die Arbeitsmigration kamen dementsprechend v. a. dem

15 Eigene Darstellung. Vgl. Interregionale Arbeitsmarktbeobachtungsstelle (IBA): Die Arbeitsmarktsituation in der Großregion. Gren₹gängermobilität. 9. Bericht der Interregionalen Arbeitsmark:tbeobachtungsstelle an den 14. Gipfel der Exekutive der Großregion November 2014, Saarbrücken: IBA, 2014; vgl. IBA-Aktuell, 20.05.2016; vgl. Wille, Christian: Grenzüberschreitender Arbeitsmarkt in der Großregion SaarLorLux. Politische Visionen und empirische Wirklichkeiten, in: Lorig, Wolfgang H./Regolot, Sascha/Henn, Stefan (Hg.): Die Großregion SaarLorLux. Anspruch, Wirklichkeiten, Perspektiven, Wiesbaden: Springer, 2016, S. 115-143, hier S. 121, S. 129.

16 Vgl. IBA: Die Arbeitsmarktsituation in der Großregion, hier S. 18-23. 
luxemburgischen Dienstleistungssektor zugute und trugen wesentlich zum wirtschaftlichen Aufstieg Luxemburgs bei.

Zunehmend gewinnt auch der Pendelverkehr von Deutschland nach Luxemburg an Bedeutung, allerdings mit leichten Verschiebungen hinsichtlich der Branchen und den damit verbundenen Qualifikationsanforderungen. Besonders hervorzuheben ist dabei, dass die aus Deutschland stammenden Beschäftigten in Luxemburg aufgrund ihrer höheren Qualifikationen und stärkeren internationalen Ausrichtung vorrangig im Finanzsektor und bedingt durch das hohe Ansehen der dualen Berufsausbildung im Baugewerbe beschäftigt sind, während die aus Frankreich stammenden Erwerbstätigen traditionell besonders stark im verarbeitenden Gewerbe und in jüngster Zeit verstärkt im Handel und Kfz-Bereich tätig sind. Bemerkenswert ist auch die Tatsache, dass in dem für Universitätsabsolventen besonders wichtigen Bereich der freiberuflichen wissenschaftlichen und technischen Dienstleistungsberufe vorwiegend Belgier einen Arbeitsplatz in Luxemburg finden. ${ }^{17}$

Die Entwicklung im Saarland, welches seit Ende des Zweiten Weltkriegs mit seiner Montanindustrie für viele lothringische Arbeitnehmer Beschäftigungsmöglichkeiten bot, verlief deutlich anders. Im Unterschied zu den Betrieben auf der französischen Seite gelang es besser, den industriellen Bestand zu sichern und neue Produktionsanlagen zu etablieren. Dies betraf v. a. die Automobilindustrie, welche grenzüberschreitend die Großregion zu einem bedeutenden Standort der Zulieferindustrie werden ließ. Im Saarland sind mittlerweile $40 \%$ der Industriebeschäftigten in diesem Sektor tätig. Hierdurch blieb bis in die jüngste Zeit weiterhin die Industrie (speziell der Automobilsektor) und weniger der Dienstleistungssektor Antriebskraft für die grenzüberschreitende Arbeitsmobilität: $56 \%$ der lothringischen Arbeitnehmerinnen und Arbeitnehmer sind in der Industrie tätig, in Luxemburg beträgt dieser Anteil lediglich $18 \%{ }^{18}$

Diese hat sich allerdings in den letzten zehn Jahren in zweierlei Hinsicht deutlich verändert. Erstens ist entgegen des Trends die absolute Zahl der aus Lothringen ins Saarland pendelnden Personen kontinuierlich gesunken und zweitens verlagerte sich diese Wanderungsbewegung sukzessive in Richtung ,atypischer ${ }^{6}$ Grenzgänger, also deutschen Staatsbürgern, die ihren Wohnsitz nach Frankreich verlagert haben, ohne dort über einen Arbeitsplatz zu verfügen. Die Grenzgänger-Population im Saarland altert im Durchschnitt und die Sogwirkung für junge lothringische Arbeitskräfte ist gering.

Die umgekehrte Wanderungsrichtung - also aus dem Saarland und Rheinland-Pfalz nach Lothringen - hat in der Großregion seit den 1950er

17 Vgl. IBA: Die Arbeitsmarktsituation in der Großregion, S. 24.

18 Vgl. IBA: Grenzgänger und grenzüberscbreitender Arbeitsmarkt in der Großregion, Saarbrücken: IBA, 2005, S. 47. (Themenheft im Rahmen des Gesamtvorhabens „Stand, Perspektiven und Handlungserfordernisse des Arbeitsmarkts der Großregion bis 2020“). 
Jahren und den ersten Krisen des Kohlebergbaus in Lothringen keine besondere Rolle gespielt. Aktuell überqueren 1028 Deutsche vorrangig aus dem Saarland und Rheinland-Pfalz die Grenze nach Lothringen, um dort zu arbeiten. ${ }^{19}$ Eine ,Frankreichstrategie ${ }^{6}$ zur Veränderung dieser Fakten käme einem Wirtschaftsförderungsprogramm für Lothringen gleich, welches das über zwei Jahrhunderte gewachsene wirtschaftliche Gefälle ebenso wirksam verändern möchte, wie dies in Luxemburg in den letzten dreißig Jahren geschehen ist.

Aus saarländischer Sicht ist allerdings fraglich, ob eine solche ,Frankreichstrategie‘ erstrebenswert wäre. Angesichts des demographischen Wandels, der mittlerweile im Saarland zu einem spürbaren Bevölkerungsrückgang führt, muss es vorrangiges Ziel des Bundeslandes sein, seine Attraktivität für junge Fachkräfte zu erhöhen und zur Vermeidung eines gravierenden Fachkräftemangels wirksame Maßnahmen in diese Richtung zu implementieren. Eine ,Frankreichstrategie' macht in diesem Kontext also durchaus Sinn und junge Lothringerinnen und Lothringer könnten hierfür eine wichtige Zielgruppe darstellen. Gegenwärtig ziehen diese allerdings eindeutig den Luxemburger Arbeitsmarkt vor und im Saarland müssten daher gezielt Barrieren abgebaut und attraktive Arbeitsplätze im Dienstleistungsbereich geschaffen werden. Dies müsste aus wirtschaftlichen und arbeitsmarktpolitischen Erwägungen wesentlicher Bestandteil einer saarländischen ,Frankreichstrategie‘ sein.

Die Universität des Saarlandes kann in diesem Rahmen sicherlich eine wichtige Rolle spielen. Zum einen wird dies bedingt durch den Höherqualifizierungstrend am Arbeitsmarkt, der insbesondere im Dienstleistungsbereich zum Tragen kommt. Während die traditionellen Arbeitsplätze in der Montanindustrie (und auch im Automobilsektor) durch die Facharbeiterebene getragen werden und in diesem Bereich auch viele angelernte Arbeiterinnen und Arbeiter einzusetzen waren, gilt dies für den Finanzsektor und die unternehmensnahen Dienstleistungen nicht mehr in demselben Ausmaß. Hier gewinnen akademische Ausbildungen zunehmend an Bedeutung und damit auch ein höheres Gewicht für den grenzüberschreitenden Pendelverkehr.

Zum anderen stellen Universitätsabsolventen nicht nur aufgrund von Unternehmensgründungen ein Innovationspotenzial für den regionalen Arbeitsmarkt dar, sondern auch durch die Herausbildung von Forschungseinrichtungen und Thinktanks, die besonders im unternehmensnahen Dienstleistungsbereich Neuerungen entwickeln und vermarkten können. Hier hat es im Saarland in den letzten Jahren durchaus erfolgreiche Bemühungen gegeben. 
Bisher sind deren Auswirkungen für den grenzüberschreitenden Arbeitsmarkt jedoch eher bescheiden geblieben. ${ }^{20}$ Obwohl z. B. die Saaruniversität in Deutschland zu den Hochschulen mit dem höchsten Ausländeranteil gehört und jeder vierte Studienanfänger nicht aus Deutschland stammt, finden nur wenige Hochschulberechtigte aus der nicht deutschen Großregion ihren Weg nach Saarbrücken oder Homburg. Lediglich knapp $5 \%$ der Studienanfänger kommen aus Lothringen, Luxemburg oder Wallonien (vgl. Abb. 3).

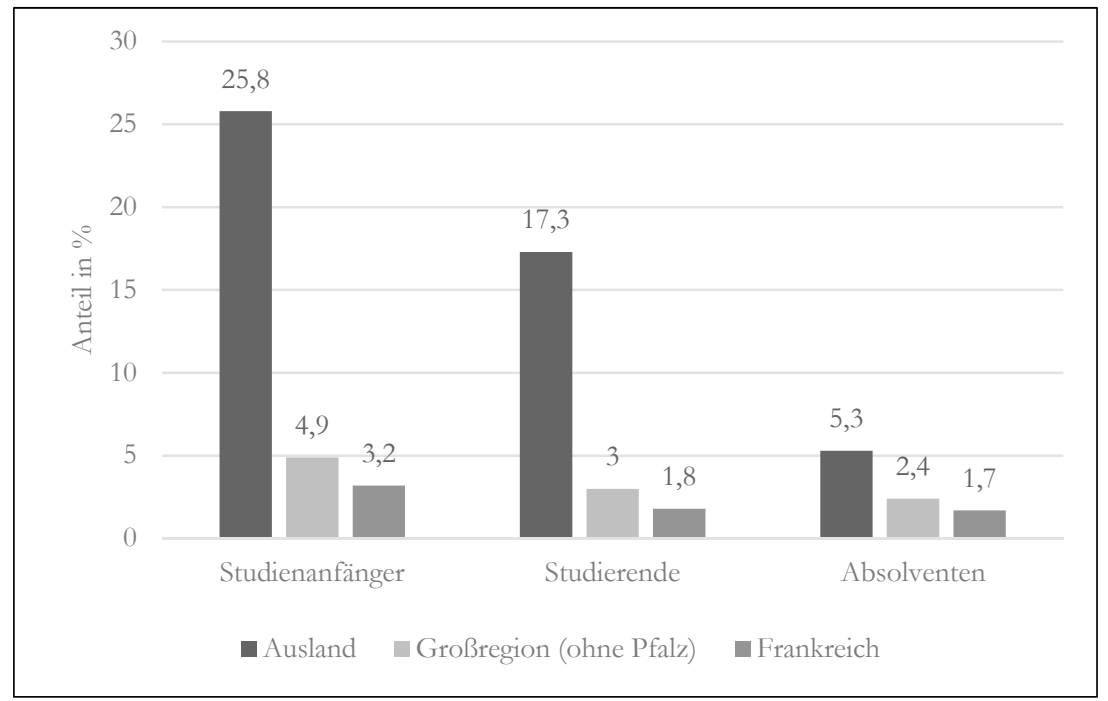

Abb. 3: Herkunft der Studierenden der Universität des Saarlandes (WS 2014/15). ${ }^{21}$

Insbesondere der geringe Anteil von Französinnen und Franzosen bei Studienanfängern, Studierenden und Absolventen (2-3\%) kann sicher als Argument für eine Frankreichstrategie gesehen werden, v. a. unter Berücksichtigung der französischen Wurzeln der Saaruniversität. ${ }^{22}$ Dies gilt auch

20 Vgl. Rech, Jörg/Meyer, Wolfgang: Europakompetenz in der saarländischen Arbeitswelt: Wie sieht die saarländische Arbeitswelt Europakompetenz?, in: Rampeltshammer, Luitpold/Kurtz, Hans Peter (Hg.): Europakompetenz entwickeln Interregionalkompetenz stärken, Saarbrücken: Verlag Alma Mater, 2009, S. 93-134.

21 Eigene Darstellung. Vgl. Gassmann, Freya [u. a.] (Hg.): Was kommt nach dem Studium an der Universität des Saarlandes? Empirische Befunde einer fächerübergreifenden Absolventenstudie, Saarbrücken: universaar, 2015, hier S. 79 f.

22 Vgl. Müller, Wolfgang: L’Université de Nancy, ,,mère“ des institutions universitaires sarroises et la coopération entre la Sarre et la Lorraine dans le domaine universitaire, in: Le Pays 
bezüglich der Erwerbstätigkeit, denn nur ein ähnlich niedriger Prozentsatz der Absolventen der Universität des Saarlandes findet eine Beschäftigung in Frankreich und nur wenig mehr ziehen dies überhaupt in Erwägung (12\%). Die Sprache stellt hier - wenig überraschend - die wichtigste Barriere dar (vgl. Abb. 4).

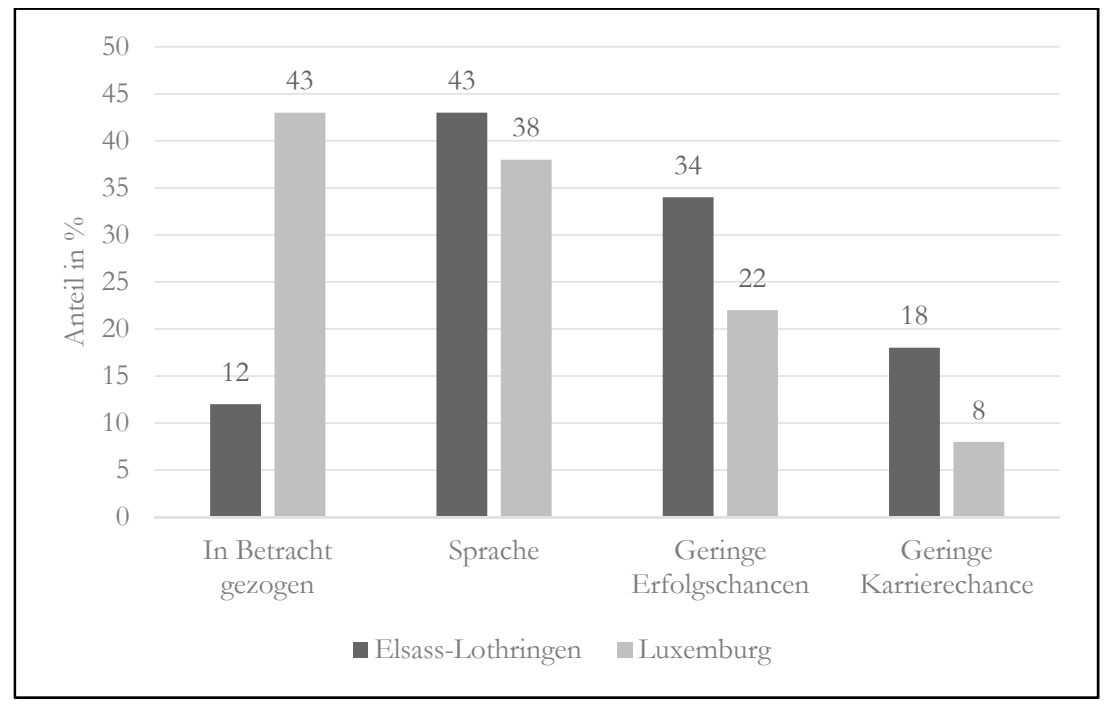

Abb. 4: Gründe für fehlende Bewerbungen in der Großregion (Absolventen 2007-2014). ${ }^{23}$

In den gegenwärtigen Diskussionen über die Zukunft der Saaruniversität spielen allerdings solche Überlegungen keine Rolle. Vielmehr entsteht hier der Eindruck, als ginge es vorrangig um den Aufbau einer technischen Universität mit Schwerpunktbereichen, die v. a. der Industrie nützlich sind. ${ }^{24}$ Die Affinität zu den technisch-naturwissenschaftlichen Fächern der Verantwortungsträger ist zwar aufgrund der saarländischen Industriegeschichte verständlich, geht aber an der Realität der Universität des Saarlandes vorbei und verkennt

Lorrain, Revue de la Societé d'Histoire de la Lorraine et du Musée Lorrain, 107e Année/Vol. 91, 03.09.2010, S. 221-230.

23 Eigene Darstellung. Vgl. Gassmann [u. a.]: Was kommt nach dem Studium?, hier S. 121-124.

24 Dies gilt speziell bei den Stellungnahmen der IHK als Vertreter der saarländischen Wirtschaft. So heißt es z. B. bei Giersch, Volker: Mehr Profil, weniger Breite. Unsere Hochschulen brauchen eine klare Perspektive, in: Saarwirtschaft 3 (2014), S. 62-63, hier S. 63: „Der für die Saarwirtschaft wichtigste Hochschulbereich werden auch in Zukunft die Ingenieurwissenschaften sein“. 
ihre tatsächliche Ausbildungsleistung für das Land sowie die regionalen Potenziale. In der Tat finden nur sehr wenige Absolventen der Universität unmittelbar eine Beschäftigung in der Industrie und selbstverständlich fragt die Saarwirtschaft nicht primär Ingenieure nach (vgl. Abb. 5).

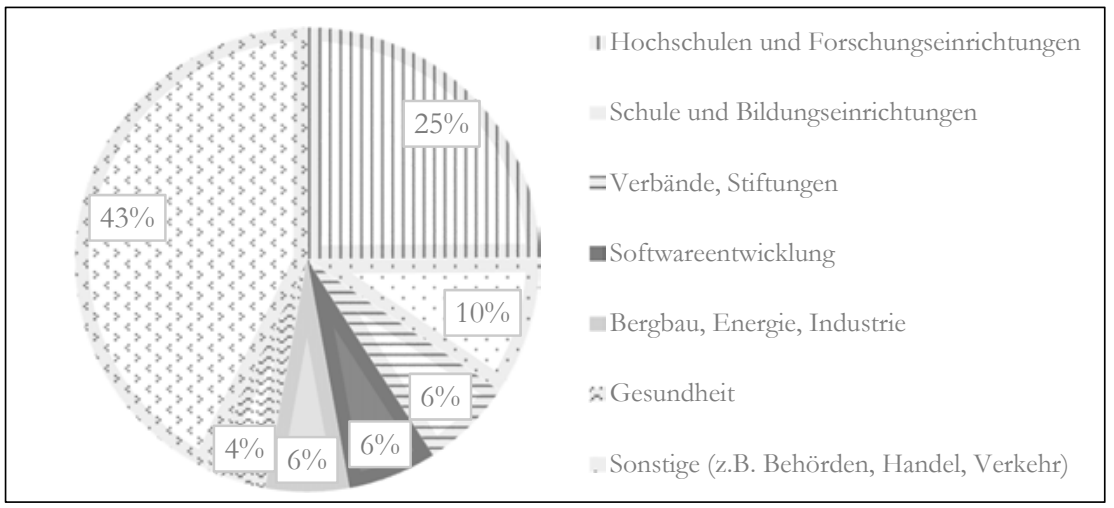

Abb. 5: Branchen der Erstbeschäftigung von Absolventen der Universität des Saarlandes (2007-2014).25

Universitäten sind zunächst Ausbildungseinrichtungen für sich selbst, d. h. Professorinnen und Professoren bilden für die Grundlagenforschung und die Hochschullehre aus. Ohne diese Dienstleistung könnten das akademische System und die in ihm eingebundenen Forschungseinrichtungen nicht überleben. Die zweite große Gruppe betrifft Studienfächer, die mit einem spezifischen Berufsbild verbunden sind. Hier dominieren Fächer mit Staatsprüfungen, aus denen die Zulassung für staatlich regulierte Berufe wie z. B. das Lehramt resultiert. Für die einzige Landesuniversität ergeben sich hieraus besondere Verpflichtungen. Darüber hinaus gibt es v. a. in der Medizin und in technischen Studiengängen ebenfalls Fächer mit einem eindeutigen Berufsbezug, die allerdings quantitativ eine geringere Rolle spielen. Die überwiegende Mehrheit der an einer Universität wählbaren Studiengänge führt zu einem eher universellen Abschluss, der in unterschiedlichen Bereichen einsetzbar ist und von Wirtschaft, Behörden und Verbänden je nach Bedarf genutzt werden kann. Dies gilt z. B. für die Betriebswirtschaftslehre, die nicht

25 Eigene Darstellung. Vgl. Gassmann [u. a.]: Was kommt nach dem Studium?, S. 105. Anmerkung: Die hier dargestellten Ergebnisse sind allerdings weiter differenziert als in der zitierten Buchpublikation (aus dem Originaldatensatz). 
aufgrund ihrer Spezialisierung, sondern ihrer Breite vermittelter Kompetenzen von vielen Arbeitgebern geschätzt wird. ${ }^{26}$

Die Universität des Saarlandes ist in der Tat sehr breit aufgestellt und wer hier im Sinne einer stärkeren regionalen Nützlichkeit mit Blick auf Frankreich steuern möchte, braucht entsprechende Regulierungsmechanismen. Auf diesen Aspekt soll im Folgenden eingegangen werden.

\section{Verkehrsregeln - und ihre Grenzen}

Wie bei jedem Verkehr bedarf es auch beim Grenzverkehr Regeln. Selbst wenn neoliberale Theoretiker prinzipiell Eingriffe in den Arbeitsmarkt ablehnen, so werden selbst sie die Notwendigkeit zur Regulierung in der internationalen Praxis anerkennen. Der Regelungsbedarf ist vielfältig: Es geht um die Kompatibilität von Abschlüssen, die Steuerpflicht, die Ausgleichszahlungen von Sozialversicherungsbeiträgen, die Lohnfortzahlung im Krankheitsfall, das Haftungsrecht bei Arbeitsunfällen, die Mitbestimmungs- und Vertretungsrechte und vieles andere mehr. All diese Bereiche sind in den Ländern unterschiedlich geregelt und die nationale Rechtsprechung der Arbeits- und Sozialgerichte sowie die zuständigen politischen Gremien der Legislative gestalten diese Rahmenbedingungen in einem kontinuierlichen Entwicklungsprozess immer weiter. Trotz aller Bemühungen zur Homogenisierung innerhalb der EU sind auch zwischen Belgien, Deutschland, Frankreich und Luxemburg die Unterschiede groß und nicht einfach zu klären.

Der Steuerungsbedarf am Arbeitsmarkt entsteht allerdings nicht nur passiv als Reaktion auf bestehende Unklarheiten für Grenzgänger. Wenn - wie am Beispiel der Universität im vorherigen Kapitel angedeutet - aktiv in den Arbeitsmarkt eingegriffen und hierdurch die Entwicklung des Ausgleichs von Arbeitsangebot und -nachfrage sinnvoll gestaltet werden soll, stellt sich die Frage nach der institutionellen Regelung solcher Eingriffe. Wer ist hierfür zuständig und welche Schritte müssen befolgt werden?

Auf nationaler Ebene sind solche Fragen zu beantworten, weil es hierzu ausgearbeitete Verfahren und gesetzlich bestimmte Regelungen gibt. Die politische Steuerung erfolgt innerhalb bestehender Institutionen unter Einsatz geeigneter Maßnahmen, die in zuständigen Gremien diskutiert und entschieden werden. Manchmal kommt es dabei allerdings in Mehrebenensystemen zu

26 Vgl. Staub-Ney, Nadine [u. a.]: Die Universität und ihre Studenten aus Sicht von Wirtschaft, Industrie und Politik - Ergebnisse qualitativer Interviews, in: Emrich, Eike/Meyer, Wolfgang/Rampeltshammer, Luitpold (Hg.): Die Universität des Saarlandes in sozio-ökonomischer Perspektive. Ausgewählte Analysen sozialer und wirtschaftlicher Effekte, Saarbrücken: universaar, 2013, S. 135-178. 
institutionellen Konflikten (z. B. zwischen Bund und Ländern oder zwischen der EU und ihren Mitgliedstaaten), die entweder auf Regelungslücken oder Interessenkonflikte zurückzuführen sind und sich durch die Politikverflechtung ergeben. ${ }^{27}$

In der Großregion besteht die Besonderheit des Mehrebenensystems in der Verknüpfung unterschiedlicher Systemebenen über Grenzen hinweg, wobei zudem noch die Zuständigkeiten der einzelnen Ebenen national höchst unterschiedlich geregelt sind. In der Großregion sind auf politischer Ebene miteinander verbunden: ein Nationalstaat (Luxemburg), ein deutsches Bundesland (Saarland), drei Kreise innerhalb eines weiteren Bundeslandes (Rheinland-Pfalz), drei Departments innerhalb einer französischen Verwaltungsregion, die zudem seit Januar 2016 im Zuge einer Verwaltungsreform mit zwei weiteren Regionen (Elsass und Champagne-Ardenne) vereint wurde (Lothringen) und zwei Provinzen innerhalb eines belgischen Gliedstaats sowie der deutschsprachigen Gemeinschaft, die ebenfalls den Status eines Gliedstaats besitzt (Wallonien). Die Einbindung zivilgesellschaftlicher Interessenvertretungen - im Falle der Arbeitsmarktregulierung primär die Arbeitgeber- und Arbeitnehmervertretungen - stoßen bezüglich ihrer organisatorischen Gliederung auf ähnliche Probleme, die zudem noch durch den unterschiedlichen Status und die Einflussmöglichkeiten der Akteure im jeweiligen nationalen Steuerungssystem verkompliziert werden. ${ }^{28}$

In der mittlerweile ebenfalls fast vierzigjährigen Entwicklungsgeschichte der Großregion hat sich ein komplexes Gefüge zur Regulierung des Arbeitsmarktes herausgebildet (vgl. Abb. 6.)

Wichtige Kennzeichen dieses Geflechts sind die fehlenden Regelungen und formalen Steuerungskompetenzen, die den Institutionen zugestanden werden. Auf dieser Basis kommt es zu einer Politik der freiwilligen Selbstverpflichtung und Konsensorientierung, in der die Kommunikation deutlich über der Entscheidungsfindung steht. Mangels eigener Gestaltungsmöglichkeiten müssen die Institutionen und ihre Mitglieder zur Entscheidungsfindung die Beratungsergebnisse an die zuständigen Entscheidungsinstitutionen auf europäischer, regionaler und v. a. auf nationaler Ebene vermitteln, wobei diese Wege aufgrund der institutionellen Gegebenheiten in den einzelnen Ländern unterschiedlich lang und kompliziert sind.

27 Vgl. Benz, Arthur: Politik in Mehrebenensystemen, Wiesbaden: VS Verlag, 2009.

28 Vgl. hierzu die Analysen zum Interregionalen Gewerkschaftsrat der Großregion in Filsinger, Dieter/Lüsebrink, Hans-Jürgen/Rampeltshammer, Luitpold (Hg.): Interregionale Gewerkschaftsräte. Historische, sozialwissenschaftliche und interkulturelle Analysen, Baden-Baden: Nomos/Berlin: Edition Sigma, 2015. 


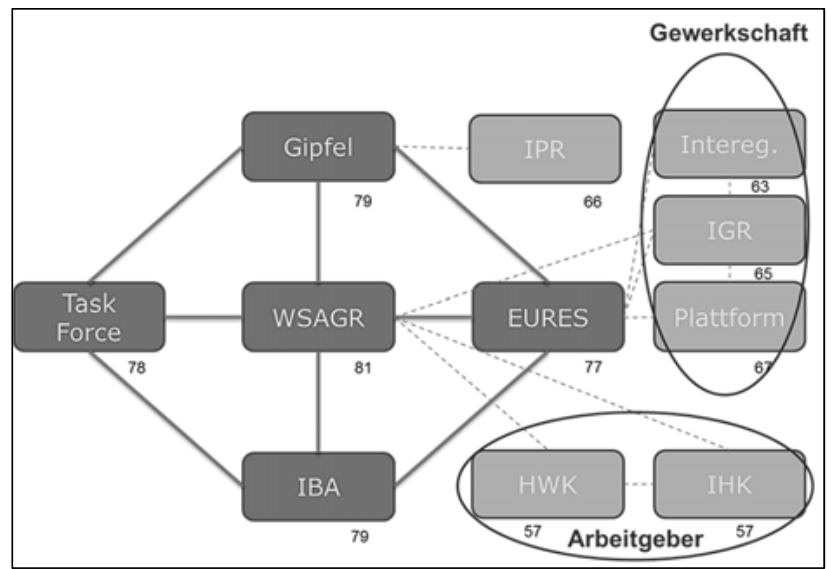

EURES = European Employment Services

HWK = Handwerkskammer

IBA $=$ Interregionale Arbeitsmarktbeobachtungsstelle

IGR = Interregionaler Gewerkschaftsrat

IHK = Industrie- und Handelskammer

Intereg. = Interregionale IRS de trois frontières

IPR = Interregionaler Parlamentarierrat

WSAGR $=$ Wirtschafts- und Sozialausschuss der Großregion

Abb. 6: Institutionelle Steuerung des grenzüberschreitenden Arbeitsmarktes. ${ }^{29}$

Die gezielte Steuerung und gemeinsame Entwicklung des grenzüberschreitenden Arbeitsmarktes liegt somit in den Händen der nationalen Gremien, denen es allerdings an einer gemeinsamen Strategie zur Entwicklung der Großregion fehlt und die im eher konfliktscheuen Rahmen der transnationalen Verhandlungen bisher nicht entwickelt wurde. ${ }^{30}$ Eine Frankreichstrategie des Saarlandes zur Gestaltung des grenzüberschreitenden Arbeitsmarktes und eine entsprechende Abstimmung mit den Nachbarländern wären sehr hilfreich.

29 Eigene Darstellung. Vgl. Albrecht, Maria/Meyer, Wolfgang: Grenzüberschreitende Arbeitsmarktpolitik. Institutionen und institutionelle Steuerung des Arbeitsmarktes in der Großregion SaarLorLux-Rheinland-Pfalz-Wallonien, in: Meyer, Jürgen/Rampeltshammer, Luitpold (Hg.): Grenzüberschreitendes Arbeiten in der Großregion SaarLorLux, Saarbrücken: universaar, 2012, S. 79-152. Im Oktober 2016 wurden der IGR, Intereg. und die Plattform zum Interregionalen Gewerkschaftsrat der Großregion (IGRGR) fusioniert (vgl. OGBL: Gründung des Interregionalen Gewerkschaftsrates der Groß-Region (IGRGR), http:// www.ogbl.lu/de/blog/creation-du-conseil-syndical-interregional-de-la-grande-region/ (20.12.2016))

30 Vgl. Meyer, Wolfgang: Transnationale Netzwerke, Organisationen und Institutionen im Kontext von Arbeitsmarkt und Wohlfahrtsstaatsregimen, in: Filsinger/Lüsebrink/ 


\section{Epilog: Alles Frankreich oder was... ist eigentlich an Belgien und Luxemburg verkehrt?}

Aus den Ausführungen hier lassen sich zwei Anforderungen an eine Frankreichstrategie des Saarlandes ableiten:

- Erstens verliert der saarländische Arbeitsmarkt im Vergleich zum luxemburgischen für die junge Generation aus Lothringen zunehmend an Attraktivität. Maßnahmen des Saarlandes müssen die Durchlässigkeit des Systems erhöhen und insbesondere im Dienstleistungsbereich geeignete Angebote schaffen.

- Zweitens ist die Einbindung der Universität des Saarlandes in die Grenzregion mangelhaft und das Studienangebot sowie die damit verbundenen Arbeitsmarktchancen müssen besser an die junge Generation in Lothringen vermittelt werden.

Beide Aspekte fehlen völlig in der Frankreichstrategie, die eher eine ,Französischstrategie` ist und sehr einseitig die Multilingualität als Ziel betont. Mit Bezug auf die Arbeitsmarkterfordernisse greift dieses Ziel allerdings zu kurz. Die Frankreichstrategie ist schließlich auch keine ,Strategie', weil sie als solche weder ein klares politisches Ziel zur Regionalentwicklung noch daraus abgeleitet geeignete Maßnahmen zur Zielerreichung enthält. Der Erhalt des Saarlandes als politische Einheit und seine Positionierung im Vergleich zu anderen Bundesländern sind ziemlich ,deutsche‘ Ziele, die sich vom Gedanken einer gemeinsamen Großregion entfernen. Multilingualität wird genauso wenig die Probleme der Region lösen wie der Status des Saarlandes als Bundesland. Die saarländische Landesregierung hat eine Chance vertan, in schwierigen Zeiten einen klaren grenzüberschreitenden Akzent zu setzen und ein Bekenntnis zur gemeinsamen Gestaltung der Großregion nicht nur aber auch in wirtschaftlicher Hinsicht abzugeben.

Rampeltshammer (Hg.): Interregionale Gewerkschaftsräte, S. 83-110; vgl. Meyer, Wolfgang: Großregion ohne Grenzen? Handlungskoordination jenseits von Staat und EU am Beispiel der Arbeitsmarktpolitik, in: Lorig, Wolfgang H./Regolot, Sascha/Henn, Stefan (Hg.): Die Großregion SaarLorLux. Anspruch, Wirklichkeiten, Perspektiven, Wiesbaden: Springer, 2015, S. $145-168$. 


\section{Literaturverzeichnis}

Albrecht, Maria/Meyer, Wolfgang: Grenzüberschreitende Arbeitsmarktpolitik. Institutionen und institutionelle Steuerung des Arbeitsmarktes in der Großregion SaarLorLux-Rheinland-Pfalz-Wallonien, in: Meyer, Jürgen/Rampeltshammer, Luitpold (Hg.): Grenæüberschreitendes Arbeiten in der Großregion SaarLorLux, Saarbrücken: universaar, 2012, S. 79-152.

Als, Georges: L'évolution de l'industrie luxembourgeoise. Mutations économiques et mutations industrielles, in: FEDIL (Fédération des industriels luxembourgeois) (Hg.): FEDIL 19181993, Luxembourg: FEDIL, 1993, S. 43-63.

Becker, Susan: „Multinationalität hat verschiedene Gesichter“. Formen internationaler Unternehmenstätigkeit der Société Anonyme des Mines et Fonderies de Zinc de la Vieille Montagne und der Metallgesellschaft vor 1914, Wiesbaden: Franz Steiner Verlag, 2002.

Benning, Hermann J.: Robert Schuman. Leben und Vermächtnis, München [u. a.]: Verlag Neue Stadt, 2013.

Benz, Arthur: Politik in Mebrebenensystemen, Wiesbaden: VS Verlag, 2009.

Czymoch, Kai-Uwe: Die deutsche Stablindustrie im 20. Jabrbundert: Der Niedergang eines Führungssektors, Saarbrücken: AV Akademiker Verlag, 2012.

Dautel, Vincent/Walther, Olivier: Beschäftigungsdynamik in der Metropolregion, in: Bousch, Patrick [u. a.] (Hg.): Der Luxemburg Atlas - Atlas du Luxembourg, Luxemburg: emons, 2009, S. 128-129.

Filsinger, Dieter/Lüsebrink, Hans-Jürgen/Rampeltshammer, Luitpold (Hg.): Interregionale Gewerkschaftsräte. Historische, sozialwissenschaftliche und interkulturelle Analysen, Baden-Baden: Nomos/Berlin: Edition Sigma, 2015.

Gassmann, Freya [u. a.] (Hg.): Was kommt nach dem Studium an der Universität des Saarlandes? Empirische Befunde einer fächerübergreifenden Absolventenstudie, Saarbrücken: universaar, 2015.

Gehring, Jean-Marie: Développement industriel en espace transfrontalier: l'exemple de SaarLor-Lux, in: Mosella. Revue du Centre d'études géographiques de l'Université de Mets, Tome XVII (1987), $\mathrm{n}^{\circ}$ spécial, S. 43-56.

Giersch, Volker: Mehr Profil, weniger Breite. Unsere Hochschulen brauchen eine klare Perspektive, in: Saarwirtschaft 3 (2014), S. 62-63.

Glunck, Fritz R. (Hg.): Das MAI und die Herrschaft der Konzerne. Die Veränderung der Welt durch das Multilaterale Abkommen über Investitionen, München: dtV, 1998.

Großregion: http://www.granderegion.net (10.07.2016).

Großregion (Statistiken): http://www.grande-region.lu/ (09.11.2016).

Henning, Friedrich-Wilhelm: Die Industrialisierung in Deutscbland 1800 bis 1914, Paderborn [u. a.]: Schöningh, 2008 (UTB, 9).

IBA-Aktuell, 20.05.2016, http://www.iba-oie.eu/fileadmin/user_upload/IBA-Aktuell/ 160520_Entwurf_IBA-Aktuell_Einpendlerzahlen_Lux_SL_RLP_Wallonie_2015_FR.pdf (20.12.2016).

Institut national de la statistique et des études économiques (INSEE): Un tissu productif régional toujours spécialisé dans l'industrie, Strasbourg: INSEE, 2016 (INSEE Analyses Alsace-Champagne-Ardenne-Lorraine $n^{\circ} 6$ Mars).

Interregionale Arbeitsmarktbeobachtungsstelle (IBA): Grenægänger und grenzüberschreitender Arbeitsmarkt in der Großregion, Saarbrücken: IBA, 2005 (Themenheft im Rahmen des Gesamtvorhabens „Stand, Perspektiven und Handlungserfordernisse des Arbeitsmarkts der Großregion bis $2020^{\circ}$ ). 
Interregionale Arbeitsmarktbeobachtungsstelle (IBA): Die Arbeitsmarktsituation in der Großregion. Grenəgängermobilität. 9. Bericht der Interregionalen Arbeitsmarktbeobacbtungsstelle an den 14. Gipfel der Exekutive der Großregion November 2014, Saarbrücken: IBA, 2014.

Meyer, Wolfgang: Großregion ohne Grenzen? Handlungskoordination jenseits von Staat und EU am Beispiel der Arbeitsmarktpolitik, in: Lorig, Wolfgang H./Regolot, Sascha/Henn, Stefan (Hg.): Die Großregion SaarLorLux. Anspruch, Wirklichkeiten, Perspektiven, Wiesbaden: Springer, 2015, S. 145-168.

Meyer, Wolfgang: Transnationale Netzwerke, Organisationen und Institutionen im Kontext von Arbeitsmarkt und Wohlfahrtsstaatsregimen, in: Filsinger/Lüsebrink/Rampeltshammer (Hg.): Interregionale Gewerkschaftsräte, S. 83-110.

Müller, Wolfgang: L'Université de Nancy, „mère“ des institutions universitaires sarroises et la coopération entre la Sarre et la Lorraine dans le domaine universitaire, in: Le Pays Lorrain, Revue de la Société d'Histoire de la Lorraine et du Musée Lorrain, 107e Année/Vol. 91, 03.09.2010, S. 221-230.

OGBL: Gründung des Interregionalen Gewerkschaftsrates der Groß-Region (IGRGR), http:// www.ogbl.lu/de/blog/creation-du-conseil-syndical-interregional-de-la-grande-region/ (20.12.2016).

Pudlat, Andreas: Schengen. Zur Manifestation von Grenze und Grenæschutz in Europa, Hildesheim [u. a.]: Georg Olms Verlag, 2013 (Historische Europa Studien Band 7).

Rech, Jörg/Meyer, Wolfgang: Europakompetenz in der saarländischen Arbeitswelt: Wie sieht die saarländische Arbeitswelt Europakompetenz?, in: Rampeltshammer, Luitpold/Kurtz, Hans Peter (Hg.): Europakompeten₹, entwickeln Interregionalkompeten₹, stärken, Saarbrücken: Verlag Alma Mater, 2009, S. 93-134.

Roth, François: Réflexions sur l'industrialisation de la Lorraine et du Luxembourg (1850-1950), in: Hémecht. Revue d'bistoire luxembourgeoise 3 (1994), S. 637-653.

Schengen I; EUR-Lex: http://eur-lex.europa.eu/legal-content/DE/TXT/?uri=CELEX\% 3A42000A0922(01) (11.06.2016).

Schreiber, Karsten/Zwick, Martin: Die regionalwirtschaftliche Bedeutung der Stablindustrie für das Saarland, Saarbrücken: Verband der Saarhütten, 2012.

Slotta, Delf: Das Steinkoblerevier an der Saar. Eine Zeitreise durch mehr als 250 Jabre Industrie- und Landesgeschichte, Saarbrücken: RAG, 2011.

Staub-Ney, Nadine [u. a.]: Die Universität und ihre Studenten aus Sicht von Wirtschaft, Industrie und Politik - Ergebnisse qualitativer Interviews, in: Emrich, Eike/Meyer, Wolfgang/ Rampeltshammer, Luitpold (Hg.): Die Universität des Saarlandes in sozio-ökonomischer Perspektive. Ausgewählte Analysen sozialer und wirtschaftlicher Effekte, Saarbrücken: universaar, 2013, S. $135-178$.

Wehner, Markus/Lohse, Eckart: „Nicht als Nachbarn“ Gauland beleidigt Boateng, in: Frankfurter Allgemeine Zeitung, 29.05.2016, http://www.faz.net/aktuell/politik/inland/afd-vizegauland-beleidigt-jerome-boateng-14257743.html (20.12.2016).

Wille, Christian: Grenzüberschreitender Arbeitsmarkt in der Großregion SaarLorLux. Politische Visionen und empirische Wirklichkeiten, in: Lorig, Wolfgang H./Regolot, Sascha/Henn, Stefan (Hg.): Die Großregion SaarLorLux. Anspruch, Wirklichkeiten, Perspektiven, Wiesbaden: Springer, 2016, S. 115-143.

Ziegler, Dieter (Hg.): Rohstoffgewinnung im Strukturwandel. Der deutsche Bergbau im 20. Jabrbundert, Münster: Aschendorff, 2013. 


\section{Grenzüberschreitende Gesundheitsversorgung im Grenzraum Saarland-Lothringen: Aktueller Stand, Herausforderungen und Potenziale}

Dans les régions frontalières en Europe, la prise en charge transfrontalière en matière de santé promet une amélioration de l'accès aux soins et un maintien de la qualité des services médicaux. Concernant l'espace frontalier Sarre-Lorraine, le renforcement de l'activité transfrontalière dans le secteur de la santé est un objectif important du Land de Sarre, exprimé dans la 'Stratégie France' du gouvernement sarrois. Face à cette volonté politique, deux questions se posent au chercheur: Premièrement, les déclarations politiques expliquant la 'Stratégie France' contiennent-elles des propositions concrètes pour réaliser cet objectif? Deuxièmement, dans ces mêmes déclarations, l'estimation du statu quo de l'accès aux soins transfrontalier est-elle réaliste? L'analyse des préalables régionaux met en évidence les potentiels et les défis d'un accès aux soins par-delà les frontières. Les résultats empiriques montrent qu'il existe bien des projets transfrontaliers dans la région ainsi qu'une mobilité des patients, mais que celle-ci est sélective à plusieurs égards. Ces constatations doivent être prises en compte lorsqu'il s'agit de développer des concepts à la fois concrets et nuancés suivant les besoins pour améliorer l'accès aux soins transfrontalier.

Im Januar 2015 bezeichnete die saarländische Gesundheitsministerin Monika Bachmann den Ausbau der grenzüberschreitenden Gesundheitsversorgung als „wichtigen Baustein im Rahmen der Frankreichstrategie“1. Für die Ringvorlesung: „Alles Frankreich oder was?" ergeben sich aus dem Zitat zwei interessante Fragen: 1. Enthält die Frankreichstrategie konkrete Ziele und Umsetzungsvorschläge für den Gesundheitsbereich? 2. Welche Realität der grenzüberschreitenden Gesundheitsversorgung im Grenzraum Saarland-Lothringen steht den politischen Ambitionen gegenüber?

Unter grenzüberschreitender Gesundheitsversorgung werden alle Fälle verstanden, in denen ein Patient im Ausland behandelt wird (Patientenmobilität), ein Arzt oder eine medizinische Fachkraft eine Leistung in einem anderen Staat erbringt oder Anbieter bei Behandlungen grenzüberschreitend kooperieren. Im Folgenden werden nur geplante Behandlungen im Nachbarland betrachtet und Notfälle, die während eines Auslandsaufenthaltes

1 Ministerium für Soziales, Gesundheit, Frauen und Familie des Saarlandes: Sozialministerin Monika Bachmann: Ausbau der grenzüberschreitenden Gesundheitsversorgung ist wichtiger Baustein im Rahmen der Frankreichstrategie, 2015, http://saarland.de/123066.htm (23.03.2015). 
eintreten, ausgeklammert. Im Jahr 2014 nahmen $2 \%$ der Bürger der Europäischen Union (EU) geplant medizinische Dienstleistungen in einem anderen EU-Staat in Anspruch. ${ }^{2}$ In der EU dürfen sich Nichtgrenzgänger in einem anderen EU-Staat behandeln lassen, müssen die Kosten zunächst selbst tragen und bekommen von der Heimatkrankenkasse maximal den Betrag, der im Heimatland angefallen wäre, erstattet. Für besonders teure oder stationäre Behandlungen kann eine Vorabgenehmigung notwendig sein. ${ }^{3}$ Grenzgänger haben sowohl im Heimatland als auch im Beschäftigungsland freien Zugang zum Gesundheitssystem. ${ }^{4}$

Der Beitrag analysiert zunächst die Aussagen zum Gesundheitsbereich in den Dokumenten zur Frankreichstrategie. Anschließend werden die Rahmenbedingungen der grenzüberschreitenden Gesundheitsversorgung im Grenzraum Saarland-Lothringen erörtert. Die darauffolgenden Abschnitte stellen Beispiele für grenzüberschreitende Kooperationen und Ergebnisse zur grenzüberschreitenden Patientenmobilität vor.

\section{Grenzüberschreitende Gesundheitsversorgung und die Frankreichstrategie}

Die Suche nach konkreten Aussagen zur grenzüberschreitenden Gesundheitsversorgung in der Frankreichstrategie fällt ernüchternd aus. Für das Jahr 2043 wird lediglich das vage Ziel formuliert, dass das Gesundheitssystem an die angestrebte Mehrsprachigkeit und den Ausbau der Beziehungen des Saarlandes zu Frankreich ,angepasst wird und sich als Modell für Europa etabliert.“5 Die Fenille de route strebt zwar an, dass ,auf der Grundlage des saarländisch-lothringischen Abkommens zur grenzüberschreitenden medizinischen Zusammenarbeit $[\ldots]$ neben der grenzüberschreitenden Notfallversorgung

2 Vgl. Europäische Kommission: Patientenrechte bei gren₹überschreitenden Gesundheitsdienstleistungen in der Europäischen Union (= Spezial Eurobarometer 425), Brüssel: Europäische Union, 2015.

3 Vgl. Europäisches Parlament und europäischer Rat: Richtlinie 2011/24/EU des Europäischen Parlamentes und des Rates vom 9. März 2011 über die Ausübung der Patientenrechte in der grenzüberschreitenden Gesundheitsversorgung, in: Amtsblatt der Europäischen Union, 04.04.2011, L 88.

4 Europäisches Parlament und europäischer Rat: Verordnung (EG) Nr. 883/2004 des Europäischen Parlamentes und des Rates vom 29. April 2004 zur Koordinierung der Systeme der sozialen Sicherheit, in: Amtsblatt der Europäischen Union, 30.04.2004, L 166.

5 Staatskanzlei des Saarlandes: Eckpunkte einer Frankreichstrategie für das Saarland, 2014, http:// www.saarland.de/dokumente/res_stk/D_Eckpunkte_Frankreich-Strategie_210114.pdf (13.05.2015), S. 11. 
nun auch die Krankenhaus-Kooperation intensiviert" ${ }^{\star 6}$ wird. Allerdings existiert kein Abkommen mit dieser Bezeichnung, es gibt lediglich das 2005 vereinbarte Rahmenabkommen über die grenzüberschreitende Zusammenarbeit im Gesundheitsbereich zwischen der Bundesrepublik Deutschland und der Republik Frankreich ${ }^{7}$ und die darauf basierende 2008 abgeschlossene Vereinbarung zum grenzüberschreitenden Einsatz der Rettungsdienste ${ }^{8}$ zwischen Lothringen und dem Saarland.

\section{Regionale Rahmenbedingungen: Potenziale und Herausforderungen}

Für die Bewohner von Grenzregionen entstehen bei einer Behandlung im Nachbarland Vorteile, wie z. B. geringere Kosten, kürzere Wartezeiten und Wege oder zusätzliche Behandlungsangebote. Ärzte und Krankenhäuser sehen Potenziale wie eine höhere Auslastung ihrer Einrichtungen durch die Ausweitung des Einzugsgebietes auf das Nachbarland. ${ }^{9}$ Auch politische Initiativen sind wirtschaftlich motiviert: Die grenzüberschreitende Zusammenarbeit kann kostspielige Doppelstrukturen beiderseits der Grenze vermeiden und bietet Einsparpotenziale bei der gleichzeitigen Aufrechterhaltung oder Verbesserung des Versorgungsangebotes.

Viele der Vorteile, die sich für Patienten aus grenzüberschreitenden Behandlungen ergeben, gehen daraus hervor, dass die Gesundheitssysteme der EU-Mitgliedstaaten nicht harmonisiert sind. In Frankreich und Deutschland folgt z. B. die Finanzierung des Gesundheitssystems unterschiedlichen Prinzipien und die Planungskompetenzen sind anders verteilt. Für die Patienten konkret spürbare Unterschiede gibt es etwa bei der Rolle der Hausärzte und bei der Regelung des Zugangs zu Fachärzten sowie durch die Existenz von

6 Landesregierung des Saarlandes: Fenille de route Frankreich-Strategie 2015/2016, 2015, http://saarland.de/dokumente/ressort_finanzen/Feuille_de_route.pdf (13.05.2015).

7 Regierung der Bundesrepublik Deutschland/Gouvernement de la République Française: Rahmenabkommen zwischen der Regierung der Bundesrepublik Deutschland und der Regierung der Französischen Republik über die grenzüberschreitende Zusammenarbeit im Gesundheitsbereich vom 22.07.2005, in: Bundesgesetzblatt 32 (2006), Teil II (21.12.2006).

8 Agence Régionale de l'Hospitalisation de Lorraine/Ministerium für Inneres und Sport des Saarlandes: Vereinbarung zwischen dem Direktor der Agence Régionale de l'Hospitalisation de Lorraine und dem Minister für Inneres und Sport des Saarlandes über das grenzüberschreitende Gesundheitswesen vom 11.06.2008, http://www.saarland.de/dokumente/thema_SaarLorLux/Vereinbarung 2008_06_11_Rettungsdienste_SL-LOR_geringe_Aufloesung.pdf (27.05.2013).

9 Vgl. Fröhlich, Mareike/Lahann, Tilmann/Trautmann, Anja: Gesundheitsdienstleistungen in der Großregion SaarLorLux. Die praktische Umsetzung der Rechtsprechung des Europäischen Gerichtshofs im Hinblick auf Krankenkassensystem im grenzüberschreitenden Kontext (= eVeröffentlichungen des Europa-Instituts Bd. 2), Saarbrücken: Europa-Institut, 2011, S. 46. 
Laboratoires d'analyse médicale in Frankreich. ${ }^{10}$ Grenzüberschreitende Patientenströme werden auch durch Behandlungsunterschiede zwischen den beiden Gesundheitssystemen, z. B. bei der Verschreibung von Medikamenten oder bei der Erstattungsfähigkeit von Behandlungsmethoden, verursacht. Die unterschiedlichen Funktionsweisen der Gesundheitssysteme bergen gleichzeitig Herausforderungen für die grenzüberschreitende Gesundheitsversorgung.

Weitere Motive gehen aus den Kapazitäten der medizinischen Infrastrukturen im Grenzraum hervor. Die in Tab. 1 dargestellten Werte bedeuten nicht automatisch, dass im Saarland eine bessere Versorgung vorliegt oder Überkapazitäten bestehen und es in Lothringen Versorgungslücken gibt. Auf ihrer Grundlage lassen sich jedoch zumindest Auswirkungen auf die Wartezeiten antizipieren.

\begin{tabular}{|l|l|l|}
\hline & Saarland & Lothringen \\
\hline Allgemeinärzte & 204 & 149 \\
\hline Fachärzte & 274 & 156 \\
\hline Krankenhausbetten & 647 & 381 \\
\hline
\end{tabular}

Tab. 1: Medizinische Infrastrukturen pro 100000 Einwohner im Jahr 2014.11

Für die Erreichbarkeit spielt die räumliche Verteilung der Infrastrukturen eine wichtige Rolle. In den ehemaligen Bergbauregionen und grenznahen Gebieten des Departements Moselle ist das Angebot vergleichsweise gering, größere Krankenhäuser mit einem vielfältigen und spezielleren Angebot konzentrieren sich in Metz, ebenso die niedergelassenen Fachärzte. ${ }^{12}$ Im Saarland sind die Krankenhäuser gleichmäßiger verteilt, entlang der Grenze zu Lothringen sind mehrere große und hochspezialisierte Krankenhäuser zu finden. Auch

10 Vgl. Euro-Institut: Das Gesundheitssystem in Deutschland und Frankreich. Dokumentation erstellt im Rahmen der Veranstaltung „Europa wächst zusammen - Gesundheit ohne Grenzen. Deutsch-Französisches Rahmenabkommen über die grenzüberschreitende Zusammenarbeit im Gesundheitsbereich“, Karlsruhe, 26.09.2007, http://www.euroinstitut. org/pdf/Download-Unterlagen/2007-Gesundheit-ohne-Grenzen/Gesundheitswesen-Du-F.pdf (08.02.2013).

11 Eigene Darstellung. Daten basierend auf: Statistische Ämter der Großregion (Hg.): Statistiques en bref/Statistische Kurzinformationen 2014, Saarbücken [u. a.]: Statistische Ämter, 2014.

12 Vgl. Agence Régionale de Santé de Lorraine: Statistique Annuelle des Etablissements de santé lorrains 2013, 2015, http://www.ars.lorraine.sante.fr/fileadmin/LORRAINE/ARS_ LORRAINE/ACTUALITES/SAE_01/ARS_Lorraine-BrochureSAE2013.pdf (22.11.2015); Observatoire National de la Démographie des Professions de Santé: Rapport de l'ONDPS 2006-2007 Région Lorraine. La médecine générale. Les internes en médecine. Les métiers de la périnatalité. Le bloc opératoire. Les métiers de la cancérologie, 2009, http://drees.social-sante. gouv.fr/IMG/pdf/ondps.pdf (26.11.2016). 
niedergelassene Fachärzte sind durch ihre Konzentration auf den Regionalverband Saarbrücken in geringer Distanz zur Grenze zu finden. ${ }^{13}$ Im Grenzraum kann deshalb der Weg zu einem Angebot im Nachbarland kürzer als zu einem Anbieter im Heimatland sein, insbesondere bei spezielleren Behandlungen. ${ }^{14}$

Die Sprachkenntnisse der Bevölkerung sowie der Ärzte und der medizinischen Fachkräfte sind ein weiterer wichtiger Faktor, da die Gesundheitsversorgung wesentlich sprachsensibler ist als andere grenzüberschreitende Aktivitäten. Während aufgrund der historischen Grenzverschiebungen die Sprachkenntnisse bei älteren Bewohnern des Grenzraums besser als in anderen Regionen sind, nehmen sie in den jüngeren Generationen tendenziell ab. ${ }^{15}$ Bei einzelnen Ärzten und medizinischen Fachkräften, jedoch nicht beim gesamten medizinischen Personal, kann von Kenntnissen der Nachbarsprache ausgegangen werden.

Da Grenzgänger Zugang zur Gesundheitsversorgung im Beschäftigungsland haben, die Nachbarregion besser als die Gesamtbevölkerung kennen und über bessere Sprachkenntnisse verfügen, ist für sie die grenzüberschreitende Behandlung eher eine Handlungsoption als für die übrige Bevölkerung. Die Grenzgängerströme im Grenzraum sind sehr einseitig. Am 30. Juni 2014 waren 12289 Lothringer im Saarland beschäftigt, nur 1000 Saarländer arbeiteten in Lothringen. ${ }^{16}$

13 Vgl. Gesundheitsberichterstattung Saarland: Indikator (L) 8.8 Ärztinnen/Ärzte und Zahnärztinnen/Zahnärzte in ambulanten Einrichtungen, Saarland im Regionalvergleich, 2009, http://www.gbe.saarland.de/medien/download/08_008_2009.htm (04.07.2013); Ministerium für Gesundheit und Verbraucherschutz des Saarlandes (Hg.): Krankenhausplan für das Saarland 2011-2015, 2011, http://saarland.de/dokumente/res_gesundheit/Krankenhausplan. pdf (18.07.2011).

14 Vgl. Ruffray, Sophie/Hamez, Grégory: L'accessibilité transfrontalière aux maternités. Enjeux territoriaux d'une coopération sanitaire dans la Grande Région, in: Moullé, François/ Duhamel, Sabine (Hg.): Frontières et santé. Genèses et maillages des réseaux transfrontaliers, Paris: L'Harmattan, 2010, S. 29-41, hier S. 36-37; Schneider, André: Rapport fait au de nom de la commission des affaires étrangères sur le projet de loi $n^{\circ} 3120$, autorisant l'approbation de l'accord cadre entre le Gouvernement de la République francaise et le Gouvernement de la République Fédérale d'Allemagne sur la coopération sanitaire transfrontalière. Annexe II Calcul des distances entre les différentes communes de Sarre et Moselle et les services d'urgence les plus proches, 2006, http://www. assemblee-nationale.fr/12/pdf/rapports/r3198.pdf (07.11.2012), S. 25.

15 Vgl. Haubrichs, Wolfgang: Germanophone Dialekte in Lothringen, in: Brücher, Wolfgang/ Franke, Peter Robert (Hg.): Probleme von Gren₹regionen. Das Beispiel Saar-Lor-Lux-Raum, Beiträge zum Forschungsschwerpunkt des Philosophischen Fakultät der Universität des Saarlandes, Saarbrücken: Universität, 1987, S. 99-121; Geiger-Jaillet, Anemone: Nationale, regionale und sprachliche Grenzen. Das Saar-Lor-Lux-Modell (= Bausteine Europas VIII), St. Augustin: Asgard, 2011, S. 138-143.

16 Vgl. Statistisches Amt Saarland: Pendlerverhalten der sozialversicherungspflichtig beschäftigten Arbeitnehmer des Saarlandes am 30. Juni 2014, in: Statistische Berichte A VI 5-S - j 
Im Grenzraum Saarland-Lothringen ermöglicht das bereits angesprochene deutsch-französische Rahmenabkommen von 2005 grenzüberschreitende Kooperationsvereinbarungen zwischen Ministerien, Gesundheitseinrichtungen und Sozialversicherungsträgern, um den grenzüberschreitenden Zugang zu Leistungen zu erleichtern, Planungen abzustimmen und Know-how auszutauschen. ${ }^{17}$ Eine stärkere Nutzung des Abkommens wird dadurch eingeschränkt, dass eine Zusammenarbeit in Frankreich nur genehmigt werden kann, wenn in Frankreich ein Defizit besteht, das durch die Kooperation behoben wird. ${ }^{18}$

\section{Beispiele grenzüberschreitender Gesundheitsversorgung}

Die im Folgenden präsentierten Beispiele lassen sich entsprechend ihrer Ziele in drei Kategorien unterteilen:

1. Patientenversorgung: Das Saarland und Lothringen vereinbarten 2008 auf der Grundlage des Rahmenabkommens von 2005 eine Zusammenarbeit im Rettungswesen. ${ }^{19}$ Allerdings wird die dadurch geschaffene Möglichkeit des grenzüberschreitenden Einsatzes der Rettungsdienste nur in geringem Umfang und nur sehr einseitig genutzt (vgl. Tab. 2). Die Vereinbarung zum Rettungswesen wird von vielen Akteuren deshalb als „en sommeil“20 (,ruhend“, IF) bezeichnet.

2014 (2015), http://www.saarland.de/dokumente/thema_statistik/STALA_BER_AVI5SJ-14.pdf (02.03.2016).

17 Vgl. Regierung der Bundesrepublik Deutschland/Gouvernement de la République Française: Rahmenabkommen über die grenzüberschreitende Zusammenarbeit im Gesundheitsbereich.

18 Vgl. Direction de la sécurité sociale/Division des affaires communautaires et internationales/Direction de l'hospitalisation et de l'organisation des soins/Mission des relations européennes et internationales: Circulaire DSS/DACI no 2007-291 du 18 juillet 2007 relative à la mise en œuvre de l'accord-cadre de coopération sanitaire transfrontalière entre le Gouvernement de la République française et le Gouvernement de la République fédérale d'Allemagne, signé le 22 juillet 2005, in: Bulletin Officiel Santé - Protection sociale - Solidarité 8 (2007), 15.09.2007, http://www.sante.gouv.fr/fichiers/bo/2007/07-08/bo0708.pdf (20.09.2015), Abschnitt II, S. 395-399; Beck, Joachim/Dussap-Köhler, Anne/Pradier, Eddie: Evaluation de la mise en cuvre de l'accord-cadre franco-allemand sur la coopération sanitaire transfrontalière, Kehl: Euro-Institut, 2012, http://www.ars.alsace.sante.fr/fileadmin/ ALSACE/Internet/Strategie_de_sante/cooperation_transfrontaliere/accord_cadre_fran co_ald/Rapport_Final_Evaluation_AC_FA_2012.pdf (11.07.2015), S. 10-14.

19 Vgl. Agence Régionale de l'Hospitalisation de Lorraine/Ministerium für Inneres und Sport des Saarlandes: Vereinbarung über das grenzüberschreitende Gesundheitswesen.

20 Vgl. Beck/Dussap-Köhler/Pradier: Evaluation, S. 34. 


\begin{tabular}{|l|l|l|l|l|}
\hline Jahr & $\mathbf{2 0 0 8}$ & $\mathbf{2 0 0 9}$ & $\mathbf{2 0 1 0}$ & $\mathbf{2 0 1 1}$ \\
\hline $\begin{array}{l}\text { Einsätze saarländischer Rettungsdienste in } \\
\text { Lothringen }\end{array}$ & 25 & 51 & 68 & 60 \\
\hline $\begin{array}{l}\text { Einsätze lothringischer Rettungsdienste im } \\
\text { Saarland }\end{array}$ & 0 & 0 & 0 & 0 \\
\hline
\end{tabular}

Tab. 2: Grenzüberschreitender Einsatz der Rettungsdienste (Notfälle und Transporte) in den Jahren 2008-2011. ${ }^{21}$

Ebenfalls auf der Grundlage des Rahmenabkommens entstand 2013 eine Kooperation zwischen dem Krankenhaus CHIC UNISANTE+ in Forbach und den SHG-Kliniken Völklingen, welche die Behandlung französischer Patienten mit akutem Herzinfarkt auf deutscher Seite ermöglicht, um den Transport ins 70 Kilometer entfernte Metz zu vermeiden. ${ }^{22}$ Im ersten Jahr der Vereinbarung wurden 19 französische Patienten in Deutschland behandelt. ${ }^{23}$

Weiterhin gab und gibt es Projekte zwischen den psychiatrischen Einrichtungen in Sarreguemines und in Saarbrücken, eine Kooperation zwischen dem Klinikum Saarbrücken und dem Centre Hospitalier Marie-Madeleine in Forbach im Bereich der Versorgung von Neugeborenen sowie Möglichkeiten zur Dialyse in Völklingen und zu Kernspintomographien in Saarbrücken für lothringische Patienten. Allerdings wurden einige Initiativen nicht in dauerhafte Strukturen überführt oder endeten nach dem Wegfallen eines zuvor vorhanden gewesenen Defizits. ${ }^{24}$

Das neueste Projekt ist die im März 2015 für den Raum Saarland-Moselle angekündigte Einrichtung einer sogenannten ZOAST MOSAR ${ }^{25}$. In dieser Zone hätten alle Bewohner ohne Genehmigungspflicht grenzüberschreitend Zugang zu stationären Einrichtungen, z. B. in den Bereichen Neurochirurgie,

21 Eigene Darstellung, Daten basierend auf Beck/Dussap-Köhler/Pradier: Evaluation, hier S. 33 .

22 Vgl. L'Observatoire Franco-Belge de la Santé: Flash Santé transfrontalière 7 (2015), http:// www.interreg-fwvl.eu/sites/default/files/documents/flash7_novembre_2015.pdf (04.03.2016).

23 Vgl. Wagner, Peter: Nach zähem Ringen: Medizin ohne Grenzen, in: Saarbrücker Zeitung, 04.12.2013.

24 Vgl. Mertens, Karin: Kurzdarstellung der Ergebnisse des Projekts 2003-2006 „Vergleich der Gesundbeitssysteme Saarland-Moselle", Saarbrücken: LAGS, 2007, S. 40.

25 ZOAST $=$ Zone organisée d'accès aux soins transfrontaliers ('Zone mit grenzüberschreitendem Zugang zu Gesundheitsleistungen’, IF). 
Kardiologie, Neonatologie oder Nuklearmedizin und medizinische Großgeräte könnten gemeinsam genutzt werden. ${ }^{26}$ Die Umsetzung stockt, weil die Zustimmung politischer Akteure fehlt, wird aber für 2016 angestrebt. ${ }^{27}$

2. Aus- und Weiterbildung medizinischer Fachkräfte: Das Institut de Formation en Soins Infirmiers du Centre Hospitalier de Sarreguemines und die SHG-Kliniken Völklingen kooperieren bei der Ausbildung von medizinischen Fachkräften. Sie bieten z. B. grenzüberschreitende Praktika und Sprachkurse an. ${ }^{28}$ Das Institut de Formation en Soins Infirmiers in Forbach arbeitet bei der Krankenpflegeausbildung mit der Hochschule für Technik und Wirtschaft des Saarlandes zusammen und organisiert Austausche mit der Altenpflegeschule der Arbeiterwohlfahrt in Saarbrücken. ${ }^{29}$

3. Forschung und Verwaltung: Es existieren z. B. Forschungsprojekte der Universitäten und Abrechnungsabkommen. ${ }^{30}$

Keine grenzüberschreitenden Projekte gibt es im ambulanten Bereich, der auch in der Frankreichstrategie nicht thematisiert wird. Von der 2013 anvisierten schnellstmöglichen Einrichtung von ,grenzüberschreitende[n] Arztpraxen" 31 ist man weit entfernt.

Die Gründe für das Scheitern von Projekten sind vielfältig: Eigeninteressen der Projektpartner, Ängste, Patienten und Einnahmen zu verlieren, Uneinigkeit über die Ziele der Zusammenarbeit oder komplizierte juristische Konstruktionen der Vereinbarungen. Praktische Probleme sind mangelnde Sprachkenntnisse oder die starke Bindung von Projekten an Einzelpersonen.

26 Vgl. Eurodistrict SaarMoselle: Der Eurodistrict SaarMoselle spricht sich einstimmig für die Schaffung einer Zone mit grenzüberschreitendem Zugang zu Gesundheitsdienstleistungen (ZOAST) aus, Pressemitteilung vom 19.03.2015, Saarbrücken: Eurodistrict und Interview mit Karin Mertens am 13.05.2015.

27 Vgl. Kohl, Jasmin: Warten auf die Gesundheitszone. Lothringer und Saarländer zahlen für Behandlungen im Partnerland weiterhin drauf, in: Saarbrücker Zeitung, 23.11.2015; Französisch-deutscher Ministerrat: Gemeinsame Erklärung zwischen Marisol Touraine, Ministerin für Soziales und Gesundheit, und Hermann Gröhe, Bundesminister für Gesundheit. Französisch-Deutscher Ministerrat, 7. April 2016 in Metz, https://www. bundesgesundheitsministerium.de/fileadmin/Dateien/3_Downloads/E/Erklaerungen/1 60407_Declaration_commune_sante_DE.pdf (08.12.2016).

28 Vgl. L'Observatoire Franco-Belge de la Santé: Flash Santé transfrontalière 7, S. 8-9.

29 Vgl. Interviews am IFSI am 22.06.2012 und in der Altenpflegeschule der AWO am 03.09.2012.

30 Vgl. Mertens: Kurzdarstellung der Ergebnisse, S. 23.

31 Auswärtiges Amt/République Française: Erklärung von Saarbrücken zur deutsch-franžösischen Zusammenarbeit in den Grenzregionen vom 15.07.2013, http://www.saarland.de/dokumente/ thema_frankreichjahr/Erklaerung_DEU_final.pdf (30.09.2013). 


\section{Grenzüberschreitende Patientenmobilität im Grenzraum Saarland-Lothringen}

Die Zahl der Patienten, die im Grenzraum grenzüberschreitend behandelt wird, ist kaum dokumentiert und gemessen an der Gesamtzahl der Patienten und Behandlungen gering. Franzosen sind zwar die größte Gruppe ausländischer Patienten in saarländischen Krankenhäusern, erreichen jedoch lediglich einen Anteil von 1,3\%.32 Eine Versorgung saarländischer Patienten in Lothringen gibt es de facto nicht bzw. nicht mehr, seit saarländische Ärzte nach ihrer Hospitation in Nancy eine bestimmte Tumorbehandlung selbst anbieten. Bekannt ist lediglich, dass saarländische Patienten das Preisgefälle bei bestimmten Medikamenten ausnutzen und deshalb Apotheken in Lothringen aufsuchen. ${ }^{33} \mathrm{Da}$ es keine Erkenntnisse zu ambulanten grenzüberschreitenden Behandlungen und zur Behandlung lothringischer Grenzgänger bei saarländischen Anbietern gibt, kann davon ausgegangen werden, dass der Umfang der grenzüberschreitenden Patientenströme bislang unterschätzt wurde.

Die Dissertation Grenఇüberschreitende Patientenmobilität im saarländisch-lothringischen Grenzraum ${ }^{34}$ zeigt auf, dass es rege grenzüberschreitende Patientenströme im ambulanten Bereich gibt. Die Zahl französischer Patienten ist in einigen saarländischen Praxen sehr hoch und die grenzüberschreitende Behandlung hat für einzelne Patienten eine große subjektive Bedeutung. Die Behandlung französischer Patienten konzentriert sich in grenznahen hausärztlichen und fachärztlichen Praxen. ${ }^{35}$

Anlass für die Grenzüberschreitung ist meist ein Bündel von Gründen, zu denen Wartezeit, Entfernung des Angebots, technische Ausstattung, Qualifikation und Patientenorientierung zählen. Das größte Problem stellt erwartungsgemäß die Sprache dar. Allerdings werden in den Praxen oft funktionierende Arrangements zwischen Patient und Arzt gefunden und auch Patienten mit geringen und mittleren Deutschkenntnissen lassen sich im Saarland behandeln. Höhere Kosten im Saarland, die rechtliche Situation und fehlende Sprachkenntnisse führen dazu, dass sich in erster Linie Grenzgänger grenzüberschreitend behandeln lassen.

32 Vgl. Mertens: Kurzdarstellung der Ergebnisse, S. 20.

33 Vgl. Funk, Ines: Grenzü̈berschreitende Patientenmobilität im saarländisch-lotbringischen Grensraum, Saarbrücken: Univ. Diss., 2015, S. 121.

34 Funk: Grenzüberscbreitende Patientenmobilität.

35 Vgl. Funk: Grenæüberschreitende Patientenmobilität, S. 120-124. 
Ärzte und Krankenhäuser nennen Informationsdefizite und die mangelnde politische Unterstützung als größte Hemmnisse für die grenzüberschreitende Gesundheitsversorgung. ${ }^{36}$ Auch die Patienten vermissen leicht zugängliche Informationen und greifen deshalb bei der grenzüberschreitenden Arztsuche auf Empfehlungen von Familienmitgliedern, Freunden und Kollegen zurück.

Mit französischen Patienten durchgeführte problemzentrierte Interviews zeigen, dass die Entscheidung für die grenzüberschreitende Inanspruchnahme medizinischer Leistungen stark von der subjektiven Wahrnehmung von Vorteilen und Hemmnissen, der Einstellung zum Saarland sowie den persönlichen Rahmenbedingungen abhängig ist. Ein Faktor kann bei einem Patienten förderlich und bei einem anderen hemmend wirken, die Motive sind z. T. scheinbar widersprüchlich und subjektiv rational.

\begin{tabular}{|c|c|}
\hline $\begin{array}{l}\text { Typ I: } \\
\text { Routinier }\end{array}$ & $\begin{array}{l}\text { Typ II: } \\
\text { Anhänger der saarländischen } \\
\text { Gesundheitsversorgung }\end{array}$ \\
\hline $\begin{array}{l}\text { Persönliche Rahmenbedingungen: } \\
\text { sehr förderlich, da gute } \\
\text { Deutschkenntnisse, familiäre Bindung an } \\
\text { das SL, fühlt sich z. T. als Saarländer, oft } \\
\text { schon als Kind im SL in Behandlung }\end{array}$ & $\begin{array}{l}\text { Persönliche Rahmenbedingungen: } \\
\text { förderlich bis neutral, aufgeschlossen } \\
\text { gegenüber dem Saarland, Sprachkenntnisse } \\
\text { variieren }\end{array}$ \\
\hline $\begin{array}{l}\text { Motive: } \\
\text { - Sprache: medizinisches Fachvoka- } \\
\text { bular z. T. auf Deutsch besser } \\
\text { bekannt als auf Französisch } \\
\text { - Vertrauen in die saarländische } \\
\text { Gesundheitsversorgung }\end{array}$ & $\begin{array}{l}\text { Motive: } \\
\text { - } \quad \text { sucht kompetente Versorgung und } \\
\text { sorgfältige Diagnostik } \\
\text { - } \quad \text { will als Patient ernstgenommen werden } \\
\text { - } \quad \text { aus schlechten Erfahrungen in L und } \\
\text { guten Erfahrungen im SL hat sich eine } \\
\text { Begeisterung für die saarländische } \\
\text { Gesundheitsversorgung entwickelt }\end{array}$ \\
\hline 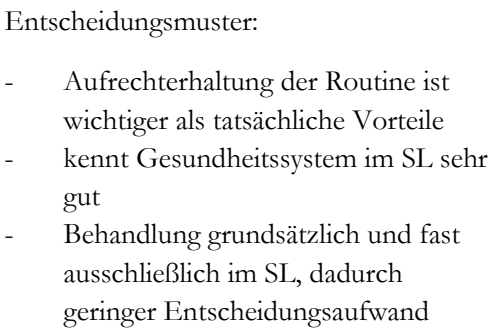 & $\begin{array}{l}\text { Entscheidungsmuster: } \\
\text { - } \quad \text { medizinische Aspekte sind } \\
\text { entscheidend } \\
\text { - } \quad \text { einzelfallbezogen, z. B. Behandlung } \\
\text { von Routineangelegenheiten in L und } \\
\text { von ernsteren, Fachqualifikationen } \\
\text { erfordernden Beschwerden im SL } \\
\text { - Behandlung in L und im SL }\end{array}$ \\
\hline
\end{tabular}

36 Vgl. Funk: Grenæüuberschreitende Patientenmobilität, S. 140-165. 


\begin{tabular}{|c|c|}
\hline $\begin{array}{l}\text { Typ III: } \\
\text { Border surfer }\end{array}$ & $\begin{array}{l}\text { Typ IV: Unfreiwilliger } \\
\text { grenzüberschreitender Patient }\end{array}$ \\
\hline $\begin{array}{l}\text { Persönliche Rahmenbedingungen: } \\
\text { sehr unterschiedlich, sucht das SL v. a. auf, } \\
\text { wenn es Vorteile verspricht }\end{array}$ & $\begin{array}{l}\text { Persönliche Rahmenbedingungen: } \\
\text { alle Ausprägungen denkbar }\end{array}$ \\
\hline $\begin{array}{l}\text { Motive: } \\
\text { - die Suche nach Vorteilen: die } \\
\text { billigste, schnellste, bequemste } \\
\text { Behandlung }\end{array}$ & $\begin{array}{l}\text { Motive: } \\
\text { - Patient möchte sich nicht im SL } \\
\text { behandeln lassen, wird aber von der } \\
\text { deutschen Krankenkasse oder vom } \\
\text { deutschen Arbeitgeber aufgrund } \\
\text { langwieriger Erkrankung dazu } \\
\text { aufgefordert }\end{array}$ \\
\hline $\begin{array}{l}\text { Entscheidungsmuster: } \\
\text { - Wahlmöglichkeit durch Grenzlage als } \\
\text { Potenzial } \\
\text { - } \quad \text { praktische Aspekte sind wichtiger als } \\
\text { medizinische } \\
\text { - } \quad \text { einzelfallbezogen, nach Kosten- } \\
\text { Nutzen-Abwägung } \\
\text { - } \quad \text { Empfehlungen spielen große Rolle } \\
\text { - Behandlung in L und im SL }\end{array}$ & $\begin{array}{l}\text { Entscheidungsmuster: } \\
\text { - } \quad \text { nur Auswahl des Arztes oder des } \\
\text { Anbieters im SL } \\
\text { - } \quad \text { aufgrund fehlender eigener Motivation, } \\
\text { fehlenden Informationen und } \\
\text { hemmenden persönlichen } \\
\text { Rahmenbedingungen schwieriger } \\
\text { Entscheidungsprozess }\end{array}$ \\
\hline
\end{tabular}

Tab. 3: Typen grenzüberschreitender Patienten $(\mathrm{L}=$ Lothringen, $\mathrm{SL}=$ Saarland $) \cdot{ }^{37}$

Auf der Grundlage von Einzelfallanalysen und eines horizontalen Vergleichs der Interviews wurden vier unterschiedliche Typen grenzüberschreitender Patienten unter den Grenzgängern im saarländisch-lothringischen Grenzraum identifiziert, die sich bezüglich der persönlichen Rahmenbedingungen, der Motive und des Entscheidungsmusters unterscheiden (vgl. Tab. 3).38

Welche Folgerungen können aus dieser Typisierung für die grenzüberschreitende Gesundheitsversorgung im Grenzraum Saarland-Lothringen gezogen werden? Zunächst ist festzustellen, dass eine starre Bewertung einzelner Faktoren wie Sprache, Verschiedenartigkeit der Gesundheitssysteme und Rechtsgrundlagen als förderlich oder hemmend nicht zielführend ist. Vielmehr bestehen Ambivalenzen, die eine differenzierte Betrachtung von Bevölkerungsgruppen, Behandlungsformen und Projekten erfordern. Deutlich wird

37 Eigene Darstellung. Daten basierend auf Funk: Grenzüuberschreitende Patientenmobilität, hier S. 214-232.

38 Vgl. Funk: Gren₹überschreitende Patientenmobilität, S. 166-213. 
dies an den definierten Typen: Typ I und Typ IV sind keine vielversprechenden Zielgruppen für die Förderung der grenzüberschreitenden Patientenmobilität und Gesundheitsversorgung. Die größten zu erwartenden Potenziale liegen in den Typen II und III, die für unterschiedliche Argumentationen empfänglich sind. Typ II wird sich für eine grenzüberschreitende Behandlung interessieren, wenn sie die medizinische Qualität der Versorgung verbessert. Typ III spricht die Aussicht auf eine schnellere oder günstigere, insgesamt praktischere bzw. bequemere Behandlung an.

Es bleibt die Frage, inwiefern diese Ergebnisse auf die Gesamtbevölkerung übertragen werden können. Die durchgeführten Befragungen zeigen, dass die grenzüberschreitende Gesundheitsversorgung der lothringischen Gesamtbevölkerung nicht bekannt ist und auch nicht für alle Grenzgänger eine Option darstellt. Die Grenzgänger spielen eine wichtige Rolle als Pioniere, weil sie aufzeigen, wo die grenzüberschreitende Gesundheitsversorgung Vorteile verspricht und welche Probleme bestehen. Von den dargelegten Vorteilen könnte auch die Gesamtbevölkerung stärker profitieren, wenn die geplante ZOAST MOSAR in Kraft tritt.

Die Analyse der grenzüberschreitenden Verflechtungen im Gesundheitsbereich deckt Diskrepanzen zwischen den politischen Willensbekundungen und der tatsächlich stattfindenden grenzüberschreitenden Gesundheitsversorgung bzw. der von den Akteuren der Gesundheitsversorgung und den $\mathrm{Pa}$ tienten erfahrenen Realität auf. Die grenzüberschreitenden Beziehungen im Gesundheitsbereich sind weniger ausgeprägt als in anderen Kooperationsfeldern und in anderen Grenzregionen, wo z. B. bereits ZOASTs und grenzüberschreitende Krankenhäuser existieren. ${ }^{39}$

Die in der Erklärung von Metz über die grenzüberschreitende deutsch-franæösische Zusammenarbeit im Juli 2015 attestierte „Dynamik der grenzüberschreitenden Zusammenarbeit im Gesundheitswesen" ${ }^{40}$ bestätigt sich nicht. Die Visionen der Frankreichstrategie sind zu vage formuliert und zu wenig mit Inhalt unterfüttert, um sie kurz- oder mittelfristig umsetzen zu können. Im Grenzraum Saarland-Lothringen bestehen eine Reihe von aktivierbaren Potenzialen für die grenzüberschreitende Gesundheitsversorgung und Möglichkeiten zur Reduzierung bestehender Hemmnisse. Erste Schritte dazu sind die Verbesserung der Informationslage bei allen Beteiligten und die Erzielung eines Konsenses darüber, dass die grenzüberschreitende Gesundheitsversorgung eine

39 Vgl. Funk: Grenæüberschreitende Patientenmobilität, S. 65-71, S. 92-97 und L'Observatoire Franco-Belge de la Santé: Flash Santé transfrontalière 7.

40 Ministère des Affaires Étrangères et du Développement International/Auswärtiges Amt: Erklärung von Metz. über die grenzü̈berschreitende deutsch-französische Zusammenarbeit, 07.07.2015, http://www.auswaertiges-amt.de/cae/servlet/contentblob/709948/publicationFile/206602/ 07072015_Metz_Gemeinsame_Erkl\%C3\%A4rung.pdf (22.09.2015), S. 9. 
Win-Win-Situation für Lothringen bzw. für die Nachfolgeregion und das Saarland darstellen kann.

\section{Literaturverzeichnis}

Agence Régionale de l'Hospitalisation de Lorraine/Ministerium für Inneres und Sport des Saarlandes: Vereinbarung zwischen dem Direktor der Agence Régionale de l'Hospitalisation de Lorraine und dem Minister für Inneres und Sport des Saarlandes über das grenzüberschreitende Gesundheitswesen vom 11.06.2008, http://www.saarland.de/dokumente/thema_SaarLorLux/Vereinbarung 2008_06_11_Rettungsdienste_SL-LOR_geringe_Aufloesung.pdf (27.05.2013).

Agence Régionale de Santé de Lorraine: Statistique Annuelle des Etablissements de santé lorrains 2013, 2015, http://www.ars.lorraine.sante.fr/fileadmin/LORRAINE/ARS_LORRAINE/ ACTUALITES/SAE_01/ARS_Lorraine-BrochureSAE2013.pdf (22.11.2015).

Auswärtiges Amt/République Française: Erklärung von Saarbrücken zur deutsch-französischen Zusammenarbeit in den Grensregionen vom 15.07.2013, http://www.saarland.de/dokumente/ thema_frankreichjahr/Erklaerung_DEU_final.pdf (30.09.2013).

Beck, Joachim/Dussap-Köhler, Anne/Pradier, Eddie: Evaluation de la mise en cuvre de l'accord-cadre franco-allemand sur la coopération sanitaire transfrontalière, Kehl: Euro-Institut, 2012, http:// www.ars.alsace.sante.fr/fileadmin/ALSACE/Internet/Strategie_de_sante/cooperation_ transfrontaliere/accord_cadre_franco_ald/Rapport_Final_Evaluation_AC_FA_2012.pdf (11.07.2015).

Direction de la sécurité sociale/Division des affaires communautaires et internationales/Direction de l'hospitalisation/et de l'organisation des soins/Mission des relations européennes et internationales: Circulaire DSS/DACI no 2007-291 du 18 juillet 2007 relative à la mise en œuvre de l'accord-cadre de coopération sanitaire transfrontalière entre le Gouvernement de la République française et le Gouvernement de la République fédérale d'Allemagne, signé le 22 juillet 2005, in: Bulletin Officiel Santé - Protection sociale - Solidarité 8 (2007), 15.09.2007, http://www.sante.gouv.fr/fichiers/bo/2007/07-08/bo0708.pdf (20.09.2015) S. 395-399.

Eurodistrict SaarMoselle: Der Eurodistrict SaarMoselle spricht sich einstimmig für die Schaffung einer Zone mit grenzüberschreitendem Zugang zu Gesundheitsdienstleistungen (ZOAST) aus, Pressemitteilung vom 19.03.2015, Saarbrücken: Eurodistrict.

Euro-Institut: Das Gesundheitssystem in Deutschland und Frankreich. Dokumentation erstellt im Rahmen der Veranstaltung „Europa wächst zusammen - Gesundheit ohne Grenzen. DeutschFranzösisches Rahmenabkommen über die grenzüberschreitende Zusammenarbeit im Gesundheitsbereich“, Karlsruhe, 26.09.2007, http://www.euroinstitut.org/pdf/ Download-Unterlagen/2007-Gesundheit-ohne-Grenzen/Gesundheitswesen-D-u-F.pdf (08.02.2013).

Europäische Kommission: Patientenrechte bei grenzüberschreitenden Gesundheitsdienstleistungen in der Europäischen Union (= Spezial Eurobarometer Bd. 425), Brüssel: Europäische Union, 2015.

Europäisches Parlament und europäischer Rat: Verordnung (EG) Nr. 883/2004 des Europäischen Parlamentes und des Rates vom 29. April 2004 zur Koordinierung der Systeme der sozialen Sicherheit, in: Amtsblatt der Europäischen Union, 30.04.2004, L 166.

Europäisches Parlament und europäischer Rat: Richtlinie 2011/24/EU des Europäischen Parlamentes und des Rates vom 9. März 2011 über die Ausübung der Patientenrechte in der grenzüberschreitenden Gesundheitsversorgung, in: Amtsblatt der Europäischen Union, 04.04.2011, L 88 . 
Französisch-deutscher Ministerrat: Gemeinsame Erklärung zwischen Marisol Touraine, Ministerin für Soziales und Gesundheit, und Hermann Gröhe, Bundesminister für Gesundheit. Französisch-Deutscher Ministerrat, 7. April 2016 in Metz, https://www. bundesgesundheitsministerium.de/fileadmin/Dateien/3_Downloads/E/Erklaerungen/1 60407_Declaration_commune_sante_DE.pdf (08.12.2016).

Fröhlich, Mareike/Lahann, Tilmann/Trautmann, Anja: Gesundheitsdienstleistungen in der Großregion SaarLorLux. Die praktische Umsetzung der Rechtsprechung des Europäischen Gerichtshofs im Hinblick auf Krankenkassensystem im gren₹überschreitenden Kontext (= eVeröffentlichungen des EuropaInstituts Bd. 2), Saarbrücken: Europa-Institut, 2011.

Funk, Ines: Gren₹überschreitende Patientenmobilität im saarländisch-lothringischen Gren₹raum, Saarbrücken: Univ. Diss, 2015.

Geiger-Jaillet, Anemone: Nationale, regionale und spracbliche Grenzen. Das Saar-Lor-Lux-Modell (= Bausteine Europas VIII), St. Augustin: Asgard, 2011.

Gesundheitsberichterstattung Saarland: Indikator (L) 8.8 Ärztinnen/Ärzte und Zahnärztinnen/Zahnärzte in ambulanten Einrichtungen, Saarland im Regionalvergleich, 2009, http:// www.gbe.saarland.de/medien/download/08_008_2009.htm (04.07.2013).

Haubrichs, Wolfgang: Germanophone Dialekte in Lothringen, in: Brücher, Wolfgang/Franke, Peter Robert (Hg.): Probleme von Grenæregionen. Das Beispiel Saar-Lor-Lux-Raum, Beiträge zum Forschungsschwerpunkt des Philosophischen Fakultät der Universität des Saarlandes, Saarbrücken: Universität, 1987, S. 99-121.

Kohl, Jasmin: Warten auf die Gesundheitszone. Lothringer und Saarländer zahlen für Behandlungen im Partnerland weiterhin drauf, in: Saarbrïcker Zeitung, 23.11.2015.

Landesregierung des Saarlandes: Feuille de route Frankreich-Strategie 2015/2016, 2015, http:// saarland.de/dokumente/ressort_finanzen/Feuille_de_route.pdf (13.05.2015).

L'Observatoire Franco-Belge de la Santé: Flash Santé transfrontalière 7 (2015), http://www. interreg-fwvl.eu/sites/default/files/documents/flash7_novembre_2015.pdf (04.03.2016).

Mertens, Karin: Kurzdarstellung der Ergebnisse des Projekts 2003-2006 „Vergleich der Gesundheitssysteme Saarland-Moselle", Saarbrücken: LAGS, 2007.

Ministère des Affaires Étrangères et du Développement International/Auswärtiges Amt: Erklärung von Metz, über die grenzüberschreitende deutsch-französische Zusammenarbeit, 07.07.2015, http://www.auswaertiges-amt.de/cae/servlet/contentblob/709948/publicationFile/ 206602/07072015_Metz_Gemeinsame_Erkl\%C3\%A4rung.pdf (22.09.2015).

Ministerium für Gesundheit und Verbraucherschutz des Saarlandes (Hg.): Krankenhausplan für das Saarland 2011-2015, 2011, http://saarland.de/dokumente/res_gesundheit/Krankenhausplan. $\operatorname{pdf}(18.07 .2011)$.

Ministerium für Soziales, Gesundheit, Frauen und Familie des Saarlandes: Sozialministerin Monika Bachmann: Ausbau der grenzüberschreitenden Gesundheitsversorgung ist wichtiger Baustein im Rahmen der Frankreichstrategie, 2015, http://saarland.de/123066.htm (23.03.2015).

Observatoire National de la Démographie des Professions de Santé: Rapport de l'ONDPS 20062007 Région Lorraine. La médecine générale. Les internes en médecine. Les métiers de la périnatalité. Le bloc opératoire. Les métiers de la cancérologie, 2009, http://www.lorraine.sante.gouv.fr/statetu/ etud/doc/sante/ondps.pdf (26.11.2016).

Regierung der Bundesrepublik Deutschland/Gouvernement de la République Française: Rahmenabkommen zwischen der Regierung der Bundesrepublik Deutschland und der Regierung der Französischen Republik über die grenzüberschreitende Zusammenarbeit im Gesundheitsbereich vom 22.07.2005, in: Bundesgesetz̧blatt 32 (2006), Teil II, 21.12.2006. 
Ruffray, Sophie/Hamez, Grégory: L’accessibilité transfrontalière aux maternités. Enjeux territoriaux d'une coopération sanitaire dans la Grande Région, in: Moullé, François/Duhamel, Sabine (Hg.): Frontières et santé. Genèses et maillages des réseaux transfrontaliers, Paris: L'Harmattan, 2010, S. 29-41.

Schneider, André: Rapport fait au de nom de la commission des affaires étrangères sur le projet de loi $n^{\circ}$ 3120, autorisant l'approbation de l'accord cadre entre le Gouvernement de la République française et le Gouvernement de la République Fédérale d'Allemagne sur la coopération sanitaire transfrontalière. Annexe II Calcul des distances entre les différentes communes de Sarre et Moselle et les services d'urgence les plus proches, 2006, http://www.assemblee-nationale.fr/12/pdf/rapports/r3198.pdf (07.11.2012).

Staatskanzlei des Saarlandes: Eckpunkte einer Frankreichstrategie für das Saarland, 2014, http:// www.saarland.de/dokumente/res_stk/D_Eckpunkte_Frankreich-Strategie_210114.pdf (13.05.2015).

Statistische Ämter der Großregion (Hg.): Statistiques en bref/Statistische Kurzinformationen 2014, Saarbücken [u. a.]: Statistische Ämter, 2014.

Statistisches Amt Saarland: Pendlerverhalten der sozialversicherungspflichtig beschäftigten Arbeitnehmer des Saarlandes am 30. Juni 2014, in: Statistische Bericbte A VI 5-S - j 2014 (2015), http://www.saarland.de/dokumente/thema_statistik/STALA_BER_AVI5S-J-14. pdf (02.03.2016).

Wagner, Peter: Nach zähem Ringen: Medizin ohne Grenzen, in: Saarbrücker Zeitung, 04.12.2013. 



\section{Zwischen Marketing und Mindset \\ Zur Rolle von Medien und grenzüberschreitender Berichterstattung im Kontext der Frankreichstrategie}

Avec la proclamation de la 'Stratégie France' en janvier 2014, le gouvernement du Land de la Sarre a lancé un véritable coup médiatique national et international. La 'Stratégie France' participe donc activement à la création d'une image de marque régionale de la Sarre dans la perspective d'un 'place branding'. Le rôle des médias est aussi essentiel pour réaliser les objectifs de la stratégie et pour ancrer une perspective franco-allemande dans le quotidien des Sarrois, notamment par l'établissement d'un espace public médiatique transfrontalier et interrégional. Dans les médias de la Grande Région, une telle orientation est certainement en émergence, mais encore assez.peu développée.

Les réflexions présentées dans cette contribution sont inspirées d'une rencontre-débat autour de deux ouvrages portant sur les cadres de la vie quotidienne et sur les constructions politiques dans la Grande Région SaarLorLux ainsi que sur la dimension médiatique de cet espace transfrontalier. ${ }^{1}$

Die Verkündung der Frankreichstrategie der Saarländischen Landesregierung im Januar 2014 kann als eine auf den ersten Blick recht erfolgreiche Marketingmaßnahme betrachtet werden, die breite Beachtung fand. Innerhalb von 30 Jahren soll das Saarland zu einem ,multilingualen Raum deutsch-französischer Prägung“"2 werden, sodass 2043 das Französische gleichsam als Zweitsprache in dem kleinen Bundesland im Dreiländereck etabliert wäre. Das Saarland, das sich schon zuvor als „französischstes aller Bundesländer“"3 bezeichnete, möchte dazu nicht nur das Erlernen der Sprache des Nachbarn weiter stärken, sondern damit auch seine „Frankreichkompetenz" ${ }^{\text {" }}$ weiter ausbauen.

1 Goulet, Vincent/Vatter, Christoph (Hg.): Gren₹überschreitende Informationsfliusse und Medien in der Großregion SaarLorLux/La circulation transfrontalière des informations médiatiques dans la Grande Région SaarLorLux, Baden-Baden: Nomos, 2015; Wille, Christian (Hg.): Lebenswirklichkeiten und politische Konstruktionen in Grensregionen. Das Beispiel der Großregion SaarLorLux: WirtschaftPolitik - Alltag - Kultur, Bielefeld: transcript, 2015.

2 Staatskanzlei des Saarlandes: Eckpunkte einer Frankreichstrategie für das Saarland, 2014, http:// www.saarland.de/dokumente/res_stk/D_Eckpunkte_Frankreich-Strategie_210114.pdf (31.01.2017), S. 9.

3 Vgl. Schönwald, Antje: Identitäten und Stereotype in grenzüberscbreitenden Verflechtungsräumen. Das Beispiel der Großregion, Wiesbaden: VS, 2012, S. 108.

4 Staatskanzlei des Saarlandes: Eckpunkte einer Frankreichstrategie, S. 1. 
Im zentralen Eckpunktepapier zur Frankreichstrategie ist die Rede von einer „Stärkung der Frankreichkompetenz im Land“ als Binnen-Strategie, und einer „Außen- und Kommunikationsstrategie“, die eben diese saarländische Frankreichkompetenz außerhalb des Saarlandes vermitteln soll. ${ }^{5}$ Einerseits gelang es dem kleinen Bundesland mit der Initiative der Frankreichstrategie in der Tat eine große mediale Aufmerksamkeit über seine Grenzen hinaus zu erreichen, sowohl in den nationalen als auch internationalen Medien; andererseits ist damit auch ein an die verschiedensten saarländischen Akteure adressiertes Programm zur Bündelung und Verstärkung zahlreicher auf Frankreich und das Erlernen der französischen Sprache sowie die grenzüberschreitende Zusammenarbeit ausgerichtete Initiativen verbunden.

Während die Außenwirkung also im Sinne eines, regional branding ${ }^{6}$ die ,Marke' Saarland mit neuer Orientierung auf die Grenzlage und damit verbundene kulturelle und sprachliche Kompetenzen mit frischem Elan aufwerten soll, kann unter der Binnenperspektive in erster Linie der Versuch der Stärkung und Motivierung der Akteure der deutsch-französischen Zusammenarbeit sowie der Förderung eines Verständnisses der Grenzlage und deutsch-französischen Geschichte des Saarlandes als Stärke und Kompetenz im Sinne eines ,empowerment ${ }^{\natural}-$ verstanden werden. Hierfür spielen die Berichterstattung und (kritische) Begleitung des Vorhabens durch die Medien eine zentrale Rolle, insbesondere ist an die Saarbrücker Zeitung und den Saarländischen Rundfunk als wichtigste regionale Medien zu denken. ${ }^{6}$

Im Folgenden sollen einige Aspekte zur Rolle der Medien im Kontext der Frankreichstrategie des Saarlandes im Spannungsfeld zwischen der Außenwirkung und der Binnenperspektive der saarländischen Öffentlichkeit diskutiert werden. Dabei ist es zunächst erforderlich zu erörtern, wie eine mit der Frankreichstrategie des Saarlandes angestrebte ,Frankreichkompetenz' profiliert sein könnte. In einem zweiten Schritt sollen dann die Medien im Hinblick auf eine interkulturelle, deutsch-französische Dynamik im Sinne der Außenund Binnenperspektive Frankreichstrategie betrachtet werden.

5 Staatskanzlei des Saarlandes: Eckpunkte einer Frankreichstrategie, S. 3.

6 Zur Rolle der Medien vgl. Staatskanzlei des Saarlandes: Eckpunkte einer Frankreichstrategie, S. 26-28. 


\section{Frankreichkompetenz, interkulturelle Kompetenz und interregionale Kompetenz}

In den zentralen Publikationen und öffentlichen Reden der Saarländischen Landesregierung zur Frankreichstrategie wird deutlich, dass der Begriff ,Frankreichkompetenz' zwar eine zentrale Rolle spielt, dieser aber in unterschiedlicher Art und Weise dargestellt und an keiner Stelle eindeutig definiert wird. Das in diesem Kontext häufigste Verständnis ist das einer auf das Erlernen und Beherrschen der französischen Sprache bezogenen „Französischkompetenz ${ }^{\text {"67 }}$, die konsistent mit der erklärten Zielvorstellung eines mehrsprachigen, vornehmlich deutsch-französisch geprägten Raums und den zahlreichen Maßnahmen aus dem (vor-)schulischen Bereich ist. An anderen Stellen wird diese, vornehmlich auf Fremdsprachenkompetenzen bezogene Vorstellung jedoch erweitert: „Frankreich-Kompetenz beinhaltet nicht nur entsprechende Sprachkompetenzen, sondern auch die Vertiefung weiterer Kompetenzfelder, wie Fachkompetenz, Regionalkompetenz und interkulturelle Kompetenz." 8 Hieraus geht hervor, dass eine deutsch-französische Ausrichtung des Saarlandes nur unter Rückbezug auf die regionale Ebene der grenzüberschreitenden Zusammenarbeit mit französischen Partnern unmittelbar jenseits der Grenze, aber auch im Rahmen der Großregion SaarLorLux denkbar ist, zu der neben dem Saarland, Lothringen ${ }^{9}$ und Luxemburg auch die Region Wallonien mit der deutschsprachigen und der französischen Gemeinschaft Belgiens sowie Rheinland-Pfalz gehören.

Die Vielzahl verschiedener Ansätze, ,Frankreichkompetenz' und damit verknüpfte Kompetenzbereiche im Rahmen der Frankreichstrategie zu konzeptualisieren, ${ }^{10}$ lässt sich auch auf unterschiedliche Akteursebenen zurückführen, wie beispielsweise Aussagen wie die folgende belegen, die eindeutig auf die Landesregierung als übergeordnete Instanz mit Koordinations- und Leitungsfunktion verweist: „Frankreich-Kompetenz dokumentiert sich sowohl in der Fähigkeit, die in der Breite des Saarlandes vorhandenen Aktivitäten frankreichspezifischer Art zu bündeln, als auch Spitzenleistungen hervorzuheben." 11

Mit dieser übergeordneten institutionellen Ebene sind auch im Eckpunktepapier verwendete Metaphern wie „Brücke“ bzw. „Tor“ zu Frankreich,

7 Staatskanzlei des Saarlandes: Eckpunkte einer Frankreichstrategie, S. 5.

8 Staatskanzlei des Saarlandes: Eckpunkte einer Frankreichstrategie, S. 20.

9 Seit der am 1. Januar 2016 in Kraft getretenen französischen Territorialreform ist Lothringen Bestandteil der Region Grand Est, zu der auch das Elsass und Champagne-Ardenne gehören, sodass die interregionale Zusammenarbeit in diesem Kontext neu konfiguriert werden muss.

10 Vgl. auch den Beitrag von Hans-Jürgen Lüsebrink in diesem Band.

11 Staatskanzlei des Saarlandes: Eckpunkte einer Frankreichstrategie, S. 7. 
„Mittler“ oder auch - in die Gegenrichtung gedacht - ,,Türöffner“ zu Deutschland" verknüpft. ${ }^{12}$ In zahlreichen weiteren Punkten verweist die Frankreichstrategie dagegen auf zivilgeschichtliche Akteure von Schulen über Vereine bis zum einzelnen Bürger, deren jeweilige Rollen auch durch jeweils spezifische Kompetenzprofile beschrieben werden könnten. Kenntnisse über Frankreich, die französische Kultur oder auch Spezifika im französischen Kommunikationsverhalten, Sprachkenntnisse und interkulturelle Handlungskompetenzen sind - um nur einige Beispiele zu nennen - eher auf einer individuellen Ebene angesiedelt und können dem Einzelnen helfen, erfolgreich mit französischen Gesprächspartnern zu kommunizieren.

Eine interkulturelle Frankreichkompetenz könnte demnach als Fähigkeit definiert werden, mit französischen Partnern auf der Grundlage von kulturellen und sprachlichen Kenntnissen in angemessener, wertschätzender und konstruktiver Art und Weise zu kommunizieren und zu interagieren. Sie ist in erster Linie als eine Transferkompetenz zu verstehen, da sie im Kern darauf abzielt, individuelle, soziale, fachliche und strategische Kompetenzen in ihrer bestmöglichen Kombination auf interkulturelle, deutsch-französische Handlungskontexte zu übertragen. ${ }^{13}$ Hierzu sind neben Sprachkenntnissen auch landeskundliche und kulturelle Kompetenzen notwendig. Im Rahmen der Frankreichstrategie für das Saarland kann eine so verstandene, deutsch-französisch profilierte interkulturelle Kompetenz nur als aus der spezifischen historischen Erfahrung der Region gewachsen und auf die lange erprobte interregionale Zusammenarbeit und das Zusammenleben in der Großregion bezogen verstanden werden. Auf der individuellen Ebene bezieht dies die Möglichkeit einer grenzüberschreitenden Alltagspraxis - vom Einkaufen bis zum Besuch von Kulturveranstaltungen oder Sport - mit ein; und auch auf der institutionellen Ebene können die langjährigen Erfahrungen aus der grenzüberschreitenden Zusammenarbeit in vielfältigen Bereichen für eine übergreifende, deutsch-französische (nationale) Ebene fruchtbar gemacht werden, wie beispielsweise die Vertretung des Saarlandes in Paris oder die Ansiedlung deutsch-französischer Institutionen wie die Deutsch-Französische Hochschule ${ }^{14}$ zeigen.

Interkulturelle Frankreichkompetenz im saarländischen Kontext muss also auf der Erfahrung der grenzüberschreitenden regionalen Zusammenarbeit und Alltagspraxis aufbauen. Diese ist jedoch keineswegs eine Selbst-

12 Staatskanzlei des Saarlandes: Eckpunkte einer Frankereichstrategie, S. 13.

13 Vgl. Bolten, Jürgen: Interkulturelle Kompeten₹, Erfurt: Landeszentrale für politische Bildung, 52012, S. 126-130.

14 Vgl. den Beitrag von Patricia Oster-Stierle in diesem Band. 
verständlichkeit, die für das gesamte Bundesland gilt. Wie Studien zur Großregion SaarLorLux zeigen, besteht diese aus einem „funktionalen Kern"15 entlang der deutsch-französischen Grenze sowie um Luxemburg, während für die Bewohner weiter entfernt liegender Gegenden die Nachbarn jenseits der Grenze eine weitaus geringere Rolle spielen und kaum Bestandteil alltäglicher Praktiken sind. Ein zentraler Ansatzpunkt in der Umsetzung der Frankreichstrategie stellt also die Förderung eines, interregionalen Mindsets' dar, d. h. die Verankerung einer grenzüberschreitenden, mehrsprachigen Realität in den Mentalitäten der Menschen, sodass diese selbstverständlich ,mitgedacht ${ }^{\star}$ wird - auch von den Saarländerinnen und Saarländern, die nicht entlang des Korridors der deutsch-französischen nationalen Grenze leben. Für die Ausbildung eines solchen interregionalen Mindsets, das nicht nur als eigene „Regionalkompetenz"16 für die Großregion, sondern als zentrale Voraussetzung für eine interkulturelle Frankreichkompetenz zu verstehen ist, und seiner Verankerung in der Alltagspraxis und den Mentalitäten der Menschen spielen die Medien eine zentrale Rolle; aber auch die institutionelle Ebene der innerdeutschen, interregionalen und internationalen (Außen-)Beziehungen des Saarlandes ist auf die mediale Berichterstattung angewiesen, damit die Ambitionen der Frankreichstrategie erfüllt werden können. In den folgenden Abschnitten soll daher zunächst die Rolle der Medien für die Außenwirkung des Saarlandes näher beleuchtet werden, ehe wieder die Binnenperspektive der regionalen Medien und ihrer Vermittlungsfunktion im Sinne des genannten interregionalen, deutsch-französischen Mindsets in den Fokus rückt.

\section{Zur Rezeption der Frankreichstrategie außerhalb des Saarlandes}

Die Verkündung der Frankreichstrategie im Januar 2014 verhalf dem Saarland zu einer großen medialen Aufmerksamkeit. Fast alle nationalen und zahlreiche internationale Zeitungen berichteten über die Initiative. Der Ruf als ,französischstes Bundesland" schien sich weiter zu konsolidieren und auch ein Blick in die aktuellen Daten zum Fremdsprachenlernen in deutschen Schulen, veröffentlicht in der Studie Schulen auf einen Blick (2016), bestätigt dies: 59,7 \% der saarländischen Schülerinnen und Schüler lernten im Schuljahr 2014/15 Französisch, etwas weniger $(54,3 \%)$ die englische Sprache. ${ }^{17}$ Damit führt das

15 ESPON: METROBORDER. Grenæüberschreitende polyzentrische Metropolregionen. Zielgerichtete Analysen 2013/2/3. Abschlussbericht, Luxemburg: ESPON/University of Luxembourg, 31.12.2010, http://www.dat.public.lu/publications/documents/metroborder/metroborder_ final_report_de.pdf (31.01.2017).

16 Staatskanzlei des Saarlandes: Eckpunkte einer Frankreichstrategie, S. 20.

17 Statistisches Bundesamt (Hg.): Schulen auf einen Blick. 2016, Wiesbaden: Statistisches Bundesamt, 2016, S. 20. Die hohen Werte für das Französische gehen sicherlich auf die verstärkte 
Saarland die Rangliste an. Es folgen Baden-Württemberg (26,3 \%), Thüringen $(23,5 \%)$ und Rheinland-Pfalz $(23,4 \%)$, d. h. auch unter den unmittelbar an Frankreich angrenzenden Bundesländern nimmt das Saarland eine Spitzenposition ein - der Bundesdurchschnitt lag bei $18 \%$.

Diese Form von Öffentlichkeit und Führungsrolle in Bezug auf das Französische ist in der Frankreichstrategie fest verankert, denn diese ist als eine Ausprägung von Public Diplomacy zu verstehen, d. h. sie zielt darauf ab, das Saarland national wie international weiter bekannt zu machen, sein Image in der öffentlichen Wahrnehmung zu verbessern und mit der Frankreichstrategie als „Dachmarke“18 fest zu verbinden. Dies kann jedoch nur im Zusammenspiel mit den Medien erreicht werden, wie auch am Beispiel der im Saarland angesiedelten deutsch-französischen und französischen Institutionen im Eckpunktepapier der Landesregierung ausgeführt wird:

Eine noch bessere Wahrnehmung und Sichtbarkeit dieser Einrichtungen in ganz Deutschland, Frankreich und Europa würde dazu beitragen, dass das Land mit seiner FrankreichKompetenz noch ernster genommen würde. Dabei kommt den Medien eine wichtige Vermittlungsfunktion zu. ${ }^{19}$

Die Herausforderung besteht darin, die Frankreichstrategie und die damit verknüpfte Vorstellung einer saarländischen Frankreichkompetenz in ihrer Vielfalt zu vermitteln, damit auch politische und ökonomische Effekte wie z. B. neue Kooperationen für Wirtschaftsunternehmen oder auch die Steigerung der Attraktivität des Saarlandes als Wohnregion erzielt werden können. Diese Problematik wird bei einem Blick in die überregionale und internationale Berichterstattung deutlich. ${ }^{20}$ Denn hier dominiert zunächst die Idee

Förderung von Frühfranzösisch im Saarland zurück. Englisch ist fester Bestandteil der in der Frankreichstrategie verankerten Mehrsprachigkeitsperspektive, in der sowohl Französisch als auch Englisch einen festen Platz einnehmen. Die Zahlen dürften aber weniger als direkte Erfolge der Frankreichstrategie interpretiert werden, sondern vielmehr als Früchte von Vorarbeiten, v. a. im Rahmen des Sprachenkonzepts des Saarlandes von 2011, nach dem alle saarländischen Schüler Französisch und Englisch lernen sollen. Vgl. Ministerium für Bildung des Saarlandes: Sprachenkonzept Saarland 2011. Neue Wege zur Mehrsprachigkeit im Bildungssystem, Saarbrücken, 2011, http://www.saarland.de/dokumente/res_bildung/Das_ Sprachkonzept_Saarland_2011.pdf (31.01.2017).

18 Staatskanzlei des Saarlandes: Eckpunkte einer Frankreichstrategie, S. 3.

19 Staatskanzlei des Saarlandes: Eckpunkte einer Frankreichstrategie, S. 6.

20 Vgl. hierzu die Bachelorarbeit von Eichler, Steve: Die Rezeption der Frankreichstrategie des Saarlandes in deutschen und französischen Tageszeitungen in den Jabren 2014 und 2015, Universität des Saarlandes/Université de Lorraine, Bachelorarbeit, 2015. 
einer Zweisprachigkeit, die z. T. auch als gegen das Englische gerichtet interpretiert wird, ${ }^{21}$ was den Intentionen der Frankreichstrategie und des saarländischen Sprachenkonzepts völlig entgegenläuft. Insgesamt dominiert jedoch in der nationalen Berichterstattung im Januar 2014 eine kritische Analyse zwischen Standortmarketing und Kampf um die Überlebensfähigkeit des kleinen, durch die ,Schuldenbremse' stark belasteten Bundeslandes. In der französischen Presse werden diese Aspekte zwar durchaus angesprochen; zahlreiche Artikel beziehen sich aber auch auf die wirtschaftliche Dimension und unterstreichen die engen Verbindungen zwischen dem Saarland und Frankreich, aus denen sich neue Potenziale ergeben können. ${ }^{22}$ Diese Wahrnehmung spiegelt sich auch in einigen Initiativen wieder, für die die Kommunikation der Frankreichstrategie Anlass war, eine saarländische Delegation mit Vertretern aus Politik, Wirtschaft und Wissenschaft einzuladen, um Perspektiven der Kooperation im Sinne eines ,Tors nach Deutschland' auszuloten, z. B. aus den französischen Regionen Burgund und Normandie sowie dem frankophonen Nordafrika mit Tunesien. ${ }^{23}$

Trotz einer eher selektiv-verengten Wahrnehmung der Frankreichstrategie als Bilingualismus-Politik in vielen nationalen und internationalen Medien kann die damit verbundene Presse- und Öffentlichkeitsarbeit, die auch in französischer Sprache erfolgte und die sozialen Netzwerke Facebook und Twitter einbezieht, ${ }^{24}$ eine Reihe von Erfolgen verbuchen, v. a. durch die große Aufmerksamkeit, die dem Saarland in den überregionalen Medien Deutschlands zuteil wurde - und dies jenseits finanzpolitischer Debatten, sowie auch durch die internationale Wahrnehmung, insbesondere auf europäischer Ebene und in Frankreich.

21 Vgl. z. B. Höll, Susanne: Französisch? Nää merci, in: Süddentsche Zeitung, 30.01.2014, S. 6; Nonnenmacher, Günther: Die saarländische Vision, in: FAZ, 25.01.2014, S. 1.

22 Vgl. z. B. Madelin, Thibaut: La Sarre veut devenir un Land bilingue, in: Les Echos, 28.01.2014, S. 12; Le Tallec, Camille: La région allemande de la Sarre veut écrire son avenir en français, in: La Croix, 04.11.2014, S. 5.

23 Zum Potenzial der außereuropäischen Kooperation mit frankophonen Ländern vgl. den Beitrag von Sylvère Mbondobari in diesem Band.

24 Eine Analyse der Nutzung der sozialen Medien im Kontext der Frankreichstrategie bestätigt die zentrale Rolle der saarländischen Ministerpräsidentin - fast alle Tweets und Postings offizieller saarländischer Akteure zur Frankreichstrategie gehen von der Staatskanzlei aus; sie legt aber auch deutliche Defizite in der Kommunikation offen, wie z. B. die kaum genutzten interaktiven Möglichkeiten zur Vernetzung und Einbeziehung französischer Akteure. Vgl. hierzu Masterarbeit von Picart, Malika: La stratégie „France" $d u$ Land de Sarre: campagne d'information du gouvernement sarrois et impact dans la presse en France et en Allemagne, Universität des Saarlandes/Université de Lorraine, Masterarbeit, 2016. 
Dies wird insbesondere im Kontrast zur Deutschlandstrategie Lothringens deutlich. ${ }^{25}$ Zunächst nur im französischen Departement Moselle, dann auch in der Region Lorraine wurde als Reaktion auf die saarländische Initiative ein entsprechendes Strategiepapier erarbeitet, das im Sommer 2015 veröffentlicht wurde. Im Gegensatz zu den umfangreichen PR-Maßnahmen im Rahmen der Frankreichstrategie, wie z. B. Broschüren, Image-Kampagnen oder auch das Label „Partner der Frankreichstrategie“, zeichnet sich der Umgang mit der Deutschlandstrategie Lothringens eher durch Diskretion aus. Sogar das Strategiepapier selbst ist nur auf Umwegen zu finden. Diese mangelnde Sichtbarkeit ist allerdings sicherlich auch im Kontext der Neuordnung der französischen Regionen zu sehen, im Zuge derer Lothringen seit Januar 2016 gemeinsam mit dem Elsass und Champagne-Ardenne zur Region Grand Est vereinigt wurde.

Insgesamt kann die Außenwirkung der Frankreichstrategie zumindest für den unmittelbaren Kontext ihrer Verkündung eher positiv bewertet werden; inwiefern dies auch nachhaltig der Fall ist, bleibt abzuwarten. Für die Verankerung einer interkulturellen Frankreichkompetenz im Alltag der Saarländerinnen und Saarländer und die Etablierung einer grenzüberschreitenden, deutsch-französischen Perspektive in Form eines interregionalen Mindsets ist die überregionale und internationale Berichterstattung dagegen eher von mittelbarer Bedeutung, wenn die positive Außenwahrnehmung beispielsweise medial ins Saarland zurückgespiegelt wird.

\section{Frankreichstrategie und grenzüberschreitende Berichterstattung in den saarländischen Medien}

Die Meinungsforschung scheint der Frankreichstrategie einen starken Rückhalt in der saarländischen Bevölkerung zu bescheinigen. So sprachen sich in einer Umfrage des Saarländischen Rundfunks 67 \% der 1000 befragten Saarländerinnen und Saarländer für ein bilinguales Saarland aus, ${ }^{26}$ und auch eine Forsa-Umfrage im Auftrag des Magazins Forum im November 2016 kommt zu einem positiven Ergebnis: 70 \% Zustimmung zur Frankreichstrategie wird

25 Vgl. dazu ausführlich den Beitrag von Reiner Marcowitz in diesem Band. Die Deutschlandstrategie Lothringens wird außerdem in der Bachelorarbeit von Nadine Fischer untersucht, vgl. Fischer, Nadine: Regionale Strategien für das Partnerland? Die Deutschlandstrategie Lotbringens und die Frankereichstrategie des Saarlandes im Vergleich, Universität des Saarlandes, Bachelorarbeit, 2016.

26 Brenner, Ulrich: Zwei Drittel der Saarländer wollen eine zweisprachige Heimat, in: Saarbrücker Zeitung, 16.05.2014. 
berichtet. ${ }^{27}$ Ein genauerer Blick in die Befragung zeigt aber, dass nach dem Stellenwert des Französischunterrichts als erste Fremdsprache im Saarland gefragt wurde, was in der Tat von einer großen Mehrheit unterstützt wird, nicht aber explizit nach dem politischen Projekt Frankreichstrategie. ${ }^{28}$ In der gleichen Umfrage bejahen aber auch $73 \%$, dass „eine stärkere Einbindung des Saarlandes in die Saar-Lor-Lux-Region für das Saarland konkrete Vorteile" bringt ${ }^{29}$ Dies bestätigt, dass einerseits das Erlernen der Nachbarsprache und die Bedeutung der Vernetzung in der Großregion als Basis für die breite Verankerung einer Frankreichkompetenz unverzichtbar sind.

Den regionalen Medien kommt hier eine besondere Rolle zu, wie auch das Eckpunktepapier zur Frankreichstrategie unterstreicht:

Hier tragen auch die regionalen Medien eine besondere Verantwortung. Nur wenige nutzen bislang konsequent die Möglichkeiten der grenzüberschreitenden Berichterstattung zum unmittelbaren Nutzen ihrer Zielgruppe im regionalen und nationalen Wettbewerb. ${ }^{30}$

In einem eng vernetzten, grenzüberschreitenden Raum, in dem die Grenze eher als Kontakt- und Begegnungszone gedacht wird, sollten die Medien also aus Sicht der Frankreichstrategie die deutsch-französische bzw. interregionale Dimension in der ganzen Breite ihrer Berichterstattung mit berücksichtigen.

Die saarländischen Medien begleiten die Frankreichstrategie intensiv. So zeigt beispielsweise eine Auswertung der Saarbrücker Zeitung, ${ }^{31}$ dass 2014 insgesamt 98 Artikel zur Frankreichstrategie publiziert wurden, davon 37 im ersten Quartal, also im Kontext der Verkündung der Initiative der saarländischen Landesregierung. Die Berichterstattung ging danach zwar zurück, die Thematik blieb aber beständig präsent. So wurden im vierten Quartal 2014 noch 18 Artikel veröffentlicht und auch im ersten Halbjahr 2015 finden sich noch 27 Berichte zum Thema. Diese intensive Berichterstattung ist in erster Linie darauf zurückzuführen, dass die Ministerpräsidentin Annegret Kramp-Karrenbauer die Frankreichstrategie zur, Chefsache` erklärte, sodass viele Politikfelder damit verknüpft wurden und sich häufig Anlässe zur Berichterstattung mit Bezug auf die Frankreichstrategie ergaben. Auch die zahlreichen Akteure der deutsch-französischen Zusammenarbeit im Saarland erhielten auf diese Weise einen privilegierten Zugang zur Öffentlichkeit und zu den Medien.

27 Vgl. z. B. die Meldung auf Radio Salü: Große Zustimmung zur Frankreichstrategie, 25.11.2016, www.salue.de/nachrichten/message.phtml?id=80859 (25.11.2016).

28 Vgl. Hilt, Oliver: Großer Stimmungstest zur Wahl, in: Forum. Das Wochenmagazin, 25.11.2016, http://www.magazin-forum.de/news/politik/gro\%C3\%9Fer-stimmungstestzur-wahl (31.01.2017).

29 Hilt: Großer Stimmungstest zur Wahl.

30 Staatskanzlei des Saarlandes: Eckpunkte einer Frankreichstrategie, S. 8.

31 Vgl. Eichler: Die Rezeption der Frankreichstrategie des Saarlandes. 
Während die Berichterstattung über die Frankreichstrategie in der saarländischen Presse also einen großen Stellenwert einnimmt, ist dies für die grenzüberschreitende und deutsch-französische Berichterstattung nur sehr bedingt der Fall, wie auch inhaltsanalytische Studien, Untersuchungen der grenzüberschreitenden Mediennetzwerke sowie Erkenntnisse zu interkulturellen Herausforderungen in der Großregion aufgrund unterschiedlicher Journalismuskulturen bestätigen. ${ }^{32}$

Eine Voraussetzung für die Verbreitung eines interregionalen Mindsets in der Bevölkerung stellt allerdings die Verwirklichung einer (medialen) Öffentlichkeit im Habermas'schen Sinne dar, die ebenfalls grenzüberschreitend-interregional aufgestellt ist und eine interkulturelle, deutsch-französische Dimension mit berücksichtigt. ${ }^{33}$

Eine solche interregionale (Medien-)Öffentlichkeit könnte - in Analogie zu Forschungen zu einer europäischen Öffentlichkeit - in struktureller Hinsicht auf zwei verschiedene Weisen aufgebaut sein. ${ }^{34}$ Erstens als gemeinsame, länderübergreifende Öffentlichkeit mit einer eng verzahnten, mehrsprachigen Medienlandschaft, in der Medien dies- und jenseits der Grenzen wechselseitig aufeinander Bezug nehmen. In diesem Modell würden auch die Menschen der Region ungeachtet ihres Wohnorts auf die gleichen Medien zugreifen, sodass diese als Foren für gesellschaftliche Debatten in einem gemeinsamen, mehrsprachigen und interkulturellen Raum dienten. Zweitens ist eine interregionale Öffentlichkeit über die Grenzen hinweg auch in Form von ,interregionalisierten' national-regionalen Öffentlichkeiten denkbar. Dieses Modell zeichnet sich dadurch aus, dass die Medien der jeweiligen Teilregionen - wie das Saarland, Lothringen oder auch Luxemburg - verstärkt Themen aus der Großregion aufgreifen, multiperspektivisch auf die Sichtweisen jenseits der Grenzen eingehen und es so erlauben, gesellschaftliche Debatten in einem grenzüberschreitenden, interregionalen Kontext zu führen.

32 Vgl. Goulet/Vatter: Grenzüberschreitende Informationsflüsse; Goulet, Vincent/Vatter, Christoph: L'espace médiatique transfrontalier: médias, flux d'informations et pratiques journalistiques, in: Wille (Hg.): Lebenswirklichkeiten und politische Konstruktionen in Grenaregionen, S. 229-248.

33 In Ansätzen wird eine konsequente Einbeziehung der Realitäten jenseits der Grenzen am ehesten in der Luxemburger Gratispresse umgesetzt, die damit auf die Berufspendler nach Luxemburg als wichtiger Teil der Leserschaft reagiert. Vgl. Goulet/Vatter: L'espace médiatique transfrontalier.

34 Vgl. Gerhards, Jürgen: Europäisierung von Ökonomie und Politik und die Trägheit der Entstehung einer europäischen Öffentlichkeit, in: Bach, Maurizio (Hg.): Die Europäisierung nationaler Gesellscbaften, Wiesbaden: VS Verlag für Sozialwissenschaften, 2000, S. 277-305; Wimmel, Andreas: Transnationale Diskurse in Europa. Der Streit um den Türkei-Beitritt in Deutschland, Frankreich und Großbritannien, Frankfurt/M.: Campus, 2006. 
Mit Blick auf das Saarland und die Großregion ist eine Realisierung der ersten Option wenig wahrscheinlich - zu sehr fallen noch sprachliche Hürden, die nationalen und regionalen politischen Spezifika, ihre jeweiligen Journalismuskulturen und Medienlandschaften ins Gewicht. Die zweite Perspektive mit dominant nationalen bzw. regionalen Öffentlichkeiten, die allerdings im Sinne einer interregionalen, multiperspektivischen Öffnung operieren, erscheint dagegen realistisch und - mit etwas Optimismus - vielleicht sogar schon im Entstehen.

Trotz einiger positiver Tendenzen zu einer insgesamt steigenden Präsenz grenzüberschreitender Themen zeigt aber beispielsweise schon der Blick in die Rubriken des Online-Auftritts der Saarbrücker Zeitung, dass Grenzen auf der strukturellen Ebene noch wenig überschritten werden, sondern die traditionellen politischen und territorialen Strukturen deutlich überwiegen (Saarland, Regionalverband, Landkreise, Gemeinden...). Unter lokaler und regionaler Berichterstattung wird also in erster Linie das eigene Bundesland verstanden und eher punktuell über die Grenze geblickt, die noch eine stark trennende Wirkung zu haben scheint.

Dass jedoch eine Pauschalverurteilung der saarländischen Medien nicht angemessen ist, wird im Vergleich mit der Frankreichberichterstattung des Saarländischen Rundfunks (SR) deutlich. Frankreichkompetenz ist traditionell fest im Selbstverständnis des Senders verankert, das sich auch im Slogan „Grenzgänger aus Passion“/,passionnément frontalière“ und einer aktiven, zweisprachigen Kommunikation über die eigenen Frankreich bezogenen Aktivitäten ausdrückt. ${ }^{35}$ Neben dem Engagement im Bereich der frankophonen Musik - im Hörfunkprogramm wie auch als Veranstalter von Konzerten betrifft dies beispielsweise die Sportberichterstattung (Tour de France), Radiosendungen wie Kindernachrichten in französischer Sprache und auch eine Verankerung grenzüberschreitender, v. a. deutsch-französischer Berichterstattung im Fernsehprogramm. Darüber hinaus sind auf institutioneller Ebene die vom SR bereits 1963 mitbegründete Deutsch-Französische Hörfunkkommission sowie die Veranstaltung des Deutsch-Französischen Journalistenpreises zu nennen.

In den Zeitraum seit Ausrufung der Frankreichstrategie fallen beispielsweise die Einrichtung eines eigenen Online-Frankreichthemenportals ${ }^{36}$, eine feste Verankerung des grenzüberschreitenden Magazins „Grenzenlos“ im wöchentlichen Sendeschema als Teil von „Wir im Saarland“ seit Ende 2016 und eine Überarbeitung der Wetterkarte, die seit Herbst 2014 nicht mehr an

35 Vgl. Saarländischer Rundfunk: Gelebte Nacbbarschaft. Der SR als Medium und Faktor in der Großregion/La transfrontalité au quotidien. La Saarländischer Rundfunk média et facteur de la Grande Région, Saarbrücken, 2016, http://www.sr.de/sr/home/nachrichten/vis_a_vis/broschuere_ gelebte_nachbarschaft100.pdf (31.01.2017).

36 Saarländischer Rundfunk: VIS-A-VIS, http://www.sr.de/visavis (31.01.2017). 
der saarländischen Landesgrenze endet. Maßnahmen wie die letztgenannten sprechen für eine Verankerung der grenzüberschreitenden Berichterstattung in einem regionalen Alltagsgeschehen und können so einen wichtigen Beitrag für die Etablierung eines interregionalen Mindsets leisten.

Diese deutlichen Unterschiede zwischen Rundfunk und regionaler Tageszeitung müssen allerdings differenziert betrachtet werden und können nicht allein auf Aspekte wie ein mehr oder weniger ausgeprägtes grenzüberschreitendes Bewusstsein oder deutsch-französisches Engagement zurückgeführt werden. Diese stellen zwar eine unabdingbare Voraussetzung dafür dar, ${ }^{37}$ aber die Platzierung einer regionalen Tageszeitung und einer Rundfunkanstalt der ARD in der Medienlandschaft mit ihren spezifischen medialen und wirtschaftlichen Kontextbedingungen führt zu grundverschiedenen Voraussetzungen für ein Frankreichengagement. Denn der Saarländische Rundfunk kann Frankreichkompetenz auch für die eigene Positionierung innerhalb der Sendeanstalten der ARD nutzen. Damit steht der kleine Sender vor ähnlichen Herausforderungen wie das Saarland im Reigen der Bundesländer: Die grenzüberschreitende, deutsch-französische Orientierung und Frankreichkompetenz können als Standortvorteil genutzt werden und die Überlebensfähigkeit in der ARD sichern. Bei der Saarbrücker Zeitung handelt es sich demgegenüber um eine regionale Tageszeitung mit quasi Monopolcharakter, die nicht in einer direkten Konkurrenz zu anderen Regionen bzw. überregionalen Zeitungen steht. Sie muss daher auch die ,Frankreich-Karte' nicht unbedingt ausspielen, um sich von diesen abzugrenzen.

\section{Perspektiven}

Wie aufgezeigt, gibt es v. a. seit 2014 Tendenzen in den regionalen Medien, grenzüberschreitende Wirklichkeiten im Sinne eines interregionalen, deutschfranzösischen Mindsets zu integrieren, aber insbesondere in der Presse scheint man noch eher darauf zu warten, dass die Leser eine stärkere Verankerung auch über die Grenze hinweg einfordern. Um eine interkulturelle Frankreichkompetenz nachhaltig zu fördern und in der Breite zu verankern, könnten die saarländischen Medien (ebenso wie die jenseits der Grenze) einen wichtigen Beitrag leisten, indem sie die Grenze konsequent in ihrer Berichterstattung, Rubriken und Organisationsstrukturen mit-denken, über-denken und vielleicht auch manchmal weg-denken.

37 Vgl. Vatter, Christoph: Die Pressekonferenz in Deutschland und Frankreich - eine interkulturelle Herausforderung für die grenzüberschreitende Medienkommunikation? Journalistische Praktiken und Kommunikationsinstrumente am Beispiel der Großregion, in: Goulet/Vatter (Hg.): Grenzü̈berschreitende Informationsflïsse, S. 283-304. 
Als Anregung zur Förderung eines interregionalen Mindsets als Basis dafür, dass die Bevölkerung das Projekt Frankreichstrategie mit trägt und sich aktiv gestaltend einbringt, mag der soziologische Ansatz der Sozialintegration dienen, der zwar in erster Linie auf die Migrationsgesellschaft abzielt, der aber auch für die Integration neuer Ideen wie die Frankreichstrategie Denkanstöße vermitteln kann. Hartmut Esser unterscheidet vier Dimensionen der Sozialintegration: $:^{38}$ 1. Kulturation, d. h. der Erwerb von Wissen und Kompetenzen, beispielsweise zu typischen Situationen im Alltagshandeln oder gemeinsamen Wissensbeständen; 2. Platzierung, d. h. die Einnahme von gesellschaftlichen Funktionen durch die Akteure, wie z. B. bestimmte berufliche Positionen, woraus sich dann Möglichkeiten ergeben, um soziale Beziehungen untereinander zu pflegen; 3. Interaktion, d. h. verschiedene Beteiligte bauen Beziehungen zueinander auf, es entsteht ein Austausch über Wissensbestände und Symbole; 4. Identifikation, eine Einstellung, bei der Akteure sich als Teil des sozialen Gebildes betrachten und damit eine Einheit entsteht. Alle vier Dimensionen stehen in einem Wechselverhältnis, so ist z. B. eine gewisse Kulturation Voraussetzung für die Einnahme gesellschaftlicher Positionen (Platzierung), die wiederum Interaktion und Identifikation fördern kann.

Im Kontext der Frankreichstrategie und der Förderung eines deutschfranzösischen, interregionalen Bewusstseins im Alltag der saarländischen Bevölkerung, d. h. einer Identifikation im Sinne Essers, ist der Erwerb von Wissen und Kompetenzen (Kulturation) notwendig, damit grenzüberschreitende Beziehungen zwischen Menschen und Institutionen aufgebaut werden können (Platzierung und Interaktion). Sowohl für die Vermittlung von Wissen über den Anderen als auch die Identifikation als Teil einer gemeinsamen sozialen Einheit sind Medien mit grenzüberschreitender Berichterstattung und die Schaffung eines gemeinsamen Raums (Öffentlichkeit) für den gesellschaftlichen Austausch unabdingbar. Eine strukturelle Verankerung der grenzüberschreitenden Dimension in der Berichterstattung und eine interregional, deutsch-französisch ausgerichtete Grundeinstellung von Journalisten und Verantwortlichen der Medieninstitutionen stellen daher einen entscheidenden Schritt für eine nachhaltige Umsetzung der Frankreichstrategie des Saarlandes dar.

38 Vgl. Esser, Hartmut: Integration und ethnische Schichtung, in: Mannheimer Zentrum für Europäische Sozialforschung (Hg.): Arbeitspapiere 40 (2001), Mannheim: MZES, http:// www.mzes.uni-mannheim.de/publications/wp/wp-40.pdf (31.01.2017); Esser, Hartmut: Soziologie. Spezielle Grundlagen, Band 2: Die Konstruktion der Gesellschaft, Frankfurt/M. [u. a.]: Campus, 2000, insb. S. 272-275. 
Seit November 2014 werden Reisende auf der Autobahn an der Landesgrenze des Saarlandes mit Willkommensschildern mit der Aufschrift „Großes entsteht immer im Kleinen“ und auch der französischen Übersetzung „Les petits ruisseaux font les grandes rivières" begrüßt. ${ }^{39}$ Die Analyse der regionalen Medien zeigt, dass ein interregionales, deutsch-französisches Bewusstsein im geschilderten Sinne zumindest in Ansätzen bereits festzustellen ist. Seit Bekanntgabe der Frankreichstrategie sind diese Rinnsale grenzüberschreitender Berichterstattung stetig gewachsen; es ist ihnen zu wünschen, dass sie einmal zu großen Strömen werden. Das Potenzial dazu ist bereits sichtbar, aber es sind noch große Anstrengungen nötig, nicht nur auf dem Gebiet der Medien.

\section{Literaturverzeichnis}

Bolten, Jürgen: Interkulturelle Kompeten₹, Erfurt: Landeszentrale für politische Bildung, ${ }^{5} 2012$.

Brenner, Ulrich: Zwei Drittel der Saarländer wollen eine zweisprachige Heimat, in: Saarbrücker Zeitung, 16.05.2014.

Eichler, Steve: Die Rezeption der Frankreichstrategie des Saarlandes in deutschen und französischen Tageszeitungen in den Jabren 2014 und 2015, Universität des Saarlandes/Université de Lorraine, Bachelorarbeit, 2015.

Ernst, Nora: Imagepflege an der Grenze, in: Saarbrücker Zeitung, 29.11.2014.

ESPON: METROBORDER. Grenzüberschreitende polyzentrische Metropolregionen. Zielgerichtete Analysen 2013/2/3. Abschlussbericht, Luxemburg: ESPON/University of Luxembourg, 31.12.2010, http://www.dat.public.lu/publications/documents/metroborder/metroborder_ final_report_de.pdf (31.01.2017).

Esser, Hartmut: Soziologie. Spezielle Grundlagen, Band 2: Die Konstruktion der Gesellschaft, Frankfurt/M. [u. a.]: Campus, 2000.

Esser, Hartmut: Integration und ethnische Schichtung, in: Mannheimer Zentrum für Europäische Sozialforschung (Hg.): Arbeitspapiere 40 (2001), Mannheim: MZES, http://www. mzes.uni-mannheim.de/publications/wp/wp-40.pdf (31.01.2017).

Fischer, Nadine: Regionale Strategien für das Partnerland? Die Deutschlandstrategie Lotbringens und die Frankreichstrategie des Saarlandes im Vergleich, Universität des Saarlandes, Bachelorarbeit, 2016.

Gerhards, Jürgen: Europäisierung von Ökonomie und Politik und die Trägheit der Entstehung einer europäischen Öffentlichkeit, in: Bach, Maurizio (Hg.): Die Europäisierung nationaler Gesellschaften, Wiesbaden: VS Verlag für Sozialwissenschaften, 2000, S. 277-305.

Goulet, Vincent/Vatter, Christoph (Hg.): Grenzüberscbreitende Informationsflüsse und Medien in der Großregion SaarLorLux/La circulation transfrontaliere des informations médiatiques dans la Grande Région SaarLorLux, Baden-Baden: Nomos, 2015.

Goulet, Vincent/Vatter, Christoph: L'espace médiatique transfrontalier: médias, flux d'informations et pratiques journalistiques, in: Wille (Hg.): Lebenswirklichkeiten und politische Konstruktionen in Grensregionen, S. 229-248.

Hilt, Oliver: Großer Stimmungstest zur Wahl, in: Forum. Das Wochenmagazin, 25.11.2016, http://www.magazin-forum.de/news/politik/gro\%C3\%9Fer-stimmungstest-zur-wahl (31.01.2017).

39 Ernst, Nora: Imagepflege an der Grenze, in: Saarbrücker Zeitung, 29.11.2014. 
Höll, Susanne: Französisch? Nää merci, in: Süddeutsche Zeitung, 30.01.2014, S. 6.

Le Tallec, Camille: La région allemande de la Sarre veut écrire son avenir en français, in: $L a$ Croix, 04.11.2014, S. 5.

Madelin, Thibaut: La Sarre veut devenir un Land bilingue, in: Les Echos, 28.01.2014, S. 12.

Ministerium für Bildung des Saarlandes: Sprachenkonzept Saarland 2011. Neue Wege zur Mehrsprachigkeit im Bildungssystem, Saarbrücken, 2011, http://www.saarland.de/dokumente/res_ bildung/Das_Sprachkonzept_Saarland_2011.pdf (31.01.2017).

Nonnenmacher, Günther: Die saarländische Vision, in: FAZ, 25.01.2014, S. 1.

Picart, Malika: La stratégie „France“ $d u$ Land de Sarre: campagne d'information du gouvernement sarrois et impact dans la presse en France et en Allemagne., Universität des Saarlandes/Université de Lorraine, Masterarbeit, 2016.

Radio Salü: Große Zustimmung zur Frankreichstrategie, 25.11.2016, www.salue.de/nachrichten/ message.phtml?id=80859 (25.11.2016).

Saarländischer Rundfunk: Gelebte Nachbarschaft. Der SR als Medium und Faktor in der Großregion/La transfrontalité au quotidien. La Saarländischer Rundfunk média et facteur de la Grande Région, Saarbrücken, 2016, http://www.sr.de/sr/home/nachrichten/vis_a_vis/broschuere_gelebte_ nachbarschaft100.pdf (31.01.2017).

Saarländischer Rundfunk: VIS-A-VIS, http://www.sr.de/visavis (31.01.2017).

Staatskanzlei des Saarlandes: Eckpunkte einer Frankreichstrategie für das Saarland, 2014, http:// www.saarland.de/dokumente/res_stk/D_Eckpunkte_Frankreich-Strategie_210114.pdf (31.01.2017).

Statistisches Bundesamt (Hg.): Schulen auf einen Blick 2016, Wiesbaden: Statistisches Bundesamt, 2016.

Schönwald, Antje: Identitäten und Stereotype in grenæüberschreitenden Verflechtungsräumen. Das Beispiel der Großregion, Wiesbaden: VS, 2012.

Vatter, Christoph: Die Pressekonferenz in Deutschland und Frankreich - eine interkulturelle Herausforderung für die grenzüberschreitende Medienkommunikation? Journalistische Praktiken und Kommunikationsinstrumente am Beispiel der Großregion, in: Goulet/ Vatter (Hg.): Grenzüberscbreitende Informationsflüsse und Medien in der Großregion SaarLorLux, S. 283-304.

Wille, Christian (Hg.): Lebenswirklichkeiten und politische Konstruktionen in Grenzregionen. Das Beispiel der Großregion SaarLorLux: Wirtschaft - Politik - Alltag - Kultur, Bielefeld: transcript, 2015.

Wimmel, Andreas: Transnationale Diskurse in Europa. Der Streit um den Türkei-Beitritt in Deutschland, Frankereich und Großbritannien, Frankfurt/M.: Campus, 2006. 

Zum internationalen Kontext - Einordnung und Ausblick Le contexte international - Orientation et avenir 



\section{Interkulturelle Dimensionen und Herausforderungen der Frankreichstrategie im Kontext der gegenwärtigen deutsch-französischen Beziehungen}

Le présent article aborde la question de la 'Stratégie France' du gouvernement de la Sarre dans une perspective interculturelle. Il ne propose pas une synthèse au sens propre des différentes conférences rassemblées dans ce volume, et il ne prétend pas non plus présenter une synthèse globale du sujet abordé. Il choisit de proposer une réflexion critique concernant la 'Stratégie France' de la Sarre dans une optique universitaire et à partir d'une discipline spécifique, la Romanistik dans son orientation interculturelle. Cette analyse critique s'effectue à partir de quatre angles différents structurant cet article, qui peuvent au premier abord sembler assez abstraits, mais qui s'avèrent rapidement très concrets: 1. Terminologie et concepts; 2. Niveaux et dimensions; 3. Priorités et déficiences; 4. Défis et perspectives.

\section{Begriffe und Konzepte}

Der vorliegende Beitrag, der aus einem am Ende der Ringvorlesung ,,Alles Frankreich oder was?' Die saarländische Frankreichstrategie im europäischen Kontext - Interdisziplinäre Zugänge und kritische Perspektiven" gehaltenen Vortrag hervorgegangen ist, möchte keine Synthese der anderen, sehr vielfältigen und nuancenreichen Beiträge dieses Bandes präsentieren; und er möchte auch keine Bilanz im engeren Sinn ziehen. Sondern aus einem universitären Blickwinkel und einer spezifischen fachlichen Ausrichtung - der Romanistik mit kulturwissenschaftlich-interkultureller Ausrichtung - die Frankreichstrategie des Saarlandes kritisch und perspektivisch hinterfragen. Und zwar unter vier Gesichtspunkten, die zunächst recht abstrakt klingen, aber sehr rasch sehr konkret werden sollen und den vorliegenden Beitrag strukturieren:

1. Begriffe und Konzepte

2. Ebenen und Dimensionen

3. Schwerpunkte und Lücken

4. Herausforderungen und Perspektiven.

Der erste Punkt möchte v. a. zwei Begriffe bzw. Konzepte der Frankreichstrategie (und auch der Beiträge des vorliegenden Sammelbandes) aufgreifen, nämlich die Begriffe (oder Konzepte) ,Beziehungen‘ und ,Frankreichkompetenz'. ,Beziehungen' (französisch relations oder auch rapports) stellen sich, wenn man sie auf zwei Länder wie Deutschland und Frankreich bezieht, auf sehr 
unterschiedlichen und zugleich in vielfältiger Weise miteinander verzahnten Ebenen dar: als politische Beziehungen; als Wirtschaftsbeziehungen; als kulturelle und Medienbeziehungen; und als soziale Beziehungen, d. h. Beziehungen zwischen den Zivilgesellschaften, die sehr unterschiedlich und im Strategiepapier der Frankreichstrategie und in den folgenden Feuilles de route in einigen Bereichen wenig bzw. eher marginal berücksichtigt worden sind. $\mathrm{Zu}$ dieser Art von ,Beziehungen“ im deutsch-französischen Kontext zählen auf der Ebene der Zivilgesellschaft ganz unterschiedliche Prozesse und Phänomene: Pendlerströme zwischen dem Saarland und Lothringen ebenso wie Städtepartnerschaften zwischen saarländischen und französischen Städten, Schulpartnerschaften und Schulaustauschprogramme, Partnerschaften zwischen Vereinen unterschiedlichster Art, Kontakte informeller und formalisierter Art zwischen Gewerkschaften beiderseits der Grenze, u. a. in Institutionen wie den Interregionalen Gewerkschaftsräten (IGR) ${ }^{1}$, Besuche von Theatern, Ausstellungen und Festivals beiderseits der Grenze sowie der grenzüberschreitende Tourismus, ein trotz aller Anstrengungen noch relativ wenig entwickeltes Feld der saarländisch-französischen Beziehungen im Schnittbereich von Zivilgesellschaft, Kultur und Wirtschaft; grenzüberschreitendes Einkaufen mit den hierbei entstehenden Kontakten und Kommunikationsformen; und schließlich auch Partikularitäten wie die in ihrer Zahl nicht zu unterschätzenden Besuche von Französinnen und Franzosen in saarländischen Diskotheken und Schwimmbädern und die hieraus entstehenden persönlichen Kontakte und Begegnungen. Viele dieser zivilgesellschaftlichen deutsch-französischen Beziehungsbereiche und Kontaktfelder sind noch relativ wenig erforscht, und ihre Erforschung bedarf auch einer methodischen Präzisierung, die bei dem recht vagen Begriff ,Beziehungen' ansetzen muss: Dieser impliziert Austausch, aber auch Kommunikation - genauer gesagt: interkulturelle Kommunikation -, Kultur- und Sprachkontakte, Informations- und Kulturtransfer und schließlich auch gegenseitige, reziproke Wahrnehmungsmuster, die sich im interkulturellen Kontakt entwickeln und eine eigene Dynamik beinhalten. ${ }^{2}$

1 Vgl. hierzu Filsinger, Dieter/Lüsebrink, Hans-Jürgen/Rampeltshammer, Luitpold (Hg.): Interregionale Gewerkschaftsräte. Historische, sozialwissenschaftliche und interkulturelle Analysen, Baden-Baden: Nomos Verlagsgesellschaft, 2015 (Forschung aus der Hans Böckler-Stiftung 179), S. 311.

2 Vgl. zu den genannten methodischen Aspekten und den Verzahnungen von Interaktion und Kulturtransfer Lüsebrink, Hans-Jürgen: Interkulturelle Kommunikation. Interaktion Kulturtransfer - Fremdwahrnehmung, Stuttgart: J.B. Metzler-Verlag, 2005 (Metzler Studienbücher), ${ }^{42016, ~ S . ~} 236$. 
Der Begriff ,Frankreichkompetenz' ist einer der am häufigsten verwendeten Begriffe in dem Eckpunktepapier der Landesregierung ${ }^{3}$ für eine Frankreichstrategie des Saarlandes. Er wird in diesem Papier fünfzehnmal im eigentlichen Sinn verwendet, über zwanzigmal, wenn man spezifische Ausprägungen des Begriffs oder Begriffsfeldes wie ,interkulturelle Kompetenz', ,Französischkompetenz' und ,Verwaltungskompetenz' einbezieht. Schaut man sich das Strategiepapier unter diesem Blickwinkel genauer an, so lassen sich zwei Verwendungsweisen dieses Zentralbegriffs der ,Frankreichkompetenz' herausarbeiten:

- Zum einen werden die Begriffe ,Frankreichkompetenz' und ,deutschfranzösische Kompetenz ${ }^{6}$ als zentrale Konzepte für die Standortmarkierung des Saarlandes gesehen: „Angesichts eines verstärkten Wettbewerbs mit anderen Regionen in Deutschland und Europa“ solle sich das Saarland auf das „konzentrieren, was seinen Markenkern ausmacht, um damit unverwechselbar und unverzichtbar zu werden. $\mathrm{Zu}$ diesem Markenkern gehört die deutsch-französische Kompetenz. Daraus folgt das Ziel, dass das Saarland zum französischsten aller Bundesländer wird. “4 Bei der im grundlegenden Eckpunktepapier der Landesregierung von 2014 erwähnten „Frankreichkompetenz" wiederum wird unterschieden zwischen einer „BinnenStrategie (Stärkung der Frankreich-Kompetenz im Land)" und einer „Außen- und Kommunikationsstrategie (Vermarktung der saarländischen Frankreich-Kompetenz nach außen, d. h. nach Frankreich und nach Deutschland) “. 5

- Zum anderen soll die „Frankreichkompetenz“, über die das Saarland bereits in weit stärkerem Maße als andere Bundesländer verfüge, im Saarland selbst weiter entwickelt werden, ${ }^{6}$ durch institutionelle, sprachliche, aber auch interkulturelle Maßnahmen. So ist etwa davon die Rede, das ,interkulturelle Bewusstsein“ solle gestärkt werden ${ }^{7}$ und um „Kompetenzfelder, wie Fachkompetenz, Regionalkompetenz und interkulturelle Kompetenz"8 erweitert werden, wobei für interkulturelle Fachkompetenz auch konkrete Handlungsfelder wie Verwaltung und Polizei genannt werden. Schließlich wird im Zusammenhang mit der Erwähnung der deutsch-französischen Städtepartnerschaften - allerdings auch nur für dieses zivilgesellschaftliche

Vgl. Staatskanzlei des Saarlandes: Eckpunkte einer Frankreichstrategie für das Saarland, 2014. Vgl. online mit teilweise variierenden Seitenzahlen verfügbar unter: http://www.saarland. de/dokumente/res_stk/D_Eckpunkte_Frankreich-Strategie_210114.pdf (30.01.2017).

4 Staatskanzlei des Saarlandes: Eckpunkte einer Frankreichstrategie, S. 3.

5 Staatskanzlei des Saarlandes: Eckpunkte einer Frankereicbstrategie, S. 3.

6 Staatskanzlei des Saarlandes: Eckpunkte einer Frankreichstrategie, S. 15.

7 Staatskanzlei des Saarlandes: Eckpunkte einer Frankreichstrategie, S. 10.

8 Staatskanzlei des Saarlandes: Eckpunkte einer Frankreichstrategie, S. 20. 
Feld, das eines unter vielen darstellt - betont, dass in diesem Rahmen die „Kommunikationskompetenz und Empathie ${ }^{\text {"9 }}$ zwischen den Kooperationspartnern ausgebaut werden solle.

Sieht man interkulturelle Kompetenz als einen Lernprozess an, der sich in verschiedenen Stufen vollzieht und sich entweder im institutionellen Rahmen im Schulunterricht, in Universitätskursen, in Weiterbildungskursen oder auch in interkulturellen Trainings und Coachings in Unternehmen und der Verwaltung - oder auch im sozialen, zivilgesellschaftlichen Alltag vollziehen kann, so erscheint es notwendig, von präziseren Definitionen auszugehen, um interkulturelle Kompetenz, zu der auch die Frankreichkompetenz zu zählen ist, gezielt fördern zu können. Interkulturelle Kompetenz basiert nach Jürgen Bolten, Professor für Interkulturelle Wirtschaftskommunikation an der Universität Jena, auf allgemeinen Handlungskompetenzen, die jedoch im interkulturellen Bereich eine spezifische Ausprägung als „Interkulturelle Handlungskompetenz" erfahren und individuelle, soziale, fachliche und strategische Kompetenzen umfassen. ${ }^{10}$

Die verschiedenen Sichtweisen und Definitionen interkultureller Kompetenz hängen auch von den jeweiligen betroffenen Fachdisziplinen ab, sodass von einem sehr unterschiedlichen Profil interkultureller Kompetenz beispielsweise in der Psychologie, den Wirtschafts- und den Kulturwissenschaften gesprochen werden kann. Es lassen sich jedoch trotz der Vielfalt der vorliegenden Ansätze dominierende Tendenzen herausarbeiten, die sich in folgenden Definitionen spiegeln. So definiert der Wirtschaftswissenschaftler Alexander Bergmann den Begriff, interkulturelle Kompetenz' wie folgt:

Es handelt sich bei interkultureller Kompetenz um die Fähigkeit, sich in fremden Kulturen erfolgreich zu verständigen und bewegen zu können, d. h. eine Brücke zwischen seinen eigenen und anderen Denkweisen, Gefühlen, Wertvorstellungen, Ausdrucksformen, Verhaltensmustern und Gewohnheiten zu schlagen. ${ }^{11}$

Die Linguisten Karlfried Knapp und Annette Knapp-Potthoff rücken stärker die kommunikative und damit interpersonale Dimension interkultureller Kompetenz in den Blick, die sie wie folgt definieren:

Es geht im Wesentlichen um einen Komplex von analytisch-strategischen Fähigkeiten, die das Interpretations- und Handlungsspektrum des betreffenden Individuums in interpersonaler Interaktion mit Mitgliedern anderer Kulturen erweitern. In diese analytisch-

9 Staatskanzlei des Saarlandes: Eckpunkte einer Frankreichstrategie, S. 23.

10 Bolten, Jürgen: Interkulturelle Kompetenz, Erfurt: Thüringer Landeszentrale für politische Bildung, 2001. Zum Begriff ,Interkulturelle Handlungskompetenz'vgl. ders. S. 157, S. 164.

11 Bergmann, Alexander: Interkulturelle Managemententwicklung, in: Haller, Matthias (Hg.): Globalisierung der Wirtschaft, Bern [u. a].: Haupt, 1993, S. 193-216, hier S. 200. 
strategischen Fähigkeiten sind Wissen über andere Kulturen generell, die Veränderung von Einstellungen und eine Sensibilität (awareness) gegenüber kultureller Andersartigkeit integriert. ${ }^{12}$

Aus kulturwissenschaftlicher Sicht lässt sich wiederum interkulturelle Kompetenz als das „Vermögen definieren, mit fremden Kulturen und ihren Angehörigen in adäquater, ihren Wertesystemen und Kommunikationsstilen angemessener Weise zu handeln, mit ihnen zu kommunizieren und sie zu verstehen."13

Generell lässt sich interkulturelle Kompetenz somit als die „Fähigkeit einer Person“ fassen, „Werte, Denkweisen, Kommunikationsregeln und Verhaltensmuster einer anderen Kultur zu verstehen, um in interkulturellen Interaktionssituationen eigene Standpunkte transparent zu kommunizieren und somit kultursensibel, konstruktiv und wirkungsvoll zu handeln." ${ }^{14}$ Die mit den genannten Definitionen erfassten Einzelkompetenzen umfassen Fremdsprachenkenntnisse (als eine Grundvoraussetzung für das Verstehen anderer Kulturen und die Kommunikation mit Angehörigen anderer Kulturen), landeskundliche Kenntnisse (etwa über die Wirtschaftsstruktur und das politische System Frankreichs) sowie Kommunikations- und Verstehenskompetenzen, die das Beherrschen der Kommunikations-, Denk- und Handlungsstile anderer Kulturen betreffen. Zu letzteren gehören Phänomene wie Körperdistanz, Gestik, Mimik, soziale Codes der Höflichkeit, Erfassen des implizit Gemeinten oder auch Formen der Gesprächsdynamik. In ,High-Context-Kulturen ${ }^{15}$ wie der französischen Kultur verlaufen Kommunikationsprozesse weniger explizit, Anspielungen und Andeutungen sprachlicher, gestischer oder mimischer Art spielen eine weitaus größere Rolle als in ,Low-Context-Kulturen' wie der deutschen und US-amerikanischen Kultur. Auch in anderen Bereichen der Kommunikation bestehen zwischen den Kulturen grundlegende Unterschiede, deren Erkennen und deren Bewältigung einen wichtigen Bestandteil interkultureller Kompetenz darstellen. Im Französischen beispielsweise ist die Gesprächsdynamik im Vergleich etwa zum Englischen oder Deutschen durch ein weit häufigeres Unterbrechen und, ins Wort fallen' gekennzeichnet, was in französischer Sicht keineswegs als Zeichen für unhöfliches Kommunikationsverhalten zu werten ist, wie etwa im Deutschen, sondern ganz im Gegenteil als sicheres Indiz für ein lebhaftes, die Gesprächspartner interessierendes,

12 Knapp, Karlfried/Knapp-Potthoff, Annette: Interkulturelle Kommunikation, in: Zeitschrift für Fremdsprachenforscbung 1 (1990), S. 62-93, hier S. 83.

13 Lüsebrink: Interkulturelle Kommunikation, S. 8.

14 Barmeyer, Christoph: Taschenlexikon Interkulturalität, Göttingen: Vandenhoeck \& Ruprecht, 2012 (UTB 3739), s.v. Kompetenz, interkulturelle, S. 86-90, hier S. 86.

15 Vgl. Hall, Edward T.: The Silent Language, New York: Anchor Books, 1981. 
nicht steifes Gespräch. ${ }^{16}$ Interkulturelle Kompetenz umgreift somit sowohl ,harte Faktoren' wie die Kenntnis ökonomischer Sachverhalte und Entwicklungen, wichtiger historischer Fakten, sozialer Gegebenheiten (beispielsweise des Kastensystems in Indien oder der Bedeutung von Laizität in Frankreich) sowie steuerlicher, rechtlicher und politischer Rahmenbedingungen als auch ,weiche Faktoren', zu denen die Kenntnis und der verständnisvolle Umgang mit differenten, fremden' Kommunikationsformen und Wertesystemen gehören.

Im Rahmen der Frankreichstrategie erscheint die Frage zentral, wie interkulturelle Kompetenz - in den offiziellen Unterlagen zur Frankreichstrategie spezifisch gefasst als Frankreichkompetenz -, gezielt gefördert werden kann: institutionell etwa durch die Förderung der Französischkenntnisse und generell der Mehrsprachigkeit, als einer (von drei) Komponenten interkultureller Kompetenz;17 aber auch durch vielfältige andere Maßnahmen wie die Entwicklung (oder gezielte Weiterentwicklung) von interkulturellen Fort- und Weiterbildungsmaßnahmen in Unternehmen, in der Verwaltung, in der Polizei, im Gesundheitswesen sowie die Weiterentwicklung von schulischen Curricula im Hinblick auch auf die landeskundlich-kulturwissenschaftlichen Komponenten (oder Säulen) interkultureller Kompetenz. Im Strategiepapier der Landesregierung ist diesbezüglich von einem „Cluste[r] ,Deutsch-Französisches Kompetenzzentrum " für Geschäfts- und Endkunden" ${ }^{\prime 18}$ die Rede - eine zweifellos interessante Idee, die jedoch angesichts des Stellenwerts, den interkulturelle Kompetenz insgesamt in der Gesamtkonzeption der Frankreichstrategie einnimmt, viel zu partiell und fragmentarisch bleibt und in einer mittel- bis längerfristigen Perspektive konsequenterweise auf die genannten anderen Handlungsbereiche ausgedehnt werden müsste. Das in der Feuille de route II 2017/2019 genannte „Saarländische Hochschulzentrum für akademische/ wissenschaftliche Weiterbildung ${ }^{\text {“19, }}$, das am 28.11.2016 offiziell gegründet wurde und an dem die Universität des Saarlandes und die Hochschule für Technik und Wirtschaft des Saarlandes (HTW) beteiligt sind, ${ }^{20}$ ist als ein weiterer Schritt in diese Richtung zu sehen. Es bedarf jedoch noch weiterer

16 Vgl. hierzu Lüsebrink: Interkulturelle Kommunikation, S. 57-58; und Heringer, Hans-Jürgen: Interkulturelle Kommunikation, Tübingen: Francke, 2014 (UTB 2550), S. 58f.

17 Vgl. hierzu den Beitrag von Claudia Polzin-Haumann im vorliegenden Band.

18 Staatskanzlei des Saarlandes: Eckpunkte einer Frankereichstrategie, S. 22.

19 Landesregierung des Saarlandes: Frankreichstrategie Fenille de route II 2017/2019, 2016, hier S. 10 (Ausbau der grenzüberschreitenden Angebote im Bereich wissenschaftliche Weiterbildung), http://www.saarland.de/dokumente/thema_europa/2016-10-17_Feuille_de_route_ 2017-2019.pdf (30.01.2017).

20 Staatskanzlei des Saarlandes: Kooperationsvertrag zum Saarländischen Hochschulzentrum für akademische Weiterbildung unterzeichnet, 28.11.2016, http://www.saarland.de/SIDEC74342B-90D2A3CB/218636.htm (30.01.2017). 
Konkretisierung, gerade auch im Hinblick auf die Vermittlung von Frankreichkompetenz und im weiteren Sinn von interkultureller Kompetenz.

\section{Ebenen und Dimensionen}

Die Frankreichstrategie betrifft die deutsch-französischen Beziehungen auf zumindest zwei Ebenen: der nationalen Ebene, auf der das Saarland eine, wie das Strategiepapier und andere Stellungnahmen zur Frankreichstrategie, wie die sogenannte Fenille de route (oder Road map) 2015/1621, auch nachdrücklich betonen, traditionell zentrale Mittlerrolle zwischen Deutschland und Frankreich eingenommen hat; und zum anderen die regionale bzw. transregionale Ebene, die seit den 1970er Jahren, seit der sukzessiven Entwicklung der politischen, wirtschaftlichen, kulturellen und universitären Kooperation innerhalb des Saar-Lor-Lux-Raums und dann der Grande Région, eine zunehmende Bedeutung erlangt hat. Beide Ebenen sind derzeit - und bereits seit einigen Jahren - durch Krisen und grundlegende Veränderungen bestimmt, auf die einige der Beiträge des vorliegendes Bandes auch detaillierter eingehen: Die nationale Ebene wird weiterhin - und in einigen Bereichen in zunehmendem Maße - durch sehr unterschiedliche Vorstellungen, auf deutscher und französischer Seite, der Europapolitik, v. a. der Wirtschafts- und Finanzpolitik und der Flüchtlingspolitik, auf die noch zurückzukommen sein wird, bestimmt; und die transregionale Ebene ist durch die französische Territorialreform, die zum 1. Januar 2016 eingetreten ist, strukturell in grundlegender Weise verändert worden. Während sich auf deutscher Seite Zahl und Struktur der westlichen Bundesländer seit über 60 Jahren nicht geändert hat und Reformansätze - selbst im Bereich des Länderfinanzausgleichs - nur sehr zäh und mühsam vorankommen, wurde auf französischer Seite erstmals seit 1982 die regionale Struktur grundlegend verändert. Insbesondere wurde die Zahl der Regionen im europäischen Teil Frankreichs stark reduziert, von 22 auf 13 (hinzu kommen fünf Überseeregionen).

Für die transregionale, deutsch-französische Kooperation der Landesregierung des Saarlandes, die im Eckpunktepapier zur Frankreichstrategie mehrfach die Entwicklung der Frankreichstrategie als ,eine große Chance für die Zukunft und die Eigenständigkeit unseres Landes" 22 sieht, stellt dies eine wichtige und in ihrer Tragweite kaum zu unterschätzende Herausforderung und in gewisser Hinsicht sogar eine gewisse politische Provokation - dar: Erstmals seit der Entwicklung der transregionalen Zusammenarbeit seit den

21 Landesregierung des Saarlandes: Feuille de route Frankreichstrategie 2015/2016, 2015, http:// www.saarland.de/dokumente/res_stk/D_Eckpunkte_Frankreich-Strategie_210114.pdf (30.01.2017).

22 Staatskanzlei des Saarlandes: Eckpunkte einer Frankreichstrategie, S. 1. 
1970er Jahren sieht sich das Saarland statt mit der Region Lothringen mit einem anderen, sehr viel größeren und geopolitisch anders ausgerichteten Partner konfrontiert, der neuen Region Grand Est (Alsace, ChampagneArdenne, Lorraine). Die transregionale Kooperation, ein zentraler Pfeiler der Frankreichstrategie, ist somit neu zu denken und auszuhandeln. Erste Grundlagen hierfür wurden bereits angelegt, auch aufgrund des Engagements und der ausgesprochenen Kooperationsbereitschaft des Präsidenten der neuen Region Grand Est, des Elsässers Philippe Richert, der in seiner Rede am 11. Dezember 2016 in Saarbrücken im Rahmen der Europa-Matinée „Das Saarland und die Frankreichstrategie“ die Region Grand Est und die „gesamte deutsch-französische Grenzregion“ als eine „echte europäische Kernregion“ bezeichnete, „le noyau dur de l'Europe“.23 Parallel zur Frankreichstrategie des Saarlandes seien v. a. im Elsass in den letzten Jahren bilinguale Kindergärten und Schulformen stark ausgebaut worden mit dem Zukunftsziel, dass $50 \%$ der elsässischen Schülerinnen und Schüler ab der ersten Grundschulklasse in beiden Sprachen (Deutsch und Französisch) unterrichtet werden sollen. Dieses Modell solle, mit geringeren Prozentanteilen an Schülern, auch auf Lothringen und Champagne-Ardenne übertragen werden. Die Region Grand Est solle hierdurch „die erste mehrsprachige Region Frankreichs werden“. ${ }^{24}$ Insgesamt sah Richert in der Region Grand Est einen „Multiplikatorfaktor für die grenzüberschreitende Zusammenarbeit", zumal sich durch die neuen Regionen die Beziehungen zwischen der nationalen und der regionalen Ebene zugunsten der Regionen verändert hätten. ${ }^{25}$ Trotz dieser politischen Zielsetzungen und Entwicklungen stellt die grundlegende Regionalreform in Frankreich durch die entstandenen neuen demographischen, geopolitischen und ökonomischen Asymmetrien jedoch die grenzüberschreitende Zusammenarbeit vor völlig neue und in ihrer Tragweite noch nicht genau abzusehende Herausforderungen.

Die supranationale Ebene der deutsch-französischen Beziehungen, die eine zunehmend wichtiger werdende Rolle spielt, wird im Eckpunktepapier der Frankreichstrategie kaum und auch in den Beiträgen des vorliegenden Bandes nur wenig angesprochen. Sie betrifft v. a. die europäische Ebene, bei-

23 Ministerium für Finanzen und Europa des Saarlandes: Europa-Matinée „Das Saarland und die Frankreichstrategie“ im Saarbrücker Schloss. Abschluss der Veranstaltungsreihe mit Ministerpräsidentin Annegret Kramp-Karrenbauer und dem Präsidenten der Region Grand Est, Philippe Richert, in: Medien-Info 149 (12/2016), S. 2.

24 Handschriftliche Notizen (H.-J. Lüsebrink) zum Vortrag von Philippe Richert am 11.12.2016 im Festsaal des Saarbrücker Schlosses.

25 Handschriftliche Notizen (H.-J. Lüsebrink) zum Vortrag von Philippe Richert am 11.12.2016 im Festsaal des Saarbrücker Schlosses. 
spielsweise die Konvergenzen und - wie Luuk van Middelaar in einem grundlegenden Beitrag hierzu in der französischen Zeitschrift Le Débat betonte ${ }^{26}$ Divergenzen in der deutsch-französischen Europapolitik. Welche gemeinsamen europapolitischen Positionen lassen sich auf transregionaler Ebene, zwischen dem Saarland und Lothringen und seit 2016 der neuen Region Grand Est (Alsace, Champagne-Ardenne, Lorraine) erkennen und erarbeiten? Der Beitrag von Sylvère Mbondobari im vorliegenden Band zeigt darüber hinaus deutlich auf, dass das Französische nicht nur die Sprache Frankreichs darstellt, sondern die einer Vielzahl von Gesellschaften und Kulturen außerhalb Frankreichs, in Europa ebenso wie im außereuropäischen Raum, v. a. in Afrika, in der Karibik und in Kanada. ${ }^{27}$ Das Saarland und seine Institutionen wie das Kanada- und das Québec-Zentrum an der Universität des Saarlandes, die Vernetzung mit Luxemburg und der Wallonie im Rahmen der Universität der Großregion sowie zahlreiche Kooperationsprojekte mit Afrika und mit Afrikanern an den Hochschulen und in der Zivilgesellschaft - bilden sehr gute Ansatzpunkte für eine Erweiterung der Frankreichkompetenz um eine ,frankophone Kompetenz', eine Kompetenz für die Kommunikation mit und das Verstehen von frankophonen Gesellschaften und Kulturen außerhalb Frankreichs.

\section{Schwerpunkte und Lücken}

Das Strategiepapier der saarländischen Landesregierung von 2014, die nachfolgenden Stellungnahmen zur Frankreichstrategie, u. a. die Fenille de route Frankreichstrategie 2015/16 und die Beiträge des vorliegenden Bandes decken ein sehr breites Spektrum von Themen ab, die die deutsch-französischen Beziehungen auf nationaler ebenso wie auf transregionaler Ebene betreffen: Kindergärten, Schulen, berufliche Bildung, Hochschulen, Wirtschaft, Medien, Sprach- und Bildungspolitik, Kulturinstitutionen, Sozial- und Gesundheitswesen, Arbeits- und Ausbildungsmärkte sowie Polizei, Verwaltungen und Verwaltungskooperation. Drei Bereiche blieben jedoch weitgehend ausgeblendet, die von wichtiger Bedeutung erscheinen, auch für die Frankreichstrategie des Saarlandes und seine zukünftige Weiterentwicklung:

1. die Zivilgesellschaft und hier insbesondere die Städtepartnerschaften,

2. die Gewerkschaften und die interregionale Gewerkschaftskooperation und

3. die Flüchtlingspolitik.

26 Van Middelaar, Luuk: France-Allemagne: une incompréhension permanente, in: Le Débat $\mathrm{n}^{\circ} 187$ (2015), S. 4-20.

27 Vgl. Sylvère Mbondobari in diesem Band. 
Die Partnerschaften zwischen deutschen und französischen Kommunen stellen eine der großen Erfolgsgeschichten der deutsch-französischen Annäherungen seit den 1950er Jahren dar. Es gibt keine anderen Zivilgesellschaften des Globus, die auch nur annähernd in so intensiver Weise durch Städtepartnerschaften und die hiermit verbundenen Kontakt- und Austauschprogramme vernetzt waren (und großenteils noch sind) wie Deutschland und Frankreich. Seit dem ersten Partnerschaftsvertrag zwischen den Städten Montbéliard und Ludwigsburg im Jahre 1950 hat sich die Zahl der deutschfranzösischen Städtepartnerschaften geradezu explosionsartig entwickelt: V. a. in den 1960er und 1970er Jahren und dann erneut nach der Wiedervereinigung zu Beginn der 1990er Jahre nahm sie sprunghaft zu, als zahlreiche Kommunen in den neuen Bundesländern Partnerschaftsverträge mit französischen Kommunen abgeschlossen haben. 1981 bestanden 1000 Partnerschaften zwischen deutschen und französischen Städten, seit dem Jahr 2000 sind es über $2000 .{ }^{28}$ Das Saarland nimmt hinsichtlich der Dichte deutschfranzösischer Städtepartnerschaften eine Spitzenposition nach RheinlandPfalz ein: Während im Bundesdurchschnitt 25 deutsch-französische Städtepartnerschaften auf eine Million Einwohner entfallen, sind es im Saarland über 60 (in Rheinland-Pfalz waren es im Jahr 2000 75). „Die deutlichste Veränderung hinsichtlich der Entwicklungsdynamik der Städtepartnerschaften“ sei, so Lucie Filipová in ihrer sehr gut dokumentierten Studie Erfüllte Hoffnung. Städtepartnerschaften als Instrument der deutsch-französischen Aussöbnung, 1950-2000, im Saarland zu beobachten, ,,womit sich bestätigt, dass das Interesse an einer Zusammenarbeit mit französischen Kommunen in denjenigen Kommunen am größten war [und ist], die geographische wie historische Verbindungen zu Frankreich hatten - dank ihrer Lage und der gemeinsamen Vergangenheit, zu der auch die ersten Nachkriegsjahre unter französischer Besatzungsverwaltung zählten““. ${ }^{29}$ Neben Partnerschaften mit geographisch relativ weit auseinander liegenden Kommunen - wie im Falle der Städtepartnerschaft Saarbrücken-Nantes - findet sich im Saarland insbesondere ein relativ dichtes Netz grenzüberschreitender Partnerschaften mit lothringischen Städten und Kommunen, wie die Verbindungen zwischen Völklingen und Forbach sowie

28 Vgl. hierzu Filipová, Lucie: Erfiullte Hoffnung. Städtepartnerschaften als Instrument der dentschfranzösischen Aussöhnung, 1950-2000, Göttingen: Vandenhoeck \& Ruprecht, 2015 (Veröffentlichungen des Instituts für Europäische Geschichte Mainz 237); Defrance, Corine/Pfeil, Ulrich: Der Elysée-Vertrag und die deutsch-französischen Beziehungen. Eine Einleitung, in: dies. (Hg.): Der Elysée-Vertrag und die deutsch-französischen Beziebungen 1945 1963 - 2003, München: Oldenbourg Verlag, 2005, S. 9-46, hier S. 39; Schäfer, Claus W.: Freundschaft von unten: Wie die deutsch-französische Verständigung vorbereitet wurde, in: Deutsch-Französisches Institut (Hg.): Frankreich Jabrbuch 2012, Wiesbaden: Springer, 2013, S. 77-88.

29 Filipová: Städtepartnerschaften, S. 346. 
Klarenthal und Schoeneck. Hinzu kommen die grenzüberschreitenden Partnerschaften zwischen den Landkreisen Merzig-Wadern und dem SaarpfalzKreis mit dem Departement Moselle.

Die deutsch-französische ,Erfolgsgeschichte der Städtepartnerschaften hat in den letzten 15 Jahren bundesweit und auch frankreichweit deutlich an Dynamik verloren, wenn auch weniger in ganz nahen Regionen wie dem Saarland als anderswo. Die Zahl der Partnerschaftsaustauschprogramme und der an ihnen beteiligten Teilnehmer sinkt seit etwa 20 Jahren kontinuierlich. Die Verantwortlichen und die Beteiligten repräsentieren zunehmend die älteren Generationengruppen - eines unter vielen Symptomen dafür, dass der Generationenwechsel zwischen der engagierten Nachkriegsgeneration und den folgenden Generationen keineswegs bruchlos verläuft, sondern sich in vielen zivilgesellschaftlichen Bereichen in einem Rückgang der Austauschzahlen und der Begegnungsprogramme äußert. Als neue Tendenz, die auch auf eine größere Attraktivität der Partnerschaften für die jüngeren Generationen abzielt, ist seit etwa 20 Jahren die verstärkte Entwicklung trilateraler und multilateraler Kooperationen mit europäischen Partnern oder Schwellenländern zu beobachten, wie sie die Kooperation zwischen Saarbrücken, Nantes und Tbilissi in Georgien verkörpert.

Einen zweiten, in der Frankreichstrategie bisher ausgeblendeten Bereich bilden Gewerkschaften und v. a. auch die interregionale Gewerkschaftszusammenarbeit. Das Saarland, Lothringen und Luxemburg nehmen in diesem Bereich, wie ein von den Soziologen Dieter Filsinger und Luitpold Rampeltshammer und mir gemeinsam herausgegebener Sammelband mit dem Titel Interregionale Gewerkschaftsräte. Historische, sozialwissenschaftliche und interkulturelle Analysen zeigt, eine Pionierrolle ein. ${ }^{30}$ Bereits 1976 wurde der erste Interregionale Gewerkschaftsrat (IGR) von deutschen, französischen und luxemburgischen Gewerkschaftsräten gegründet, eine „organisatorische Innovation". 31 Seitdem sind in ganz Europa in den Grenzräumen über 50

30 Vgl. Filsinger/Lüsebrink/Rampeltshammer: Interregionale Gewerkschaftsräte; Lüsebrink, Hans-Jürgen/Rampeltshammer Luitpold: Interkulturelle Kommunikation in transnationalen Arbeitnehmerinteressenvertretungen, in: Rüb, Stefan/Müller, Torsten (Hg.): Arbeitsbeziehungen im Prozess der Globalisierung und Europäischen Integration. Ökonomische und soziale Herausforderungen im Zeichen der Euro-Krise. Festschrift für Hans-Wolfgang Platzer, Baden-Baden: Nomos-Verlag, 2013, S. 123-138. Julia Frisch (TU Kaiserslautern) bereitet zum Thema Interkulturelle Dimensionen grenzüberschreitender Gewerkschaftšusammenarbeit am Beispiel der Großregion und der Region Öresund. Eine vergleichende Analyse der Strukturen, Akteure, Themenschwerpunkte und Medienwirkungen (Arbeitstitel) eine Dissertation vor, die kurz vor dem Abschluss steht. Vgl. http://www.uni-saarland.de/lehrstuhl/luesebrink/forschung/ doktorandinnen-und-doktoranden/laufende-dissertationsprojekte.html (30.01.2017).

31 Filsinger, Dieter/Lüsebrink, Hans-Jürgen/Rampeltshammer, Luitpold: Interregionale Gewerkschaftsräte (IGR) - Fragestellung, Forschungsstand, theoretischer Rahmen und methodisches Vorgehen, in: dies. (Hg.): Interregionale Gewerkschaftsräte, S. 7-20, hier S. 9. 
interregionale Gewerkschaftsräte entstanden, die neue Formen der grenzüberschreitenden Wahrnehmung von Arbeitnehmerinteressen entwickelt haben. Sie repräsentieren Institutionen, die grenzüberschreitende Kooperationen von regionalen (meist Landesbezirke oder Bezirke) oder nationalen Gewerkschaftsbünden in einer Grenzregion mit dem Ziel organisieren,

die Probleme, die durch die zunehmende wirtschaftliche Integration, die Zunahme
grenzüberschreitender Pendlerströme, regionale Prozesse des Strukturwandels und die
unterschiedlichen gesetzlichen Zuständigkeiten in der Region auftreten, zu bearbeiten. Das
übergeordnete Ziel der UGRs ist dabei die gemeinsame regionale Vertretung von
Arbeitnehmerinteressen über nationale Grenzen hinweg mit Hilfe von Vernetzung und
Kooperation. ${ }^{32}$

Der IGR Saar-Lor-Lux hatte nicht nur eine europäische Initial- und Modellfunktion in diesem Bereich der institutionalisierten grenzüberschreitenden Gewerkschaftszusammenarbeit und Arbeitnehmervertretung, sondern auch eine wichtige - und kaum zu überschätzende - Inkubationsrolle bei der Entstehung weiterer grenzüberschreitender Institutionen, wie etwa des Wirtschaftsund Sozialausschusses der Großregion. Zugleich macht die Studie - u. a. durch die Beiträge von Julia Frisch und Thomas Schmidtgall ${ }^{33}$ - deutlich, dass die Problembereiche der institutionalisierten grenzüberschreitenden Gewerkschaftszusammenarbeit nicht nur in den sehr unterschiedlichen Gewerkschaftsstrukturen in Deutschland und Frankreich sowie in unzureichenden Handlungskompetenzen, sondern auch in der fehlenden oder nicht hinreichend entwickelten interkulturellen Kompetenz der Beteiligten liegen - ein Gesichtspunkt, auf den ja in besonderer Weise die Frankreichstrategie des Saarlandes zielt.

Ein dritter, weder in der Frankreichstrategie noch in anderen Beiträgen des vorliegenden Bandes erwähnter Problembereich betrifft die Immigration und spezifisch die ,Flüchtlingskrise'. Die ,Flüchtlingskrise', die sich durch den stetigen Anstieg von Asylbewerberzahlen in der EU seit 2008 ankündigte, legt, in noch deutlich prononcierterem Maße als die Finanz- und Wirtschaftskrise und die hiermit verbundene, Griechenlandkrise ${ }^{6}$ in den letzten Jahren, deutsch-französische Divergenzen und einen nur oberflächlich verdeckten deutsch-französischen Dissens offen. Sowohl Präsident François Hollande als auch Bundeskanzlerin Angela Merkel betonten seit September 2015, dass sie in dieser Beziehung eine grundlegend gemeinsame Politik verfolgen und nach

32 Filsinger/Lüsebrink/Rampeltshammer: Interregionale Gewerkschaftsräte, S. 9.

33 Frisch, Julia/Schmidtgall, Thomas: Interkulturelle Kommunikation und Interaktion im Interregionalen Gewerkschaftsrat Saar-Lor-Lux-Trier/Westpfalz, in: Filsinger/Lüsebrink/ Rampeltshammer (Hg.): Interregionale Gewerkschaftsräte, S. 179-212; vgl. auch Lüsebrink, Hans-Jürgen: Interkulturelle Kommunikation in transnationalen Organisationen, in: Filsinger/Lüsebrink/Rampeltshammer (Hg.): Interregionale Gewerkschaftsräte, S. 69-82. 
einer gemeinsamen europäischen Lösung suchen. Le Monde kommentierte diese vorgeblich gemeinsame politische Position mehrfach, u. a. am 22. Januar 2016, als einen geschickten Kommunikationstrick. Die Wirklichkeit sehe völlig anders aus und werde von aktuellen Zahlen belegt. Während Deutschland 2015 über eine Million Asylbewerber aufgenommen hat, waren es in Frankreich 80 000. Das Bundesland Nordrhein-Westfalen allein hat 2015 mehr Flüchtlinge aufgenommen als Frankreich insgesamt. Aktuellen Meinungsfragen zufolge, sind $63 \%$ der Franzosen, aber nur $33 \%$ der Deutschen der Meinung, dass es in ihrem Land bereits ,,viele Ausländer und Personen mit Migrationshintergrund" gebe und keine weiteren aufgenommen werden könnten. ${ }^{34} 67 \%$ der Deutschen, aber nur $37 \%$ der Franzosen sind hingegen der Ansicht, dass dies nicht der Fall sei und ihr Land weitere Immigranten aufnehmen könne. ${ }^{35}$ Insgesamt wolle Frankreich, so der damalige französische Premierminister Manuel Valls, 2016 maximal 30000 Flüchtlinge aufnehmen, deutlich weniger als in der Vergangenheit. ${ }^{36}$ Die französische Regierung, die bis Anfang 2016 von den zugesagten 25000 Flüchtlingen aus Syrien lediglich 2000 aufnahm, bot der deutschen Regierung v. a. Zusammenarbeit bei der deutlichen Reduktion der Flüchtlings- und Asylbewerberzahlen an. Zunächst, so Manuel Valls, der anders als Staatspräsident François Hollande seine Positionen häufig unverblümt und ohne konziliante Kommunikationsstrategien zum Ausdruck bringt, müsse mit Entschlossenheit die klare Botschaft ausgesendet werden, dass nicht alle Flüchtlinge in Europa willkommen geheißen werden könnten. Europa könne, so Valls, die große Zahl von Migranten nicht verkraften. Der Zustrom bedrohe zudem die Idee der Europäischen Union und deren Stabilität. Eine Botschaft 'kommt, ihr seid willkommen' werde zu tiefgreifenden Veränderungen führen. ${ }^{37}$ Wolf Lepenies,

34 Blanchard, Pascal/Dubucs, Hadrien/Gastaut, Yvan: Atlas des immigrations en France. Histoire, mémoire, héritage, Paris: Éditions Autrement, 2016 (Coll. Atlas/Monde), S. 41. Die Umfrage wurde 2015 durchgeführt. Die genannten Prozentzahlen betreffen die zustimmenden Umfragewerte (,Tout à fait d'accord“, „,Plutôt d'accord“), die in Frankreich $35 \%$ und $28 \%$ und in Deutschland $14 \%$ und $19 \%$ betrugen. Die gestellte Frage lautete: „Notre pays compte déjà beaucoup d'étrangers ou de personnes d'origine étrangère, et accueillir des immigrés supplémentaires n'est pas possible.“

35 Blanchard/Dubucs/Gastaut: Atlas des immigrations en France, S. 41. Differenzierte Prozentzahlen: „Plutôt pas d'accord“: Frankreich $23 \%$, Deutschland $38 \%$; „Pas du tout d'accord“: Frankreich $14 \%$, Deutschland $29 \%$.

36 Bonnefous, Bastien: Crise des réfugiés. Valls joue la fermeté face à Angela Merkel, in: Le Monde, 13.02.2016, http://www.lemonde.fr/europe/article/2016/02/13/crise-des-refugiesle-discours-de-fermete-de-manuel-valls_4864979_3214.html (30.01.2017).

37 Bonnefous: Crise des réfugiés: „Il souhaite donc que la politique d'accueil de l’Union européenne soit désormais bien plus restrictive. ,Dire 'venez tous' peut finir par détruire les fondements de l'Europe', estime-t-il. Pour M. Valls, il faut un contrôle assuré des frontières extérieures de l'Union, sinon ce sera le retour des frontières intérieures. 'Un discours dur et alarmiste à quelques 
ehemaliger Leiter des Wissenschaftskollegs in Berlin und ein vorzüglicher Frankreichkenner, kommentierte diese Sachlage in einem Artikel vom 22. Dezember 2015 in der Tageszeitung Die Welt wie folgt:

\begin{abstract}
Deutschland und Frankreich haben ihre wirtschaftlichen und finanzpolitischen Differenzen nicht beigelegt, sie haben es nicht verstanden, gemeinsam eine Wirtschaftspolitik zu verfolgen, in der Ausgabenstabilität sich mit energischen Wachstumsimpulsen verbindet. Die routinierten Bekundungen einer Entente cordiale zwischen Präsident und Kanzlerin können nicht darüber hinwegtäuschen, dass die Interessendifferenz zwischen Frankreich und Deutschland weiter besteht. Sie lähmt ein wirksames Krisenmanagement innerhalb der EU - und sie hat auch eine deutsch-französische Abstimmung in der Flüchtlingspolitik verhindert. Weite Teile der französischen Öffentlichkeit sehen in der deutschen Willkommenskultur den Versuch, die demographischen Probleme einer alternden Gesellschaft zu lösen und billige Arbeitskräfte zu gewinnen. ${ }^{38}$
\end{abstract}

Die ,Flüchtlingskrise‘ und ihre deutsch-französische Aufarbeitung (bzw. Nicht-Aufarbeitung) sind mit der Frankreichstrategie und insbesondere auch mit der im vorliegenden Beitrag zentralen Problematik der interkulturellen Kompetenz unmittelbar verknüpft: Die Tatsache, dass in wichtigen sozialen und politischen Bereichen - wie der Migrations- und Flüchtlingsproblematik derzeit in Deutschland stark divergierende Positionen zu beobachten sind, erfordert interkulturelle Kompetenzen, insbesondere auch historisches und landeskundliches Wissen, um zu einem gegenseitigen Verständnis und möglichst auch zu einer Annäherung zu kommen. Mit dem Saarland - dem Bundesland mit dem statistisch geringsten Auftreten von Ausländerfeindlichkeit - und Lothringen bzw. dem Departement Moselle kooperieren zwei Grenzregionen miteinander, die lange, intensive und zugleich auch unterschiedliche Migrationsgeschichten und Migrationserfahrungen aufweisen und deshalb, auf den verschiedensten Ebenen, interkulturell voneinander lernen können. Es gilt nur, auch hierfür geeignete Diskussions- und Lernforen zu konzipieren, auf politischer Ebene, aber auch in der Zivilgesellschaft sowie in Schulen und Hochschulen.

\title{
4. Herausforderungen und Perspektiven
}

Die Frankreichstrategie, die in den Beiträgen des vorliegenden Bandes aus wissenschaftlicher Perspektive - und damit auch aus kritischer Distanz - betrachtet werden sollte, ist visionär und zukunftsorientiert: Die Entwicklung eines deutsch-französischen, mehrsprachigen, durch kulturelle Diversität

jours du sommet des dirigeants européens à Bruxelles les 18 et 19 février, qui doit notamment se pencher sur l'afflux des réfugiés en Europe“.

38 Lepenies, Wolf: Deutschland allein zu Haus, in: Die Welt, 22.12.2015, S. 2. 
geprägten Raums ist eine Vision, die vielversprechend und zukunftsweisend ist und einer Gesellschaft und Kultur wie der des Saarlandes eine völlig neue Entwicklungsdynamik zu verleihen vermag. Zugleich ist die Frankreichstrategie zweifellos dazu geeignet, die Attraktivität des Saarlandes als Wirtschaftsstandort und Wohnregion zu erhöhen und das Land insgesamt durch die gezielte Entwicklung von Alleinstellungsmerkmalen (wie ,Frankreichnähe', ,Frankreichkompetenz', savoir-vivre) für Arbeitnehmer ebenso wie für Arbeitgeber attraktiver zu machen und ihm ein unverwechselbares und zugleich positiv besetztes Profil zu geben. ${ }^{39}$

Hinsichtlich der Herausforderungen und Perspektiven der Frankreichstrategie sind in diesem Beitrag (und in anderen Beiträgen des vorliegenden Bandes) bereits eine ganze Reihe von Gesichtspunkten genannt worden. Zwei Gesichtspunkte, die jeweils Herausforderungen darstellen, aber auch Perspektiven der weiteren Entwicklung eröffnen könnten, sollen pointiert abschließend hinzugefügt werden.

Zum einen ist die Herausforderung zu betonen, die das Austarieren von Marketingstrategie bzw. Standortmarketing und substanzieller Weiterentwicklung der Frankreichstrategie, insbesondere auch der Frankreichkompetenz, darstellt. Oder, anders formuliert: Soll es bei der Frankreichstrategie primär um Vermarktung, bessere Darstellung und Bündelung bereits vorhandener Frankreichkompetenzen gehen; oder geht es eher und in erster Linie um die gezielte, koordinierte und innovative Weiterentwicklung vorhandener Frankreichkompetenzen, auf die ja auch die ambitiöse - aber auch in mancher Hinsicht zu präzisierende ${ }^{40}$ - Zielsetzung ausgerichtet ist, das Saarland bis $2040 \mathrm{zu}$ „einer leistungsfähigen multilingualen Region deutsch-französischer Prägung zu entwickeln"? 41 Beide Gesichtspunkte greifen zweifelsohne zusammen. In den letzten Jahren seit 2014 ist bereits eine Reihe von konkreten Projekten entwickelt oder weiterentwickelt worden (v. a. im Vorschul-

39 Vgl. hierzu die sehr gut dokumentierte und überzeugende Bachelorarbeit von Veit, Nicola: Frankreich im Regional- und Standortmarketing des Saarlandes. Eine Analyse der Kampagne „Großes entstebt immer im Kleinen" und der „Frankreich-Strategie“, Universität des Saarlandes, Studiengang „Deutsch-Französische Studien: Grenzüberschreitende Kommunikation und Kooperation" der Universitäten Lorraine (Metz) und Saarbrücken, 2017, 80 S.

40 So werden in den verschiedenen Papieren zur Frankreichstrategie in diesem Zusammenhang unterschiedliche Begriffe verwendet, wie ,bilingual', ,multilingual', ,vielsprachig', ,mehrsprachig' etc. Unter der multilingualen Dimension des Saarlandes wird hierbei zum einen die Verwendung sowohl des Deutschen als auch des Französischen im „öffentlichen Raum" (Staatskanzlei des Saarlandes: Eckpunkte einer Frankreichstrategie, S. 9) verstanden, die gelegentlich auch als ,Verkehrssprachen“ bezeichnet werden, andererseits aber auch die generelle Entwicklung von Mehrsprachigkeit unter Einbeziehung des Englischen und anderer Sprachen, wobei dem Französischen als Sprache des Nachbarn eine privilegierte Stellung zukommen müsse.

41 Landesregierung Saarland: Fenille de route 2015/2016, o. S. [S. 1]. 
und Schulbereich sowie in der Verwaltungskooperation), die die Dynamik der Frankreichstrategie belegen und aufzeigen, dass es um deutlich mehr geht als um regionales Standortmarketing. Letzteres weist allerdings auch, v. a. hinsichtlich der Nutzung sozialer Medien ${ }^{42}$, noch deutliche Defizite auf. Andere zentrale Bereiche, in denen Frankreichkompetenz eine Rolle spielt und in denen sie gezielt weiterentwickelt werden müsste, sind jedoch - wie die Hochschulen ${ }^{43}$ oder auch die im vorliegenden Beitrag umrissenen Bereiche der interregionalen Gewerkschaftskooperation oder der grenzüberschreitenden Zusammenarbeit bei der Integration von Migranten und Flüchtlingen eher vernachlässigt oder gar völlig ausgeblendet worden.

Zum anderen wirft dies die herausfordernde Frage nach Kosten und Finanzmitteln auf. Ist eine ambitiöse Vision wie die Frankreichstrategie ohne zusätzliche Mittel - oder zumindest eine dezidierte Umschichtung vorhandener Mittel im Sinne einer Schwerpunktbildung - überhaupt zu leisten und zu realisieren? Wahrscheinlich nicht. Insbesondere ist sie dann nicht zu leisten, wenn auch in die Bereiche, auf die im Rahmen der Frankreichstrategie bereits neue Anforderungen und Herausforderungen zukommen werden bzw. zugekommen sind (wie auf den Bereich der bilingualen Grundschullehrerausbindung), nicht nur keine zusätzlichen Mittel fließen, sondern dort paradoxerweise sogar drastisch gespart wird. In den frankreichbezogenen und auf Interkulturalitäts- und Mehrsprachigkeitsforschung ausgerichteten Bereichen, Fachrichtungen und Instituten an der Universität des Saarlandes und auch in der mittleren Finanzplanung ist dies zu geradezu drastischer Weise der Fall, mit Kürzungen zwischen $12 \%$ und $20 \%$ im Personal- und Sachmittelbudget. Als Romanist, Historiker und Spezialist für interkulturelle Kommunikation mit deutsch-französischer Biographie halte ich die Frankreichstrategie für ein vielversprechendes Programm und eine ambitiöse Zukunftsvision, an der es sich lohnt kooperativ, kritisch und produktiv mitund weiterzuarbeiten; aber es wäre schade, und für das Saarland fatal, wenn die Grundvoraussetzungen institutioneller und finanzieller Art für die Weiterentwicklung und Umsetzung der Frankreichstrategie weiterhin eingeschränkt

42 Vgl. hierzu die originelle und sehr gut dokumentierte Masterarbeit von Malika Picart über La stratégie „France" $d u$ Land de la Sarre: campagne d'information du gouvernement sarrois et impact dans la presse en France et en Allemagne im trinationalen Studiengang „Deutsch-französische Studien: grenzüberschreitende Kommunikation und Kooperation" der Universitäten Saarbrücken, Lorraine (Metz) und Luxembourg, Saarbrücken, 2016, 113 S., mit Anhang; sowie die bereits erwähnte Bachelorarbeit von Veit: Frankreich im Regional- und Standortmarketing des Saarlandes, 2017 (vgl. Fußnote 39).

43 So wird der Punkt 8. „Wissenschaft“ in der Fenille de route II 2017/2019 der Landesregierung den sehr breiten und differenzierten deutsch-französischen Kooperationen in Lehre und Forschung, die an der Universität des Saarlandes bestehen, nicht gerecht. Vgl. Landesregierung des Saarlandes: Frankreichstrategie Fenille de route II 2017/2019, S. 9f. 
werden und sogar wegbrechen. Erfolgreiches Marketing - das Eckpunktepapier zur Frankreichstrategie spricht, wie bereits zitiert, vom „Markenkern“ des Saarlandes, zu dem ,die deutsch-französische Kompetenz [gehört]“44 setzt ein qualitätsvolles Produkt voraus. Dieses muss ständig - dies gilt auch für die Frankreichstrategie - weiterentwickelt werden, um sich im „Wettbewerb" der Regionen (von dem auch auf S. 3 des Eckpunktepapiers zur Frankreichstrategie ausdrücklich die Rede ist) durchsetzen und bestehen zu können: durch ständige Innovation; durch kreative Teamarbeit und interdisziplinäre, grenzüberschreitende Kooperation; und durch finanzielle und personale Investitionen, die möglichst erhöht werden sollten, auf jeden Fall auf dem bisherigen Stand bleiben müssen, aber keinesfalls zurückgefahren werden sollten.

\section{Literaturverzeichnis}

Barmeyer, Christoph: Taschenlexikon Interkulturalität. Göttingen: Vandenhoeck \& Ruprecht, 2012 (UTB 3739).

Bergmann, Alexander: Interkulturelle Managemententwicklung, in: Haller, Matthias (Hg.): Globalisierung der Wirtschaft, Bern [u. a.]: Haupt, 1993, S. 193-216.

Blanchard, Pascal/Dubucs, Hadrien/Gastaut, Yvan: Atlas des immigrations en France. Histoire, mémoire, héritage, Paris: Éditions Autrement, 2016 (Coll. Atlas/Monde).

Bolten, Jürgen: Interkulturelle Kompeten₹, Erfurt: Thüringer Landeszentrale für politische Bildung, 2001.

Bonnefous, Bastien: Crise des réfugiés. Valls joue la fermeté face à Angela Merkel, in: Le Monde, 13.02.2016, http://www.lemonde.fr/europe/article/2016/02/13/crise-des-refugies-lediscours-de-fermete-de-manuel-valls_4864979_3214.html (30.01.2017).

Defrance, Corine/Pfeil, Ulrich: Der Elysée-Vertrag und die deutsch-französischen Beziehungen. Eine Einleitung, in: dies. (Hg.): Der Elysée-Vertrag und die deutsch-franæösischen Beziehungen 1945 - 1963 - 2003, München: Oldenbourg Verlag, 2005, S. 9-46.

Filipová, Lucie: Erfüllte Hoffnung. Städtepartnerschaften als Instrument der deutsch-französischen Aussöbnung, 1950-2000, Göttingen: Vandenhoeck \& Ruprecht, 2015 (Veröffentlichungen des Instituts für Europäische Geschichte Mainz 237).

Filsinger, Dieter/Lüsebrink, Hans-Jürgen/Rampeltshammer, Luitpold (Hg.): Interregionale Gewverkschaftsräte. Historische, sozialwissenschaftliche und interkulturelle Analysen, Baden-Baden: Nomos Verlagsgesellschaft, 2015 (Forschung aus der Hans Böckler-Stiftung 179).

Filsinger, Dieter/Lüsebrink, Hans-Jürgen/Rampeltshammer, Luitpold: Interregionale Gewerkschaftsräte (IGR) - Fragestellung, Forschungsstand, theoretischer Rahmen und methodisches Vorgehen, in: Filsinger/Lüsebrink/Rampeltshammer: Interregionale Gewverkschaftsräte, S. 7-20.

Frisch, Julia/Schmidtgall, Thomas: Interkulturelle Kommunikation und Interaktion im Interregionalen Gewerkschaftsrat Saar-Lor-Lux-Trier/Westpfalz, in: Filsinger/Lüsebrink/ Rampeltshammer: Interregionale Gewerkschaftsräte, S. 179-212.

Hall, Edward T.: The Silent Language, New York: Anchor Books, 1981.

Heringer, Hans-Jürgen: Interkulturelle Kommunikation, Tübingen: Francke, 2014 (UTB 2550).

44 Staatskanzlei des Saarlandes: Eckpunkte einer Frankreichstrategie, S. 3. 
Knapp, Karlfried/Knapp-Potthoff, Annette: Interkulturelle Kommunikation, in: Zeitschrift für Fremdsprachenforschung 1 (1990), S. 62-93.

Landesregierung des Saarlandes: Feuille de route Frankreichstrategie 2015/2016, 2015, http:/ /www. saarland.de/dokumente/res_stk/D_Eckpunkte_Frankreich-Strategie_210114.pdf (30.01.2017).

Landesregierung des Saarlandes: Frankreichstrategie Feuille de route II 2017/2019, 2016, http:// www.saarland.de/dokumente/thema_europa/2016-10-17_Feuille_de_route_2017-2019.pdf (30.01.2017).

Lepenies, Wolf: Deutschland allein zu Haus, in: Die Welt, 22.12.2015, S. 2.

Lüsebrink, Hans-Jürgen: Interkulturelle Kommunikation. Interaktion - Kulturtransfer - Fremdwahrnehmung, Stuttgart: J.B. Metzler-Verlag, 2005 (Metzler Studienbücher), ${ }^{42016 .}$

Lüsebrink, Hans-Jürgen: Interkulturelle Kommunikation in transnationalen Organisationen, in: Filsinger/Lüsebrink/Rampeltshammer: Interregionale Gewerkschaftsräte, S. 69-82.

Lüsebrink, Hans-Jürgen/Rampeltshammer Luitpold: Interkulturelle Kommunikation in transnationalen Arbeitnehmerinteressenvertretungen, in: Rüb, Stefan/Müller, Torsten (Hg.): Arbeitsbeziebungen im Prozess der Globalisierung und Europäischen Integration. Ökonomische und soziale Herausforderungen im Zeichen der Euro-Krise. Festschrift für Hans-Wolfgang Platzer, BadenBaden: Nomos-Verlag, 2013, S. 123-138.

Ministerium für Finanzen und Europa des Saarlandes: Europa-Matinée „Das Saarland und die Frankreichstrategie“ im Saarbrücker Schloss. Abschluss der Veranstaltungsreihe mit Ministerpräsidentin Annegret Kramp-Karrenbauer und dem Präsidenten der Region Grand Est, Philippe Richert, in: Medien-Info 149 (12/2016), S. 2.

Picart, Malika: La stratégie „France“ $d u$ Land de la Sarre: campagne d'information du gouvernement sarrois et impact dans la presse en France et en Allemagne, Universität des Saarlandes, Masterarbeit, 2016.

Schäfer, Claus W.: Freundschaft von unten: Wie die deutsch-französische Verständigung vorbereitet wurde, in: Deutsch-Französisches Institut (Hg.): Frankreich Jabrbuch 2012, Wiesbaden: Springer, 2013, S. 77-88.

Staatskanzlei des Saarlandes: Eckpunkte einer Frankreichstrategie für das Saarland, 2014, http:// www.saarland.de/dokumente/res_stk/D_Eckpunkte_Frankreich-Strategie_210114.pdf (30.01.2017).

Staatskanzlei des Saarlandes: Kooperationsvertrag zum Saarländischen Hochschulzentrum für akademische Weiterbildung unterzeichnet, 28.11.2016, http://www.saarland.de/SIDEC74342B-90D2A3CB/218636.htm (30.01.2017).

Van Middelaar, Luuk: France-Allemagne: une incompréhension permanente, in: Le Débat $\mathrm{n}^{\circ} 187$ (2015), S. 4-20.

Veit, Nicola: Frankreich im Regional- und Standortmarketing des Saarlandes. Eine Analyse der Kampagne „Großes entsteht immer im Kleinen" und der „Frankreich-Strategie“, Universität des Saarlandes, Bachelorarbeit, 2017. 


\section{Frankophones Afrika in den deutsch-französischen (saarländischen) Beziehungen}

Quelle est la place de l'A frique francophone dans les relations franco-allemandes? L'Afrique francophone présente-t-elle un intérêt pour la Sarre? Pour comprendre la complexité et les évolutions de ces dernières décennies, l'article se propose de partir de l'bistoire coloniale pour saisir les enjeux d'aujourd'bui. D'une part, il met l'accent sur la spécificité voire la particularité des liens qui unissent la France à l'Afrique francophone, et, d'autre part, il montre comment l'Allemagne, après avoir perdu ses colonies au lendemain de la première Guerre mondiale, conserve une présence discrète mais bien réelle dans les pays dit du «champ».

\section{Einleitung}

Vor etwas mehr als zehn Jahren, als Frankreich dank seines pré carré noch eine Vormachtstellung hatte, wäre eine Zusammenarbeit zwischen Frankreich und Deutschland, so wie es im Moment in Mali der Fall ist, ganz undenkbar gewesen. Inzwischen haben sich die tiefgreifenden Veränderungen im europäischen und internationalen System, die in den letzten Jahrzehnten zu verzeichnen waren, auch im frankophonen Afrika niedergeschlagen. Die Reise von Angela Merkel nach Mali, Niger und Äthiopien im Oktober 2016 kann als Ergebnis einer neuen Ära der deutsch-französisch-afrikanischen Beziehungen angesehen werden, in der Deutschland seine führende Rolle in Europa konsolidiert und die frankophone Welt als Partner für die Zukunft gewinnt. Wie ist dieser Trend zu erklären? Welche Rolle spielt Frankreich in seinem pré carre?

Seit Jahren wird Frankreichs Engagement im frankophonen Afrika kontrovers diskutiert. Meinungsverschiedenheiten gibt es v. a. über das Gewicht, das den einzelnen Aufgaben und den dabei entwickelten Aktivitäten Frankreichs zuzumessen ist. Dabei wird mit unterschiedlichen, auch kritischen Stimmen geurteilt. Über eines ist sich die Forschung aber im Wesentlichen einig: Frankreich spielt nach wie vor politisch, wirtschaftlich und kulturell eine besondere Rolle im frankophonen Afrika und bleibt der wichtigste Partner im internationalen Geschäft. Dies war bis jetzt nicht der Fall für Deutschland. Allerdings, wie die Vergangenheit gezeigt hat, spielen die frankophonen Länder bisher politisch, strategisch und wirtschaftlich nur eine geringe Rolle für die deutsche Außenpolitik, die sich v. a. auf Ost- und Südafrika konzentriert. In Deutschland wird mehr oder weniger erwartet, dass die 
ehemalige Kolonialmacht Frankreich und die Europäische Union als supranationale Institution die Verantwortung übernehmen, wenn es darum geht, gemeinsame Strategien für die europäisch-afrikanische Zusammenarbeit zu entwickeln oder Konflikte zu lösen. Mit der Flüchtlingskrise, dem Kampf gegen den Terrorismus und dem Klimawandel hat sich die Haltung Deutschlands gegenüber dem französischen chasse gardée in der Hinsicht geändert, dass seit 2015 Bundeswehrsoldaten an einem UN-Einsatz zur Sicherung und Stabilisierung Malis beteiligt sind.

Im Mittelpunkt dieses Beitrags stehen die Beziehungen zwischen Frankreich und Afrika auf der einen Seite und die Stellung Deutschlands zu den frankophonen Ländern Afrikas auf der anderen Seite. Dabei wird zunächst auf die besondere Situation Frankreichs auf dem afrikanischen Kontinent sowie auf die politischen, kulturellen und wirtschaftlichen Beziehungen zwischen Frankreich und den frankophonen afrikanischen Ländern eingegangen. Anschließend soll perspektivisch die Stellung Afrikas in der deutschen Außenpolitik dargestellt und analysiert werden.

\section{Die französische Afrikapolitik:} von der mission civilisatrice zum pré carré

Um die gegenwärtige französische Afrikapolitik zu verstehen, kommen wir nicht umhin, von seiner Kolonialgeschichte auszugehen. Bereits im 14. Jahrhundert findet man französische Kaufleute aus Nantes und Umgebung an der Küste Westafrikas. Bis ins 19. Jahrhundert hinein besitzt Frankreich in Afrika lediglich Stützpunkte, an denen v. a. Sklavenhandel betrieben wird. Erst ab der Mitte des 19. Jahrhunderts wird Land erworben und es werden Kolonien im modernen Sinne des Wortes aufgebaut. Das Vordringen ins Landesinnere beginnt 1854 mit Louis Faidherbe, der als Gouverneur des Senegal für Frankreich ein riesiges Territorium mit Gewalt erobert. Die AEF (Afrique Equatoriale Française) wird etwa dreißig Jahre später im Jahre 1880 von Pierre Savorgnan de Brazza erobert.

Betrachtet man die Kolonialideologie Frankreichs im Laufe der Jahre, kann festgestellt werden, dass das französische Kolonialsystem von Anfang an auf den Ideen der Gleichheit und der Brüderlichkeit von 1789 und der vollen Integration aller Einwohner der Kolonien in die Gemeinschaft der französischen Nation beruht. Aus dieser ideologischen Sichtweise ergibt sich eine enge Verbindung von zivilisatorischem Sendungsbewusstsein, missionarischem Eifer und kolonialer Expansion, die sich in der Assimilationspolitik herauskristallisiert hat. Assimilationspolitik bedeutet hier v. a. die Übernahme der französischen Sprache, die Angleichung der Kolonien an das französische Vorbild und die Anpassung des politischen Systems der eroberten Gebiete. Der Begriff der Assimilation beinhaltet eine kulturelle und eine politische 
Dimension; er konnte sowohl positiv als auch negativ konnotiert sein. Damals sollten die unterworfenen Völker die Sprache, Gebräuche und Religion der Sieger übernehmen. Für János Riesz ist die Assimilationspolitik „zwiespältig und gestattet sowohl eine [...] emanzipatorische wie eine repressive Auslegung $^{\text {"1 }}$. Mit anderen Worten: Frankreich setzt bereits zu Beginn der Kolonisierung Eroberungs- und zivilisatorische Mission gleich. Die Expansionspolitik erklärt sich aber auch durch die Niederlage von 1871. Frankreich sieht die „,koloniale Expansion in Übersee [...] auch als eine Gelegenheit, [seinen] militärischen Ruhm aufzupolieren und die eigenen Soldaten im Hinblick auf eine künftige ,Revanche“ in militärischer Übung zu halten“"2. In seinem 1874 veröffentlichten Werk De la colonisation chez les peuples modernes fasste LeroyBeaulieu die französische Kolonialdoktrin zusammen:

La colonisation est pour la France une question de vie ou de mort ou la France deviendra une grande puissance africaine, ou elle ne sera dans un siècle ou deux qu'une puissance européenne secondaire; elle comptera dans le monde, à peu près comme la Grèce ou la Roumanie compte en Europe. ${ }^{3}$

Ob die Aussage in dieser Tragweite zutrifft, ist zwar fraglich, fest steht allerdings, dass die Wahrnehmung der kolonialen Eroberung als Kompensation der verlorenen Provinzen Teil des Prozesses der Identitätsfindung Frankreichs ist. Zu dieser Frage schreibt Robert Randau: „La France, au lendemain des revers de 1870/71, trouve dans son expansion coloniale une compensation aux amertumes de la défaite" ${ }^{\text {"4 }}$. Nach der Niederlage von 1871 wendet sich Frankreich entschlossen der überseeischen territorialen Expansion zu. Was die französische Kolonialpolitik vor und nach 1870 von derjenigen der anderen europäischen Nationen unterscheidet, ist, wie János Riesz anführt,

1 Riesz, János: Franzö̈sisch in Afrika. Herrschaft durch Sprache, Frankfurt/M.: IKO Verlag, 1998, S. 114.

2 Riesz, János: Koloniale Mythen - Afrikanische Antworten. Europäisch-afrikanische Literaturbeziebungen, Frankfurt/M.: IKO Verlag, 22000 (Bd. 1), S. 68.

3 Leroy-Beaulieu, Paul: De la colonisation chez, les Peuples Modernes, Paris: Guillaume et Cie Libraires, ${ }^{21882, ~ S . ~ V I I I-I X . ~ V g l . ~ D e s c h a m p s, ~ H u b e r t: ~ L e s ~ m e ́ t h o d e s ~ e t ~ l e s ~ d o c t r i n e s ~ c o l o n i a l e s ~ d e ~ l a ~}$ France du XV Te siècle à nos jours, Paris: Colin, 1953, S. 124-131.

4 Randau, Robert: La Littérature coloniale, in: Le Temps Colonial, 1929, zit. nach Lüsebrink, Hans-Jürgen: Die Niederlage als Trauma - L'Empire Colonial als Kompensation, in: Grunewald, Michel/Schlobach, Jochen (Hg.): Médiations - Vermittlungen. Aspekte der deutsch-französischen Beqiehungen vom 17. Jabrbundert bis zur Gegenwart, Frankfurt/M.: Peter Lang, 1992, S. 357-370. 
„,ihre stärkere Orientierung am Prestige-Gedanken“5. Henri Brunschwig ${ }^{6}$ vertritt die gleiche Meinung, denn er schreibt, die Kolonien sollen ,affirmer à la face du monde la présence, la grandeur, le rayonnement de la France ${ }^{\text {"7 }}$.

Die Entkolonisierung der 1960er Jahre stellt keine grundlegende Zäsur dar, sie ist vielmehr ein Übergang zu einer neuen Form der Beziehungen zwischen Frankreich und seinen Kolonien in West- und Zentralafrika. So gesehen ist die Postkolonialzeit ideologisch und geostrategisch als Kontinuität der kolonialen Zeit zu betrachten. Sie führt den kolonialen Gedanken mit anderen Mitteln weiter, wie Alfred Grosser zeigt: „Vous voyez les étapes: en 1959, une organisation commence à naître au sein de l'Afrique; en 1960, on s'écarte complètement de la communauté primitive par l'accession à l'indépendance et, à partir de 1961, c'est l'entrée en fonction des accords de coopération et le retour au bercail de ceux qui s'étaient séparés". 8 Es ging Frankreich damals darum, an seinem wirtschaftlichen, politischen und kulturellen Einfluss festzuhalten. So waren die sogenannten pays du champ (auch pré carré genannt) verpflichtet die accords de coopération zu unterzeichnen, wie man am Beispiel Gabun feststellen kann:

Je vous serais obligé de bien vouloir, en accusant réception de cette communication, me confirmer que, dès la proclamation de l'indépendance de la République gabonaise, le gouvernement de la République gabonaise procédera à la signature des accords de coopération [...] Il va de soi qu'il en sera de même de la part du gouvernement de la République française. ${ }^{9}$

In diesem Brief an Präsident Léon Mba weist Michel Debré Gabun auf die Verpflichtung hin, die Vertragsvereinbarungen zu respektieren. Als Kernpunkt der Vereinbarungen, die eine enge zwischenstaatliche Zusammenarbeit im Bereich der Außen-, Sicherheits-, Wirtschafts-, Kultur-, und Bildungspolitik vorsah, standen die regelmäßigen Konsultationen mit der ehemaligen Kolonialmacht. Für Frankreich, so Stefan Brüne, ist die Vision einer Einbindung und Anbindung des frankophonen Afrikas immer ein prägender Leitgedanke gewesen. Dabei kam die Idee einer Einigung von kulturell und historisch eng verbundenen Staaten immer im Zusammenhang mit der Vorstellung einer wichtigeren Rolle Frankreichs als grande puissance in der Welt. Dies wird durch das 1994 veröffentlichte Livre Blanc bekräftigt: „Au-delà de ces intérêts qui répondent directement à une logique de sécurité, la France a des intérêts qui correspondent à ses responsabilités internationales et à son rang dans le

5 Riesz: Koloniale Mythen - Afrikanische Antworten, S. 57.

6 Brunschwig, Henri: Mythes et réalités de l'impérialisme colonial français (1871-1914), Paris: Colin, 1960.

7 Riesz: Koloniale Mythen - Afrikanische Antworten, S. 69.

8 Grosser, Alfred: La politique extérieure de la Ve République, Paris: Editions du Seuil, 1965, S. 73.

9 Debré, Michel zitiert nach Grosser: La politique extérieure de la Ve République, S. 74. 
monde“10. Es mag also nicht verwundern, wenn Jean-Marc Châtaigner, der ehemalige Direktor in der Agence Française de Développement, von der Einzigartigkeit und der Spezifizität der französischen Afrikapolitik spricht:

\begin{abstract}
Die französische Afrikapolitik wurde lange als grundlegende aber zugleich einzigartige und spezifische Dimension der französischen Außenpolitik betrachtet. Grundlegend erschien sie, weil Afrika aus geopolitischer Sicht der einzige Kontinent war, auf dem Frankreich nach Abschluss der Entkolonisierung erwarten konnte, weiterhin bedeutenden Einfluss aufrechterhalten zu können. [...] Einzigartig und spezifisch erschien französische Afrikapolitik dabei, weil sie nie wirklich in der französischen Außenpolitik aufging. Bekanntlich ist dies institutionell daran abzulesen, dass bis 1999 neben dem Außenministerium ein politisch autonomes Entwicklungshilfeministerium existierte. ${ }^{11}$
\end{abstract}

Es ist auffällig, dass die französische Afrikapolitik nicht nur eine strategische Frage stellt, sondern auch eine symbolische, die die Stellung Frankreichs als Weltmacht definiert. Durch die politique de coopération und ohne reale Alternative bleiben die frankophonen Länder noch heute in einem starken Abhängigkeitsverhältnis, das sie daran hindert, wichtige wirtschaftliche oder politische Entscheidungen frei zu treffen, obwohl Interessengegensätze zwischen den beiden Parteien immer wieder besonders offensichtlich werden. Es sei nur daran erinnert, dass zu den Abkommen über die Zusammenarbeit auf dem Gebiet der Verteidigung außerdem Vereinbarungen über strategisch wichtige Rohstoffe und Produkte zählten, die die afrikanischen Länder verpflichteten, Erdöl, Erdgas, Uran usw. in erster Linie (en prioritê) nach Frankreich zu exportieren. ${ }^{12}$ Dies gilt, wie Stefan Brüne zeigt, auch im kulturellen Bereich: ,[]n [Kulturabkommen] verpflichteten sich die Staaten des ,frankophonen' Afrikas, das Französische als offizielle Sprache und ,Instrument ihrer Entwicklung' beizubehalten und sich zur Deckung ihres Lehrkräftebedarfs bevorzugt [...] an Frankreich zu wenden". 13

Zum Schluss ist es wichtig zu betonen, dass Frankreich sich bis in die 1980er Jahre, d. h. bis kurz vor dem Zusammenbruch des Ostblocks, als ,Anwalt der Afrikaner' bzw. als Wahrer und Schützer ihrer Interessen auf der Weltbühne stilisiert hat. So gesehen beinhaltet die Afrikapolitik Frankreichs notwendigerweise eine historisch-identitätsstiftende und eine geostrategische Dimension, die „,vom gaullistischen Staatsverständnis der Etat-Nation gebildet

10 République Française/Ministère de la Défense: Livre Blanc de la Défense, Paris: Éditions des Livres blancs, 1994, S. 25 f.

11 Châtaigner, Jean-Marc: Zwischen Reform und Tradition: Die französische Afrikapolitike beute, Oktober 2006, S. 1-11, http://library.fes.de/pdf-files/iez/03982.pdf (04.11.2016), hier S. $1 \mathrm{f}$.

12 Vgl. Brüne, Stefan: Die französische Afrikapolitik. Hegemonialinteressen und Entwicklungsanspruch, Baden-Baden: Nomos Verlagsgesellschaft, 1995, S. 60.

13 Brüne: Die fran₹ösische Afrikapolitik, S. 63. 
[wird], der engen Verbindung zwischen dem Staat, [...] und der Nation als Verkörperung der geeinten Gesellschaft." ${ }^{14}$

\section{Die 1990er Jahre und die Wende der französischen Afrikapolitik}

In der Rede von La Baule wurden praktisch die Grundzüge der heutigen französischen Afrikapolitik festgelegt. ${ }^{15}$ Die 1970er und 1980er Jahre waren gekennzeichnet durch Misswirtschaft, innere Instabilität und massive Menschenrechtsverletzungen. Es war v. a. die Zeit der „Françafrique“, d. h. die Zeit „der Beteiligung an Wahlfälschungen, an Putsch(versuchen) zur Unterstützung befreundeter politischer Regime oder gar an militärischen Geheimoperationen gegen missliebige Regierungen afrikanischer Staaten"16. Selbstverständlich wurden die Hoffnungen auf Investitionen für die wirtschaftlichen Entwicklungen ebenso wie die Erwartung, dass Freiheit und Wohlstand sich einstellen, nicht erfüllt. Die Kooperation, insbesondere die militärischen Interventionen, dienten lediglich der Unterstützung von Diktatoren wie Bongo in Gabun, Mubutu in Zaire oder Habyarimana in Ruanda, die als Wahrer französischer Interessen galten.

Nach dem Zusammenbruch des kommunistischen Blocks sahen sich Frankreich und die westliche Welt vor die Frage gestellt, mit welcher politischen Strategie Europa sich den afrikanischen Ländern am besten zuwenden und ihnen beistehen könne. In Afrika selbst wurde die Forderung nach mehr Freiheit und Demokratie entsprechend immer lauter. „Le vent de l'est secoue les cocotiers" 17 soll der damalige Kooperationsminister Jacques Pelletier gesagt haben. Es war aber François Mitterrand, der sich für „,une nouvelle politique africaine " 18 einsetzte und als Erster wesentlich zur Idee und zum Prozess einer Erneuerung und Neuorientierung der Afrikapolitik Frankreichs beitrug. Ein Schwerpunkt seiner Rede von La Baule war, im Zuge der Veränderungen in Osteuropa, die Einführung demokratischer Strukturen in den frankophonen Ländern Afrikas und der Kampf gegen Korruption.

14 Löhr, Johanna: Frankreichs Afrikapolitik: Kontinuität und Wandel seit 1990, Trier: Univ. Diss., 2003, S. 11.

15 Mitterrand, François: Discours de la Baule, 20.06.1990, http://nsarchive.gwu.edu/ NSAEBB/NSAEBB461/docs/DOCUMENT\%203\%20-\%20French.pdf (21.03.2017).

16 Thorel, Julien: Der schwierige Abschied von der „Françafrique“. Die französische Afrikapolitik zwischen Kontinuität und Wandel, in: Bundeszentrale für politische Bildung (Hg.): Dossier Frankreich, Bonn: Bundeszentrale für politische Bildung, 02.08.2013, http://www.bpb. de/internationales/europa/frankreich/166091/abschied-von-der-francafrique (05.11.2016).

17 Jacques Pelletier zitiert nach Brüne, Stefan: Zwischen Grandeur und Afrikapessimismus. Frankreich Afrikapolitik im Zwiespalt, in: Der Überblick 3 (1990), S. 62-68, hier S. 64.

18 Mitterrand: Discours de la Baule. 
Jean-Marc Châtaigner nennt vier Gründe, die die Neuorientierung der Afrikapolitik Frankreichs und die Entwicklungen in Afrika erklären sollen: Erstens das Ende des Kalten Krieges und die Beschleunigung der Globalisierung; zweitens der Rückgang des Interesses der französischen Öffentlichkeit an den Entwicklungen in Afrika: „,D]ie aktuelle politische Elite Frankreichs [hat] keine so engen und schon gar keine so gefühlsbetonten Beziehungen mehr zu den afrikanischen Eliten wie ihre Vorgänger" "19; drittens die politischen Generationswechsel in den afrikanischen Ländern und viertens die wirtschaftliche Krise in Frankreich, durch die das Land sich gezwungen sah, das Finanzvolumen für Afrika zu reduzieren. Hinzu kommen, so Denis M. Tull, zwei weitere Gründe: erstens die Rolle Frankreichs in Ruanda und zweitens die öffentlichkeitswirksamen Skandale (Elf, Angolagate), in die hochrangige französische Politiker verstrickt waren. ${ }^{20}$ Die jüngsten Ereignisse in Mali, Libyen, Gabun, der Elfenbeinküste und im Kongo etc. zeigen aber, dass bis jetzt kein tiefgreifendes Umdenken in der Afrikapolitik stattgefunden hat. Die demokratischen Reformen erweisen sich meist als kosmetische Anpassungen. Die Reformen führten ,nur selten zu[r] demokratischen Ablösung der herrschenden Eliten und haben keinen weitreichenden Einfluss auf autoritäre Regierungspraxis, Korruption, Unterdrückung der politischen Opposition und der Meinungsfreiheit" ${ }^{\text {"21 }}$, schreibt Johanna Löhr. Es fehlt an substanziellen politischen Reformen, sodass immer noch der Eindruck entsteht, Frankreich wolle um jeden Preis seine Interessen und seinen Einfluss wahren. Bestätigt wird dies von François Mitterrand, denn er schreibt: „Il n'y a pas de hiatus dans la politique africaine de la France avant mai 1981 et après. Si la méthode a changé, l'objectif est resté. Il consiste à préserver le rôle et les intérêts de la France en Afrique“.22 Auch während der Präsidentschaften von Jacques Chirac ${ }^{23}$, Nicolas Sarkozy und François Hollande wurde ein grundlegender Wandel der französischen Afrikapolitik nicht herbeigeführt, auch wenn sich François Hollande ${ }^{24}$ im Vergleich zu Nicolas Sarkozy stets um eine Normalisierung der Kooperationsbeziehungen mit dem pré carré bemüht hat. ${ }^{25}$ Was die Ära

19 Châtaigner: Zwischen Reform und Tradition, S. 2.

20 Tull, Denis M.: Zeitenwende in der französischen Afrikapolitik, in: SWP-Aktuell 44/10 (2005), S. 1-4, hier S. 2.

21 Löhr: Frankreichs Afrikapolitik, S. 74.

22 Vgl. Marchesin, Philippe: Mitterand l'Africain, in: Politique africaine 6 (1995), S. 9.

23 Mit Genehmigung von Jacques Chirac und des Ölkonzerns Elf-Aquitaine sind 1997 Waffen an die Unterstützer des zu Beginn der 1990er Jahre gestürzten Diktators Sassou Nguesso geliefert worden. Dessen Angriffe waren gegen den amtierenden und demokratisch gewählten Präsidenten Pascal Lissouba gerichtet.

24 Vgl. die Reden von François Hollande in Dakar (12.10.2012) und in Bamako (19.09.2013).

25 Dies ist ein Zeichen für ,path dependancy“. Vgl. Pierson, Paul: Increasing returns. Path Dependence, and the Study of Politics, in: American Political Science Review 94/2 (06/2000), S. 251-267. 
Hollande betrifft, weisen Aline Lebœuf und Hélène Quénot-Suarez auf eine positive Entwicklung hin, auch wenn es in den letzten zwei Jahren noch ein großes Hin und Her gab. Im Bezug auf die Afrikapolitik vertritt Hollande keine klare Linie: „L'hésitation entre retrait, ,normalisation“ et réinvestissement ne semble pas encore avoir été parfaitement tranchée [...]. Elle traduit une volonté de regagner une plus grande autonomie et d'assainir la relation sans toutefois perdre d'influence [...]“. ${ }^{26}$ Hollandes Doktrin lautet dabei: Respekt der Souveränität der Länder, Nicht-Einmischung in innere Angelegenheiten und Solidarität. Betrachtet man diese Position aus der Perspektive der neusten Entwicklungen in West- und Zentralafrika, stößt man jedoch alsbald auf eine unwiderlegbare Realität, die auf die Kontinuität der Afrikapolitik seit De Gaulle hindeutet, so Denis M. Tull:

Im Bereich der Förderung von Demokratie und Menschenrechten blieb Paris noch weiter hinter den offiziellen Bekenntnissen zurück als andere Staaten. Das Ergebnis war eine wenig konsistente, teilweise orientierungslose Afrikapolitik, die zwischen notwendigen Reformen und tradierten Politikmustern oszillierte, wobei erstere von Jospin und letztere von Chirac personifiziert wurde, der der traditionellen gaullistischen Afrikapolitik seit jeher verhaftet ist. ${ }^{27}$

Die Vorstellung von einer französischen Afrikapolitik, die sich nicht in innere Angelegenheiten der Staaten einmischt und die Demokratie und Menschenrechte unterstützt, ja sogar fördert, hat zwar eine lange Tradition, ist aber von der Realität weit entfernt. Sehr selten geht man über das Stadium der politischen Rhetorik hinaus. Fakt ist, dass Frankreich sich seit der Amtszeit von Jacques Chirac immer mehr für einen multilateralen Kurs und für eine Zusammenarbeit mit der EU, insbesondere mit Deutschland, entschieden hat, dies soll aber unter französischer Führung stattfinden. ${ }^{28}$ Nur so kann die führende Rolle Frankreichs bei der Bekämpfung des Terrorismus in der Sahelzone (Mali, Niger, Tschad, etc.) und die Zusammenarbeit mit der ECOWAS (Economic Community of West African States), Deutschland und anderen EULändern funktionieren. Dies scheint in absehbarer Zeit das Zukunftsmodell der französischen Afrikapolitik zu sein, unter der Voraussetzung, wie Denis M. Tull schreibt, dass Frankreich „erstens Abschied [nimmt] von dem seit Jahrzehnten praktizierten ,Geoklientelismus' in Afrika, der von Deutschland

26 Lebœuf, Aline/Quénot-Suarez, Hélène: La politique africaine de la France sous François Hollande. Renouvellement et impensé stratégique, Paris: Institut français des relations internationales (ifri), 2014, S. 3.

27 Tull: Zeitenwende in der französischen Afrikapolitik, S. 2.

28 Außerdem bemüht sich Frankreich immer mehr für afrikanische Lösungen mit der Einbindung der Afrikanischen Union (AU) und der regionalen Organisationen wie die ECOWAS in Westafrika und die CEEAC in Zentralafrika. Vgl. Châtaigner: Zwischen Reform und Tradition. 
lange akzeptiert wurde, sowie zweitens ein politischer Dialog ,auf Augenhöhe nicht nur zwischen Paris und Berlin und der EU insgesamt [stattfindet]" .29 Denis M. Tull sieht in dem von Frankreich angekündigten Multilateralismus eine Chance für die Bundesregierung, ,die eigenen afrikapolitischen Zielsetzungen als gleichberechtige Partner einzubringen und französischen Versuchen, multilaterale Ansätze zu instrumentalisieren, eine deutliche Absage zu erteilen". 30

\section{Deutsche Afrikapolitik: Afrika als historische Aufgabe}

Nach der Niederlage im Ersten Weltkrieg verlor das Deutsche Reich gemäß dem Versailler Vertrag von 1919 u. a. die Kolonien Togo und Kamerun, die später unter französische und englische Verwaltung fielen. ${ }^{31}$ Auch nach dem Zweiten Weltkrieg unterhielt Deutschland keine besonderen Beziehungen zu seinen ehemaligen Kolonien mit Ausnahme von Namibia, wo noch etwa 20000 deutschsprachige Bewohner leben. Fest steht, dass Deutschland wirtschaftlich, politisch und kulturell mit vielen Ländern Afrikas unabhängig von seiner Kolonialgeschichte kooperiert. Deshalb ging es Deutschland bisher nicht um eine Hegemonialrolle, sondern um eine funktionale Rolle zu Gunsten der ökonomischen, gesellschaftlichen und politischen Entwicklungen der frankophonen Länder Afrikas. Strategisch war für Deutschland in den 1960er Jahren von besonderer Bedeutung, Afrika in der westlichen Einflusssphäre zu halten. Deutschland hatte v. a. die Rolle Europas in der Welt im Blick. Hierzu bemerkte Helmut Bley Ende der 1980er Jahre:

West Germany belongs to the three leading trading- and investment powers with regard to Africa as whole and very often also in bilateral relations. However, Africa is covering only between 6 and $8 \%$ of West Germany's trade with the World [sic]. The importance of Africa is stronger accentuated in looking on its function for raw-materials, which accounts for about a third. ${ }^{32}$

Er fügt hinzu:

West Germany belongs also to the three leading donor-states through bilateral and multilateral aid operations, which of course influences generally and on the day to day basis

29 Tull: Zeitenwende in der französischen Afrikapolitik, S. 2.

30 Tull: Zeitenwende in der französischen Afrikapolitik, S. 4.

31 Vgl. Brunschwig, Henri: L'expansion allemande outre-mer. Du XVe siècle à nos jours, Paris: PU de France, 1957, S. 185 f.

32 Bley, Helmut: West German Politics Towards Africa since the Seventies, in: Kum'a Ndumbe III, Alexandre: L'Afrique et l'Allemagne. De la colonisation à la coopération 1884-1886 (Le cas du Cameroun), Yaoundé: Editions AfricAvenir, 1986, S. 380-390, hier S. 380. 
bilateral relations to African states. A more recent development is that the share of development aid for Africa is increasing - now close to fifty percent of the aid activities, reflecting the intensified non-aid relations to Asian and Latin-American countries with a higher growth-rates and also reflecting the deep-rooted economic crisis in many African countries. $^{33}$

Auch wenn sich die Zeiten und die Rahmenbedingungen seitdem ein wenig geändert haben, wird Afrika in Deutschland v. a. als Kontinent der Krisen und Katastrophen wahrgenommen. Cord Jakobeit spricht von „medialen (Zerr)Bildern und binären Bewertungen", die eine notwendige Differenzierung erforderlich machen ${ }^{34}$. Die Zahlen sprechen aber eine eindeutige Sprache: Afrika war bis vor kurzem kein strategischer Partner für Deutschland, wie man aus Tab. 1 ablesen kann.

Die Afrikapolitik der Bundesregierung war bis Ende der 1980er Jahre v. a. als Armutsbekämpfung durch Hilfe im Bereich der Bildung, Gesundheit, Landwirtschaft und Wirtschaftspolitik gedacht. Das Bundesministerium für wirtschaftliche Zusammenarbeit und Entwicklung (DEG (Deutsche Investitions- und Entwicklungsgesellschaft mbH), GTZ (Deutsche Gesellschaft für Technische Zusammenarbeit), GIZ (Deutsche Gesellschaft für Internationale Zusammenarbeit), etc.) und zahlreiche deutsche Hilfsorganisationen (Brot für die Welt, Misereor, Deutsche Welthungershilfe, etc.) sind seit vielen Jahren in einigen frankophonen Ländern wie Mali, Senegal, Niger oder Kamerun tätig.

\begin{tabular}{|c|c|c|c|c|c|c|}
\hline & \multicolumn{5}{|c|}{ Eignung als Partner } \\
\hline & & $\begin{array}{l}\text { hoch } \\
(+2)\end{array}$ & $\begin{array}{l}\text { relativ hoch } \\
(+1)\end{array}$ & mittel $(0)$ & $\begin{array}{l}\text { relativ gering } \\
(-1)\end{array}$ & gering $(-2)$ \\
\hline \multirow{4}{*}{ 禹 } & $\begin{array}{l}\text { hoch } \\
\text { (5) }\end{array}$ & $\begin{array}{l}\text { Süd- } \\
\text { afrika* }\end{array}$ & & & & \\
\hline & $\begin{array}{l}\text { relativ } \\
\text { hoch } \\
\text { (4) }\end{array}$ & & & & Nigeria* & Sudan* \\
\hline & $\begin{array}{l}\text { mittel } \\
\text { (3) }\end{array}$ & & $\begin{array}{l}\text { Ghana* } \\
\text { Kenia* } \\
\text { Mali* } \\
\text { Senegal* }\end{array}$ & & $\begin{array}{l}\text { Angola* } \\
\text { Äthiopien* } \\
\text { Côte d'Ivoire } \\
\text { DR Kongo* } \\
\text { Ruanda* } \\
\text { Uganda* }\end{array}$ & Simbabwe \\
\hline & $\begin{array}{l}\text { relativ } \\
\text { gering } \\
(2)\end{array}$ & & $\begin{array}{l}\text { Mauritius } \\
\text { Mosambik* } \\
\text { Sambia* } \\
\text { Tansania* }\end{array}$ & & $\begin{array}{l}\text { Burkina } \\
\text { Faso* } \\
\text { Gabun } \\
\text { Kamerun* }\end{array}$ & Eritrea \\
\hline
\end{tabular}

33 Bley, Helmut: West German Politics Towards Africa since the Seventies, S. 380 f.

34 Jakobeit, Cord: Die postkoloniale (Fehl-)Entwicklung Afrikas, in: Afrika - der vergessene Kontinent? 19. Sinclair-Gespräch (2003), S. 22-39, hier S. 22. 


\begin{tabular}{|l|l||l|l|l|l|l|}
\hline & gering & & Benin* & Burundi* & Dschibuti & Äquatorial- \\
& & Botsuana & Gambia & Guinea & guinea \\
& & Kap Verde & Komoren & Guinea- & Somalia \\
& & Madagas- & Lesotho & Bissau & Togo \\
& & kar* & Liberia & Kongo & Tschad \\
& & Namibia* & Malawi* & Mauretanien* & \\
& & São Tomé e & Niger* & Swasiland & \\
& & Príncipe & Sierra & Zentralafri- & \\
& & Seychellen & Leone & kan. Republik & \\
\hline
\end{tabular}

Tab. 1: Bedeutung afrikanischer Staaten für deutsche Politik und ihre Eignung als Partner. ${ }^{35}$

Anfang der 1990er Jahre erweiterte die Bundesregierung die Ziele der Entwicklungshilfe um die sogenannte, nachhaltige Entwicklung, ${ }^{6}$ die als Schwerpunkte die Entwicklung des privaten Sektors, den Umweltschutz und die Förderung demokratischer Strukturen vorsah. Die Parole lautete „Hilfe zur Selbsthilfe" 36 . Trotz massiven Geldtransfers sitzt die Enttäuschung tief, wie Christoph Eisenring aus einer Studie der Universität Aarhus berichtet:

Seit 1960 haben die Industriestaaten rund 4000 Mrd. \$ den Entwicklungsländern zur Verfügung gestellt. Martin Paldam von der Universität Aarhus hat 141 Studien seit den 1970er Jahren ausgewertet, die den Effekt der Entwicklungshilfe auf das Wachstum untersucht haben. Sein Fazit ist enttäuschend: Im Schnitt gibt es keinen Zusammenhang, die Korrelation ist praktisch null. ${ }^{37}$

Timothy J. Bork und Christoph Eisenring sind der Meinung, dass sowohl die Zielsetzung, der Modus Operandi, als auch die Strategie der Entwicklungshilfe radikal überdacht werden müssen. Axel Dreher vertritt seinerseits die Auffassung, dass Entwicklungshilfe autokratische Regime an der Macht halte ${ }^{38}$ und Korruption fördere. Deshalb sprechen sich die Experten für neue Modelle aus, die erstens den Handel durch den sogenannten ,Trade not aid' fördern

35 Nach Mair, Stefan/Tull, Denis M.: Deutsche Afrikapolitik, in: SWP-Berlin 3 (2009), S. 1 47, hier S. 33. Die mit einem* bezeichneten Länder sind Partnerländer des BMZ. Im Falle Sudans betrachtet das BMZ Süd-Sudan als Partnerland.

36 Bork, Timothy J.: Hilfe zur Selbsthilfe. Eine Bilanz westlicher Entwicklungspolitik, in: Afrika-der vergessene Kontinent? 19. Sinclair-Gespräch (2003), S. 50-65.

37 Eisenring, Christoph: Entwicklungshilfe hilft nicht viel. Viele Projekte werden positiv evaluiert, die Länder kommen dennoch nicht voran, in: Neue Zürcher Zeitung (NZZ), 07.12.2015, S. 13.

38 Christoph Eisenring zitiert Axel Dreher, Entwicklungsökonom an der Universität Heidelberg. Vgl. Eisenring: Entwicklungshilfe hilft nicht viel, S. 13. Weiter heißt es, dass „Entwicklungsländer, die vorübergehend im Uno-Sicherheitsrat Einsitz nehmen, bis zu $60 \%$ mehr Entwicklungshilfe erhalten als vorher. Etwas zugespitzt setzt man die Gelder also ein, um Stimmen in internationalen Organisationen zu kaufen“. 
sollen, und zweitens die Indikatoren bezüglich Korruption, Rechtstaatlichkeit oder Achtung der Menschenrechte berücksichtigen. ${ }^{39}$

Für viele Experten scheint die Bundesregierung weder konzeptionell noch strategisch eine durchdachte Afrikapolitik zu haben, vielmehr ,wirkt Deutschland häufig wie ein Getriebener afrikapolitischer Initiativen Frankreichs und Großbritanniens, in Einzelfällen auch Belgiens, Portugals und der Europäischen Kommission" "40. Die deutsche Afrikapolitik lässt sich in einigen Schlüsselbegriffen zusammenfassend charakterisieren: Governance-Förderung, Sicherheit und Krisenprävention, Nachhaltigkeit, Wirtschaftsförderung und Dialog mit den afrikanischen Partnern. ${ }^{41}$

\section{Die Neue Ordnung: „Das Wohl Afrikas liegt im deutschen Interesse“642}

Mit dem Klimawandel, der ,Flüchtlingskrise und dem Kampf gegen den Terrorismus hat Afrika in der deutschen Politik, insbesondere die Sahelzone, einen Zuwachs an strategischer Bedeutung erfahren: „Das Wohl Afrikas liegt im deutschen Interesse" soll Angela Merkel bei ihrer letzten Reise in Mali gesagt haben. ${ }^{43}$ In den letzten Jahren hat Deutschland sein Engagement in Afrika ausgebaut und die Entwicklungshilfen sind in den letzten zwei Jahren von 10 Mrd. US-Dollar auf 16 Mrd. US-Dollar gestiegen. Zum einen haben die Bundeswehreinsätze in West- und Ostafrika die Präsenz Deutschlands in Afrika gestärkt, und zum anderen hat die Bundesrepublik in den letzten vier Jahren ihre operativen Kapazitäten in der Entwicklungs- und Zusammenarbeit ausgebaut. Für die kommenden vier Jahre sollen die Entwicklungsausgaben gegenüber den ursprünglichen Plänen um 8 Mrd. US-Dollar aufgestockt werden. ${ }^{44}$

39 Vgl. auch Bork: Hilfe zur Selbsthilfe, S. 65.

40 Mair/Tull: Deutsche Afrikapolitik, S. 37. Vgl. auch Internationale Politik und Gesellschaft: Deutsche Afrikapolitik: Uneinig und Inkohärent, 17.03.2014, http://www.ipg-journal.de/kolumne/ artikel/deutsche-afrikapolitik-uneinig-und-inkohaerent-317/ (07.11.2016).

41 Vgl. Die Bundesregierung: Afrikapolitik der Bundesregierung. Verstärktes Engagement in Afrika, 21.05.2014, https://www.bundesregierung.de/Content/DE/Artikel/2014/05/2014-0520-verstaerktes-engagement-afrika.html (07.11.2016).

42 Meyer, Sascha: Flüchtlingskrise. Merkels afrikanische Lehren, in: RP Online, 11.10.2016, http://www.rp-online.de/politik/ausland/diese-lehren-zieht-angela-merkel-aus-der-afrikareise-2016-aid-1.6318572_(07.11.2016).

43 Meyer: Flüchtlingskrise.

44 Vgl. Tull, Denis M.: Zeitenwende in der französischen Afrikapolitik, S. 2. Vgl. auch o.A.: Bundeswehr. Soldaten und „Tornados“ starten zum Syrien-Einsatz, in: Spiegel Online, 04.01.2016, http://www.spiegel.de/politik/ausland/bundeswehr-soldaten-und-tornadosstarten-zum-einsatz-in-syrien-a-1070451.html (22.03.2017). 
Betrachtet man die Situation aus heutiger Sicht, stellt man fest, dass die ,Flüchtlingskrise eine neue Herausforderung sichtbar gemacht hat. Auf ihr basiert die strategische Partnerschaft, auf der Deutschland eine nachhaltige und zukunftsorientierte Afrikapolitik ausbauen möchte. Die ,Flüchtlingskrise beruht auf der Tatsache, dass, wie Horst Köhler sagt, „krasse Armut und fehlende Bildung [... es möglich machen], dass der Islamismus bei jungen Menschen verfängt“45. Er mahnt: „Bildung, berufliche Perspektiven und Teilhabe für junge Menschen können dem Terror die Grundlage entziehen. Da müssen die Afrikaner, aber auch wir, viel mehr investieren" ${ }^{\text {"46. }}$. Mit anderen Worten sind die Zukunft Afrikas und Deutschlands aufs Engste miteinander verbunden und eine gegenseitige Unterstützung soll Europa vor einer ,Flüchtlingskrise" bewahren und in Afrika Frieden und Wachstum bringen. In diesem Zusammenhang strebt Deutschland mit Mali, Niger und Tschad eine sogenannte Migrationspartnerschaft an, in enger Kooperation mit Frankreich und Italien. Christoph Eisenring sieht diese Entwicklung jedoch mit Skepsis und weist darauf hin, dass ,,solche Entwicklungshilfe [...] besonders dem Geberland hilft, da die Flüchtlinge eher zum Bleiben animiert werden“"47. Der damalige Bundespräsident Köhler mahnt:

Wenn sich Afrika positiv entwickelt, profitiert Europa: Der Handel wächst, Arbeitsplätze entstehen, der Migrationsdruck geht zurück. Wenn der Kontinent aber im Chaos versinkt, dann wird das vor allem Europa riesige Probleme bereiten. Deshalb muss Afrika ein Kernthema europäischer Außenpolitik werden. Das ist eine historische Aufgabe, die Europa und der Westen viel zu lange vernachlässigt haben. ${ }^{48}$

\section{Frankophonie und Frankreichstrategie des Saarlandes}

Die Frankreichstrategie kann nur als Teil der gesamten deutschen Afrikapolitik betrachtet werden. Stand die Entwicklungszusammenarbeit bisher deutlich unter nationalem Privileg, wird sie nun immer mehr, in einer Zeit der Dezentralisierung, zu einem Schlüsselbereich der regionalen Politik. Die weltweiten Herausforderungen, denen die Welt heute gegenübersteht, wie z. B. die ,Flüchtlingskrise', der Klimawandel oder der Terrorismus, erfordern globale Partnerschaften; die Lösungen sind aber meistens lokal. Bezeichnend

45 Bröcker, Michael/Quadbeck, Eva: Horst Köhler im Interview. „Afrika ist eine historische Aufgabe“, in: RP Online, 07.10.2016, http://www.rp-online.de/politik/deutschland/horstkoehler-afrika-ist-eine-historische-aufgabe-aid-1.6312947 (08.12.2016).

46 Bröcker/Quadbeck: Horst Köhler im Interview.

47 Eisenring: Entwicklungshilfe hilft nicht viel, S. 13.

48 Bröcker/Quadbeck: Horst Köhler im Interview. 
dafür ist beispielsweise das Engagement des Saarlandes für die Fairtrade Initiative. Mit Saarbrücken als erster „Fairtrade Stadt Deutschlands“49 ist das Land ein wichtiger Akteur der Entwicklungszusammenarbeit geworden. In diesem Bereich arbeiten bereits Organisationen wie (I)ntact ${ }^{50}$, die sich mit afrikanischen Partnern gegen die Beschneidung in Westafrika engagiert, oder die Afrikanischen Filmtage, die seit 15 Jahren Regisseure und Filmexperten aus Afrika und Deutschland zusammenbringen. Auch die Universität des Saarlandes kann durch die vielen Partnerschaften mit frankophonen afrikanischen Universitäten (Libreville, Dakar, Dschang, etc.) dazu beitragen, dass Saarbrücken sich als Brücke zur frankophonen Welt profiliert. Alle Nachbarländer des Saarlandes (Luxemburg und Frankreich) sowie Belgien sind Mitglieder der OIF (Organisation Internationale de la Frankophonie). Denkbar wäre auch eine saarländische Mitgliedschaft als Beobachter, denn die OIF umfasst 75 Staaten und Regierungen und damit einen Sprachraum von etwa 890 Mio. Menschen. Wirtschaftlich gesehen machen die Länder der OIF etwa ein Zehntel der Weltbevölkerung aus. Sie haben einen Anteil von $19 \%$ am Welthandel und von $26 \%$ an internationalen Investitionen.

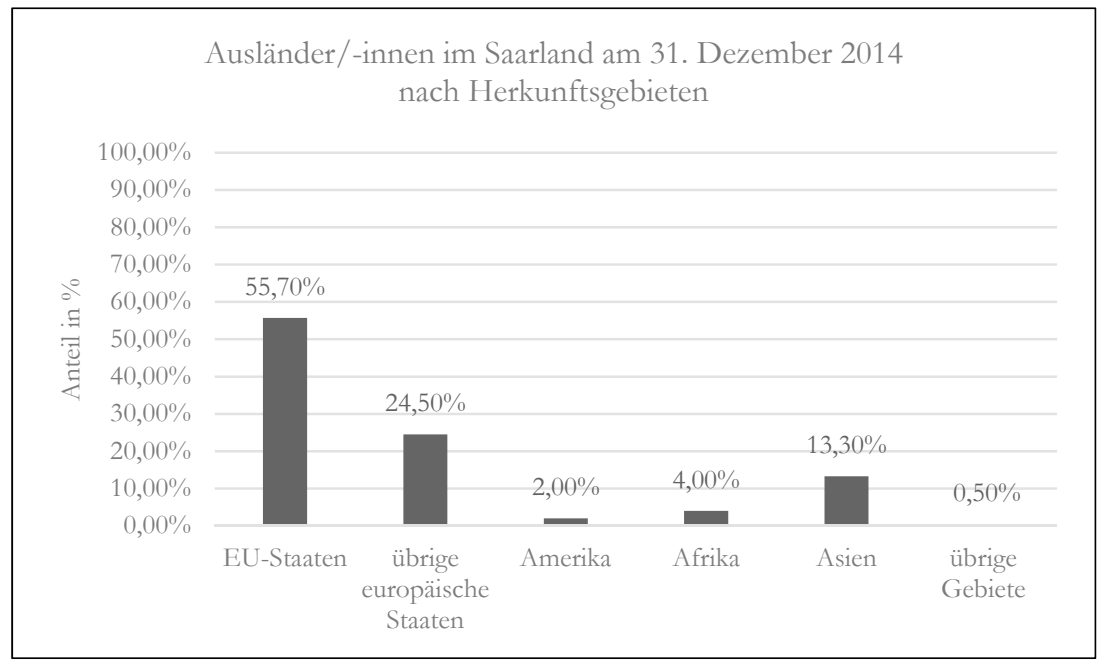

Abb. 1: Ausländer/-innen im Saarland am 31.12.2014 nach Herkunftsgebieten. ${ }^{51}$

49 Vgl. Fairtrade Initiative Saarbrücken: http://www.faires-saarbruecken.de/ (07.11.2016).

50 Vgl. (I)ntact e.V.: http://www.afroport.de/intact/ (07.11.2016).

51 Nach Statistisches Amt Saarland: Ausländer/-innen im Saarland am 31. Dezember 2014 nach Herkunftsgebieten, Stand: 14.09.2015, http://www.saarland.de/dokumente/thema_ statistik/AI4-J-Grafik_Internet.pdf (05.04.2017). 


\section{Fazit und Ausblick}

Frankreich spielt nach wie vor politisch, wirtschaftlich und kulturell eine besondere Rolle im frankophonen Afrika und bleibt der erste und wichtigste Partner im internationalen Geschäft. Aus französischer Sicht bedeutet eine Europäisierung der Afrikapolitik zugleich eine Chance und eine Gefahr, den eigenen politischen, wirtschaftlichen und kulturellen Einfluss zu verlieren. Deshalb verweisen Denis M. Tull und andere Experten auf das Eigengewicht Deutschlands in Europa und in der Welt und darauf, sich für einen Ausbau der Beziehungen und einen strategischen Dialog mit den frankophonen Ländern auszusprechen. Unabhängig von Frankreich oder als Ergänzung zur französischen Afrikapolitik sollte Deutschland eigene strategische Ziele formulieren und durchsetzen. Es ist von besonderer Bedeutung, dass Frankreich und Deutschland ihr gegenseitiges Vertrauen stärken und sich auf gemeinsame Prinzipien einigen. Die verstärkte Zusammenarbeit sollte sich auf die Förderung von demokratischen Strukturen und Menschenrechten, den Kampf gegen die Korruption, die Unterstützung der Zivilgesellschaft, sowie auf den Dialog über globale Fragen erstrecken. V. a. sollte Frankreich auf Dauer endgültig von der Idee des pré carré oder des Françafrique Abschied nehmen. Die neuesten politischen Entwicklungen in Frankreich und in Deutschland sprechen für eine Annäherung der beiden Länder auf politischer und militärischer Ebene (Mali, Niger). In der aktuellen Konfiguration könnte sich das Saarland durch die Frankreichstrategie als passeur de langue et de culture profilieren.

\section{Literaturverzeichnis}

Bley, Helmut: West German Politics Towards Africa since the Seventies, in: Kum'a Ndumbe III, Alexandre: L'Afrique et l'Allemagne. De la colonisation à la coopération 1884-1886 (Le cas du Cameroun), Yaoundé: Editions AfricAvenir, 1986, S. 380-390.

Bork, Timothy J.: Hilfe zur Selbsthilfe. Eine Bilanz westlicher Entwicklungspolitik, in: Afrika der vergessene Kontinent? 19. Sinclair-Gespräch (2003), S. 50-65.

Bröcker, Michael/Quadbeck, Eva: Horst Köhler im Interview. „Afrika ist eine historische Aufgabe“, in: RP Online, 07.10.2016, http://www.rp-online.de/politik/deutschland/horstkoehler-afrika-ist-eine-historische-aufgabe-aid-1.6312947 (08.12.2016).

Brüne, Stefan: Zwischen Grandeur und Afrikapessimismus. Frankreich Afrikapolitik im Zwiespalt, in: Der Überblick 3 (1990), S. 62-68.

Brüne, Stefan: Die französische Afrikapolitik. Hegemonialinteressen und Entwicklungsanspruch, BadenBaden: Nomos Verlagsgesellschaft, 1995.

Brunschwig, Henri: L'expansion allemande outre-mer. Du XVe siècle à nos jours, Paris: PU de France, 1957.

Brunschwig, Henri: Mythes et réalités de l'impérialisme colonial français (1871-1914), Paris: Colin, 1960.

Châtaigner, Jean-Marc: Zwischen Reform und Tradition: Die französische Afrikapolitik heute, Oktober 2006, S. 1-11, http://library.fes.de/pdf-files/iez/03982.pdf (04.11.2016). 
Deschamps, Hubert: Les méthodes et les doctrines coloniales de la France du XVTe siècle à nos jours, Paris : Colin, 1953.

Die Bundesregierung: Afrikapolitik der Bundesregierung. Verstärktes Engagement in Afrika, 21.05.2014, https://www.bundesregierung.de/Content/DE/Artikel/2014/05/2014-0520-verstaerktes-engagement-afrika.html (07.11.2016).

Eisenring, Christoph: Entwicklungshilfe hilft nicht viel. Viele Projekte werden positiv evaluiert, die Länder kommen dennoch nicht voran, in: Neue Zürcher Zeitung (NZZ), 07.12.2015, S. 13.

Fairtrade Initiative Saarbrücken: http://www.faires-saarbruecken.de/ (07.11.2016).

Grosser, Alfred: La politique extérieure de la Ve République, Paris: Editions du Seuil, 1965.

(I)ntact e.V.: http://www.afroport.de/intact/ (07.11.2016).

Internationale Politik und Gesellschaft: Deutsche Afrikapolitik: Uneinig und Inkobärent, 17.03.2014, http://www.ipg-journal.de/kolumne/artikel/deutsche-afrikapolitik-uneinig-und-inkohaerent317/ (07.11.2016).

Jakobeit, Cord: Die postkoloniale (Fehl-) Entwicklung Afrikas, in: Afrika - der vergessene Kontinent? 19. Sinclair-Gespräch (2003), S. 22-39.

Lebœuf, Aline/Quénot-Suarez, Hélène: La politique africaine de la France sous François Hollande. Renouvellement et impensé stratégique, Paris: Institut français des relations internationales (ifri), 2014.

Leroy-Beaulieu, Paul: De la colonisation chez les Peuples Modernes, Paris: Guillaume et Cie Libraires, 21882.

Löhr, Johanna: Frankreichs Afrikapolitik: Kontinuität und Wandel seit 1990, Trier: Univ. Diss., 2003. Lüsebrink, Hans-Jürgen: Die Niederlage als Trauma - L'Empire Colonial als Kompensation, in Grunewald, Michel/Schlobach, Jochen (Hg.): Médiations - Vermittlungen. Aspekte der deutschfranzösischen Beziebungen vom 17. Jabrhundert bis ₹ur Gegenwart, Frankfurt/M.: Peter Lang, 1992, S. $357-370$.

Mair, Stefan/Tull, Denis M.: Deutsche Afrikapolitik, in: SWP-Berlin 3 (2009), S. 1-47.

Marchesin, Philippe: Mitterand l'Africain, in: Politique africaine 6 (1995), S. 9.

Meyer, Sascha: Flüchtlingskrise. Merkels afrikanische Lehren, in: RP Online, 11.10.2016, http:// www.rp-online.de/politik/ausland/diese-lehren-zieht-angela-merkel-aus-der-afrika-reise2016-aid-1.6318572_(07.11.2016).

Mitterrand, François: Discours de la Baule, 20.06.1990, http://nsarchive.gwu.edu/NSAEBB/ NSAEBB461/docs/DOCUMENT\%203\%20-\%20French.pdf (21.03.2017).

o.A.: Bundeswehr. Soldaten und „Tornados“ starten zum Syrien-Einsatz, in: Spiegel Online, 04.01.2016, http://www.spiegel.de/politik/ausland/bundeswehr-soldaten-und-tornadosstarten-zum-einsatz-in-syrien-a-1070451.html (22.03.2017).

Pierson, Paul: Increasing returns. Path Dependence, and the Study of Politics, in: American Political Science Review 94/2 (06/2000), S. 251-267.

Randau, Robert: La Littérature coloniale, in: Le Temps Colonial, 1929, zit. nach Lüsebrink, HansJürgen: Die Niederlage als Trauma - L'Empire Colonial als Kompensation, in: Grunewald, Michel/Schlobach, Jochen (Hg.): Médiations - Vermittlungen. Aspekte der deutsch-französischen Beziehungen vom 17. Jabrbundert bis zur Gegenwart, Frankfurt/M.: Peter Lang, 1992, S. 357370.

République Française/Ministère de la Défense: Livre Blanc de la Défense, Paris: Édition des Livres blancs, 1994.

Riesz, János: Franz̧ösisch in Afrikea. Herrschaft durch Sprache, Frankfurt/M.: IKO Verlag, 1998.

Riesz, János: Koloniale Mythen - Afrikanische Antworten. Europäisch-afrikanische Literaturberiehungen, Frankfurt/M.: IKO Verlag, 22000 (Bd. 1). 
Statistisches Amt Saarland: Ausländer/-innen im Saarland am 31. Dezember 2014 nach Herkunftsgebieten, Stand: 14.09.2015, http://www.saarland.de/dokumente/thema_ statistik/AI4-J-Grafik_Internet.pdf (05.04.2017).

Thorel, Julien: Der schwierige Abschied von der „Françafrique“. Die französische Afrikapolitik zwischen Kontinuität und Wandel, in: Bundeszentrale für politische Bildung (Hg.): Dossier Frankereich, Bonn: Bundeszentrale für politische Bildung, 02.08.2013, http://www. bpb.de/internationales/europa/frankreich/166091/abschied-von-der-francafrique (05.11.2016).

Tull, Denis M.: Zeitenwende in der französischen Afrikapolitik, in: SWP-Berlin 44/10 (2005), S. 1-4. 

2. Berichte 

Workshop: Neue Energien. Energiezukunft an der Schnittstelle von Technik, Kultur und Gesellschaft (24.-25.09.2015) 



\section{Pour une formation doctorale transfrontalière et pluridisciplinaire - le service INTERDOC au Pôle France (Sarrebruck) se présente à l'occasion d'un atelier interdisciplinaire sur l'énergie ${ }^{1}$}

Das Frankereichzentrum initiiert und fördert grenzüberschreitende Aktivitäten in der Graduiertenausbildung. Von 2011-2016 unterstütəte das Koordinationsbüro INTERDOC die grenzüberschreitende Doktorandenausbildung in der Großregion. Das ehemalige Interreg IV-A GR-Projekt vermittelte Informationen zu fächerübergreifenden und fachbezogenen Angeboten der Graduiertenausbildung mit Frankreich- bzw. Frankophoniebezug an der Universität des Saarlandes sowie zur Orientierung auf dem deutschen und französischen Arbeitsmark.t. Darüber binaus stand das Frankreichzentrum als Ansprechpartner für Fragen zu diesem Bereich zur Verfügung und veranstaltete selbst Workshops für Doketoranden der Großregion. Ein Novum war 2015 die Durchfübrung eines zweitägigen interdisziplinären Doktoranden-Workshops zum Thema „Neue Energien. Energiezukunft an der Schnittstelle von Technik, Kultur und Gesellschaft". Im Folgenden wird auf die Erfahrungen und Perspektiven künftiger grenzüberschreitender Kooperationen in den Bereichen Graduiertenausbildung und Forschung eingegangen.

Le Pôle France soutient le lancement et la promotion d'activités transfrontalières dans le cadre de la formation doctorale. De 2011 à 2016, le Pôle France disposait du service de coordination INTERDOC pour promouvoir la formation doctorale transfrontalière dans la Grande Région. Le Pôle France pilotait de l'ancien projet Interreg IV-A GR, INTERDOC, de 2014 à 2016. ${ }^{2}$ Sa mission était de fournir des informations sur les offres pluridisciplinaires et spécifiques de la formation doctorale en lien avec la France proposées par l'Université de la Sarre, ainsi que sur les marchés de l'emploi français et allemand. Outre cela, le bureau INTERDOC lui-même proposait des manifestations et des ateliers pour doctorants.

1 Le Pôle France remercie l'Université de la Grande Région (UniGR) pour le précieux soutien de ce projet.

2 Voir Pôle France de l'Université de la Sarre : INTERDOC, http://www.uni-saarland.de/ $\mathrm{fr} /$ service/pole-france/formation-doctorale/interdoc.html (07.11.2016). 


\section{Genèse d'un atelier interdisciplinaire sur l'énergie}

Pourquoi cette thématique ? L’approvisionnement énergétique représente sur le plan économique et écologique l'un des grands défis mondiaux de l'avenir avec des conséquences considérables pour un grand nombre de développements sociaux. Avec des domaines porteurs tels que la technique d'entrainement, la science des matériaux et l'informatique, la recherche en sciences naturelles et en technologie dans la Grande Région peut largement contribuer à répondre à ces défis. Pourtant, dans le contexte interculturel de la Grande Région, il s'avère que la question des énergies nouvelles ne peut être envisagée d'un point de vue purement technologique. Les quatre Etats de la Grande Région proposent des voies tout à fait différentes pour aborder l'avenir énergétique. Certaines utopies sociales se heurtent au problème de la faisabilité technique et économique, et la recherche en sciences naturelles dépend, elle aussi, du contexte social ainsi que de paradigmes culturels. C'est sur ces réflexions que ce sujet, apte à être traité d'un point de vu interdisciplinaire intégrant les sciences 'dures' et les sciences 'humaines' -, a été choisi.

Née en 2014, l'idée d'organiser un atelier sur l'énergie a rapidement pris forme après une première rencontre en janvier 2015. Intitulé « Energies nouvelles. L'avenir énergétique entre technologie, culture et société », le projet a attiré l'attention de nombreux chercheurs de la Grande Région, issus surtout des sciences naturelles et techniques, mais aussi des sciences humaines, notamment de la géographie et de l'histoire. Une deuxième rencontre préparatoire en juin 2015 a servi à clarifier les détails de l'atelier. Outre le travail thématique, un objectif de l'atelier était également de faire vivre aux doctorants une expérience interdisciplinaire, interculturelle et plurilingue. Dans le cadre de l'atelier, les doctorants de la Grande Région entière étaient invités à se figurer leur projet de recherche dans un contexte plus large et à discuter avec des professeurs renommés de la région ainsi qu'avec d'autres jeunes chercheurs issus des sciences naturelles et techniques tout comme des sciences humaines et sociales. Il a été financé à but non lucratif par l'association Université de la Grande Région (UniGR) et le programme international pour les diplômés « GradUS global » (DAAD/SYCMA) de l’Université de la Sarre.

\section{L'atelier : thèmes abordés et résultats}

L'atelier comportait des sessions de travail intenses en petits groupes interdisciplinaires composés de cinq à six doctorants travaillant sur des sous-thématiques du thème général. Les six petits groupes étaient chacun supervisés par deux enseignants et traitaient des sujets suivants : «Energy generation, acceptance, and political power »; « Energy justice »; « Energy and resource efficiency »; « Energy distribution »; « Safety and security » et « Energy transitions ». 
La principale langue de travail était l'anglais, mais le français et l'allemand étaient également utilisés pendant les discussions. Le travail en petits groupes était complété par des sessions plénières qui commençaient par une introduction thématique du sujet par Eva Hauser, politologue et spécialiste des marchés énergétiques à l'Institut für ZukunftsEnergieSysteme (IZES gGmbH, Sarrebruck), ensuite il y avait une présentation des résultats des groupes de travail et pour conclure une discussion finale structurée et animée par la conférencière Eva Hauser.

\subsection{Introduction : «New Energies. The Future of Energy at the Interface of Technology, Culture, and Society » par Eva Hauser, IZES gGmbH ${ }^{3}$}

L'IZES est un institut de recherche interdisciplinaire fondé en 1999. Il traite depuis plus de 15 ans de la transition énergétique, de la protection et de l'utilisation efficace des ressources naturelles et de la protection du climat. Composé de cinq départements (« marchés de l'énergie », « gestion des ressources naturelles et espaces ruraux », «infrastructures et développement communal », « innovations techniques » et " psychologie environnementale »), l'IZES poursuit une approche interdisciplinaire et systémique. L'institut travaille sur des projets régionaux, nationaux, européens et parfois aussi avec des pays africains et asiatiques pour le compte d'institutions telles UN Habitat, etc. Dans ce cadre, l'IZES lie les questions de mise en œuvre de mesures pratiques avec les considérations scientifiques. Il prend aussi en compte les effets politiques, économiques, géographiques, naturels, technologiques et psychologiques des politiques et mesures examinées.

La conférence d'Eva Hauser a fourni les bases pour le travail en groupe : des principes tels que la composition du secteur de l'énergie, la transition énergétique, les défis technologiques, économiques et socio-politiques qui en résultent ont été expliqués. Comme son titre « New Energies. The Future of Energy at the Interface of Technology, Culture, and Society » le laisse supposer, cette conférence présente la transition énergétique en tant que projet de toute la société, la perspective technique seule s'avérant insuffisante pour résoudre les défis liés à cette tâche.

\subsection{Critères d'évaluation des mesures politiques pour la transition énergétique}

En premier lieu, la discussion s'est portée sur le 'triangle cible de la politique énergétique' avec ses trois piliers (la sécurité de l'approvisionnement, la durabilité et l'accessibilité). Malgré son utilisation courante par les médias et la politique, sa mise en œuvre s'avère difficile car les trois objectifs ne sont pas clairement définis. Faut-il comprendre par accessibilité que tout le monde 
pourrait disposer de l'énergie pour la gaspiller? Quelle est l'échelle temporelle sur laquelle on juge la 'sécurité d'approvisionnement' : est-ce exclusivement celle de notre génération ou aussi celle des générations suivantes ? Ces définitions manquantes pointent aussi le fait que l'on néglige bien souvent les conflits d'intérêts entre les trois objectifs.

C'est à ce titre qu'Eva Hauser propose plutôt de juger la politique énergétique selon les trois principales fonctions que le secteur de l'énergie doit remplir :

- Les infrastructures nécessaires: il s'agit d'abord de construire ces infrastructures qui comprennent d'un côté les réseaux et de l'autre les centrales de production. Au début, il faut les construire, ce qui veut dire qu'il faut les acteurs nécessaires qui ont besoin d'incitations financières suffisantes, mais aussi les connaissances et le personnel dédiés. Ensuite, il faut aussi savoir utiliser et maintenir ces infrastructures. En fin de vie, il est aussi important que ces installations soient correctement démantelées afin de ne pas nuire à l'environnement et afin de regagner le plus d'espace possible et que les matériaux utilisés soient recyclés.

- La sécurité d'approvisionnement: afin de mieux opérationnaliser ce terme, il faut regarder la dimension temporelle (court-terme et long-terme) ainsi que la disponibilité des réseaux et des centrales.

- Les critères sociaux (dans un sens large) de l'utilisation de l'énergie: cette classe de fonctions réunit les critères émanant d'un choix de la société et comprend donc également les critères environnementaux qui sont à l'origine de la transition énergétique. C'est d'abord l'utilisation rationnelle des ressources énergétiques et naturelles puis la réduction, voire même l'évitement des émissions nuisibles liées à notre consommation énergétique. Parmi ces émissions nuisibles, il faut citer les gaz à effet de serre responsables du réchauffement climatique de notre planète, sans oublier les autres nuisances comme les particules émises lors des processus de combustion ou les composés d'azote qui causent l'acidification et l'eutrophisation de nos eaux et sols. Les autres critères sociaux comprennent l'accessibilité à l'énergie, c'est-à-dire à des prix qui permettent à chacun de couvrir ses besoins ou à des mesures politiques dédiées à la création d'un accès égal aux énergies. Finalement, il y a la fonction d'établir une répartition juste de l'accès à l'énergie entre les différents pays et l'intergénérationnel, i. e. entre les générations actuelles et les générations futures.

Ayant élaboré les critères d'évaluation de la politique énergétique selon les fonctions que le secteur de l'énergie doit remplir, Eva Hauser explique la chaîne de valeur du secteur énergétique permettant de mieux appréhender les tâches techniques liées à la transition énergétique. Ce schéma a aussi servi à accompagner la discussion finale et à situer le travail de chaque groupe. 


\subsection{Les tâches techniques de la transition énergétique}

Pour expliquer simplement, il s'agit dans cette transition de remplacer de manière successive les énergies fossiles et l'énergie nucléaire par des énergies renouvelables dans chaque étape de la chaine de valeur de l'utilisation de l'énergie (voir figure 1).

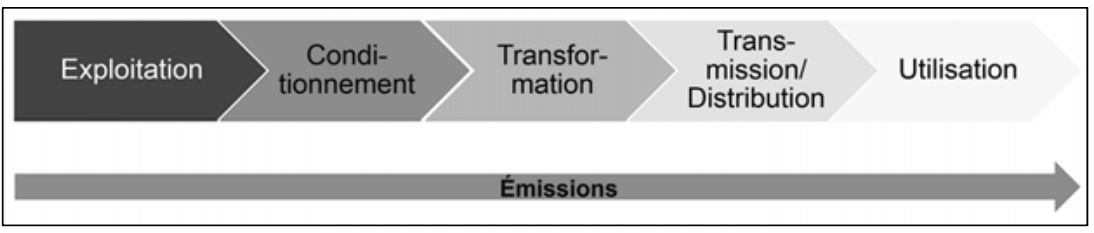

Fig. 1: La chaîne de valeur du secteur de l'énergie (illustration par Eva Hauser).

Ces étapes de la chaîne de valeur sont quasiment les mêmes pour tous les combustibles et pour les trois utilisations principales de l'énergie : l'électricité, la chaleur (et le froid) et la mobilité. En ce qui concerne les sources d'énergie renouvelables (et plus spécialement l'électricité éolienne et photovoltaïque), leur entrée dans la chaîne de valeur commence directement avec l'étape de transformation en énergie utile. Au début, il y a, pour tous les autres combustibles, les étapes d'exploitation ou d'extraction et du conditionnement du combustible afin qu'il puisse être transformé dans une centrale (ou dans un chauffage ou dans un moteur) en énergie utile. Puis il faut que cette énergie soit transmise à l'endroit où elle sera utilisée. Cette transmission peut se faire par le biais du réseau électrique, d'un réseau ou d'un conduit de chaleur ou dans le cas d'une voiture sur les roues. Ces processus sont la cause de multiples émissions qui peuvent nuire à l'environnement et à la santé des êtres humains et diminuer l'acceptation de ce type d'énergie.

C'est un type d'émission des processus de combustion, celui du dioxyde de carbone - le $\mathrm{CO}_{2}$ - qui est un des premiers responsables du réchauffement climatique de notre planète. Afin d'arrêter au mieux ce réchauffement et tous les dangers qui en émanent, la communauté internationale ainsi que l'Union Européenne et ses Etats membres (dont fait partie la Grande Région) ont mis en place des mesures concernant la transition énergétique et la réduction des émissions de $\mathrm{CO}_{2}$ liées à la production d'énergie.

\subsection{Les tâches économiques de la transition énergétique}

L'utilisation des énergies renouvelables est en passe de changer tout le système énergétique de nos pays : ceci est principalement dû au fait que ce seront les énergies dites 'variables' qui auront un rôle très important dans un futur système renouvelable. Cette variabilité est une des caractéristiques principales de ce 
type d'énergie : la quantité disponible à un instant donné de ces énergies comme l'énergie photovoltaïque et l'éolienne - n'est pas influençable par l'être humain car leur offre dépend exclusivement des conditions météorologiques. La quantité 'offerte' ne peut donc ni être augmentée ni diminuée comme c'est le cas pour les combustibles fossiles et nucléaires. Le seul choix qui en découle, c'est d'utiliser cette énergie ou non. C'est pour cette raison que ces énergies sont appelées 'variables'.

Or, elles possèdent une deuxième caractéristique principale : la quasi-absence de coûts marginaux. Cette donnée signifie un défi majeur pour le système énergétique tel que nous le connaissons actuellement: contrairement aux combustibles fossiles et nucléaires, il n'y a pas de coûts marginaux, i. e. les coûts sont directement liés à la production d'une unité d'énergie dans un moment donné. Comme il n'y a ni carburant, ni opérateur de centrales ni un coût direct lié à l'émission de $\mathrm{CO}_{2}$ sous forme d'un certificat d'émission, la production en elle-même d'une unité d'énergie éolienne ou solaire ne coûte rien. Les seuls coûts qu'une installation solaire ou éolienne produit sont les coûts de construction (ceux du financement et des bénéfices attendus inclus), les frais fixes et les éventuels frais de démantèlement. Si on compare les coûts pleins des différents types d'énergies (fossiles, nucléaire et renouvelables), on constate que les coûts des énergies renouvelables sont parfois déjà en dessous de ceux des énergies 'conventionnelles'. Si on incluait dans ce calcul aussi les coûts liés aux risques environnementaux (p. ex. le traitement des déchets, les émissions nuisibles) et technologiques (p. ex. les accidents), ce seraient les énergies renouvelables qui coûteraient le moins cher.

En outre, comme les marchés de l'énergie actuels sont basés sur les coûts marginaux, les nouveaux entrants dans ces marchés, les énergies renouvelables, y changent entièrement la donne. Le principe qui prévaut dans les marchés (et bourses) de gros de l'électricité est celui du uniform pricing. Cela veut dire que chaque offrant dépose son offre de production selon ses coûts variables, mais le prix retenu est pour chaque heure celui du dernier offrant encore nécessaire pour couvrir la demande. N'ayant pas de coûts marginaux, les énergies renouvelables se placent en avant de la merit order ${ }^{4}$ des sources d'énergie et mènent à une baisse des prix sur ces marchés. Cette baisse des prix est appelé 'l'effet merit order' des énergies renouvelables. Bien que présentant des avantages pour les acheteurs d'électricité et de manière indirecte aussi pour les consommateurs, ce développement est beaucoup moins favorable pour les producteurs d'électricité eux-mêmes, qu'il s'agisse de producteurs conventionnels ou renouvelables: quand il y a beaucoup d'électricité renouvelable sur le marché, les prix sont bas pour tout le monde, énergies renouvelables ou non. Selon les technologies et leurs coûts complets, ils ne permettent pas de 
gagner des marges (ou seulement peu) sur les coûts variables. Les seules centrales qui en sont peu concernées sont les centrales dont les coûts d'investissement sont déjà amortis. Quand l'offre des énergies variables est limitée, les prix augmentent ainsi que les marges. Par principe, ces prix profitent assez peu aux énergies renouvelables. Or, ces heures pendant lesquelles les prix sont bien au-dessus de la moyenne sont peu nombreuses et ne permettent pas non plus aux centrales de pointe (spécialement les centrales au gaz, émettant peu de $\mathrm{CO}_{2}$ ) de gagner suffisamment d'argent.

Au stade actuel de la transition énergétique, un refinancement des énergies renouvelables par les prix obtenus sur les marchés de l'électricité est peu probable. A ce titre, les mécanismes de refinancement (p. ex. les tarifs d'achat) sont alors nécessaires pour garantir le déploiement des énergies renouvelables. En ce qui concerne les centrales conventionnelles, il reste un déséquilibre entre les centrales déjà amorties et les installations récentes (bien souvent plus modernes et moins émettrices en $\mathrm{CO}_{2}$ ). Un moyen pertinent pour contrer ce déséquilibre serait de mettre hors service les centrales les plus anciennes et les plus dangereuses pour l'environnement.

\subsection{La transition énergétique : un enjeu pour toute la société}

La transition énergétique ne se limite pourtant pas à la résolution des problèmes techniques et économiques décrits ci-dessus. Elle nécessite des changements de comportements d'une multitude d'acteurs. La figure 2 illustre les défis économiques, techniques et sociaux de la transformation du système électrique :

D'un point de vue technique, il s'agit surtout du maintien de la stabilité du réseau électrique dans un sens large (voir le centre et les pétales pointus de la figure 2). En plus du maintien instantané de la stabilité du réseau, cela implique aussi la conservation ou le renouvellement des infrastructures du réseau qui sont étroitement liées à l'emplacement des installations de production d'électricité à base de sources variables. Devenant prépondérantes dans le système électrique futur, les énergies renouvelables doivent délivrer elles aussi ce que l'on appelle les 'services système', i. e. les services techniques nécessaires à la stabilité du réseau. Ceci comprend entre autres le réglage de fréquence, de puissance et de tension. Un autre défi consiste à gérer techniquement le couplage du système électrique avec les autres secteurs d'utilisation de l'énergie (mobilité et production de chaleur et de froid). Etant donné qu'ils se serviront aussi de l'électricité, il faut veiller à l'efficacité des appareils utilisés (p. ex. voitures économes ou pompes à chaleur installées dans des bâtiments aux standards énergétiques élevés) et à une utilisation dans les moments où la production renouvelable est suffisante afin de réellement contribuer à une baisse des émissions de $\mathrm{CO}_{2}$ et des nuisances écologiques. 


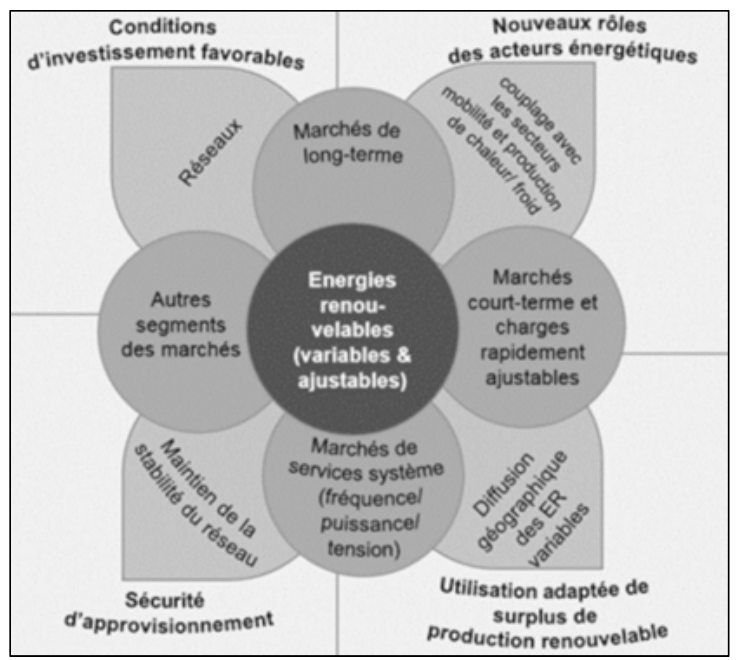

Fig. 2: Défis économiques, techniques et sociaux de la transformation du système électrique vers un système basé sur les énergies renouvelables (illustration par Eva Hauser).

D'un point de vue économique, c'est d'abord la question d'une refonte des marchés de l'électricité actuellement peu adaptés aux énergies variables sans coûts marginaux (voir les pétales ronds de la figure 2). Il faut que les énergies renouvelables soient intégrées dans les différents segments des marchés tout en veillant au refinancement correct de toutes les composantes nécessaires au futur système électrique. A ce jour, une simple intégration des énergies renouvelables dans les marchés avec leur configuration actuelle semble insuffisante pour résoudre les défis économiques. Il semble plutôt nécessaire de mettre hors service les centrales les plus anciennes et les plus polluantes afin de rééquilibrer les marchés et de faire progresser la lutte contre le changement climatique. Une mesure complémentaire consisterait à inclure correctement dans les prix des énergies les coûts des dommages environnementaux et des risques technologiques.

De plus, il y a de multiples défis de société qui émanent de la transition énergétique (voir l'arrière-plan de la figure 2). Ceux-ci concernent essentiellement tous les défis liés au caractère décentralisé des énergies renouvelables. Comme ces installations doivent être très nombreuses afin de pouvoir couvrir nos besoins en énergie, il faut de larges investissements financiers. Les énergies renouvelables nécessitent et permettent un grand engagement de la part des citoyens et des entreprises pour participer au financement de ces centrales. Il leur faut donc des conditions d'investissement favorables et plutôt simples afin de mobiliser leur capital. Pour ce nouveau système énergétique, il faut 
aussi de nouveaux rôles pour les acteurs énergétiques car les anciens rôles de producteur ou de consommateur se rapprocheront de plus en plus. Ceci est d'autant plus le cas quand il y aura des surplus de production d'énergies variables, i. e. une production plus grande que la demande. Tous ces nouveaux rôles doivent en fin de compte être conçus de manière à ce que la sécurité d'approvisionnement sur le court et le long terme ne soit pas mise en cause.

Finalement, il faut aussi veiller à ce que l'acceptation par la population de la transition énergétique soit maintenue car celle-ci changera aussi l'aspect de nos paysages et devra se faire dans toutes les régions européennes.

\section{Suite de l'atelier : travail en groupes}

Les participants ont ensuite continué à travailler en six petits groupes sur les thèmes mentionnés ci-dessus. Le premier groupe a traité le côté physique de la transition énergétique, les impacts environnementaux associés et le rôle du pouvoir politique et économique. Les participants ont discuté des avantages et des inconvénients de l'approvisionnement énergétique central versus décentralisé et ont comparé ensuite les conditions économiques, politiques et sociales de l'approvisionnement énergétique en France et en Allemagne à partir des années 1960 jusqu'à aujourd'hui. Par ailleurs, ils ont défini la notion de durabilité dans le secteur de l'énergie comme l'interaction entre l'efficacité, la suffisance et la cohérence. Le deuxième groupe a analysé l'accès à l'énergie et l'utilisation de l'énergie par des chiffes et a discuté des aspects tels que les conséquences d'un manque d'accès à l'énergie et l'impact négatif d'une consommation excessive de l'énergie. Ils ont présenté leurs résultats sous forme d'une petite pièce de théâtre. Le troisième groupe a parlé de l'efficacité des ressources en prenant en compte les intérêts économiques et politiques dans la conception et la sélection des matériaux ainsi que dans la durée de vie des produits. L'approche globale a révélé les conflits d'intérêts connus : bien qu'il soit tout à fait possible de développer par exemple des produits avec des cycles de vie plus longs, cela n'est souvent pas voulu en termes d'économie. Le quatrième groupe avait comme sujet les réseaux de distribution électrique intelligents dits smart-grids, incluant des technologies de stockage, l'électromobilité et les compteurs intelligents. Les participants se sont focalisés sur les avantages et les inconvénients de l'approvisionnement énergétique par des super-réseaux versus des micro-réseaux, concluant qu'un approvisionnement de l'Europe à $100 \%$ en énergie renouvelable pourrait probablement mieux être assuré sur la base de micro-réseaux. Le cinquième groupe a traité de la sécurité dans le secteur de l'énergie sur un niveau mondial et des risques spécifiques des diverses sources d'énergie (fossile, nucléaire, renouvelable), tels que le changement climatique, l'acidification des océans ou encore l'irradiation. Les participants ont également examiné les risques de l'approvisionnement en énergie et 
de la transition énergétique, en particulier dans les pays en développement. Ceux-ci manquent souvent de moyens financiers et technologiques pour un approvisionnement sûr en énergie; de même, ils connaissent des problèmes de gouvernance et de fonctionnement quant aux structures sociales. De ce fait, mêmes des énergies renouvelables telles que la biomasse et les biocarburants peuvent être un risque et conduire à la pollution, à la déforestation et à des risques graves pour la santé, comme cela est le cas au Tibet, en Inde et en Afrique. Ainsi, la question n'est pas de savoir s'il faut ou non, par exemple, développer davantage la biomasse, mais il s'agit plutôt d'un mix énergétique équilibré. Le sixième groupe a comparé les objectifs et les différentes possibilités de la transition énergétique en France et en Allemagne. Les participants ont présenté un aperçu historique de la production énergétique locale partant de la société agraire médiévale, basée sur l'énergie solaire, en passant par le tournant vers les combustibles fossiles - ce qui a permis un approvisionnement super-local en abondance - pour arriver à la transition aux énergies renouvelables d'aujourd'hui, qui, une nouvelle fois, est basée plutôt localement. Selon eux, la transition énergétique devrait, toutefois, s'effectuer sur un niveau mondial à cause des enjeux globaux du changement climatique. Eva Hauser a conclu l'atelier par un résumé ponctué des résultats des groupes de travail et par leur classement aux différents niveaux de la chaîne de valeur énergétique (exploitation, conditionnement, transformation/côté 'production', transformation/côté 'usage', nuisance).

\subsection{Evaluation et perspectives pour la coopération transfrontalière} (formation des doctorants et recherche en général)

Cet atelier interdisciplinaire pour doctorants était un projet pilote du Pôle France visant à tester le potentiel d'une telle offre et de futures coopérations interdisciplinaires et transfrontalières sur des thématiques importantes pour la société. L'approche interdisciplinaire a été très bien reçue par les participants et les enseignants. Les paragraphes concernant l'évaluation de l'atelier reprennent aussi bien des informations données oralement que sur les fiches de commentaires ainsi que des observations du comité organisateur.

\subsubsection{Aspects positifs}

La conférence de Eva Hauser ainsi que les présentations de chaque groupe et les débats en plénière ont donné une bonne vue d'ensemble sur le sujet. L'équilibre entre débats et travail en groupes était généralement apprécié, tout comme la taille de l'atelier et des groupes, même si certains étaient presque trop petits en raison d'annulations de dernière minute. Le concept d'un atelier interdisciplinaire avec des groupes de travail multidisciplinaires a permis des échanges scientifiques et académiques vifs et la comparaison des informations, 
méthodes et résultats des différentes disciplines. Par ailleurs, les chercheurs étrangers pouvaient se faire une idée du système universitaire allemand et de ses modes de fonctionnement. L'atelier n'a pas seulement fourni de nouveaux contacts, mais a également stimulé diverses idées et futurs projets entre collègues francophones et allemands. Le potentiel d'innovation de l'atelier s'est montré dans le caractère de réflexion ('think-tank') des discussions et des idées originales comme 'le calcul vite fait' du deuxième groupe (concernant l'utilisation de l'énergie en chiffres), ce qui a permis un regard neuf sur les problèmes de durabilité bien connus et a donné de l'inspiration pour leur propre recherche et enseignement.

\subsubsection{Aspects perfectibles}

Durant le déroulement des séances de travail en groupes, il s'est avéré que certains d'entre eux avaient en fait des difficultés à élaborer des résultats et à préparer leur présentation pour la séance plénière dans le temps attribué. Ils auraient donc eu évidemment besoin de thématiques plus focalisées - cellesci ayant été intentionnellement formulées largement - et d'instructions plus précises. Ce fait est peut-être dû aux différentes cultures disciplinaires - le travail autonome étant plus usuel dans les sciences sociales et humaines que dans les sciences dures - et nationales (plus d'interaction active dans la culture académique germanophone). Néanmoins, les participants ont apprécié cette manière de travailler. Plusieurs d'entre eux auraient même préféré avoir encore plus de temps pour discuter et interagir avec les intervenants, le tout en se concentrant sur un ou deux sujets principaux. Concernant les contenus des groupes de travail, certains groupes n'ont que partiellement traité les points essentiels de leur sujet : le premier groupe s'est largement concentré sur l'énergie nucléaire et son histoire, tout comme le sixième groupe sur les transitions d'énergie du passé. Le deuxième groupe n'a pas suffisamment traité le sujet de la justice en lien avec l'énergie parce qu'un des chargés de cours n'a pas pu assister au séminaire ; c'est pourquoi il n'a pas pu présenter son introduction dont le contenu a par la suite manqué pour le travail en groupe. En conclusion, les aspects historiques de la production d'énergie et l'énergie nucléaire ont absorbé trop de temps, au détriment des nouveaux concepts et des énergies nouvelles.

\subsection{Interdisciplinarité, communication interculturelle et langues}

Le concept interculturel de l'atelier a été jugé très positif et inspirant : selon les participants, il a contribué à élargir leur horizon, à stimuler leur propre recherche et il les a incités à s'exprimer face à des non-spécialistes. La possibilité, parfois même la nécessité, de communiquer en trois langues différentes a fait avancer la connaissance des langues étrangères et des termes techniques 
appropriés. L'interdisciplinarité et l'interculturalité étaient alors un atout important. L'atelier a été néanmoins dominé par les sciences dures et l'ingénierie. Dans ce sens, l'interdisciplinarité aurait pu être davantage appliquée. Les points de vue des sciences humaines et sociales sur ces questions ont été peu discutés et mis en avant. Par ailleurs, il manquait des conférenciers issus des sciences politiques et de l'IT ainsi que des juristes et des économistes. Outre les questions techniques, la réglementation juridique et l'économie sont essentielles pour, par exemple, des décisions sur les réseaux de distribution électrique.

Bien que les doctorants et chercheurs en sciences naturelles et en ingénierie se soient entendus du côté technique, certaines barrières linguistiques ont persisté et ont parfois ralenti la discussion. Quelques participants ne parlaient pas assez bien l'anglais pour suivre la trame de la discussion. Ce sont cependant des insuffisances auxquelles il faut faire face dans la vie professionnelle, soit lors de conférences scientifiques ou dans d'autres contextes. Offrir un groupe de travail exclusivement en français et un groupe exclusivement en allemand aurait été une solution temporaire pour mieux intégrer ceux avec moins de connaissances en anglais.

\subsection{Contribution au travail de recherche personnel des participants}

Puisqu'il a été défini au sens large, l'atelier a contribué d'une manière plutôt générale aux travaux de recherche des doctorants, par exemple, ils ont pu confronter leurs différentes perspectives sur le sujet des énergies nouvelles et de l'avenir énergétique entre technologie, culture et société. Outre l'obtention d'une bonne vue d'ensemble sur le sujet, l'atelier a permis aux participants d'approfondir leurs connaissances dans les domaines suivants: le secteur énergétique d'un point de vue politique et socio-économique ; la transition énergétique en France et en Allemagne; l'approvisionnement énergétique central versus décentralisé ; l'énergie et l'efficacité des ressources; les risques de l'industrie énergétique mondiale ; les possibilités de la distribution énergétique en Europe. L'atelier leur a également permis d'améliorer des compétences transversales telles que la communication interculturelle et générale, la présentation généralement compréhensible de sujets spécialisés et le travail en équipes interdisciplinaires et internationales dans une ou plusieurs langues étrangères. Ainsi, les participants ont mis en pratique des compétences incontournables dans le monde professionnel, soit dans la recherche, soit dans le secteur privé d'entreprises. L'atelier a aussi servi à l'apprentissage personnel et au réseautage. Les contacts établis lors de l'atelier ont entre autres contribué à recevoir des idées novatrices et des impulsions pour leur propre projet de recherche.

Côté réseautage, la coopération de scientifiques et d'ingénieurs d'une part et d'humanistes d'autre part a été particulièrement intéressante. Certains conférenciers venaient pour la première fois à l'Université de la Sarre, y compris 
ceux qui jusqu'à présent maintenaient peu de contacts de recherche avec l'Allemagne. Cela prouve que le pays voisin peut être loin, également en raison d'obstacles linguistiques. De nombreux enseignants-chercheurs ont exprimé l'espoir de continuer la coopération et d'explorer de nouveaux domaines de recherche. De premières initiatives ont déjà été lancées au cours de l'atelier. Lors d'une rencontre d'évaluation en décembre 2015, les enseignants participants se sont prononcés clairement en faveur d'un nouvel atelier interdisciplinaire (et non pas plus fortement disciplinaire) et d'une coopération future dans le cadre de projets de recherches ou structurels de l'Union Européenne. Grâce aux contacts établis autour de l'atelier, un projet INTERREG V-A Grande Région sur l'efficacité de ressources dans des bâtiments avec la participation de l'Université Technique de Kaiserslautern (Prof. Wolfram Wellßow), du Campus environnemental d'Arlon/Université de Liège (Prof. Philippe André), de l'IUT Longwy/Université de Lorraine (Prof. Mohammed El Ganaoui) et de l'IZES sera déposé en 2016. Une telle coopération future est d'ailleurs en ligne avec la 'Stratégie Allemagne' de la Lorraine (priorités 'énergie écologique/technologies environnementales' et 'science des matériaux' dans les secteurs 'économie/emploi/recherche et technologie') et avec les domainesphares de l'Université de la Grande Région (UniGR) «Border Studies » et «Science des matériaux et utilisation rationnelle des ressources ».

Malgré le succès de l'atelier pilote, le projet INTERDOC ne sera pas poursuivi comme tel pour des raisons de restructuration du Pôle France, mais il sera intégré dans le nouveau domaine «Zukunftsthemen im Dialog » et continuera sous cette forme à nourrir la coopération transfrontalière dans la recherche. 

Veranstaltungsreihe: Exil und Migration von Frauen (Sommersemester 2016) 



\section{Exil und Migration von Frauen}

Rückblick auf eine Veranstaltungsreihe im Sommersemester 2016

Es bedarf wohl keiner weiteren Begründung, weshalb es sinnvoll und notwendig erscheint, sich derzeit mit dem Thema Migration zu beschäftigen: Abgesehen davon, dass der Anteil der Menschen ,mit Migrationshintergrund seit Jahren kontinuierlich ansteigt, stellt die Flucht und Aufnahme der zahlreichen Flüchtlinge und Migranten nicht nur Deutschland sondern Europa insgesamt vor eine große gesamtgesellschaftliche Herausforderung. Frankreich, das zu Beginn des 20. Jahrhunderts bereits ein bedeutendes Einwanderungsland war und aufgrund seiner Kolonialvergangenheit seit den 1950er Jahren eine Vielzahl von Migranten aufgenommen hat, erlebt gerade die dramatischen Auswirkungen seiner fehlgeschlagenen Integrationspolitik.

Die Veranstaltungsreihe zum Thema Exil und Migration von Frauen - eine deutsch-französische Perspektive, die vom Frankreichzentrum und der Fachrichtung Romanistik der Universität des Saarlandes in Kooperation mit der Landeshauptstadt Saarbrücken und dem Institut français Saarbrücken im Sommersemester 2016 durchgeführt wurde, hatte zum Ziel, diese aktuelle gesellschaftliche Entwicklung aus wissenschaftlicher und künstlerischer Sicht zu beleuchten. Zentrales Anliegen war es, die Spezifik der Ursachen der Migration von Frauen, deren Fluchterfahrungen und ihre Lebenssituationen in den Blick zu nehmen. Außerdem sollten die unterschiedlichen Auswirkungen von Migration auf Männer und Frauen bei der Analyse berücksichtigt und mögliche Gemeinsamkeiten und/oder Unterschiede in der Migrationspolitik von Frankreich und Deutschland herausgearbeitet werden. Der dabei zugrunde gelegte interdisziplinäre Ansatz, bei dem historische, politische und soziale Faktoren ebenso betrachtet wurden wie die Wahrnehmung und Deutung der Realität in den Medien Literatur und Film, boten eine multifaktorielle, differenzierte Sicht auf das komplexe Thema.

Im Jahr 2013 haben insgesamt 111 Millionen Frauen ihr Heimatland verlassen. Sie repräsentieren damit 48 \% der Migranten in der Welt. In Frankreich sind inzwischen mehr als die Hälfte der Migranten Frauen. Man spricht auch von einer ,Feminisierung der Migration ${ }^{1}$. Für Frauen bedeutet die erzwungene Mobilität häufig eine genderspezifische Gewalterfahrung; sie eröffnet teilweise aber gleichzeitig auch die Möglichkeit für neue Lebensperspektiven

1 Vgl. Beauchemin, Cris/Borrel, Catherine/Régnard, Corinne: Les immigrés en France: en majorité des femmes, in: Populations et sociétés 502 (2013), S. 1-4, hier S. 1. 
jenseits von Rollenklischees. Migranten, das sind Menschen, d. h. Männer und Frauen, die in einem bestimmten Verhältnis zueinander stehen. Die Geschlechterordnung, d. h. die Vorstellungen über das, was Mann und Frau ausmacht, ist historisch geworden und kulturell geprägt und wird immer wieder neu ausgehandelt. Gleichberechtigung ist etwas, was in allen Gesellschaften dieser Erde erkämpft werden muss. Doch diese Feststellung sollte nicht den Blick dafür verstellen, dass es Unterschiede gibt und dass in verschiedenen Ländern und Regionen dieser Erde noch sehr patriarchale, traditionelle Vorstellungen vom Platz der Männer und Frauen, ihrer Rolle und Wertigkeit bestehen. Davor die Augen zu verschließen und dies als ,essenziellen', d. h. wesenhaften Teil der Kultur der Migranten anzusehen und zu tolerieren, bedeutet sowohl die eigenen Werte zu verraten als auch das Gegenüber auf eine vermeintliche, ein für alle Mal gegebene kulturelle Identität zu fixieren, ihm jegliche Wandlungs- und Entwicklungsfähigkeit abzusprechen. Kulturelle Identität ist ebenso wie die Geschlechterordnung eine Konstruktion, etwas von Menschen Gemachtes, das veränderbar ist. Zur Entwicklung der westlichen Gesellschaften gehört die Forderung nach individueller Freiheit und Gleichberechtigung. Dass diese auch in Europa noch nicht im gewünschten und angestrebten Sinn erreicht ist, sollte kein Argument dafür sein, diese Zielsetzung nicht auch von Anderen, den Migranten zu fordern. Zunächst gilt es überhaupt erst einmal eine Sensibilität dafür zu schaffen, dass Migration - wie alle anderen Lebensbereiche auch - durch die Geschlechterordnung geprägt und bestimmt ist.

Genau dies war die Zielsetzung der Veranstaltungsreihe, die am 18. Mai 2016 im Rathaus der Stadt Saarbrücken mit einem Vortrag und einer von der Gender- und Gleichstellungsbeauftragten der Evangelischen Kirche im Rheinland konzipierten Ausstellung mit dem Titel „Frauen in der Migration Wege in die Gefahr?" eröffnet wurde. Prof. Sabine Liebig vom Institut für transdisziplinäre Sozialwissenschaft der Pädagogischen Hochschule Karlsruhe zeigte in ihrem - in diesem Band abgedruckten - Beitrag zu „Flucht und Migration von Frauen aus Genderperspektive: ein Perspektivwechsel“, welche spezifischen Erkenntnisse sich im Hinblick auf Migration bei der Berücksichtigung der Genderperspektive ergeben. ${ }^{2}$ Auch wenn Frauen schon immer migrierten - selbstständig oder im Familienverband, als Mitreisende oder Versorgerinnen - wurden sie lange in der Migrationsforschung einfach nicht beachtet, weil der Blick der Forscher auf den männlichen Migranten lag. Diese Perspektive hat sich inzwischen verändert. Der spezifische Fokus auf

2 Die Veranstaltung stand in Verbindung mit der Vortragsreihe Migration \& Flüchtlingsfrage: grenz(en)überschreitende und interdisziplinäre Perspektiven einer europäischen Herausforderung, die von der Universität der Großregion durchgeführt wurde. Der Vortrag konnte per Videoübertragung an den beteiligten Universitäten der Großregion verfolgt werden und ist auf der Seite der Großregion dokumentiert. Universität der Großregion: Perspektivwechsel: Flucht und Migration von Frauen, http://www.uni-gr.eu/index.php?id=591 (25.10.2016). 
Migrantinnen hat neue Forschungs- und Reflexionsperspektiven erschlossen und den Blick auf das Phänomen Migration insgesamt erheblich erweitert. Frauen mit Migrationshintergrund müssen in ihrem Leben vielfältige Probleme bewältigen, die sie mit anderen Frauen mit ähnlichem Bildungsstand und sozialökonomischer Situation teilen. Sie unterliegen Mehrfachbelastungen, wie Erwerbstätigkeit, Haus-, Erziehungs- und Pflegearbeit. Gravierend sind Arbeitslosigkeit, Armut, Gewalterfahrungen, Einschränkungen durch Erkrankungen oder Alter. Ausschlaggebend für positive Entwicklungen sind persönliche Ressourcen wie Lernfähigkeit, Flexibilität sowie Unterstützungsnetze. Ein Migrationshintergrund wirkt verschärfend, wenn Diskriminierungen nicht nur der Frau, sondern auch der Fremden gelten, Integrationsdefizite mangelnde Deutschkenntnisse und eingeschränkte Kontaktmöglichkeiten bedeuten oder Zugangsbarrieren zu Beratungsstellen dringende Hilfe verwehren. Existenzielle Auswirkungen auf Frauen hat ein unsicherer oder fehlender Aufenthaltsstatus, der Zukunftsplanungen verhindert und sie angreif- oder erpressbar macht.

Der Vortrag von Sabine Liebig wurde durch die Performance Migrantes von Claire Audhuy ${ }^{3}$ und der Theatergruppe Rodéo d'Ame aus Straßburg am 15. Juni in eindrücklicher Weise konkretisiert und bestätigt. Das Stück basiert auf Erzählungen von Migrantinnen, die Claire Audhuy in Genf in einem Zentrum für Migrantinnen und ihre Kinder traf und interviewte. Die von Audhuy bearbeiteten und in eine poetische Sprache gefassten Berichte von insgesamt acht Frauen aus Afghanistan, dem Irak, Bosnien, Somalia, Guinea und Liberia wurden von ihr vorgelesen. Parallel dazu setzte ein Zeichner, Nicolas Lefevbre, diese in bildnerische Kommentare um, die an die Wand projiziert wurden. Zwei Musiker, Lamine Gueye und Alexandrine Guedron, lieferten begleitend einen sonoren Hintergrund. Auf diese Weise entstand ein synästhetischer Klang- und Bildteppich, der eine große Intensität erzeugte und damit den Erzählungen einen besonders nachhaltigen Eindruck verschaffte.

Der am 22. Juni im Kino 8 1/2 gezeigte Film Fatima (2015) des renommierten französischen Filmemachers Philippe Faucon behandelt die Spezifik weiblicher Migration am Beispiel einer alleinerziehenden Migrantin aus dem Maghreb. Philippe Faucon, dessen Film in Frankreich ein großer Erfolg war, thematisiert in all seinen Filmen kritische Aspekte der durch Kolonialisierung und Migration geprägten französischen Gesellschaft. In seinem Film Samia (Philippe Faucon, 2000), der auf der autobiographischen Erzählung von Soraya Nini Ils disent que je suis une beurettet aus dem Jahr 1993 beruht, nimmt er die spezifische Situation junger maghrebinischer Frauen in den französischen Vorstädten unter die Lupe; in La Trabison (Philippe Faucon, 2005)

3 Die Performance basiert auf folgender Publikation: Audhuy, Claire/Lefebvre, Nicolas: Les migrantes, Straßburg: Rodéo d'âme, 2016.

4 Nini, Soraya: Ils disent que je suis une beurette, Paris: Fixot, 1993. 
thematisiert er das schwierige Verhältnis zwischen französischen Soldaten und ihren algerischen Mitstreitern, den barkis während des Algerienkriegs und in La Désintégration (Philippe Faucon, 2012) analysiert er die Hintergründe und Mechanismen der Radikalisierung junger Männer aus den banlieues. Philippe Faucon registriert wie ein Seismograph die Erschütterungen der Migrationsgesellschaft und setzt seine Beobachtungen in seinen Filmen ästhetisch und formal schnörkellos in Szene. Mit seinem letzten Film Fatima liefert er ein eindrückliches und zugleich liebevolles Porträt der weithin unsichtbaren Migrantinnen, eine Hommage der ,Heldinnen des Alltags', oftmals alleinerziehende Mütter, die sich mit schlechtbezahlten Jobs durchschlagen und isoliert in einem fremden Land wiederfinden. Der Film beruht auf den autobiographischen Aufzeichnungen von Fatima Elayoubi ${ }^{5}$, die mit ihrem Mann als Analphabetin nach Frankreich kam und sich als Putzfrau durchschlägt. Der außergewöhnliche literarische Text dokumentiert die kontinuierliche Sprachaneignung und klarsichtige Selbstreflexion dieser Frau, die sich ihres Lebens und ihrer selbst zunehmend bewusst wird. Der Film war bei der Quinzaine des Réalisateurs in Cannes im letzten Jahr ein großer Erfolg und erhielt 2016 den César, die höchste Auszeichnung in Frankreich, für den besten französischen Film. Er zeichnet sich durch große Nüchternheit und eine auf das Wesentliche reduzierte filmische Sprache aus. Die Hauptdarstellerin, Sonia Zeroual, die Faucon im Rahmen eines über zweijährigen Prozesses aus 700 Kandidatinnen ausgewählt hat, ist eine Laienschauspielerin, die durch ihre Natürlichkeit überzeugt. Philippe Faucon, der aufgrund seiner sozialkritischen und naturalistischen Filme auch als der französische Ken Loach bezeichnet wird, hat die Textvorlage in überzeugender Weise verfilmt. Wie bereits mit seinen anderen Filmen, hat er damit ein bis dahin im französischen Kino unterrepräsentiertes Thema - in diesem Fall die weibliche Seite der Migration ins allgemeine Bewusstsein gerückt.

Abgeschlossen wurde die Reihe am 29. Juni mit einem Vortrag von Prof. Susanne Gehrmann vom Institut für Afrikawissenschaft der Humboldt-Universität Berlin zu „Neue[n] literarische[n] Perspektiven auf Migration im Werk der franko-senegalesischen Autorin Fatou Diome“, der ebenfalls im Folgenden abgedruckt ist. Auch in ihrem Vortrag wurde die Ambivalenz von Migration deutlich, die neben allen Schwierigkeiten - insbesondere für Frauen oder gesellschaftlich Ausgegrenzte - immer auch Chancen bereithält. Wie Susanne Gehrmann zeigt, gelingt es der wortgewandten Autorin Fatou Diome mit Ironie und Sprachgewalt neue Aspekte in die sogenannte Migrationsliteratur einzubringen. In ihren Romanen und Kurzgeschichten agiert eine selbstbewusste, intellektuelle afrikanische Frau als Gegenfigur zu den in anderen Texten häufig thematisierten bemitleidungswerten Armutsflüchtlingen. Damit

5 Vgl. Elayoubi, Fatima: Prière à la lune, Paris: Bachari, 2006 und Elayoubi, Fatima: Enfin, je peux marcher seule, Paris: Bachari, 2001. 
bringt Fatou Diome ein neues und unerwartetes Element in diese Literatur ein. Außerdem beschreibt sie als eine der wenigen Autorinnen die Zurückgebliebenen im Herkunftsland in Afrika, für deren Schicksal man sich bisher wenig interessiert hat. Und schließlich gibt sie den Männern eine Stimme, die sich den herkömmlichen Mustern und Geschlechterrollen entziehen: Sei es, dass sie homosexuell oder transsexuell sind, oder sich nicht den vorherrschenden Vorstellungen, von dem was als ,männlich' gilt, unterwerfen.

Aus den unterschiedlichen Betrachtungen und Annäherungen im Rahmen der Veranstaltungsreihe in historischer, soziologischer, literarischer und filmischer Sicht ergab sich schließlich ein komplexes und vielschichtiges Bild von Migration aus einer gendersensiblen Perspektive.

Dass diese Veranstaltung in dieser Form möglich war, ist der Unterstützung und dem Engagement der verschiedenen Kooperationspartner zu verdanken. Ihnen wie allen Mitwirkenden möchte ich an dieser Stelle meinen Dank ausdrücken.

\section{Literaturverzeichnis}

Audhuy, Claire/Lefebvre, Nicolas: Les migrantes, Straßburg: Rodéo d'âme, 2016.

Beauchemin, Cris/Borrel, Catherine/Régnard, Corinne: Les immigrés en France: en majorité des femmes, in: Populations et sociétés 502 (2013), S. 1-4.

Elayoubi, Fatima: Enfin, je peux marcher seule, Paris: Bachari, 2001.

Elayoubi, Fatima: Prière à la lune, Paris: Bachari, 2006.

Faucon, Philippe: Samia, Frankreich, 2000.

Faucon, Philippe: La Trahision, Frankreich, 2005.

Faucon, Philippe: La Désintégration, Frankreich, 2012.

Faucon, Philippe: Fatima, Frankreich, 2015.

Nini, Soraya: Ils disent que je suis une beurette, Paris: Fixot, 1993.

Universität der Großregion: Perspektivwechsel: Flucht und Migration von Frauen, http://www.unigr.eu/index.php?id=591 (25.10.2016). 



\section{Flucht und Migration von Frauen aus Genderperspektive Ein Perspektivwechsel}

La catégorie du genre dans le contexte intersectionnel a facilité et enrichi les études sociobistoriques sur la migration en leur apportant de nouveaux points de vue. A cela s'ajoutent les approches interdisciplinaires ainsi que l'observation des mouvements migratoires extraeuropéens.

De tout temps, des femmes ont migré, et cela souvent de manière autonome. Il existe des formes spécifiques de migration féminine. De ce fait, il ne suffit pas d'analyser la migration des femmes dans une perspective masculine. Lorsqu'on étudie la migration des femmes, on observe des tendances contraires selon le point de vue adopté, qu'il soit général ou individuel: les tendances observées sur la société dans son ensemble ne se recoupent pas forcément avec les expériences variées vécues par l'individu. Ainsi, il n'est pas toujours possible de trouver un dénominateur commun au vécu personnel de chacune de ces migrantes. La catégorie du genre permet de centrer les réflexions sur la vision des migrantes concernées.

Die systematische Verwendung der Kategorie ,Geschlecht ${ }^{`}$ in der Migrationsforschung macht deutlich, warum eine solche Betrachtung sinnvoll ist. Bis in die 1990er Jahre war die Migrationsforschung männlich dominiert und richtete ihren Fokus, v. a. bei der Arbeitsmigration, auf die Männer. ${ }^{1}$

\section{Entwicklung der Forschung}

Nachdem Wissenschaftlerinnen bereits Anfang der 1980er Jahre kritisiert hatten, dass Frauen als eigene Gruppe in der Migrationsforschung vernachlässigt bzw. ausgeblendet wurden, forderten sie in den 1990er Jahren, neben den Kategorien ,Klasse“ und ,Ethnizität‘ auch die Kategorie des ,Geschlechts in den Blick zu nehmen.

Gerade die Genderforscherinnen brachten hier die Migrationsforschung weiter. Sie lenkten den Blick besonders auf die weibliche Arbeitsmigration ${ }^{2}$ und untersuchten die Migration von Frauen v. a. ab der Frühen Neuzeit.

Die ersten Impulse kamen aus der angelsächsischen feministischen Forschung, zum Thema Arbeitsmigration von Frauen unter dem Aspekt labour

1 Vgl. Hahn, Silvia: Historische Migrationsforschung, Frankfurt/New York: Campus, 2012, S. 8.

2 Vgl. Hahn: Historische Migrationsforschung, S. 57. 
and familiy history, ${ }^{3}$ im Rahmen der seit den 1970er Jahren aufkommenden Alltagsgeschichte. Der Fokus ging weg von den makrohistorisch-strukturellen Ansätzen hin zu mikrohistorischen Betrachtungen, sodass bei Einwanderungsgruppen ihre Familien- und Haushaltskonstellationen, ihre ethnischen und familiären Netzwerke in den Blick rückten. ${ }^{4}$

Statt struktureller Forschungsmethoden wurden qualitative Methoden in Form von individuell-biographischem Quellenmaterial, meist Oral-HistoryInterviews, verwendet, weshalb der Schwerpunkt der Forschung vorwiegend auf dem 20. Jahrhundert lag. Diese Methode bietet den Vorteil, dass detailliert Auskunft über die individuellen Beweggründe, Ausgangssituationen und Migrationsformen gewonnen werden kann. ${ }^{5}$

Interdisziplinarität spielt in der feministischen Migrationsforschung eine wichtige Rolle, d. h. Migration wird aus dem Blickwinkel verschiedener Disziplinen (Geschichte, Soziologie, Ökonomie, Politik, Erziehungswissenschaft) betrachtet und die gewonnenen Ergebnisse werden miteinander verknüpft. Am Beispiel der „Transnational Motherhood“ ist zu sehen, wie wichtig die Zusammenarbeit der unterschiedlichen Disziplinen ist, ${ }^{6}$ denn nur so können die sozialen, kulturellen, politischen und wirtschaftlichen Konzepte der Mutterschaft dargestellt werden. ${ }^{7}$

Intersektionalität ist ein weiterer Ansatz. Kategorien wie ,Geschlecht', ,Rasse/Ethnie', ,Schichtzugehörigkeit/Klasse ${ }^{6}$ aber auch ,Alter', ,Bildung', ,Arbeit', ,Herkunft', ,Sexualität ${ }^{\circ}$ sowie ,Sesshaftigkeit' und ihre Wechselwirkungen müssen exakt betrachtet und zusammen gedacht werden, um den Blick zu weiten. Die Berücksichtigung der verschiedenen Kategorien sind wichtige Kriterien für die Darstellung von Ungleichheit, gerade im Kontext der Migration.

3 Siehe auch Yans-McLaughlin, Virginia (Hg.): Immigration Reconsidered, New York/Oxford: Oxford University Press, 1990; Gabaccia, Donna R.: From Sicily to Elizabeth Street, Albany: State University New York Press, 1983; Jacobsen, Grethe: Female Migration and the Late Medieval Town, in: Gerhard, Jarik/Müller, Albertz (Hg.): Migration in der Fendalgesellschaft, Frankfurt/New York: Campus, 1988, S. 43-55.

4 Siehe auch Lamphere, Louise: From Working Daughters to Working Mothers: Immigrant Women in a New England Industrial Community, Ithaca: Cornell University Press, 1987; Tilly, Charles: Transplantet Networks, in: Yans-McLaughlin (Hg.): Immigration Reconsidered, S. 79-95; Vecoli, Rudolph J./Sinke, Suzanne M. (Hg.): A Century of European Migrations, 1830-1930, Illinois: University of Illinois Press, 1991.

5 Vgl. Hahn: Historische Migrationsforschung, S. 58.

6 Vgl. Hahn: Historische Migrationsforschung, S. 59; Millman, Heather L.: Mothering from Afar: Conceptualizing Transnational Motherhood, 2013, (20.10.2016).

7 Vgl. Millman, Heather L.: Mothering from Afar.

8 Vgl. Winkler, Gabriele/Degele, Nina: Intersektionalität als Mehrebenenanalyse, 01.11.2007, http://www.feministisches-institut.de/intersektionalitaet/ (18.07.2016). 
In Deutschland waren die Migrantinnen wichtige Impulsgeberinnen ${ }^{9}$, da sie mit ihrer Kritik am weißen, westlichen Feminismus zum Nachdenken und zum Perspektivwechsel anregten. Eine der ersten Wissenschaftlerinnen, die Gender und Migration im deutschsprachigen Raum zusammenbrachte, war Christiane Harzig, die sich auf den deutschen und US-amerikanischen Raum konzentrierte. ${ }^{10}$

Die Feminisierung von Migration wird betont, weil über $50 \%$ der Migranten weiblich sind. ${ }^{11}$ Frauen sind zum großen Teil die alleinigen Ernährerinnen ihrer Familien und migrieren eben nicht mehr im Gefolge ihrer Männer, ${ }^{12}$ was nur deshalb so schien, weil die Forschung die falschen Fragen gestellt hatte. Selbst 1999 fand eine Expertengruppe der UNO heraus, dass Frauen in vielen Statistiken immer noch als sogenannte ,associational“, also Mitreisende und passive Migranten geführt wurden. ${ }^{13}$ Fakt ist, Frauen wanderten schon immer. Dies zeigen Hoerder/Kaur in ihren Arbeiten anhand der Veränderung von Geschlechterverhältnissen (d. h. jeweiliger Anteil von Männern und Frauen an Migration) im Laufe der Zeit auf. Bei der europäischen transatlantischen Migration von Weißen im 19. Jahrhundert lag das Verhältnis bei 60 Männern zu 40 Frauen, nach 1930 bei 50 zu 50; die transatlantische schwarze Migration lag bei $67 \mathrm{zu} 33$. Im Rahmen der chinesischen Migration nach Malaysia veränderte sich das Geschlechterverhältnis von zunächst 70 Männern zu 30 Frauen Anfang der 1880er Jahre auf 43 zu 57 um 1938, weil die Einwanderung männlicher Chinesen durch Quoten reguliert wurde, die der Frauen aber nicht. ${ }^{14}$

Hoerder/Kaur weisen durch globale Studien nach, dass nicht erst heute von einer Feminisierung der Migration gesprochen werden kann. ${ }^{15}$ Der Perspektivwechsel ist also notwendig, um weiterführende Erkenntnisse zu gewinnen und mit Vorurteilen aufzuräumen.

Im Folgenden wird am Beispiel einiger Fragestellungen gezeigt, welche Ergebnisse Migrationsforschung aus Genderperspektive gewinnt.

9 Nach Walgenbach, Katharina: Intersektionalität - eine Einführung, 2012, http://portalintersektionalitaet.de/theoriebildung/ueberblickstexte/walgenbach-einfuehrung/ (18.07.2016).

10 Vgl. Hahn: Historische Migrationsforschung, S. 65 und S. 68.

11 UNDESA/OECD United Nations. Department of Economic and Social Affairs/Organisation for Economic Co-operation and Development: World Migration in Figures, 2013, http://www.oecd.org/els/mig/World-Migration-in-Figures.pdf (1991, 1995, 1997, 2001 (global domestic servants) und 2006 (Migration als Erinnerungskultur)) (18.07.2016).

12 Vgl. Rohr, Elisabeth: Frauen auf der Flucht, in: Rohr, Elisabeth/Jansen, Mechthild M. (Hg.): Grenægängerinnen. Frauen auf der Flucht, im Exil und in der Migration, Gießen: Psychosozial Verlag, 2002, S. 11-38, hier S. 25.

13 Vgl. Hoerder, Dirk/Kaur, Amarjit: Proletarian and Gendered Mass Migrations, Leiden: Brill Verlag, 2013, S. 6.

14 Vgl. Hoerder/Kaur: Proletarian and Gendered Mass Migrations, S. 5.

15 Vgl. Hoerder/Kaur: Proletarian and Gendered Mass Migrations, S. 5. 


\section{Gibt es spezifisch weibliche Migrationserfahrungen?}

Die Frage, ob eine spezifisch weibliche Migrationserfahrung zu beobachten ist, kann mit Ja beantwortet werden. So unterscheidet sich die Migration von Frauen bezogen auf die Situation in der Herkunftsgesellschaft, die Erfahrungen auf dem Weg der Migration und schließlich bezogen auf das Leben in der Aufnahmegesellschaft. Dies ist bedingt durch die kulturellen und gesellschaftlichen Konstrukte von Geschlecht, ${ }^{16}$ denn Geschlechterbeziehungen sind kulturell geformt ${ }^{17}$ und beeinflussen weibliche Migration.

$\mathrm{Da}$ die Rollenzuweisungen nicht in jeder Gesellschaft ${ }^{18}$ gleich sind, ist eine differenzierte Betrachtungsweise notwendig und die unterschiedlichen gesellschaftlichen Bedingungen zwischen Ländern ${ }^{19}$ fordern eine genaue Analyse der Geschlechterrollen in Abhängigkeit von Bildung, Alter, sozialem Milieu/Schichtzugehörigkeit und Sexualität.

Ökonomische Gründe sind ebenfalls zu beachten. Migrantinnen sind für einen großen und erheblichen Anteil der Rücküberweisungen in ihre Heimatländer verantwortlich und leisten damit einen immensen Beitrag zur Armutsbekämpfung. Sie spielen eine bedeutende ökonomische Rolle, sowohl im Herkunftsland als auch im Aufnahmeland. Deshalb ist es für viele Familien unter dem Aspekt Erfolg attraktiv, weibliche Mitglieder als Arbeitskräfte ins Ausland zu schicken (Dienstmädchen, Servicekräfte, Fließbandarbeit, etc.), da sie in manchen Regionen leichter Arbeit finden und gleichzeitig die Familien entlasten. Mit dem Geld, das sie zurück schicken, können v. a. männliche Familienmitglieder vielfältig unterstützt werden. Dennoch profitieren auch die weiblichen Familienmitglieder, sowohl ökonomisch als auch mit Blick auf die Geschlechterrollen, da sie neue Vorbilder bekommen. ${ }^{20}$

Ein anderer Beweggrund ist die Stellung von Frauen in undemokratischen und patriarchalisch strukturierten Gesellschaften, die sie von vielen Formen der rechtlichen, gesellschaftlichen und politischen Teilhabe oder Mitbestimmung, von Bildung und gut bezahlter Erwerbstätigkeit ausschließen oder sie sexuell ausbeuten. Wollen Frauen an ihrer abhängigen, untergeordneten Situation etwas verändern, bleibt oft nur die Migration.

16 Vgl. Han, Petrus: Frauen und Migration, Stuttgart: UTB, 2003, S. 12.

17 Vgl. Hormel, Ulrike/Scherr, Albert: Interkulturelle Probleme in den Geschlechter- und Generationenverhältnissen, in: Nicklas, Hans/Müller, Burkhard/Kordes, Hagen (Hg.): Interkulturell denken und handeln, Frankfurt: Campus, 2006, S. 131-140, hier S. 133.

18 Vgl. Krauss, Marita/Sonnabend, Holger: Frauen und Migration. Eine einleitende Problemskizze, in: dies. (Hg.): Frauen und Migration, Frankfurt: Campus, 2001, S. 9-19, hier S. 10.

19 Vgl. Kristof, Nicholas D./WuDunn, Sheryl: Half the Sky. Turning oppression into opportunity for women worldwide, New York: Vintage, 2010.

20 Vgl. Yurtdas, Hatice: Frauen, Migration und der Stellenwert des Geldes, in: Krauss/Sonnabend (Hg.): Frauen und Migration, S. 29-36. 
Mit Blick auf die Flucht- oder Migrationswege sind Frauen ohne männlichen Schutz gefährdeter, da sie häufig der Gefahr von sexuellen Übergriffen und Erpressung ausgesetzt sind, besonders, wenn sie alleine oder in kleinen Gruppen reisen, ${ }^{21}$ was sie in zunehmendem Maße tun. ${ }^{22}$ Sie müssen aufgrund ihrer erhöhten Verwundbarkeit durch ihr Geschlecht mit größeren Risiken und Gefahren rechnen. Ein Problem ist, dass Migrantinnen, die im Heimatland und/oder auf der Wanderung Missbrauch und Gewalt erleben, ihre Rechte oftmals nicht kennen und niemandem vertrauen, selbst wenn sie in einen demokratischen Rechtsstaat einwandern. ${ }^{23}$

\section{Gibt es eigene weibliche Migrationswege und -formen?}

Es gibt eindeutig geschlechtsspezifische Migrationsformen. Eine davon ist die Heiratsmigration, die schon lange vor den sogenannten philippinischen MailOrder-Bräuten $^{24}$ der 1980er Jahre in Europa existierte. Für einen großen Teil der weiblichen Bevölkerung war Heiratsmigration im Lebenszyklus vorgesehen - meist zogen die Frauen zu den Männern. Diese Form der Migration war unabhängig von sozialen und religiösen Zugehörigkeiten, sondern für Angehörige des (Hoch-)Adels, des Militärs, des Handels- und Bildungsbürgertums und selbst in den Unterschichten eher alltäglich. ${ }^{25}$

Heiratsmigration ist immer noch ein bedeutender Faktor, ${ }^{26}$ wobei die Formen sehr vielfältig geworden sind, sich die Herkunftsregionen der Frauen veränderten und das Internet natürlich als Plattform für Heiratsvermittlungen in jeglicher Form eine neue Variante der Kontaktaufnahme bietet.

Ebenfalls frauentypisch ist Migration im informellen Sektor zum Zweck der Arbeitsaufnahme als Reproduktionskraft in Haushalten und pflegerischen Berufen. Diese Form ist im 21. Jahrhundert verbreiteter denn je. Die Nachfrage im Dienstleistungs- sowie im Gesundheitsbereich verzeichnete in den reichen westlichen aber auch in den superreichen Ländern des arabischen Raums einen enormen Anstieg und führte zu einer weltweiten Mobilisierung weiblicher Arbeitskräfte. Sie stammen wie viele Krankenschwestern aus Surinam oder den Philippinen, wie viele Haushaltshilfen in Kalifornien aus Mexiko,

21 Vgl. Lipkam, Susanne: Flüchtlingsfrauen im Asylverfahren in Deutschland, in: Rohr/Jansen (Hg.): Grenzgängerinnen, S. 39-52, hier S. 39.

22 Vgl. UNHCR: World Migration Report, Genf: International Organization for Migration, 2015, http://www.iom.int/world-migration-report-2015 (08.12.2016).

23 Vgl. UNFPA United Nations Population Fund: Weltbevölkerungsbericht 2006, 2006, S. 35 , http://www.frauen-ohne-grenzen.org/news/archiv/75/ (18.07.2016).

24 Vgl. Bade, Klaus [u. a.]: Ensylklopädie Migration in Europa, Paderborn/München: Schöningh/Fink, 2008, S. 850-852.

25 Vgl. Hahn: Historische Migrationsforschung, S. 149.

26 Vgl. UNFPA: Weltbevölkerungsbericht, S. 24. 
oder wie viele Kindermädchen in New York aus China. ${ }^{27}$ Die Öl-Staaten (Vereinigte Arabische Emirate, Saudi-Arabien, etc.) rekrutieren ihre Haushaltshilfen in Ostafrika und Asien und in Deutschland sind es vorwiegend Frauen aus Polen und Rumänien, die im pflegerischen privaten Bereich tätig sind.

Flüchtlingsfrauen, illegal und legal eingereiste Frauen sowie Exilantinnen erledigen v. a. im Haushalt nicht anerkannte und unsichtbare Arbeit zur Entlastung der Frauen in der Aufnahmegesellschaft, aber die geschlechtsspezifische Arbeitsteilung bleibt dabei bestehen.

\subsection{Fluchtursachen}

Wenn Flucht über die Landesgrenzen geht, dann werden nicht nur geographische Grenzen überschritten, sondern u. a. auch mentale, religiöse, sprachliche, ethnische oder soziale. Und gerade für Frauen gibt es weitere Grenzen, die sie überschreiten, z. B. die der Geschlechterrollen.

Ein sehr großer Teil der Migrantinnen und Migranten gehört zu den Flüchtlingen, die aufgrund von (Bürger-)Kriegen, Genoziden, Rassismus, Fanatismus, Gewalt, Menschenrechtsverletzungen, Hungersnöten und Naturkatastrophen sowie aufgrund der Zerstörung ihrer Lebensgrundlage ihre Heimat verlassen müssen. Hiervon sind Männer wie Frauen gleichermaßen betroffen, doch bei genauer Betrachtung wird deutlich, dass meist die Männer die Akteure, und somit die Auslöser sind, während Frauen und Kinder unverhältnismäßig oft zu den Opfern zählen. ${ }^{28}$ Dies liegt mitunter daran, dass die Unterdrückung von Frauen in ihren unterschiedlichen Formen weltweit ein charakteristisches Merkmal von Herrschaftsstrukturen ist. Diese Strukturen verstärken sich in Krisen- und Kriegszeiten und die ohnehin Schwächsten werden am wenigsten geschützt und am ehesten zu Opfern.

In Kriegszeiten sind Frauen aufgrund ihrer Position und ihrer Rolle als Versorgerinnen von Kindern und Alten weniger mobil. Wenn sie flüchten müssen, können sie das in der Regel nicht alleine, sondern sind verantwortlich für ihre Kinder und weitere Angehörige..$^{29}$

Die Vergewaltigung von Frauen dient meist dazu, die gegnerischen Männer zu demütigen und ihnen die eigene Ohnmacht vorzuführen, da sie nicht in der Lage sind, ihre Frauen, die sie als Besitz betrachten, zu schützen. ${ }^{30}$ Dies

27 Vgl. Hahn: Historische Migrationsforschung, S. 195.

28 Vgl. z. B. UNHCR The UN Refugee Agency: World at War. UNHCR Global Trends. Forced Displacement in 2014, Genf: UNHCR, 2014, http://www.unhcr.org/556725e69.pdf (08.12.2016).

29 Vgl. Rohr: Frauen auf der Flucht, S. 12.

30 Vgl. z. B. Münkler, Herfried: Die nenen Kriege, Hamburg: Rowohlt, 2011; Henry, Nicola: War and Rape. War memory and justice, New York: Routledge, 2011; Skjelsbaeg, Inger: The Political Psychology of War Rape. Studies from Bosnia and Herzegovina, New York: Routledge, 2012. 
bedeutet, dass Frauen neben der allgemeinen Verfolgung eine spezifisch frauenfeindliche Verfolgung erleben, der sie fast schutzlos ausgeliefert sind. ${ }^{31}$

Aber auch in nicht kriegerischen Zeiten wird Frauen und Mädchen in vielen Ländern das Recht auf ein selbstbestimmtes Leben verweigert, sodass Flucht die einzige Chance auf ein freieres Leben bietet.

\subsection{Erfahrungen auf Migrationswegen}

Sexualisierte Gewalt und Ausbeutung sind bei der Flucht oft an der Tagesordnung. Frauen und Mädchen sind hier besonders durch Menschenhandel und Prostitution gefährdet, schreibt die European Women's Lobby ${ }^{32}$ :

Schmuggler machen mit Menschenhändlern gemeinsame Sache, um Frauen und Mädchen zu missbrauchen, sie in Bordellen oder anderen Prostitutionsstätten auszubeuten. Frauen sind womöglich auch gezwungen, sich zu prostituieren, um die Flucht zu überleben, um einen Schlafplatz oder Nahrungsmittel zu bekommen. ${ }^{33}$

Erschreckend ist, dass die Weltgemeinschaft erst 1998 Vergewaltigung, sexuelle Versklavung und Zwangsprostitution als Verbrechen gegen die Menschlichkeit anerkannte. Es ist aber heute noch für viele Frauen schwer, bei Asylanträgen diese frauenspezifischen Gründe anzugeben, weil sie aus Scham kaum darüber reden können und weil sie wissen, wie schwierig der Nachweis ist. In einem Land wie Deutschland müssen Frauen und ihre Unterstützerinnen hart um die Anerkennung als Flüchtling kämpfen und immer noch werden „,mehr Männer als Flüchtlinge anerkannt, da sie häufiger die geschlechtsneutral formulierten Anforderungen der Genfer Flüchtlingskonvention erfüllen“"34.

\subsection{Erfahrungen im Aufnahmeland}

Viele Flüchtlinge sind nicht auf das Aufnahmeland vorbereitet. Oftmals sind sie traumatisiert und benötigen psychologische Hilfe, doch fehlen adäquat ausgebildete Therapeutinnen und Beraterinnen.

Während beide Geschlechter unter der neuen Situation wie Statusverlust, Arbeitslosigkeit oder dem Wegfall der sozialen Netzwerke leiden und die

31 Vgl. Rohr: Frauen auf der Flucht, S. 12.

32 Vgl. European Women's Lobby, http://www.womenlobby.org/?lang=en (18.07.2016).

33 Vgl. Deutscher Frauenrat: Frauen auf der Flucht. Asyl ist nicht geschlechtsneutral, 2015, https://www.frauenrat.de/deutsch/infopool/nachrichten/informationdetail/jahres_arch iv/2010/article/asyl-ist-nicht-geschlechtsneutral.html (15.12.2016).

34 Vgl. Angenendt, Steffen: Migration - Entwicklungstrends - Feminisierung, 2009, http://www. bpb.de/themen/QU9986,0,0,Feminisierung.html (18.07.2016). 
Sprachlosigkeit aushalten müssen, sind die Belastungen aufgrund der frauenspezifischen Verfolgung für Frauen weitaus höher.

Frauen können von dem Ausschluss aus der Gesellschaft besonders betroffen sein und erleiden unter Umständen Gewalt und Diskriminierung aufgrund ihres Geschlechts. Ihre Notlage wird ausgenutzt, sodass viele Flüchtlingsfrauen nach der spezifischen Erfahrung der sexuellen Gewalt auf der Flucht im Aufnahmeland weiterem Missbrauch ausgesetzt sind und zu sexuellen Diensten gezwungen werden. ${ }^{35}$

In der Regel haben Frauen als Ehefrauen und Mütter die Aufgabe, im Aufnahmeland ein kulturelles Refugium zu schaffen, das die Familie wieder emotional stabilisiert. Erschwert wird die Situation durch den Verlust ihres eigenen traditionellen Beziehungsgefüges, wie etwa weibliche Verwandte oder die Frauen des früheren Umfeldes. Hinzu kommen die ganz anderen soziokulturellen Bedingungen in der neuen Gesellschaft, die einerseits befremdlich wirken, andererseits faszinieren, aber anfangs in keiner Weise mit der gewohnten Kultur in Einklang zu bringen sind. ${ }^{36}$

Exil ist eine erzwungene Form von Migration, die das Leben in kürzester Zeit grundlegend verändert. Diese Veränderungen können einhergehen mit einem Identitätsverlust, denn ein Großteil der Frauen ist heimatlos, sprachlos, einsam und ohne Hoffnung auf Besserung ihrer Situation, da ihr Status in den meisten Aufnahmeländern unsicher ist und sie nicht wissen, ob und wann sie wieder in das Land, aus dem sie fliehen mussten, abgeschoben werden.

Doch es gibt auch positive Beispiele von Frauen, die im neuen Leben erfolgreich sind, über ihre traditionellen Rollen hinaus wachsen und Stärke und Kraft entwickeln. ${ }^{37}$

\subsection{Sexarbeit und Menschenhandel}

Der Aufenthaltsstatus ist ebenfalls eines der großen Probleme für die sogenannten Sexarbeiterinnen und Zwangsprostituierten.

Aufgrund der spezifischen Problematik von Frauen, die in Ländern mit schwierigen wirtschaftlichen Bedingungen leben, laufen zahlreiche Frauen Gefahr, in moderne Sklaverei oder Menschenhandel zu geraten. Schätzungen zufolge werden jedes Jahr ca. 2,45 Millionen Menschen ausgebeutet ${ }^{38}$ und ca.

35 Vgl. Roß, Bettina: Migration, Geschlecht, in: dies. (Hg.): Migration, Geschlecht und Staatsbürgerschaft, Wiesbaden: Verlag für Sozialwissenschaften, 2004, S. 9-28, hier S. 15.

36 Vgl. Rohr: Frauen auf der Flucht, S. 22-23.

37 Vgl. Akashe-Böhme, Farideh: Lebensentwürfe und Verstrickungen: Biographien im Exil und in der Migration, in: Rohr/Jansen: Grenægängerinnen, S. 53-63, hier S. 54.

38 Nach Angaben der Internationalen Arbeitsorganisation werden weltweit 2,45 Millionen Menschen als Folge von Menschenhandel in Zwangsarbeit ausgebeutet. Die meisten Menschenhandelsopfer werden zur Prostitution gezwungen (43\%) - überwiegend Frauen und Mädchen - oder als Dienstboten in Privathaushalten ausgebeutet (32 \%). Schätzungen 
1,2 Millionen innerhalb und außerhalb ihrer Landesgrenzen verschleppt. $80 \%$ sind weiblich, wobei auch ein hoher Prozentsatz von Frauen als Schlepperinnen arbeitet. ${ }^{39}$

Menschenhandel rangiert damit an dritter Stelle der lukrativsten illegalen Einnahmequellen mit einem geschätzten Jahresumsatz von 7 bis 12 Milliarden Dollar. Weitere 32 Milliarden Dollar kommen dazu, wenn die Opfer im Zielland ,arbeiten'.40

Das Problem bleibt die Illegalität, da sich die Opfer kaum wehren können bzw. Angst vor Ausweisung haben. Oft sind die Anwerber Bekannte, die mit guten Jobangeboten locken. Am stärksten betroffen sind Südostasien und Südasien, gefolgt von den Ländern der ehemaligen Sowjetunion ${ }^{41}$ und Osteuropa.

Frauenhandel als Teil von buman trafficking ist schon sehr alt und bis in die Antike zurückzuverfolgen. Die Zahlen in diesem Sektor sind aufgrund der günstigen und schnellen Verkehrswege und Transportmöglichkeiten immens gestiegen und inzwischen agieren global vernetzte Schlepperbanden. ${ }^{42}$

Es gibt Stimmen, die davor warnen, diese Frauen nur zu viktimisieren, da sie in ihrer Opferrolle als Individuen entmächtigt werden, was eine differenzierte Sicht auf ihre Handlungsmöglichkeiten verhindert. ${ }^{43}$ In Fachdiskussionen wird darauf hingewiesen, dass die Frauen aktiv versuchen, ihre ökonomische Situation zu verbessern und sich bewusst für die Sexarbeit entscheiden. Damit wird in keiner Weise Sexarbeit und Frauenhandel gerechtfertigt. Der Begriff ,Sexarbeit" konnotiert eine ökonomisch machtvolle Dienstleistung als Form der Einkommensbeschaffung.

Zahlreiche Frauen sind bereit, im sogenannten Vergnügungssektor zu arbeiten, wobei ihnen selten klar ist, wie kurz der Weg in die Prostitution sein kann. Die wenigsten wissen, worauf sie sich einlassen, denn sie sind schlecht

zufolge verbringen Menschenhändler jährlich Hunderttausende in die EU oder verschleppen sie innerhalb der EU. Vgl. European Commission: EU Kommission verstärkt Kampf gegen Menschenhandel, 2010, http://europa.eu/rapid/press-release_IP-10-380_de.htm (18.07.2016).

39 Vgl. UNODC United Nations Office on Drugs and Crime: UNODC Report on human trafficking exposes modern form of slavery, http://www.unodc.org/unodc/en/humantrafficking/global-report-on-trafficking-in-persons.html (26.10.2016).

40 Vgl. Walter, Bernd: Irreguläre Migration und Scbleusungskriminalität - die unbeilvolle Allianz, 2015, http://goo.gl/8Dxnjk (18.07.2016).

41 Vgl. UNFPA: Weltbevölkerungsbericht, S. 48 f.; Vgl. Kristof/WuDunn: Half the Sky.

42 Vgl. Hahn: Historische Migrationsforschung, S. 195.

43 Vgl. Zimowska, Agnieszka: Der internationale Frauenhandel als Migrationschance? Neue Perspektiven auf Handlungsstrategien migrantischer Sexarbeiterinnen in der deutsch-polnischen Grenzprostitution, in: Roß (Hg.): Migration, Gescblecht und Staatsbürgerschaft, S. 4966, hier S. 49. 
informiert über die Arbeitsbedingungen ${ }^{44}$ oder ihnen ist gar nicht klar, was die Arbeit bedeutet. Diese Form des Frauenhandels, den sie als ihre einzige Chance sehen, ist gleichzeitig eine der extremsten Ausbeutungsformen und unter dem Aspekt der Menschenrechte als Menschenrechtsverletzung zu betrachten. ${ }^{45}$

Hier greift die These, dass die meisten Menschen nicht naiv und uninformiert auswandern; es stimmen jedoch nicht immer alle Informationen, die sie erhalten. Migrantinnen, die sich bewusst für Sexarbeit entscheiden, können genau dort landen, wo von Anfang an irregeführte, verschleppte und missbrauchte Frauen sind, nämlich in extrem ausbeuterischen Verhältnissen des Frauenhandels und der Zwangsprostitution. Die Kritik gilt aber den Gesellschaften, die diese Dienste nutzen und wegsehen, wenn es um Prostitution geht.

Dass Frauen nur noch diesen Handlungsspielraum haben, um ihre ökonomische Situation zu verbessern, liegt u. a. an der Migrationspolitik der EULänder, die ihnen keinen sicheren Aufenthaltsstatus bieten. So werden die Sexarbeiterinnen - nicht nur, aber v. a. - zu rechtlosen Arbeitsmigrantinnen gemacht ${ }^{46}$ und diese Rechtlosigkeit führt sie genau in jene Abhängigkeit und Wehrlosigkeit gegenüber denjenigen, über die sie zur Sexarbeit kommen.

\section{Machen Migrantinnen andere Erfahrungen in der Aufnahmegesellschaft?}

Migrantinnen machen andere Erfahrungen in der Aufnahmegesellschaft, da sie die ihnen zugedachte Rolle mit den neuen Anforderungen in Einklang bringen müssen. Sie sind sehr oft für das Wohlbefinden der Familienmitglieder und für eine gute Familienatmosphäre verantwortlich, denn in Zeiten allgemeiner Unsicherheit aufgrund der Migrationserfahrungen muss wenigstens die Familie Stabilität und Sicherheit bieten. Die Frauen sind einer Differenzerfahrung zur eigenen Kultur unterworfen, teilweise auf sich alleine gestellt, wenn sie keine Netzwerke knüpfen können und erfahren gegebenenfalls Ausgrenzung ${ }^{47}$ aufgrund von ,Anderssein' oder mangelnden Sprachkenntnissen. Gleichzeitig sehen sie, was Demokratie, Rechtsgleichheit, Freiheit und Gleichberechtigung bedeuten können. Viele Migrantinnen machen die Erfahrung von Selbstständigkeit, gewinnen höheres Selbstvertrauen, knüpfen

44 Vgl. Geisler, Alexandra: Gehandelte Frauen. Menschenhandel zum Zweck der Prostitution mit Frauen aus Osteuropa, Berlin: Trafo Verlag, 2005, S. 24 f.

45 Vgl. Zimowska: Der internationale Frauenhandel, S. 53; vgl. Geisler: Gehandelte Frauen, S. 18.

46 Vgl. Zimowska: Der internationale Frauenhandel, S. 55.

47 Vgl. Krauss/Sonnabend: Frauen und Migration, S. 15. 
unter Umständen eigene Kontakte zur Aufnahmegesellschaft über Frauennetzwerke und stellen mitgebrachte Traditionen und Wertvorstellungen in Frage, was wiederum zu familiären Konflikten führen kann.

\section{5. Ändern sich Paar- und Familienbeziehungen durch Migration?}

Nicht nur die Migrantinnen müssen sich umstellen, sondern auch die Männer. Wenn plötzlich die Frau zur Familienernährerin wird, weil sie arbeiten geht oder der Mann arbeitssuchend ist, dann kehren sich möglicherweise traditionelle Rollen um. Diese Veränderung müssen beide aushalten und es ist gerade für patriarchalisch geprägte Männer nicht einfach, sich in die neue Rolle hineinzufinden.

Dass Migrantinnen oft schneller Arbeit finden als ihre Männer liegt daran, dass Frauen eher bereit sind, Arbeiten anzunehmen, die weit unter ihrem Ausbildungsniveau liegen, denn sie stellen die Notwendigkeit einer Erwerbsmöglichkeit über die eigenen Befindlichkeiten. ${ }^{48}$

Hinzu kommt, dass traditionelle Rollen durch das Leben in der Aufnahmegesellschaft Veränderungen erfahren, denn durch Medien, den Kontakt zu Arbeitskolleginnen, durch die Schule der Kinder usw. fließen unweigerlich Impulse von außen in die Familien ein und verändern das Bewusstsein. Damit verknüpft ist ein neues Rollenverständnis, gerade auch der Töchter, das zu innerfamiliären Problemen führen kann. Das Bildungsniveau der Migrantenfamilie spielt dabei eine wichtige Rolle, da in der Regel Ehepartner aus bildungsfernen Schichten eher am traditionellen Rollenverständnis für ihre Kinder festhalten. ${ }^{49}$ Allerdings sind hier Verallgemeinerungen sehr gefährlich, aber eines ist klar: Paar- und Familienstrukturen ändern sich durch Migration, denn eine neue Situation in einem fremden Land bringt selbstverständlich Veränderungen mit sich. In welche Richtung diese gehen, ist aber schwer vorherzusagen.

48 Vgl. Kofman, Eleonore/Raghuram, Parvati: Probleme qualifizierter Migrantinnen, 2009, http://www.bpb.de/gesellschaft/migration/kurzdossiers/57297/probleme?p=all (08.12.2016); Bundesministerium für Bildung und Forschung (BMBF), Referat Chancengerechtigkeit in Bildung und Forschung: Arbeitsmarktintegration hochqualifizierter Migrantinnen. Berufsverläufe in Naturwissenschaft und Technik, Bonn/Berlin: BMBF, 2012.

49 Vgl. Le Yondre, Dina: Binationale (Ehe)Paare in Trikulturalität, Karlsruhe: Pädagogische Hochschule, 2014, S. 100-196. 


\section{Hat die Migration Einfluss auf die Rolle der Frau in der Herkunfts- und in der Aufnahmegesellschaft?}

Hatice Yurtdas schreibt: „Die Erwerbstätigkeit, d. h. das Geldverdienen, erzeugt bei den Migrantinnen das Bewusstsein von Macht und den Mut zum selbstständigen Handeln. " ${ }^{50}$ Der Stellenwert der Frauen kann sich durch die Geldsendungen an die Familie in der Herkunftsgesellschaft erhöhen, zumindest aus ökonomischer Perspektive, denn v. a. die männlichen Familienmitglieder profitieren davon. ${ }^{51}$ Allerdings setzen die familiären Erwartungen die Frauen enorm unter Druck, im Aufnahmeland wirtschaftlich erfolgreich zu sein, bei gleichzeitiger Einschränkung der eigenen Ausgaben. Verweigern sie sich, bedeutet das einen Abbruch der familiären Beziehungen und ein Dasein ohne Netzwerk. Die Chance besteht wiederum darin, dass sich diese Migrantinnen stärker um andere Kontakte kümmern.

Kehren die Migrantinnen wieder in ihre Heimat zurück, können sie sich, bedingt durch Erfahrungen in den Aufnahmeländern, häufig nicht mehr an die dortigen Geschlechterrollenzuschreibungen anpassen. Der Aufenthalt im Ausland hat ihnen in der Regel mehr Selbstbewusstsein und Selbstständigkeit gebracht; Kompetenzen, die sie nicht einfach negieren können. Durch ihr Verhalten verändern sich langfristig auch die Gesellschaftsformen, die auf der Ungleichheit der Geschlechter basieren.

In der Aufnahmegesellschaft treten ebenfalls Veränderungen auf, die sich gerade im informellen Sektor der Hausarbeit, der Dienstleistungen in Hotel und Gewerbe und in der Pflege manifestieren. Die Frauen der Aufnahmegesellschaft werden hier zu großen Teilen nicht mehr benötigt und haben die Chance in höher dotierte und qualifizierte Berufe zu wechseln. Es ist für sie einfacher ihrer Erwerbstätigkeit nachzugehen, weil eine hohe Zahl von Migrantinnen die Arbeiten für sie erledigt, die ihnen immer noch aufgrund der traditionellen Geschlechterrollenverteilung zugeschrieben werden. Selbst in einer westlichen Gesellschaft des 21. Jahrhunderts sind Haushalt, Kinderbetreuung, Betreuung oder Pflege von Angehörigen in der Regel Frauensache. Somit ändert sich an den traditionellen Geschlechterrollen in der Aufnahmegesellschaft nichts.

50 Yurtdas: Frauen, Migration und der Stellenwert des Geldes, S. 29-36, hier S. 30.

51 Vgl. Yurtdas: Frauen, Migration und der Stellenwert des Geldes, S. 29-36. 


\section{Welche Auswirkungen hat der Perspektivwechsel auf den Umgang mit Migration?}

Die Leistung des Genderansatzes liegt in der Sichtbarmachung der geschlechtsspezifischen Erfahrung von Flucht und Migration. Im Zeitalter der Globalisierung kommen die Migrantinnen nicht aus einer sozial wie räumlich abgeschlossenen Gesellschaft, in der traditionelle Festlegungen selbstverständlich und alternativlos sind. ${ }^{2}$ Dank der modernen Informations- und Kommunikationstechnologien haben viele Menschen auf unterschiedliche Weise Zugang zu anderen Kulturen, sodass Kulturen vielschichtige, dynamische und widersprüchliche Gebilde sind, die sich gegenseitig beeinflussen.

$\mathrm{Da}$ Geschlechterbeziehungen kulturell geform $\mathrm{t}^{53}$, konstruiert ${ }^{54}$ und die Rollenzuweisungen nicht in jeder Gesellschaft ${ }^{55}$ gleich sind, ist eine differenzierte Betrachtungsweise notwendig, um nicht falsche Schlüsse zu ziehen.

Gerade die unterschiedlichen gesellschaftlichen Bedingungen in den einzelnen Ländern ${ }^{56}$ fordern eine genaue Analyse der Geschlechterrollen in Abhängigkeit von Bildung, Alter, sozialem Milieu/Schichtzugehörigkeit und Sexualität. Darüber hinaus spielt das Verständnis von Geschlechterbeziehung in den Herkunfts- und in den Aufnahmeländern eine wichtige Rolle, denn unterschiedliche Geschlechterkonzepte können zu Distanz und Konflikten zwischen Einheimischen und Migrantinnen führen, wobei zu beachten ist, dass in den sogenannten modernen Gesellschaften zwischen den normativen Gleichheitsansprüchen und der faktischen Ungleichheit der Geschlechter in der Regel eine erhebliche Diskrepanz besteht.

Es lohnt sich, einen gesonderten Blick auf die positiven Aspekte der Lebensbewältigung von Migrantinnen und ihren Umgang mit Brüchen und Neuanfängen, mit Fremdheitserfahrung und Integration, mit Verlusten und Familienzusammenführung zu werfen; kurz, ihre Biografien zu beleuchten, denn daraus ergeben sich neue Perspektiven. So werden Handlungsspielräume von Migrantinnen erkennbar, die sich zuvor nicht im Blickfeld befanden. Die Handlungsfähigkeit von Migrantinnen schlägt sich in ihrem Wissen über sich selbst und die Welt nieder, sodass sie ihr Leben selbst bestimmen und gestalten können. ${ }^{57}$

52 Vgl. Hormel/Scherr: Interkulturelle Probleme, S. 134-138.

53 Vgl. Hormel/Scherr: Interkulturelle Probleme, S. 133.

54 Vgl. Hahn: Frauen und Migration, S. 12.

55 Vgl. Krauss/Sonnabend: Frauen und Migration, S. 10.

56 Vgl. Kristof/WuDunn: Half the Sky.

57 Vgl. Erel, Umut: Qualifikation von Migrantinnen - eine Frage der Bürgerrechte?, in: $A P u Z$ Aus Politik und Zeitgescbicbte: Migration und Arbeitsmarkt, Heft 44 (2009), 26. Oktober 2009, http://www.bpb.de/apuz/31665/qualifikation-von-migrantinnen-eine-frage-derbuergerrechte-essay (19.12.2016). 
Insgesamt tritt durch eine gendersensible Betrachtung der Migration die Perspektive der Migrantinnen in den Mittelpunkt und sie werden als Akteurinnen sowohl von der internationalen Politik als auch von den Aufnahmeländern wahrgenommen. ${ }^{58}$

\section{Literaturverzeichnis}

Akashe-Böhme, Farideh: Lebensentwürfe und Verstrickungen: Biographien im Exil und in der Migration, in: Rohr/Jansen (Hg.): Grenzgängerinnen, S. 53-63.

Angenendt, Steffen: Migration - Entwicklungstrends - Feminisierung, 2009, http://www.bpb.de/ themen/QU9986,0,0,Feminisierung.html (18.07.2016).

Bade, Klaus [u. a.]: Ensykklopädie Migration in Europa, Paderborn/München: Schöningh/Fink, 2008.

Bundesministerium für Bildung und Forschung (BMBF) Referat Chancengerechtigkeit in Bildung und Forschung: Arbeitsmarktintegration bochqualifizierter Migrantinnen. Berufsverläufe in Naturwissenschaft und Technik, Bonn/Berlin: BMBF, 2012.

Deutscher Frauenrat: Frauen auf der Flucht. Asyl ist nicht geschlechtsneutral, 2015, https:// www.frauenrat.de/deutsch/infopool/nachrichten/informationdetail/jahres_archiv/2010 /article/asyl-ist-nicht-geschlechtsneutral.html (15.12.2016).

Erel, Umut: Qualifikation von Migrantinnen - eine Frage der Bürgerrechte?, in: $A P u Z$ - Aus Politik und Zeitgeschichte: Migration und Arbeitsmarkt, Heft 44 (2009), 26. Oktober 2009, http://www.bpb.de/apuz/31665/qualifikation-von-migrantinnen-eine-frage-derbuergerrechte-essay (19.12.2016).

European Commission: EU Kommission verstärkt Kampf gegen Menschenhandel, 2010, http://europa.eu/rapid/press-release_IP-10-380_de.htm (18.07.2016).

European Women's Lobby: http://www.womenlobby.org/?lang=en (18.07.2016).

Gabaccia, Donna R.: From Sicily to Elizabeth Street, Albany: State University New York Press, 1983.

Geisler, Alexandra: Gehandelte Frauen. Menschenhandel zum Zweck der Prostitution mit Frauen aus Osteuropa, Berlin: Trafo Verlag, 2005.

Hahn, Sylvia: Historische Migrationsforschung, Frankfurt/New York: Campus, 2012.

Han, Petrus: Frauen und Migration, Stuttgart: UTB, 2003.

Henry, Nicola: War and Rape. War memory and justice, New York: Routledge, 2011.

Hoerder, Dirk/Kaur, Amarjit: Proletarian and Gendered Mass Migrations, Leiden: Brill Verlag, 2013.

Hormel, Ulrike/Scherr, Albert: Interkulturelle Probleme in den Geschlechter- und Generationenverhältnissen, in: Nicklas, Hans/Müller, Burkhard/Kordes, Hagen (Hg.): Interkulturell denken und handeln, Frankfurt: Campus, 2006, S. 131-140.

Jacobsen, Grethe: Female Migration and the Late Medieval Town, in: Gerhard, Jarik/Müller, Albertz (Hg.): Migration in der Feudalgesellschaft, Frankfurt/New York: Campus, 1988, S. 43-55.

Kofman, Eleonore/Raghuram, Parvati: Probleme qualifizierter Migrantinnen, 2009, http:// www.bpb.de/gesellschaft/migration/kurzdossiers/57297/probleme?p=all, (08.12.2016).

Krauss, Marita/Sonnabend, Holger (Hg.): Frauen und Migration, Stuttgart: Franz Steiner Verlag, 2001.

Krauss, Marita/Sonnabend, Holger: Frauen und Migration. Eine einleitende Problemskizze, in: dies. (Hg.): Frauen und Migration, S. 9-19.

Kristof, Nicholas D./WuDunn, Sheryl: Half the Sky. Turning oppression into opportunity for women worldwide, New York: Vintage, 2010. 
Lamphere, Louise: From Working Daughters to Working Mothers: Immigrant Women in a New England Industrial Community, Ithaca: Cornell University Press, 1987.

Le Yondre, Dina: Binationale (Ehe)Paare in Trikulturalität, Karlsruhe: Pädagogische Hochschule, 2014.

Lipkam, Susanne: Flüchtlingsfrauen im Asylverfahren in Deutschland, in: Rohr/Jansen (Hg.): Grenzgängerinnen, S. 39-52.

Millman, Heather L.: Mothering from Afar: Conceptualizing Transnational Motherhood, 2013, http:ir.lib.uwo.ca/totem/vol21/iss1/8 (20.10.2016).

Münkler, Herfried: Die neuen Kriege, Hamburg: Rowohlt, 2011.

Rohr, Elisabeth: Frauen auf der Flucht, in: dies./Jansen (Hg.): Grenagängerinnen, S. 11-38.

Rohr, Elisabeth/Jansen, Mechthild M. (Hg.): Grenzgängerinnen. Frauen auf der Flucht, im Exil und in der Migration, Gießen: Psychosozial Verlag, 2002.

Roß, Bettina (Hg.): Migration, Gescblecht und Staatsbürgerschaft, Wiesbaden: Verlag für Sozialwissenschaften, 2004.

Roß, Bettina: Migration, Geschlecht, in: dies. (Hg.): Migration, Gescblecht und Staatsbürgerschaft, S. 9-28.

Skjelsbaeg, Inger: The Political Psychology of War Rape. Studies from Bosnia and Herzegovina, New York: Routledge, 2012.

Tilly, Charles: Transplantet Networks, in: Yans-McLaughlin (Hg.): Immigration Reconsidered, S. 79_ 95.

UNDESA/OECD United Nations. Department of Economic and Social Affairs/Organisation for Economic Co-operation and Development: World Migration in Figures, 2013, http:// www.oecd.org/els/mig/World-Migration-in-Figures.pdf (18.07.2016).

UNFPA United Nations Population Fund: Weltbevölkerungsbericht 2006, 2006, http://www. frauen-ohne-grenzen.org/news/archiv/75/ (18.07.2016).

UNHCR The UN Refugee Agency: World at War. UNHCR Global Trends. Forced Displacement in 2014, Genf: UNHCR, 2014, http://www.unhcr.org/556725e69.pdf (08.12.2016).

UNHCR: World Migration Report, Genf: International Organization for Migration, 2015, http:// www.iom.int/world-migration-report-2015 (08.12.2016).

UNODC United Nations Office on Drugs and Crime: UNODC Report on human trafficking exposes modern form of slavery, http://www.unodc.org/unodc/en/human-trafficking/ global-report-on-trafficking-in-persons.html (26.10.2016).

Vecoli, Rudolph J./Sinke, Suzanne M. (Hg.): A Century of European Migrations, 1830-1930, Illinois: University of Illinois Press, 1991.

Walgenbach, Katharina: Intersektionalität - eine Einführung, 2012, http://portal-intersektionalitaet. $\mathrm{de} /$ theoriebildung/ueberblickstexte/walgenbach-einfuehrung/ (18.07.2016).

Walter, Bernd: Irreguläre Migration und Schleusungskriminalität - die unbeilvolle Allian₹, 2015, http:// goo.gl/8Dxnjk (18.07.2016).

Winkler, Gabriele/Degele, Nina: Intersektionalität als Mehrebenenanalyse, 01.11.2007, http:// www.feministisches-institut.de/intersektionalitaet/ (18.07.2016).

Yans-McLaughlin, Virginia (Hg.): Immigration Reconsidered, New York/Oxford: Oxford University Press, 1990.

Yurtdas, Hatice: Frauen, Migration und der Stellenwert des Geldes, in: Krauss/Sonnabend (Hg.): Frauen und Migration, S. 29-36.

Zimowska, Agnieszka: Der internationale Frauenhandel als Migrationschance? Neue Perspektiven auf Handlungsstrategien migrantischer Sexarbeiterinnen in der deutsch-polnischen Grenzprostitution, in: Roß (Hg.): Migration, Geschlecht und Staatsbürgerschaft, S. 49-66. 



\section{Neue literarische Perspektiven auf Migration im Werk der franko-senegalesischen Autorin Fatou Diome ${ }^{1}$}

Cet article donne un apercu de l'approche initiale du sujet de la migration qui est au centre de l'cuvre de l'écrivaine franco-sénégalaise Fatou Diome. Par une lecture transversale de ses romans, nous relevons les aspects innovateurs de l'écriture de Diome qui a introduit de nouveaux types de personnages dans la littérature francophone, qui parle de la migration africaine vers l'Europe et qui brise certains tabous. Tout d'abord, dans ses nouvelles et dans plusieurs de ses romans, Fatou Diome introduit l'intellectuelle africaine, étudiante et parfois écrivaine, une migrante en contradiction avec l'image stéréotypée de la femme africaine victime et elle scrute la société française tout comme celle du Sénégal d'un xil critique et perspicace. Ensuite, avec son roman Celles qui attendent (2010), Diome se focalise sur les mères et épouses des nombreux migrants masculins de sa région natale du Sine Saloum en narrant des histoires de femmes qui étaient jusque-là ignorées tant par les médias que par la littérature. Finalement, avec notamment Kétala (2006), la romancière met en scène des masculinités transgressives au travers d'hommes qui vivent une sexualité dite 'déviante' et qui passent outre le rôle masculin accompagné d'un code d'bonneur strict qui leur est imposé par l'ordre des genres dans leur société - un ordre étouffant qui peut être une autre raison de la migration.

\section{Einleitung}

2003 landete Fatou Diome mit dem Roman Le Ventre de l'Atlantique einen Überraschungserfolg. ${ }^{2}$ Sie war 35 Jahre alt, lebte als Doktorandin der Literaturwissenschaften in Straßburg und hatte bis dato einen Kurzgeschichtenband veröffentlicht. ${ }^{3}$ Dieser Roman, in dem Fatou Diome die in der frankophonen

1 Der Beitrag beruht bis auf kleine Änderungen auf einem Vortrag, der am 29.06.2016 im Rahmen der Veranstaltungsreihe „Exil und Migration von Frauen“ der Universität des Saarlandes und der Landeshauptstadt im Lesecafé der Stadtbibliothek Saarbrücken gehalten wurde. Der allgemein-öffentliche Gestus des Vortrags wurde beibehalten. Ich danke Prof. Mechthild Gilzmer für die Einladung und den herzlichen Empfang. Dem RöhrigUniversitätsverlag danke ich für die Wiederabdruckgenehmigung einzelner Passagen aus meinem Aufsatz „Die Farben der Migration. Differenz und Hybidität bei Fatou Diome“, in: Dion, Robert [u. a.] (Hg.): Interkulturelle Kommunikation in der frankophonen Welt. Literatur, Medien, Kulturtransfer. Festscbrift zum 60. Geburtstag von Hans-Jürgen Lüsebrink, St. Ingbert: Röhrig-Universitätsverlag, 2012, S. 149-169, hier S. 158-166.

2 Diome, Fatou: Le Ventre de l'Atlantique, Paris: Anne Carrière, 2003.

3 Diome, Fatou: La Préferénce nationale, Paris: Présence Africaine, 2001. 
Literatur schon klassischen Themen Migration und Identität durch den geschickten Einbezug des populären Themas Fußball dynamisch neu gestaltet hat, war in Frankreich ein Bestseller und wurde auch in ihrem Heimatland Senegal, das Fatou Diome 13 Jahre vorher verlassen hatte, viel gelesen und diskutiert. Die erzählte Zeit beginnt zur Europameisterschaft 2000 und endet mit der Weltmeisterschaft 2002. In der Rahmenhandlung versucht die Protagonistin und Ich-Erzählerin Salie, die in Straßburg lebt, per Telefon ihren jüngeren (Halb-)Bruder, der von einer Fußballerkarriere in Europa träumt, davon zu überzeugen, dass es besser ist, im Land zu bleiben und sich dort etwas aufzubauen. Dieser Rahmen gibt vielfachen Anlass für Erinnerungen an eine Kindheit im Senegal und das Erzählen von Migrationsgeschichten, die selten gut ausgehen. In Deutschland wurde Fatou Diome 2005 für die deutsche Übersetzung dieses Romans mit dem LiBeraturpreis ausgezeichnet. ${ }^{4}$

Inzwischen ist Fatou Diome eine anerkannte Schriftstellerin und eine bekannte öffentliche Person, deren Meinung von den Medien nachgefragt wird. Von 2004 bis 2006 moderierte sie eine Literatursendung im Fernsehkanal France 3, gab aber die Medienkarriere auf, um sich ganz dem Schreiben widmen zu können. In den aktuellen Debatten um Flucht und Migration meldet sich Fatou Diome meinungsstark zu Wort. Insbesondere ein Auftritt im April 2015 bei der Talkshow Ce soir ou jamais!, die nach der zweiten großen Flüchtlingskatastrophe vor Lampedusa mit dem tendenziösen Titel „Accueillir la misère du monde ou non?" auf Sendung ging, verbreitete sich weltweit in den sozialen Medien. Den Verteidigern von Frontex hielt die Autorin u. a. unerschrocken den Beitrag der Migrantinnen und Migranten zur Entwicklung der französischen Wirtschaft vor Augen.

Seit Fatou Diome schreibt, ist das Thema Migration in ihren Werken zentral. Sie hat nicht nur selbst die Erfahrung des Fortgehens, einer schwierigen Ankunft und des Zwischen-den-Welten-Lebens gemacht, sondern sie kommt aus einem Land und noch genauer aus einer Region, die besonders bekannt dafür sind, dass viele Menschen, v. a. junge Männer, den Weg der illegalen Einwanderung mit Booten über das Mittelmeer oder durch die marokkanische Wüste nach Melilla und Ceuta wählen: Senegal ist ein Sahelland, das weniger für massive politische Probleme bekannt ist - für Senegalesen werden seit Jahrzehnten keine klassischen Asylgründe wie Krieg oder Diktatur anerkannt - als vielmehr für eine stagnierende Wirtschaft, die jungen Menschen nur wenig Zukunftschancen bietet. Fatou Diome stammt aus der Region Sine

4 Diome, Fatou: Der Bauch des Oreans, Köln: Diogenes, 2006. Der LiBeraturpreis war von 1987 bis 2012 ein kirchlicher Literaturpreis für Autorinnen aus den sogenannten ,DritteWelt-Ländern', die ins Deutsche übersetzt wurden. Seit 2013 wird er von dem Verein Litprom - Gesellschaft zur Förderung der Literatur aus Afrika, Asien und Lateinamerika verliehen. 
Saloum, genauer von den Inseln vor der Petite Côte, Senegals malerisch schöner Touristenregion südlich der Hauptstadt Dakar. Sie wurde 1968 auf der Insel Niodior als uneheliches Kind geboren und wuchs bei ihren Großeltern auf. Die maritime Landschaft Sine Saloums und das bescheidene Leben der einfachen Leute auf den Inseln sind in ihrer Literatur sehr präsent. Quasi alle Familien der Sine Saloum-Inseln haben Familienmitglieder in der Migration, jedoch sehr viel häufiger sind es Männer als Frauen.

Trotz der Schwierigkeiten für Fatou Diomes Großeltern das Schulgeld aufzubringen, gelingt es ihr in der Schule zu bleiben, da sie früh als begabt auffällt. Um das Gymnasium in der Küstenstadt Mbour zu absolvieren und später die Universität in Dakar zu besuchen, muss sie sich immer wieder als Hausangestellte verdingen. Mit 22 Jahren verliebt sie sich in einen Franzosen und folgt ihm nach Frankreich. Die Ehe ist nur von kurzer Dauer, frisch geschieden schreibt sie sich zum Studium der vergleichenden Literaturwissenschaft in Straßburg ein und lebt nunmehr seit 1994 in der elsässischen Provinzhaupstadt als ihrer Wahlheimat. Vor ihrem Durchbruch als Autorin arbeitete sie in Frankreich als Kindermädchen und Putzfrau, erlebte Alltagsrassismus; auch dies fließt in ihr Schreiben ein.

Angesichts des Lebenswegs von Fatou Diome und dessen, was ich in Folge über ihre Werke ausführen werde, drängt sich die Frage nach dem Autobiographischen im Schreiben der Autorin auf, eine Frage, die klassischerweise auch bei Lesungen oder Vorträgen aus dem Publikum gestellt wird. Zwar lehnt Fatou Diome die Autobiographie als Gattung für sich ab. Dennoch macht sie Referenzen auf ihren eigenen Lebenslauf und spezifischen kulturellen und familiären Hintergrund immer wieder zu strategischen Elementen in ihren Texten. Beispielsweise bestätigt sie in einem Interview: „La petite Salie dans Le ventre de l'Atlantique, l'étudiante de La préférence nationale. Oui, c'est absolument moi ${ }^{\text {“ } 5}$. Die Figur der Salie aus dem ersten Roman wird in Diomes letztem Roman Impossible de grandir (2013) ${ }^{6}$ wieder aufgenommen, sie wird immer noch von ihren schönen und schmerzhaften Kindheitserinnerungen eines sozial ausgegrenzten unehelichen Kindes in der kleinen Welt der Insel Niodior heimgesucht. Zum Umgang mit ihren eigenen Lebenserinnerungen erläutert die Autorin:

Alors moi je n'aime pas fondamentalement l'autobiographie. Je pense qu'aucune vie n'est si intéressante pour faire un roman en entier. Je dis toujours que je ne fais pas d'autobiographie. Je prends juste quelques petits morceaux de vécu, d'expériences que j’insère dans

5 Diouf, Mbaye: „J'écris pour apprendre à vivre“. Entretien avec Fatou Diome. Québec, 18 avril 2008, in: Stichproben. Wiener Zeitschrift für kritische Afrikastudien 17 (2009) (Heft Klang, Bild, Text. Intermedialität in afrikanischen Literaturen, hg, von Gehrmann, Susanne/Prüschenk, Viola), S. 137-151, hier S. 139.

6 Diome, Fatou: Impossible de grandir, Paris: Flammarion, 2013. 
le livre pour le côté exemple, pour renforcer une intrigue, et après, l'histoire se tisse autour pour s'ouvrir aux autres. ${ }^{7}$

Eine Schreibweise, die zwischen dem Referentiell-Autobiographischen und einer fiktionalen Überformung changiert und die Leserschaft über mehrere Werke hinweg erneut mit bereits vertrauten Motiven konfrontiert, findet man in der senegalesischen Literatur schon bei Ken Bugul, Autorin aus der Vorgängergeneration senegalesischer Schriftstellerinnen. Fatou Diome hat allerdings mit Kétala ${ }^{8}$ und Celles qui attendent ${ }^{\ominus}$ auch zwei Romane vorgelegt, für die sie eine ganz andere Erzählperspektive wählt und deren fiktive Hauptfiguren deutliche Distanz zur Autorin wahren.

Um mich dem facettenreich behandelten Thema Migration im Werk Fatou Diomes nun anzunähern, möchte ich drei Punkte herausgreifen, die ich in ihrem Schreiben für besonders innovativ halte und die über das, was in der Literatur der Migration vor 2003 vorherrschte, hinausgehen:

a) Bildungsmigration - Fatou Diome führt in ihren ersten Büchern die intellektuelle afrikanische Frau als Gegenfigur zu bemitleidenswerten Armutsflüchtlingen in die Literatur ein. Diese hat zudem die Funktion einer kritischen Beobachterin sowohl der französischen als auch der senegalesischen Gesellschaft.

b) Die Zurückgebliebenen - Fatou Diome schreibt als erste Westafrikanerin einen Roman über die Ehefrauen und Mütter, deren Männer und Söhne in die Migration gehen. In der frankophonen subsaharischen Literatur hatte sich bis dato niemand für die Geschichten derer, die zu Hause bleiben (müssen), interessiert.

c) Transgressionen von Männlichkeit - Fatou Diome schreibt als eine der ersten afrikanischen Autorinnen offensiv über Männer, die ihrer gesellschaftlichen Geschlechterrolle nicht gerecht werden: über homosexuelle und transsexuelle Männer, aber auch einfach über Männer, welche den strengen Ehrenkodex der männlichen Geschlechterrolle hinter sich lassen - auch dies im Zusammenhang mit Migration.

Punkt a) bezieht sich auf mehrere Bücher Fatou Diomes und wird deshalb von mir ausführlicher besprochen, während die Punkte b) und c) sich schwerpunktmäßig jeweils auf einen Roman beziehen und entsprechend kürzer abgehandelt werden.

7 Diouf: ,J'écris pour apprendre à vivre“, S. 138.

8 Diome, Fatou: Kétala, Paris: Flammarion, 2006.

9 Diome, Fatou: Celles qui attendent, Paris: Flammarion, 2010. 


\section{Bildungsmigration - die intellektuelle afrikanische Migrantin als innovative Figur}

In den beiden ersten Büchern Fatou Diomes, der Kurzgeschichtensammlung La Préférence nationale und dem Roman Le Ventre de l'Atlantique, treffen wir auf die Figur einer Literaturstudentin und angehenden Schriftstellerin aus Senegal in Straßburg, die sich mit Jobs als Putzfrau und Kindermädchen über Wasser halten muss. Die erste Lektion, die Fatou Diome der europäischen Leserschaft über diese Figur erteilt, ist, auf das Faktum der Bildungsmigration hinzuweisen, einer Motivation zu migrieren, um sich in einem in der postkolonialen Weltkonstellation privilegierten universitären System aus- und weiterzubilden. Diese Motivation liegt jenseits klassischer politischer oder humanitärer Gründe und treibt doch viele Migrantinnen und Migranten aus Afrika an. Die äußerst belesene und gewitzte Figur der Salie bei Diome ist eine ganz andere Konstruktion der afrikanischen Migrantin, als diejenige, die landläufig in den Medien gezeigt wird: Statt vielfache Mutter, ungebildet, gar Analphabetin und vom afrikanischen Patriarchat unterjocht, ist sie ein kritischer und freier Geist, sie lebt allein und liest französische Philosophen ebenso wie Weltliteratur aller Kontinente.

Damit unterscheidet sich diese Figur, die von Xavier Garnier treffend auch als „exilée lettrée“10 bezeichnet wurde, auch sehr deutlich von den Frauenfiguren in den Texten anderer afrikanischer Autorinnen und Autoren, die vor Diome über Migration geschrieben haben. Die bekannteste französischsprachige Autorin der 1990er Jahre, Calixthe Beyala, die aus Kamerun zunächst nach Spanien und dann nach Frankreich migrierte, stellte beispielsweise in ihren zahlreichen Romanen immer wieder die prekären Lebensverhältnisse ungebildeter afrikanischer Frauen in der Migration in den Mittelpunkt. Ihre Protagonistinnen sind häufig tatsächlich Analphabetinnen, illegal Beschäftigte, Prostituierte und nicht zuletzt in unbefriedigende Beziehungen mit sie einschränkenden französischen oder afrikanischen Männern verstrickte Frauen. Zwar gab es schon in der ersten Hälfte des 20. Jahrhunderts Romane über afrikanische Studenten in Frankreich, aber in diesen kamen keine afrikanischen Frauen vor, sondern ausschließlich männliche Studierende und ggf. deren Beziehungen mit französischen Frauen. Tatsächlich waren vor 1960 Studentinnen aus den Kolonien nur sehr selten in Frankreich anzutreffen. Heute ist eine starke akademische Präsenz afrikanischer Migrantinnen in Europa ein Faktum, das aber nur bedingt in das gesellschaftliche Bewusstsein eingedrungen ist.

Eine schreibende intellektuelle Frau aus Afrika ist eine Innovation in der literarischen Darstellung von Migration. Allerdings begegnet diese Figur als Migrantin und Afrikanerin in der Arbeitswelt verbreiteten Stereotypen der

10 Garnier, Xavier: L'exil lettré de Fatou Diome, in: Notre Librairie 155-156 (2004), S. 30-35. 
europäisch-weißen Vorstellung von Afrikanerinnen als ungebildet, ja naiv und unterwürfig. Diomes Heldinnen des Alltags begegnen solchen Zuschreibungen jedoch nicht mit Verzweiflung, sondern v. a. mit humorvoller Ironie. Diomes Protagonistinnen gehören zu einer Generation afrikanischer Bildungsmigrantinnen im Zeitalter globalisierter Zirkulation von Wissen und Menschen, die sich aufgrund des postkolonialen wirtschaftlichen Gefälles häufig zwangsläufig am Westen orientieren. Darüber hinaus beanspruchen sie einen Status als Schriftstellerin; sie leben diese Identität als schreibende Intellektuelle, auch wenn sie sich diese in einer Gesellschaft, der das Bild einer selbstbestimmten schwarzen Frau, die geistig arbeitet, fremd ist, immer wieder neu erkämpfen müssen.

Fatou Diomes Kurzgeschichten entlarven den Alltagssexismus, -klassismus und -rassismus der Gegenwart. Als schwarze Frau ist die Protagonistin und Ich-Erzählerin auf der Straße einem stigmatisierenden Blick ausgesetzt:

Dans la rue, je marchais vite, j'avais l'impression que les gens me regardaient plus que d'habitude. Soudain, j'eus envie d'être invisible. Je me demandais, pourquoi ces regards insistants qui semblaient tout à la fois me bousculer et m'interroger. [...] l'Afrique tout entière, avec ses attributs vrais ou imaginaires, s'était engouffrée en moi, et mon visage n'était plus le mien mais son hublot sur l'Europe. ${ }^{11}$

Von den französischen Mittelstandsfamilien, für die sie aus materieller Not als Kindermädchen und Putzfrau arbeitet, wird die namenlos bleibende Erzählerin nur als die Afrikanerin oder die Schwarze wahrgenommen und automatisch als ungebildete, billige und gefügige Arbeitskraft klassifiziert. Doch anstatt einseitig die tragische Seite der rassistischen Kontinuitäten aufzugreifen, entlarvt Diome über den wachen und ironisch distanzierten Blick ihrer intellektuellen Migrantin die menschliche Ignoranz und Dummheit, aus der sich Rassismus speist, auf oftmals humorvolle Weise. Es gelingt der Erzählerin, ihren französischen Arbeitgebern die eigene Borniertheit vorzuführen, indem sie zum Schein eine Zeit lang die Rolle der naiven und wortwörtlich sprachlosen Hausangestellten erfüllt, um ihrem Gegenüber schließlich ihre Identität als eloquente Bildungsmigrantin zu eröffnen. Die ironisch feine und intellektuell ausgefeilte Sprache der Ich-Erzählerin in den Kurzgeschichten steht im extremen Widerspruch zur Rolle, die sie zeitweise spielt, indem

11 Diome, Fatou: Le Visage de l'emploi, in: dies.: La Préférence nationale, Paris: Présence Africaine, 2001, S. 59. Die im Zitat beschriebene Situation verweist klar auf Frantz Fanons Studie Peau noire, masques blancs, Paris: Seuil, 1952. Zur intertextuellen Verbindung mit Fanon vgl. auch Mertz-Baumgartner, Birgit: „L'écriture est mon vrai lieu de liberté [...]“. Originalité et créativité littéraires chez Fatou Diome, in: Mathis-Moser, Ursula/MertzBaumgartner, Birgit (Hg.): La littérature ,française' contemporaine. Contact de cultures et créativité, Tübingen: Narr, 2007, S. 189-198. 
sie ihr Vokabular auf ein gefügiges „Bonjour, madame“, „Oui, madame“"12 reduziert. Beispielsweise erfährt der mit Sexismus gepaarte Rassismus des Familienvaters mit dem sprechenden Namen M. Dupire eine heftige Abkühlung, als er seine von ihm als hirnlos, aber körperlich attraktiv eingestufte Hausangestellte eines Tages zufällig in der Straßburger Nationalbibliothek antrifft, wo sie ihn endlich über ihre vertieften Voltaire-Kenntnisse aufklären kann und er einsehen muss: „[L]a serpillière dessèche le carrelage et non le cerveau"13. Diome hat über ihre Erzählerinnen-Figur einen völlig neuen Typ Migrantin in die Literatur eingeführt: eine selbstbewusste Intellektuelle, die rassistische und sexistische Strukturen in Europa vorführt und humorvoll untergräbt.

\section{Der doppelte kritische Blick der Emigrantin und Immigrantin}

Die Funktion des kritischen Blicks der Migrantin auf die französische Gesellschaft ist seit den Kurzgeschichten ein herausragendes Element des Schreibens Fatou Diomes und wird in ihrem Werk konsequent fortgeführt. Genauso trifft die Kritik der Ausgewanderten aber auch die senegalesische Herkunftsgesellschaft mit ihren Geschlechter- und Klassenhierarchien. Der kritische Blick ist bei Fatou Diome insofern zumeist ein doppelter: derjenige der Emigrantin, die zurückblickt, und derjenige der Immigrantin, welche die Zielgesellschaft beobachtet. Das heißt aber nicht, dass nicht auch das Schöne und Wertvolle in beiden Gesellschaften in Diomes Texten vorkommt. Dazu sagt die Autorin in einem Interview:

Je regarde l'Afrique avec distance: il y a des choses qui sont bien et que je voudrais garder, mais il y a d'autres que je n'hésiterais pas de mettre à la poubelle, et je le dis ouvertement. Je regarde la culture occidentale de la même façon. J'écris entre ces deux cultures qui forment une sorte de miroir à double face, et j'essaie de regarder les deux cultures de la même manière: honnêtement, avec franchise et lucidité. ${ }^{14}$

Dieser doppelte kritische Blick ist den Ich-Erzählerinnen in Diomes Erzähltexten zu Eigen. Auch in ihren Romanen widmet Fatou Diome sich vorrangig den Themen Migration und Selbstbestimmung, Letzterer sowohl in der Herkunftsgesellschaft als auch am Zielort der Wanderung. Die interkontinentalen Bezugspunkte, zwischen denen Diomes Figuren sich hin- und herbewegen sind Afrika und Europa, Senegal und Frankreich, die Insel Niodor im Sine-

12 Diome: La Préférence nationale, S. 60, S. 67.

13 Diome: La Préférence nationale, S. 99.

14 Tervonen, Taina: Partir pour vivre libre. Entretien avec Fatou Diome, octobre 2003, in: Africultures 57 (2004), http://www.africultures.com/php/index.php?nav $=$ article\&no $=$ 3227 (24.08.2011). 
Saloum und Straßburg im Elsass. Auffallend ist, dass die Autorin sich großen globalen Fragen, wie dem wirtschaftlichen Gefälle zwischen Nord und Süd ${ }^{15}$ und den Rechten von Frauen, Homosexuellen und älteren Menschen annimmt, diese aber narrativ jeweils in einem ausgeprägt lokalen Setting verortet. Ihre Texte sind häufig dem Lokalkolorit der Insel Niodor und der elsässischen Provinz verpflichtet. Spezifische kulturelle Motive aus den beiden Regionen werden zu Symbolen erhoben, die von der Mikroebene einer lokalen Geschichte auf die Makroebene übergeordneter globaler Zusammenhänge verwiesen.

In Inassowvies, nos vies (2008) spielt der elsässische Gugelhupf die Rolle eines solchen Symbols. Die gemeinsame Vorliebe für diesen Kuchen führt zu Begegnungen zwischen der Ich-Erzählerin Betty und der älteren Französin Félicité $^{16}$, die zunächst wenig Gemeinsamkeiten aufweisen: Betty ist Akademikerin und Schriftstellerin, Mitte 30, Félicité eine Kriegswitwe und ehemalige Arbeiterin. Dass Betty zudem aus Afrika nach Frankreich migriert ist, erschließt sich in diesem Roman erst relativ spät, sodass die sozialen Implikationen von Migration und Rassismus in den Hintergrund treten, während die kritische Beobachtung der französischen Gesellschaft im Vordergrund steht. Dank des Gugelhupfs, für den beide eine Schwäche haben, werden Betty und Félicité allen Differenzen zum Trotz Freundinnen und aus der ,espionnage sociologique“ von „Betty, la loupe“ ${ }^{17}$ den Nachbarn gegenüber werden echte Begegnungen. Als Félicité von ihrer Familie in ein Altersheim abgeschoben wird, wird Betty als Besucherin in der ,Einrichtung' zur Rezipientin einer Vielzahl von Geschichten der alten Menschen, die ihre schriftstellerische Kreativität inspirieren. Auch diese Geschichten sind Teil des Romans, der so zu einem erzählerischen Mosaik wird.

\section{Das Mosaik als Erzählstruktur}

Die Erzähltechnik, eine Rahmenhandlung mit einer Fülle von Mikrogeschichten zu verbinden, hatte Diome bereits in Le Ventre de l'Atlantique angewendet. Ausgangspunkt ist die globale Fußballbegeisterung, welche die erzählende Migrantin in Straßburg, Salie, mit ihrem Bruder Madické auf der Insel Niodior verbindet. Die beiden telefonieren regelmäßig nach wichtigen Spielen und streiten sich über Madickés Begehren, selbst als Fußballer nach Frankreich zu

15 Siehe Thomas, Dominic: African Youth in the Global Economy, in: ders.: Black France. Colonialism, Immigration, and Transnationalism, Bloomington: Indiana University Press, 2007, S. $185-205$.

16 Der Name liest sich als intertextuelles clin d'oeil an Flauberts Un Coeur simple (1877).

17 Diome, Fatou: Inassouvies, nos vies. Paris: Flammarion, 2008, S. 17. 
kommen, um am Wohlstand des Westens zu partizipieren. Die Schwierigkeiten der Erzählerin, ihrem Bruder die Schattenseiten des Lebens in Europa klar zu machen, erinnern sie an eine Reihe von Schicksalen gescheiterter Migrationen, deren Geschichten sie in die Rahmenhandlung einflicht. Diese vermischen sich wiederum mit Episoden aus Kindheitserinnerungen, in denen die Geschlechter- und Klassenordnung in der Heimat kritisch beleuchtet wird. Die vielfachen Geschichten über die Hoffnungen und Täuschungen der Migration verknüpfen sich mit solchen über Außenseiter in einer Gesellschaft mit einem strikten Ehrenkodex. In diesem Mosaik aus Geschichten werden viele unbequeme und schmerzhafte Wahrheiten ausgesprochen, beispielsweise auch die Lügen, mit denen viele Migranten leben, um zu Hause nicht zugeben zu müssen, dass sie in der Migration gescheitert sind. Dabei trifft die Kritik im luziden Blick der Erzählerin die beiden Gesellschaften gleichermaßen, während sie selbst für sich einen lebbaren, nicht fixierten Zwischenraum sucht und im Schreiben findet: „Enracinée partout, exilée tout le temps, je suis chez moi là où l'Afrique et l'Europe perdent leur orgueil et se contentent de s'additionner: sur une page, pleine de l'alliage qu'elles m'ont léguée. ${ }^{18}$ Selbst wenn Salie den sozialen Zwängen innerhalb ihrer Familie und als Migrantin nicht entkommen kann, so werden doch das Erzählen und der Schreibakt selbst zu einem Ort der Freiheit, an dem sie eine positiv besetzte hybride Kultur leben kann. ${ }^{19}$ Nicht zuletzt ist die Ich-Erzählerin als migrierte Frau, die mehr Wissen über die Realität in Europa hat als ihre männlichen Familienmitglieder und die auch Antiheldengeschichten über gescheiterte männliche Migranten erzählt, ein Novum innerhalb der literarischen Geschlechterordnung: „Diome's innovative tale of a female migrant who encourages a male counterpart to stay at home is an important riposte to the typical migration narrative in the Francophone African novel"“. 20

Sowohl Inassouvies, nos vies als auch Le Ventre de l'Atlantique lassen sich als Romane beschreiben, die sich aus einem Mosaik von Mikrogeschichten zusammensetzen. Diese werden von der Klammer der migrantischen Erzählerin, welche sich zwischen geographischen, kulturellen und emotionalen Bezugspunkten in einem ,Dritten Raum ' im Sinne Homi Bhabhas ${ }^{21}$ befindet, zusammengehalten. Die vielfältigen Geschichten der Anderen werden vor dem Bewusstseinshorizont der Erzählerin entfaltet, einem Bewusstsein, das sich weder einseitig in Afrika noch in Europa verortet, sondern vielmehr in

18 Diome: Le Ventre de l'Atlantique, S. 210.

19 Vgl. auch die Lektüre von Mbiga, Sylvie zur Verschmelzung der Kulturen in Le Ventre de l'Atlantique, in: dies.: Selbstindungsprozesse im interkulturellen Roman. Eine Analyse zur Identitätssuche im postkolonialen Afrika, Berlin/Münster: LIT, 2010, hier S. 122-128.

20 Hogarth, Christopher: What Will the New Generation Generate? Gendering Accumulation in Fatou Diome's Celles qui attendent, in: Studies in Twentieth and Twenty-First Century Literature 38/2, article 5 (2014), http://dx.doi.org/10.4148/2334-4415.1090 (20.09.2016), 13 S., S. 1.

21 Bhabha, Homi: The Location of Culture, London/New York: Routledge, 1994. 
beiden zugleich. Das Schreiben wird dabei als der eigentliche Raum der Selbstentfaltung gepriesen. ${ }^{22}$

\section{Die Zurückgebliebenen}

Während in den meisten Werken von Fatou Diome klar ein transnationales Schreiben bevorzugt wird, insofern als das doppelte Setting Frankreich-Senegal in einem ausgewogenen Verhältnis von Szenen im Hier und Dort steht, wird dem Mikrokosmos der Insel Niodior in Roman Celles qui attendent - Die Wartenden deutlich der Vorzug gegeben. Die Abenteuer der beiden klandestinen Migrantenfiguren Issa und Lamine in Europa werden nur äußerst knapp zusammengerafft erzählt. Die beiden jungen Männer sind, dem Druck ihrer Mütter folgend, die auf ein gutes Auskommen ihrer Söhne in Europa zählen, das die Armut der Großfamilien auf der Insel mildern soll, mit einem der berühmten Fluchtboote übers Mittelmeer nach Spanien gelangt. Um sie dennoch an ihre Heimat zu binden, hat man sie vorher schnell noch verheiratet bzw. den religiösen Ehebund mit der Jugendliebe in Abwesenheit ausgesprochen, wie es im Islam möglich ist. Christopher Hogarth fasst treffend zusammen: „She [Diome] concentrates in the ways in which migration to Europe is presented as a male rite of passage that is a necessary part of accumulation, experience and adventure - regardless of the experience of the women left behind“23. Im Mittelpunkt des Romans steht dann jedoch v. a. der Alltag auf der Insel, stehen die zurückgebliebenen Frauen, die erst auf ein Lebenszeichen, dann auf die Postanweisungen und Anrufe, schließlich auf die Rückkehr der Männer warten. Der erste Satz des Romans, der den poetischen und melancholischen Ton dieses Romans setzt, lautet:

\footnotetext{
Arame, Bougna, Coumba, Daba, mères et épouses de clandestins, portaient jusqu'au fin des pupilles des rêves gelés, des fleurs d'espoir flétries et l'angoisse permanente d'un deuil hypothétique, mais quand le rossignol chante, nul ne se doute du poids de son cœur. Longtemps, leur dignité rendit leur fardeau invisible. Tous les suppliciés ne hurlent pas. ${ }^{24}$
}

Fatou Diomes Vorliebe für das Lokale wird in diesem Roman noch zugespitzt. In penibler Genauigkeit nehmen wir als Leserinnen und Leser am Alltag der einfachen Frauen von Niodior teil, an der Routine von Wasserholen, Essen kochen, Rivalitäten mit Nachbarinnen und Mitehefrauen, der ständigen Sorge um die Zukunft der Kinder. Dieses ausführliche Erzählen über das Alltägliche mag manchmal langatmig wirken, hat aber auch eine

22 Vgl. Mbiga: Zur Verschmelzung der Kulturen, S. 126.

23 Hogarth: What Will the New Generation Generate?, S. 7.

24 Diome: Celles qui attendent, S. 9. 
stilistische Funktion. Die Dehnung der Zeit in einem von Gleichförmigkeit und Warten geprägten Leben wird so greifbar gemacht: „Diome’s slow-paced style reflects the excruciating nature of the long, painful process of waiting these women undergo" 25 . Diesmal hat Diome eine übergeordnete auktoriale Erzählstimme gewählt, welche die Gefühle aller beteiligten Figuren durchleuchtet und zugleich über deutlich mehr Wissen als die Handlungsträgerinnen verfügt, sodass sie übergreifende Zusammenhänge herzustellen und zu analysieren vermag. Beispielsweise zeigt diese allwissende Erzählstimme auf, wie das Handwerk der Fischer, das Generationen von Familien an der senegalesischen Küste ihr Grundeinkommen sicherte, durch die multinationalen großen Fangflotten vor den afrikanischen Küsten zerstört wird. Auch bestimmte Rezepte der Entwicklungshilfe, wie z. B. Mikrokredite, die oft als ein Heilmittel gepriesen werden, um gerade Frauen zur geschäftlichen Selbstständigkeit zu verhelfen, werden vorgeführt und kritisch hinterfragt ${ }^{26}$. Arame und Bougna verschulden sich durch den Mikrokredit immer mehr, da sie für dessen Rückzahlung auf die Hilfe ihrer emigrierten Söhne angewiesen sind, die im erhofften großen Stil jedoch ausbleibt.

Die $W$ artenden ist v. a. auch ein Roman über die Geschlechterordnung, die an der Problematik der klandestinen Migration verdeutlicht wird: Von den jungen Männern wird erwartet, dass sie sich unter größten Gefahren in die Migration begeben und ihre Familien wirtschaftlich unterstützen, unter welchen Umständen auch immer. Von den jungen Frauen wird erwartet, dass sie klaglos als alleinerziehende Mütter von oftmals hastig gezeugten Kindern zurechtkommen. Beim häufig vergeblichen Warten auf die Geldanweisung aus dem Ausland liegt die Bürde der täglichen Ernährung großer Familien umso schwerer auf den Frauen.

Auch das seit Mariama Bâs Une si longue lettre ${ }^{27}$ klassische Kritikthema senegalesischer Autorinnen wird von Fatou Diome erneut aufgegriffen: die Polygamie als Eheform, die den Männern Privilegien zugesteht und den Frauen oftmals eine zermürbende Rivalität auferlegt. Bougna schickt ihren Sohn deshalb in die Migration, weil sie als zweite Ehefrau unter Druck steht, dass ihre Kinder ebensolche Erfolge vorweisen wie die der ersten Ehefrau. Ironischerweise bleibt jedoch der Sohn der Erstfrau, der nur innerhalb Senegals von Sine Saloum in die Hauptstadt Dakar migriert, bis zum Schluss der einzige Sohn mit einem stabilen Einkommen, der seine Eltern unterstützen kann, während der nach Spanien migrierte Issa, der dort nur Hilfsarbeiter bleibt, kaum in der Lage ist, überhaupt Geld in die Heimat zu schicken. Zudem setzt Issa selbst die Tradition der Polygamie auf eine pervertierte Weise fort: Um der Papiere Willen heiratet er eine Spanierin, mit der er dann jedes

25 Hogarth: What Will the New Generation Generate?, S. 10.

26 Vgl. Hogarth: What Will the New Generation Generate?, S. 8.

27 Bâ, Mariama: Une si longue lettre, Dakar: NEA, 1979. 
Jahr die Ferien auf der Insel verbringt - den einen Monat im Jahr, den er seine senegalesische Frau sieht, die zugleich für die europäische Zweitfrau putzen und kochen muss. Coumba erhält nach außen hin ihre Würde aufrecht, innerlich jedoch geht sie an der Situation zugrunde. Ein Leitmotiv des Ro-

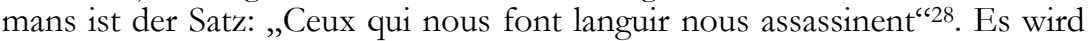
zudem betont, dass die im Roman geschilderten Einzelschicksale als repräsentativ für viele andere Situationen stehen, wenn es beispielsweise heißt: „Coumba était une de ces nombreuses femmes qui attendent Ulysse à quai en restant fidèles à leurs chambres vides“"29.

\section{Transgressionen von Männlichkeit}

Transgressionen männlicher Geschlechterrollen kommen in Diomes Werk an verschiedenen Stellen vor, am radikalsten jedoch in ihrem zweiten Roman Kétala von 2006. In diesem Text haben wir es mit einer ungewöhnlichen erzählerischen Konstruktion zu tun und zwar mit einer Vervielfachung verdinglichter Erzählerstimmen, die auf eine Hauptgeschichte fokussieren. Es sind die Möbel, Kleidungsstücke und andere Gegenstände aus dem Besitz der verstorbenen Protagonistin, welche die Geschichte ihrer Herrin mit dem symbolischen Namen Mémoria erzählen. Der Romantitel speist sich aus diesem Rahmen: Kétala bezeichnet auf Fatou Diomes Muttersprache Serer die Zeremonie der Erbverteilung. Die erinnernde Trauerarbeit der beseelten Gegenstände führt so zu einer vielstimmigen Erzählung nach dem Motto „Pour peindre une vie, il faut toutes les couleurs de la nuit ${ }^{\text {“30 }}$, bei der diesmal der kritische Blick auf die Menschen von Instanzen außerhalb menschlicher Existenz übernommen wird.

Mémoria ist eine Senegalesin aus der Mittelschicht, die nach ihrer Zwangsverheiratung mit einem Mann, dessen Eltern ihn von seiner Homosexualität , heilen' wollen, nach Frankreich migriert und sich nach dem Scheitern dieser Ehe prostituiert, um zu überleben. Diome spricht mit diesem Roman mehrere Tabus an. Zu ihrer in allen ihren Texten präsenten Kritik an der Geschlechterordnung und der Verherrlichung von Migration, addiert sich hier die Problematik der freien sexuellen Orientierung. Auch HIV/AIDS wird offensiv thematisiert. Dabei dreht Diome bestimmte Klischeevorstellungen um: Während im Senegal Homosexualität häufig als ein Import, westlicher Dekadenz ${ }^{6}$ als unafrikanisch deklariert wird, leben die Figuren Makhou und Tamsir ihre queeren Identitäten bereits in Dakar und der Migrant wird nicht etwa in Straßburg damit ,angesteckt'. Hingegen wird HIV/AIDS in Europa

28 Diome: Celles qui attendent, S. 266.

29 Diome: Celles qui attendent, S. 274.

30 Diome: Kétala, S. 12. 
immer noch als afrikanische Plage begriffen, Diomes Protagonistin infiziert sich jedoch bei ihren europäischen Freiern mit dem Virus.

In dem Roman wird als ein Erzählstrang rückblickend auch die Liebesgeschichte von Makhou und Tamsir, seinem transsexuellen Geliebten, der in Frauenkleidern als Tamara lebt, erzählt. Beide Familien der jungen Männer unterdrücken deren transgressive Sexualität und Geschlechtsidentität durch drastische Maßnahmen: Tamsir wird zum Militär geschickt, bis er nach vielen Demütigungen desertiert, sich in Makhou verliebt und fortan unter falscher Identität als Frau lebt. Makhou wird mit Mémoria verheiratet. Die beiden Männer bleiben jedoch heimlich Liebhaber, bis sie entdeckt werden und ein neuer Skandal droht. Schließlich schlägt Makhou seiner Frau vor, nach Frankreich zu migrieren, um ihre Ehe zu retten. Doch Makhou wird es nie gelingen, mehr als brüderliche Gefühle für seine Frau zu entwickeln und er verlässt sie für einen französischen Liebhaber. Im Gegensatz zu Mémoria, die das tragische Opfer der Intoleranz und Dominanz der älteren Generation wird, die sie mit einem Schwulen zwangsverheiratet hat, wird den beiden liebenden Männern Makhou und Tamsir ein Happy End beschieden. Dies liest sich als Plädoyer für die Akzeptanz sexueller Differenz in einem Land, in dem Homosexualität weitgehend tabuisiert ist und mit Gefängnis bestraft werden kann. ${ }^{31}$

Diomes transgressive Männerfiguren in Kétala verweisen auch darauf zurück, dass es im Senegal schon seit vorkolonialer Zeit Transexuelle gab und gibt, die sogenannten Goor-Jiggen (Wolof: wörtlich 'Männermädchen'), und dass diese lange toleriert wurden. Es liegt am Erstarken bestimmter religiöser Tendenzen, dass die Diskriminierung Transsexueller und Homosexueller zunimmt und zunehmend als etwas Fremdes, vom Westen Importiertes wahrgenommen wird. ${ }^{32}$ Auch die Suche nach sexueller Freiheit kann eine Motivation für die Migration darstellen. Aktivisten fordern heute zu Recht ein, dass kriminalisierte queere Sexualität ein anerkannter Asylgrund werden muss.

Männer, die eine ihnen traditionell zugeschriebene Geschlechterrolle als stolze, starke Enährer und Familienoberhäupter durchbrechen, gibt es auch noch an anderer Stelle in Fatou Diomes Werk. Wenn der Auswanderer Lamine in Celles qui attendent das Kind, das seine Frau, die er sieben Jahre lang hat warten lassen, in seiner Abwesenheit empfangen und geboren hat, als sein eigenes annimmt, obwohl er genau weiß, dass sein Rivale der biologische Vater ist, handelt er gegen die Prinzipien der Männlichkeit in der dargestellten Gesellschaft. Die an ihn herangetragene Erwartung ist, dass er die Frau mit

31 Vgl. Tischmacher, Jürgen/Gehrold, Stefan: Homosexualität im Senegal - Gefäbrliche Intoleran₹, auf Raten? Länderbericht der Konrad-Adenauer-Stiftung, Mai 2009, http://www.kas.de/wf/ doc/kas_16497-1522-1-30.pdf?090522135758 (24.08.2011).

32 Siehe M'Baye, Babacar: The Origins of Senegalese Homophobia: Discourses on Homosexuals and Transgender People in Colonial and Postcolonial Senegal, in: African Studies Revien 56 (2013), S. 109-128. 
dem Kind verstoßen müsste, mindestens aber das Kind, wenn er denn die Frau behalten will, zu der er dann aber eine tugendhafte Zweitfrau hinzunehmen sollte. Während die Gesellschaft weibliche Untreue als unverzeihlichen Fehltritt wertet, wird auf der anderen Seite den jungen Männern in der Migration wie selbstverständlich zugestanden, dass sie sich Geliebte oder um der Papiere willen - sogar europäische Ehefrauen nehmen. Lamine ist eine männlich transgressive Figur deshalb, weil er mit seinem unerwarteten Handeln die ungerechte Ungleichbehandlung der Geschlechter außer Kraft setzt und eingesteht, dass es ebenso unmöglich ist, die Sexualität einer jungen Frau sieben Jahre lang auszusetzen wie seine eigene als Mann.

\section{Fazit}

Fatou Diome hat mit ihren Romanen und Kurzgeschichten neue Aspekte in die frankophonen Literaturen Senegals und Frankreichs, die sich mit den Migrationsbewegungen zwischen Afrika und Europa auseinandersetzen, eingebracht. Sie exponiert und verhandelt die strukturelle Gewalt globaler Wirtschaftspolitik und auf Differenzkategorien beruhende Ungerechtigkeiten entlang von Gender, Klasse, ,Rasse', Alter und sexueller Orientierung insbesondere im Kontext von Migration. Dabei verwebt sie häufig unterschiedliche Geschichten und Blickwinkel, um verbreiteten vereinfachenden Darstellungen ein differenziertes Bild gegenüberzustellen. Diome zeigt anhand ihrer innovativen literarischen Charaktere Facetten für die Ursachen von und das Leben in sowie mit der Migration auf, welche im Spektrum der transnationalen Literatur zwischen Senegal und Frankreich bis dato unterbelichtet blieben: Die Alter Ego-Figuren der intellektuellen afrikanischen Bildungsmigrantin mit ihrem doppelt kritischen Blick, die erstmals literarische Würdigung findenden zurückgebliebenen Mütter und Ehefrauen sowie die ihnen zugeschriebene Geschlechtermuster durchbrechenden transgressiven männlichen Figuren tragen dazu bei, die Komplexität von Migration narrativ fassbar zu machen. Denn so wie bei ihren öffentlichen Auftritten ist es auch in der Literatur Fatou Diomes unerschrockene Fähigkeit, unbequeme Wahrheiten auszusprechen und Tabuthemen anzugehen, die ihre Strahlkraft als Autorin maßgeblich ausmacht. 


\section{Literaturverzeichnis}

Bâ, Mariama: Une si longue lettre, Dakar: NEA, 1979.

Bhabha, Homi: The Location of Culture, London/New York: Routledge, 1994.

Diome, Fatou: La Préferénce nationale, Paris: Présence Africaine, 2001.

Diome, Fatou: Le Visage de l'emploi, in: dies.: La Préférence nationale, Paris: Présence Africaine, 2001.

Diome, Fatou: Le Ventre de l'Atlantique, Paris: Anne Carrière, 2003.

Diome, Fatou: Der Bauch des Ozeans, Köln: Diogenes, 2006.

Diome, Fatou: Kétala, Paris: Flammarion, 2006.

Diome, Fatou: Inassowies, nos vies, Paris: Flammarion, 2008.

Diome, Fatou: Celles qui attendent, Paris: Flammarion, 2010.

Diome, Fatou: Impossible de grandir, Paris: Flammarion, 2013.

Diouf, Mbaye: „J'écris pour apprendre à vivre“. Entretien avec Fatou Diome. Québec, 18 avril 2008, in: Stichproben. Wiener Zeitschrift für kritische Afrikastudien 17 (2009) (Heft Klang, Bild, Text. Intermedialität in afrikanischen Literaturen, hg, von Gehrmann, Susanne/Prüschenk, Viola), S. 137-151.

Fanon, Frantz: Peau noire, masques blancs, Paris: Seuil, 1952.

Garnier, Xavier: L'exil lettré de Fatou Diome, in: Notre Librairie 155-156 (2004), S. 30-35.

Gehrmann, Susanne: Die Farben der Migration. Differenz und Hybidität bei Fatou Diome, in: Dion, Robert [u. a.] (Hg.): Interkulturelle Kommunikation in der frankophonen Welt. Literatur, Medien, Kulturtransfer. Festschrift zum 60. Geburtstag von Hans-Jürgen Lüsebrink, St. Ingbert: Röhrig-Universitätsverlag, 2012, S. 149-169.

Hogarth, Christopher: What Will the New Generation Generate? Gendering Accumulation in Fatou Diome's Celles qui attendent, in: Studies in Twentieth and Twenty-First Century Literature 38/2, article 5 (2014), http://dx.doi.org/10.4148/2334-4415.1090 (20.09.2016).

M'Baye, Babacar: The Origins of Senegalese Homophobia: Discourses on Homosexuals and Transgender People in Colonial and Postcolonial Senegal, in: African Studies Review 56 (2013), S. 109-128.

Mbiga, Sylvie: Selbstfindungsprozesse im interkulturellen Roman. Eine Analyse zur Identitätssuche im postkolonialen Afrika, Berlin/Münster: LIT, 2010.

Mertz-Baumgartner, Birgit: „L'écriture est mon vrai lieu de liberté [...]“. Originalité et créativité littéraires chez Fatou Diome, in: Mathis-Moser, Ursula/Mertz-Baumgartner, Birgit (Hg.): La littérature française' contemporaine. Contact de cultures et créativité, Tübingen: Narr, 2007, S. 189-198.

Tervonen, Taina: Partir pour vivre libre. Entretien avec Fatou Diome, octobre 2003, in: Africultures 57 (2004), http://www.africultures.com/php/index.php?nav $=$ article\&no $=3227$ (24.08.2011).

Thomas, Dominic: African Youth in the Global Economy, in: ders.: Black France. Colonialism, Immigration, and Transnationalism, Bloomington: Indiana University Press, 2007, S. 185-205.

Tischmacher, Jürgen/Gehrold, Stefan: Homosexualität im Senegal - Gefäbrliche Intoleran₹ auf Raten? Länderbericht der Konrad-Adenauer-Stiftung, Mai 2009, http://www.kas.de/wf/doc/kas_ 16497-1522-1-30.pdf?090522135758 (24.08.2011). 

3. Rezensionen 

Alemann, Ulrich von/Morlok, Martin/Roßner, Sebastian (Hg.): Politische Parteien in Frankereich und Deutschland. Späte Kinder des Verfassungsstaates, BadenBaden: Nomos, 2015, $201 \mathrm{~S}$.

In den Parteiensystemen Deutschlands und Frankreichs vollziehen sich derzeit tiefgreifende Veränderungen. Sie dürften schon recht bald ,tektonische Ausmaße annehmen: Nach langen Jahrzehnten grundsätzlicher ,Bipolarität ${ }^{‘}$ könnte sich in Frankreich spätestens nach den nationalen Wahlen im Jahre 2017 (Präsidentschaft, Nationalversammlung) endgültig ein système tripartite etablieren - mit unabsehbaren Folgen für Politik und Mehrheitsbildung im Regierungssystem der V. Republik. Auch in Deutschland stehen die seit Jahrzehnten gewohnten Mechanismen der Koalitions- und Mehrheitsbildung grundsätzlich zur Debatte: In einem derzeit äußerst, volatilen 'Sechsparteiensystem verlieren die bisherigen Volksparteien auf rasante Weise ihre Bindungskraft. Häufig reichen die früher dominierenden Zweierkoalitionen zur parlamentarischen Mehrheitsbildung bereits jetzt nicht mehr aus. Es kommt v. a. in den deutschen Ländern zu einem mehr oder weniger unüberschaubaren ,Sammelsurium ' von Koalitionsvarianten. Von diesen ,tektonischen Verschiebungen in den beiden Ländern ist im vorliegenden Band so gut wie keine Rede: Die Beiträge und die im Buch dokumentierten Diskussionsrunden gehen auf eine Tagung zurück, die im Oktober 2008 an der HeinrichHeine Universität in Düsseldorf veranstaltet wurde. Dass die Veröffentlichung aus dem Jahr 2015 stammt, obwohl sie vom Verlag bereits im Jahr 2011 erstmals angekündigt worden war, ist deshalb wenig nachvollziehbar. Noch weniger nachvollziehbar ist, dass diese große zeitliche Distanz zum Zeitpunkt der Tagung von den Herausgebern nicht thematisiert und problematisiert wird. Eine entsprechende Einordnung wäre v. a. zur Bewertung der aktuellen Relevanz von Beiträgen und Aussagen unabdingbar gewesen. Somit hat die Publikation - zumindest in Teilen - ein veritables Aktualitätsproblem, mit dem die interessierten Leserinnen und Leser insgesamt etwas ratlos zurückgelassen werden. Einige Beiträge dürften wegen ihres historischen Schwerpunktes gewiss in weiten Teilen dennoch ihren Wert behalten haben. Dazu zählen sicherlich die beiden ebenso spannenden wie kompetenten Beiträge in vergleichender Perspektive, mit denen die beiden französischen Rechtswissenschaftler Armel Le Divellec (zur Geschichte der verfassungsrechtlichen Verankerung der Parteien in beiden Ländern, vgl. S. 13 ff.) und Yves-Marie Doublet (Rechtsvergleich im Hinblick auf die Parteiensysteme, vgl. S. 49 ff.) die Tagung und die Diskussionen eröffnet hatten. Zu dieser Kategorie darf man sicherlich auch den Vortrag des Münchner Politikwissenschaftlers Michael Koß zählen, der den äußerst instruktiven komparativen Faden mit einem Beitrag über die in beiden Ländern gleichermaßen heikle und historisch folgenreiche Frage der Parteienfinanzierung wieder aufnimmt. Koß geht in 
diesem Kontext u. a. der Frage nach, ob und inwieweit hier ein Zusammenhang mit der Dominanz unterschiedlicher Funktionen der deutschen und französischen Parteien im jeweiligen politischen System besteht (vgl. S. 133 ff.). Auch die große historische Skizze des emeritierten Heidelberger „Nestors" der deutschen Politikwissenschaft ${ }^{1}$, Klaus von Beyme, dürfte in wichtigen Teilen und trotz der zeitlichen Distanz noch Bestand haben (vgl. S. 93 ff.). Warum aber hat man von Beyme, einen der seit Jahrzehnten international renommiertesten Vertreter der vergleichenden Politikanalyse ${ }^{2}$, ausschließlich über die Funktionen der Parteien im politischen System der Bundesrepublik referieren lassen? Wo bleibt entsprechend der ausführliche, systematische und gerade für Politikwissenschaftlerinnen und Politikwissenschaftler überaus wichtige diesbezügliche Vergleich mit Frankreich? Abgesehen von vereinzelt eingestreuten Hinweisen, die u. a. Klaus von Beyme selbst gibt (vgl. z. B. S. 98, S. 109 f.), tauchen Elemente zu dieser Frage (strukturelle und funktionale Unterschiede zwischen den Parteien in Deutschland und Frankreich) leider nur en passant bzw. themenabhängig hauptsächlich in den Beiträgen von Doublet und Koß auf (vgl. S. 67 ff., S. 133 ff.). Trotz des erwähnten Aktualitätsproblems bietet die Publikation mit ihrer Verknüpfung von historischem und komparativem Ansatz an vielen Stellen gerade auch für Kulturwissenschaftlerinnen und Kulturwissenschaftler überraschende Perspektiven: Zahlreiche Hinweise ergeben sich in (fast) allen Beiträgen (Referate und Diskussionen) auf die unter Umständen sehr unterschiedlichen kulturellen Fundamente von Politik und Recht in Deutschland und Frankreich. Und diese reichen in ihren Ursprüngen selbstverständlich viel weiter zurück als bis zu den konkreten Anlässen, die als Grund für die Tagung mit vergleichender Perspektive im Jahre 2008 genannt werden: dem damals bevorstehenden 60. Jahrestag der Verkündung des deutschen Grundgesetzes (1949) und dem 50. Jahrestag der Begründung der französischen V. Republik (1958). Beide Ereignisse haben demnächst (2018/2019) wieder einen, runden Geburtstag. Wäre dies nicht ein ausgezeichneter Anlass das o. a. Aktualitätsmanko und gewisse deutsch-französische ,Asymmetrien', die den vorliegenden Band in Teilen kennzeichnen, ,zu heilen'?

Gregor Halmes, Saarbrücken

1 Eckhard Jesse in der Neuen Zürcher Zeitung (NZZ), 30. März 2016, S. 7.

2 Vgl. Jun, Uwe/Zimmer, Klaus: Klaus von Beyme (geboren 1934), in: Jesse, Eckhard/Liebhold, Sebastian (Hg.): Deutsche Politikwissenschaftler - Werk und Wirkung. Von Abendroth bis Zellentin, Baden-Baden: Nomos, 2014, S. 117; Klaus von Beyme: Vergleichende Politikwissenschaft, Wiesbaden: VS Verlag für Sozialwissenschaften, 2010. Schon 1982 hatte von Beyme auch zum o. a. Themenkomplex bereits einen Band publiziert: von Beyme, Klaus: Parteien in westlichen Demokratien, München: Piper, 1982. 
Bauer, Elisabeth Carolin: Frankophone digitale Literatur. Geschichte, Strukturen und Ästhetik einer neuen Mediengattung, Bielefeld: transcript, 2016, 338 S.

In ihrer Dissertation von 2010 widmet sich die Literatur- und Informationswissenschaftlerin Elisabeth Carolin Bauer der Untersuchung frankophoner digitaler Literatur.

Ziel der Untersuchung ist, die Funktionsweise einer neuen Mediengattung nachzuvollziehen - wobei sich herausstellt, dass diese seit der Entwicklung des Web 2.0 nicht mehr ganz neu ist, sondern bereits von anderen, hier nicht untersuchten Formen abgelöst wurde. Insofern widmet sich Bauer den Pionierjahren der digitalen Literatur und grenzt diese auf den frankophonen Raum ein.

Aufschlussreich sind ihre Erläuterungen, welche Schwierigkeiten ihr bei der Zusammenstellung ihres Korpus begegnen. Aufgrund der Proliferation von Definitionen und Etiketten für digitale Literatur und einer Vielzahl verwandter Formen muss Bauer Kriterien für die Aufnahme der Texte in ihr Korpus entwickeln. Ausgeschlossen werden nicht-literarische digitale Texte, wobei Bauer ihren Literaturbegriff nicht näher erläutert, sowie nachträglich digitalisierte Printwerke. Positive Auswahlkriterien sind u. a. das Vorhandensein des Strukturkonzepts Hypertext, die Nutzung von Multimedia-Elementen und die Verwendung eines medienspezifischen Zeicheninventars. Unberücksichtigt bleiben kollaborative Projekte, Internettagebücher und Webblogs - also Formen, die im Wesentlichen auf der späteren Web 2.0-Technologie basieren -, sowie net-art und Computerspiele. Damit konzentriert sich die Untersuchung im Wesentlichen auf Hyperfictions, also auf jene Hypertexte, die Bauer zur ,Narrativik‘ zählt, worunter sie Erzähltexte im Sinne der klassischen Einteilung von Literatur in die Großgattungen Lyrik, Dramatik und Epik versteht. Problematisch an dem Gegenstand ist, wie die Verfasserin selbst bedauernd feststellt, die Flüchtigkeit der Texte, die häufig die Domain wechseln oder unauffindbar sind - dies mag der Grund sein, warum Bauer ihre Untersuchung auf digitale Poesie ausweitet, die überwiegend auf CD-Rom verfügbar ist, auch wenn sie sich hinsichtlich des Trägermediums, des Vertriebs und der Nutzung von Algorithmen von Hyperfictions unterscheidet.

Dank Bauers Untersuchungen erhält auch der nicht informationswissenschaftlich vorgebildete Leser einen Einblick in die gattungsspezifische Verwendung der Ausdrucksmöglichkeiten, die das World Wide Web der digitalen Literatur bietet, und kann die Auswirkungen des Mediums auf Narration, Ästhetik und das Verhältnis Autor-Erzähler-Leser nachvollziehen. Als hilfreich erweist sich bei der Analyse die Übertragung von Kristevas Unterscheidung zwischen Geno- und Phänotext auf die digitale Literatur als einem unübersichtlichen Bündel von Lektüreoptionen einerseits und einem durch die Rezeption linearisierten, einmaligen Text andererseits. 
$\mathrm{Zu}$ den von Bauer herausgearbeiteten Merkmalen von Hyperfictions zählen die Unterstrukturierung des Genotexts aufgrund seiner vielen Handlungsvarianten und mangelnden Chronostrukturen, die mit einer Überstrukturierung durch Nutzung neuer Textorte in der Benutzeroberfläche oder durch die Beigabe von Gebrauchsanleitungen kompensiert werden. Da zentrale Regeln der Softwareergonomie regelmäßig subvertiert werden, spricht Bauer hier von einer Poetik der Deautomatisierung. Typisch für Hyperfictions seien außerdem eine kaum ausgearbeitete Figurenpsychologie und das Fehlen einer manifesten Erzählerfigur.

Eine Schwäche, die die Arbeit ironischerweise mit ihrem Gegenstand teilt, ist ihre mangelnde Strukturiertheit. So unterschlägt das Inhaltsverzeichnis zahlreiche Unterpunkte der Gliederung. Die Arbeit weist außerdem viele Redundanzen auf. Auch vermisst man eine klar dargelegte Methode bei der Analyse der Hyperfictions und der digitalen Poesie. Stattdessen werden, teilweise ohne Diskussion der Begriffe, Einzelaspekte wie ,Textort', ,Erzähleridentität', ,Fokalisierung', ,Perspektive' und ,Kommunikationssituation' abgearbeitet. Eine Auseinandersetzung mit aktuellen erzähltheoretischen Ansätzen und mit der Frage nach der Ubertragbarkeit dieser Ansätze auf digitale Literatur wäre hier ebenso wünschenswert gewesen wie die Untersuchung der Gründe für den offensichtlichen Misserfolg der Hyperfictions beim Publikum.

Nathalie Mälzer, Hildesheim

Beck, Joachim/Larat, Fabrice (dir.) : Transnationale Verwaltungskulturen in EuropaBestandsaufnabme und Perspektiven. Les cultures administratives transnationales en Europe - Etat des lieux et perspectives, Baden-Baden : Nomos/Zürich : Dike, 2015, $351 \mathrm{p}$.

Cet ouvrage collectif est basé sur les résultats d'un projet de recherche et de plusieurs séminaires conduits par l'Euro-Institut de Kehl, l'Ecole Nationale d'Administration et le Pôle européen d'administration public de Strasbourg. Produit dans une zone frontalière dans le cadre d'un projet transnational, cet ouvrage bilingue est dirigé par deux professeurs, Joachim Beck et Fabrice Larat, spécialistes des cultures administratives, ayant tous deux des parcours de formation franco-allemands. Le titre est plus général que son contenu, la plupart des 19 contributions, à part quelques exceptions comme celles du Suisse Martin Weber et de Michel Casteigts, ont une perspective et un contenu franco-allemand. Cette spécificité contextuelle n'est aucunement un point faible, ni pour les lecteurs du Frankreich-Forum, ni non plus pour la qualité du contenu, tant la spécificité contextuelle permet ici d'offrir une profondeur de réflexion en offrant de multiples et exhaustifs éclairages sur les acteurs, les structures et les règles, les enjeux et les mécanismes de la construction d'une 
culture de travail franco-allemande dans le champ des coopérations administratives transfrontalières et transnationales.

S'il est impossible de rendre compte de l'ensemble des contributions de l'ouvrage, il faut souligner que l'ouvrage présente trois types de contributions :

Certains chapitres sont des résultats d'études empiriques, c'est le cas par exemple du chapitre d'Ulrike Becker-Beck et de Joachim Beck qui présente une enquête menée auprès des acteurs administratifs dans la région du Rhin supérieur sur les différences entre cultures administratives nationales et transnationale et met en évidence l'émergence d'une culture de la coopération administrative transfrontalière ; Fabrice Larat présente également une autre enquête originale sur la culture administrative des projets de coopération francoallemande auprès d'agents ministériels, l'enquête souligne aussi l'existence d'un modus operandi hybride entre positions françaises et allemandes.

D'autres chapitres sont plutôt des contributions conceptuelles d'experts qui visent à cerner certaines notions clefs ou certains éléments du cadre de référence des pratiques administratives, c'est le cas par exemple du juriste Karl-Peter Sommermann qui traite de l'influence de l'européanisation du droit sur les cultures administratives nationales, ou du chapitre du sociologue Cédric Duchêne-Lacroix qui définit les éléments d'une culture administrative transnationale commune.

Enfin, et c'est une force de l'ouvrage, certains chapitres sont des témoignages d'acteurs clefs de ces projets de coopération franco-allemands, par exemple celui de Bertrand Cadiot, ancien fonctionnaire d'échange français au Ministère fédéral allemand de l'Intérieur, ou celui de Ben Behmenburg et Jean-Luc Taltavull sur le centre commun de coopération policière et douanière de Kehl.

Cette diversité de chapitres permet des entrées multiples pour comprendre la dynamique de la construction d'une culture administrative francoallemande (ou des cultures administratives franco-allemandes, tant il y a ici diversité). Mais surtout, la présence de nombreux témoignages et les cadres conceptuels utilisés donnent de l'importance aux acteurs, à leur socialisation, leur légitimité personnelle, leurs réseaux et leurs compétences, qui sont des ressources essentielles de cette construction transnationale et des constructions européennes à venir.

Parce qu'il permet une meilleure compréhension de l'action administrative transnationale, l'ouvrage devrait intéresser un public large, au-delà d'une communauté de spécialistes. Sa lecture est à recommander aux acteurs des administrations régionales, nationales et européennes et aux acteurs politiques, mais aussi à tous les citoyens des zones frontalières pour comprendre les enjeux et les difficultés des projets de coopération. De manière plus générale, c'est aussi un excellent ouvrage de management interculturel franco-allemand contextualisé, avec une richesse d'études empiriques et d'approches théoriques, qui permet de comprendre comment se construit une culture de travail franco-allemande dans le domaine administratif. 
Enfin, l'ouvrage propose deux grandes conclusions intéressantes. Premièrement, Beck et Larat rappellent que le succès des projets de coopération franco-allemands passe par des acteurs qui développent des compétences interculturelles et des connaissances intimes du système administratif voisin ainsi que des interactions privilégiées avec certains acteurs de l'autre pays (par des échanges, des séjours à l'étranger, des missions de coopération, des projets transnationaux...). Ces compétences mais aussi ces liens entre acteurs spécialistes (Fachbrïderschaften) sont un facteur de succès essentiel des projets de coopération administrative. Le deuxième enseignement majeur de l'ouvrage, c'est que la coopération administrative transnationale est un élément moteur d'une construction administrative européenne trop souvent conçue comme un processus d'intégration supranational venant de Bruxelles. En mettant l'accent sur les compétences et les ressources des acteurs nationaux développés dans les projets et les coopérations administratives transnationales, Beck et Larat rappellent que ce sont ces compétences et ces acteurs que l'on peut et doit mobiliser dans le cadre de la construction européenne.

La notion, et surtout le phénomène, de Fachbrüderschaft dans les coopérations transnationales m'ont particulièrement intéressé, car il confirme ce que nous observons, avec mon collègue et Fachbruder Christoph Barmeyer, dans nos propres travaux sur les cultures de travail franco-allemandes chez ARTE ou ALLEO (SNCF/DB) où nous soulignons l'importance de ces liens privilégiés entre experts des deux pays pour l'apprentissage organisationnel. Il est intéressant de constater que cette notion de «ebenen-übergreifenden administrativen Fachbrüderschaften » (p. 25) qui apparait dans l'introduction de Joachim Beck apparait autrement formulée (« connivences administratives trans-niveaux ») (p. 52) dans la version française de l'introduction de Fabrice Larat. Ce seul exemple d'une notion allemande intraduisible en français mais ayant un fort potentiel de réflexion théorique justifierait, entre autres exemples, l'existence d'une double introduction et d'un ouvrage bilingue franco-allemand. Cet exemple offre une belle illustration aux arguments de Michel Casteigts pour la défense d'un multilinguisme administratif européen face à l'envahissant globish bruxellois, un multilinguisme administratif qui rend certes la communication plus lente et plus compliqué mais qui permet un travail de conceptualisation plus riche et permet surtout de rendre plus fidèlement compte de la complexité des contextes nationaux.

Eric Davoine, Fribourg/Suisse 
Boubeker, Ahmed/Ottersbach, Markus (dir.): Diversité et participation. Approches franco-allemandes de l'action sociale pour la jeunesse des quartiers marginalisés, Paris: Téraèdre, 2015, 203 S.

Der von Ahmed Boubeker und Markus Ottersbach herausgegebene Sammelband beinhaltet interessante Reflexionen zur Jugendsozialarbeit in den marginalisierten Stadtvierteln in Frankreich und Deutschland. Sie stammen von einer durch das Deutsch-Französische Jugendwerk (DFJW) finanzierten Forschergruppe namens „Diversität und Partizipation“. Diese hat das vom DFJW und der Stiftung Genshagen seit 2006 finanziell unterstützte deutsch-französische Netzwerk „Integration und Chancengleichheit fördern“ - seit einem Jahr heißt es wie die Forschergruppe selbst „Diversität und Partizipation fördern“ - evaluiert. Zum Netzwerk gehören 30 deutsch-französische Austauschprojekte von Jugendlichen. Es geht dabei um die Bekämpfung von Vorurteilen und sozialer Ausgrenzung, die Förderung sozialer und professioneller Integration sowie das Erlernen interkultureller Kompetenzen. Der Sammelband ist als Begleitbuch zum Evaluationsbericht der Forschergruppe erschienen.

In einem einführenden theoretischen Aufsatz sieht Markus Ottersbach den Erfolg der qualitativen Forschung in der heutigen sozialwissenschaftlichen Forschung als das Resultat von Modernisierungs- und Individualisierungsprozessen. Es geht um Erzeugung von Sinnhaftigkeit und um Biografien. Ottersbach plädiert bezüglich der Migrationsforschung für die Untersuchung reflexiver interkultureller Kompetenzen im Sinne Franz Hamburgers: Differenzen werden auf ihre angebliche kulturelle Dimension reflexiv und kritisch überprüft. Dabei wird die Intersektionalität berücksichtigt. Kultur wird hier in Anlehnung an Georg Auernheimer als Orientierungssystem dynamisch und nicht statisch betrachtet.

Ahmed Boubeker, Professor für Soziologie und Demografie in SaintEtienne, relativiert den Gegensatz zwischen einer französischen politischen und einer deutschen ethnischen Definition der Nation. In Anlehnung an Gérard Noiriel betont er, dass republikanisches Gedankengut schon immer auch in Deutschland zu finden war, und dass der u. a. von Le Bras scharf beanstandete „démon des origines“ (S. 29) auch im französischen Republikanismus einen festen Platz hat. Zugleich setzt er sich für eine stärkere Berücksichtigung der ethnischen Dimension sozialer Ungleichheiten in Frankreich ein und wünscht sich für dieses Land weniger Farbenblindheit. Er nimmt zu sogenannten ,ethnischen Statistiken“ Stellung (S. 30). Boubeker erwähnt den Ruf Philippe Genestiers nach einer ,kommunitaristischen Integration“ (S. 37), ein in Frankreich echtes Tabuthema, wobei er zugleich auch wie Ottersbach auf die kreative Dimension bei der Konstruktion von Normen- und Wertesystemen durch Migrantenkinder der zweiten Generation Wert legt. 
Ottersbach und Sonja Preissing stellen fest, dass es mehrere Formen von Diskriminierungen gibt, die zur Ausgrenzung führen. Sie erwähnen auch unterschiedliche Typen von marginalisierten Quartieren. Einige werden schnell durch Gentrifizierung zu angesehenen Stadtvierteln, während andere unter einer strukturellen Stigmatisierung leiden. Weitere profitieren von Rehabilitierungsmaßnahmen. Die Autorinnen und Autoren finden in den Studien der Stadtsoziologen Hinweise, dass Städte sehr wohl Integrationspotenziale vorweisen können. Dafür soll allerdings die Zivilgesellschaft mobilisiert werden und die Fähigkeit der Einwohner, ihre Lage positiv zu verändern, besser wahrgenommen werden (vgl. S. 53).

Nach einem Beitrag Piero Galloros zur Bedeutung der Jugend in der heutigen Sozialwissenschaft in Frankreich, stellen Andreas Thimmel und Schahrzad Farrokhazd die Strukturen und Maßnahmen der Jugendsozialarbeit in Deutschland gekonnt dar, während Hervé Paris die auf die Jugendlichen gerichtete Integrationspolitik in Frankreich analysiert. Dabei wird klar, dass wir es in diesem Land trotz mehrerer öffentlicher Berichte mit einer Anhäufung von Regelungen und Interventionen ohne Gesamtlogik zu tun haben. Bei der

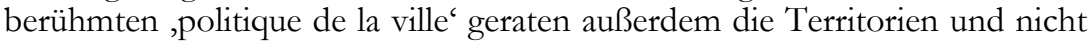
die Einzelnen ins Zentrum des öffentlichen Interesses. Anerkennungspolitik und Öffnung einer Zukunftsperspektive sollten im Kern der Integrationspolitik stehen, nicht das Herausreißen von Einzelnen aus ihren Milieus u. a. durch positive Diskriminierung. Die politischen Maßnahmen in den beiden Ländern werden in den Beiträgen äußerst kenntnisreich geschildert. In einem Anhang stellt Paris die Chronologie der französischen Integrationspolitik bezüglich der Jugendlichen dar (vgl. S. 127-132). Es fehlt jedoch hier, wie auch im ganzen Buch, eine wirklich vergleichende Perspektive. Nach der Lektüre der beiden Beiträge wissen wir nicht, welche Gemeinsamkeiten und Unterschiede es in Frankreich und Deutschland bei den Problemen und bei der Suche nach Problemlösungen gibt. Insofern bleiben die Herausgeber dem "methodologischen Nationalismus" verhaftet, den sie in der Schlussfolgerung ausdrücklich kritisieren (S. 175).

Schahrzad Farrokhazd und Markus Ottersbach beschäftigen sich in einem Aufsatz mit der Erziehung als Alternative zur Sozialarbeit, wobei die Autoren zu Recht die Komplementarität der beiden betonen. V. a. eine interkulturelle Erziehung und eine multiperspektive Sicht der Geschichte können ihrer Meinung nach die Integration von Jugendlichen mit einem Migrationshintergrund fördern. Wie Thomas Pierre feststellt, ist es wichtig, die Handlungsfähigkeiten und den Erfindungsreichtum der Jugendlichen aus den marginalisierten Stadtvierteln anzuerkennen und positiv hervorzuheben. 
Der Beitrag des DFJW-Netzwerks „Integration und Chancengleichheit fördern" zur Erreichung dieses Ziels wird in den Schlussworten von Ahmed Boubeker und Markus Ottersbach positiv hervorgehoben.

Yves Bizeul, Rostock

Dumoulin, Michel/Elvert, Jürgen/Schirmann, Sylvain (dir.) : Encore ces chers voisins. Le Benelux, l'Allemagne et la France aux XIXe et XXe siècles, Stuttgart: Franz Steiner, 2014 (Studien zur Geschichte der Europäischen Integration 7), $256 \mathrm{p}$.

L'ouvrage dont il est rendu compte ici rassemble les contributions issues d'un colloque du groupe de recherche « Ces chers voisins », composé d'historiennes et historiens belges, luxembourgeois, néerlandais, français et allemands et dont les travaux sont centrés sur l'étude de l'intégration au niveau des Etats, des institutions et des individus des territoires de l'aire constituée par le Benelux, l'Allemagne et la France.

Le colloque en question, dédié plus particulièrement à la période qui va des années 1860 au milieu des années 1950, a eu lieu à Cologne du 19 au 21 novembre 2008.

Deux thèses structurent l'ensemble du volume. La première est que, malgré toutes les ruptures qui l'ont traversée, l'histoire de l'espace formé par les cinq pays envisagés est caractérisée par une évolution commune qui a commencé lorsque s'est mis en place le second Reich allemand en 1871 et a connu un aboutissement provisoire au cours des années 1950. A la base de cette évolution, on trouve les débats issus en Belgique et aux Pays-Bas de la guerre franco-prussienne de 1870-1871 et dont le sujet central était le positionnement des deux pays dans le nouveau système européen issu de ce conflit. Ce sont ces débats et les expériences de trois générations qui, après la Seconde Guerre mondiale, rendront les esprits mûrs pour avancer sur la voie de l'intégration européenne. Les réflexions menées par ces trois générations servent de fil conducteur aux seize contributions réunies dans le présent volume et regroupées en six chapitres.

Le premier chapitre est centré sur l'entre-deux-guerres et propose deux mises au point très denses traitant des positions qui ont été celles des intellectuels sur la question de l'Europe ainsi que sur l'héritage des deux conflits mondiaux dans le système et la culture politiques de la Belgique jusqu'à sa transformation en Etat fédéral.

Le chapitre suivant propose trois éclairages qui envisagent dans la durée les relations triangulaires entre la France, l'Allemagne et le Benelux, puis examinent plus particulièrement les lignes de force de la politique de la République fédérale d'Allemagne à l'égard du Benelux et, enfin, situent la place de la 
France dans la construction européenne, en insistant sur la manière dont ce pays s'est positionné face à l'Allemagne et au Benelux.

Après ces deux chapitres dédiés à l'histoire de la construction européenne, l'accent est porté tout d'abord sur la situation des régions transfrontalières dans le triangle Benelux-France-Allemagne. Celle-ci, dans un premier temps (chapitre 3), est envisagée au plan économique au moment de la mise en place d'un nouveau système européen dans la foulée de Locarno, puis en fonction de la situation particulière de la région d'Eupen-Malmedy. Ensuite (chapitre 4), ce sont les problèmes d'organisation territoriale et d'aménagement de l'espace transfrontalier au tournant des années 2000 qui sont examinés. Cet aspect comporte un volet économique très important dont il est ensuite question (chapitre 5) aux niveaux transnational et transrégional. L'ouvrage se termine par un chapitre qui envisage les transferts culturels et scientifiques dans l'aire considérée sous trois angles : les perceptions réciproques dans l'espace germanobelge, les images de l'Allemagne diffusées dans les historiographies belge, néerlandaise et française et enfin les visions allemande et belge de la 'collaboration' pendant les années 1940-1945.

L'intérêt de l'ouvrage réside essentiellement dans la diversité et la densité des mises au point synthétiques qu'il propose sur une question dont les auteurs parviennent à démontrer l'importance pour qui s'intéresse à la construction européenne et aux relations transfrontalières. On regrettera que dans sa version française, traduite de l'allemand, le texte de l'introduction soit franchement défectueux en raison de nombreuses impropriétés, approximations de vocabulaire et fautes de langue qui ne manquent pas d'étonner.

Michel Grunewald, Metz

Filipová, Lucie: Erfiullte Hoffnung. Städtepartnerschaften als Instrument der deutschfran₹ösischen Aussöbnung, 1950-2000, Göttingen: Vandenhoeck \& Ruprecht, 2015 (Veröffentlichungen des Instituts für Europäische Geschichte Mainz, Bd. 237), 409 S.

In diesem von der Abteilung für Universalgeschichte des Instituts für Europäische Geschichte Mainz herausgegebenen Buch wird ein wichtiges Kapitel der europäischen Geschichte behandelt. Die Autorin, Lucie Filipová, beschäftigte sich im Rahmen einer 2012 fertig gestellten Dissertation an der KarlsUniversität Prag mit den Städtepartnerschaften (jumelages) als eines der wichtigsten und erfolgreichsten Instrumente der deutsch-französischen Aussöhnung. Das hier besprochene Werk ist eine überarbeitete deutsche Version der im Prager Verlag Academia 2013 zum ersten Mal veröffentlichten Arbeit, die von Nina Lohmann aus dem Tschechischen übersetzt worden ist. 
Die Idee der Städtepartnerschaften als Mittel, um kriegerischen Konflikten entgegenzuwirken, geht auf ein 1943 vom Baseler Professor für Verfassungsgeschichte, Adolf Gasser, entwickeltes Modell zurück. Nach einem ersten Treffen in der Schweiz - also auf neutralem Boden - im Jahre 1948 war es 1950 zur Gründung der Bürgermeister-Union für deutsch-französische Verständigung und europäische Zusammenarbeit sowie zur Bildung der ersten Städtepartnerschaften gekommen. Wertvoll an dem Buch ist die wissenschaftlich fundierte Vorgehensweise bei der Analyse der spezifischen Entwicklung der deutsch-französischen Städtepartnerschaften, deren Modellfunktion und Vielfalt. Hierbei finden nicht nur die beabsichtigte politische, kulturelle und wirtschaftliche Dimension, sondern v. a. auch die zivilgesellschaftlichen Aktivitäten, also die vielen Initiativen auf lokaler Ebene, Beachtung.

Nachdem im ersten Kapitel methodische Aspekte besprochen und interdisziplinäre Zugänge vorgestellt werden, widmet sich das zweite Kapitel einer Analyse der allgemeinen Rahmenbedingungen. Die strukturellen Unterschiede zwischen beiden Staaten, aber auch die konkreten politischen Entwicklungen und Maßnahmen sowie der gesamteuropäische Kontext werden hier vorgestellt. In den fünf folgenden Kapiteln (Kapitel 3 bis 7) findet sich eine chronologische Darstellung der deutsch-französischen Partnerschaften und eine genaue Analyse der verschiedenen Phasen der bilateralen Zusammenarbeit auf kommunaler Ebene.

In Kapitel 3 „Unsichere Erfolgsaussichten (1950-1962)“ wird gezeigt, wie die erste Phase vom Gefühl, an einem Experiment mit unsicherem Ausgang teilzunehmen, geprägt war. Die Zahl der geschlossenen Partnerschaften dient als Maß für den Erfolg der Idee, wobei immer wieder nach den Ursachen für ein Stagnieren oder eine Beschleunigung gefragt wird. Von besonderem Interesse ist die Auswirkung der offiziellen politischen Beziehungen auf die Intensität der kommunalen Zusammenarbeit.

Unter dem Titel „Wachsende Popularität und geographische Ausweitung (1963-1973)“ widmet sich das vierte Kapitel der Zeit nach dem ElyséeVertrag, der sowohl ideell wie auch materiell eine eigenständige Weiterentwicklung der Aktivitäten in beiden Ländern ermöglichen sollte. Für diese Zeit ist von mehreren „Zwischenstaatliche[n] Krisen“ (S. 180) und von bisweilen sehr angespannten politischen Beziehungen in den Jahren 1964, 1968 und 1973 die Rede, während die Zahl von neu geschlossenen Partnerschaften weiter zunimmt und die Popularität der kommunalen Zusammenarbeit bei den Menschen in der Bundesrepublik und in Frankreich immer größer wird.

Im fünften Kapitel wird die „Suche nach neuen Inhalten (1974-1981)“ der folgenden Periode dargestellt. Diese Zeit des Aufschwungs ist durch eine bewusste Abkehr vom „Zwang des Elysée-Vertrags“ (Ziebura 1997, zitiert S. 189) charakterisiert, während „losere Kooperationsformen“ (Ziebura 1997, zitiert S. 226) entstehen. Die Zusammenarbeit zwischen deutschen und französischen Gemeinden wird in dieser Phase als „Massenphänomen“ (S. 227) 
mit einer „eigenen Dynamik“ (S. 227) beschrieben, sodass die deutsch-französischen Städtepartnerschaften immer mehr zu einem fixen und normalen Bestandteil der kommunalpolitischen Agenda werden.

Wie im Kapitel 6 „Die Hochphase der Kooperation und ihre Klippen (1982-1989)“ festgehalten, ist das gemeinsame Wirken von Helmut Kohl und François Mitterrand in dieser Phase entscheidend, wobei sich die Dezentralisierung in Frankreich günstig auf die Bildung von neuen Kooperationen auswirkte. Die unterschiedlichen Entwicklungen in den verschiedenen Regionen werden hier auch unter Einbeziehung aller möglichen Wirkfaktoren dargestellt. Diese Phase, in welcher die deutsch-französische Versöhnung als erfolgreich abgeschlossen betrachtet wird, ist von einer stärkeren Einbindung der Bürger, besonders der jungen Generation, geprägt.

Im siebten Kapitel „Neue Mittel zur Erreichung neuer Ziele (19902000)“ wird die notwendige Neugestaltung der deutsch-französischen Kooperation vor dem Hintergrund der deutschen Wiedervereinigung wie auch der zunehmenden europäischen Integration spürbar. Wie von der Autorin im Schlusskapitel erwähnt, wird hier eine Fülle von wichtigen Fragen aufgeworfen. Diese müssten von weiteren Forschungen aufgegriffen werden. Die von der Autorin angeführten Themenfelder betreffen dabei einerseits die Arbeit mit den zur Verfügung stehenden Daten. Hier geht es um die Überprüfung der Gründe für „einige statistische Ausschläge“ (S. 368). Andererseits werden von der Autorin auch Themen wie die Untersuchung der Entwicklung und des Wandels der kommunalen Kooperation zwischen der DDR und Frankreich oder die Suche nach den Gründen für die zahlenmäßigen Unterschiede bei den regionalen Abschlüssen von Partnerschaften erwähnt.

Im siebten Kapitel wird auch eine Reihe von Fallbeispielen detailliert besprochen. Während die involvierten Gemeinden und Bürger die politischen Entwicklungen genau verfolgten und $z$. B. durch zahlreiche Jugendaustauschprogramme und weitere Aktivitäten zu unterstützen versuchten, fehlte auf höherer Ebene eine entsprechende Reflexion über den Stellenwert der deutschfranzösischen Beziehungen. Dies wird als Bestätigung dafür gewertet, dass der bilaterale Rahmen zugunsten einer Verlagerung auf die europäische Ebene verlassen wurde. Denn in immer mehr Bereichen wurden neue Förderungen und so auch neue Spielregeln eingeführt.

Das vorliegende Buch ist ein wertvoller Beitrag, um die deutsch-französische Aussöhnungspolitik nach dem Zweiten Weltkrieg zu verstehen. Es ist das Ergebnis einer intensiven Forschungsarbeit in Archiven und einer Auswertung von vorhandenem statistischem Material, wobei die Autorin immer wieder auf einige Schwächen der Datenlage hinweist. Von besonderem Interesse ist die Darstellung des Spannungsverhältnisses zwischen höherer Politik und Bürgerinitiativen, wenn von der ,eigenständigen Dynamik der deutschfranzösischen Städte- und Gemeindepartnerschaften“ (S. 360) die Rede ist. Insgesamt handelt es sich um eine sehr lesenswerte historische Darstellung, 
in welcher sich der Pioniergeist der europäischen Idee wiederfindet und die die von der Politik übersehene Rolle der Zivilgesellschaft bei der Durchsetzung solcher Ideen erkennt. Darüber hinaus wird deutlich, wie sehr die deutsch-französischen Städtepartnerschaften Teil der Kulturgeschichte beider Länder geworden sind und wie wichtig es wäre, im Zeitalter der europäischen Integration mehr auf solchen Fundamenten aufzubauen.

Marie-France Chevron, Wien

Hähnel-Mesnard, Carola/Herbet, Dominique (Hg.): Fuite et expulsions des Allemands. Transnationalité et représentations 19e-21e siècle, Villeneuve d'Ascq: PU du Septentrion, 2016, 330 S.

Die Konstellation, die dem hier zu besprechenden Sammelband zugrunde liegt, ist durchaus reizvoll: Auf Initiative der beiden in Lille lehrenden Germanistinnen Carola Hähnel-Mesnard und Dominique Herbet haben sich 22 Autorinnen und Autoren aus verschiedenen Nationen und verschiedenen Disziplinen versammelt, um den Platz von Flucht und Vertreibung der Deutschen Ost- und Ostmitteleuropas im öffentlichen Diskurs und in der kollektiven Erinnerung zur Zeit der Wende vom 20. zum 21. Jahrhundert zu beleuchten. Der übliche (und natürlich überaus wertvolle) Dialog der ,Betroffenen' wird hier auf eine sehr willkommene und fruchtbare Weise um die Perspektive der Beobachter erweitert.

Dabei decken die Beiträge des Bandes ein ausgesprochen breites Spektrum ab, sowohl hinsichtlich der untersuchten Medien und Modi der Erinnerung an Flucht und Vertreibung als auch hinsichtlich der untersuchten Vertreibungsfälle: So stehen zwar die Zwangsmigrationen der Deutschen aus Polen und der ehemaligen Tschechoslowakei im Vordergrund, aber auch der Deportation und späteren Aussiedlung der Wolgadeutschen sowie der komplexen Geschichte der deutschen Siedler in Rumänien (Banatschwaben und Siebenbürger Sachsen) sind einzelne Beiträge gewidmet. Ein im eigentlichen Sinne ,transnationaler ${ }^{6}$ Ansatz, wie ihn der Untertitel verspricht, wird allerdings nur in wenigen Arbeiten konsequent umgesetzt. So interessiert sich etwa Katarzyna Woniak (Berlin) in ihrem Beitrag für die gemeinsame Erinnerungsarbeit, die von Deutschen und Polen in dem kleinen Städtchen Lobez/Labes in Pommern geleistet wird. In den meisten Beiträgen hingegen ist transnational nur der ereignisgeschichtliche Hintergrund, also die Vertreibung; seine mediale Repräsentation hingegen wird im nationalen Rahmen untersucht.

Den Auftakt bilden vier Beiträge, die unter dem Titel „Approches globales et histoire croisée“ zusammengefasst werden. Michael Schwarz widmet sich der Frage nach der angemessenen geographischen und zeitlichen Analyseebene für das Phänomen der Vertreibungen und plädiert engagiert für 
einen weiten Ansatz, der die Zwangsmigrationen des Kriegsendes in den globalen Kontext der ethnischen Säuberungen integriert und der zeitlich bis in das 19. Jahrhundert zurückreicht. Bill Niven untersucht anhand zweier Fernsehserien der frühen 1980er Jahre die ,Konkurrenz der Erinnerungen' (vgl. S. 44) zwischen Holocaust und Vertreibung und macht darauf aufmerksam, dass der Vertreibungsdiskurs nicht isoliert von der allgemeinen Entwicklung der ,Vergangenheitsbewältigung ${ }^{6}$ analysiert werden kann. Anne Bazin und Helmut Fehr widmen sich anschließend dem Thema von Flucht und Vertreibung im politischen Diskurs: Bazin mit einem Fokus auf die bilateralen Beziehungen zwischen der Bundesrepublik und ihren östlichen Nachbarn, Fehr aus einer primär innenpolitischen Perspektive, wobei er interessante Parallelen, aber auch Unterschiede zwischen Polen und Tschechien aufzeigt: Während in beiden Ländern der Reiz weiterhin groß ist, die Geschichte zu instrumentalisieren und antideutsche Ressentiments in Wahlkämpfen zu mobilisieren - Fehr spricht gar von einer ,Re-Traditionalisierung' (vgl. S. 74) -, beobachtet er in Tschechien eine deutlich größere Bereitschaft der jüngeren Generation, in lokalen Initiativen einen neuen, von europäischem Geist und gegenseitiger Empathie geprägten Blick auf die geteilte Geschichte von Krieg, Unterdrückung, Holocaust und Vertreibung zu wagen.

Im zweiten Block „Approches historiographiques“ widmet sich Gwénola Sebaux zunächst den in den 1950er Jahren erschienenen ,Heimatbüchern' der Russlanddeutschen und betont die historiographische Qualität dieser Quelle. Pierre de Trégomain hingegen zeigt am Beispiel der Siebenbürger Sachsen, dass sich auch Gruppen ohne Vertreibungserfahrung im engeren Sinne bemühen, ihre Geschichte in den allgemeinen Diskurs um Flucht und Vertreibung einzuschreiben. Pascal Fagot und Jerzy Józef Kołacki richten den Blick auf die jüngere polnische Historiographie: Deren Erträge beurteilt Kołacki in seiner Gesamtschau der polnischen Forschung allerdings eher skeptisch, auch wenn es irreführend sei, von einem Tabu zu sprechen. Museen und audiovisuelle Medien stehen im Fokus des folgenden Abschnitts: Catherine Perron zeigt, dass in der Bundesrepublik in den letzten Jahren eine Reihe neuer Museen und Ausstellungen entstanden ist, die, indem sie anstelle der Vertriebenen die Vertreibungsgebiete in den Mittelpunkt rücken, eine deutlich transnationale Perspektive einnehmen und auch die Zusammenarbeit mit polnischen oder tschechischen Partnern suchen; Michael Dorrmann stellt anschließend die Konzeption der geplanten Dauerausstellung der Stiftung Flucht, Vertreibung und Versöhnung vor. Maren Röger und Christian Jacques widmen sich dokumentarischen und fiktionalen Fernsehproduktionen der letzten Jahre, Röger in synchroner Perspektive im deutsch-polnischen Vergleich, Jacques in diachroner Perspektive, indem er die ARD-Dokumentation von 1981 „Flucht und Vertreibung“" (die auch schon Niven in seinem Beitrag analysiert hatte) mit der ZDF/Guido Knopp-Produktion „Die Große Flucht" von 2001 kontrastiert. 
Mit nicht weniger als sieben Beiträgen bildet die literarische Verarbeitung des Vertreibungsthemas den thematischen Schwerpunkt des Bandes. Während Friederike Eigler über den ,Raum' und Emmanuelle Aurenche über die ,Reise einen motivisch-thematischen Zugang gewählt haben, analysieren Meike Penkwitt und Katja Schubert den Aspekt der Vertreibung im Werk einzelner Autoren (Erica Pedretti und Christa Wolf). Dass die Vertreibung inzwischen auch in der polnischen und tschechischen Literatur thematisiert wird, zeigen anschließend Martin Cieński, Kristyna Matysova und Martin Petras in ihren Beiträgen, wobei sich der Eindruck bestätigt, dass in Tschechien eine größere Bereitschaft besteht, neue Wege in der Verarbeitung der historischen Ereignisse zu gehen.

Der abschließende Themenblock steht unter dem gemeinsamen Titel „Dimensions mémorielles“. Während Alice Volkwein aus einer Makroperspektive den Charakter von Flucht und Vertreibung als nationaler, transnationaler oder europäischer ,Erinnerungsort' diskutiert, widmet sich Katarzyna Woniak in ihrer lokalen Fallstudie dem gemeinsamen deutsch-polnischen Gedenken. Ségolène Plyer wiederum untersucht mit dem Instrumentarium der Oral History in einer erfahrungsgeschichtlichen Perspektive die individuelle, biographische Verarbeitung der Vertreibung, während Gwénola Sebaux in ihrem Beitrag über die Banatschwaben primär auf das Gruppengedächtnis und die Gruppenidentität fokussiert. Die gemeinsame Klammer, die die vier Beiträge zusammenhält, ist hier - wie auch an anderen Stellen des Bandes nicht leicht zu erkennen. Auch die Zuordnung der Einzelbeiträge zu den verschiedenen Blöcken erscheint nicht immer ganz glücklich. Deren Qualität tut dies jedoch keinen Abbruch: Insgesamt handelt es sich um einen ausgesprochen anregenden Band, der die Vielschichtigkeit und den Facettenreichtum des Themas widerspiegelt und zudem einen Einblick in die erstaunlich lebendige französische Forschung zum Komplex Flucht, Vertreibung und Erinnerung bietet.

Daniel Mollenhauer, München

Hörner, Fernand/Mathis-Moser, Ursula (dir.) : Das französische Chanson im Licht medialer (R)evolutionen/La chanson française à la lumière des (R)évolutions médiatiques, Würzburg : Königshausen \& Neumann, 2013, 262 p.

La chanson francophone, longtemps considérée comme 'mineure', est un genre hybride. Elle se distingue, si l'on cherche par exemple des équivalents allemands, autant du Lied que du Schlager. La chanson française en particulier est un phénomène historique ancien, que l'on peut étudier dans la diachronie : rappelons simplement l'étude d'Annette Keilhauer sur la chanson française à la fin de l'Ancien Régime, les travaux de Dietmar Rieger sur la « chanson du 
Pont-Neuf» (p. 51 s.) aux XVII et XVIII e siècles, les travaux sur la chanson pendant l'Occupation et la Résistance, ou encore le phénomène du rap comme « chanson enragée et engagée » (selon la formule d'Eva Kimminich) (p. 239 s.).

Depuis les années 1990, l'étude de la chanson francophone s'est solidement ancrée dans la romanistique germanophone et elle s'est dotée de groupes de recherche dans ce domaine. Ainsi, une banque de données sur la chanson féminine a été établie par Andrea Oberhuber à Innsbruck dès la fin des années 1990. En 2011, un Chansonarchiv Saarbrücken (CAS) a ouvert, et en 2014 un Zentrum für populäre Kultur und Musik - issu du Deutsches Volksliedarchiv (DVA).

L'ouvrage bilingue dirigé par Fernand Hörner et Ursula Mathis-Moser, issu d'une section du congrès allemand des franco-romanistes en 2012, s'inscrit dans le champ disciplinaire de la 'cantologie', d'inspiration française et il relève également des approches en termes de Textmusik, concept développé par Werner Faulstich en 1978. Le 'canteur', catégorie d'analyse créée par Stéphane Hirschi en 1995, désigne ainsi le sujet chantant d'une chanson, par analogie avec le narrateur pour le récit. L'excellente introduction (bilingue) des directeurs scientifiques de l'ouvrage souligne que la chanson, « genre impossible » (p. 9), invite tout particulièrement à s'intéresser au jeu complexe des interactions et imbrications entre trois instances qui font une chanson : l'auteur, le compositeur et l'interprète. L'article d'Ursula Mathis-Moser - assorti d'une bibliographie très utile - resitue l'intérêt pour la chanson dans le contexte scientifique franco-allemand des 'études culturelles', influencées par les Cultural Studies et qui insistent sur le rejet des hiérarchies, l'étude des rapports de domination culturelle et l'intérêt pour les subcultures.

La chanson performée suscite constamment des interférences entre le texte, la musique et l'interprétation. En raison de cette hybridité fondamentale, le volume se situe logiquement au croisement entre l'histoire culturelle, les études cinématographiques, les arts de la scène, les sciences de la communication et, bien évidemment, des approches littéraires contemporaines mettant l'accent sur les phénomènes d'intermédialité et d'intertextualité. Signalons au passage la très belle lecture intertextuelle que Timo Obergöker fait du film Les Chansons d'amour (Christophe Honoré).

La chanson au XIX ${ }^{\mathrm{e}}$ siècle a été influencée par toutes les (r)évolutions médiatiques et technologiques, à commencer par l'invention du scopitone dans les années 1960 (thème de l'article de Fernand Hörner). Dès lors, la chanson doit être vue comme un "événement multimédia » (p. 101 s.) (selon la terminologie d'Andreas Bonnemeier), qui donne lieu à des phénomènes complexes multi-, hyper- voire transmédiatiques. Dans la mesure où il est impossible de rendre compte ici de toutes les contributions au volume, on signalera juste deux articles centrés sur la dimension scénique et performée : celui de JeanMarie Jacono sur les spectacles de Barbara et la relation entre performance, réception et sens du texte; celui d'Andrea Oberhuber sur le phénomène 
québécois de l'Osstidcho (qui signifie « hostie de show »), pratiqué au début de leur carrière par Robert Charlebois ou Diane Dufresne. Il s'agit là d'une belle réflexion sur le potentiel subversif de la chanson, lorsque celle-ci est détournée par une subculture.

Le volume, agréable, tout en présentant une grande cohérence, donne un aperçu varié du phénomène de la chanson, qui se révèle être un vaste champ d'étude. Peut-être manque-t-il une réflexion sur les voix étrangères dans la chanson francophone, sur ses aspects 'racialisés', ou plutôt une réflexion sur la 'blanchité' de ce genre aux tendances facilement dominantes voire hégémoniques. Enfin, à l'ère du multimédia, on ne peut que conseiller aux auteur(e)s de ne pas reproduire tels quels des textes repris en ligne, sauf à en reproduire les erreurs d'orthographe et de grammaire!

Patrick Farges, Paris

Krumeich, Gerd/Prost, Antoine : Verdun 1916. Die Schlacht und ibr Mythos aus deutsch-französischer Sicht, Essen : Klartext, 2016, 272 p.

Cet ouvrage est sorti parallèlement en français (il a été publié en 2015 aux éditions Tallandier) et en allemand, traduit par Ursula Böhme (il en est à sa deuxième édition au Klartext Verlag). Outre des précisions factuelles et des références aux archives, outre un bilan de l'historiographie française et allemande, il fournit des réflexions approfondies sur la culture mémorielle. Les deux éminents spécialistes de la Grande Guerre que sont Gerd Krumeich et Antoine Prost nous offrent ici la démonstration du bien-fondé de l'histoire dite 'croisée' et de la somme de connaissances qui sont requises pour y parvenir : ils ajustent et réajustent d'une façon continue et cohérente les comparaisons qu'ils ont menées et les variations qu'ils ont observées dans l'interprétation et la représentation de la bataille de Verdun, en France et en Allemagne, depuis 1916 jusqu'à nos jours.

Ils renouvellent l'étude de cette bataille en commençant par déconstruire ce qui, en France, a pu l'auréoler de 'légende' ou, en Allemagne, en faire un 'mythe'. Cette déconstruction s'opère à partir de la question : pourquoi, plutôt que d'autres sanglantes batailles, est-ce Verdun qui est devenu le symbole de la Grande Guerre ? Les faits sont détaillés : opérations militaires, logistique et matériels, durée - 21 février-15 décembre 1916 -, nombre terrifiant des victimes des deux côtés - près de 700000 morts, disparus ou blessés. Mais deux noms ont pu très tôt servir de points de cristallisation impulsant l'émergence d'un mythe : Pétain, glorifié dès 1916 en 'vainqueur de Verdun', dont la phrase du 10 avril 1916 'on les aura' devint historique ; et Falkenhayn, qui, en 1919, se trouva acculé à justifier son offensive sur Verdun et qui a alors antidaté le moment où il aurait écrit à l'Empereur (Noël 1915) qu'il fallait attaquer cette 
place car les Français y tiendraient plus que tout. Selon les deux auteurs, cela ne correspondait pas à la situation d'origine car l'état-major français n'avait pas d'emblée envisagé Verdun comme un lieu destiné à être défendu à tout prix ; il fallut attendre la décision politique (Briand) et militaire (Joffre) en février.

On pouvait s'attendre à ce que les mentalités des soldats aient présenté des similitudes. Les deux auteurs ne s'en tiennent pourtant pas à ce simple constat et ils insistent aussi sur les différences. Par exemple, la pratique de la 'noria' était spécifique à l'armée française et a renforcé le sentiment national puisque les soldats obtenaient des permissions puis revenaient dans les lieux; en revanche, les Allemands n'étaient pas dans le même état d'esprit car, s'ils partaient, ils ne revenaient plus à Verdun. Et pourtant, les uns et les autres ont éprouvé des sentiments similaires face à cette association de combats rapprochés et d'utilisation de techniques modernes qui caractérisa la bataille de Verdun, et donc aussi face à la mort ou face à des exercices qui leur paraissaient inadaptés. Leurs textes relatant des tragédies sont interchangeables, par exemple à propos de l'explosion du fort Douaumont occupé par les Allemands ou de l'incendie du tunnel de Tavannes abritant les services médicaux français, accidents qui prouvaient de part et d'autre qu'il n'existait pas de refuges sûrs en temps de guerre. Pour autant, les blessés ont pu connaitre des oasis d'humanité : Montmédy pour les uns, Bar-le-Duc pour les autres.

Parmi les autres facteurs ayant été propices à la 'légende', il y eut en France, dès 1916 et durant l'entre-deux-guerres, la convergence de deux orientations mémorielles. Celle des instances officielles, avec l'attribution de médailles aux combattants par la ville de Verdun ou avec l'aménagement d'un ossuaire à l'initiative de l'évêque Ginisty. Et celle des anciens combattants qui témoignaient de leur fierté d'y 'avoir été'; ils étaient relayés par des écrivains de talent comme Romains ou Genevoix. Le sens qu'ils donnaient à la bataille de Verdun était qu'il y avait eu réplique et victoire, que la modernité de l'armement n'avait diminué ni la valeur ni le courage des hommes, et qu'il n'était plus envisageable de revivre pareilles souffrances.

Dans l'Allemagne de Weimar, il fut en revanche peu question de Verdun, bien que des lettres envoyées depuis le front aient été conservées. Le professeur Philipp Witkop entreprit de publier dès 1916 les Kriegsbriefe dentscher Studenten (nous savons que c'est surtout depuis les années 2000, avec l'accent mis sur les ego-documents, que les lettres des particuliers seront collectées par les archives et les musées, celles de gradés comme celles de simples soldats). De sorte que l'idéalisation de la bataille de Verdun se produisit à la fin des années 1920, en particulier par le biais de nombreux romans comme ceux de Beumelburg ou Ettighoffer. Puis ce fut la récupération par les nazis de cette bataille qu'ils instrumentalisèrent comme le lieu où s'étaient noués les sentiments d'une solidarité indéfectible et exemplaire entre soldats. 
Le dernier chapitre, consacré aux années 1945-2016, fait constater qu'il a fallu un long cheminement avant d'assister à la poignée de main du 22 septembre 1984 entre Mitterrand et Kohl devant l'ossuaire de Douaumont. Ainsi, quand de Gaulle vint célébrer le 50e anniversaire de la bataille de Verdun en 1966, ni des représentants du gouvernement Erhard ni des soldats de la Bundeswehr ne furent invités. Tout cela fait pleinement comprendre l'importance de la Mission du centenaire de la Première Guerre mondiale et la portée politique et scientifique des manifestations qui se sont déroulées en 2016 dans le Mémorial de Verdun et à Douaumont : l'hommage longtemps réservé aux héros s'accompagne dorénavant du respect dû aux morts.

Cette approche 'croisée' de l'histoire militaire, sociale et culturelle a déjà été pratiquée par Krumeich, notamment avec Becker. Dans cet ouvrage-ci aussi, Prost et Krumeich renouvellent la manière de traiter des objets de recherche historiques. Ils incitent à pratiquer des analyses différenciées, à retourner chaque cas de figure pour examiner comment il se présentait dans l'autre camp, et à revenir inlassablement sur des hypothèses qui, à force d'avoir été répétées, semblaient constituer des évidences. Ils mettent en relief les décalages temporels, en reconstituent les causes et montrent comment et pourquoi la 'légende' auréolant Verdun s'est créée plus tôt en France qu'en Allemagne. Ils soulignent que des lacunes perdurent et appellent à travailler encore sur le nombre des pertes, sur le vécu des hommes en guerre, sur les catégories des mobilisés, sur les relations 'intra-militaires'.

Adopter cette optique binationale ou transnationale n'exclut pas à leurs yeux la prise en compte de perspectives internationales et l'enfer de Verdun n'est qu'un élément de l'histoire de la Grande Guerre. Mais cette version allemande de leur livre rendra d'autant plus service que les témoignages des poilus sont notoirement plus accessibles que les équivalents allemands ; au demeurant, le lecteur devra souvent remonter à la source indiquée en note s'il veut vérifier la nationalité des épistoliers, tant leurs descriptions sont similaires.

Françoise Knopper, Toulouse

Larralde, Jean-Manuel/Leclerc, Stéphane (dir.): Les 50 ans du traité de l'Elysée 1963-2013. Le couple franco-allemand dans la construction européenne, Paris: L'Harmattan, 2016, $191 \mathrm{~S}$.

Seit sich 2013 die Unterzeichnung des Elysée-Vertrags, mit der die beiden Staatsmänner Konrad Adenauer und Charles de Gaulle einen bis heute beispiellosen institutionalisierten Annäherungsprozess auf den Weg brachten, zum 50. Mal jährte, wurde in einer Fülle von Publikationen die historische Bedeutung sowie die konkrete Wirkung des deutsch-französischen Freundschaftsvertrags untersucht. 
Der vorliegende Tagungsband versammelt Beiträge der „7' ${ }^{\text {èmes }}$ Rencontres européennes", die im Jubiläumsjahr 2013 an der Universität Caen in der Normandie stattfanden. Die beiden Herausgeber Jean-Manuel Larralde und Stéphane Leclerc stellen die Thematik der deutsch-französischen Annäherung in den Kontext der friedlichen Einigung Europas seit dem Ende des Zweiten Weltkrieges. Im ersten Teil gehen die Historiker Ulrich Pfeil und Matthieu Osmont ausführlich auf die Geschichte des Elysée-Vertrags in seiner internationalen Dimension und mit Blick auf die Bedeutung der Diplomatie ein. Der in Metz lehrende Ulrich Pfeil, selbst Autor und Herausgeber zahlreicher Referenzwerke zu den deutsch-französischen Kulturbeziehungen inklusive der Rolle der DDR, analysiert das vielschichtige Beziehungsgeflecht zwischen Ost- und Westmächten während des Kalten Kriegs. Der inzwischen als Direktor des deutsch-französischen Kulturinstituts Tübingen tätige Matthieu Osmont weist darauf hin, dass der Elysée-Vertrag in der diplomatischen Praxis bereits bewährte politische Praktiken, wie regelmäßige Treffen der deutschen und französischen Staats- und Regierungschefs, festschrieb und ihnen institutionelle Bedeutung sowie langfristige Ziele gab. Die vertraglich geregelten Rahmenbedingungen wurden dann von den jeweiligen Akteuren unterschiedlich genutzt sowie von einer sich intensivierenden und ausdifferenzierenden diplomatischen Zusammenarbeit begleitet. Beide Historiker würdigen in ihrem Fazit die Vorbildrolle der deutsch-französischen Beziehungen und die potenzielle Übertragbarkeit ihrer Instrumente der Zusammenarbeit auf andere zwischenstaatliche Konstellationen bis hin zur Europäischen Union.

Die amtierenden Generalsekretäre des Deutsch-Französischen Jugendwerks (DFJW), Béatrice Angrand und Markus Ingenlath, berichten in ihrem Beitrag, der ein auf die Praxis ausgerichtetes Zwischenspiel bildet, aus der Geschichte und der aktuellen Arbeit der deutsch-französischen Institution, die dem Elysée-Vertrag ihre Entstehung verdankt. Seit 1963 haben sich die Aktionsfelder des DFJW erweitert, ist die interkulturelle Arbeit mit jungen Menschen insgesamt vielfältiger geworden.

Im zweiten Teil des Tagungsbandes geht es aus der Perspektive von 2013 darum, jenseits der Erfolgsgeschichten auch die Schwierigkeiten und Baustellen der aktuellen deutsch-französischen Zusammenarbeit in Europa zu erkunden. Sébastien Botreau-Bonnetaire, Direktor des Internationalen Instituts für Menschenrechte und Frieden in Caen, untersucht die Gründe für das anhaltende Scheitern der Vorstöße zu einer gemeinsamen europäischen Verteidigungspolitik, die aus dem Elysée-Vertrag hätte entstehen können. Der Jurist Fabien Terpan (Jean-Monnet-Lehrstuhl, Grenoble) veranschaulicht in seinem Beitrag die Kohäsion der deutschen und französischen Außenpolitik in Europa. Seine Ergebnisse gelten für den Zeitraum bis 2011 und belegen, dass das deutsch-französische Zusammenspiel für Europa ein wichtiges Stabilitätselement, jedoch nicht den alleinigen Motor darstellt, sondern eher eine 
Dreiecksbeziehung Frankreich - Deutschland - Großbritannien die europäische Position bestimmt. Vor dem Hintergrund der jüngsten Entwicklungen von der ,Flüchtlingskrise ‘ bis hin zum ,Brexit‘ wird sich diese Ausgangslage sicher in Zukunft anders darstellen. Jean-Marc Trouille von der Universität Bradford, ebenfalls Inhaber eines Jean-Monnet-Lehrstuhls, geht in seinem Beitrag der Frage nach, ob Frankreich in Bezug auf die wirtschaftliche und währungspolitische Einigung Europas eine Schwachstelle darstellt. Aus seiner Sicht sind das deutsche und das französische Wirtschaftssystem eng miteinander verflochten und dennoch so stark von gegensätzlichen Modellen und Strategien geprägt, dass sie trotz gemeinsamer Interessen nur dann miteinander in Einklang zu bringen sind, wenn ein gemeinsamer politischer Wille zu Veränderungen da ist.

Der Tagungsband bietet seinen universitären Lesern und darüber hinaus durchaus auch einem breiteren Publikum Anregungen zur Analyse der europäischen Gegenwart aus deutsch-französischer Perspektive.

Sandra Schmidt, Paris

Lejot, Eve: Pratiques plurilingues en milieu professionnel international. Entre politiques linguistiques et usages effectifs, Frankfurt/M. [u. a.]: Peter Lang, 2015, 396 S.

Ziel des Bandes ist es, die tatsächliche Umsetzung sprachpolitischer Vorgaben in mehrsprachigen Arbeitskontexten Europas näher zu beschreiben. Anhand der Beobachtung von Mitarbeitenden eines in Deutschland ansässigen Unternehmens aus dem Bereich der Luftfahrtindustrie sowie einer ebenfalls in Deutschland niedergelassenen, international agierenden Institution geht die Autorin der Frage nach, welche Schlüsselfaktoren die Sprachenwahl in mehrsprachigen beruflichen Settings determinieren. Der Studie liegt ein interdisziplinäres Analyseinstrumentarium zugrunde, das linguistische, didaktische und interaktionistische Ansätze miteinander vereint.

Der Band gliedert sich in sieben Kapitel und schließt mit einer Zusammenfassung. Am Ende der Arbeit befinden sich eine Liste der verwendeten Akronyme, ein Abbildungsverzeichnis sowie ein Autoren- und Sachregister, die dem Leser das rasche Auffinden von Autorennamen und Bezeichnungen im Band ermöglichen. Der erste der beiden großen thematischen Blöcke, der sich den theoretischen und methodischen Grundlagen der Studie widmet, umfasst drei Kapitel. Im ersten Kapitel („Les politiques linguistiques officielles") stellt die Autorin die für ihre Arbeit relevanten Hintergründe der europäischen Sprachenpolitik im Kontext der Mehrsprachigkeitspolitik vor und legt hierbei einen Akzent auf die Besonderheiten der geltenden nationalen Gesetzgebung in Frankreich und Deutschland, bevor sie auf branchenspezifische Besonderheiten verweist, die nicht immer deckungsgleich mit den 
Gesetzesvorgaben sind. Abgeschlossen wird das erste Kapitel mit Überlegungen zu wirtschaftlichen Auswirkungen unterschiedlicher sprachenpolitischer Ansätze. In Kapitel 2 („Deux terrains d'investigation à Hambourg“) stellt die Autorin die von ihr ausgewählten, im Arbeitsalltag mehrsprachig agierenden Organisationen (die UNESCO und ein Luftfahrtunternehmen, ansässig in Hamburg) vor und beschreibt das Korpus. Fundierte Informationen sowie kritische Reflexionen zu den Methoden der Datenerhebung und -auswertung vermittelt das dritte Kapitel des Methodenteils („Recueil d'informations et échantillonnage des discours professionnels").

Im Zentrum des zweiten Themenblocks, der sich aus vier Kapiteln zusammensetzt, stehen die eigentliche Analyse und die Ergebnisdiskussion. In Kapitel 4 („Les questionnaires: une analyse de contenu“) erfolgt die Präsentation der Ergebnisse der Fragebogenanalyse, die mittels der Methode der qualitativen Inhaltsanalyse ausgewertet werden. In Kapitel 5 („Les réunions: une analyse linguistique à orientation interactionniste ") werden mehrsprachige Arbeitssitzungen in den von der Autorin gewählten Kontexten bezüglich der Prozesse des Aushandelns der Sprachenwahl näher betrachtet. Der dritte Pfeiler des Analysemodells, die Auswertung von Gesprächen mit Angehörigen der beiden Organisationen mithilfe des Instrumentariums der Diskursanalyse, steht im Zentrum von Kapitel 6 („Les entretiens: une analyse indicielle de discours sur le travail“"), bevor in Kapitel 7 eine Interpretation der Materialanalyse vorgenommen wird, die die drei zentralen methodischen Konzepte (qualitative Inhaltsanalyse, Interaktionslinguistik, Diskursanalyse) zusammenführt. In diesem Kontext stellt die Autorin entscheidende Faktoren vor, die, basierend auf der Auswertung des empirischen Materials, die Sprachenwahl beeinflussen können.

Die Autorin nimmt sich in ihrer Studie eines Themas an, das im Kontext der Arbeitsrealität in einem vielsprachigen Europa von höchster Relevanz ist. Dabei stellt sie das Spannungsfeld von einer institutionell erwünschten bzw. geforderten Mehrsprachigkeit in Europa einerseits und dem Zwang der Unternehmen zu einer möglichst effizienten Art der Kommunikation heraus, das nicht selten im Gebrauch einer allen Akteuren gemeinsamen lingua franca mündet. Aber auch wenn oftmals davon ausgegangen wird, dass in mehrsprachig agierenden Unternehmen oder Institutionen Englisch als lingua franca verwendet wird, weist Lejot, gestützt auf ein fundiertes Datenkorpus, nach, dass der verordnete Gebrauch des Englischen in vielen Fällen lediglich eine ,inoffizielle', unterschwellige Mehrsprachigkeit überlagert, in deren Kontext die Sprachenwahl von den Kommunikationspartnern immer wieder neu verhandelt werden muss.

Die Arbeit überzeugt durch eine klare Gliederung und eine sorgfältige sprachliche Präsentation der Ergebnisse; zahlreiche Graphiken und Abbildungen erleichtern dem Leser das Verständnis. Sehr informativ und die Argumentation der Autorin stützend sind die ausführlichen Diskussionen der 
Gesprächstranskripte im Rahmen der Materialauswertung. Das interdisziplinär konzipierte Analyseinstrumentarium ermöglicht es der Autorin, ihr Datenkorpus unter verschiedenen, sich ergänzenden Kriterien zu untersuchen, was zu einer überzeugenden und aspektenreichen Interpretation der Ergebnisse führt. Neben der wissenschaftlichen Deskription des Phänomens der Mehrsprachigkeit in beruflichen Kontexten erscheint das Plädoyer der Autorin sinnvoll und unterstützenswert, in der (hoch-)schulischen Fremdsprachenausbildung stärker die funktionale Differenzierung des Gebrauchs unterschiedlicher Sprachen im beruflichen Kontext zu berücksichtigen und vom Postulat des English only abzurücken.

Nadine Rentel, Zwickau

Martin, Barbara : Zwischen Verklärung und Verfübrung. Die Frau in der französischen Plakatkunst des späten 19. Jahrbunderts, Bielefeld : transcript, 2015, 450 p.

L'objectif de Barbara Martin est l'analyse des représentations du féminin dans le domaine de l'affiche publicitaire à la fin du XIX ${ }^{\mathrm{e}}$ siècle. L'enjeu idéologique de cette instrumentalisation de la femme comme accroche et appel à la consommation semble à l'auteure un domaine jusque-là négligé par les études de genre.

L'affiche comme support d'une stratégie publicitaire naissante se répand en France dans le contexte de l'accroissement de la population urbaine et de l'intensification de la production industrielle de biens. De grands dessinateurs (Jules Chéret, Alfons Mucha, Henry Thiriet, Leonetto Capiello...) et artistes (Toulouse-Lautrec) s’y investissent alors avec succès, générant une véritable «affichomanie » (p. 7). Dès les années 1880, des expositions sont organisées dans des galeries spécialisées et l'affiche devient un objet de collection recherché. Mais elle prend surtout toute sa place dans l'espace public qui se transforme en une " galerie de la rue » (p. 7 et p. 285) ou encore en un « salon du pauvre» (p. 285). Elle est placardée sur les murs des immeubles, sur les innombrables palissades de chantier (nous sommes à l'époque du grand remodelage de Paris par le baron Haussmann), ou encore sur les colonnes Morris qui font dorénavant partie du mobilier urbain des nouveaux boulevards où flânent désormais les foules qu'elle incite à la consommation. Pour susciter l'attention et séduire, elle se sert des figures traditionnellement positives du féminin (la jeune fille, la fiancée, l'épouse, la mère...), mais aussi de plus en plus souvent de représentations plus osées de femmes 'libres'. Le message d'émancipation implicite qu'elle émet rejoint alors certaines aspirations féministes formulées lors du premier congrès international pour les Droits de la femme qui s'était tenu à Paris en 1878. 
Ces figures du féminin - conventionnelles ou d'avant-garde - sont bien sûr à considérer comme autant de constructions sociales qui se réfèrent à un contexte historique et culturel précis. Dans le contexte de la publicité, celles-ci obéissent à des objectifs économiques évidents. En déclenchant un processus d'identification ou de reconnaissance, elles sont censées éveiller le désir et déclencher l'achat, une stratégie conforme aux premières théories du marketing moderne formulées par exemple à la même époque aux Etats-Unis par E. St. Elmo Lewis et que la création des premiers grands magasins rend encore plus efficace.

Parmi les nombreuses déclinaisons du féminin que Barbara Martin détaille avec précision se détache celle de «la Parisienne » (à qui est consacré le chapitre 3) incarnant 'l'éternel féminin', le charme et le chic français. Par hybridation avec les stéréotypes de la courtisane, de la danseuse, de l'actrice - des femmes 'libres' - elle devient le symbole d'une modernité qui servira à vendre tous les produits imaginables, du champagne aux cigarettes que certaines de ces femmes émancipées fument désormais en public, ou à la bicyclette dont la pratique demande des concessions vestimentaires encore scandaleuses comme le port du pantalon (le bloomer). Sur les supports destinés à la promotion de revues ou de spectacles, des vedettes comme Yvette Guilbert, Loïe Fuller ou Sarah Bernhardt tiennent bientôt le haut de l'affiche. Mais la femme s'y trouve aussi représentée en tant que spectatrice, observatrice et partie prenante, bref comme ayant dorénavant accès à des lieux de divertissement qui lui ont longtemps été refusés.

Les dessinateurs inventent leur propre style et créent des figures emblématiques. Aucune confusion possible entre l'esthétique intemporelle de la «femme Mucha» (p. 366), les femmes tout en mouvement de Capiello, la théâtralisation des corps féminins de Manuel Orazi, les aimables et consensuelles «Chérettes » (p. 342) de Jules Chéret... Sans surprise, peu de femmes parmi les noms cités, même si Barbara Martin mentionne Jane Atché ou Clémentine-Hélène Dufau : en cette fin du XIX ${ }^{\mathrm{e}}$ siècle, l'art de l'affiche est un art masculin. S’il recourt volontiers à la mise en scène conventionnelle ou détournée des stéréotypes (la gardienne du foyer, la mère nourricière, la femme fatale, la séductrice, la muse...), toutes ces constructions du féminin se retrouvent in fine réunies sous une seule bannière : celle de la prescriptrice d'achat et/ou consommatrice. L'utilisation du corps féminin (stylisé) sert ainsi à magnifier le produit et à valoriser de manière plus ou moins éphémère celle ou de celui qui se laisse séduire - et passe à l'achat.

Fruit d'une thèse soutenue en 2014, le travail de Barbara Martin est tout à fait instructif. Il souffre un peu d'une structuration assez académique, et notamment d'une multitude de sous-chapitres parfois extrêmement courts. Ses analyses sont cependant souvent pertinentes, et l'ouvrage se distingue par la richesse de sa documentation et de sa bibliographie. Parmi les idées particulièrement heureuses, la mise en perspective de nombreuses affiches 
publicitaires avec des peintures de la même époque (Renoir, Cassatt, Degas...), procédé qui permet non seulement la comparaison mais aussi de constater la perméabilité des motifs. Tout à fait intéressant aussi, le chapitre sur la censure qui rappelle opportunément la (double) morale du XIX ${ }^{\mathrm{e}}$ siècle.

Walter Benjamin, cité fort à propos par l'auteure, avait constaté que la « réclame moderne » procédait par l'articulation de la séduction féminine et du produit dans une société pensée et façonnée par les hommes (p. 315). L'affiche publicitaire qui livre, pour vendre, la femme - ou plutôt ses représentations à la convoitise du regard masculin en est le parfait exemple.

Ingeborg Rabenstein-Michel, Lyon

Perrefort, Marion (in Zusammenarbeit mit Martin Bauch und Dominique Granoux): Der deutsch-franzö̈sische Grundschullehreraustausch. Mobilitätserfabrungen im Perspektivenwechsel, Münster/New York: Waxmann, 2015, 174 S.

Im Zentrum der Veröffentlichungen stehen die biographischen Erinnerungen deutscher und französischer Lehrkräfte, die in den Jahren zwischen 1999 und 2009 an einem einjährigen Austauschprogramm für Grundschullehrkräfte teilgenommen haben. In einer Verbindung von quantitativen und qualitativen, ethnosoziologisch orientierten Methoden wurden - in der rückblickenden Betrachtung und Erinnerung - mithilfe von Fragebögen die Motivation, an dem Programm teilzunehmen, und Erfahrungen, die im Laufe des Aufenthalts im anderen Land gemacht wurden, erhoben. Im Mittelpunkt stehen sodann die Portraits von 21 Lehrkräften, die im Rahmen von Gruppengesprächen an der weitergehenden qualitativen Studie teilgenommen haben. Recht umfangreiche Texte (Gedichte, Berichte, fiktive Briefe etc.) der an der Studie beteiligten Lehrkräfte durchziehen die Veröffentlichung und bieten den Leserinnen und Lesern Anschaulichkeit, Reflexions- und Identifikationspotenzial unterschiedlicher Stärke und Zielgerichtetheit - nicht zuletzt in Abhängigkeit von Erfahrungen im deutschen und französischen Bildungsbereich.

Das Buch ist in zehn Kapitel gegliedert, gefolgt von einem kurzen abschließenden Teil; vorangestellt sind Dank, Präambel, Einleitung und eine recht ausführliche Erläuterung des Aufbaus des Buches. Diese ist hilfreich bei der Lektüre, denn in den einzelnen Kapiteln werden oft unterschiedliche Aspekte behandelt, deren Zusammenstellung sich in einem Kapitel nicht ohne Weiteres erschließt. Das erste Kapitel, mit 42 Seiten das umfangreichste, führt in die Materie ein, indem zunächst der deutsch-französische Grundschullehreraustausch in seiner historischen und politischen Entwicklung als Rahmen gesetzt wird. Sodann werden die Fragebögen der 127 Grundschullehr- 
kräfte, die sich an der Befragung beteiligt haben, mit den Ergebnissen vorgestellt. Im Zentrum stehen die Gründe für ihre Teilnahme am Austausch (u. a. Attraktivität des Partnerlandes vor dem Austausch, erhoffter persönlicher Gewinn, Persönlichkeitsvariablen) und die rückblickenden Einschätzungen unterschiedlicher Aspekte der Schule im Partnerland. Daran anschließend werden die für die Gespräche ausgewählten Lehrkräfte in Kurzbiographien vorgestellt. Grundlage der Auswahl war die Beantwortung des Fragebogens und die Bereitschaft, an den Gruppengesprächen teilzunehmen. Das zweite Kapitel behandelt zunächst theoretische Aspekte von Austausch- und Mobilitätsforschung, vorrangig im Schul- und Ausbildungsbereich, fragt dann nach Definition und Veränderung von Identität in der heutigen Zeit. Eine umfassendere, tiefergreifende Diskussion dieses wichtigen Aspekts, die nicht nur Veröffentlichungen über den deutsch- und französischsprachigen Bereich hinaus integriert hätte, sondern auch zielgerichteter auf die Identitätserfahrungen der Teilnehmer der Studie zugeschnitten gewesen wäre, wäre hilfreich gewesen, nicht zuletzt auch, um dem Begriff „Perspektivenwechsel“ des Buchtitels näher zu kommen. Im weiteren Verlauf des Kapitels wird das als Methode gewählte Gruppengespräch als Möglichkeit des Aushandelns von Identität begründet. Kapitel 3 führt diesen Argumentationsstrang unter dem Titel „Gemeinsames Erzählen als sinnstiftende Ko-Konstruktion des Erlebten" weiter und legt insgesamt die methodische Vorgehensweise dar.

Die folgenden Kapitel führen die Auswertung der Gespräche unter unterschiedlichen Fragestellungen fort. So geht es im vierten Kapitel um die berufsbezogenen Gründe für die Teilnahme am Austauschprogramm. Das kurze fünfte Kapitel arbeitet zunächst Vorstellungen und Wünsche des WoandersSein-Wollens heraus; darauf folgt die Thematisierung von Selbstzuschreibungen in Hinsicht auf Mobilitätswillen und -fähigkeiten. Im sechsten Kapitel werden Emotionen und Haltungen gegenüber dem anderen Land und der anderen Sprache, insbesondere bezogen auf die entstehenden Schwierigkeiten und Unsicherheiten, behandelt, während das kurze siebte Kapitel das soziale Umfeld, v. a. die Familie, in den Mittelpunkt stellt. In Kapitel 8 geht es um das Ankommen und Leben in der sprachlich und sozial neuen Umgebung. Das nächste Kapitel ist v. a. der „konstruktiven Marginalität“ gewidmet, dem positiven Abweichen von Normalität, das bereits im vierten Kapitel als „emblematische [...] Identitätskategorie der Mobilen“ (S. 94) herausgestellt wurde. Das mit 22 Seiten verhältnismäßig lange, zehnte Kapitel befasst sich mit unterschiedlichen Aspekten der Rückkehr in Leben und Schulalltag des Herkunftslandes. Der Darstellung der Reintegration in vormals quasi naturwüchsig-vertraute Umgebungen auf der Grundlage der während der Austauschzeit erlebten und verarbeiteten, im doppelten Sinn gemachten Erfahrungen wird breiter Raum gegeben. 
Alle Kapitel beinhalten viele und interessante Zitate aus den Gesprächssitzungen, darüber hinaus finden sich von den Teilnehmern verfasste Gedichte, Prologe etc. Sie alle haben jedoch eher illustrativen denn analytisch-induktiven Charakter. Dies begründet sich nicht zuletzt in dem auf S. 67 dargelegten methodischen Vorgehen: Die Gespräche wurden nach der Aufzeichnung transkribiert, sodann ,geglättet'. Dabei wird u. a. generell auf die Angabe der Transkriptionsmerkmale (wie beispielsweise verzögerte Rede, lange Pause; Stimmhebungen) verzichtet, sodass der Leser es bereits mit einer einer Interpretation unterzogenen Wiedergabe des Teilnehmertextes zu tun hat. Hinzu kommt, dass alle französischsprachigen Redebeiträge - wie im Übrigen auch alle französischsprachigen Zitate aus anderen Veröffentlichungen - ins Deutsche übertragen wurden. Dies ist nicht nur angesichts der mit großer Wahrscheinlichkeit beim potenziellen Leserkreis voraussetzbaren Sprachkenntnisse bedauerlich. Denn gerade bei den behandelten Themenkreisen sind Übersetzungen nicht nur Interpretation, sondern auch hinlänglicher Diskussions- und Reflexionsanlass (zur Veranschaulichung möge das folgende kurze Beispiel dienen: „en communiquant on se «fabrique» les uns les autres“ wird übersetzt als „durch Kommunikation ,fabrizieren“ wir uns und die anderen“ (S. 61)).

Eine aus Sicht der Rezensentin die Grenze der Toleranz überschreitende Reihe von Ungenauigkeiten erschwert das Lesen bzw. Nachvollziehen der bibliographischen Angaben. Beispielhaft seien nur die folgenden erwähnt: Auf S. 61 findet sich ein direktes Zitat Maffesolis ohne weitere Angaben zur Veröffentlichung, aus der das Zitat stammt, sodass - da sich in der Literaturliste vier Veröffentlichungen dieses Autors finden - die Zuordnung nicht direkt möglich ist. Auf S. 64 wird Bezug genommen auf Perrefort 2008; da in der Literaturliste für das Jahr zwei Veröffentlichungen aufgeführt sind und in beiden die angegebene Seitenzahl vorkommt, ist eine Zuordnung nicht möglich. Die Reihe von Unstimmigkeiten aufzuzählen, sprengte den Rahmen dieser Rezension. In der Literaturliste fehlen beispielsweise Simmel 1908 und Ehrenreich/Perrefort 2008 (S. 59); Weber 1992 und Strauß 1992 (S. 68), Sacks 1992 (S. 69), Hirsch 1992 (S. 150) bzw. sind nicht alphabetisch eingeordnet (Schütz 1987), nicht chronologisch aufgelistet (die Veröffentlichungen Morins) oder die im Text angegebenen Erscheinungsjahre korrespondieren nicht mit den in der Literaturliste angegebenen (S. 59: Brougère/Colin/Perrefort [u. a.], 2007 vs. Brougère/Colin/Perrefort (eds.), 2006).

Die Veröffentlichung bietet für alle im deutsch-französischen Bildungsbereich Engagierten bzw. daran Interessierten eine kommentierte und interpretierte Zusammenschau von persönlichen, identitätsrelevanten Austauscherfahrungen von Grundschullehrkräften der Jahre bis 2009. Allerdings bleibt allein dies im Zentrum, sodass - da seitdem gerade auch im Bildungsbereich neue, mit einer anderen Art von Mobilität verbundene Aspekte in den Vordergrund gerückt sind - die Lektüre des Bandes, so interessant und anregend 
sie für initié(e)s sein mag, eher rückwärts gerichtet denn hilfreich für die Analyse gegenwärtiger und kommender Mobilität erscheint.

Heidemarie Sarter, Potsdam

Picker, Marion/Kimmich, Dorothee (dir.) : Exil - Transfer - Gedächtnis/Exil Transfert - Mémoire. Deutsch-französische Blickwechsel/Regards croisés franco-allemands, Frankfurt/M. [u. a.] : Peter Lang, 2016, 294 p.

En observant la table d'Exil - Transfert-Mémoire, le lecteur est d'abord frappé par la diversité des 17 articles qui composent ce volume s'adressant aux personnes intéressées par l'interculturalité. En les lisant on s'aperçoit en revanche de l'apport de ces « regards croisés franco-allemands».

Si le mot exil évoque un champ de recherche défini de la germanistique, il est plus flou pour le spécialiste d'études francophones. Les articles de la partie «Exil et engagement» concernent tous la période nazie et quatre sur cinq relèvent du littéraire et du philosophique. Deux d'entre eux, consacrés à des auteurs français, méritent d'être lus en parallèle. Bernanos connut un exil, dit Jurt, « douloureux », mais volontaire (p. 21), alors que Céline eut un exil forcé à la fin de la guerre. Si l'engagement de Bernanos lui fit abandonner provisoirement un roman, l'exil semble avoir eu une plus faible incidence sur son œuvre littéraire que pour Céline. Sa situation, dit Mecke, le fit s'engager sur la voie autobiographique et développer « une poétique de l'exil » (p. 67 s.). Cette dernière résonne avec l'article de Nouss, qui démontre que l'exil « marque la langue autant que la langue $[\mathrm{le}]$ trace $[\ldots] »(\mathrm{p} .89)$. Ses exemples et sa démonstration sont intéressants, mais on doit regretter qu'avec un tel objectif, il ne cite les auteurs qu'en traduction. Influence poétique de l'exil, mais aussi réflexion sur la pensée en exil. En visant à replacer la pensée de Landsberg dans le contexte de son exil en France, Bock montre la productivité des échanges intellectuels franco-allemands pour influencer, à un moment tragique de l'Histoire, le 'personnalisme' philosophique. Aux deux articles sur des auteurs français répondent deux articles sur des écrivains allemands. Karpenstein-Eßbach offre une étude philologique de poèmes de Nietzsche et Heine thématisant, notamment, leur expérience d'exilé. L'étude de Becker s'intéresse à Vanderbeke. En partant de cinq de ses textes, elle montre l'apport de la métalepse comme procédé narratologique pour étudier les « textes d'auteurs dotés d'une expérience migrante » (p. 161). Zaramba évoque les relations germano-polonaises vues de Pologne, plus exactement sous le prisme de quatre écrivains.

Les articles touchant à l'histoire des idées et à la psychanalyse se trouvent tous dans la partie "Transfert». L'étude des «seuils culturels » permet à Eßbach de montrer que si l'on peut les étudier dans l'histoire de l'humanité 
ou dans celle de chaque individu, on peut aussi les étudier par l'examen des dimensions ontogénétiques et historiques des phénomènes de seuils, qui sont liées. C'est le mérite de Rothacker, un philosophe dont la réception fut tardive en raison de son engagement nazi, de nous avoir donné des clés pour cela. Ce n'est pas à un concept, mais à l'histoire d'une discipline que s'intéresse Picker. Son article retrace l'histoire de la géographie en Allemagne sur un peu plus d'un siècle. Illustrer ce parcours des frères Humboldt à la géopolitique lui permet de montrer son importance tout au long du XIX siècle, de son rôle éducatif de lien « émotionnel à la patrie » (p. 116) comme militaire. Elle montre aussi son évolution méthodologique et évoque les relations et différences entre géographies allemande et française. Il y a la géographie, mais aussi la psychanalyse. Lojkine étudie l'importance de Heidegger pour Lacan et réévalue l'importance du philosophe pour sa réflexion : « Le transfert heideggérien constitue le soubassement» (p. 145) de sa pensée. Kimmich s'intéresse à la « magie moderne du fétiche » dans lequel elle évoque le parcours de ces concepts dans la théorie culturelle de la modernité.

Parmi les quatre articles historiques, deux illustrent une différence mémorielle intéressante entre la France et l'Allemagne. Großmann s'intéresse à l'évacuation des zones frontières en 1939-1940. Cet évènement longtemps trop peu étudié et mentionné illustre, comme l'indique le titre de l'article, un « destin partagé », mais une "mémoire séparée » (p. 181 s.). A travers L'Amicale de Buchenwald, Constantin montre les changements que dut apporter cette organisation française à sa narration et à sa manière de commémorer au contact d'autres mémoires. Guillon consacre lui un article au développement (inespéré) du Comité américain de secours, soit «la mieux connue des organisations d'assistance aux réfugiés antinazis » (p. 53) après l'expulsion de son fondateur. S'interrogeant sur la possibilité d'une mémoire commune européenne, l'article de Götze montre ses difficultés et note qu'elle ne naîtra pas de la reconstitution de la bataille de Waterloo.

Les deux derniers textes sont un hommage de Gérard Raulet à Thomas Keller, à qui le livre est dédié, et un article de celui-ci dans lequel il retrace, notamment, son parcours d'historien des idées franco-allemand.

Au final, ce volume offre au lecteur un intéressant ensemble d'études sur les relations franco-allemandes, susceptible d'intéresser tout universitaire ou étudiant de sciences humaines. La diversité de ces « regards croisés » démontre la richesse des recherches actuelles sur ces relations. Néanmoins, la diversité est aussi le point faible du volume dans la mesure où celui-ci peine à faire ressortir l'unité de ces recherches. 
Roffat, Sébastien: Esthétique et réception du dessin animé français sous l'occupation (1940-1944). L'émergence d'une école française?, Paris: L'Harmattan, 2014, 352 S.

Bei Sébastien Roffats Monographie handelt es sich um den dritten Teil einer vierbändigen Dissertation über die Entwicklung des französischen Zeichentrickfilms zur Zeit der deutschen Besatzung.

Der Fokus des Bands liegt auf der Frage, ob sich im Bereich des Zeichentrickfilms eine eigenständige französische Ästhetik in Abgrenzung zum amerikanischen Cartoon entwickeln konnte und welche Versuche seitens des Vichy-Regimes unternommen wurden, um eine prestigeträchtige nationale Produktion ins Leben zu rufen.

Dazu hat der Filmhistoriker Roffat in minutiöser Recherchearbeit Briefe, Zeitungsartikel und Fotos aus Archiven und Privatsammlungen zusammengetragen, die den massiven Einfluss des französischen Informationsministeriums auf die damalige Zeichentrickfilmproduktion zwischen 1940 und 1944 dokumentieren.

Im ersten Kapitel erhalten die Leser einen tiefen Einblick in die Art und Weise, wie Louis-Emile Galey (directeur général de la Cinématographie) versuchte, einen klassischen französischen Zeichenstil zu etablieren. Dieser sollte sich von Walt Disney und den damaligen Avantgarden gleichermaßen abgrenzen, ein breites Publikum ansprechen und dazu erzieherisch wirken. Dass dies nicht gelingen wollte, davon zeugen die vielen abgebrochenen Projekte aus diesem Zeitraum. Eindrucksvoll sind die teils jahrelangen Korrespondenzen zwischen Galey und den Künstlern, in denen der Generaldirektor verblüffend genaue Anweisungen hinsichtlich des Zeichenstils, der Inhalte einzelner Szenen, der Bewegungen und der Musik gab.

Aus dem zweiten Kapitel der Monographie geht hervor, wie schwierig es war, für diese arbeitsintensiven Produktionen geeignete Zeichner zu finden. Die in Paris und Nizza gegründeten Ausbildungsstätten blieben weitgehend erfolglos. Die Geschichte des französischen Zeichentrickfilms zwischen 1940 und 1944, daran lässt Roffat keinen Zweifel, ist eine Geschichte des Scheiterns. Neben technischen Schwächen, die mit den Zeichenstilen zusammenhängen, wiesen die Künstler einen akuten Ideenmangel auf und präsentierten dem Publikum einfallslose Disney-Plagiate oder Propagandafilme mit flachen Gags, die die einfachsten Regeln der Narration missachteten.

Walt Disney, ob man ihn liebte oder hasste, stellte für die Zeichner offenbar den Übervater dar - und Schneewittchen und die sieben Zwerge (1937) einen anscheinend unerreichbaren Meilenstein -, an dem sich die Künstler erfolglos abarbeiteten.

Eine Ausnahme bildete die Produktionsgesellschaft Gémeaux (mit dem Zeichner Paul Grimault), der Roffat das dritte Kapitel seines Buchs widmet. Dort gelinge es, die Disney-Qualität und den amerikanischen Zeichenstil zu übernehmen, ohne ins Plagiat abzudriften. Vielmehr wurden die Geschichten 
mit subversiven Erzählelementen angereichert und wurde der Animation eine eigene Handschrift aufgeprägt.

Das vierte Kapitel widmet sich der Rezeption: zunächst mit den Versuchen Galeys einen Prix Emile Cohl für den Zeichentrickfilm einzurichten, der jedoch zweimal hintereinander nicht vergeben wurde. Anschließend geht Roffat auf das Echo der Filme in der Presse und auf die Zuschauerreaktionen ein, wobei in diesem Abschnitt vergleichsweise wenig Material zur Verfügung steht. Mit einem Blick über das Ende des Krieges hinaus und einem kurzen Fazit schließt das Buch.

Roffats Monographie hat sicher zu Recht den Wissenschaftspreis Aguirre-Basualdo erhalten; der Autor muss sich aber der Frage stellen, warum er unentwegt Position bezieht und sich in seine teils harschen Werturteile Empörung und Verachtung mischen. Selbst wenn Roffats Haltung dem verständlichen Wunsch geschuldet sein mag, sich von Kollaborateuren wie Raymond Jeannin zu distanzieren, hätte er seinen Leserinnen und Lesern ruhig zutrauen dürfen, sich dank des reichen Materials ihr eigenes Urteil zu bilden.

Nathalie Mälzer, Hildesheim

Stoupy, Joëlle: La littérature française dans „Betrachtungen eines Unpolitischen“(1918) de Thomas Mann, Frankfurt/M.: Lang, 2015 (Interkulturelle Begegnungen 19), $297 \mathrm{~S}$.

Thomas Manns Betrachtungen eines Unpolitischen (1918) wurden wegen ihrer antidemokratischen politischen Position und ihrer gedanklichen Unabgeschlossenheit in der deutschen Forschung lange marginalisiert. Joëlle Stoupy legt nun eine wohlinformierte Studie zu den Bezügen zur französischen Literatur in den Betrachtungen vor. Angeregt wurde sie durch die 2009 erschienene Neuausgabe des Textes von Hermann Kurzke, auf deren verdienstvollen Kommentar sie sich bezieht. Stoupy ist allen Erwähnungen französischer Literatur in den Betracbtungen systematisch nachgegangen. Die Nennungen französischer Autoren von Molière bis Romain Rolland präsentiert sie chronologisch, nach Jahrhunderten geordnet. Diese Darstellungsform hat den Vorteil, dass sich Bezüge zu einzelnen Autoren systematisch nachschlagen lassen. Andererseits führt sie zu Wiederholungen, was die Einordnung in Thomas Manns Denken, die Polemik gegen die französischen ,Zivilisationsliteraten und Heinrich Manns Konzept des politisch engagierten Romans angeht. Auch einige Kernzitate erscheinen mehrfach. Die Lesbarkeit der detailreichen Studie hätte meines Erachtens durch einige übergreifende Texte - etwa eine einleitende Überblicksdarstellung zur Rivalität der Mann-Brüder und der geistesgeschichtlichen Einordnung der Betracbtungen im Kontext des Ersten Weltkriegs - verbessert werden können. Zu jedem Fund bietet Stoupy allerdings 
eine gründliche Kontextualisierung innerhalb des Mannschen Werks sowie der deutschen und französischen Forschungsliteratur.

Für die französischen Autoren des 17. Jahrhunderts sind die Ergebnisse recht unbefriedigend, da es sich meist um bloße Erwähnungen der Namen oder um kurze Zitate, die Thomas Mann aus sekundären Quellen übernahm, handelt. Stoupy kann hier keine eigenständige Lektüre der Primärtexte durch Thomas Mann nachweisen. Auch Manns Auseinandersetzung mit Voltaire und Rousseau beruht auf Vermittlung, etwa der Literaturgeschichte von Georg Brandes und der revolutionskritischen Abhandlung Les Origines de la France contemporaine von Hippolyte Taine (1875-1893), die er in deutscher Übersetzung gelesen hatte.

An den französischen Romanciers des 19. Jahrhunderts, v. a. Flaubert und Zola, arbeitete Thomas Mann sich deutlicher ab, sodass hier einige von ihm selbst später verschwiegene oder geleugnete Bezüge nachweisbar sind. So wendet sich Thomas Mann gegen das, l'art pour l'art-Konzept' Flauberts, nachdem er die Briefe des französischen Romanciers gelesen hatte. Stoupy zeigt auch auf, wie Zola erst 1915 durch Heinrich Manns Zola-Essay zum Zankapfel zwischen den Brüdern wird. So sind etwa in Königliche Hoheit von 1909 noch Bezüge zu Zola nachweisbar. Erst in den Betrachtungen eines Unpolitischen greift Thomas Mann Zolas Konzept des sozialkritischen Romans, das Heinrich Mann zu dem seinen gemacht hatte, scharf an und setzt ihm deutsche Geistesgrößen wie Kleist, Schiller und Wagner als Antithesen entgegen.

Unter den französischen Autoren des 20. Jahrhunderts kritisiert Thomas Mann Anatole France und Romain Rolland, die er als gegenwärtige französische Vertreter einer politisch engagierten Literatur ablehnt. Eine interessante Ausnahme in seiner Ablehnung französischer Literatur bietet seine Begeisterung für Paul Claudel, dessen Theaterstück L'Annonce faite à Marie (1912) ihn, wie viele deutsche Literaten seiner Generation, in der Übersetzung von Jakob Hegner stark beeindruckt hatte.

Da Thomas Mann gerade mit den Betrachtungen eines Unpolitischen dezidiert gegen die literarische wie politische Frankophilie seines Bruders Heinrich anschreibt, erforscht Stoupy einen zunächst negativen Kulturtransfer. Abschließend muss sie selbst konstatieren, wie weit Thomas Manns Rezeption der französischen Literatur hinter Heinrich Manns intensiver Beschäftigung mit Frankreich zurückbleibt. Dennoch kann sie nachweisen, dass Thomas Mann sich mit der französischen Literatur beschäftigen musste, um seinem Bruder etwas entgegensetzen zu können. Zudem kann sie aufzeigen, dass Thomas Manns Interesse an französischer Literatur erst durch die politischen Debatten des Ersten Weltkriegs unterbrochen wurde. So zitiert sie einen Brief von 1916, in dem Thomas Mann bedauernd bemerkt, dass ,das VordergrundFrankreich dieses Krieges“ ihn derart „abgestoßen und erbittert" habe, dass er die französische Literatur nicht angemessen schätzen könne (S. 207). 
Die Studie macht deutlich, wie stark Thomas Manns Bezüge zur französischen Literatur ein vermittelter Kulturtransfer sind. Natürlich spielte die Sprachbarriere eine Rolle: Thomas Mann las die französischen Autoren, wenn er sie denn las, in deutschen Übersetzungen und arbeitete nur in sehr wenigen Ausnahmefällen, so bei Claudel, die Originaltexte durch. Sein Blick auf Frankreich war stark durch die deutsche Literatur, etwa Nietzsches Rezeption französischer Autoren, und durch deutschsprachige Biographien und Literaturgeschichten geprägt. Interessant ist auch der starke Einfluss seiner WagnerVerehrung auf sein Frankreichbild: So rezipiert er Baudelaire und den Symbolisten Maurice Barres v. a. vor dem Hintergrund ihrer positiven Aussagen über Wagner. Stoupys Arbeit hat das Verdienst, diesen Vermittlungen detailliert nachzugehen.

Die Studie bietet somit eine differenzierte Darstellung zu Thomas Manns Auseinandersetzung mit französischer Literatur um 1916. Indem sie die Bezüge zur französischen Literatur in den Betrachtungen eines Unpolitischen erstmals systematisch aufarbeitet, schließt sie eine Forschungslücke. Da Thomas Manns Lektüren oft nicht eindeutig zu belegen sind, ist eine solche Studie, die von einem konkreten Text ausgeht, eine solide Grundlage, auf die sich spätere Arbeiten zu Frankreichbezügen bei den Mann-Brüdern stützen können. Ganz im Sinne Kurzkes trägt Stoupy zudem dazu bei, die Betrachtungen eines Unpolitischen wieder in die Forschungsdebatte einzuführen - was möglicherweise aus der Sicht einer französischen Germanistin leichter fällt als aus der deutschen Forschung heraus.

Leslie Brückner, Metz

Taylor, Imogen : Das zweisprachige Paar im französischen Roman von ,Zaide' bis ,Corinne', Würzburg : Königshausen \& Neumann, 2016 (Epistemata Literaturwissenschaft 828), 272 p.

L'ouvrage regroupe sept études sur la communication amoureuse en situation plurilingue dans la littérature française classique entre 1670 et 1807 . L'auteur observe la rencontre entre différentes cultures au sein de couples sur un siècle et demi. Chaque chapitre se consacre à la difficulté éprouvée ou à la solution particulière trouvée par une femme et un homme pour se comprendre en l'absence de langue commune au début de leur relation.

Dans Zaïde de Mme de Lafayette (1670), l'hérö̈ne gréco-mauresque est recueillie après un naufrage par l'Espagnol Goncalves. La situation allophone est source d'une incommunicabilité langagière qui ne se résout qu'à partir de la moitié de l'ouvrage, lorsque chacun des protagonistes apprend la langue de l'autre. Mais au fur et à mesure de leur apprentissage, c'est la bienséance qui devient le véritable obstacle à la communication amoureuse. Malgré une fin 
heureuse dans la tradition galante, les échecs révèlent la difficulté à trouver l'harmonie dans la relation de couple. Ce premier roman d'amants de langues différentes fait de la compréhension mutuelle la pierre de touche de l'amour bilingue.

La seconde œuvre, L'illustre Parisienne (1679) de Jean de Préchac, maitre de langues à la cour de Louis XIV, dépeint l'apprentissage des langues comme remède à tous les problèmes d'interaction entre étrangers. La langue allemande qu'a apprise l'héroïne pour aider son père banquier lui permet de nouer une relation avec un jeune Allemand venu à Paris. Les affaires et l'amour profitent fort bien de ce que « la connaissance des Langues étrangères n'est pas de ces curiositez vaines et steriles [sic], qui ne servent à l'esprit que d'une espèce d'amusement ; mais qu'elle est en effet d'un grand usage pour mille fins differentes [sic] » (p. 58) : l'aristocrate allemand épousera cette jeune bourgeoise qui lui aura enseigné le français. La conclusion, peu réaliste, vante l'excellent investissement qu'a représenté l'apprentissage de l'allemand : la connaissance des langues permet la mobilité géographique et sociale.

La troisième étude analyse le premier roman de Marivaux, Effets surprenants de la sympathie (1713), et notamment quelques entretiens entre Merville, Français prisonnier en Turquie, et Frosie, esclave d'origine française, le rencontrant pour le compte de sa maitresse turque. La communication entre les deux, forme pionnière de marivaudage dans la mesure où il est parlé d'un amour que Merville n'éprouve pour aucune des deux femmes, qui sont toutes deux amoureuses de lui, se termine mal, l'interprète froissée les dénonçant faussement au mari violent. On peut cependant regretter qu'Imogen Taylor s'intéresse plus à la vision pessimiste de l'amour chez Marivaux qu'à la conception de la traduction comme trahison qui aboutit à ce dénouement tragique.

La quatrième étude porte sur un roman de Prévost, Histoire d'une Grecque moderne (1740), dans lequel une jeune Grecque vivant dans un harem turc s'entretient avec le galant ambassadeur français. L'évolution de leurs rapports démontre que le problème de compréhension n'est pas d'abord langagier: l'ambassadeur parle fort bien le turc, tandis que la jeune Théophé apprend le français en faisant «des progrès surprenants » (p. 120), mais le badinage du Français, qui donne à l'héroïne des cours de langue avec beaucoup d'arrièrepensées, se heurte à la morale sincère de la jeune femme. Acculée dans cette impasse, Théophé sera délivrée par la mort.

L'incommunicabilité due à l'altérité est plus prononcée encore dans les Lettres d'une Péruvienne, de Mme de Grafigny (1747) : ce roman épistolaire a pour figure centrale une princesse inca ayant appris le français et philosophant sur la vie française qu'elle découvre, à la façon des Lettres persanes. Le style de ses lettres, qui se veut inca, mais que la narratrice construit d'après les stéréotypes sur le style oriental, est, bien qu'en langue française, incompréhensible par ses métaphores et périphrases au personnage masculin, qui parle évidemment le français clair loué par Rivarol. Malgré l’amour que lui porte le héros, la 
philosophique princesse ne veut pas l'épouser : cette fin peu romanesque, qui a chagriné les critiques de l'époque, est interprétée par I. Taylor comme une préfiguration d'auto-détermination féministe de l'hérö̈ne.

Le roman Trois femmes (1798) de Madame de Charrière triple quant à lui la constellation bilingue : la jeune émigrée française ne parvient pas à apprendre la langue du noble Allemand qui l'a épousée, tandis que sa sympathique domestique et sa très raisonnable amie ne se préoccupent nullement d'un tel apprentissage. Mais l'absence d'intégration langagière de ces trois femmes ne remet pas en cause leur vie heureuse en Allemagne, dont la sociabilité demeure sous influence française.

Enfin, Corinne ou l'Italie de Mme de Staël (1807) raconte un amour angloitalien qui se termine mal : la poétesse polyglotte italienne Corinne perd l'amour de l'Anglais Oswald, ses capacités d'improvisation artistique, puis se meurt. Dans ce roman à thèse, le malheur des personnages n'invalide pas l'idéal d'un cosmopolitisme éclairé : les considérations sur la nécessaire interculturalité de la littérature européenne priment sur des comportements monolingues qui restent l'apanage de la plupart des protagonistes.

Les analyses d'Imogen Taylor se nourrissent principalement de la recherche littéraire anglo-saxonne et sortent de l'ombre la coulisse langagière des couples 'internationaux' du roman classique. Mais, peut-être par désintérêt pour l'acquisition langagière concrète, on constate que l'obstacle langagier s'évanouit magiquement ou au contraire se cimente pour des raisons mystérieuses : ces auteur/e/s convaincu/e/s de la supériorité culturelle française décrivent la rencontre de diverses cultures essentiellement comme soumission de la culture étrangère aux valeurs françaises. La littérature ne s'est finalement pas tant occupée de la communication bilingue que de la difficulté de la relation amoureuse. L'ouvrage présente quelques coquilles (Einsetzten, p. 16, Vermittling, p. 88) et une tendance au mélange des langues dans l'écriture, la rédaction en allemand étant traversée de très nombreuses citations en français. Mais fin et approfondi, ce livre montre bien que, pour l'époque, la langue n'était guère que le signe d'autre chose.

Odile Schneider-Mizony, Strasbourg

Thomann, Pierre-Emmanuel: Le couple franco-allemand et le projet européen. Représentations géopolitiques, unité et rivalités, Paris: L'Harmattan, 2015, 658 S.

Der auf Geopolitik spezialisierte Wissenschaftler und Politikberater PierreEmmanuel Thomann, der inzwischen eine eigene Internetseite (www. eurocontinent.eu) betreibt, hat mit seiner Doktorarbeit, die er 2015 am Institut français de géopolitique (IFG) der Universität Paris verteidigt und im Verlag L'Harmattan veröffentlicht hat, eine geradezu monumentale Analyse der 
deutsch-französischen Beziehungen im Kontext des europäischen Projekts auf über 600 Seiten vorgelegt. Der Autor geht bei seiner geopolitischen, also an der Schnittstelle zwischen Politik, Zeitgeschichte und Geographie angesiedelten Konzeption, mit aller gebotenen Umsicht ans Werk und bedenkt die typisch deutsch-französischen Unterschiede in Terminologie und Wissenschaftsgeschichte. Denn anders als in Frankreich hatte der geopolitische Ansatz mit seinen Fragenstellungen nach Konfliktpotenzial von Territorium, Macht und Einflussnahme in Deutschland aufgrund seiner Diskreditierung durch den Gebrauch im Nationalsozialismus lange Zeit keinen leichten Stand.

Seinem Untersuchungszeitraum nähert sich Thomann aus der diachronen Perspektive mit dem gebotenen Abstand, um nach dem historischen Fundament (ab 1870) in einem weiten Bogen in die Nachwendezeit vorzustoßen und schließlich in der unmittelbaren Gegenwartsgeschichte anzukommen. Ziel seiner Überlegungen ist es, aufzuzeigen, in welcher Weise jenes von Politik, Medien und Öffentlichkeit vielbeschworene couple franco-allemand die Funktion erfüllt, eine befriedete, friedliche Beziehung zwischen zwei Nationen zu demonstrieren, denen es gelungen ist, die alte Erbfeindschaft dauerhaft hinter sich zu lassen und gemeinsam am Projekt Europa zu arbeiten. Unter der Oberfläche dieser auf Ausgleich und Parität ausgerichteten Konstellation des deutsch-französischen Tandems sind allerdings historische Rivalitäten, kontinuierlich weiterwirkende Spannungen und gegensätzliche Machtinteressen am Werk, die gerade dann handlungsbestimmend werden, wenn es darum geht, das politische Europa der Zukunft zu gestalten. Der Autor untersucht neben den Auswirkungen der deutschen Wiedervereinigung, mit der Deutschland als geeinte Nation eine Machtposition erlangte und ein neues geopolitisches, Ungleichgewicht ${ }^{\varsigma}$ entstand, auch die unterschiedlichen Perzeptionen und Perspektiven für ein erweitertes Europa. Im zweiten Teil seiner Arbeit unterzieht Thomann die Eurokrise und im dritten Teil die europäische Verteidigungs- und Sicherheitspolitik einer geopolitischen Analyse aus deutsch-französischer Sicht. Diese großen Themenblöcke hätten jeweils schon für sich genommen eine vollwertige Doktorarbeit ergeben können. Aus der Material- und Analysefülle ergibt sich, dass Thomanns Gesamtwerk den Charakter eines Nachschlagewerks hat, das gerade Studierenden der deutsch-französischen Beziehungen sehr empfohlen werden kann, zumal sich der Autor mit den insgesamt 75 geopolitischen und -strategischen Schaubildern um Anschaulichkeit bemüht und insgesamt vorbildlich mit Quellen arbeitet.

Die vorliegende Arbeit regt auch dazu an, sich zu fragen, ob der rein nationalstaatliche Untersuchungsansatz die deutsch-französischen Beziehungen nicht doch allzu sehr auf die wechselseitige Bezugnahme vermeintlich homogener politischer Gebilde reduziert. Gerade die Karten sind mit ihrem 
notwendig eingeschränkten Visualisierungspotenzial zum Teil stark auf Andeutungen von Oberflächenphänomenen begrenzt. Im letzten seiner zahlreichen Anhänge - leider nicht in seinem Fazit - umreißt der Autor selbst eine Vielzahl sinnvoller Erweiterungs- und Differenzierungsmöglichkeiten, die seinem Ansatz weitere Tiefenschärfe verleihen können.

Insgesamt merkt man der Arbeit Pierre-Emmanuel Thomann an, dass sie aus einem umfassenden und langwierigen individuellen Erkenntnisprozess erwachsen ist, durch den sich der Autor sein analytisches Handwerkszeug und sein fundiertes Wissen erworben hat. Auf seine nächsten Publikationen darf man also gespannt sein.

Sandra Schmidt, Paris

Watrelot, Martine/Polzin-Haumann, Claudia : L'évaluation des compétences langagières: Un regard franco-allemand sur les défis et perspectives actuels, Namur: PU de Namur, 2015, 235 p.

Le volume L'évaluation des compétences langagières réalisé et édité sous la direction de Watrelot et Polzin-Haumann est le produit d'une rencontre pédagogicoscientifique entre les acteurs éducatifs allemands et français dans le cadre d'une coopération franco-allemande riche et axée sur l'éducation. Cette œuvre significative de neuf articles dans le domaine de l'enseignement des langues revisite dans son introduction le contexte historique et actuel de l'évaluation des compétences linguistiques dans le cadre de l'Union Européenne, notamment en France et en Allemagne, et met en relief les problèmes d'évaluation des compétences en langue dus à la complexité de la question de l'évaluation des compétences en soi, au manque d'une formation adéquate des enseignants et à la non-disponibilité des outils appropriés permettant aux enseignants de pouvoir mesurer avec objectivité les performances des élèves dans leur progression vers l'acquisition des compétences linguistiques. Les cinq thèmes traités en concordance avec la structure de ce volume de cinq chapitres portant essentiellement sur l'évaluation des compétences des élèves en langue concernent les politiques éducatives (chap. 1), le contenu et la méthodologie des évaluations (chap. 2), l'intégration des nouvelles technologies de l'information et de la communication dans l'enseignement des langues (chap. 3), l'évaluation de l'écrit (chap. 4) et la compétence interculturelle (chap. 5).

Les retombées positives de la nouvelle politique éducative allemande de 2004 au profit de l'enseignement des langues étrangères, notamment le français en Allemagne, qui sont mises en évidence dans ce livre, permettent de constater l'avancée significative des acteurs de l'éducation dans l'élaboration des contenus d'enseignement et d'évaluation ainsi que dans l'élaboration des méthodes d'évaluation qui intègrent des nouvelles compétences favorisant 
l'apprentissage autonome, le développement du plurilinguisme et l'acquisition des savoirs et des habilités interculturels.

Une telle avancée n'est pas encore perceptible en France, où le traditionalisme pédagogique de l'enseignement par objectifs cède difficilement place à l'éducation au service des apprentissages ou l'enseignement par projets pour le développement des compétences complexes. La nécessité de dépasser les balises ou les standards du Cadre européen commun de référence pour les langues (CECRL) ainsi que ceux des référentiels régionaux ou nationaux semblables (e. g.: Socle commun de connaissances et de compétences de France) s'impose pour ouvrir la voie à la créativité et à l'innovation, en tournant en même temps la page de l'évaluation certificative traditionnelle et de l'apprentissage mécanique pour des succès ponctuels dans l'atteinte des objectifs prédéfinis dans des cadres pédagogiques fermés. Ce relâchement des ficelles qui limitent l'imagination, la créativité et l'action de l'apprenant permet de placer ce dernier au centre de l'apprentissage et donne un sens à l'évaluation formative et à l'autoévaluation dans le développement des compétences, notamment celle de l'autorégulation dans la quête et l'acquisition du savoir. En outre, force est de constater que la considération de la langue comme outil de communication et de transmission de la culture dans le cadre des cours spécialisés faits en langue étrangère au profit des apprenants d'une discipline particulière modifie en profondeur les contenus et les méthodes de l'évaluation des compétences linguistiques des élèves en mettant en exergue les volets pragmatique et discursif de la langue. L'exemple de l'apprentissage des langues étrangères à l'aide des situations authentiques (cas de l'allemand, du français ou de l'anglais) par visioconférence présenté dans ce livre permet en outre de constater que l'intégration des NTIC dans l'enseignement des langues rend très productif le volet de la communication et favorise le développement des compétences interactionnelles, linguistiques et techniques chez les apprenants.

En intégrant la perspective de la didactique du plurilinguisme et l'interculturalité dans l'enseignement des langues étrangères, notamment en Europe où la multitude des langues et le brassage des cultures font sa particularité, l'enseignement des langues s'enrichit davantage et va au-delà des compétences purement linguistiques; il embrasse les domaines de l'intercompréhension et de la culture, contribuant de ce fait au développement de la compétence intercompréhensive (plurilingue) et de la compétence interculturelle chez des apprenants vivant dans un environnement global ayant un besoin de communication et de compréhension mutuelle urgent. L'évaluation dans ce contexte complexe ne vise plus des connaissances hors situation, mais plutôt des stratégies d'apprentissage, le raisonnement logique, des habiletés de communication, l'aptitude au jugement critique, les compétences sociales dans le cadre de l'interaction communicative et culturelle. Cette nouvelle option de l'évaluation contribue énormément au développement de la personnalité et de l'individualité de l'apprenant et lui prépare son intégration réussie dans la communauté. 
L'évaluation des compétences langagières est un chef-d'œuvre qui propose, par des méthodes d'évaluation diverses, des orientations pertinentes et des tâches authentiques, un changement de paradigme dans les domaines de l'enseignement des langues et de l'évaluation des compétences. Il revient aux enseignants d'appliquer ces suggestions et recommandations dans leurs classes ou dans le cadre d'une recherche-action pour faire avancer la science de l'éducation et enrichir la formation des apprenants.

Eugeune Colinet Tatchouala, Montréal

Witzigmann, Stéfanie/Rymarczyk, Jutta (Hg.): Mehrsprachigkeit als Chance. Herausforderungen und Potentiale individueller und gesellschaftlicher Mehrsprachigkeit, Frankfurt/M. [u. a.]: Peter Lang, 2015, 290 S.

Der Band ist in fünf Teile untergliedert. Der erste, mit „Sprachen- und Bildungspolitik“" überschriebene, vereint drei Aufsätze, die sich mit bildungspolitischen Aspekten von Mehrsprachigkeit in unterschiedlichen Regionen Europas befassen. Lidia Cámara de la Fuente gibt in „Mehrsprachigkeit in Barcelona: Im Spannungsfeld zwischen Familie und Sprachbildungspolitik“" zum einen einen kurz gefassten Überblick über die festgelegte Sprachverwendung in den Schulen Barcelonas, zum anderen berichtet sie von einer empirischen Umfrage zu den Verhaltensweisen mehrsprachiger Eltern bzw. Familien in Barcelona. Deutsch und (maghrebinisches) Arabisch als Herkunftssprachen der befragten Eltern stehen im Mittelpunkt, ohne dass jedoch Fragen unterschiedlichen Prestiges der Sprachen oder Erfahrungen ihrer unterschiedlichen Akzeptanz angesprochen würden oder dass die Auswahl gerade dieser Herkunftssprachen begründet oder der vergleichende Aspekt in der Auswertung herausgearbeitet würde. So handelt es sich insgesamt um eine Auflistung mehr oder weniger bekannter Positionen und Verhaltensweisen, angereichert durch die Eigenperspektive der involvierten Eltern bzw. Familien. Eine Verbindung zwischen institutioneller Sprachpolitik und Umfrage wird nicht hergestellt. Ferit Rustemi und Gëzim Xhaferri befassen sich in ihrem Artikel „Sprachenpolitik und mehrsprachige Bildung in Mazedonien“ mit der Rolle und Funktion von Albanisch im Vergleich mit Mazedonisch. Allerdings tauchen bildungspolitische Aspekte nur sehr am Rande auf und Fragen der Mehrsprachigkeit sind auf Albanisch und Mazedonisch reduziert. Dennoch gibt der Artikel gerade in der aktuellen Situation in deutschen Schulen wertvolle Hinweise. Im dritten Aufsatz behandelt Anne-Birte Krüger „Sprach- und Kulturbrücken: innovative Schulsprachenpolitik im Kanton Basel-Stadt“. Die Autorin betrachtet zwei Projekte des Baseler Gesamtsprachenkonzepts („Heimatliche Sprache und Kultur“ und „Sprach- und Kulturbrücke") genauer, um herauszufinden, ob und ggf. wie der aus der Familie 
mitgebrachten Mehrsprachigkeit der Schülerinnen und Schüler in den Schulen der Stadt Rechnung getragen wird. Dabei findet der Aspekt, dass diese oftmals eine weniger positive Einschätzung der von Seiten der Lehrkräfte positiv gesehenen Maßnahmen haben, mehrfach Erwähnung, ohne dass dieser wichtigen Frage jedoch weiter nachgegangen würde.

Der zweite Teil enthält vier Artikel zur frühen Mehrsprachigkeit. Manuela Boccignone zeichnet in ihrem Beitrag „Mehrsprachigkeit in den ersten Jahren: eine Fallstudie" den simultanen Erwerb dreier Sprachen durch ihren Sohn nach, während Claudia Menzel in „Mehrsprachige Kinder im Kindergarten. Ein Bericht aus der Praxis" die unterschiedlichen Versionen von Mehrsprachigkeit in den Familien der Kindergartenkinder vorstellt. Beide Artikel sind interessant und lesen sich flüssig, ohne jedoch den bereits bekannten Ebenen der Mehrsprachigkeitsforschung Neues hinzuzufügen. Gleiches gilt im GroBen und Ganzen auch für „,Wo gehen gleich? Wo? Wo?' erste Beobachtungen aus einem empirischen Forschungsprojekt zu zweitsprachlichen Interaktionen im Kindergarten" von Lesya Skintey. Allerdings finden sich hier umfangreiche Transkriptionen von Interaktionen aus der von ihr durchgeführten Untersuchung. Der Fokus der Analyse liegt auf den Äußerungen des Deutsch als Zweitsprache erwerbenden Kindes; die Äußerungen der Erzieherin als hilfreiche Unterstützung bzw. - wie im vorliegenden Fall - potenziell irreleitende Antwort im Rahmen der transkribierten Interaktion zu analysieren, wäre für eine Weiterentwicklung der Forschungen zum kindlichen Zweitspracherwerb allerdings mindestens ebenso interessant gewesen, gerade wenn es - so der Anspruch der Verfasserin - darum geht, „, [...] das Potenzial alltäglicher Interaktionen im Kindergarten im Hinblick auf eine sensible sprachliche Begleitung der Kinder mit DaZ [...]“ (S. 119) auszuloten. Kristel Ross berichtet in ihrem Beitrag über „Veränderungen im Gebrauch von Kommunikationsstrategien bei mehrsprachigen Kindern in der reziproken Immersion des FiBi-Projektes in Biel/Bienne (CH) “. Aufbauend auf einer früheren Veröffentlichung, in der sie bei den Kindern ihrer Versuchsgruppe aufzeigen konnte, dass ,„[...] die Kinder ihre Kommunikationsstrategien sprachübergreifend, verbal und nonverbal, interaktional und lernstrategisch einsetzen [...]“ (S. 125), kommt die Verfasserin nun zu dem Ergebnis, dass die „Komplexität der verwendeten Kommunikationsstrategien" beim vierten Sprachstandstest komplexer als beim ersten sind, dass eine größere Variabilität vorhanden ist, dass zunehmend Kommunikationsstrategien miteinander kombiniert werden und dass sich die Funktion der nonverbalen Kommunikationsstrategie von eigen-/lernorientiert zu fremd-/verständnisnuancenorientiert verändert. Nicht erkennbar ist, dass bzw. ob dies die Eingangshypothesen - da die Erkenntnisse nach menschlichem Ermessen und bisherigem Kenntnisstand zu erwarten sind - waren, die im Verlauf der Untersuchung verifiziert wurden. Auch der Frage nach einer Parallelität zu ein- bzw. erstsprachigen Kommunikationsstrategien bleibt ausgespart. 
Der dritte Teil steht unter der Überschrift „Mehrsprachigkeit im Fremdsprachenunterricht". In den ersten beiden Beiträgen behandelt Eva Maria Fernández Ammann zunächst die „Sprachliche und kulturelle Vielfalt als Ressource im Spanischunterricht: Zur Entwicklung von Language Awareness und Cultural Awareness", sodann geht es Amina Kropp um den „Vorsprung durch Vorwissen: Das Potenzial von Transferleistungen für die Nutzung herkunftsbedingter Mehrsprachigkeit im schulischen Fremdsprachenunterricht". In beiden Beiträgen geht es v. a. um eine Diskussion vorhandener Literatur und Positionen, ohne dass wesentlich Neues hinzukäme. Die in „Der Sprachrhythmus bei deutsch-türkischen L3-Spanischlernern: Positiver Transfer aus der Herkunftssprache?" von Christoph Gabriel und Exequiel Rusca-Ruths verfolgte Fragestellung wird durch die von ihnen durchgeführte Untersuchung positiv beantwortet und hätte dadurch das Potenzial, in verstärktem Maße Forschungsinteresse für intonatorische und prosodische Vergleichsstudien zwischen Herkunftssprachen und schulischen Fremdsprachen zu wecken. In ganz ähnlicher Weise anregend ist der einzige englischsprachige Beitrag „Using CLIL-Methodology: Developing Learner Motivation in Learners of English as a Second Language through Content Area Guided Reading" von Michael Alvarez. Ihm geht es um einen paradigmatischen Wechsel in Bezug auf das Lesen unterrichtsbezogener zweitsprachiger Texte, der zu einer engen Verzahnung von ,content instruction concurrent with explicit language training“" (S. 226) führt.

Im vierten Teil geht es um „Lehrer- und Schülerperspektiven“. Dass sich in den letzten Jahren bereits wesentliche Positionsveränderungen zugunsten von Mehrsprachigkeit vollzogen haben, zeigt Sylvie Méron-Minuth in „Einstellungen zweier Lehrerinnen zur Frage der Mehrsprachigkeit im Fremdsprachenunterricht“ auf und Senem Özkul geht „Einflussfaktoren für den Englischlernerfolg aus der Sicht mehrsprachiger Gymnasiastinnen mit Migrationshintergrund" nach, um daraus ggf. Motivierungspotenzial für Andere herauszuarbeiten. Allerdings werden in dem Beitrag fast ausschließlich Begründung und methodisch-methodologisches Forschungsdesign dargelegt; die durch die Untersuchung erzielten Erkenntnisse hinsichtlich der Einflussfaktoren werden nicht vorgestellt.

Der abschließende fünfte Teil besteht aus dem Beitrag von Giulia PelilloHestermeyer „Mehrsprachiger und lokaler Radiojournalismus: Ein interdisziplinärer Ansatz zur Förderung von Medien- und Sprachkompetenzen“, in dem die unterstützende Funktion, die mehrsprachige Radiosendungen im öffentlichen, aber auch für den schulischen Raum haben kann, aufgezeigt wird.

Zusammenfassend lässt sich sagen, dass das Anliegen, einen „vielseitigen Einblick in individuelle und gesellschaftliche Mehrsprachigkeit in unterschiedlichen Ländern, Regionen bzw. Institutionen“ (Herausgeberin Stéfanie 
Witzigmann, „Einleitung“', S. 12) zu gewähren, dem Band insgesamt zum Nachteil gereicht. Die bereits vorhandene Breite und Tiefe der - internationalen Forschung zu Mehrsprachigkeit erfordert qualitative, immer präzisere, konkretisierend weiterführende Untersuchungen, die - beispielsweise im Rahmen eines most similar cases-Ansatzes - einschlägige, vorhandene Forschungsergebnisse im Detail vergleichen, verarbeiten und weiterführen. Die überwiegende Mehrzahl der im Band versammelten Beiträge ist jedoch gefüllt mit Aussagen, die inzwischen eher als verités de La Palice zu betrachten sind, als dass sie qualitativ weiterführten.

Heidemarie Sarter, Potsdam

Zier, Alexander : Frankreichs Sicherbeitspolitik. Effiziente Selbstbehauptung ₹u Gunsten Europas?, Baden-Baden : Nomos, 2014, 507 p.

Cette étude est la version publiée de la thèse de doctorat soutenue par Alexander Zier à Heidelberg en 2013 sous la direction du Professeur Klaus von Beyme. L'auteur examine la politique de sécurité et de défense de la France depuis la fin de la Seconde Guerre mondiale jusqu'à 2009, en interrogeant les rapports de cette politique avec les deux dimensions européenne (UEO, PESC, PESD/PSDC, UE) et atlantique (OTAN, USA). Il s'agit notamment de comprendre ce qui est qualifié d' "énigme» (puzzle, p. 54) : le retour en 2009 de la France dans l'OTAN, alors qu'elle l'avait quittée depuis près de 40 ans, sous l'impulsion du Général De Gaulle. Comment expliquer que l'option atlantique paraisse ainsi plus intéressante que l'option jusque-là défendue par la tradition gaulliste, celle d'une stratégie de sécurité et de défense française s’appuyant sur l'Europe puissance' ? Et est-ce vraiment le cas ? Telles sont les questions posées par Alexander Zier, auxquelles il répond par une description et une analyse extrêmement fouillée de l'évolution de la politique française, en permanence rapportée également à son action en Europe et au sein des projets de politique de sécurité et de défenses européenne.

L'étude suit une progression chronologique avec un découpage en trois périodes : de 1945 à 1989, de 1989 à 2001, et de 2001 à 2009. Deux événements qualifiés de tournants essentiels sur le plan de la géopolitique sont identifiés comme moments pivot: la date du 9 novembre 1989 («11/9 » pour l'auteur, p. 55) et celle du 11 septembre 2001 («9/11», p. 55). Ces deux dates marquent chaque fois une modification des conditions internationales structurelles, et la nécessité de nouveaux concepts et orientations de la politique de sécurité et de défense française, mais aussi européenne, se fait alors sentir.

Pour décrire et analyser l'évolution de la position française, l'auteur montre qu'en réalité celle-ci est en permanence à comprendre dans le cadre, et surtout en interaction avec la construction européenne, comprise comme 
un chemin vers l'Europe puissance'. En effet, même si depuis 1989 la marge de manœuvre des acteurs a changé, dans un monde qui n'est plus seulement bipolaire, la France cherche à maintenir son influence et/ou son autonomie, poursuivant en réalité (c'est ce que montre l'auteur) sa stratégie gaulliste de défense de ses intérêts (indépendance) et de maintien de son influence (grandeur). Ainsi, le glissement vers une position plus atlantiste pour finir la réintégration dans l'OTAN ne serait qu'un tournant pragmatique, permettant à la France de réaliser au mieux ses deux objectifs. Mais si l'on suit l'analyse proposée ici, il ne s'agirait en aucun cas de se détourner du choix européen. Seulement, ce modèle qui poussait les acteurs au pouvoir en France à soutenir la construction européenne parce que l'Europe était vue également comme un moyen d'accroitre la position française doit évoluer, à l'heure où la France perd, avec la disparition de l'opposition des blocs, sa position particulière et sa place de médiatrice entre les deux grandes puissances, grâce à la 'force de frappe' (dissuasion nucléaire). Conscient de l'importance des pertes, Paris doit envisager de nouvelles options. Il s'agira, en élaborant une nouvelle relation avec les partenaires de l'OTAN et avec les USA, d'acquérir un nouveau poids afin d'influencer plus efficacement le processus transatlantique mais aussi, audelà, d'amener l'Europe à avoir une politique de sécurité et de défense propre.

L'étude est conduite selon les théories de politique extérieure du néoréalisme, développées et complétées par les penseurs de l'école de Tübingen, Rainer Baumann, Volker Rittberger et Wolfgang Wagner. L'objet de l'étude est les liens de la France avec les projets européens de défense, liens qui sont eux-mêmes inextricablement liés avec la politique qu'elle mène envers les Etats-Unis et l'OTAN. Tout au long de l'ouvrage, l'attention de l'auteur se porte à la fois sur l'action et sur le discours (la dimension rhétorique de la politique extérieure).

Dans sa conclusion, Alexander Zier évoque les efforts que poursuit la France pour renforcer une 'Europe puissance', qui serait enfin capable de mener à bien une politique extérieure, de sécurité et de défense commune. Les développements les plus récents, en Syrie notamment, montrent que cet objectif n'est toujours pas atteint, avec les conséquences dramatiques que l'on sait. Dans une Union Européenne de plus en plus confrontée à la défiance des citoyens et à des défis économiques, sociaux, mais aussi de politique extérieure, la France défend une position et une vision certes controversées, mais qui, l'auteur en est convaincu, restent indispensables et pourront peutêtre entraîner une nouvelle dynamique.

Tout lecteur qui souhaiterait acquérir une compréhension plus fine des logiques que suit la France dans sa politique de sécurité en interaction avec l'Union Européenne lira avec profit l'ouvrage d'Alexander Zier. Il y perdra sans doute une grande partie de ses idées reçues. 

Autorenverzeichnis 



\section{CORINE DEFRANCE}

Historienne et directrice de recherche au CNRS (UMR SIRICE, Paris), enseignante à l'université de Paris 1-Panthéon-Sorbonne et membre du Labex EHNE («Écrire une Histoire nouvelle de l'Europe»), dont elle codirige l'axe 5 «L'Europe des guerres et des traces de guerre». Ancienne boursière de l'Institut für Europäische Geschichte (Mainz), 1995 post-doc-Stipendiatin de la Alexander-von-Humboldt-Stiftung à Bonn, 2011-2012 professeure invitée à la Freie Universität de Berlin.

Principaux axes de recherche : L'histoire de l'Allemagne et l'histoire des relations franco-allemandes aux $\mathrm{XX}^{\mathrm{e}}$ et $\mathrm{XXI}^{\mathrm{e}}$ siècles ainsi que les processus de réconciliation en Europe depuis le $\mathrm{XX}^{\mathrm{e}}$ siècle.

Choix de publications : Verständigung und Versöhnung nach dem «Zivilisationsbruch »? Deutschland in Europa nach 1945, Bonn 2016 (avec Ulrich Pfeil) ; Vaincus! Histoires de défaites. Europe, XIX-XX e siècles, Paris 2016 (avec Catherine Horel, François-Xavier Nérard); Histoire Franco-Allemande, vol. 10 : Entre Guerre froide et Intégration européenne. Reconstruction et Rapprochement, 1945-1963, Villeneuve d'Ascq 2012 (avec Ulrich Pfeil) [version allemande, Darmstadt 2011] ; Wege der Verständigung zwischen Deutschen und Franzosen nach 1945. Zivilgesellschaftliche Annäherungen, Tübingen 2010 (avec Michael Kißener, Pia Nordblom) ; Sentinelle ou Pont sur le Rhin? Le Centre d'Études Germaniques et l'apprentissage de l'Allemagne en France (1921-2001), Paris 2008.

\section{INES FUNK}

Studium der Historisch orientierten Kulturwissenschaften, 2015 Promotion an der Universität des Saarlandes, seit 2010 wissenschaftliche Mitarbeiterin in der Fachrichtung Geographie der Universität des Saarlandes.

Forschungsschwerpunkte: Grenzregionen, insbesondere die Großregion SaarLorLux, grenzüberschreitende Gesundheitsversorgung und Patientenmobilität, grenzüberschreitende Ausbildungs- und Arbeitsmärkte.

Veröffentlichungen u. a.: Öffentliches Gesundheitswesen, Luxemburg 2009; Grenzüberschreitende Patientenmobilität im saarländisch-lothringischen Grenæraum, Saarbrücken 2015.

\section{SUSANNE GEHRMANN}

Studium romanischer Sprachen, Literaturwissenschaften und Afrikanologie in Bochum, Paris, Köln und Bayreuth. Promotion 2001 in Bayreuth, ab 2002 Juniorprofessorin und seit 2011 Professorin für Afrikanische Literaturen und 
Kulturen an der Humboldt-Universität zu Berlin, 2008/2009 Féodor Lynen Fellow der Alexander von Humboldt-Stiftung an der Université Laval/Québec.

Forschungsschwerpunkte: frankophone afrikanische und transnationale Literaturen, Autobiographik, Gender, Repräsentationen von Gewalt.

Ausgewählte Publikationen: Kongo-Greuel. Zur literarischen Konfiguration eines kolonialkritischen Diskurses (1890-1910), Hildesheim 2003; Cosmopolitanism with African roots. Afropolitanism's ambivalent mobilities, in: Journal of African Cultural Studies 28, 1 (2016), S. 61-72; Geschichtsbewältigung und Sprachexperimente. Small Soldiers in afrikanischen Literaturen, Berlin 2011.

Mithg.: Conventions \& Conversions. Generic Innovations in African Literatures/ Innovations génériques dans les littératures africaines, Trier 2012 (mit Flora VeitWild); Créativité intermédiatique au Togo et dans la Diaspora, Münster 2015 (mit Dotsé Yigbe).

\section{MECHTHILD GILZMER}

Studium der Romanistik, Germanistik, der Allgemeinen und Vergleichenden Literaturwissenschaft an den Universitäten Saarbrücken und Paris-Sorbonne Nouvelle; 1984-1989 DAAD-Lektorin in Frankreich; 1993 Promotion an der Freien Universität in Berlin; 2004 Habilitation an der Universität Stuttgart; 2004-2011 Gastprofessorin im Fachgebiet Französische Philologie der Technischen Universität Berlin. Seit 2012 apl. Professorin und Lehrkraft für besondere Aufgaben im Fachgebiet Romanische Kulturwissenschaft und Interkulturelle Kommunikation der Universität des Saarlandes. Gastdozenturen u. a. an den Universitäten Paris 7, Paris 13, Université Sidi Mohammed Ben Abdallah in Fes, Marokko und am Centre canadien d'études allemandes et européennes, Université de Montréal, Québec.

Forschungsschwerpunkte: Deutsch-französischer Kulturtransfer im 20. Jahrhundert; Erinnerungskultur in Frankreich; Maghreb in Literatur und Film; sephardische Juden im Maghreb und in der Diaspora.

Veröffentlichungen u. a.: Denkmäler als Medien der Erinnerungskultur in Frankreich seit 1944, München 2007 [frz. Übersetzung: Mémoires de pierre. Les monuments commémoratifs en France après 1944, Paris 2009]; Franeninternierungslager in Südfrankreich. Rieucros und Brens. 1939-1944, Berlin 1994 [frz. Übersetzung: Camps de femmes: chroniques d'internées, Rieucros et Brens 1939-1944, Paris 2000]; Widerstand und Kollaboration in Europa, Münster 2004.

Mithg.: Les Femmes dans la Résistance en France, Paris 2003 (mit Chr. LévisseTouzé und S. Martens); Geschlechterordnungen in Nordafrika - Umbrüche und Perspektiven in Literatur, Film und Gesellschaft, Mainz 2008 (mit Susanne Gehrmann). 
Aktuelle Publikationen: Histoire partagée - mémoire divisée? Erinnerungskultur in grenzüberschreitender Perspektive, Saarbrücken 2016 (mit Sonja Kmec); Transformations. Changements et renouveaux dans la littérature et le cinéma au Maghreb depuis 1990, München 2016 (mit Ricarda Bienbeck, Maroua El Naggare und Ute Fendler); Germaine Tillion. Die gestohlene Unschuld. Ein Leben zwischen Résistance und Ethnologie, Berlin 2015 [mit einem Essay herausgegebene Übersetzung des französischen Originals Fragments de vie].

\section{EVA HAUSER}

Studium der Politikwissenschaft, Wirtschaftsgeschichte und Anthropogeographie in Saarbrücken und Cardiff mit Abschluss zur Magistra Artium im Jahr 1997. 1997-2003 tätig als Projektleiterin bei Energie-Cités im französischen Besançon und in leitender Funktion in zwei eingetragenen Vereinen im Bereich der Forschungsförderung und der Abfallverwertung in Frankreich. Im Jahr 2007 Tätigkeit als selbstständige Beraterin für in Frankreich aktive EEProjektierer; gleichzeitig Anfertigung von Studien zum Thema der Braunkohlenutzung in Ostdeutschland und zur Weiterentwicklung von Geschäftsmodellen für Ökostrom. Seit 2008 wissenschaftliche Mitarbeiterin der IZES gGmbH; seit April 2016 stellvertretende wissenschaftliche Leiterin des Instituts.

Forschungsschwerpunkte: Empirie und Regulierung der Teilmärkte des Stromsektors sowie die Schaffung geeigneter Rahmenbedingungen für die Transformation des Energiesektors, Einbindung von Bürgern und bürgerschaftlichem Engagement im Rahmen der Energiewende.

Veröffentlichungen u. a.: Herausforderungen bei der Allokation von Strom aus fluktuierenden erneuerbaren Energien: Probleme und mögliche Lösungskonzepte, in: Vierteljahreshefte zur Wirtschaftsforschung. DIW Berlin, 82. Jahrgang, Nr. 3 (2013), S. 155-169 (mit Alexander Zipp); Systemaufbau eines künftigen Stromsystems, in: Jörg Böttcher (Hg.): Stromleitungsnetze. Rechtliche und wirtschaftliche Aspekte, München 2014, S. 12-29.

Mithg.: Kompassstudie Marktdesign. Leitideen für ein Design eines Stromsystems mit einem hohen Anteil fluktuierender Erneuerbarer Energien, Bochum 2012 (u. a. mit Uwe Leprich); Nutzeneffekte von Bürgerenergie. Eine wissenschaftliche Qualifizierung und Quantifizierung der Nutzeneffekte der Bürgerenergie und ibrer möglichen Bedeutung für die Energiewende, Saarbrücken 2015 (u. a. mit Jan Hildebrand). 


\section{MARIA HEGNER}

Studium der Romanistik, Anglistik und Germanistik an den Universitäten Leipzig, Exeter (UK) und Heidelberg. Promotion 2013 in Romanischer Philologie an der Universität des Saarlandes. 2007-2013 wissenschaftliche Mitarbeiterin am Lehrstuhl für Romanische Philologie; seit 2014 Projektmitarbeiterin in der deutsch-französischen sowie grenzüberschreitenden Zusammenarbeit an der Hochschule für Technik und Wirtschaft des Saarlandes (htw saar). Redakteurin beim Dictionnaire étymologique roman (Schweickard, Wolfgang/Buchi, Éva (Hg.): DÉRom, Berlin [u. a.] 2008-); Erstellung der französischen Äquivalente für das Wörterbuch zur Lexikographie und Wörterbuchforschung (Wiegand, Herbert Ernst [u. a.] (Hg.): WLWF, Berlin [u. a.]; mit Franz Joseph Hausmann).

Forschungsschwerpunkte: Historische Sprach- und Übersetzungswissenschaft seit der Frühen Neuzeit, Sprach- und Übersetzungsvergleich, Textsorten und Stilistik, Terminologie, Sprach- und Kulturgeschichte.

Veröffentlichungen u. a.: Die frühen Übersetzungen aus dem Englischen ins Französische am Beispiel der Nordamerikaliteratur (1572-1700), Berlin 2013; Neue Welt und Kulturkontakt: Lexikalische Aspekte der französischen Übersetzung (1688) von Richard Blomes The Present State of His Majesties Isles and Territories in America (1687), in: Dahmen, Wolfgang [u. a.] (Hg.): America Romana. Romanistisches Kolloquiuum XXVI, Tübingen 2012, S. 193-209; Noms propres et terminologie métalinguistique dans les Recherches curieuses sur la diversité des langues et religions (1640) d'Edward Brerewood et son original anglais (1614), in: Revue de Linguistique Romane (RliR) (im Druck); Lexique et traduction: aspects généraux, in: Albrecht, Jörn/Métrich, René (Hg.): Manuel de traductologie, Berlin 2016, S. 316-332.

\section{DIETMAR HÜSER}

Dietmar Hüser hatte 2004-2013 den Lehrstuhl für Geschichte Westeuropas (19./20. Jahrhundert) an der Universität Kassel inne und arbeitet seitdem als Professor für Europäische Zeitgeschichte an der Universität des Saarlandes. Seit 2017 leitet er das dortige Frankreichzentrum.

Seine zentralen Forschungsachsen sind neben der Geschichte Frankreichs nach 1945 die deutsch-französischen und westeuropäischen (politischen) Beziehungen, die (gesellschaftlichen) Vergleiche und (kulturellen) Transfers sowie Aspekte der Europäischen Integration und der Internationalen Geschichte. Laufende Projekte behandeln die Rolle von Produkten, Phänomenen und Praktiken aus dem Bereich der Populärkultur für gesellschaftliche und politische Umbrüche nach dem Zweiten Weltkrieg. 
Zuletzt publizierte Bücher: Hg.: „Frankreichs Empire schlägt zurück“ - Gesellschaftswandel, Kolonialdebatten und Migrationskultur, Kassel 2010; Populärkultur transnational - Lesen, Sehen, Hören, Erleben im Europa der langen 1960er Jahre, Bielefeld 2017.

Mithg.: Tour de France - Eine bistorische Rundreise, Stuttgart 2008 (mit Armin Heinen); Medien - Debatten - Öffentlichkeiten in Deutschland und Frankreich im 19. und 20. Jabrbundert, Stuttgart 2011 (mit Jean-François Eck); Deutschland und Frankreich in der Globalisierung des 19. und 20. Jabrbunderts, Stuttgart 2012 (mit Jean-François Eck); Skandale zwischen Moderne und Postmoderne - Interdisそiplinäre Perspektiven auf Formen gesellschaftlicher Transgression, Berlin 2014 (mit Andreas Gelz und Sabine Ruß-Sattar); Populärkultur und deutsch-franæösische Mittler. Akteure, Medien, Ausdrucksformen, Bielefeld 2015 (mit Ulrich Pfeil); Fußball und Diversität in Frankreich und Deutschland (Lendemains 161 (2016), mit JeanChristophe Meyer und Pierre Weiss); Markgrafschaft - Metropolen - Medien. Krisen, Kommunikation und Politisierung europä̈scher Gesellschaften: Festscbrift für Clemens Zimmermann, Trier 2016 (mit Gabriele Clemens et al.).

\section{SABINE LIEBIG}

Sabine Liebig ist Professorin für Neuere und Neueste Geschichte und ihre Didaktik an der Pädagogischen Hochschule Karlsruhe. Ihre Promotion an der PH-Weingarten behandelt die Themen Gender, Migration und Leben in Siebenbürgen: Maria Klein, eine Frau geht ibren Weg - von Ravensburg nach Siebenbürgen.

Sie lehrt neben dem Lehramt auch im Masterstudiengang Interkulturalität, Migration und Mehrsprachigkeit und hat außerdem diverse Projekte zu Migration durchgeführt (u. a. 2008/2009: „Migration in Karlsruhe - Kooperationsprojekt mit dem Stadtarchiv und dem Stadtmuseum“; 2009/2010: „Migrantinnen in Karlsruhe erzählen - ein ,Frauenprojekt ${ }^{\star}$ mit Migrantinnen und Studentinnen“; 2012: „Generationendialog in Migrantenfamilien“).

Veröffentlichungen u. a.: Migration aus weiblicher Perspektive, in: Treibel, Annette/Soff, Marianne (Hg.): Gender interdisziplinär. Forschungsbeiträge der Pädagogischen Hochscbule Karlsrube, Karlsruhe 2014, S. 45-62; Migration und Geschlecht. Eine Einführung in das Thema, in: Aubele, Edeltraud/Pieri, Gabriele (Hg.): Femina Migrans. Frauen in Migrationsprozessen (18.-20. Jabrbundert), Sulzbach/Taunus 2011, S. 19-38; Give me all your tired, your poor, your huddled masses - Interkulturelles Seminar in New York zu „Migration und Integration“, in: Karlsruber Pädagogische Beiträge, 78 (2011) (Internationale Beziehungen), (mit Annette Deschner), S. 65-76. 


\section{HANS-JÜRGEN LÜSEBRINK}

Studium der Romanistik und der Geschichtswissenschaft in Mainz, Tours und Paris; 1981 Promotion an der Universität Bayreuth in Romanischer Philologie; 1984 Promotion im Fach Geschichtswissenschaft an der Ecole des Hautes Etudes en Sciences Sociales (EHESS) in Paris; 1987 Habilitation in Romanischer Philologie an der Universität Bayreuth. Inhaber des Lehrstuhls für Romanische Kulturwissenschaft und Interkulturelle Kommunikation an der Universität Saarbrücken. Gastprofessuren u. a. an der Universität Laval (Québec), der EHESS (Paris), der ENS (Paris), der EPHE (Paris), der Universität Warschau (Polen), der Northwestern University (Evanston) und der University of California at Los Angeles (UCLA). 2001 Diefenbaker-Preisträger des Conseil des Arts du Canada, 2005 Ernennung zum Officier dans l'Ordre des Palmes Académiques. Mit York-Gothart Mix (Marburg) und Christophe Charle (Paris) Leiter des binationalen ANR-DFG-Forschungsprojekts „Die Transkulturalität nationaler Räume. Prozesse, Vermittler- und Übersetzerfiguren sowie soziokulturelle Wirkungen des literarischen Kulturtransfers in Europa (1750-1900)“ (2012-2016). Stellvertretender Sprecher des Internationalen Graduiertenkollegs GRK 1864, „Diversity. Mediating Difference in Transcultural Spaces“ der Universitäten Montréal, Trier und Saarbrücken (DFG/Conseil de Recherche en Sciences Humaines du Canada, 2013-2017).

Forschungsschwerpunkte: Europäisch-außereuropäische Literatur- und Kulturbeziehungen 18.-20. Jahrhundert; Kulturtransfer Deutschland-Frankreich; frankophone Literaturen und Kulturen außerhalb Europas mit Schwerpunkt Afrika und Québec; Theorie der Interkulturellen Kommunikation mit Schwerpunkt Kulturtransfer.

Neuere Buchveröffentlichungen u. a.: Einführung in die Landeskunde Frankreichs. Wirtschaft - Gesellschaft - Staat - Kultur - Mentalitäten, Stuttgart 42017; Interkulturelle Kommunikation. Interaktion - Kulturtransfer - Fremdwahrnehmung, Stuttgart/ Weimar ${ }^{4} 2016$.

Mithg.: Am Wendepunk.t. Deutschland und Frankreich um 1945 - zur Dynamik eines ,transnationalen' kulturellen Feldes, Bielefeld 2008 (mit Patricia Oster); Städtischer Raum im Wandel. Modernität - Mobilität - Repräsentationen/Espaces urbains en mutation. Modernités - mobilités - représentations, Berlin 2011 (mit Gabriele Clemens und Jean El Gammal); Zwischen Transfer und Vergleich. Theorien und Methoden der Literatur- und Kulturbeziehungen aus deutsch-französischer Perspektive, Wiesbaden 2013 (mit Christiane Solte-Gresser und Manfred Schmeling); 50 Jahre Elysée-Vertrag (1963-2013)/Les 50 ans du Traité de l'Elysée (1963-2013). Traditionen, Herausforderungen, Perspektiven/Traditions, défis, perspectives, Bielefeld 2014 (mit Mechthild Gilzmer und Christoph Vatter); Interregionale Gewerkschaftsräte. Historische, sozialwissenschaftliche und interkulturelle Analysen, Baden-Baden 2015 (mit Dieter Filsinger und Luitpold Rampeltshammer); Interkulturelle Kompetenz in deutsch- 
französischen Studiengängen. Les compétences interculturelles dans les cursus franco-allemands, Wiesbaden 2017 (mit Gundula Gwenn Hiller, Patricia Oster-Stierle und Christoph Vatter).

\section{REINER MARCOWITZ}

Studium der Germanistik und Geschichte an der Universität zu Köln. 1992 ebendort Promotion mit einer Studie zu den deutsch-französischen Beziehungen zwischen 1958 und 1969. 1999 Habilitation an der Technischen Universität Dresden mit einer Studie über die Interdependenz französischer AuBen- und Innenpolitik von der Restauration bis zum Second Empire. Seit 2007 Professor für Deutschlandstudien an der Université Paul Verlaine - Metz (seit 2012 Université de Lorraine). Seit 2010 Direktor des Centre d'études germaniques interculturelles de Lorraine (CEGIL).

Forschungsschwerpunkte sind die deutsche und die französische Geschichte sowie die deutsch-französischen Beziehungen im 19. und 20. Jahrhundert und die europäische Integrationsgeschichte nach 1945.

Jüngste Veröffentlichungen: Mithg.: France - Allemagne au XXe siècle: la production académique de savoir sur l'Autre, vol. I-IV/Deutschland und Frankereich im 20. Jahrhundert. Akademische Wissensproduktion über das andere Land, Bd. I-IV, Bern 2011-2014 (mit Michel Grunewald, Hans-Jürgen Lüsebrink und Uwe Puschner); 50 ans de relations franco-allemandes, Paris 2012 (mit Hélène MiardDelacroix); La longue mémoire de la Grande Guerre, Villeneuve d'Ascq 2017 (mit Laurent Jalabert und Arndt Weinrich).

\section{SYLVERE MBONDOBARI}

Maître de conférences für Allgemeine und Vergleichende Literaturwissenschaft an der Université Omar Bongo in Libreville (Gabun). Zurzeit DAADGastdozent am Lehrstuhl für Romanische Kulturwissenschaft und Interkulturelle Kommunikation (Prof. Dr. Lüsebrink) an der Universität des Saarlandes in Saarbrücken. Studium der Interkulturellen Germanistik, Komparatistik und Politikwissenschaft an der Universität Bayreuth. Promotion im Fach Komparatistik mit einer Arbeit zum Albert Schweitzer-Mythos in Europa und in Afrika. Humboldt-Stipendiat 2007-2009 und 2013.

Forschungsschwerpunkte: Colonial und Postcolonial Studies, Literatur und Medien, Gedächtnis und Erinnerungskultur, Populäre Kulturen, Reiseliteratur.

Wichtige Veröffentlichungen: Mithg.: Mémoires et lieux de mémoire. Enjeux interculturels et relations médiatiques, Saarbrücken 2016 (mit Hans-Jürgen Lüsebrink); Villes coloniales/Métropoles postcoloniales. Représentations littéraires, images médiatiques et regards croisés, Tübingen 2015 (mit Hans-Jürgen Lüsebrink); Le roman policier francophone d'Afrique. Textes - Contextes -Tendances, Metz 2013 (mit 
Bernard De Meyer und Pierre Halen); Archäologie eines modernen Mythos. Albert Schweitzer Nachrubm in europäischen und afrikanischen Text- und Bildmedien, Frankfurt/M. [u. a.] 2003.

\section{WOLFGANG MEYER}

Diplomstudium der Soziologie, Politischen Wissenschaft und Zeitgeschichte an der Universität Mannheim (1982-1989), 1997 Promotion an der Philosophischen Fakultät der TU Chemnitz-Zwickau, 2013 Habilitation durch die Fakultät Empirische Sozialwissenschaften der Universität des Saarlandes. Privatdozent, adj. Prof. (UTAMU), stellvertretender Leiter des Centrums für Evaluation (CEval) an der Universität des Saarlandes; Gründungsmitglied der Deutschen Gesellschaft für Evaluation (DeGEval).

Forschungsschwerpunkte: Arbeitsmarkt- und Umweltforschung; Methoden der empirischen Sozialforschung und Evaluation.

Veröffentlichungen u. a.: Gemeinsames bedarfs- und qualitätsorientiertes globales Lernen: Entwicklung eines Blended-Learning-Masterstudiengangs „Evaluation" in Costa Rica, Deutschland und Uganda, in: Arnold, Rolf/Wolf, Konrad/Wanken, Simone (Hg.): Offene und kompetenzorientierte Hochschule, Baltmannsweiler 2014, S. 243-256 (mit Sandra Schopper und Reinhard Stockmann); Grenzüberschreitende Arbeitsmarktpolitik: Institutionen und institutionelle Steuerung des Arbeitsmarktes in der Großregion SaarLorLux-Rheinland-Pfalz-Wallonien, in: Meyer, Jürgen/Rampeltshammer, Luitpold (Hg.): Gren₹überscbreitendes Arbeiten in der Großregion SaarLorLux, Saarbrücken 2012, S. 79-151 (mit Maria Albrecht).

Mithg.: Nachbaltige Evaluation? Auftragsforschung zwischen Praxis und Wissenschaft, Münster/New York 2015 (mit Vera Hennefeld und Stefan Silvestrini); The Future of Evaluation. Global Trends, New Challenges, Shared Perspectives, Basingstoke 2015 (mit Reinhard Stockmann).

\section{PATRICIA OSTER-STIERLE}

Studium der Romanistik, Komparatistik und Germanistik in Bonn, Toulouse und Harvard. Habilitation für die Fächer Romanische Philologie und Vergleichende Literaturwissenschaft an der Universität Tübingen. Seit Wintersemester 2003 Lehrstuhl für Französische Literaturwissenschaft an der Universität des Saarlandes. 2005-2012 Vizepräsidentin der Universität des Saarlandes. Im Anschluss zuerst Vizepräsidentin und seit 2015 Präsidentin der DeutschFranzösischen Hochschule.

Forschungsschwerpunkte: Literarische Anschauungsformen, vergleichende Medienwissenschaft und deutsch-französischer Kulturtransfer. 
Veröffentlichungen u. a.: Der Schleier im Text. Funktionsgeschicbte eines Bildes für die nenzeitliche Erfahrung des Imaginären, München 2002.

Mithg.: Am Wendepunkt. Deutschland und Frankereich um 1945. Zur Dynamik. eines 'transnationalen' kulturellen Feldes, Bielefeld 2008 (mit Hans-Jürgen Lüsebrink); darin: Die Zeitschrift als Ort der Konstitution eines 'transnationalen' kulturellen Feldes: Lancelot, der Bote aus Frankreich und Die Wandlung, S. 231-248; Zwischen Herrschaft und Kunst. Fürstliche und adlige Franen im Zeitalter Elisabeths von Lothringen, Gräfin von Nassau-Saarbrücken, Saarbrücken 2013 (mit Wolfgang Haubrichs); Palimpsestes poétiques. Fragment et superposition, Paris 2015 (mit Karl-Heinz Stierle).

Aufsätze zur Thematik des Bandes u. a.: Ce qu'on ne peut pas oublier ce qu'il ne faut pas oublier: Anselm Kiefer et Celan, in: La poésie, la mémoire, l'oubli, Colloque réuni par Yves Bonnefoy, Paris 2005; Kunst als Medium des Kulturtransfers. Methodische Reflexionen am Beispiel von Cécile Wajsbrots Berlinromanen, in: Solte-Gresser, Christiane/Lüsebrink, Hans-Jürgen/Schmeling, Manfred (Hg.): Zwischen Transfer und Vergleich, Saarbrücken 2013, S. 383396; Literarische Brücken über den Rhein, in: Bogner, Ralf/Leber, Manfred (Hg.): Neun plus eins. Literarische Beziebungen zwischen Deutschland und seinen Nachbarn, Saarbrücken 2014, S. 141-157.

\section{ULRICH PFEIL}

Professeur de civilisation allemande à l'Université de Lorraine, Metz.

Principaux axes de recherche : L'histoire de l'Allemagne et l'histoire contemporaine des relations franco-allemandes, l'histoire de la guerre froide ainsi que les processus de réconciliation en Europe depuis le $\mathrm{XX}^{\mathrm{e}}$ siècle.

Choix de publications : Die «anderen» deutsch-französischen Beziehungen. Die DDR und Frankreich 1949-1990, Cologne 2004 ; Vorgeschicbte und Gründung des Deutschen Historischen Instituts Paris. Darstellung und Dokumentation, Ostfildern 2007 ; Die DDR in den deutsch-französischen Beziehungen, Bruxelles 2013 (avec Anne Kwaschik); Der deutsche Film im Kalten Krieg = Cinéma allemand et guerre froide, Bruxelles 2014 (avec Christin Niemeyer); Populärkultur und deutsch-französische Mittler/Culture de masse et médiateurs franco-allemands. Akteure, Medien, Ausdrucksformen/Acteurs, médias, articulations (Jahrbuch des Frankreichzentrums der Universität des Saarlandes 14/2014), Bielefeld 2015 (avec Dietmar Hüser) ; Le Mur de Berlin. Histoire, mémoires, représentations, Bruxelles 2016 (avec Nicole Colin, Corine Defrance et Joachim Umlauf). 


\section{Claudia POLZIN-HAUMANN}

Seit WS 2006/07 Inhaberin des Lehrstuhls für Romanische Sprachwissenschaft (Schwerpunkt Angewandte Linguistik und Didaktik der Mehrsprachigkeit) an der Universität des Saarlandes; 2009 Ablehnung eines Rufs an die Universität Münster. Von Januar 2013 bis Februar 2017 Leiterin des Frankreichzentrums der Universität des Saarlandes; ab März 2017 Vizepräsidentin für Europa und Internationales der Universität des Saarlandes.

Forschungsschwerpunkte: Synchrone und historische französische und spanische Sprachwissenschaft, insbesondere Kontrastive Linguistik/Sprachvergleich/Mehrsprachigkeit, Text- und Varietätenlinguistik, Grammatikographie der romanischen Sprachen, linguistische Metaphernforschung, Sprachpolitik und Sprachpflege, Sprachreflexions- und Sprachbewusstseinsforschung, Romanistik und Neue Medien, Angewandte Sprachwissenschaft, z. B. im Bereich der Verbindung von Sprachwissenschaft und Sprachlehre und der Wirtschaftslinguistik.

Aktuelle Veröffentlichungen: Le français, langue difficile. Zur Diskussion über ein Stereotyp im frankophonen Internet, in: Hardy, Stéphane/Herling, Sandra/Patzelt, Carolin (Hg.): Laienlinguistik im frankophonen Internet, Berlin 2015, S. 129-154; Die „Proposition de loi constitutionnelle visant à ratifier la Charte européenne des langues régionales ou minoritaires“ - Ein neues Kapitel in der Diskussion um die Charta in Frankreich?, in: Bernsen, Michael/Eggert, Elmar/Schrott, Angela (Hg.): Historische Sprachwissenschaft als philologische Kulturwissenschaft. Festschrift für Franz. Lebsanft zum 60. Geburtstag, Göttingen 2015, S. 195-207; Frontières linguistiques et communautés de travail. Un bilinguisme à l'épreuve du changement industriel, in: questions de communication 29 (2016), S. 351-374 (mit Jean-Yves Trépos [u. a.]); Unternehmenskommunikation in einem internationalen Unternehmen in der SaarLorLux-Region. Eine Fallstudie auf interdisziplinärer Grundlage, in: Hennemann, Anja/Schlaak, Claudia (Hg.): Unternehmenskommunikation und Wirtschaftsdiskurse - Herausforderungen für die romanistische Linguistik, Heidelberg 2016, S. 103-121 (mit Christina Reissner).

Mithg.: Sprache und Sprachbewusstsein in Europa. Beiträge aus Wissenschaft, Öffentlichkeit und Politik/Langues et conscience linguistique en Europe. Une approche pluridisciplinaire: entre sciences, opinion publique et politique, Bielefeld 2011 (mit Dietmar Osthus); Angewandte Romanistische Linguistik. Kommunikations- und Diskursformen im 21. Jahrbundert, St. Ingbert 2015 (mit Alberto Gil); Manuel de linguistique française, Berlin/Boston 2015 (mit Wolfgang Schweickard). Mitherausgeberin der Zeitschrift für romanische Philologie und von metaphorik.de. 


\section{ALBERT RAASCH}

Studium der Romanistik, der Klassischen Altertumskunde, der Philosophie und der Psychologie in Kiel, Lyon, Paris (Ecole Normale Supérieure, rue d'Ulm) und Grenoble. Promotion 1957. 1968-1973 Professur für Französische Sprache und Literatur (und ihre Didaktik) an der Pädagogischen Hochschule Kiel. 1973-1999 Lehrstuhl für Angewandte Linguistik und Sprachlehrforschung Französisch am Romanistischen Institut der Universität des Saarlandes, Saarbrücken. Lehrtätigkeit und Rufe: Universitäten Hamburg, Frankfurt/M. und Dortmund. Lehrtätigkeiten und Kurzzeitdozenturen in Europa, Südamerika, Afrika, Ostasien.

Gründungsmitglied (und langjähriges Vorstandsmitglied) der DeutschFranzösischen Gesellschaft Schleswig-Holstein (1951). Gründungsmitglied der Gesellschaft für Angewandte Linguistik (1968). Begründer des Sprachenund Kommunikationszentrums der Universität des Saarlandes. Begründer der Arbeitsgruppe Angewandte Linguistik Französisch (AALF) (1968). Begründer und langjähriger Leiter des Zertifikats Französisch des Deutschen Volkshochschulverbandes. Begründer und Leiter der Nationalen Agentur LINGUA (NATALI) (1993-2000). Gründer und Vorsitzender (1991-2000) des Sprachenrates Saar. Präsident von GERFLINT pour Pays Germanophones (Groupement d'Etudes et de Recherches pour le Français Langue Internationale).

Forschungsschwerpunkte u. a. : Angewandte Linguistik, Fremdsprachendidaktik und Sprachenpolitik.

Ausgewählte neuere Veröffentlichungen: Sprachenpolitik konkret. Ein sprachenpolitischer Rahmen für das Erwerben, Lehren und Lernen von Sprachen - am Beispiel des ,Sprachenrates Saar', in: Lebreton, Marlène (Hg.): La didactique des langues et ses multiples facettes. Mélanges offerts à Jacqueline Feuillet, Professeur émérite, Université de Nantes, Paris 2015, S. 369-390; Sprachenpolitik und Förderung der Nachbarsprachen, in: Colin, Nicole [u. a.] (Hg.): Lexikon der deutsch-französischen Beziebungen nach 1945, Tübingen 2013, S. 414-416; Die Chancen der Vision? Oder: Die Risiken der Illusion? Aktuelle Anmerkungen $\mathrm{zu}$ internationalen Begegnungen, Partnerschaften und Städtepartnerschaften, in: Baur, Siegfried (Hg.): Austauschpädagogik und Austauscherfabrung. Sprach- und Kommunikationslernen durch Austausch, Baltmannsweiler 2012, S. 21-38; Im Fokus: die Sprachen. Grenzregionen rücken in das Zentrum des Interesses, in: Kliewer, Annette/Cerovska, Martina (Hg.): Wider den Einheitsunterricht. Deutschlernen an der Grenze, Liberec 2011, S. 5-14.

Hg.: La France, l'Allemagne: deux cultures d'apprentissage? Que peuvent-elles apprendre l'une de l'autre? Band 9 der Zeitschrift Synergies Pays Germanophones, 2016 (mit Florence Windmüller). 


\section{WILFRIED SCHMIDT}

Studium der Romanistik und Geschichte für das Lehramt an Gymnasien an der Universität des Saarlandes. Nach dem ersten und zweiten Staatsexamen Dozent für verschiedene saarländische Volkshochschulen. Ab 1985 hauptamtlicher pädagogischer Mitarbeiter bei der Volkshochschule Stadtverband (jetzt Regionalverband) Saarbrücken. 1997-2003 stellvertretender Leiter der Volkshochschule. Seit 2004 Leiter der Volkshochschule des Regionalverbandes Saarbrücken, seit 2006 Vorstandsmitglied der französischen UP/VHS Sarreguemines Confluences und seit 2013 Vorsitzender des Verbandes der saarländischen Volkshochschulen.

1997-2010 verschiedene Projekte zu Europa, zur grenzüberschreitenden Zusammenarbeit und zum Sprachenlernen in europäischen Grenzräumen. Seit 2008 Vertreter des Deutschen Volkshochschulverbandes beim Verband der französischen Volkshochschulen.

\section{PETER TISCHER}

Studium der Romanistik, Amerikanistik und Rechtswissenschaften in Erlangen-Nürnberg und Lille. Danach zunächst Leiter des Sprachlabors an der WISO an der Friedrich-Alexander Universität Erlangen-Nürnberg und seit 1997 Leiter des Zentralen Instituts für Sprachen und Kommunikation (Sprachenzentrum) der Universität des Saarlandes. Seit 2014 Vorsitzender des Arbeitskreises Sprachenzentren, Sprachlehrinstitute und Fremdspracheninstitute e.V. (AKS).

Forschungsschwerpunkte und Interessensgebiete: Hochschulfremdsprachenunterricht, Lehrmaterialentwicklung, eLearning, Hochschulpolitik sowie literarische Übersetzungen. Daneben Co-Autor und Sprecher des englischen Sprachlern-Podcasts RoPeCast (www.ropecast.de).

Veröffentlichungen u. a.: Career Express - Business English C1: Teacher's Book, Reading 2013 (mit Jane Maier-Fairclough); Podcasts als mündliche Prüfungen, in: Arntz, Reiner/Krings, Hans P./Kühn, Bärbel (Hg.): Autonomie und Motivation: Erträge des 2. Bremer Symposions zum autonomen Fremdsprachenlernen, Bochum 2011, S. 127-142; C plus rapide: Das computerbasierte C-Test Modul im Modulang Quiz Creator, in: Haberer, Monika/Wagner, Horst (Hg.): E-Learning, Sprache und Kultur, Aachen 2005, S. 33-42; Der gezeichnete Held: Die Serienfigur im modernen französischen Humor-Comic, Tübingen 1994.

Hg.: Neue Medien - Neues Lehren - Neues Lernen: Fremdsprachenunterricht im Informationszeitalter, Bochum 2003.

Übersetzungen u. a.: Diverse literarische Übersetzungen von poetologischen Texten, Kurzgeschichten und Gedichten aus dem Englischen, u. a. von Allen Ginsberg, Leslie M. Silko und Luci Tapahonso, zuletzt in: Breinig, 
Helmbrecht/Donat, Wolfram (Hg.): das auge des raben schwarz: Tiergedichte aus der englischsprachigen Welt, Gelnhausen 2016.

\section{HENRIK UTERWEDDE}

Studium der Politikwissenschaft und Volkswirtschaft an der Freien Universität Berlin und am Institut d'Etudes Politiques in Paris. 1987 Promotion (Dr. phil.) an der FU Berlin, 2003 Habilitation (Vergleichende Politikwissenschaft, Universität Osnabrück). 2003 Honorarprofessor am Fachbereich Sozialwissenschaften der Universität Stuttgart. Seit 1974 wissenschaftlicher Mitarbeiter am Deutsch-Französischen Institut Ludwigsburg (DFI), 1998-2014 stellvertretender Direktor des DFI.

Forschungsschwerpunkte: Politik, Wirtschaft und Gesellschaft Frankreichs; vergleichende politische Ökonomie (Deutschland-Frankreich), europäische Wirtschaftspolitik.

Veröffentlichungen u. a.: Frankereich - eine Länderkunde, Opladen/Berlin/ Toronto 2017.

Mithg.: Frankereich. Politik, Wirtschaft, Gesellschaft, Wiesbaden 2006 (mit Joachim Schild); Regards sur l'Allemagne unifiée, Paris 2006 (mit Adelheid Hege, Adolf Kimmel und Stephan Martens); Forschungszusammenarbeit zwischen Deutschland und Frankereich in den Wirtschaftswissenschaften. Bestandsaufnabme, Erfolgsbedingungen und Gestaltungsansätze für Kooperationsprojekte, Ludwigsburg 2014 (mit Frank Baasner); 2015 France Report. Sustainable Governance Indicators, Gütersloh 2015 (mit Yves Mény und Reimut Zohlnhöfer), Frankreichs V. Republik: Ein Regierungssystem im Wandel. Festschrift für Adolf Kimmel, Wiesbaden 2005 (mit Joachim Schild); Die verunsicherte Französische Republik. Wandel der Politik - und der Leitbilder?, Baden-Baden 2009 (mit Joachim Schild); Länderbericht Frankreich, Bonn ${ }^{3} 2012$ (mit Adolf Kimmel); L'aide au retour à l'emploi. Politiques françaises, allemandes et internationales, Cergy 2013 (mit Solène Hazouard und René Lasserre); France-Allemagne: Cultures monétaires et budgétaires. Vers une nouvelle gouvernance européenne?, Cergy 2015 (mit Solène Hazouard und René Lasserre).

\section{CHRISTOPH VATTER}

Studium der Fächer Romanische Kulturwissenschaft und Interkulturelle Kommunikation, Deutsch als Fremdsprache und Französische Philologie an der Universität des Saarlandes und der Université Laval (Québec, Kanada). 2008 Promotion im Rahmen einer deutsch-französischen co-tutelle de thèse in Romanistik und Sciences de l'information et de la communication; seit 2010 Juniorprofessor für Interkulturelle Kommunikation an der Universität des 
Saarlandes. Programmbeauftragter des binationalen Studiengangs „DeutschFranzösische Studien: Grenzüberschreitende Kommunikation und Kooperation“; Mitglied des Internationalen Graduiertenkollegs „Diversity. Mediating Difference in Transcultural Spaces" (Montréal/Saarbrücken/Trier).

Forschungsschwerpunkte: Interkulturelle Kommunikation und interkulturelles Lernen, französische Kultur- und Medienwissenschaft, Erinnerungskulturen, deutsch-französische Kulturbeziehungen, frankophone Kulturen in Nordamerika und Afrika.

Veröffentlichungen u. a.: Gedächtnismedium Film. Holocaust und Kollaboration in deutschen und französischen Spielfilmen seit 1945, Würzburg 2009.

Mitautor: Fran₹ösische Kultur- und Medienwissenschaft: eine Einfübrung, Tübingen 2004; Interkulturelle Kompetenz- Französisch, Stuttgart [u. a.] 2012; Interkulturelle Kompetenz-Spanisch, Stuttgart [u. a.] 2014.

Hg.: Praktikum/stage. Interkulturelle Herausforderungen, praktische Umsetzung und didaktische Begleitung von schulischen Praktika im Partnerland, St. Ingbert 2013.

Mithg.: Multiculturalisme et diversité culturelle dans les médias an Canada et au Québec, Würzburg 2013; 50 Jahre Elysée-Vertrag (1963-2013): Traditionen, Herausforderungen, Perspektiven, Bielefeld 2014; Grenzüberschreitende Informationsflüsse und Medien in der Großregion SaarLorLux, Baden-Baden 2015; Interkulturelle Kompeten₹ in deutsch-französischen Studiengängen: didaktische Konzepte, Methoden, Materialien, Wiesbaden 2016; Deutsch-französische Schnittstellen in Populärkultur und Medien, Berlin/Münster 2017.

\section{ROMANA WEIERSHAUSEN}

Studium der Fächer Deutsche Philologie und Mathematik in Göttingen, zudem Franco-Allemand/Lettres Modernes in Paris. Promotion 2004 in Göttingen, Habilitation 2013 in Bremen (venia legendi in Neuerer deutscher Literaturwissenschaft/Vergleichender Literaturwissenschaft). Gastdozenturen in der Ukraine und Russland, Vertretungsprofessuren in Berlin, Göttingen und Saarbrücken. 2014 Berufung auf die Professur für Frankophone Germanistik an der Universität des Saarlandes.

Forschungsschwerpunkte: Drama und Theater im 18. Jahrhundert, Geschlechter- und Wissenschaftsdiskurs um 1900, interkulturelle Gegenwartsliteratur und deutsch-französische Komparatistik.

Veröffentlichungen u. a.: Wissenschaft und Weiblichkeit. Die Studentin in der Literatur der Jabrbundertwende, Göttingen 2004; Paris als theatraler Schauplatz in deutschen Texten über die Französische Revolution, in: Lendemains 36 (2011), S. 164-178; Sprachpolitische Träume in traumartigem Erzählen - André Weckmanns Elsass-Roman Odile oder das magische Dreieck/La Roue du paon, in: Gätje, Hermann/Singh, Sikander (Hg.): Übergänge, Brüche, Annäherungen. Beiträge ₹̨u 
einer Geschichte der Literatur im Saarland, in Lothringen, im Elsass, in Luxemburg und Belgien, Saarbrücken 2015, S. 437-454.

Mithg.: Transkulturalität sur scène: Zum Theater in Frankreich und Deutschland um die Jahrtausendwende (Dossier), in: Lendemains 40 (2015), H. 160 (mit Natascha Ueckmann); Aufgeklärte Zeiten? Religiöse Toleran₹ und Literatur, Berlin 2011 (mit Insa Wilke und Nina Gülcher. 


\section{Politikwissenschaft}
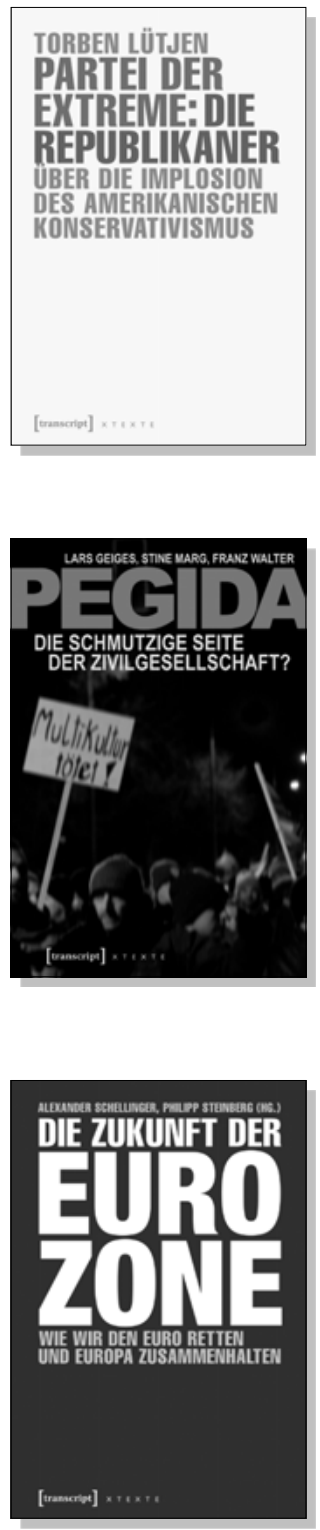

Torben Lütjen

Partei der Extreme: Die Republikaner

Über die Implosion des amerikanischen Konservativismus

2016, 148 S., kart.

$14,99 €(D E), 978-3-8376-3609-3$

E-Book

PDF: $12,99 €(D E)$, ISBN 978-3-8394-3609-7

EPUB: $12,99 €(D E)$, ISBN 978-3-7328-3609-3

Lars Geiges, Stine Marg, Franz Walter

Pegida

Die schmutzige Seite der Zivilgesellschaft?

2015, 208 S., kart., farb. Abb.

$19,99 €(D E), 978-3-8376-3192-0$

E-Book

PDF: $14,99 €(D E)$, ISBN 978-3-8394-3192-4

EPUB: $14,99 €(D E)$, ISBN 978-3-7328-3192-0
Alexander Schellinger, Philipp Steinberg (Hg.)

\section{Die Zukunft der Eurozone}

Wie wir den Euro retten und Europa zusammenhalten

2016, 222 S., kart.

$19,99 €(D E), 978-3-8376-3636-9$

E-Book

PDF: $17,99 €$ (DE), ISBN 978-3-8394-3636-3

EPUB: $17,99 €(D E)$, ISBN 978-3-7328-3636-9 


\section{Politikwissenschaft}

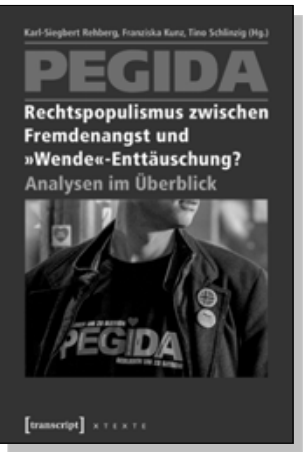

Karl-Siegbert Rehberg, Franziska Kunz, Tino Schlinzig (Hg.)

PEGIDA - Rechtspopulismus zwischen

Fremdenangst und "Wende"-Enttäuschung?

Analysen im Überblick

2016, 384 S., kart.

$29,99 €(D E), 978-3-8376-3658-1$

E-Book

PDF: $26,99 €$ (DE), ISBN 978-3-8394-3658-5

EPUB: $26,99 €(D E)$, ISBN 978-3-7328-3658-1

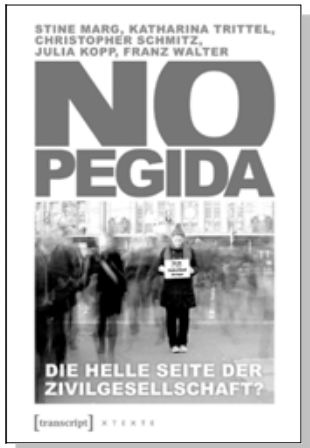

Stine Marg, Katharina Trittel,

Christopher Schmitz, Julia Kopp, Franz Walter

\section{NoPegida}

Die helle Seite der Zivilgesellschaft?

2016, 168 S., kart.

$19,99 €(D E), 978-3-8376-3506-5$

E-Book

PDF: $17,99 €(D E)$, ISBN 978-3-8394-3506-9

EPUB: $17,99 €(D E)$, ISBN 978-3-7328-3506-5

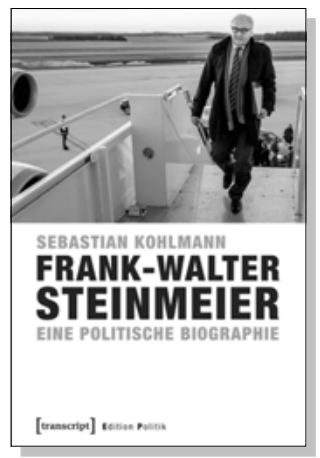

\section{Sebastian Kohlmann}

\section{Frank-Walter Steinmeier}

Eine politische Biographie

März 2017, 648 S., Hardcover

$39,99 €(D E), 978-3-8376-3951-3$

E-Book

PDF: $39,99 €$ (DE), ISBN 978-3-8394-3951-7

EPUB: $39,99 €(D E)$, ISBN 978-3-7328-3951-3 
